


\section{DOE Solar Energy Technologies Program}

Welcome to the fiscal year (FY) 2007 Annual Report for the U.S. Department of Energy's Solar Energy Technologies Program (Solar Program). The Solar Program is responsible for carrying out the federal role of researching, developing, demonstrating, and deploying solar energy technologies. This document presents a detailed description of the activities funded by DOE during FY 2007.

FY 2007 was a year of incredible importance for the Solar Program and its partners. Announced during President Bush's 2006 State of the Union address, the Advanced Energy Initiative includes the Solar America Initiative (SAI), a presidential initiative with the goal of achieving grid parity for solar electricity, produced by photovoltaic (PV) systems, across the nation by 2015 . FY 2007 was the first official year of SAI and represented a shift in Solar Program operations, budget, activities, and partnerships.

As a 9-year initiative, SAI is dependent upon wise choices made during its early years. I am pleased to report that FY 2007 represented a successful start to this critically important effort. A few of the many highlights achieved in FY 2007 and discussed in greater detail within this report include:

- $\quad$ Launch of the Technology Pathway Partnerships (TPPs), public-private partnerships with industry designed to create fully scalable PV systems that meet the SAI cost goals. The TPPs are characterized by rigorous review and down-selection processes, as well as ambitious timetables.

- Establishment of the PV Incubator activity, which funds the development of PV-system components to shorten their timeline to commercialization.

- Initiation of a groundbreaking market transformation effort to help commercialize solar technologies by eliminating market barriers and promoting deployment opportunities through outreach activities.

- Resurgence of the Solar Program's concentrating solar power (CSP) activities, including the first new solicitation in several years.

- Opening of the Process Design and Integration Laboratory (PDIL) at the National Renewable Energy Laboratory (NREL) for use by both laboratory and private industry researchers and designed to help standardize key aspects of PV-research processes.

FY 2007 was truly a banner year for the Solar Program and its partners, and we are looking forward to even greater accomplishments in FY 2008 and beyond. We remain your publiclyfunded, federal solar program and strive to conduct the most relevant, highly-valued activities to our stakeholders. Your input is always welcomed.

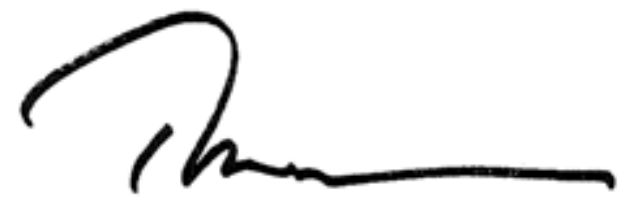

Thomas P. Kimbis

Program Manager

Solar Energy Technologies Program

Office of Energy Efficiency and Renewable Energy

U.S. Department of Energy 


\section{DOE Solar Program FY 2007 Annual Report Table of Contents}

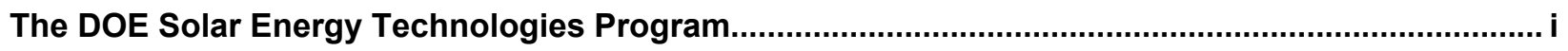

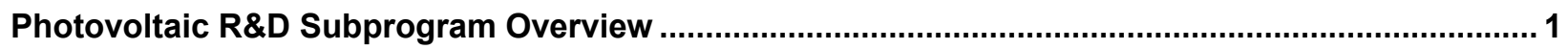

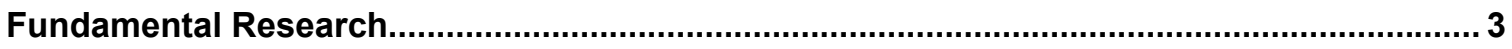

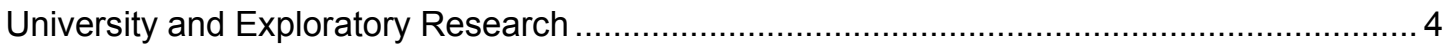

Electronic Materials and Devices

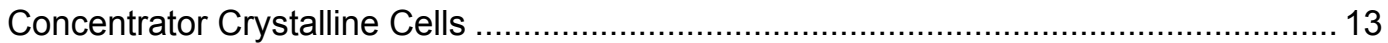

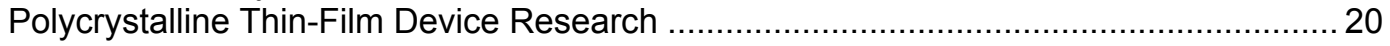

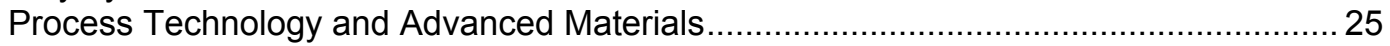

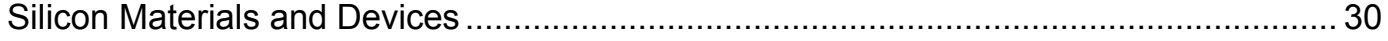

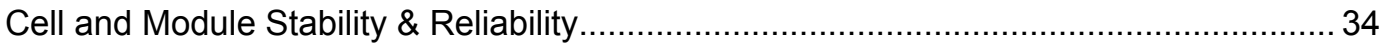

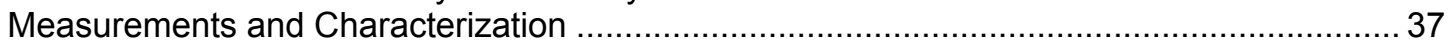

Resource and Safety Research

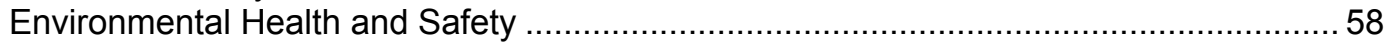

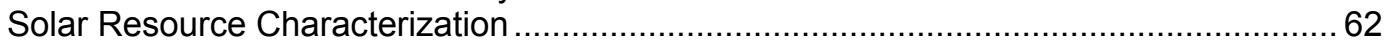

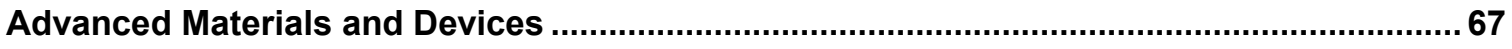

Systems Development

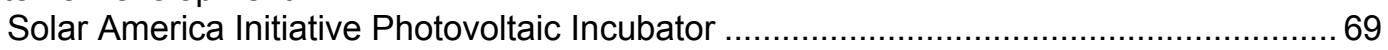

Solar America Initiative Project Monitoring …............................................................... 71

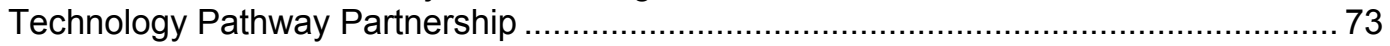

Component Development

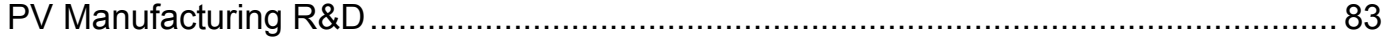

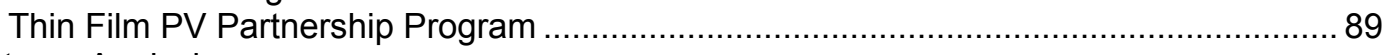

Systems Analysis

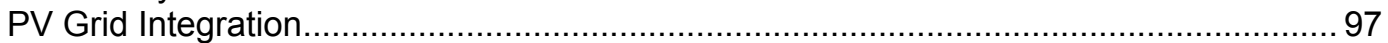

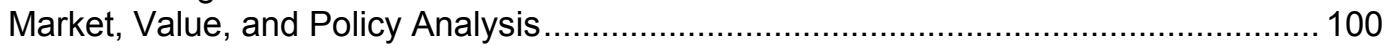

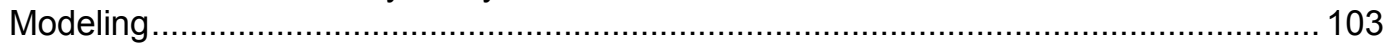

Systems Testing and Evaluation

PV Module and Array Testing

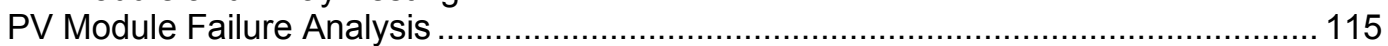

Photovoltaic System Evaluation and Optimization ................................................. 118

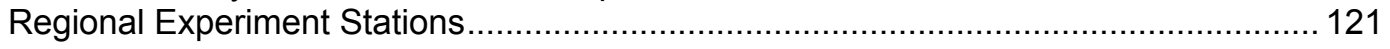

Component Testing and Evaluation

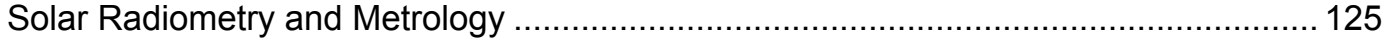

PDIL Infrastructure, Engineering, and Integration .................................................... 131

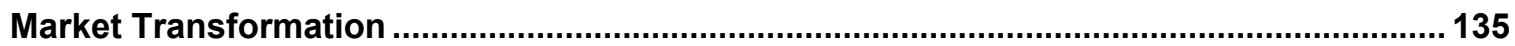

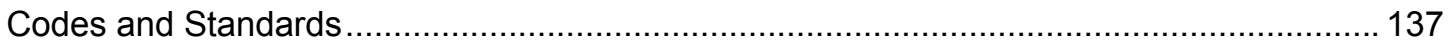

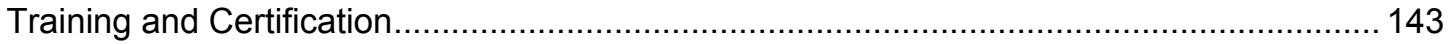

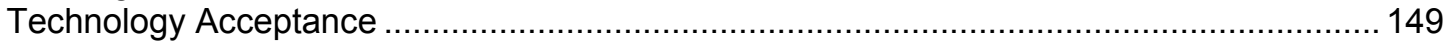

Building Integration

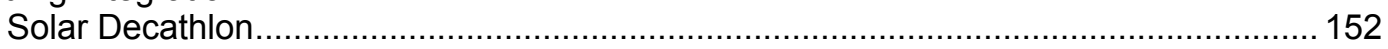

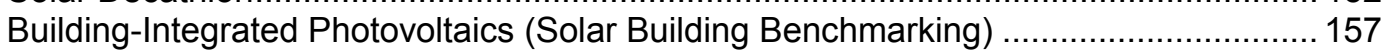

Finance and Insurance ................................................................................... 160

Technical Partnerships

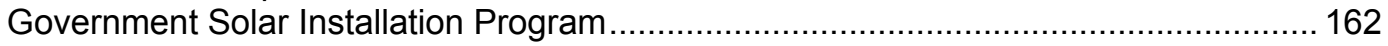

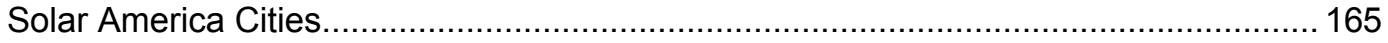

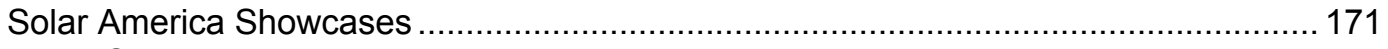

Technical Outreach

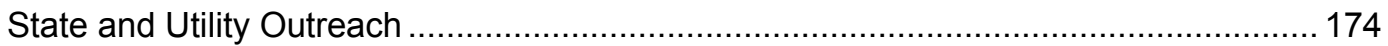




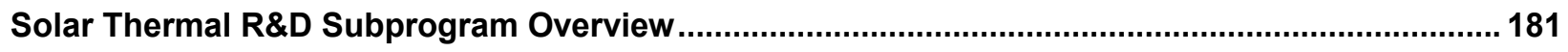

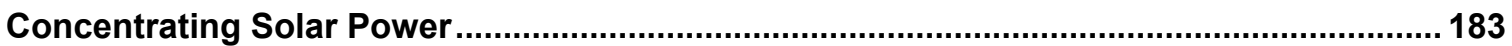

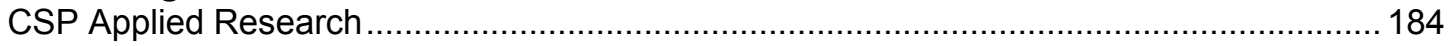

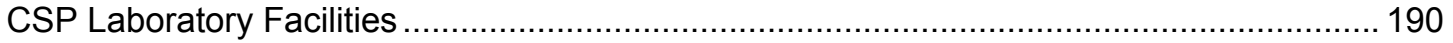

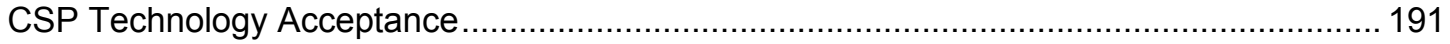

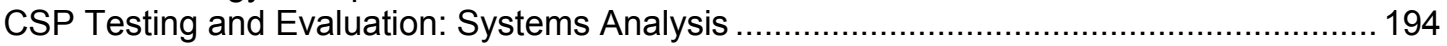

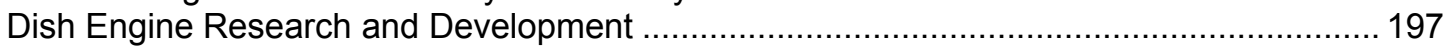

Parabolic Trough Research and Development ............................................................... 201

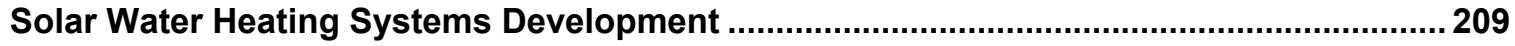

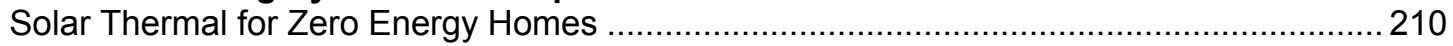

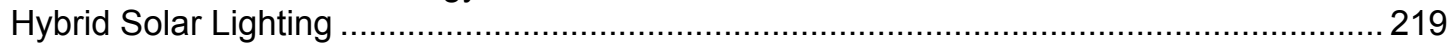

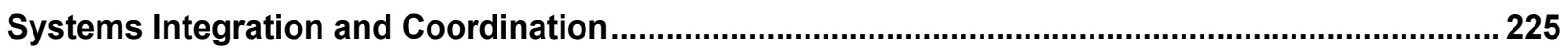

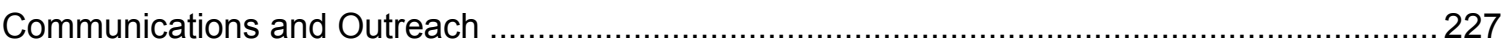

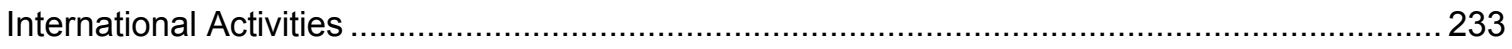

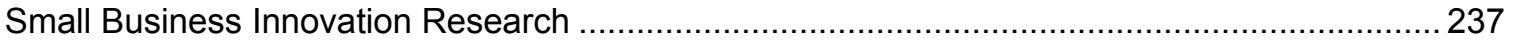

\section{Appendices}

Funding Table

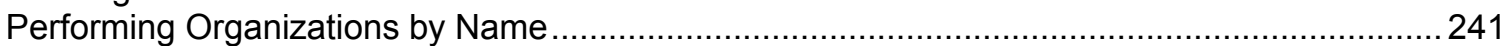

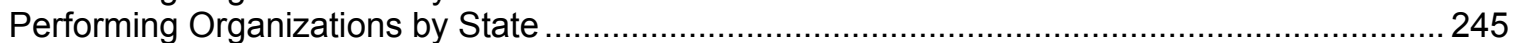

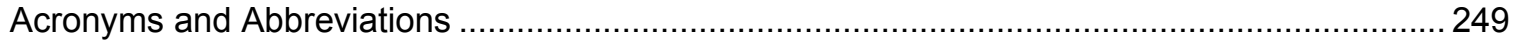




\section{Photovoltaic R\&D Subprogram Overview}

As key programs were launched under the Solar America Initiative (SAI) and other efforts were phased out, fiscal year (FY) 2007 was a year of transition for the Photovoltaic R\&D Subprogram in the U.S. Department of Energy's (DOE) Solar Energy Technologies Program (SETP). The largest increase in the SETP budget in decades was put to work in the SAI in a big push to bring the cost of solar electricity to grid parity by 2015. It is worth acknowledging that this funding increase was dwarfed by the amount of private capital invested in photovoltaic (PV) companies in 2007-around $\$ 800$ million in venture capital alone flowed into new U.S. PV start-ups.

\section{Goals and Objectives}

Within this environment, the strategy of SETP investment needed to be thoughtfully and clearly developed within the design of SAI. The goal of solar grid parity in the residential, commercial, and utility electricity markets requires system costs to be $50 \%$ to $70 \%$ lower. The wisest way to accomplish this goal was for SETP to build a portfolio from a technology-agnostic foundation, oriented to a systems-level approach. This allows companies to decide how best to trim costs in the primary metric for electricity relevant to PV, levelizing the cost of energy.

Although Technology Pathway Partnerships are the main push toward grid parity, other parts of the SETP target opportunities to diversify the SAI portfolio. In FY 2007, the SETP initiated the PV Incubator program, which targets higher risk, higher payoff approaches for less mature companies focused on quickly ramping up innovative modules into production. More solicitations will be awarded in FY 2008 that will continue to add diversity, through the maturity of the technology (next-generation concepts), other types of components (inverters, balance of systems), and new partners (more university R\&D support for companies).

National laboratory participation in the SETP is undergoing a transition under the SAI, as well. The Thin Film Partnership program, PV Manufacturing R\&D program, and the University and Exploratory Research program are being phased out because these needs will be supported by Technology Pathway Partnerships, PV Incubator, and other SAI solicitations.

Internal research and solar community support activities, conducted by the national laboratories, are being refocused during the upcoming years, both to respond appropriately to a growing number of industry requests for collaboration and testing and to spend time developing the highrisk, high-payoff projects that are best conducted in arenas like the national labs.

\section{Results and Accomplishments}

These are some of the highlights of the PV Subprogram's accomplishments in FY 2007:

- Funded 11 Phase I public/private Technology Pathway Partnership awards, the flagship program propelling the SAl. These industry-led teams comprise more than 50 companies, 14 universities, 3 nonprofits, and 2 national laboratories in 20 states across the United States. (Technology Pathway Partnerships)

- Funded 10 PV Incubator companies, which will shorten the timeline for these companies to transition prototype and precommercial PV technologies to pilot and full-scale manufacturing. (PV Incubator)

- Defined the scoped of a new effort in Grid Integration through 14 "Renewable Systems Interconnection" (RSI) reports to assess the impacts and needs related to high penetration of PV systems on today's electric infrastructure. Grid Integration has the potential to become a large, cross-cutting initiative within the DOE Office of Energy Efficiency and Renewable Energy. (PV Grid Integration) 
- Procured critical capital equipment to operate the National Renewable Energy Laboratory's (NREL's) Process Development and Integration Laboratory (PDIL), a collaborative research facility In which photovoltaic companies and university partners can work with NREL scientists. (PDIL Infrastructure, Engineering, and Integration)

- Updated the Solar Advisor Model (SAM) to make the utility financing portion more accurate from a project developer's perspective, incorporated financial incentives programs into calculations of PV systems' cost and performance, added an inverter model, and developed tools to permit the validation of performance models versus measured weather data and system output. (System Modeling)

- Maintained prominence in cell, module, and radiometer calibration. Researchers made 5020 cell current-voltage (I-V), quantum efficiency (QE), and linearity measurements on 1758 samples, and made $1567 \mathrm{I}-\mathrm{V}$ measurements on 408 modules. In addition, 26 spectral and 405 solar broadband radiometer calibrations were made within NREL and for industry and academic partners. (Measurements and Characterization; Solar Radiometry and Metrology)

- Developed an improved technique based on "coring" followed by torque strength versus angle characterization to determine and measure the strength and durability of various interfaces within many module types. The knowledge added by this technique allows the characterization of the durability of the module package - and will also serve to help in developing accelerated aging tests for extended lifetimes. (PV Module Failure Analysis)

- Provided inverter testing (performance, power quality, and utility compatibility) and improvement advice to manufacturers for two commercial inverters and three residential PV inverters, which resulted in software and hardware modifications and rectifications in beta units. (PV Inverter and Balance-of-System Testing)

- Implemented and refined an in situ technique to determine III-V concentrator film stress during growth. A multibeam optical stress sensor is used in place of time-consuming x-ray diffraction measurements, and it may be useful in the industrial production of latticemismatched junctions in inverted devices. (Concentrator Crystalline Cells and Measurements and Characterization)

- Developed a relatively easy way to detect "spectral skewing" changes in the solar spectrum produced by concentrator optics. By studying the variation of a multijunction cell's fill factor as the solar spectrum changes from the light of midday to the light of sunrise or sunset, researchers can characterize the degree of spectrum change by the concentrator's optics. (Concentrator Crystalline Cells)

- Developed a transparent conducting oxide ( $\mathrm{ZnMgO})$ for copper indium gallium selenide photovoltaics that could have both greater resistance to environmental corrosion and higher open-circuit voltage at high gallium concentrations. (Polycrystalline Thin-Film Device Research)

- Established a model for the formation of crystallites in thin-film crystalline silicon, a technique designed to produce low-cost, high-performing PV using less silicon on low-cost substrates. Experimental success was also attained by growing 10 microns of film silicon by a scalable manufacturing technique at about $620^{\circ} \mathrm{C}$; this is a tenfold increase in epitaxial thickness from previous best results. (Silicon Materials and Devices)

- Produced a nanocrystal quantum dot solar cell with $2.4 \%$ conversion efficiency and larger short-circuit currents than any existing nanostructured solar cell. This cell's deposition was accomplished with simple layer-by-layer dip coating, without the need for sintering, superlattice order, or separate phases for electron and hole transport. (University and Exploratory Research)

- Published a comparison of greenhouse gas emissions in the PV and nuclear fuel cycles. (V.M. Fthenakis and H.C. Kim, "Greenhouse Gas Emissions from Solar Electric and Nuclear Power: A Life Cycle Study," Energy Policy, 35, 2549-2557 2007). (Environmental Health and Safety)

- Conducted the first study on transport and recombination dynamics in dye-sensitized solar cells incorporating oriented $\mathrm{TiO}_{2}$ nanotube (NT) arrays (K. Zhu, N. R. Neale, A. Miedaner, and A. J. Frank, Nano. Lett., 7, 69, 2007). (University and Exploratory Research). 


\section{Fundamental Research}

Fundamental or basic research investigates the physical mechanisms of charge carrier transport, band structure, junction formation, impurity diffusion, defect states, and other physical properties of photovoltaic and photoelectrochemical materials. This area also includes solar resource characterization and environmental health and safety.

Among the research topics are innovative ideas and technologies with the potential to "leapfrog" current approaches. This high-risk research leads to new, nonconventional concepts that could dramatically improve cost effectiveness in the long term.

Fundamental research is key to the continued advancement of photovoltaic technology necessary to meeting the $2015 \mathrm{goal}$ of achieving $\$ 0.05 / \mathrm{kWh}$ to $\$ 0.10 / \mathrm{kWh}$ battery-free, grid-tied systems. Industry and university researchers work in partnership with national laboratories to improve the efficiency of cell materials and devices by investigating their fundamental properties and operating mechanisms. This teamed research approach works to identify efficiency-limiting defects in cell materials and analyze their electrical and optical properties.

FY 2007 marked a host of accomplishments in the Fundamental Research area, including:

\section{University and Exploratory Research}

- Achieved a record $40.7 \%$-efficiency metamorphic 3-junction cell, the first solar cell to reach greater than $40 \%$ efficiency, and the highest solar conversion efficiency achieved to date for any type of photovoltaic device.

\section{Electronic Materials and Devices}

- Demonstrated record efficiencies of $33.8 \%$ and $30.6 \%$ under one-sun global and space conditions, respectively, with the inverted cell.

- Completed transition to the new laboratories facilities at the National Renewable Energy Laboratory's Science and Technology facilities; cell reliability, contacts, cadmium indium gallium selenide (CIGS), and cadmium telluride (CdTe) laboratories are fully operational.

- Developed state-of-the-art infrastructure for organic-based thin-film photovoltaics (OPV).

- Achieved best-to-date efficiency of $19.1 \%$ heterojunction c-Si solar cell in the wafer silicon field.

- Developed the "cone kinetics" model to guide film-Silicon growth.

\section{Measurements and Characterization}

- Supported more than 70 PV research partners in industry, academia, and NREL with analytical microscopy, surface analysis, electro-optical characterization, and cell and module performance.

- Initiated the design of an improved solar simulator that will reduce uncertainty in highefficiency concentrator measurements.

- Developed a luminescence spectrum imaging system for characterizing industrial silicon wafers and solar cells.

\section{Resource and Safety Research}

- Conducted a life-cycle analysis of buffer options for CIGS photovoltaics.

- Completed the 1991-2005 National Solar Radiation Data Base (NSRDB) update and documentation, including the 10-km satellite-derived data grid from the State University of New York (SUNY) at Albany. 


\title{
University and Exploratory Research
}

\author{
Performing Organizations: National Renewable Energy Laboratory (NREL) \\ Key Technical Contact: $\quad$ Fannie Posey Eddy (NREL), 303-384-6773, Fannie_Eddy@nrel.gov
}

DOE HQ Technology Manager: Jeffrey Mazer, 202-586-2455, jeffrey.mazer@ee.doe.gov

FY 2007 Budgets: $\quad \$ 9,290 \mathrm{~K}$

\section{Objectives}

The project aims to explore the ultimate performance limits of photovoltaic (PV) technologies, approximately doubling their sunlight-to-electricity conversion efficiencies during its course. This work includes:

- Perform research and development (R\&D) on improved crystalline silicon cell efficiencies and fabrication methods to reduce manufacturing costs. This work is leveraged by the Center of Excellence.

- Use advanced research activities to perform leading-edge research in thin-film materials and solar cells. The R\&D activities include device fabrication, device analysis, film growth, materials characterizations, and modeling.

- Design thin-film tandem cells and modules that have approximately $25 \%$ and $20 \%$ efficiencies.

- Create multijunction pre-commercial concentrator modules that can convert more than one third of the sun's energy to electricity.

- Develop high-risk/high-payoff third-generation (3G) PV technologies beyond 2015, including high-efficiency and exciton-based solar cells.

- Target emerging state of the art, high-efficiency concepts relative to advanced super-highefficiency cells to allow cost-effective generation of electricity and hydrogen.

- Provide scientific and technical research opportunities for minority undergraduate and graduate students in solar-energy technologies via the Minority University Research Associates (MURA) project.

\section{Accomplishments}

- Completed subcontract modification to maintain continuity of research activities and scientific staff for an additional year (University Center of Excellence).

- Received IR 100 award for NREL and Spectrolab's achievement of a record $40.7 \%$-efficiency metamorphic 3-junction cell, the first solar cell to reach greater than $40 \%$ efficiency, and the highest solar conversion efficiency achieved to date for any type of photovoltaic device.

- Made modifications to add tasks to the AMONIX subcontract to build enough multijunction receiver plates to populate an entire 5-kilowatt $(\mathrm{kW})$ Mega Module at the University of NevadaLas Vegas (UNLV) using higher-efficiency multijunction cells.

- Reported fabrication of ITO/P3HT/In and ITO/ZnO NWs+CdTe (QDs) +P3HT/In PV cells and developed a scalable $\mathrm{ZnO}$ nanowire growth technology by Fisk University.

- Enabled five undergraduate students to participate in the NREL MURA Internship Program. Three posters were presented by NREL-MURA interns at the 17th Workshop on Crystalline Silicon Solar Cells: Materials and Processes, August 5-8, 2007, Vail, Colorado.

- Presented research findings by MURA PIs and students at the Renewable Academic Partnership (REAP)/Sustainable Energy from Solar hydrogen NSF/IGERT Workshop, University of Delaware, August 20-22, 2007.

- Demonstrated a 3\%-efficient hybrid inorganic polymer OPV cell at NREL.

- Assisted DOE Golden Field Office (GFO) with the Solar America Initiative (SAI) university and industry partnership solicitation and award process.

\section{Future Directions}

The project will continue to address key R\&D issues in support of the SAI including: 
- Demonstrate a 41\% III-V multijunction solar cell incorporated into a high-concentration module.

- Design approaches for fabricating solar cells with greater than $50 \%$ efficiency, in quantity, in 5 years.

- Continue to assist GFO with the technical monitoring projects with the MURA program.

- Phase out projects and complete subcontracts during the fiscal year.

\section{Introduction}

The University and Exploratory Research Project aims to explore the ultimate performance limits of PV technologies, approximately doubling their sunlight-to-electricity conversion efficiencies during its course. Research and development is directed toward advancing the progress of highefficiency technologies and their demonstration in commercial prototype products. To accomplish this, a wide range of complex issues are investigated to provide initial modeling and baseline experiments involving several advanced concepts.

The project includes both subcontract and NREL in-house activities executed in parallel to reach long-term goals (beyond 2015). A work plan is being pursued between EERE and the Office of Science to further the R\&D efforts. To ensure the success of the Solar America Initiative (SAI), NREL currently is assisting in this effort as well as with the SAI university and industry activities.

Subcontracted research categories within the University and Exploratory Research Project include the following areas: (1) polycrystalline thinfilm tandems; (2) research in III-V multijunction concentrators; (3) future generation research; and (4) research collaboration with minority universities in the Minority University Research Associates (MURA) Program.

The High-Efficiency Concepts group consists of inhouse NREL researchers and targets emerging state-of-the-art, high-efficiency concepts relative to advanced super-high-efficiency cells to allow costeffective generation of electricity and hydrogen. This group primarily is from the Basic Sciences Center and works directly with the NREL National Center for Photovoltaics (NCPV) scientists and Future Generation subcontractors.

Near-term milestones for the R\&D are listed in the CSP database and are addressed below. This R\&D will lead to new record cell efficiencies and to commercial prototype products for the disruptive and revolutionary technologies. For CPV, gaining a position in the marketplace could portend the emergence of CPV systems in the next 2 to 5 years at installed system costs of $\$ 3$ per watt. One $\mathrm{MW}$ at one sun of multijunction solar cells can power 1 gigawatt (GW) at 1000 suns of systems. Similarly $1 \mathrm{GW}$ of multijunction solar cells can power 1 terawatt (TW) of concentrator PV systems, revealing a new path to significant TWlevels of electricity production. For 3G technologies gaining market stance, 51\%-efficient solar cells could achieve below $\$ 1$ per watt.

\section{Technical Approach}

The University and Exploratory Research Project consist of five separate programs with research subcontracted through industry and university partners. All of the subcontracts are in the last phase of the agreement and end in FY 2008. However, the project is to be completed during the fiscal year.

The MURA task provides scientific and technical research opportunities for minority undergraduate students to work on various solar-energy technology projects.

\begin{tabular}{|l|c|}
\hline Task Title & $\begin{array}{c}\text { FY 2007 } \\
\text { Budget (\$K) }\end{array}$ \\
\hline $\begin{array}{l}\text { Thin-Film Polycrystalline } \\
\text { Tandems }\end{array}$ & 860 \\
\hline $\begin{array}{l}\text { III-V Multijunction } \\
\text { Concentrators }\end{array}$ & 1,128 \\
\hline Future Generation Project & 703 \\
\hline MURA & 344 \\
\hline Crystalline Si Universities & 500 \\
\hline University Center of Excellence & 1,250 \\
\hline High-Efficiency Concepts & 2,060 \\
\hline
\end{tabular}

\begin{tabular}{|l|c|}
\hline Agreement Title & $\begin{array}{c}\text { FY 2007 } \\
\text { Budget (\$K) }\end{array}$ \\
\hline $\begin{array}{l}\text { University and Exploratory } \\
\text { Research }\end{array}$ & 1,000 \\
\hline
\end{tabular}

\section{Results and Accomplishments}

\subsection{University Exploratory Research Project Management}

University Exploratory Research (UER) project management supports the management activities

Photovoltaic R\&D

Fundamental Research 
needed for high-quality research within project budgets. All subcontracted researchers work in parallel with NREL scientists to reach long-term, beyond 2015, goals.

A majority of the subcontracts under all of the UER agreements ended in FY 2007. The remaining subcontracts are slated to end in the summer of FY 2008.

\subsection{Thin-Film Polycrystalline Tandems}

A series of tandem devices on p-type ribbon or float zone (FZ) were fabricated at the Institute of Energy Conversion (IEC) at the University of Delaware and at Georgia Institute of Technology. The objective of this work is to develop a-Si thinfilm/crystalline-silicon wafer tandem cells using a very low-cost Si wafer, and to exceed the performance of low-cost c-Si solar cells, such as ribbon silicon cells. This device, illustrated in Figure 1, has unique features including: (1) a very low cost mc-Si material, such as ribbon Si, and/or low-purity wafers; (2) a wafer thickness of 100 to $200 \mu \mathrm{m}$ to reduce the cost of the wafer; (3) deposited emitter/passivation layers as an alternative to diffused emitters; and (4) a twoterminal design.

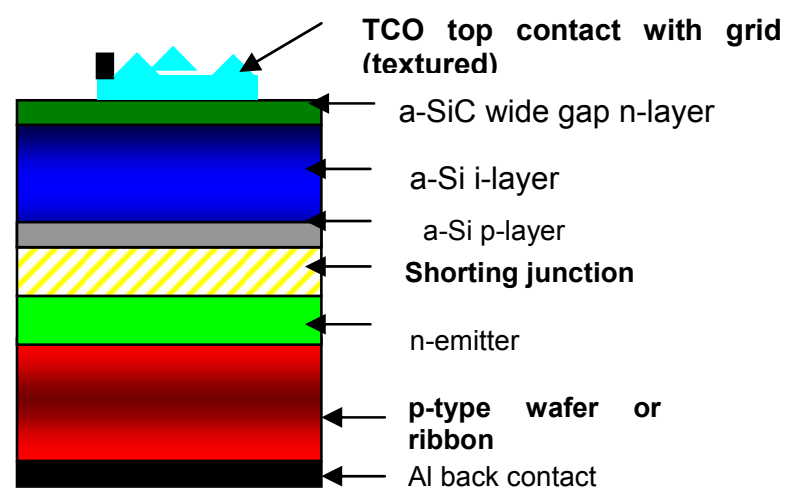

Figure 1. a-Si/c-Si tandem solar cell device schematic

The approach is twofold: (1) To fabricate seriesconnected two-terminal tandem devices having an a-Si top cell, and (2) fabricate a low-cost multi-Si p-type bottom cell using low-cost device fabrication. Investigations of the effect of the shorting junction between the top and bottom cells found that the best shorting junction was a stack composed of $5 \mathrm{~nm}$ of $\mathrm{p}+\mathrm{nc}-\mathrm{Si}$ and $5 \mathrm{~nm}$ of $\mathrm{n}+\mathrm{nc}-\mathrm{Si}$. This produced an a-Si/c-Si tandem solar cell with an efficiency of $11.3 \%$ on a float zone Si wafer.

\subsection{III-V Multijunction Concentrators}

- Modifications have been completed adding tasks to the Spectrolab and AMONIX subcontracts to build enough multijunction receiver plates to populate an entire $5 \mathrm{~kW}$ MegaModule at University of Nevada at Las Vegas (UNLV) using higher-efficiency multijunction cells (9/07). Amonix fabricated a new 21" MJ plate and installed it at UNLV. It tested greater than $30 \%$ efficiency at Amonix in FY 2006 and $29.7 \%$ at UNLV during FY 2007.

- California Institute of Technology reported having InGaP/GaAs two-junction cells on $\mathrm{Ge}$ templates on Si with performance that is quite comparable to those on $\mathrm{Ge}$ bulk wafer substrates.

- Over the period of performance (POP) the research at the University of Delaware from the contract "Novel High Efficiency Photovoltaic Devices Based on the III-N Material System" demonstrated the feasibility of the IIInitrides as a photovoltaic material, including demonstrating high-efficiency high-band-gap solar cells suitable for tandems with a large number of solar cells, novel device structures, new modeling tools, and improved understanding of the physical mechanisms controlling the device behavior. The contract ends in FY 2008 and the following summarizes the Research Highlights for the POP to date.

- First demonstration of a $\mathrm{GaN}$ and $\operatorname{InGaN}$ solar cell, including IQE of more than $60 \%$ and Vocs of $2.4 \mathrm{eV}$.

- First demonstration of InN growth on Ge.

- Demonstration of metal epitaxial interface, allowing low -resistance contacts between $\mathrm{InN}$ and $\mathrm{Ge}$ and $\mathrm{Si}$.

- Development of device design rules for InGaN solar cells which include the effects of polarization.

- Identification of mechanisms operating in InGaN solar cells include polarizationinduced band spike in low-band gap InGaN alloys.

- Development of first modeling program for solar cells to include polarization effects by modifying PC1D.

- Development of novel device structure for InGaN solar cells.

\subsection{Future Generation}

The remaining Future Generation Subcontracts end in FY 2008. 
University of Delaware $>50 \%$ (ends $3 / 08$ )

- The goal of the University of Delaware (UDEL) subcontract, "Approaches to $>50 \%$ Solar Cells," is to identify solar cell designs based on advanced concepts that are capable of reaching greater than $50 \%$ efficiency, and to determine structures that can experimentally demonstrate the feasibility of high-efficiency advanced-concept solar cells. This project has resulted in several advances, particularly for intermediate-band multiple quasi-Fermi level approaches. The major results include: (1) Analyzing the impact of fundamental nonidealities on theoretical efficiency; (2) design rules for achieving high efficiency and identification of material systems to implement highefficiency devices; and (3) experimental examination of physical processes and characterization of multiple quasi-Fermi levels devices.

- UDEL identified an expanded design space for selection of materials systems to implement a quantum dot (QD) solar cell with $\eta>50 \%$. This was done by the calculation of isoefficiency curves for a three-level system under $\mathrm{x} 1000$ concentration. Using these results and refined design rules, three III-V materials systems were identified. Preliminary experimental results from one system, InAs/GaAsSb were presented. Early results have shown the ability to tune the QD properties via the GaAsSb barrier thickness. UDEL also achieved two of the grant's major milestones by demonstrating the absorption in a simulation program and the simulation of quantum effects, absorption and recombination properties of nanostructured absorbers with deep quantum states.

Northwestern University (ends 6/08)

- Material Development: The NU group reported significant progress in developing n-type transparent electrode materials in ZITO (zinc indium tin oxide) and also p-type transparent electrode materials development. Through this work, the group describes an important link between thin-film behavior and equilibrium bulk phase defect chemistry. The existence of "special" compositions was confirmed-its composition and transparent electrode behavior correlate well with the bulk-phase diagram and the propensity for Sn-excess (donor doping) in the bulk. This is an important step toward increased understanding and control of thin-film TCOs for transparent electrodes in organic photovoltaics (OPVs).
- Novel Redox Probe Development: Northwestern University also developed a novel, self-assembling redox probe to analyze the surface electron transfer characteristics of transparent conducting oxides (TCOs) for OPVs. The NU group investigated the coverage and electron transfer of organics on inorganic (TCO) transparent electrode surfaces. In particular, the electronic properties of various TCO surfaces have been probed electrochemically via self-assembled monolayers (SAMs). A novel graftable probe molecule having a tethered trichlorosilyl group and a redox-active ferrocenyl functionality $\left(\mathrm{Fc}\left(\mathrm{CH}_{2}\right)_{4} \mathrm{SiCl}_{3}\right)$ was synthesized and characterized for this purpose. This molecule can self-assemble via covalent bonds to form monolayers on various TCO surfaces, and be used for subsequent electrochemical testing (in terms of surface coverage and electrontransfer rates). This is an important step toward realizing high-efficiency OPVs.

- Methods Development: New methods have been reported to better predict surface electronic structure-including predictions of work function, an essential property for OPV applications of TCO electrodes. One new method, the FLAPW (full-potential linear augmented plane wave) band structure method, was used to determine band structures and, for the first time, the electronic properties at oxide surfaces (e.g., $\mathrm{ZnO}, \mathrm{InN}, \mathrm{NiO}$ ).

\subsection{Novel High-Efficiency Concepts}

The task for NREL's High-Efficiency Concepts supports exploratory research in quantum dot cells, theory of III-V and thin-film solar cells, dyesensitized solar cells, and specialized characterization of III-V and thin-film solar cells. These highefficiency concepts could be leveraged into the marketplace to achieve costs of less than $\$ 1 / \mathrm{W}$.

- "Dye-sensitized solar cell project." Researchers completed the first study on the transport and recombination dynamics in dye-sensitized solar cells (DSSC) incorporating oriented $\mathrm{TiO}_{2}$ nanotube (NT) arrays (K. Zhu, N. R. Neale, A. Miedaner, A. J. Frank, Nano Lett, 7, 69 (2007)). Transport and recombination play a major role in determining the overall solar-cell conversion efficiency, therefore studying such phenomena is important for further advances in the DSSC technology. From the present study it was discovered that the charge-collection efficiencies 
were significantly greater in NT-based DSSCs than in their nanoparticle-based counterparts, due to much slower recombination in the NT films than in the nanoparticle films. Progress also was made in developing synthetic routes for preparing reproducible $\mathrm{TiO}_{2}$ nanocrystals for DSSCs using the sol-gel method. Despite the fact that sol-gel chemistry is the most common route for preparing $\mathrm{TiO}_{2}$ nanocrystalline films for DSSCs, it still is challenging to predict a priori the crystal size and structure from a particular synthetic protocol. To address this issue, researchers developed reproducible routes for controlling the growth of $\mathrm{TiO}_{2}$ nanocrystallites over a broad range of sizes and a narrow range of shapes (N. R. Neale, A. J. Frank \& J. Mater. Chem. 17, 3216 (2007)).

- "Defect properties of CdTe and CdMTe study and first-principles band-structure calculations for TCO's project." Researchers are investigating doping polarity issues with wide-band-gap (WBG) semiconductors used in solar cells as transparent conductors and window layers. Most WBG semiconductors exhibit the doping polarity problem, that is, they can be doped either n-type or p-type, but not both. NREL has investigated this doping polarity issue and proposed a universal approach to overcome the doping difficulties. The approach is based on the reduction of the ionization energies of dopants through introduction and effective doping of mutually passivated impurity bands. The approach proposed can be applied, in principle, to any WBG semiconductor to overcome the doping asymmetry problem found in these materials, and therefore will open a broad vista for the application of WBG materials.

- "Quantum Dot Solar Cells." Two types of detailed theoretical analyses were conducted for quantum dot (QD) solar cells. One was an analysis of the maximum possible thermodynamic conversion efficiency possible in a two-component tandem quantum solar cell based on multiple exciton generation (MEG) in both or even just one of the quantum dot layers, with each QD layer having a different (optimum) band gap. The maximum efficiency increased from about $32 \%$ for a normal solar cell (1 electron-hole pair/photon) to about $45 \%$ for a QD solar cell; a tandem cell did not increase the efficiency over a single-layer cell. The second analysis used an experimental simple, all-inorganic QD solar cell developed through collaboration with the BES program.
The cell produces a very large short-circuit photocurrent $\left.(\sim 25 \mathrm{~mA} \mathrm{~cm})^{-2}\right)$ via a Schottky junction between a quantum dot film deposited on a transparent conducting ITO electrode and a metal counter electrode. The PbSe NC film, deposited via layer-by-layer (LbL) dip coating, yields an EQE of $65 \%$ across the visible and up to $25 \%$ in the infrared region of the solar spectrum, with a power conversion efficiency of $2.4 \%$. This NC solar cell produces larger short-circuit currents than any existing nanostructured solar cell, without the need for sintering, superlattice order, or separate phases for electron and hole transport. The analysis was done to model the performance of such a QD solar cell as a function of the cell parameters (carrier mobility, carrier lifetime, QD cross section, film thickness), and to show the importance of MEG effects in the cell performance.

- Demonstration a 3\%-efficient hybrid inorganic poylmer OPV cell. NREL has established a reproducible process for producing bulk heterojunction cells. This process required the development of an all atmospherically controlled process. This has been extended to approximately $3 \%$-hybrid inorganic cells.

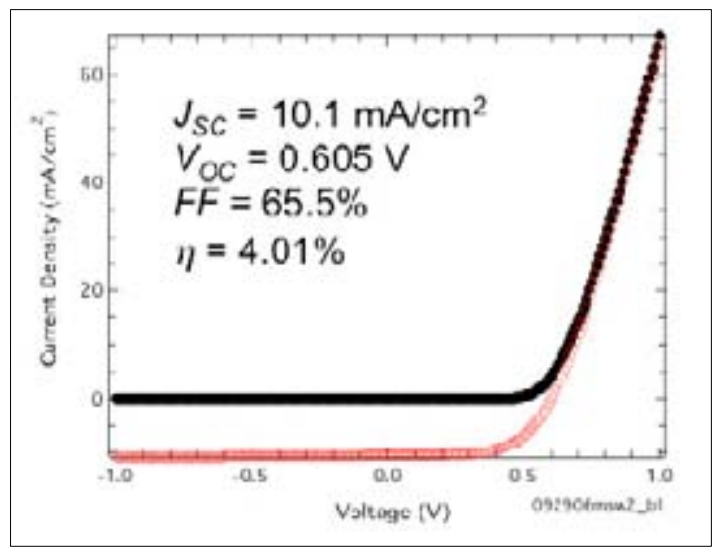

- Novel Polycrystalline Tandems. NREL reseachers are working to produce and characterize carbon nanotube transparent electrodes. Researchers studied the effects of doping in the nanotube electrodes and performed extensive temperature-dependent electrical measurements to assess transport and stability. Results showed that changes in resistivity at high temperature are irreversible and that, due to doping, thionyl chloride is a relatively thermally stable dopant. Initial tests were begun to incorporate these electrodes into organic solar cells. 


\subsection{Thin-Film Center of Excellence}

The University Center of Excellence (UCE) continues to play an important role in supporting the advanced research activities in thin-film PV materials and devices. The Institute of Energy Conversion (IEC) is designated by the U.S. Department of Energy, and for the past several years it has been the UCE at the University of Delaware. The IEC continues to make significant contributions in both scientific and advanced research in all three areas, namely, a-Si, CIS and CdTe. Additionally, the IEC continues to play a lead role in the support of new and emerging thinfilm PV companies that have limited human and technical resources. Systematic processing variations were the focus of IEC's work. The IEC routinely fabricated CdTe cells having greater than $13 \%$ efficiency. IEC provided NREL a Si heterojunction cell with the following characteristics: Efficiency $=18.84 \%$; Voc $=0.6708 \mathrm{~V}$; Jsc $=36.183$ $\mathrm{mA} / \mathrm{cm} 2$; Fill Factor $=77.61 \%$; masked area $0.247 \mathrm{~cm}^{\wedge} 2$; cell area $0.56 \mathrm{~cm}^{\wedge} 2$.

\subsection{The MURA Program}

Subcontracts under the Minority University Research Associates (MURA) Program have been modified to extend through August 2008.

- MURA principal investigators and students presented research findings at the Renewable Academic Partnership (REAP)/Sustainable Energy from Solar Hydrogen NSF/IGERT Workshop, University of Delaware, August 2022, 2007.

- Fisk University reported fabrication of ITO/P3HT/In and ITO/ZnO NWs+CdTe (QDs)+P3HT/In PV cells and is developing a scalable $\mathrm{ZnO}$ nanowire growth technology $(8 / 07)$.

- Two MURA/FISK students were awarded 2year graduate degrees $(6 / 07)$.

- Five undergraduate students participated in the NREL MURA Internship Program. Three posters were presented by NREL-MURA interns at the 17th Workshop on Crystalline Silicon Solar Cells: Materials and Processes, August 5-8, 2007, Vail, Colorado.

\subsection{Crystalline Silicon Universities}

The Crystalline Si Project subcontracts have ended or will end early in FY 2008. What remains to be done is to close out existing contracts and extend Texas Tech, NC State U., and GA Tech contracts through February 2008. These contracts will be closed out in FY 2008 due to resource constraints. It is anticipated that some of the $\mathrm{Si}$ activity will fit into the SAI University Partnerships in FY 2008.

In its final report, the Manufacturing Research Center (MARC) at Georgia Tech addressed photovoltaic manufacturing under an NREL subcontract. The initiative led to the creation of the Photovoltaic Manufacturing Laboratory (PVML) to address fundamental and practical issues related to handling and fracture of thin polycrystalline silicon wafers used in solar cells, measurement of residual and applied stresses in the wafer due to processing and handling, and the development of factory information software tools for real-time monitoring of equipment used in solar cell manufacturing. The following results were reported.

\section{Residual Stress Measurement}

- Predominant orientations were found for cast wafers.

- A relationship between dislocation density and residual stress was demonstrated.

- Full stress components were obtained for several silicon beams.

- Preliminary models were built to calculate thermal effect for the polariscopy system.

\section{Thin Wafer Handling and Breakage}

- Results of an experimental and modeling investigation of deformation and stresses produced in polycrystalline silicon wafers handled by a Bernoulli gripper showed that the air-flow rate and wafer thickness have a significant effect on wafer deformation.

- For all wafer types, a transition in the maximum in-plane principal tensile stress location from the center to the edges occurred as the air-flow rate was increased. The relation between the total stress and breakage was analyzed by calculating the critical crack length. Furthermore, breakage can be predicted by using the knowledge of residual stresses, handling stresses (calculated from the FE model), and wafer strength.

\section{Factory Information Systems}

- It was demonstrated that the CAMX standards can be used by the photovoltaic industry to improve productivity and reduce cost. 


\section{Planned FY 2008 Activities}

- Complete subcontracts in all programs.

- Demonstrate high-efficiency cell in concentrator module, 31\%-efficiency conversion.

- Perform GFO-Release Solicitation, "Minority University Research Associates Program."

\section{FY 2007 Special Recognitions}

Spectrolab and NREL received an R\&D 100 award for achievement of a record $40.7 \%$-efficiency metamorphic 3-junction cell. This cell is the first solar cell to reach efficiency greater than $40 \%$, and the achieved the highest solar conversion efficiency to date for any type of photovoltaic device.

\section{Major FY 2007 Publications}

Chen, Shiyou, X. G. Gong, and S.-H. Wei, "Band Structure Anomaly of Chalcopyrite Semiconductors Cugax $_{2}$ Versus Aggax $_{2}$ ( $X=S$ and Se) and Their Alloys," Phys. Rev. B., Vol. 75, 205209 (2007).

Da Silva, J. L. F., S.-H. Wei, J. Zhou, and X. Wu, "Stability and Electronic Structures of $\mathrm{Cu}_{\mathrm{x}} \mathrm{Te}$," Appl. Phys. Lett., Vol. 90, 091902 (2007).

Hanna, M. C. and A. J. Nozik, "Solar Conversion Efficiency of Photovoltaic and Photoelectrolysis Cells with Carrier Multiplication Absorbers," Journal of Applied Physics, Vol. 100, 74510 (2006) (published FY07).

Jena, H., M. Faruq, Gnanasekar, and B. Rambabu, "Nanocrystalline Bulk and Thin Films of $\mathrm{LaNi}_{1-\mathrm{x}} \mathrm{Fe}_{\mathrm{x}} \mathrm{O}_{3 \pm \delta} \quad(\mathrm{x}=0-0.5) \quad(\mathrm{LNF})$ as Cathode Material for IT-SOFCs," Journal of Materials Science (2007).

Jena, H., India Snowden, Fannie Posey Eddy, and B. Rambabu, "A Study on Proton Transport in Nanocrystalline Calcium Hydroxy Apatite and Its $\mathrm{Sr}$ and Mg Substituted Analogues Prepared by Sonochemical and Hydrothermal Methods," submitted to Journal of Materials Science (2008).
Jin, S., Y. Yang, J. E. Medvedeva, L. Wang, S. Li, N. Cortes, A. W. Metz, J. Ni, M. C. Hersam, A. J. Freeman, and T. J. Marks, "Tuning the Properties of Transparent Oxide Conductors. Dopant Ion Size and Electronic Structure Effects on CdO-Based Transparent Conductive Oxides. Ga- and In- Doped CdO Thin Films Grown by MOCVD," Inorg. Chem. (in press).

Song, J.-H., T. Akiyama, A. J. Freeman, "Stabilizing Mechanism of the Dipolar Structure and its Effects on Formation of Carriers in Wurtzite $\{0001\}$ Films: InN and ZnO," Phys. Rev. B. (accepted for publication).

Wu, X., J. Zhou, A. Duda, Y. Yan, G. Teeter, S. Asher, W. K. Metzger, S. Demtsu, S.-H. Wei, and R. Noufi, "Phase Control of $\mathrm{Cu}_{\mathrm{x}} \mathrm{Te}$ Film and its Effects on CdS/CdTe Solar Cell'," Thin Solid Films, Vol. 515, 5798 (2007).

Yan, Y., C.-S. Jiang, R. Noufi, S.-H. Wei, H. R. Moutinho, and M. M. Al-Jassim, "Electrical Benign Behavior of Grain-Boundary in Polycrystalline CulnSe $_{2}$ Films," Phys. Rev. Lett., Vol. 99, 235504 (2007).

Yan, Y., J. Li, S.-H. Wei, and M. M. Al-Jassim, "Possible Approach to Overcome the Doping Polarity in Wide-Band-Gap Semiconductors," Phys. Rev. Lett., Vol. 98, 135506 (2007).

Yan, Y. and S.-H. Wei, "Doping Asymmetry in Wide-Band Gap Semiconductors: Origins and Solutions," Phys. Stat. Sol., Vol. 245, 641 (2008).

Zhou, J., X. Wu, Y. Yan, S. Asher, J. D. L. F. Da Silva, S.-H. Wei, L. Weinhardt, M. Bar, and C. Heske, "The Mechanism of J-V 'rollover' in CdS/CdTe Devices," Mater. Res. Soc. Symp. Proc., Vol. 1012, Y13-03 (2007). 


\section{University and Industry Partners}

The following organizations partnered in the project's research activities during FY 2007.

\begin{tabular}{|c|c|c|c|}
\hline $\begin{array}{c}\text { Organization/ Principal } \\
\text { Investigator }\end{array}$ & Location/e-mail & $\begin{array}{c}\text { Description/ } \\
\text { Title of Research Activity }\end{array}$ & $\begin{array}{c}\text { FY } 2007 \\
\text { (\$K) }\end{array}$ \\
\hline $\begin{array}{l}\text { Amonix, Inc. } \\
\text { Vahan Garbushian }\end{array}$ & $\begin{array}{l}\text { Torrence, CA } \\
\text { drvahan@earthlink.net }\end{array}$ & $\begin{array}{l}\text { Design and Demonstration of a } \\
\text { Greater than } 33 \% \text { Efficiency High- } \\
\text { Concentration Module Using } 40 \% \\
\text { III-V Multijunction Devices }\end{array}$ & $234^{*}$ \\
\hline $\begin{array}{l}\text { California Institute of } \\
\text { Technology } \\
\text { Harry Atwater }\end{array}$ & $\begin{array}{l}\text { Pasadena, CA } \\
\text { haa@daedalus.caltech.edu }\end{array}$ & $\begin{array}{l}\text { Four-Junction Solar Cell with } 40 \% \\
\text { Target Efficiency Fabricated by } \\
\text { Wafer Bonding and Layer } \\
\text { Transfer }\end{array}$ & $184^{*}$ \\
\hline $\begin{array}{l}\text { Central State University } \\
\text { Clark Fuller }\end{array}$ & Wilberforce, OH cfuller@prodigy.net & $\begin{array}{l}\text { Renewable energy technology } \\
\text { and technology transfer in } \\
\text { developing countries }\end{array}$ & 34 \\
\hline $\begin{array}{l}\text { Duke University } \\
\text { Teh Tan }\end{array}$ & $\begin{array}{l}\text { Durham, NC } \\
\text { ttan@duke.edu }\end{array}$ & $\begin{array}{l}\text { Modeling Metallic Precipitate } \\
\text { Dissolution in Silicon Under Point } \\
\text { Defect injection }\end{array}$ & 51 \\
\hline $\begin{array}{l}\text { Fisk University } \\
\text { Richard Mu }\end{array}$ & $\begin{array}{l}\text { Nashville, TN } \\
\text { rmu@fisk.edu }\end{array}$ & $\begin{array}{l}\text { Development of Si quantum dots } \\
\text { for advanced solar cells with } \\
\text { maximum efficiency }\end{array}$ & 41 \\
\hline $\begin{array}{l}\text { Georgia Institute of } \\
\text { Technology } \\
\text { Steven Danyluk } \\
\text { Ostapenko }\end{array}$ & $\begin{array}{l}\text { Atlanta, GA } \\
\text { steven.danyluk@me.gatech.edu }\end{array}$ & Stress Evaluation & 50 \\
\hline $\begin{array}{l}\text { Georgia Institute of } \\
\text { Technology } \\
\text { Steven Danyluk }\end{array}$ & $\begin{array}{l}\text { Atlanta, GA } \\
\text { steven.danyluk@me.gatech.edu }\end{array}$ & $\begin{array}{l}\text { Stress Evaluation and } \\
\text { Manufacturing of Wafers }\end{array}$ & 200 \\
\hline $\begin{array}{l}\text { Georgia Institute of } \\
\text { Technology } \\
\text { Ajeet Rohatgi }\end{array}$ & $\begin{array}{l}\text { Atlanta, GA } \\
\text { Ajeet.Rohatgi@ece.gatec.edu }\end{array}$ & $\begin{array}{l}\text { Thin-Film Si Bottom Cells for } \\
\text { Tandem Device Structures }\end{array}$ & 200 \\
\hline $\begin{array}{l}\text { Howard University } \\
\text { J. M. Momoh }\end{array}$ & $\begin{array}{l}\text { Washington, DC } \\
\text { jmomoh@msn.com }\end{array}$ & $\begin{array}{l}\text { Developing automation/strategies } \\
\text { to improve power management } \\
\text { and distribution of renewable } \\
\text { energy resources }\end{array}$ & 50 \\
\hline $\begin{array}{l}\text { North Carolina A\&T State } \\
\text { University } \\
\text { G. Shahbazzi }\end{array}$ & $\begin{array}{l}\text { Greensville, NC } \\
\text { ash@ncat.edu }\end{array}$ & $\begin{array}{l}\text { Modeling performance of a grid- } \\
\text { connected PV system in a } \\
\text { residential area }\end{array}$ & 41 \\
\hline $\begin{array}{l}\text { North Carolina Central } \\
\text { University } \\
\text { Joe Dutta }\end{array}$ & $\begin{array}{l}\text { Durham, NC } \\
\text { jmd@nccu.edu }\end{array}$ & $\begin{array}{l}\text { Fabricating and characterizing } \\
\text { bulk and non-phase PV materials } \\
\text { for student research }\end{array}$ & 41 \\
\hline $\begin{array}{l}\text { North Carolina State } \\
\text { George A. Rozgonyi }\end{array}$ & $\begin{array}{l}\text { Raleigh, NC } \\
\text { rozgonyi@ncsu.edu }\end{array}$ & Defect Engineering & 65 \\
\hline $\begin{array}{l}\text { Northwestern University } \\
\text { Tom Mason }\end{array}$ & $\begin{array}{l}\text { Evanston, IL } \\
\text { tmason@northwestern.edu }\end{array}$ & $\begin{array}{l}\text { Interface and Electrodes for Next- } \\
\text { Generation Organic Solar Cells }\end{array}$ & 250 \\
\hline $\begin{array}{l}\text { Oregon State University } \\
\text { Douglas Keszler }\end{array}$ & $\begin{array}{l}\text { Corvallis, OR } \\
\text { Douglas.keszler@orst.edu }\end{array}$ & $\begin{array}{l}\text { Novel Materials Development for } \\
\text { Polycrystalline Thin-Film Solar } \\
\text { Cells }\end{array}$ & 224 \\
\hline $\begin{array}{l}\text { Penn State } \\
\text { S. Ashok }\end{array}$ & $\begin{array}{l}\text { University Park, Pennsylvania } \\
\text { S.Ashok@PSU.edu }\end{array}$ & $\begin{array}{l}\text { Electron Cyclotron Resonance } \\
\text { (ECR) Hydrogenation and } \\
\text { Deuteration of Solar Cell Samples }\end{array}$ & 15 \\
\hline $\begin{array}{l}\text { Southern University and A\&M } \\
\text { College } \\
\text { Rambabu Bobba }\end{array}$ & $\begin{array}{l}\text { Baton Rouge, LA } \\
\text { Rambabu@grant.phys.subr.edu }\end{array}$ & $\begin{array}{l}\text { Student research projects related } \\
\text { to energy conversion and storage } \\
\text { devices }\end{array}$ & 37 \\
\hline
\end{tabular}




\begin{tabular}{|c|c|c|c|}
\hline $\begin{array}{c}\text { Organization/ Principal } \\
\text { Investigator }\end{array}$ & Location/e-mail & $\begin{array}{l}\text { Description/ } \\
\text { Title of Research Activity }\end{array}$ & $\begin{array}{l}\text { FY } 2007 \\
(\$ K)\end{array}$ \\
\hline $\begin{array}{l}\text { Spectrolab, Inc. } \\
\text { Raed Sherif }\end{array}$ & $\begin{array}{l}\text { Sylmar, CA } \\
\text { rsherif@spectrolab.com }\end{array}$ & $\begin{array}{l}\text { Ultra-High-Efficiency Multijunction } \\
\text { Cell and Receiver Module }\end{array}$ & $318^{*}$ \\
\hline $\begin{array}{l}\text { Texas Tech } \\
\text { Stefan Estreicher }\end{array}$ & $\begin{array}{l}\text { Lubbock, TX } \\
\text { Stefan.Estreicher@ttu.edu }\end{array}$ & $\begin{array}{l}\text { Theoretical Modelling, } \mathrm{H}- \\
\text { Passivation }\end{array}$ & 75 \\
\hline $\begin{array}{l}\text { Underwriters Lab/ Arizona } \\
\text { State University } \\
\text { Liang Ji }\end{array}$ & $\begin{array}{l}\text { Phoenix, AZ } \\
\text { Liang.ji@us.ul.com }\end{array}$ & $\begin{array}{l}\text { Development of IEC Design } \\
\text { Qualification Standard for } \\
\text { Concentrator PV Modules } \\
\end{array}$ & 40 \\
\hline $\begin{array}{l}\text { University of Colorado- } \\
\text { Boulder } \\
\text { Josef Michl }\end{array}$ & $\begin{array}{l}\text { Boulder, CO } \\
\text { michlj@colorado.edu }\end{array}$ & $\begin{array}{l}\text { Ultra-High Efficiency Excitonic } \\
\text { Solar Cells }\end{array}$ & $278^{*}$ \\
\hline $\begin{array}{l}\text { University of Delaware } \\
\text { Robert Birkmire }\end{array}$ & $\begin{array}{l}\text { Newark, DE } \\
\text { Birkmire@ee.udel.edu }\end{array}$ & $\begin{array}{l}\text { Processing, Materials, Devices } \\
\text { and Diagnostics for Thin Film } \\
\text { Photovoltaics: Fundamental and } \\
\text { Manufacturing Issues }\end{array}$ & 1257 \\
\hline $\begin{array}{l}\text { University of Delaware } \\
\text { Christiana Honsberg }\end{array}$ & $\begin{array}{l}\text { Newark, DE } \\
\text { honsberg@ece.gatech.edu }\end{array}$ & $\begin{array}{l}\text { Novel High Efficiency PV Devices } \\
\text { Based on the III-N Material } \\
\text { System }\end{array}$ & $175^{\star *}$ \\
\hline $\begin{array}{l}\text { University of Delaware } \\
\text { Christiana Honsberg }\end{array}$ & $\begin{array}{l}\text { Newark, DE } \\
\text { honsberg@ee.udel.edu }\end{array}$ & $\begin{array}{l}\text { Theoretical and Experimental } \\
\text { Investigation of Approaches to } \\
>50 \% \text {-Efficient Solar Cells }\end{array}$ & $190^{*}$ \\
\hline $\begin{array}{l}\text { University of Delaware } \\
\text { Bill Shafarman }\end{array}$ & $\begin{array}{l}\text { Newark, DE } \\
\text { wns@udel.edu }\end{array}$ & $\begin{array}{l}\text { High-Performance PV } \\
\text { Polycrystalline Thin-Film Tandem } \\
\text { Cells }\end{array}$ & 90 \\
\hline $\begin{array}{l}\text { University of Oregon } \\
\text { David Cohen }\end{array}$ & $\begin{array}{l}\text { Eugene, OR } \\
\text { dcohen@darkwing.uoregon.com }\end{array}$ & $\begin{array}{l}\text { Identifying the Electronic } \\
\text { Properties Relevant to Improving } \\
\text { the Performance of High Band- } \\
\text { Gap Copper-Based I-III-VI2 } \\
\text { Chalcopyrite Thin Film PV } \\
\text { Devices }\end{array}$ & 140 \\
\hline $\begin{array}{l}\text { University of Texas, } \\
\text { Brownsville } \\
\text { M. Blanco }\end{array}$ & $\begin{array}{l}\text { Brownsville, TX } \\
\text { mjblanco@utb.edu }\end{array}$ & $\begin{array}{l}\text { Student/faculty teams for } \\
\text { designing and developing } \\
\text { computer-simulation tools for } \\
\text { design of solar concentrating } \\
\text { systems. }\end{array}$ & 34 \\
\hline $\begin{array}{l}\text { University of Texas, El Paso } \\
\text { Gregory Lush }\end{array}$ & $\begin{array}{l}\text { El Paso, TX } \\
\text { glush@gerdau.com }\end{array}$ & $\begin{array}{l}\text { Investigation, fabrication, } \\
\text { characterization, and modeling of } \\
\text { solar cells }\end{array}$ & 45 \\
\hline $\begin{array}{l}\text { University of Toledo } \\
\text { Alvin Compaan }\end{array}$ & $\begin{array}{l}\text { Toledo, } \mathrm{OH} \\
\text { adc@physics.utoledo.edu }\end{array}$ & $\begin{array}{l}\text { Sputtered II-VI Alloys and } \\
\text { Structures for Tandem PV }\end{array}$ & 113 \\
\hline
\end{tabular}

* Forward funded into FY 2008

** Modification pending for FY 2008 


\title{
Electronic Materials and Devices Concentrator Crystalline Cells
}

\author{
Performing Organization: National Renewable Energy Laboratory (NREL) \\ Key Technical Contact: Daniel Friedman (NREL), 303-384-6472, daniel_friedman@nrel.gov
}

DOE HQ Technology Manager: Marie Mapes, 202-586-3765, marie.mapes@ee.doe.gov

FY 2007 Budgets: $\quad \$ 2,369 K^{*}$

${ }^{*}$ Reference funding table in appendix

\section{Objectives}

- Demonstrate a high-efficiency inverted triple-junction concentrator solar cell at 300 suns.

- Establish optical stress sensor as an in situ probe of relaxation of lattice-mismatched solar cells.

- Transfer the recipe for the inverted triple-junction cell to the low-pressure reactor to identify differences in growth of this structure at low pressure.

- Assess the potential for further efficiency improvements in inverted three-junction solar cells.

- Grow $\sim 1 \mathrm{eV}$ GalnNAs with Bi surfactant toward achieving $>2 \mu \mathrm{m}$ depletion width in GalnNAs.

Accomplishments

- Identified a limiting series resistance in the contact layers of inverted, lattice-mismatched devices, resulting in a peak efficiency of $38.9 \pm 2.3 \%$ at 80 suns and $36 \%$ at approximately 300 suns.

- With the inverted cell, demonstrated record efficiencies of $33.8 \%$ and $30.6 \%$ under one-sun global and space conditions, respectively.

- Assessed the potential for further efficiency improvements in an inverted cell, with greater than $42 \%$ efficiency projected.

- Implemented and refined an in situ technique to determine the film stress during growth.

- Transferred cell recipes to a low-pressure metal-organic vapor phase epitaxy (MOVPE) reactor and demonstrated inverted top cells, tunnel junctions, GalnP/GaAs tandems, and GalnP grades to GalnAs.

- Grew GalnNAs solar cells with a Bi surfactant and demonstrated depletion widths in excess of $2 \mu \mathrm{m}$.

- Measured and modeled the outdoor performance of $\mathrm{GalnP}_{2} / \mathrm{GaAs}$ tandem cells under direct illumination, lending support for the use of the American Society of Testing and Materials (ASTM) G-173 direct spectrum to design concentrator cells for maximum daily energy and midday power.

\section{Future Directions}

- Demonstrate inverted, lattice-mismatched multijunction (iLMM) devices with a concentrator performance peak above 100 suns.

- Demonstrate iLMM cells with optimized second- and third-junction band gaps.

- Study the effects of growth temperature, surfactants, and impurities on lattice-mismatched epitaxy.

- Perform a comparative evaluation of degradation mechanisms in multijunction cells and plan for work to mitigate identified problems.

\section{Introduction}

A large portion of the U.S. market for photovoltaics (PV) may best be served by utility-scale PV systems. Such systems can minimize electricity costs through the use of tracking PV concentrator systems. The exciting business prospect for PV concentrators is that all sections of the supply chain are well developed to support a multigigawatt capacity, because most PV components share production technology with other commercially available products. The U.S. Department of Energy's PV research and development (R\&D) has recognized this 
opportunity and maintained a research program for the development of high-performance concentrator cells. Thus, research in the Concentrator Crystalline Cells Group at NREL focuses its resources on development of ultrahigh-efficiency solar cells that form the heart of the concentrator system. Moving the next generation of devices into manufacturing requires that we understand and control the growth of latticemismatched structures in order to reliably produce high-efficiency devices. Mismatched layers with high quality can be grown if the strain and relaxation properties are controlled in order to limit the dislocation density. This is demonstrated by the record results from NREL and Spectrolab for two different types of lattice-mismatched cell designs, both with an efficiency approaching $40 \%$. In this area, our primary activity is to expand the understanding and control of the epitaxial processes that influence strain and relaxation.

For lattice-matched devices, a higher efficiency could theoretically be achieved if the photocurrent generated in the $\mathrm{Ge}$ junction could be divided between a 1-eV material and the bottommost Ge junction. The dilute nitride material GalnNAs continues to be the most promising candidate for a 1-eV junction. Growth of GalnNAs by molecular beam epitaxy (MBE) has achieved remarkably improved photocurrents, but open-circuit voltages remain a challenge. In FY 2007, we aimed to bring this work to closure; however, this now appears to have been premature. Therefore, we are maintaining our capabilities with this materials system, because we have received very favorable estimates of the potential of this work from a potential industry partner.

As industry chooses to embrace the highefficiency concentrator approach, many questions arise, including one about the sensitivity of power generation to changing spectral conditions. The Concentrator Crystalline Cells Group continues to support the growth of industry by providing on-sun measurement and modeling of concentrator cells in real-world operation.

\section{Technical Approach}

This project is composed of three primary research tasks. These research tasks and areas of investigation are as follows:

\subsection{Inverted Lattice-Mismatched Approach}

- Decrease deleterious series resistance in inverted, metamorphic devices to improve operation at high concentration

- Assess the usefulness of in situ stress measurements for lattice-mismatched epitaxy.

\subsection{Dilute Nitrides}

- Study the effects of Bi as a surfactant for dilute nitride materials

- Use a Bi surfactant to grow $\sim 1 \mathrm{eV}$ GalnNAs with a depletion width $>2 \mu \mathrm{m}$.

\subsection{Concentrator System Device Issues}

- Address outdoor measurements of tandem cells designed for different spectral conditions

- Address modeling of on-sun data to determine the effects of spectral skewing.

\section{Results and Accomplishments}

\subsection{Inverted Lattice-Mismatched Approach}

Milestones for this activity were as follows:

- Achieve a 300 suns inverted triple-junction cell (Level 3, June 2007)

- Establish optical stress sensor as an in situ probe of relaxation of lattice-mismatched solar cells (Level 4, March 2007)

- Transfer the recipe for the inverted triplejunction cell to the low-pressure reactor to identify differences in the growth of this structure at low pressure (Level 4, June 2007)

- Assess the potential for further efficiency improvements in an inverted three-junction solar cell (Level 4, June 2007).

We have been working on a new approach for ultra-high-efficiency concentrator tandem solar cells based on inverted III-V heteroepitaxial structures that combines both lattice-matched and lattice-mismatched component subcells in a monolithic structure, as shown in Figure 1. In this approach, high-quality GalnP top junctions and GaAs middle junctions are grown inverted and lattice-matched on a GaAs substrate. A latticemismatched 1.0-eV GalnAs bottom junction is grown last on a transparent GalnP compositionally step-graded layer. After growth, the sample is attached to a convenient handle, the original substrate is removed, and the grids are applied. Quantum efficiency data for an inverted device is shown in Figure 2. An early device achieved $37.9 \%$ efficiency at about 10 suns, but it was limited from further improvement in efficiency by a series resistance. 
In FY 2007, we identified a limiting series resistance in the contact layers, thus completing an important milestone. A dedicated flash simulator donated from the measurements group was very important for quickly identifying this resistance. Optimization of semiconductor contact layers and metal grid design increased the peak efficiency to $38.9 \pm 2.3 \%$ at 80 suns. This device also operated at concentrations greater than 300 suns, completing a Level 3 milestone. Opencircuit voltage, fill factor, and efficiency data for this device are shown in Figure 3. One Se-doped GalnNAs contact layer was used to achieve high carrier concentration and reduce dopant diffusion from the contact interface during subsequent growth. A further reduction in series resistance is required for optimal performance at 500X to $1000 \mathrm{X}$ concentration. The resulting potential efficiencies were assessed at greater than $42 \%$.

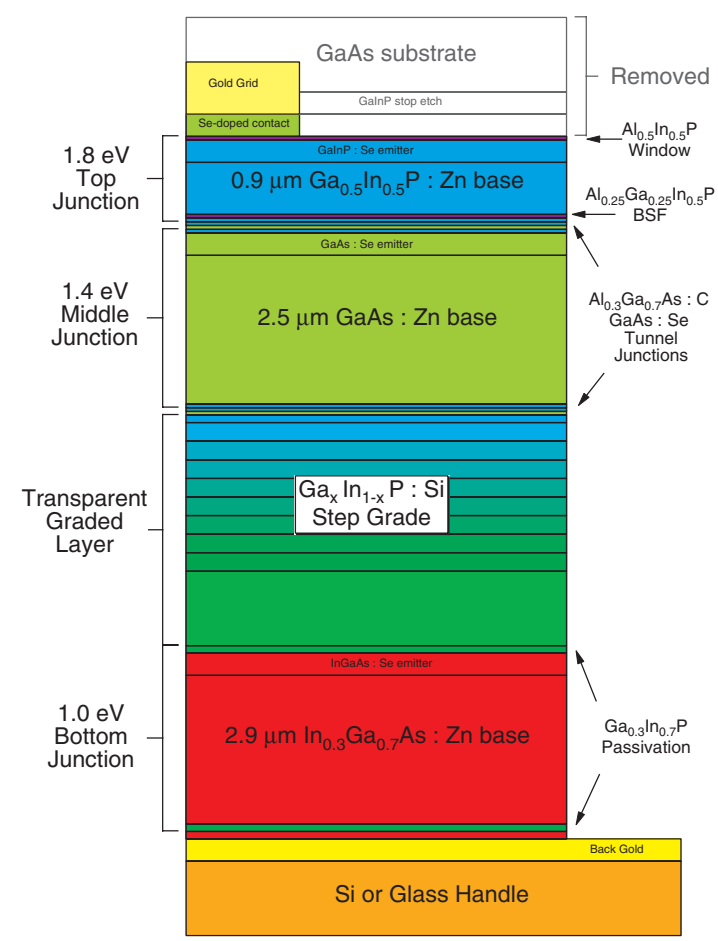

Fig. 1. Schematic of inverted triple-junction structure. The band gap of the semiconductor layers are indicated by a rainbow color scale $($ violet $=$ high, red $=$ low $)$.

While optimizing this structure for operation under high concentration, we fabricated several devices for operation under one-sun global and space conditions. These devices demonstrated record efficiencies of $33.8 \%$ and $30.6 \%$ under these conditions, respectively. This technology (referred to as IMM devices) has been transferred to Emcore, and the organization has achieved even higher efficiencies under AMO spectral conditions (31.9\% reported in Milan) while using industrial capacity processing equipment.

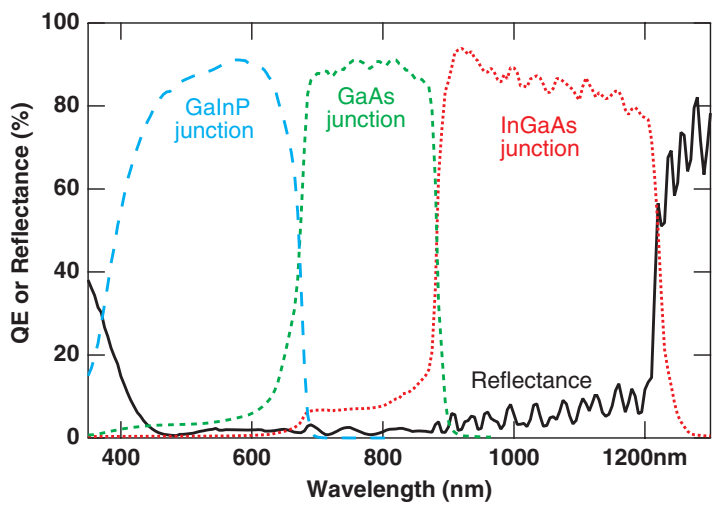

Fig. 2. External quantum efficiency and specular reflectance of the AM1.5G inverted triple-junction device.

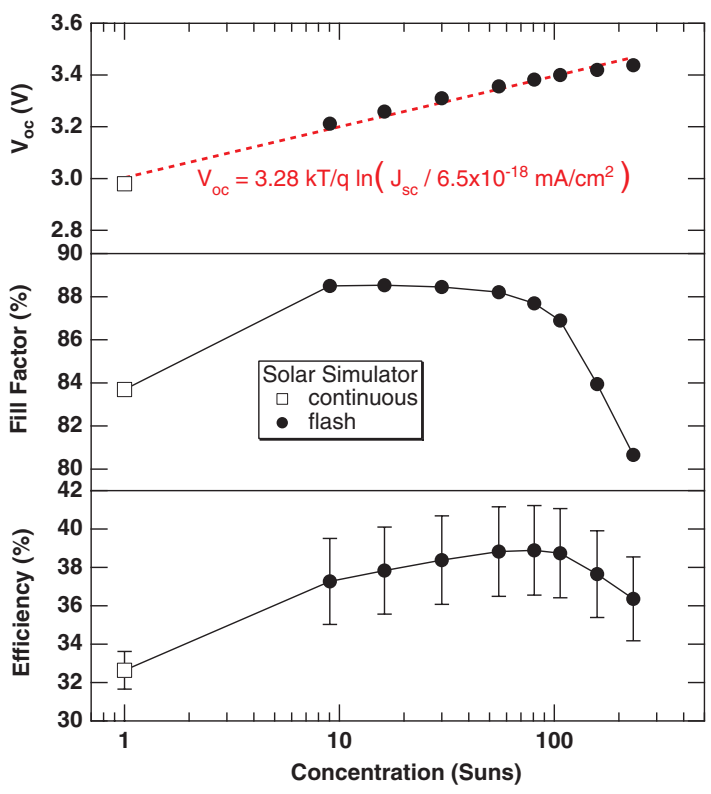

Fig. 3. Open-circuit voltage, fill factor, and efficiency of the AM1.5D (low-AOD) inverted triplejunction device as a function of irradiance (1000 $\mathrm{W} / \mathrm{m}^{2}=1$ sun). The $\mathrm{V}_{\mathrm{oc}}$ is fit with a simple diode equation (dashed line).

Engineering the strain in lattice-mismatched solar cell junctions is an important factor in optimizing their performance. Graded structures that result in near-zero strain within lattice-mismatched devices was pioneered during thermophotovoltaic studies by Mark Wanlass of NREL. Time-consuming x-ray diffraction measurements have been used in the past to characterize and improve the strain. In FY 2007, we implemented and refined an in situ

Photovoltaic R\&D

Fundamental Research 
technique to determine the film stress during growth. In situ stress data from a multibeam optical stress sensor (MOSS) were compared and correlated with ex situ strain measurements from $x$-ray diffraction and the performance of latticemismatched 1.0-eV GalnAs solar cells, as shown in Figure 4. The efficiency of these 1.0-eV devices was found to quickly degrade under tensile stress and strain, but excellent performance was demonstrated for near-zero or slightly compressive stress and strain (see Figures 5 and 6). Transmission electron microscopy (TEM) and cathodoluminescence demonstrated relatively low defect densities $\left(\sim 2 \times 10^{6} \mathrm{~cm}^{-2}\right)$ in these optimized structures. The MOSS proved to be an essential time-saving tool for optimization of stress for highperformance, lattice-mismatched junctions in inverted devices and will likely be useful for industrial production of such devices.

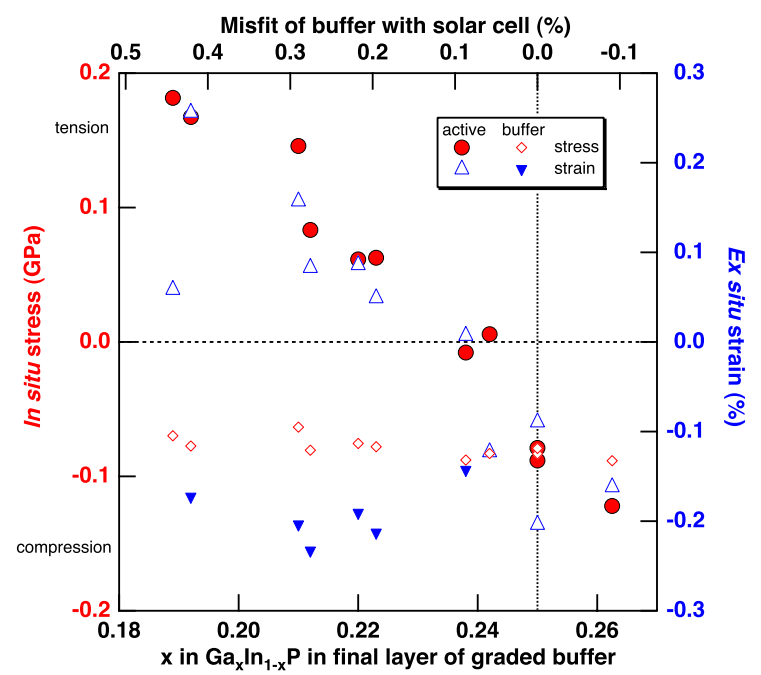

Fig. 4. Shown are growth temperature stress calculated from in situ MOSS measurements and room temperature strain calculated from ex situ $x-$ ray diffraction measurements for both the $\ln _{.27} \mathrm{Ga}_{.73}$ As active junction and the thick $\mathrm{Ga}_{\mathrm{x}} \operatorname{In}_{1-\mathrm{x}} \mathrm{P}$ layer at the top of the graded buffer as a function of the composition of this layer.

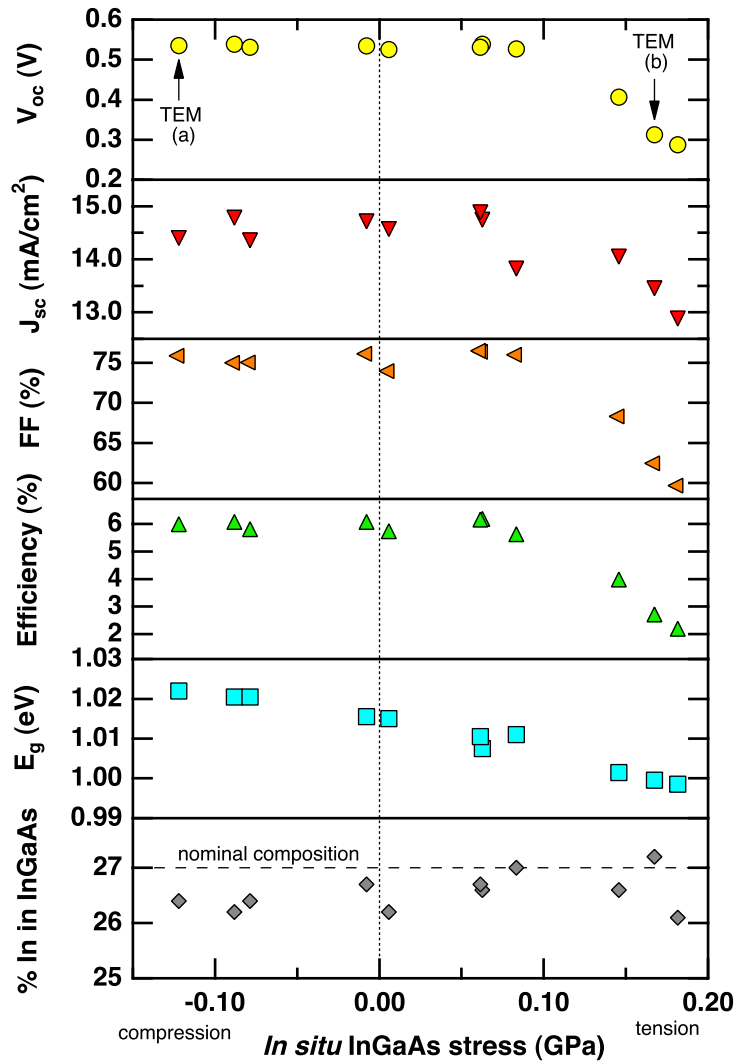

Fig. 5. Solar cell data are shown as a function of junction stress during growth. $E_{g}$ was derived from quantum efficiency data. The actual $\ln _{x} G_{1-x} A s$ composition was derived from $x$-ray measurements. 


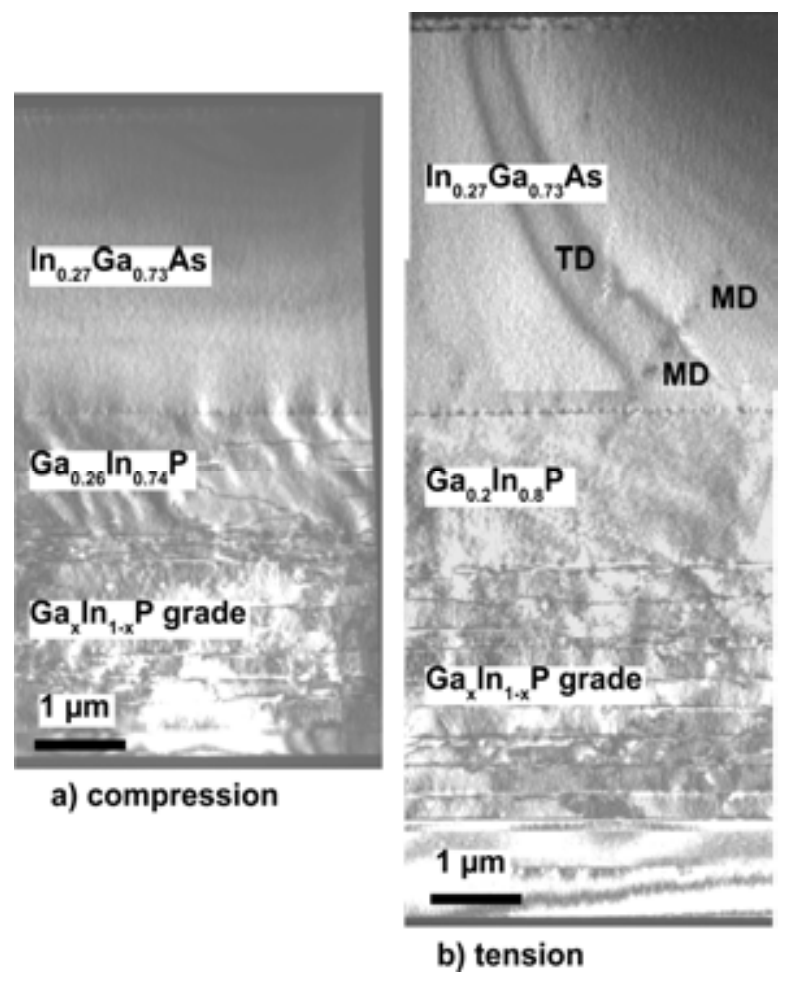

Fig. 6. Shown are 220 dark field TEM images of two inverted InGaAs solar cells grown with different film stress in the active layer: (a) 0.12 GPa compressive, (b) $0.17 \mathrm{GPa}$ tensile. Threading dislocations (TD) and the ends of misfit dislocations (MD) are observed in the thick InGaAs layer of sample b.

We have begun growing inverted cells on the lowpressure (cluster-tool) metal-organic chemical vapor deposition, or MOCVD, growth chamber, completing a Level 4 milestone. The goal of this work is a recipe for an inverted GalnP/GaAs/GalnAs three-junction device that can then be optimized and studied. Work so far has produced functional (but not optimal) inverted top cells, tunnel junctions, GalnP/GaAs tandems, and GalnP grades to GalnAs. This work will continue in FY 2008.

In addition to these activities, we have evaluated possible improvements to the lattice-mismatched device; many of these will be explored experimentally in FY 2008. These include the use of different band-gap combinations for optimum conversion efficiency, new grid designs for higher concentration, transparent back contacts for use in a mechanically stacked device, and improved antireflection coatings.

\subsection{Dilute Nitrides}

GalnNAs solar cells could be useful in nextgeneration multijunction solar cells if issues surrounding low photocurrents and photovoltages are surmounted. Wide-depletion-width devices generate significant photocurrent using a $p-i-n$ structure grown by $\mathrm{MBE}$, but these depletion widths are realized only in a region of parameter space that leads to rough surface morphologies. Thus, bismuth was explored as a surfactant for the growth of GalnNAs solar cells. Very low fluxes of $\mathrm{Bi}$ proved effective at maintaining smooth surfaces, even at high growth temperatures and In contents. However, $\mathrm{Bi}$ also increased the net donor concentration in these materials, manifested in our $n$-on- $p$ device structures as a $p n$-junction that moves deeper into the base layer with increasing $\mathrm{Bi}$ fluxes. This effect is shown in Figure 7. Quantum efficiency modelling and scanning Kelvin probe microscopy measurements confirm the type conversion of the

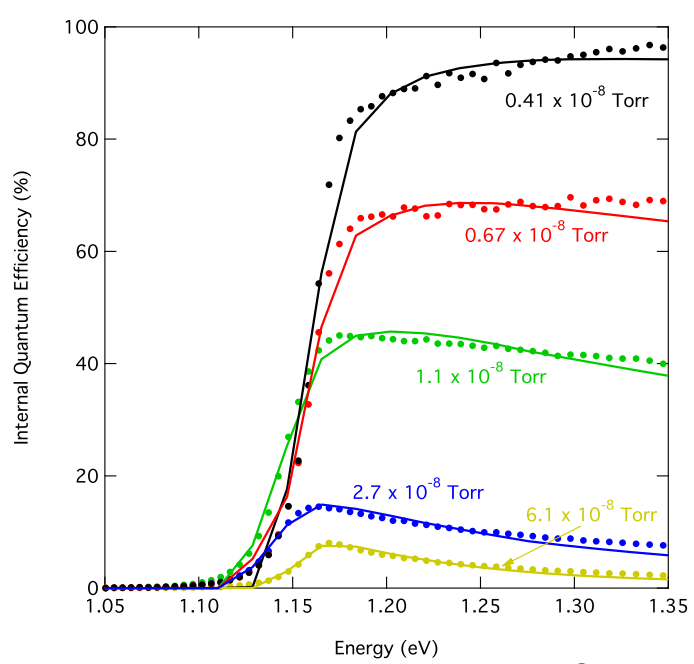

Fig. 7. Measured and calculated IQE data for a set of GalnNAs(Bi) solar cells with different impinging fluxes of $\mathrm{Bi}$ (the $\mathrm{Bi}$ flux is labelled for each curve). With $\mathrm{Bi}$ present, the base layer converts to n-type, creating a thick emitter.

base layer from $p$-type to $n$-type. Bismuth incorporation in GaAsBi samples shows signs of surface segregation, leading to a finite build-up time, and this effect may lead to slow changes in the electrical properties of GalnNAs(Bi) devices. Bismuth also appears to create a defect level, as measured by deep-level transient spectroscopy measurements, although this defect level is not deleterious enough to increase the dark current in the devices. This painstaking work has recently (in FY 2008) attracted a potential industry partner. 
3.3 Concentrator System Device Issues

We have measured and modeled the outdoor performance of $\mathrm{GalnP}_{2} / \mathrm{GaAs}$ tandem cells under direct illumination for concentrator applications.
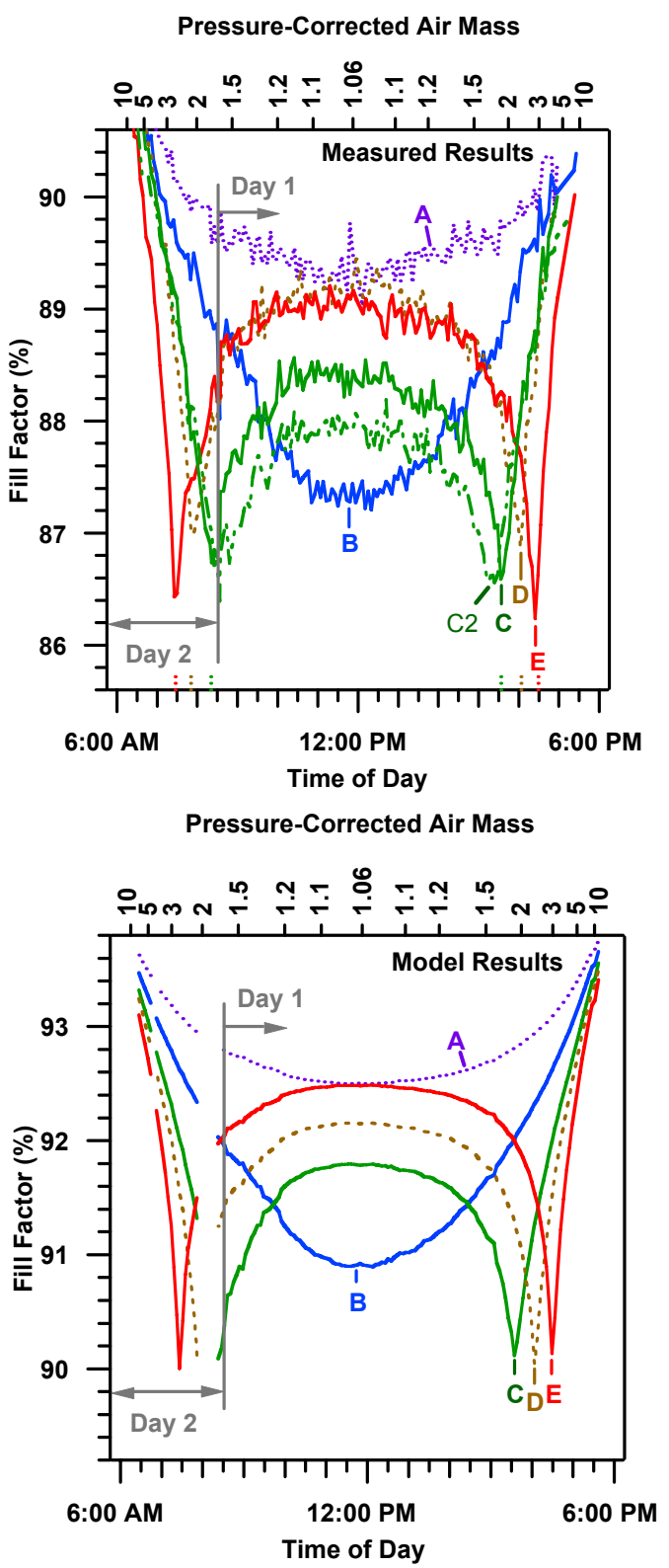

Fig. 8. Fill factor is plotted versus time for a set of tandem cells $(A-E)$ during a test day. Cell $A$ has the thinnest top cell and is well suited for a "bluerich" AM0 space spectrum. Cell E has the thickest top cell and is best suited for "red-rich" morning and evening spectra. Measured (top) and modeled (bottom) results are shown. Both plots are for cells at one-sun (collimated/direct), and the cells are cooled to $25^{\circ}-30^{\circ} \mathrm{C}$. Current-matched times for cells $\mathrm{C}, \mathrm{D}$, and $\mathrm{E}$ are indicated along the bottom axis with dashed lines.
This study lends support to the use of the ASTM G-173 direct spectrum to design cells for maximum daily energy and midday power. A similar "low AOD" spectrum, and even the AM1.5G spectrum, will also work quite well. The old G159 "AM1.5D" spectrum is a poor choice, unless maximizing morning and/or evening power production is a priority.

We also proposed an outdoor testing method for characterizing spectral skewing of the incident spectrum by the optics of a concentrator system. Here, "spectral skewing" refers to any change in the incident spectrum, which affects the current matching of a tandem cell. This method requires no modification of the concentrator system and is therefore suitable for long-term monitoring of systems in continuous use.

Our method is based upon the variation of the fill factor as the incident direct spectrum changes over the course of a clear, sunny day (see Figure 8). Sharp minima occur when cells $C, D$, and $E$ are current-matched. (Cells $A$ and $B$ are never current-matched, so only a single broad minimum is seen.) If the optics of a concentrator system preferentially remove "blue" top cell light from the incident spectrum, then a more blue-rich incident spectrum is required for current-matching, shifting the fill factor minima toward midday. If "red" bottom cell light is preferentially removed, then a more red-rich incident spectrum is required for current matching, so the fill factor minima will shift toward sunrise and sunset (away from midday). Such shifts can be used to detect and diagnose spectral skewing by concentrator optics, outdoors during continuous operation with no modification to the concentrator systems.

\section{Planned FY 2008 Activities}

During FY 2008, this project will complete several milestones, including these:

- Demonstrate an iLMM device with concentrator performance peak above 100 suns (September 2008).

- Demonstrate an iLMM cell with optimized second- and third-junction band gaps (September 2008).

- Study the effects of growth temperature, surfactants, and impurities on latticemismatched epitaxy (September 2008).

- Perform a comparative evaluation of degradation mechanisms in multijunction cells, and plan for work to mitigate identified problems (September 2008). 
5. FY 2007 Special Recognitions, Awards, and Patents

Dan David Prize: Quest for Energy

Dr. James Hansen, Dr. Sarah Kurtz, and Dr. Jerry Olson

United States Patent 7,229,498

Andrew Norman and Jerry Olson, "Nanostructures produced by phase-separation during growth of $(\mathrm{III}-\mathrm{V})_{1-\mathrm{x}}(\mathrm{IV})_{2}$ alloys; issued June 12, 2007.

Dr. Bill McMahon chaired the Solar Energy and Applications session of SPIE's Optics and Photonics conference, held 28-30 August 2007 in San Diego, California.

\section{Major FY 2007 Publications}

J.F. Geisz, S. Kurtz, M.W. Wanlass, J.S. Ward, A. Duda, D.J. Friedman, J.M. Olson, W.E. McMahon, T.E. Moriarty, and J.T. Kiehl, "High-efficiency GalnP/GaAs/InGaAs triple-junction solar cells grown inverted with a metamorphic bottom junction," Appl. Phys. Lett. 91, 023502 (2007).

J.F. Geisz, A.X. Levander, A.G. Norman, K.M Jones, M.J. Romero, "In situ stress measurement for MOVPE growth of high efficiency latticemismatched solar cells," J. Crys. Growth, in press.
A.J. Ptak, R. France, C.-S. Jiang, and R.C. Reedy, "The Effects of Bismuth on Wide-Depletion-Width GalnNAs Solar Cells," J. Vac. Sci. Technol. B, in press.

B. Fluegel, A. Mascarenhas, A. J. Ptak, S. Tixier, E. C. Young, and T. Tiedje, "Common origin of $E_{+}$ in $\mathrm{GaAs}_{1-\mathrm{x}} \mathrm{N}_{\mathrm{x}}$ and $\mathrm{GaAs}_{1-\mathrm{x}} \mathrm{Bi}_{\mathrm{x}}$ : invalidity of the BAC model," Phys. Rev. B, 76, 155209 (2007).

T. Liu, D. Korakakis, S. Chandril, T.H. Myers, and A.J. Ptak, "Bismuth surfactant effects for GaAsN and beryllium doping of GaAsN and GalnAsN grown by molecular beam epitaxy," J. Cryst. Growth 304, 402 (2007).

W.E. McMahon, K.E. Emery, D.J. Friedman, L. Ottoson, M.S. Young, J.S. Ward, C.M. Kramer, A. Duda, and S. Kurtz, "Fill Factor as a Probe of Current-Matching for GalnP $_{2} / \mathrm{GaAs}$ Tandem Cells in a Concentrator System during Outdoor Operation," Prog. in Photovoltaics, in press.

W. E. McMahon, K. E. Emery, D. J. Friedman, L. Ottoson, M. S. Young, J. S. Ward, C. M. Kramer, A. Duda, and S. Kurtz, "Daily Fill Factor Variation as a Diagnostic Probe of Multijunction Concentrator Systems during Outdoor Operation," High and Low Concentration for Solar Electric Applications II session of SPIE's Optics and Photonics conference (28-30 August 2007, San Diego); Proc. of SPIE, Vol. 6649, 664906 (2007). 


\title{
Electronic Materials and Devices Polycrystalline Thin-Film Device Research
}

\author{
Performing Organization: $\quad$ National Renewable Energy Laboratory (NREL) \\ Key Technical Contact: $\quad$ Timothy Gessert (NREL), 303-384-6451, tim_gessert@nrel.gov
}

DOE HQ Technology Manager: Marie Mapes, 202-586-3765, marie.mapes@hq.doe.gov

FY 2007 Budgets: $\quad$ \$2,537K (NREL)*

${ }^{*}$ Reference funding table in appendix

\section{Objectives}

- Finalize fit-up designs and complete the moving of equipment related to cadmium telluride (CdTe), cadmium indium gallium selenide (CIGS), transparent conducting oxides (TCO), reliability, and multi-user measurements from the NREL Solar Energy Research Facility (SERF) to the NREL Science and Technology Facility (S\&TF).

- Order initial components of the CIGS Process Development and Integration Laboratory (PDIL) platform in the S\&TF and continue the design development of the CdTe PDIL platform.

- Begin to reestablish research activities in S\&TF.

- Secure intellectual property (IP) related to the design of novel TCOs or for use in thin-film photovoltaics (PV).

- Assist with development of goals and metrics associated with CdTe and CIGS Technology Roadmaps, including the coordination of PDIL platform designs.

\section{Accomplishments}

- Completed fit-up designs and facilities coordination to enable $100 \%$ of equipment moves to the S\&TF: Cell Reliability laboratories were completed in October 2006, Contacts laboratories were completed in December 2006, CIGS laboratories were completed in February 2007, and CdTe laboratories were completed in April 2007.

- Restarted full research activities in the User Characterization and Cell Reliability laboratories.

- Completed facility and environment, safety, and health (ES\&H) requirements to allow functionality of $50 \%$ of major laboratory equipment in Contacts, CdTe, and CIGS laboratories.

- Placed the order for the CIGS PDIL platform chamber and related sputter chambers.

\section{Future Directions}

- Complete ES\&H and facilities requirements for full functionality of equipment in the remainder of the S\&TF laboratories.

- Finalize specification and engineering for the remaining components of the CIGS PDIL platform and place order(s). Finalize specification and engineering for initial components of CdTe PDIL platform and place order(s).

- Assess strategies that can establish a key metric for ultimate device performance immediately following CIGS deposition.

- Expand research on alternative processes for CIGS layer deposition.

- Accelerate research on high-band-gap absorber layers for tandem-junction polycrystalline thinfilm PV devices.

- Initiate research to foster partnerships with commercial glass companies to develop PV-specific products.

\section{Introduction}

The research undertaken by the NREL Polycrystalline Thin-Film Devices Group is directed at thin-film semiconductor materials, device properties, and fabrication processes to improve the efficiency, stability, and cost of photovoltaic solar energy conversion. This 
research can be broadly divided into three categories: (1) application of capabilities to assist industry and national research teams in addressing current problems; (2) exploration of specific techniques and processes to develop and transfer technology improvements that industry will soon need; and (3) providing the understanding that builds a solid technical foundation for the continuing improvement of thin-film PV products. Within this framework, the project supports CIGS, CdTe, and TCO thin-film technologies and develops procedures needed to understand and quantify the cell-level reliability of PV devices. Activities and time frames are consistent with those identified in the DOE Solar Program MultiYear Technical Plan and related Technology Roadmaps.

NREL's CIGS and CdTe technologies lead the world in demonstrated cell performance, while innovations related to high-quality TCO technologies are being rapidly assimilated into the thin-film industry. Because thin-film PV can generate lower cost PV electricity (in dollars per watt) than many historical alternatives, thin-film PV is the fastest growing segment of the PV market. Providing innovations and a solid technical foundation for this rapidly expanding industry is at the heart of the efforts of the NREL Polycrystalline Thin-Film Devices Group.

\section{Technical Approach}

The project is composed of research associated with CdTe and CIGS device development. FY 2007 funding for cell-level reliability was derived partly from the CdTe/CIGS device activity, and partly from the Module-Reliability Project. FY 2007 activities related to TCO research were also funded partly through the CdTe/CIGS device activity, and partly through an NREL Fellows Research Grant (providing approximately one fulltime graduate student). Research tasks are described below.

\subsection{CdTe Research}

- Baseline cell research, including advanced TCO development for superstrate devices

- Functionality and optimization of buffer layers

- Junction studies, including defect evolution during $\mathrm{CdCl}_{2}$ treatment and contacting

- Wide-band-gap absorbers for polycrystalline thin-film tandem solar cells

- Mechanisms of CdTe intrinsic device stability.

\subsection{CIGS Research}

- Baseline cell research, including advanced TCO development for substrate devices

- Examination of device performance in progressively thinner absorber layers

- Improved processes for larger-scale manufacture of CIS with high-performance

- Examination of CIGS intrinsic device stability modes.

\section{Results and Accomplishments}

Efforts in FY 2007 were dominated by activities associated with moving the research equipment of the Polycrystalline Thin-Films Group from their previous locations in the SERF laboratory building to new locations in the S\&TF laboratory building. Although the amount of time necessary for actual movement of the equipment was relatively short (and contracted to external groups), a significant amount of work on the part of the staff was required before and after each move. This included disconnection of utilities, separation of discrete components, and compliance with ES\&H pre-move procedures. After the move, technical staff performed the equipment reconstruction and modifications needed; coordinated the work of temporary technicians, S\&TF fit-up building contractors, and NREL facilities staff; and established (or reestablished) the required ES\&H documentation and compliance. By the end of FY $2007,100 \%$ of the equipment had been moved to the S\&TF, $100 \%$ of all SERF laboratories had been evacuated per ES\&H requirements, and approximately $50 \%$ of the S\&TF-located equipment was operational per ES\&H requirements. We estimate that activities associated with the S\&TF move consumed $50 \%$ $80 \%$ of the technical staff's time in FY 2007.

The following discussion describes results and accomplishments that were achieved in addition to SERF-S\&TF move-related activities.

The NREL Polycrystalline Thin-Film Devices project leads the world in the development of CdTe and CIGS thin films and related materials for use in high-performance, stable, single-junction solar cells. The project objectives support nearterm manufacturing, build a knowledge and technology base for future manufacturing improvements, and sustain innovation that supports progress toward the long-term Solar Energy Technologies Program goal of 15\%efficient commercial modules. Over the past decade, we have steadily improved the quality of

Photovoltaic R\&D

Fundamental Research 
the layers in the CdTe device and achieved a world-record efficiency of $16.5 \%$. Our work in CIGS set the world record in 2006 at $19.52 \%$. Our polycrystalline tandem solar cells of semitransparent CdTe atop CIS set a record of $15.3 \%$.

In FY 2007, shortly after the recommissioning of the CIGS deposition capabilities in the S\&TF in August, a CIGS device was fabricated that that has since been confirmed at $19.88 \%$ efficiency. This result exceeds the previous world-record efficiency $(19.52 \%)$ by a noticeable margin and has indicated a pathway toward even higher efficiency. A publication describing the process improvements that yielded these results was being finalized at the end of FY 2007. The result also confirms that the equipment and procedures used for our CIGS research have survived the rigors and design modifications associated with the move, and they can again be relied upon to produce the high baseline performance that has placed NREL at the forefront of the CIGS research community.

The reestablishment of CdTe device activities in FY 2007 was guided primarily by deliverables associated with a funds-in cooperative research and development agreement (CRADA) that began in mid-FY 2007 with Primestar Solar. (Note that FY 2007 interactions related to the Primestar CRADA were very beneficial to Primestar. Work at the end of the fiscal year resulted in cell performance levels well above $10 \%$; major contributions were made in the back contact, $\mathrm{CdC}_{12}$, and $\mathrm{CdTe}$ deposition processes.)

These activities required the reestablishment of routine $\mathrm{CdCl}_{2}$ processing, deposition of $\mathrm{Zn}_{\mathrm{x}} \mathrm{SnO}_{\mathrm{y}}$ and related buffer-layer materials, deposition of $\mathrm{Cd}_{2} \mathrm{SnO}_{4} \mathrm{TCO}$ materials, formation of $\mathrm{ZnTe}: \mathrm{Cu} / \mathrm{Ti}$ contacts, formation of graphite-paste contacts, and procedures related to baseline reliability measurements. By the end of FY 2007, all these processes and procedures were operational. Work was ongoing to reestablish the ES\&H documentation and equipment modifications required for the deposition of $\mathrm{CdTe}$ by close-space sublimation (CSS) and $\mathrm{SnO}_{2} / \mathrm{SnO}_{2}: \mathrm{F}$ by chemical vapor deposition (CVD).

Activities related to the development of novel TCOs focused on two material systems. The first was the development of an aluminum-doped zinc oxide (ZnO:Al) material designed to achieve higher infrared (IR) transmission for use in CIGS solar cells. Unlike "standard" $\mathrm{ZnO}$ :Al that contains $\sim 2$ wt. $\% \mathrm{Al}_{2} \mathrm{O}_{3}$ and is sputter-deposited in pure argon, our research determined that if a hydrogen/argon sputtering ambient is used, the $\mathrm{Al}_{2} \mathrm{O}_{3}$ content can be reduced to $\sim 0.05$ wt. $\%$ to provide significantly improved electron mobility and higher carrier activation. Because fewer free carriers (electrons) are required to produce a lowresistivity film, higher IR transparency results.

Preliminary incorporation of this new composition of $\mathrm{ZnO}: \mathrm{Al}$ into CIGS devices has yielded quantum efficiencies higher than those achieved on worldrecord CIGS devices. Therefore, further testing was actively proceeding at the end of the fiscal year.

The second TCO project involves the development of a $\mathrm{ZnO}+\mathrm{MgO}$ alloy $(\mathrm{ZnMgO})$ that may afford the ability to control the valance-band discontinuity at the $\mathrm{Zn}(\mathrm{Mg}) \mathrm{O} / \mathrm{CdS}$ interface, thereby allowing higher open-circuit voltages at higher gallium concentrations. The material may also have greater resistance to environmental corrosion when compared with that of $\mathrm{ZnO}$. Initial analysis of $\mathrm{ZnMgO}$ fabricated by radio-frequency sputter deposition has been encouraging, and results related to the incorporation of the layer into CIGS devices are expected in early FY 2008.

The final FY 2007 highlighted accomplishment is the placing of the order for the initial components of the PDIL CIGS platform tool. The components of this tool will allow CIGS deposition within the boundaries of the PDIL design guidance (i.e., 6-in. $x$ 6-in. format, multiple runs per chamber service (up to 100), 1.1-m transfer height, pod transfer, cassette loading, and robot compatibility). The order was placed with DCA Instruments in Finland, and acceptance testing by NREL staff at the DCA factory is scheduled for mid-FY 2008. The placement of this order marks a significant step toward establishing the first of the PDIL platforms being designed by the Polycrystalline Thin-Film Devices Group.

\section{Planned FY 2008 Activities}

In the early part of FY 2008, significant effort will continue to be directed at reestablishing research capabilities in the S\&TF, specifically in the area of CSS CdTe and CVD TCO deposition. This and other planned activities are as follows:

- Complete fit-up of the group's S\&TF laboratories to attain the functionality of the previous SERF laboratories.

- Finalize specification and engineering for the remaining components of the CIGS PDIL 
platform, including the solution-growth CdS component.

- Finalize specification for initial components of CdTe PDIL platform.

- Assess strategies that can establish a key metric for ultimate device performance immediately following CIGS deposition.

- Accelerate research on high-band-gap absorber layers for tandem-junction polycrystalline thin-film PV devices.

- Expand the research into alternative processes for CIGS layer deposition.

- Initiate partnerships with commercial glass companies to develop PV-specific products.

\section{FY 2007 Special Recognitions and Patents}

- T.A. Gessert was the Lead Symposium CoOrganizer for the Spring 2007 Meeting of the Materials Research Society (MRS) for a symposium on Thin Film Compound Semiconductor Photovoltaics.

- M. Contreras has been selected as a Symposium Co-Organizer for the 2007 Spring Meeting of the MRS.

- T.A. Gessert was elected chair-elect for the Vacuum Technology Division of the American Vacuum Society. His Chair responsibilities were to begin in January 2008.

- U.S. Patent No. 7,179,677 B2, was awarded on February 20, 2007, for " $\mathrm{ZnO} / \mathrm{Cu}(\mathrm{InGa}) \mathrm{Se} 2$ Solar Cells Prepared by Vapor Phase Zn Doping" to K. Ramanathan, F.S. Hasoon, S.E. Asher, J. Dolan, and J.C. Keane.

- A patent was filed, NREL (04-11) in May 2007 titled "Transparent Conducting Oxides and Production Thereof," by T.A. Gessert, Y. Yoshida, and T.J. Coutts.

- A record of invention was filed with DOE, IR 07-42, in September 2007 titled "High Quality Doped ZnO Thin Films," by T.A. Gessert, J. Duenow, T. Barnes, and T.J. Coutts.

\section{Major FY 2007 Publications}

- T. M. Barnes, X. Wu, J. Zhou, A. Duda, J. van de Lagemaat, T.J. Coutts, C.L. Weeks, D.A.
Britz, and P. Glatkowski, "Single-Wall Carbon Nanotube Networks as a Transparent Back Contact in CdTe Solar Cells," Appl. Phys. Lett., 90 (24), 243503 (2007).

- M. Contreras, T. Barnes, J. van de Lagemaat, G. Rumbles, T.J. Coutts, C. Weeks, P. Glatkowski, I. Levitsky, J. Peltola, and D.A. Britz, "Replacement of Transparent Conductive Oxides by Single-Wall Carbon Nanotubes in $\mathrm{Cu}(\mathrm{In}, \mathrm{Ga}) \mathrm{Se}_{2}$-Based Solar Cells," J. Phys. Chem. C: Nanomaterials and Interfaces, 111 (38), 14045-14048 (2007).

- R.G. Dhere, K. Ramanathan, J. Scharf, H. Moutinho, B. To, A. Duda, and R. Noufi, "Investigation of $\mathrm{Cd}_{1-x} \mathrm{Mg}_{\mathrm{x}} \mathrm{Te}$ Alloys for Tandem Solar Cell Applications," Proc. $4^{\text {th }}$ WCPVEC, Piscataway, NJ, IEEE, 546 (2006).

- J. N. Duenow, T.A. Gessert, D.M. Wood, T.M. Barnes, B. To, and T.J. Coutts, "Transparent Conducting Zinc Oxide Thin Films Doped with Aluminum and Molybdenum," J. Vac. Sci. Tech. A, 25(4), 955-960 (2007).

- T.A. Gessert, S. Asher, S. Johnston, A. Duda, and M.R. Young, "Formation of $\mathrm{ZnTe}: \mathrm{Cu} / \mathrm{Ti}$ Contacts at High Temperature for CdS/CdTe Devices," Proc. $4^{\text {th }}$ WCPVEC, Piscataway, NJ, IEEE, 432-435 (2006).

- T.A. Gessert, S. Asher, S. Johnston, M. Young, P. Dippo, and C. Corwine, "Analysis of CdS/CdTe Devices Incorporating a ZnTe:Cu Contact," Thin Solid Films, 515, 6103-6106 (2007).

- X. Wu, J. Zhou, A. Duda, Y. Yan, G. Teeter, S. Asher, W.K. Metzger, S. Demtsu, S.H. Wei, and R. Noufi, "Phase Control of $\mathrm{Cu}_{\mathrm{x}} \mathrm{Te}$ Film and its Effects on CdS.CdTe Solar Cell," Thin Solid Films, 515 (15), 5798-5803 (2007).

- J. Zhou, X. Wu, A. Duda, G. Teeter, and S.H. Demtsu, "Formation of Different Phases of $\mathrm{Cu}_{\mathrm{x}} \mathrm{Te}$ and Their Effects on CdTe/CdS Solar Cells," Thin Solid Films, 515 (18), 7364-7369 (2007). 


\section{Industry Partners}

The following organizations partnered in the project's research activities during FY 2007.

\begin{tabular}{|l|l|l|c|c|}
\hline \multicolumn{1}{|c|}{$\begin{array}{c}\text { Organization/ } \\
\text { Principal } \\
\text { Investigator }\end{array}$} & \multicolumn{1}{|c|}{ Location/e-mail } & \multicolumn{1}{|c|}{$\begin{array}{c}\text { Description/Title of } \\
\text { Research Activity }\end{array}$} & $\begin{array}{c}\text { FY 2007 } \\
\text { (\$K) }\end{array}$ & $\begin{array}{c}\text { Cost } \\
\text { Share } \\
\text { (\$K) }\end{array}$ \\
\hline $\begin{array}{l}\text { Primestar Solar } \\
\text { Fred Seymour }\end{array}$ & $\begin{array}{l}\text { Golden, CO } \\
\text { fred.seymour@primestarsolar.com }\end{array}$ & $\begin{array}{l}\text { Scale of CdTe Photovoltaic } \\
\text { Device Processes for } \\
\text { Commercial Applications }\end{array}$ & 316 & 20 \\
\hline
\end{tabular}




\title{
Electronic Materials and Devices Process Technology and Advanced Materials
}

\author{
Performing Organization: $\quad$ National Renewable Energy Laboratory (NREL) \\ Key Technical Contact: David Ginley (NREL), 303-384-6573, david_ginley@nrel.gov
}

DOE HQ Technology Manager: Jeffrey Mazer, 202-586-2455, jeffrey.mazer@ee.doe.gov

FY 2007 Budget: $\quad \$ 764 K^{*}$

${ }^{*}$ Reference funding table in appendix

\section{Objectives}

- Develop organic-based thin-film photovoltaics (OPV).

- Apply combinatorial methods to identify optimum material and demonstrate conductivity $>6200 \mathrm{~S} / \mathrm{cm}$ in transition metal oxides.

- Develop novel solution-based processes for photovoltaics (PV), including metallization and copper indium gallium selenide (CIGS).

\section{Accomplishments}

- Developed new combinatorial capabilities for Raman, work function, deposition, and elemental analysis; identified two systems with conductivities $>6000 \mathrm{~S} / \mathrm{cm}$.

- Filed applications for six patents on the direct printing of precursors for copper indium diselenide (CIS) solar cell absorbers and metallization for Si solar cell contacts.

- Developed state-of-the-art infrastructure for OPV; obtained a 4.2\%-efficient bulk heterojunction cell and $>3 \%$ inverted OPV solar cells using zinc oxide ( $\mathrm{ZnO})$ anodes; and initiated reliability lifetime studies.

\section{Future Directions}

- Develop improved polymers for OPV and address interface issues to achieve a 6\%-efficient solar cell with $>2000$ hour stabilities.

- Transfer ink-based technology to partners.

- Initiate partnerships with awardees in the Solar America Initiative (SAI).

\section{Introduction}

The Process Technology and Advanced Concepts Group supports the DOE Solar Program by developing new process technology and advanced device concepts in areas that support a wide range of solar technologies. First, we apply our capabilities to assist industry and the national research teams in addressing current problems. Second, we explore specific techniques and processes to develop and transfer technology improvements that industry will soon need. Finally, we seek to create new technologies and lead the development of the knowledge base and tools for the future of photovoltaics. Through these activities, the group analyzes and develops PV technologies at the cell and module level, in all of the application targets and time frames identified in the DOE Solar Program Multi-Year Technical Plan.

The relatively low cost of electric power in the United States will drive PV production to a lower cost-point than is needed in most of the rest of the world. This requires new processes that enable production methods that avoid vacuum processing (which is costly), minimize mechanical stress (to reduce breakage and increase yield), or dramatically increase throughput. The exploration and development of technologies to exploit these three opportunities compose the primary tasks of the Process Technology and Advanced Concepts Group. 


\section{Technical Approach}

Process and Advanced Concepts

- Jointly with Sandia National Laboratories (SNL), develop next-generation OPV devices and begin to look at issues of scalability and lifetime

- Develop combinatorial materials science deposition, diagnostics, and data analysis tools and explore application to transparent conducting oxide (TCO) materials; these will be applied to silicon (Si), CIS, and cadmium telluride (CdTe) as well as to OPV

- Develop ink-jet processing of electronic materials for application to metallization and semiconductor materials for $\mathrm{Si}, \mathrm{CIS}$, and OPV

- Develop an advanced laser process station for the laser scribing, laser annealing, and laser recrystallization of PV device structures

- Initiate Cooperative Research and Development Agreements (CRADAs) (e.g., HelioVolt, Evergreen Solar, BP, Konarka, TDA, Plextronics, and XJET).

\section{Results and Accomplishments}

\section{Process and Advanced Concepts}

3.1 Jointly with SNL, develop next-generation OPV devices and begin to look at the issues of scalability and lifetime. Our OPV program has begun to gain national and international attention as a result of our integrated approach to new acceptor and donor development along with our developments in new process technology, new characterization tools specific to OPV, and initial results addressing the lifetime (intrinsic and extrinsic) of the devices. Figure 1 shows some early encapsulation results for a bulk heterojunction device.

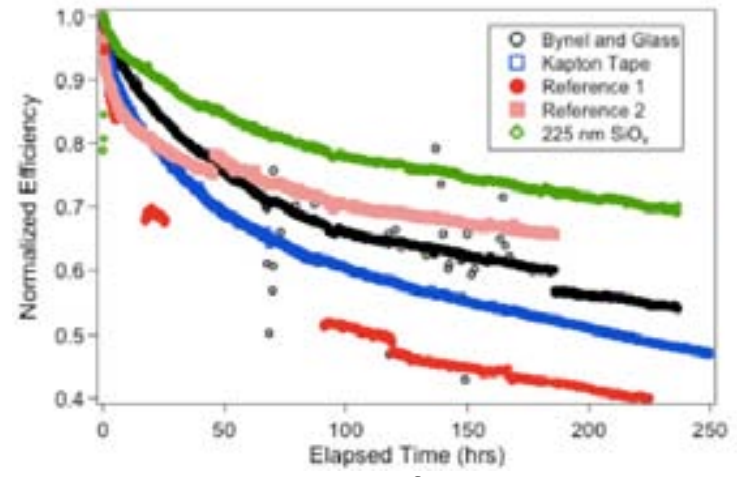

Fig. 1. Initial aging data for a bulk heterojunction device with various encapsulation techniques showing strong extrinsic effects, potentially of water and oxygen (accepted for publication in Solar Energy Materials).

Photovoltaic R\&D

Fundamental Research

Electronic Materials and Devices
Table 2. Deposition Results

\begin{tabular}{|c|c|c|c|c|c|c|}
\hline $\begin{array}{l}\text { PEDOT } \\
\text { Deposition } \\
\text { Method }\end{array}$ & $\begin{array}{c}\text { Best } \\
\text { Device } \\
\text { Efficiency } \\
(\%)\end{array}$ & $\underset{(\mathrm{mV})}{V_{w}}$ & $\underset{(\mathrm{mi})}{J_{s}}$ & $\begin{array}{l}F F \\
(\%)\end{array}$ & $\begin{array}{c}\text { PEDOT } \\
\text { Film } \\
\text { Thickness } \\
\text { (nm) }\end{array}$ & $\begin{array}{c}\text { Local } \\
\text { Roughness } \\
\text { (nm) by } \\
\text { AFM }\end{array}$ \\
\hline Spin & 3.63 & 615 & 9.46 & 39.5 & 48 & 1.2 \\
\hline Inkjet & 3.31 & 618 & 9.78 & 52,9 & $16 \pm 11$ & 1.5 \\
\hline Spray & 3.53 & 612 & 9.24 & 60.0 & 70 & 1.3 \\
\hline
\end{tabular}

Table 2 shows how the hole injection layerpoly(3,4-ethylenedioxythiophene)-polystyrene sulfonate (PEDOT/PSS) - can be deposited by spin coating, or the more scalable ink-jet printing, or ultrasonic spray deposition with nearly identical results. Recently, we have been able to spray the bulk heterojunction in air as well with $>2 \%$ conversion efficiency over a 1-in.-square device.

3.1 Develop combinatorial materials science deposition, diagnostics, and data analysis tools for application TCO materials. These will be applied to Si, CIS, and CdTe as well as OPV. The combinatorial tool development has continued with the addition of new tools for mapping work function, optical properties, and conductivity. We have now automated many of the tools and the associated data collection to move toward an integrated data management system. These have been applied to an increasingly broad range of problems, with a focus on TCOs. A key focus has been the continued investigation of amorphous TCO materials because of their excellent conductivity, transparency, smoothness, processability, and low-temperature deposition.

$$
\lambda(\mathrm{nm})
$$

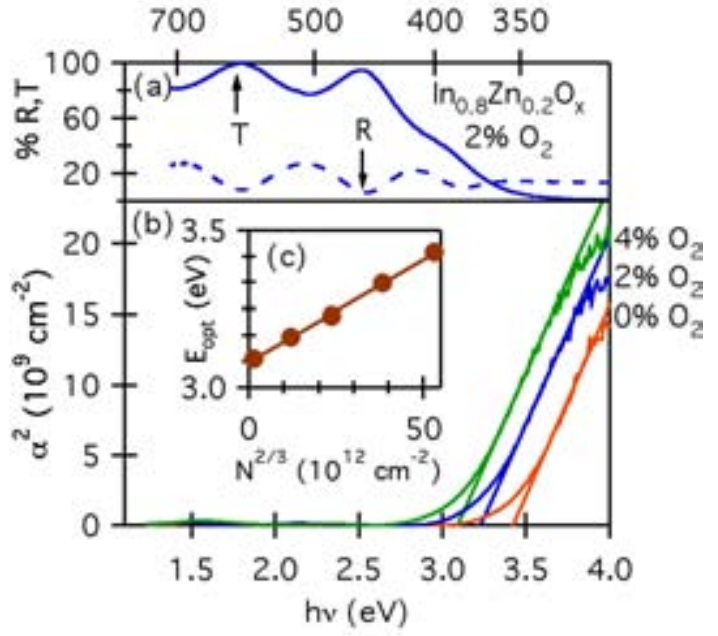

Fig. 2. (a) Conductivity ( $\sigma)$, (b) carrier concentration $(N)$, and (c) Hall mobility $(\mu)$.of the amorphous films vs. oxygen content during sputtering. 


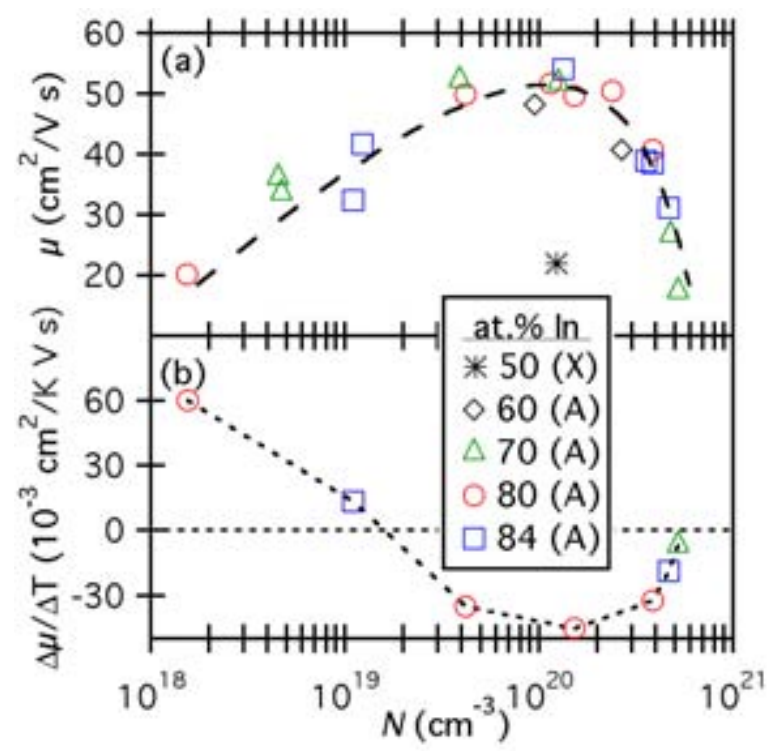

Fig. 3. (a) Hall mobility $(\mu)$ versus carrier concentration $(N)$ for amorphous and crystalline compositions denoted by $\mathrm{A}$ and $\mathrm{X}$ respectively, with a dashed line included as a guide to the eye and (b) slope of mobility versus temperature at various values of $N$.

3.3 Ink-jet processing of electronic materials: application to metallization and semiconductor materials for Si, CIS, and OPV. This work has focused on the development of new inks for CIGS solar cells and inks for contacts to PV devices. In the former case, this project focuses on the development of an atmospheric and direct write ink-based approach to CIS solar cells. Accomplishing this involves a multistage process of developing precursor inks for the various components of the cell and then integrating them via ink-jet printing and rapid thermal processing into actual devices. This period we continued to develop our new copper selenide (CuSe) ink, which has a much more appropriate $\mathrm{Cu} / \mathrm{Se}$ ratio and is leading to improved films with stoichiometry control. We have incorporated our Ga precursor with our In precursor to produce good IGS films. The combined process solution precursors with rapid thermal or FASST processing has led to the development of films with very good grain structures, as seen in Figure 4.

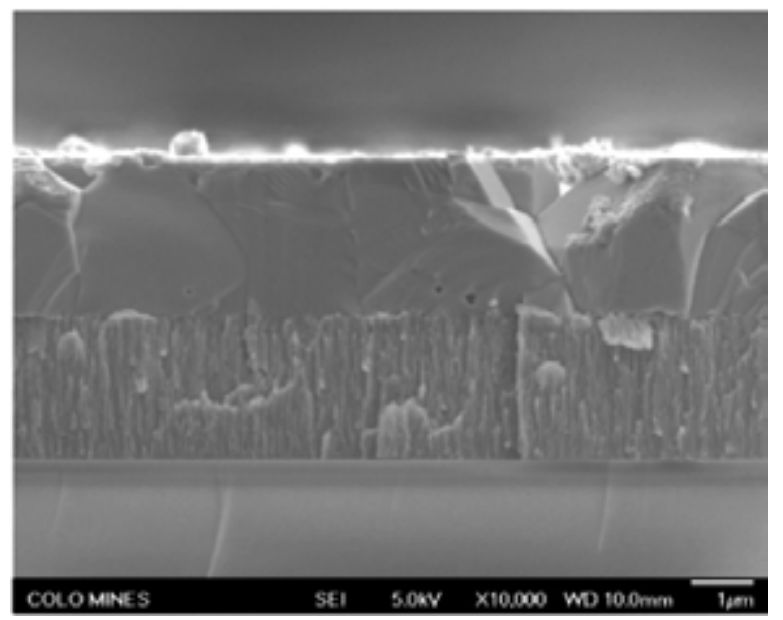

Fig. 4. Ink-based precursors incorporated with FASST processing to produce large-grain CIS. Scale bar is one micron.

The University of Minnesota has continued to focus on the development and processing of precursors to $\mathrm{ZnO}$ films. The primary focus this period has been to continue to evolve the $\mathrm{Ga}$ doped $\mathrm{ZnO}$ materials and to work on film formation. We have also begun to synthesize new precursors for the TCOs at NREL with a focus on IZO. A route has been identified that produces amorphous material at relatively low temperature, but the film quality is not good. Work has focused on optimizing film deposition for the HelioVolt process and scaling to 6 -in. wafers. Using this approach, we now have over $4 \%$-efficient solar cells over large areas. We have continued to improve solution-based metallizations by ink-jet and have demonstrated that we can write nickel (Ni) over scribed cell materials with good conductivity. This project should lead to a novel, low-cost, scalable production technique for CIS solar cells.

In the latter case, this includes Ni/silver ( $\mathrm{Ag}$ ) and $\mathrm{Ni} / \mathrm{Cu}$ for CIGS and Ag with a variety of burnthrough and doping agents for Si solar cells. We have been able to achieve up to $13 \%$-efficient $\mathrm{Si}$ solar cells on small areas $\left(>1 \mathrm{~cm}^{2}\right)$ with printed contacts and burn-through agents and are scaling the process for 6-in. wafers through the implementation of two next-generation printing systems. Figure 5 is a close-up of the $\mathrm{Ag}$ lines on Si showing a width of $40-50 \mu \mathrm{m}$ for a multilayer line with a thickness of $10 \mu \mathrm{m}$. 


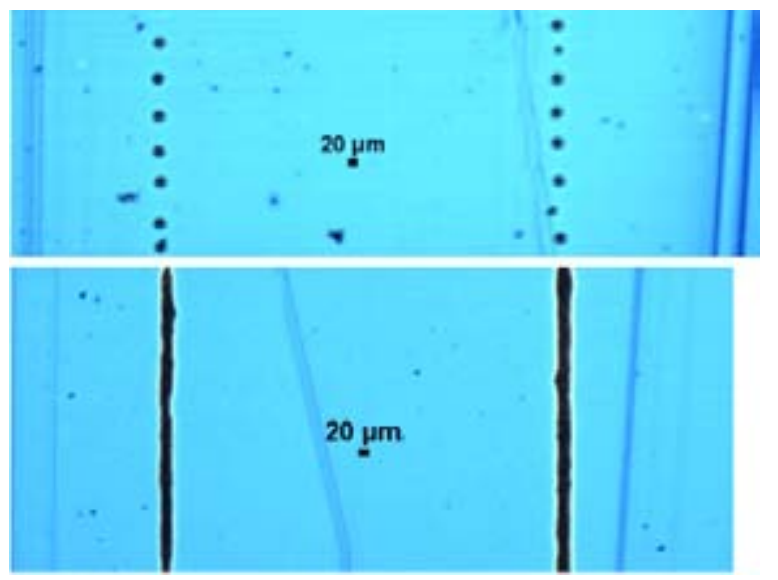

Fig. 5. Both drop on demand and multilayer printing of $\mathrm{Ag}$ on silicon nitride coated Si wafer.

3.4 Develop an advanced laser process station for the laser scribing, laser annealing, and laser recrystallization of $P V$ device structures. Figure 6 illustrates the current version of the laser process station. It has an excimer, an yttrium aluminum garnet (YAG), and a $\mathrm{CO}_{2}$ laser to be able to scribe and process from the ultraviolet to the infrared. Current optics allow for $1-\mu \mathrm{m}$ spot size with $0.1-\mu \mathrm{m}$ table positioning accuracy. The system has built-in particle removal and beam positioning and indexing systems.

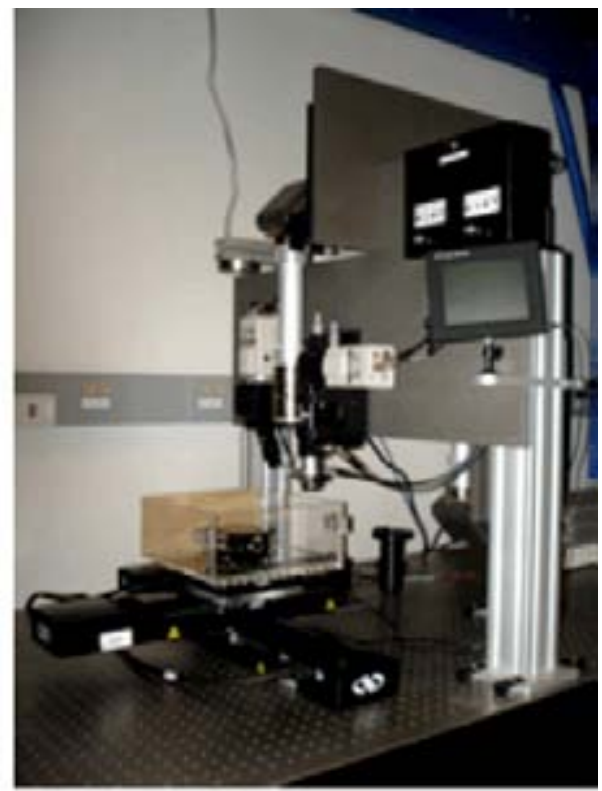

Fig. 6. Laser process station (current version).

\section{Planned FY 2008 Activities}

The primary focus will be on the following:

- Continued improvement of OPV devices, processing to larger areas and addressing reliability and packaging issues

- Technology transfer of ink-based contacts and absorbers and development of nextgeneration inks and processing

- Use of laser processing to develop large-grain template layers for thin-film Si on glass

- Development of new TCOs with a focus on very high performance, stability, interfacial chemistry, and work function; continued examination of amorphous systems and development of ink-based approaches to highperformance TCOs.

\section{FY 2007 Special Recognitions, Awards, and Patents}

Numerous project staff has been chosen by their peers to lead professional organization activities as general chair, program chair, session organizer, session chair, tutorial instructor, and similar honors. The more notable of these recognitions are:

- David Ginley served as volume organizer for the Materials Research Society's MRS Bulletin Special Addition on Harnessing Materials for Energy, a two-year project published in April

- David Ginley is editor of a Springer book on TCOs, to be published this year

- David Ginley, John Perkins, and Sean Shaheen have all been symposia organizers for MRS, SPIE, and the American Physical Society (APS) for PV or Combi-related topics.

- David Ginley and Joseph Berry received the DOE Illuminating Ideas Award for their joint effort with Pacific Northwest National Laboratory to develop new TCOs for organic light-emitting diodes based on the Combi work developed in the PV program.

- David Ginley is chairing the sustainable energy symposia at the first MRS/Chinese MRS meeting.

The group has also generated new intellectual property:

- Novel process approaches for InZnO

- Ink precursors for CIGS materials

- New contact metallizations for ink-jet contacts to solar cells. 


\section{Major FY 2007 Publications}

E. Bundgaard, S.E. Shaheen, F.C. Krebs, and D.S. Ginley, "Bulk heterojunctions based on a low band gap copolymer of thiophene and benzothiadiazole," Solar Energy Materials \& Solar Cells 91(17), 1631-1637 (2007).

M.S. Dabney, and D.S. Ginley, "In situ etch rate measurements of thin film combinatorial libraries," Applied Surface Science 254(3), 687-691 (2007).

M.S. Dabney, M.F.A.M. van Hest, C.W. Teplin, S. Arenkiel, J.D. Perkins, and D.S. Ginley, "Pulsed laser deposited $\mathrm{Nb}$ doped $\mathrm{TiO}_{2}$ as a transparent conducting oxide," Thin Solid Films 516(12), 41334138 (2008).

E. Fortunato, D. Ginley, H. Hosono, and D.C. Paine, "Transparent conducting oxides for photovoltaics," MRS Bulletin 32(3), 242-247 (2007).

D.S. Ginley, C.J. Curtis, A. Miedaner, M.F.A.M. van Hest, and T. Kaydanova, "Metal inks from metal-organic precursor," U.S. Pat. Appl. Publ., 11 pp. (2008).

A.B. Kozyrev, V.N. Osadchy, D.M. Kosmin, A. V. Tumarkin, T. Kaydanova, and D. Ginley, "Time tuning of ferroelectric film varactors under pulse voltages," Applied Physics Letters 91(2), 022905/1-022905/3 (2007).

A.J. Leenheer, A. Miedaner, C.J. Curtis, M.F.A.M. van Hest, and D.S. Ginley, "Fabrication of nanoporous titania on glass and transparent conducting oxide substrates by anodization of titanium films," Journal of Materials Research 22(3), 681-687 (2007).

A.J. Leenheer, J.D. Perkins, M.F.A.M. van Hest, J.J. Berry, R.P. O'Hayre, and D.S. Ginley, "General mobility and carrier concentration relationship in transparent amorphous indium zinc oxide films," Physical Review B: Condensed Matter and Materials Physics 77(11), 115215/1115215/5 (2008).

A. H. Mahan, S.P. Ahrenkiel, R.E.I. Schropp, H. Li, and D.S. Ginley, "A comparison of grain nucleation and grain growth during crystallization of HWCVD and PECVD a-Si:H films," Thin Solid Films 516(5), 529-532 (2008).

D.C. Olson, S.E. Shaheen, R.T. Collins, and D.S.
Ginley, "The Effect of Atmosphere and $\mathrm{ZnO}$ Morphology on the Performance of Hybrid Poly(3hexylthiophene)/ZnO Nanofiber Photovoltaic Devices," Journal of Physical Chemistry C 111(44), 16670-16678 (2007).

D.C. Olson, Y.-J. Lee, M.S. White, N. Kopidakis, S.E. Shaheen, D.S. Ginley, J.A. Voigt, and J.W.P. $\mathrm{Hsu}$, "Effect of Polymer Processing on the Performance of Poly(3-hexylthiophene)/ZnO Nanorod Photovoltaic Devices," Journal of Physical Chemistry C 111(44), 16640-16645 (2007).

J. D. Perkins, M.F.A.M. van Hest, C.W. Teplin, M.A. Gillispie, M.F.A.M. van Hest, M.S. Dabney, J.D. Perkins, and D.S. Ginley, "Sputtered Nb- and Ta-doped TiO2 transparent conducting oxide films on glass," Journal of Materials Research 22(10), 2832-2837 (2007).

J. Piris, N. Kopidakis, D.C. Olson, S.E. Shaheen, D.S. Ginley, and G. Rumbles, "The locus of free charge-carrier generation in solution-cast Zn1xMgxO/poly(3-hexylthiophene) bilayers for photovoltaic applications," Advanced Functional Materials 17(18), 3849-3857 (2007).

M.O. Reese, M.S. White, G. Rumbles, D.S. Ginley, and S. Shaheen, "Optimal negative electrodes for poly(3-hexylthiophene):[6,6]-phenyl C61-butyric acid methyl ester bulk heterojunction photovoltaic devices," Applied Physics Letters, 92(5), 053307/1-053307/3 (2008).

B. Roy, J.D. Perkins, T. Kaydanova, D.L. Young, M. Taylor, A. Miedaner, C. Curtis, H.-J. Kleebe, D.W. Readey, and D.S. Ginley, "Preparation and characterization of sol-gel derived copperstrontium-oxide thin films," Thin Solid Films 516(12), 4093-4101 (2008). 


\title{
Electronic Materials and Devices Silicon Materials and Devices
}

\author{
Performing Organization: National Renewable Energy Laboratory (NREL) \\ Key Technical Contacts: $\quad$ Qi Wang (NREL, Wafer Si), 303-384-6681, qi_wang@nrel.gov \\ Howard Branz (NREL, Film Si), 303-384-6694, howard_branz@nrel.gov
}

DOE HQ Technology Manager: Marie Mapes, 202-586-3765, marie.mapes@ee.doe.gov

FY 2007 Budgets: $\quad \$ 2,544 K^{*}$

${ }^{*}$ Reference funding table in appendix

\section{Objectives}

- $\quad$ Conduct scientific research on silicon Si-based materials and photovoltaic (PV) devices.

- Demonstrate scalable epitaxy technique for film-Si on glass.

- Understand Si based solar cells.

\section{Accomplishments}

- Achieved $19.1 \%$ heterojunction c-Si solar cell.

- Achieved low temperature high growth rate epi-Si.

- Developed the "cone kinetics" model to guide film-Si growth.

- Developed high rate low gap a-SiGe:H solar cell by hot-wire chemical vapor deposition (HWCVD).

- Completed the purchase of Si-cluster tool.

\section{Future Directions}

- Develop low-cost and high-efficiency film Si.

- Develop high efficiency c-Si solar cell for manufacturing.

- Develop novel Si for low cost and high efficiency Si.

- Collaborate with U.S. industry partners.

\section{Introduction}

The Silicon Materials and Devices Group makes science and technology advances that can help meet the DOE Solar Energy Technologies Program (SETP) targets in the near-term, midterm and long-term. Silicon-based PV modules accounted for more than $96 \%$ of commercial sales in 2007 , at a module selling price of $\$ 3-4$ per watt (W). To reach the DOE 2020 goal of $\$ 0.06 / \mathrm{kWh}$ PV electricity, $18 \%$ wafer-based modules would likely need to sell at about $\$ 1 / \mathrm{W}$. Fifteen percent film Si modules could sell at a slightly lower cost. This will require a combination of increases in cell efficiency and reduced costs in almost all components. Silicon remains the material of choice for terrestrial power photovoltaics (PV) because silicon is abundant, non-toxic and has demonstrated marketplace acceptance. There is a well-developed industrial base in all forms of silicon, and an enormous, rapidly growing, $\mathrm{Si}$ scientific literature that effectively leverages our PV research and development (R\&D) spending.

\section{Technical Approach}

Our main project in the wafer silicon field in fiscal year (FY) 2007 was the development of silicon heterojunction (SHJ) surface passivation and solar cells. Superior passivation will lead to high opencircuit voltages and a key factor for high efficiency. In the film silicon field, we worked on developing high efficiency low gap a-SiGe:H solar cell at $4 \AA / s$ to harvest red light in the multijunction cell. We also worked on high quality low temperature epitaxial (epi) Si growth to use less Si material in c-Si solar cells on low-cost substrates. We purchased a versatile multi-chamber Si cluster tool for future advanced Si research and collaboration with industry partners. 


\section{Results and Accomplishments}

The SHJ is fabricated by putting ultra-thin hydrogenated amorphous silicon (a-Si:H) layers on C-Si and this passivation is a key step toward fabrication of high-efficiency silicon solar cells $(21 \%-25 \%$ potential $)$ at low temperatures $\left(<250^{\circ} \mathrm{C}\right)$ with simple processing. Low-temperature is critical for PV-cost reduction through use of thinner wafers that incorporate less Si feedstock. In FY 2007, we made our best SHJ cell to-date with a confirmed efficiency of $19.14 \%$ and a $V_{\text {oc }}$ of 678 $\mathrm{mV}$ on p-type wafer. This is the best reported efficiency on a p-type wafer using an SHJ structure. We also achieved the best reported open circuit voltage of $0.689 \mathrm{~V}$ with a fill factor of 0.81 . This further demonstrates the passivation quality of hot-wire a-Si:H and positions our group to implement advanced device concepts requiring the extremely low SRV of the SHJ. We expect that $\mathrm{PV}$ cells employing SHJ passivation and/or emitters to be manufactured in the United States within the next 5 years and are collaborating with an industrial group to make this a reality.

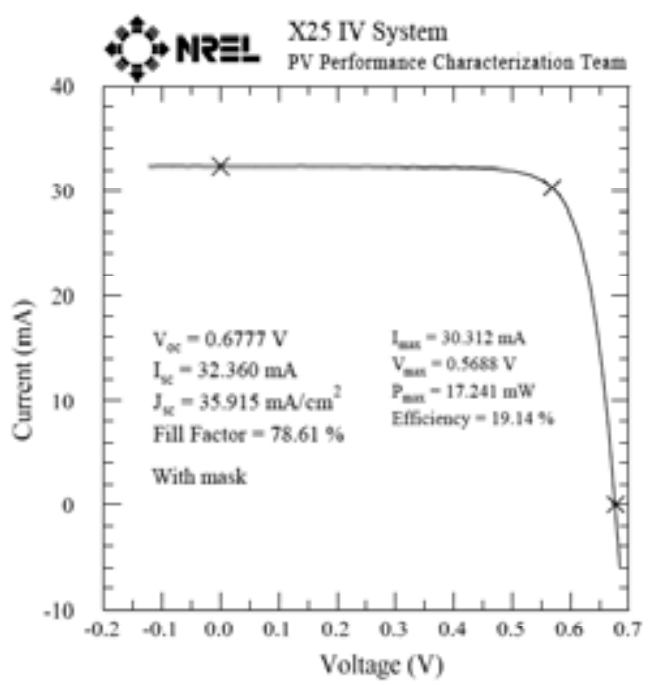

Fig.1 Silicon heterojunction solar cell on p-type wafer with a cell mask area of $0.9 \mathrm{~cm}^{2}$

We also worked to improve the lowgap (bottom) cells for multijunction Si film PV by use of hot-wire CVD a-SiGe:H at $4 \AA /$ s to effectively convert red photons to electricity. Microcrystalline $\mathrm{Si}$ bottom cells have not yet been shown to have adequate properties at economical deposition rates, so commercially successful multijunction rely mainly upon a-SiGe:H bottom cells. When the Ge content is increased to reduce the bandgap, the PECVD a-
SiGe:H electronic quality declines precipitously. We have demonstrated remarkably high quality aSiGe:H by use of a Ta-filament in HWCVD and have a collaborative program with United Solar to implement high-quality graded-bandgap devices compatible with their multijunction approach. This project resulted in solar cells with initial efficiency of $8.65 \%$ at a $1.45 \mathrm{eV}$ average bandgap.

An important applied science achievement was application of the cone kinetics model of 2-phase microstructure formation to the problem of nanocrystalline and protocrystalline $\mathrm{Si}$ film formation. The 'cone kinetics' model, explains development of cone-shaped inclusions during nanocrystalline silicon film growth and during lowtemperature silicon epitaxy breakdown. We have now extended this model with a publication in Applied Physics Letters to protocrystalline ('edge') amorphous silicon, $\mathrm{Si}$ heterojunctions and other $\mathrm{Si}$ film morpholologies. The model predicts cone growth during thin-film deposition by plasmaenhanced and other chemical vapor deposition techniques when there is isolated nucleation of a second phase which grows faster than the first phase together with isotropic growth. Protocrystalline amorphous silicon and other embedded crystallite forms are understood as nucleation of a slightly slower-growing phase that is overtaken by the more rapid growing matrix phase. Our new 'morphology phase diagram' explains the continuously varying nanocrystalline film morphology with increasing $\mathrm{H}$-dilution of silane precursors. This kind of scientific understand should lead to better control of morphologies critical to thin-film silicon solar cell performance.

Our mid-term, high-risk goal (5-10 year) is to develop crystal $\mathrm{Si}$ films on glass that can be used to fabricate $15 \%-P V$ cells. We aim for crystal Si efficiencies at costs per unit area at manufacturing costs more characacteristic of thin-films $\left(\sim 100 / \mathrm{m}^{2}\right)$. Development of this wafer-equivalent on glass requires excellent $\mathrm{Si}$ seed layers on the glass and a capability for rapid expitaxial thickening with about 5-20 microns of Si. We succeeded in making a 10-fold increase in epitaxial thickness from our best previous results; we can now grow 10 microns of film silicon by the scalable HWCVD technique at about $620^{\circ} \mathrm{C}$.

Even with improved epitaxy, defects in the Si films on glass will require hydrogen passivation, as in today's high-performance multicrystalline PV cells. We have developed an inductively-coupled hydrogenation system combined with a rapid 
thermal anneal capability. Nearly completed, this system will improve our film-PV solar cells once it has passed safety review.

Despite worldwide attention, the problem of growing quality seed layers on glass for epitaxy has been difficult. Collaborators at Hahn-Meitner Institute in Berlin have provided us thin layers on glass made by the Al-induced layer exchange method; these have 10-50 micron grain sizes with only a weak preferential orientation. We demonstrated the ability to grow microns of highquality silicon on these seeds on borosilicate glass. We appear to grow epitaxially on each grain, but of course the grain boundaries propagate through the layer. We have negotiated a Cooperative Research and Development Agreement (CRADA) with a U.S. industrial partner who can make superior grains on inexpensive substrates. Through the CRADA, they will supply seeds and we will demonstrate epitaxial thickening and work toward PV devices on their layers.

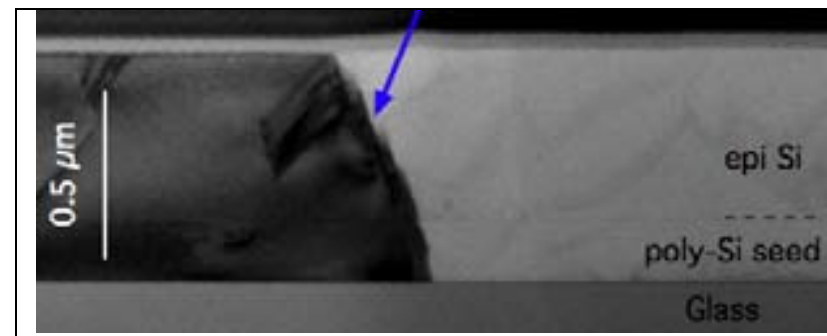

Fig. 2. Transmission electron micrograph of HWCVD epitaxial silicon layer grown on C-Si seed layer on borosilicate glass. Al-induced $\mathrm{C}$-Si layer (from HMI-Berlin) shows grain bound boundary that propagates into epitaxy (arrow).

Finally, our Group worked with the NREL Engineering Team toward construction and hookup of the first major cluster tool to be installed in NREL's large Process Development and Integration Laboratory (STF-PDIL). The system has 8 deposition chambers, including both PECVD and HWCVD chambers with high-throughput deposition capabilities. There is also a sputtering chamber in which we can finish solar cells with conducting oxides after a-Si:H layer deposition. The substrate size is significant larger than our previous capabilities, up to $15.7 \times 15.7 \mathrm{~cm}^{2}$. In FY 2008 , this cluster tool will be a keystone of our thin-film deposition capabilities for amorphous silicon and wafer Si solar cell development.

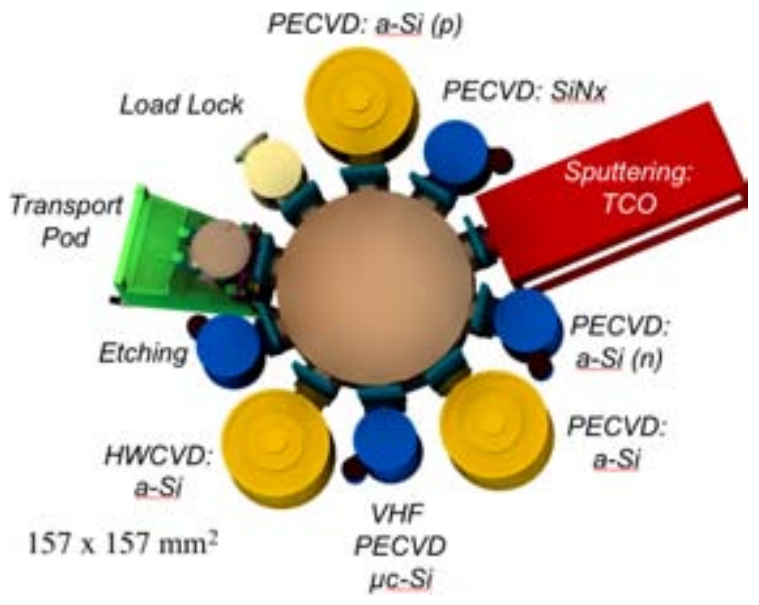

Fig. 3 Schematic diagram of $\mathrm{Si}$ cluster tool delivered to PDIL in STF building.

\section{Planned FY 2008 Activities}

Wafer Silicon

- Purchase and install CZ-crystal grower.

- Develop large size heterojunction solar cells.

- Study surface and bulk passivation of c-Si.

- Prototype interdigitated solar cell using heterojunction a-Si:H layer.

Film Silicon

- Improve low defect low temperature epitaxial growth.

- Demonstrate epitaxial growth on candidate Si seed layers.

- Develop hydrogenation methods for small grain Si film and devices.

- Install the Si cluster tool and develop a-Si:H based films and devices in.

\section{FY 2007 Patents}

- Q. Wang and E. Iwaniczko, U.S. Patent No. 7,122,736 B2.

- P. Stradins and Q. Wang, "Rapid thermal processing by stamping," filed 2007.

- Q. Wang et al, "Low-temperature junction growth using hot-wire chemical vapor deposition," filed 2007.

\section{Major FY 2007 Publications}

V. Gowrishankar, S. Scully, A. Chan, Q. Wang, H. Branz, and M.D. McGehee, "Exciton harvesting, charge transfer and charge-carrier transport in amorphous-silicon nanopillar / polymer hybrid solar cells," J. Applied Physics, August 2007. 
S. Datta, J. Cohen, Y. Xu, A. Mahan, and H. Branz, "Junction capacitance study of an oxygen impurity defect exhibiting configuration relaxation in amorphous silicon-germanium alloys deposited by hot-wire CVD," J. Non-Crystalline Solids.

D. Young, D. Williamson, P. Stradins, Y. Xu, L. Gedvilas, E. Iwaniczko, Y. Yan, H. Branz, and Q. Wang, "Nanostructure evolution in hydrogenated amorphous silicon during hydrogen effusion and crystallization," Appl. Phys. Lett., Vol. 90, 81923-6, 2007.

C. Teplin, E. Iwaniczko, B. To, H. Moutinho, P. Stradins, and $\mathrm{H}$. Branz, "Breakdown physics of low-temperature silicon epitaxy from silane radicals" Phys. Rev. B, Vol. 74, 235428, 2006.

J. Doyle, Y. Xu, R. Reedy, H. Branz, and A. Mahan, "Film Stoichiometry and Gas Phase Chemistry in HWCVD of a-SiGe:H," Thin Solid Films, 10 July 2007.

H. Branz, C. Teplin, D. Young, M. Page, E. Iwaniczko, L. Roybal, R. Bauer, A. Mahan, Y. Xu, P. Stradins, T. Wang, and Q. Wang, "Recent advances in hot-wire CVD R\&D at NREL: From $18 \%$ silicon heterojunction cells to silicon epitaxy at glassw-compatible temperatures," Thin Solid Films, 18 June 2007.

J. Cohen, S. Datta, K. Palinginis, A. Mahan, E. Iwaniczko, Y. Xu, and H. Branz, "Defect analysis of thin film Si-based alloys deposited by hot-wire CVD using junction capacitance methods," Thin Solid Films, 18 June 2007.

V. Gowrishankar, S. Scully, M. McGehee, Q. Wang, and H. Branz, "Exciton splitting and carrier transport across the amorphous-silicon/polymer solar cell interface," Appl. Phys. Lett, Vol. 89, 252102, 2006.

M. Du, H. Branz, R. Crandall, and S. Zhang, "Selftrapping enhanced carrier recombination at lightinduced boron-oxygen complexes in silicon," Phys. Rev. Lett., Vol. 97, 256602, 2006.

P. Stradins, C. Teplin, D. Young, Y. Yan, H. Branz, and $\mathrm{Q}$. Wang, "Crystallization of thin-film $\mathrm{Si}$ monitored in real time by in-situ spectroscopic techniques," J. Mat. Sci.: Mats in Electronics, Vol. 18, S309-S313, 2007.

Q. Wang, C. Teplin, P. Stradins, B. To, K. Jones, and $\mathrm{H}$. Branz, "Significant improvement in silicon chemical vapor deposition epitaxy above the surface dehydrogenation temperature," J. Appl. Phys., Vol. 100, 93520, 2006.

D. Young, D. Williamson, P. Stradins, Y. Xu, L. Gedvilas, H. Branz, R. Reedy, A. Mahan, and Q. Wang "Rapid solid-phase crystallization of highrate, hot-wire-chemical-vapor deposited hydrogenated amorphous silicon" Appl. Phys. Lett. Vol. 89, 161910, 2006.

Q. Wang, M. Page, E. Iwaniczko, Y.Q. Xu, L. Roybal, R. Bauer, D. Levi, Y. Yan, D. Meier, T. Wang, and H. Branz, "Silicon heterojunction solar cells by hot-wire CVD," Solar World Congress 2007 Beijing, China, 2007.

D. Levi, E. Iwaniczko, Q. Wang, and H. Branz, "Materials Optimization for Silicon Heterojunction Solar Cells Using Spectroscopic Ellipsometry," Proc. MRS Spring Meeting Symposium A, 2007.

P. Stradins, O. Kunz, D. Young, Y. Yan, Y. Xu, R. Reedy, H. Branz, A. Aberle, and Q. Wang, "Comparative Study of Solid-Phase Crystallization of Amorphous Silicon Deposited by Hot-wire CVD, Plasma-Enhanced CVD and Electron Beam Evaporation," Proc. MRS Spring Meeting Symposium A, 2007.

C. Teplin, Q. Wang, H. Branz, K. Jones, and P. Stradins, "Epitaxy at $100 \mathrm{~nm} / \mathrm{min}$ by Hot-Wire Chemical Vapor Deposition onto Silicon Wafers at 500 to $700^{\circ} \mathrm{C}$," Proc. MRS Spring Meeting Symposium A, 2007.

Q. Wang, M. Page, E. Iwaniczko, Y. Xu, L. Roybal, R. Bauer, D. Levi, Y. Yan, T. Wang, and H Branz, "High open-circuit voltage in silicon heterojunction solar cells," Proc. MRS Spring Meeting Symposium A, 2007.

D. Meier, M. Page, E. Iwaniczko, Y.Xu, Q. Wang, and $\mathrm{H}$. Branz, "Determination of Surface Recombination Velocities for Thermal Oxide and Amorphous Silicon on float zone silicon," Proc. 17th Workshop on Crystalline Silicon Solar Cells and Modules, pp. 214-217, August 2007.

T.H. Wang, M.R. Page, E. Iwaniczko, Y. Xu, Y. Yan, L. Roybal, D. Levi, R. Bauer, H. M. Branz, and Q. Wang, "High-efficiency p-type silicon heterojunction solar cells," 21st European Photovoltaic Solar Energy Conference Proceedings, Dresden, Germany, 2006. 


\title{
Electronic Materials and Devices Cell and Module Stability \& Reliability
}

\author{
Performing Organization: National Renewable Energy Laboratory (NREL) \\ Key Technical Contact: $\quad$ Tom McMahon, 303-384-6762, tom_mcmahon@nrel.gov
}

DOE HQ Technology Manager: Dan Ton, 202-586-4618, dan.ton@doe.gov

FY 2007 Budget: $\quad \$ 1,218 \mathrm{~K}$ (NREL)

\section{Objectives}

- Confirm reliability of new photovoltaic packaging materials and strategies to insure a 30-year module life of primarily industrial collaborations.

- Identify module reliability problems with developing technologies.

- Develop and/or acquire measurement techniques for module failure diagnostics.

- Support collaborative R\&D activities of DOE national laboratories, universities, and industry partners that focus on the identification, study, and mitigation of degradation mechanisms observed in advanced thin-film and crystalline modules.

Accomplishments

- Measured adhesion, cohesion, formation of T-F weak diodes, shunt, and series resistance problems with aging, water ingress.

- Offered Accelerated Aging Workshops, along with Sandia National Laboratories, to replace ThinFilm Partnership reliability teams.

- Identified module-level packaging issues such as:

- Alternatives to double glass for thin films (soft backsheets and hard coat barrier films).

- EVA substitutes that are cheaper/better perhaps without transparency.

- Hot/Humid survival, since field and $85 \%-85^{\circ} \mathrm{C}$ stress survival depend on adhesion, cohesion and water diffusion barriers.

- Moisture, which is relevant properties of polymers and coatings measured, by modeling of moisture ingress and egress into module structures.

\section{Future Directions}

- Identify emerging module reliability issues, such as water and heat stress to CdTe and CIGS.

- Research and identify collaborations on barrier coatings.

- Identify specific failure mechanisms with IR images.

- Support Solar America Initiative's SAI reliability teams, PV industry and suppliers.

\section{Introduction}

The development of advanced (e.g., second- and third-generation devices) PV technologies requires a thorough stage-gate type assessment of the technology's stability (e.g., degradation vs. exposure to the environment) and reliability (service lifetime, failure mechanisms, etc.). Such an assessment/evaluation is as critical as the technology's efficiency, costs, scale-up, and other manufacturing-related requirements. This agreement will serve as a consolidated (formerly these efforts were spread over several research tasks) and focused function to address the PV technologies' near- to long-term stability and reliability attributes and/or issues. The advanced technology options that are and will continue to be generated by the University and Exploratory Research and Electronic Materials and Devices projects and, most likely, by several of the SAl's Technology Pathway Partnerships (TPP) projects will be addressed with respect to the early stagegate criteria for stability and reliability for any technology. In addition, the various technical and material issues identified will be scientifically addressed (in close collaboration with the developers) in order to help mitigate the issues/shortcomings. 


\section{Technical Approach}

"Collaborative development (with industry) of improved materials (minimodules, backsheets, encapsulants)", is actually a more accurately stated fundamental research and development (R\&D) assessment of packaging (encapsulants/backsheets) approaches developed in-house and externally with many collaborators that are critical to predicting the durability, reliability, performance, lifetime of cells and modules for all technologies, and especially for particular thin-film constructions. Industry representatives regularly come through NREL asking for R\&D advice, testing, and evaluation based on our experience with a wide range of approaches and based on the testing capability we have developed. This first activity $(\$ 731 \mathrm{~K})$ goes hand-in-hand with the second activity, which is to develop and apply measurement techniques to characterize the performance of these encapsulatns/backsheets provided by collaborators.

\section{Results and Accomplishments}

R\&D on packaging approaches is fundamental to evaluating and improving module reliability and stability - in particular for new materials and technologies being developed. NREL's expertise, developed with a cross-section of manufacturers and materials, is contributed in an unbiased manner in the National Teams and in open forums. An example is mentioned in the paper, Testing of Packaging Materials for Improved PV Module Reliability, when NREL researchers evaluated a number of new encapsulants and backsheets as improved packaging materials, and presented the results in the open literature.

Examples of interactions across the industry, during FY 2007 alone, include:

- Water vapor transmission testing of AKT organic multilayer samples

- Non-disclosure agreement with Planar Systems, Inc., with tests on their coatings

- Testing (tensile strength) of Madico backfoils as a function of damp heat exposure

- Interactions with Deerfield Urethane to discuss potential use of thermoplastic polyurethane as a PV module encapsulant

- Interactions with DuPont on potential approaches, particularly for outdoor weathering and characterization

- Interactions with PPG on durability issues (their interest in becoming more involved as a supplier of glass substrates/superstrates for PV modules)

- Interactions with Dow Chemical interested in possible applications of their various technologies

- $\quad$ CRADA negotiations with BRP (ROI filed)

- Interactions with Pilkington Glass on durability, glass in particular

- Interactions with Saint Gobain, interested in polymer film materials for module construction; small module evaluation techniques

- Evaluation of samples of low-temperature sol gel coated PET from Applied Films for potential improved backsheet materials

- Meetings with Miasolé on packaging materials and options; building-integrated PV issues

- Tests and collaboration with STR on their experimental EVA product

- Interactions with Fraunhofer Institute for Solar Energy Systems on PV reliability (regarding European PV reliability program starting up)

- Discussions with InnoSense LLC on depositing barrier coatings; request for assistance testing materials (silicon oxynitride barrier coatings on thin-film cells)

- Testing of samples from Solar Roofing Systems prototype constructions

- Advice and tests for DuPont and Dow Corning.

\section{FY 2007 Milestones}

- Correlate adhesion failure for and remove cores from in-house accelerated aged modules and field-aged modules using a torque test developed at Sandia National Laboratories with an added automated torque rate control.

- Test efficacy of barrier coats and encapsulants, using our BEG (barrierencapsulant-glass) standard test, but with CIGS and CdTe cell films used instead of an Al-film.

- Develop with industry collaboration new barrier coats and encapsulants, as well as provide adhesion and water vapor transmission values, water ingress modeling, and IR imaging for failure diagnostics.

\section{Planned FY 2008 Activities}

- Utilize compositional and thickness mapping data along with adhesion and WVTR data to examine a series of depositions on PET that further explore compositions from $\mathrm{SiOx}$ to SiOxNy to Si3N4. 
- Use torque adhesion measurement device to evaluate CIGS and CdTe modules undergoing Hot and Humid outdoor testing at FSEC.

\section{Major FY 2007 Publications}

D. Ton, J. Tillerson, T.J. McMahon, M.A. Quintana, K. Zweibel, "Accelerated Aging Tests in Photovoltaics," sponsored by DOE's EERE Technologies Program, Feb. 22-23, 2006, Baltimore, MD.
J.G Jorgensen and T. J. McMahon, "Accelerated and Outdoor Aging Effects on Photovoltaic Module Interfacial Adhesion Properties," Prog. Photovolt: Res. Appl. 2008; 16:1-9.

M.D. Kempe, "Acetic acid production and glass transition concerns with ethylene-vinylacetate used in photovoltaic devices," Solar Energy Materials \& Solar Cells 91 (2007) 315-329. 


\title{
Measurements and Characterization
}

\author{
Performing Organization: National Renewable Energy Laboratory (NREL) \\ Key Technical Contacts: $\quad$ Peter Sheldon (NREL, Primary Contact), 303-384-6533, \\ peter_sheldon@nrel.gov \\ Mowafak Al-Jassim (NREL), 303-384-6602, mowafak_aljassim@nrel.gov \\ Sally Asher (NREL), 303-384-6450, sally_asher@nrel.gov \\ Keith Emery (NREL), 303-384-6632, keith_emery@nrel.gov \\ Dean Levi (NREL), 303-384-6605, dean_levi@nrel.gov
}

DOE HQ Technology Manager: Marie Mapes, 202-586-3765, marie.mapes@ee.doe.gov

FY 2007 Budgets: $\quad \$ 8,110 \mathrm{~K}$

\section{Objectives}

- Provide routine and specialized measurement and characterization support for photovoltaic (PV) program research and industry teams.

- Lead and contribute to collaborative research that addresses critical issues in PV technologies.

- Develop and implement novel measurement techniques that enhance the ability to understand and advance fundamental PV research and development.

\section{Accomplishments}

- Provided measurement support in the areas of analytical microscopy, surface analysis, electrooptical characterization, and cell and module performance to more than $70 \mathrm{PV}$ research partners in industry, academia, and NREL.

- Maintained ISO 17025 accreditation for primary and secondary cell and module calibrations; completed periodic audits, maintenance of quality systems, calibrations, software, and documentation to meet A2LA requirements.

- Initiated construction of an expansion of the Outdoor Test Facility (OTF), which will allow the Measurements and Characterization Group to support future Solar America Initiative (SAI) module test and evaluation needs.

- Investigated the structural and electronic properties of nanocrystalline hydrogenated silicon (Si:H) films and devices with nanometer-scale resolution.

- Completed an investigation of carrier depletion on individual grain boundaries in polycrystalline Si thin films using scanning capacitance microscopy.

- Developed a luminescence spectrum imaging system for characterizing industrial silicon wafers and solar cells.

- Initiated the design of an improved solar simulator that will reduce uncertainty in high-efficiency concentrator measurements.

- Procured a new solar simulator to measure large-area modules up to $137 \mathrm{~mm}$ by $200 \mathrm{~mm}$ in size.

- Completed study of the kinetics of Si wafer microcrack propagation as a function of processing.

- Organized the 17th Workshop on Crystalline Silicon Solar Cell Materials and Processes.

- Initiated development of a minority carrier lifetime measurement technique for integration into tools in the NREL Process Development and Integration Laboratory (PDIL).

- Developed advanced multidimensional computer models for multicrystalline Si devices.

- Developed a new moisture barrier package with very low water vapor transmission rates and excellent adhesion.

- Investigated the materials chemistry of copper indium gallium diselenide (CIGS) on flexible substrates, leading to an improved understanding of long-term reliability.

- Developed an improved understanding of cadmium telluride (CdTe) back contact reaction kinetics.

- Initiated PDIL tool development projects for the large platen Auger electron spectroscopy tool and the small-spot X-ray photoelectron spectroscopy (XPS) tool. 


\section{Future Directions}

- Develop an integrated plan to provide priority support to the SAI Technology Pathway Partnership (TPP) awardees that meets their research and development (R\&D) needs within the context of available resources.

- Provide measurement support in the areas of analytical microscopy, cell and module performance, electro-optical characterization, and surface analysis to PV research partners in industry, academia, and NREL.

- Maintain ISO accreditation for primary and secondary cell and module calibrations.

- Complete the construction and fit-up of the OTF expansion project.

- Install enhanced module measurement capabilities that will improve measurement uncertainty, as necessary to support the SAI.

- Bring new solar simulators on line and make them compatible with our ISO quality systems.

- Organize the 18th Workshop on Crystalline Silicon Solar Cell \& Modules; this year's theme is "Achieving Low-Cost Electricity (Grid-Parity) with Si PV."

- Design, procure, and install the Measurement and Characterization integrated PDIL tool set; integrated tools include the cluster tool robot, resonantly coupled photoconductive decay lifetime tool; photoluminescence (PL) imaging tool, spectroscopic ellipsometer tool, Auger electron spectroscopy tool, sputter/plasma etch tool, and the plasma-enhanced chemical vapor deposition (PECVD) tool.

- Design, procure, and install the Measurement and Characterization stand-alone PDIL tool set; stand-alone tools include the X-ray photoelectron spectroscopy tool, scanning electron microscopy tool, atomic force microscopy tool, wet chemistry workstation tool, reflectometer, optical processing furnace, and the lifetime mapping tool.

\section{Introduction}

The Measurements and Characterization Group provides test, measurement, and analysis support and research for the National Center for Photovoltaics and the Solar Energy Technologies Program (SETP). It supports all photovoltaic (PV) material technologies and involves essential collaborations with external research partners in university and industry laboratories, PV manufacturers, and internal research groups. Each year, this group assists clients with tests and analyses of thousands of material and device samples, helping them to better understand and direct work on their research and commercial product development. We also serve as one of the test and evaluation facilities that the Solar America Initiative (SAI) uses to evaluate subcontract stagegate deliverables.

These activities address one or more of the three areas crucial to meeting the DOE Office of Energy Efficiency and Renewable Energy (EERE) goal of reducing the levelized cost of energy for $\mathrm{PV}$ to $\$ 0.06 / \mathrm{kWh}$ by 2015 . The three areas are (1) improving device and module performance, (2) reducing manufacturing costs, and (3) improving device and module reliability. This is accomplished by selecting projects that address key issues for a broad spectrum of technologies, including

Photovoltaic R\&D

Fundamental Research

Measurements and Characterization crystalline silicon (c-Si), amorphous silicon (a-Si), thin silicon, copper indium diselenide (CIS), cadmium telluride (CdTe), III-Vs, organic photovoltaics (OPV), and other future-generation materials. As shown in Figure 1, for each technology, we allocate resources to (1) provide routine and specialized measurement and characterization support for research and industry partners; (2) lead and contribute to collaborative research that addresses critical issues in these PV technologies; (3) develop and implement novel measurement techniques that enhance our ability to understand and advance fundamental PV R\&D.

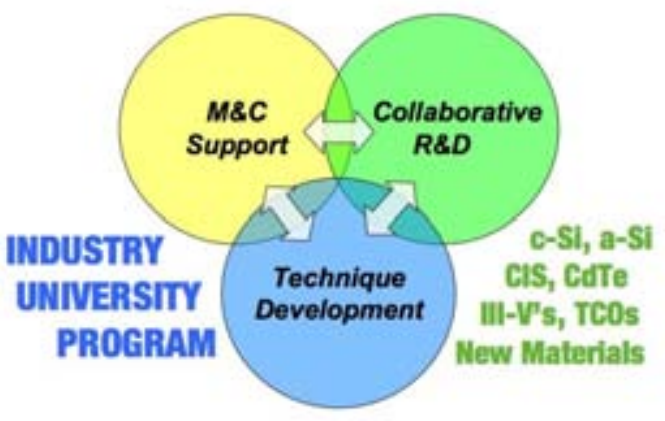

Fig. 1. Schematic showing areas of research emphasis in Measurements and Characterization. 
As indicated in Figure 1, these three areas are very complimentary and synergistic. For example, M\&C Support work often leads to a Collaborative $R \& D$ project that addresses a specific issue thought to limit device performance or reliability, or alternatively, helps to identify a Technique Development project that will ultimately allow us to measure a critical device or material parameter. In turn, the development of enhanced measurement techniques allows us to continuously advance the state of the art and is necessary to help the PV community advance toward the 2015 SAl goals of lower costs, higher performance, and improved reliability.

\section{Technical Approach}

The project is composed of four core competency research tasks and a management/coordination task. The four research tasks are Analytical Microscopy, Cell and Module Characterization, Electro-Optical Characterization, and Surface Analysis. The major nonsupport research activities pursued in FY 2007 are outlined below by task. Although a significant portion of our work involves working with industry to solve research and manufacturing problems in a timely manner, these activities are not reported in this document because of their proprietary nature. During the past year, we have collaborated with well over 70 research groups from industry, universities, and national laboratories. The FY 2007 highlighted milestones in each task are listed below, and additional details are provided in Section 3.

\subsection{Analytical Microscopy Task}

- Provided both routine and specialized measurement and characterization support for SETP PV research and industry teams.

- Investigated the structural and electronic properties of nanocrystalline Si:H films and devices with nanometer-scale resolution.

- Completed investigation of carrier depletion on individual grain boundaries in polycrystalline $\mathrm{Si}$ thin films using scanning capacitance microscopy.

- Developed a luminescence spectrum imaging system for characterizing industrial silicon wafers and solar cells.

\subsection{Cell and Module Performance Task}

- Provided both routine and specialized measurement and characterization support for SETP PV research and industry teams.

- Maintained ISO 17025 accreditation for primary and secondary cell and module calibrations. Completed periodic audits, maintenance of quality systems, calibrations, software and documentation to meet A2LA requirements.

- Initiated the design of an improved simulator that will reduce uncertainty in high-efficiency concentrator measurements.

- Procured a new solar simulator to measure large-area modules up to $137 \mathrm{~mm}$ by $200 \mathrm{~mm}$ in size.

\subsection{Electro-Optical Characterization Task}

- Provided both routine and specialized measurement and characterization support for SETP PV research and industry teams.

- Completed a study of the kinetics of Si wafer microcrack propagation as a function of processing.

- Organized the 17th Workshop on Crystalline Silicon Solar Cell Materials and Processes.

- Initiated the development of minority carrier lifetime measurement techniques for integration into PDIL tools.

- Developed advanced multidimensional computer models for multicrystalline $\mathrm{Si}$ devices.

\subsection{Surface Analysis Task}

- Provided both routine and specialized measurement and characterization support for SETP PV research and industry teams.

- Developed a new moisture barrier package with very low water vapor transmission rates and excellent adhesion.

- Investigated the materials chemistry of CIGS on flexible substrates, leading to an improved understanding of long-term reliability.

- Developed an improved understanding of CdTe back contact reaction kinetics.

- Initiated PDIL tool development projects for the large platen Auger electron spectroscopy tool and the small-spot XPS tool.

Budget allocations by task are provided below.

\begin{tabular}{|l|c|}
\hline \multicolumn{1}{|c|}{ Task Title } & $\begin{array}{c}\text { FY 2007 } \\
\text { Budget (\$K) }\end{array}$ \\
\hline Analytical Microscopy & 2,000 \\
\hline Cell and Module Performance & 1,699 \\
\hline Electro-Optical Characterization & 2,195 \\
\hline Surface Analysis & 1,495 \\
\hline Management/Maintenance & 721 \\
\hline
\end{tabular}

\section{Results and Accomplishments}

Research results outlined in this section address only FY 2007 priority milestones, and these

Photovoltaic R\&D

Fundamental Research 
represent only a portion of all our support and research activities. Highlights for each task are outlined below.

\subsection{Analytical Microscopy Task}

Investigate the structural and electronic properties of nanocrystalline Si:H films and devices with nanometer-scale resolution:

Nanocrystalline Si (nc-Si:H) materials are much more complicated than either amorphous or crystalline $\mathrm{Si}$ materials. They consist of nanocrystalline grains, grain boundaries, amorphous tissues, and voids. Therefore, structural and electrical characterization, on the atomic and nanometer scale, is required to better understand material properties. In collaboration with United Solar, we have investigated the Pdoping effects on the structure of nc-Si:H thin films. We observed for the first time P-doping induced nc-Si:H grains that were dispersed within the amorphous Si matrix. We also investigated the effects of light soaking and thermal annealing on the distribution of microelectrical conductivity, and experimentally solved the puzzle of light-soakinginduced open-circuit voltage $\left(\mathrm{V}_{\mathrm{oc}}\right)$ increases in a$\mathrm{Si}: \mathrm{H}$ and nc-Si:H mixed-phased devices. These characterization results proved very useful for United Solar in its efforts to incorporate nc-Si:H into its production lines.

The compositional, structural, and microelectrical properties of the Si:H films were investigated using complementary techniques that included secondary ion mass spectrometry (SIMS), Raman spectroscopy, atomic force microscopy (AFM), transmission electron microscopy (TEM), scanning Kelvin probe microscopy (SKPM), and conductive (C)-AFM. In the intrinsic and slightly P-doped Si:H films, the nc-Si:H grains aggregate to clusters, and SKPM and C-AFM images exhibit localized work function and conductivities. The local work function and conductivity of the nc-Si:H aggregates are significantly larger than those of the surrounding a-Si:H regions. However, as researchers increased the dopant concentration by adding small amounts of $\mathrm{PH}_{3}$ into the reactant gas during film growth, there was a large impact on film growth and structure. We found that (1) In order to reach similar crystallinity, the hydrogendilution ratio $\left(\mathrm{H}_{2} / \mathrm{SiH}_{4}\right)$ needs to be doubled; (2) the $\mathrm{PH}_{3}$ was very efficiently incorporated, resulting in doping concentrations as high as $\sim 10^{21} / \mathrm{cm}^{3}$; and (3) the nc-Si:H grains no longer aggregate to clusters, and instead disperse randomly within the a-Si:H matrix. Based on the atomic hydrogen- enhanced diffusion model for PECVD growth of nc-Si:H, we proposed a model to explain these doping effects.

Along with measuring the changes of local conductivity in the a-Si:H and nc-Si:H mixedphase devices, we experimentally demonstrated that the light-soaking induced $V_{o c}$ increase originates from the degradation of the nc-Si:H phase. Using C-AFM, we measured the local electric current flow through the nc-Si:H aggregates. As shown in Figure 2, the current increases with the aggregation area. The current density decreased significantly by light soaking and recovered to a value similar to the original value with thermal annealing. These changes in current density explain the mechanisms of the light-soaking-induced $\mathrm{V}_{\text {oc }}$ increase.

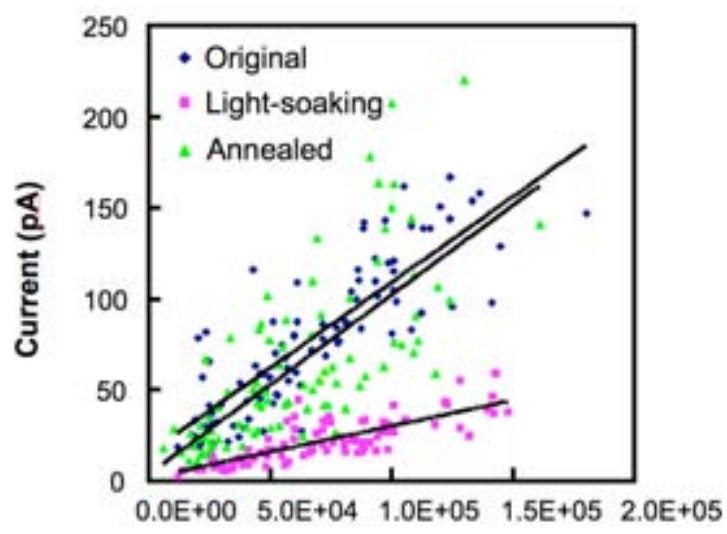

Area of aggregates $\left(\mathrm{nm}^{2}\right)$

Fig. 2 Local electric current through nc-Si:H aggregates as a function of the aggregation area. Linear fitting to the data represents the current density. The current density decreases with light soaking, and recovers after thermal annealing.

Investigation of carrier depletion on individual grain boundaries in polycrystalline Si thin films using scanning capacitance microscopy.

Grain boundaries (GBs) in polycrystalline Si thinfilm solar cells are believed to limit photovoltaic efficiencies. However, most measurement and characterization studies on the electronic properties of GBs were carried out on large samples that contain a high density of grains. As a result, one cannot resolve the electronic properties at a specific GB. In this study, in collaboration with NREL's Si group, we carried out a nanometerresolution measurement of carrier depletion at the GBs using scanning capacitance microscopy (SCM). This nanometer-resolution measurement

Photovoltaic R\&D 
allows us to examine the electronic properties of individual GBs. This is the first step toward our ultimate goal of correlating the electronic properties of specific GB structures.

As shown in Figure 3, the SCM images exhibit the following features: (1) the carrier concentration is lower at locations near the GB edges in comparison to the central region of the grains; (2) the degree of depletion varies considerably from one GB to another-for example, GBs between grains $A / B, A / C$, and $B / C$ clearly exhibit a high level of depletion, and in contrast, the GBs between $A / D$ and $A / E$ do not exhibit significant depletion; and (3) intragrain carrier depletion was also observed at point and line defects.

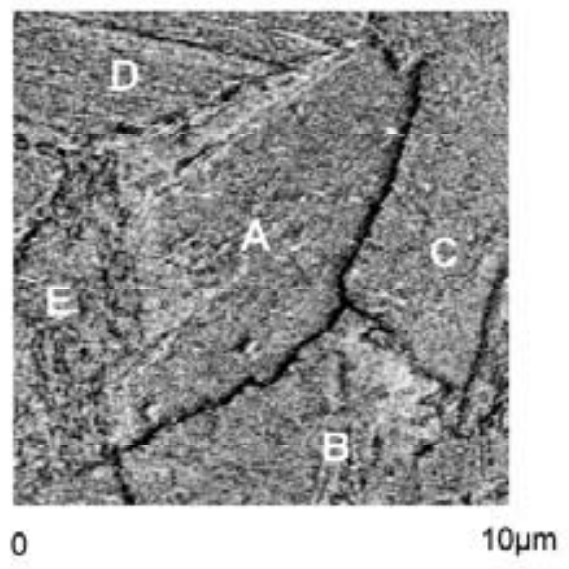

Fig. 3 An SCM image taken on a polycrystalline Si thin film grown by HWCVD on an AIC-seed layer on a glass substrate.

The direct measurement of the carrier depletion in the GBs demonstrates that the GBs in Si thin films indeed create charged gap states. The nonuniformity of the carrier depletion suggests that the gap states depend on specific GB structures, which should relate directly to the grain orientations and grain facets adjacent to the GB. The depletion around the intragrain defects indicates that the defects are charged and can be recombination centers, and thus harmful to device performance. Such in-depth studies are expected to have a direct impact on improving thin-film Si solar cells through understanding the local defect behavior at the GBs.

Conduct electron backscatter diffraction studies of CdTe thin films:

Electron-backscattered diffraction (EBSD) is a new technique that provides information about the crystalline structure of materials with high spatial resolution, in contrast to X-ray diffraction, which provides information on the bulk of the sample. In EBSD, diffracted electrons are collected and analyzed while the electron beam of a scanning electron microscope (SEM) scans the sample surface, providing diffraction patterns at every pixel of the SEM image. EBSD provides crystalline orientation maps, and it is able to identify crystalline phases and orientations with submicron spatial resolution. This capability enables the investigation of the misorientation between individual grains; the study of grain boundaries and special boundaries; the determination of grain size, grain distribution, and film texture; and the study of strain. EBSD requires a flat sample to avoid shadowing of the electrons from the detector by surface features. In this work, we investigated and developed procedures to prepare the surface of close-spaced sublimation (CSS) CdTe thin films necessary for producing artifact-free EBSD data. We found that polishing resulted in an amorphous layer on the surface and no Kikuchi pattern. However, ion-beam milling produced a relatively flat and good-quality surface, resulting in highquality patterns, and, consequently, excellent EBSD data. We used a combination of polishing and ion-beam milling or etching to study the crystalline structure of the CdTe film at different depths, as shown in Figure 4.
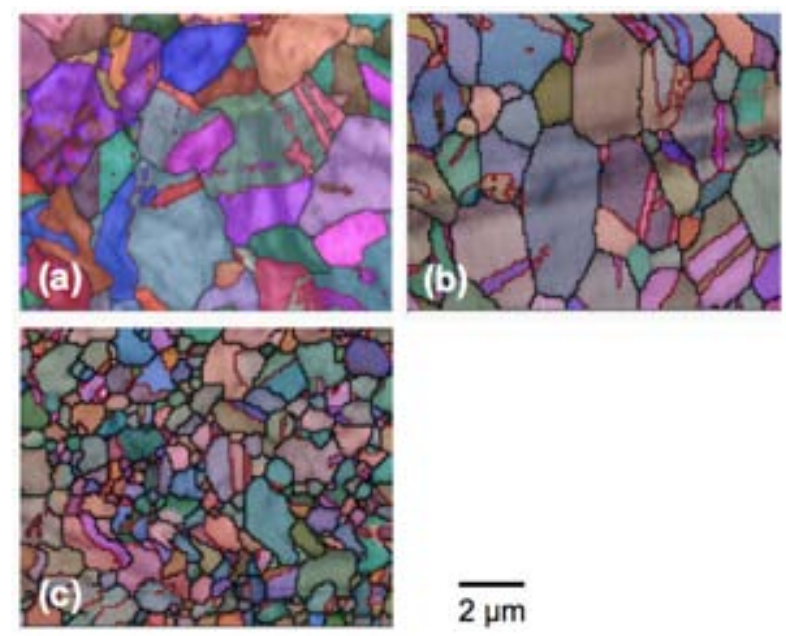

$\overline{2 \mu \mathrm{m}}$

Fig 4. EBSD data (band contrast and Euler map coloring) for an untreated CSS CdTe film after polishing with $0.05 \mu \mathrm{m}$ alumina suspension for (a) $30 \mathrm{~s}$, (b) $120 \mathrm{~s}$, and (c) $150 \mathrm{~s}$. After polishing, each sample was ion-beam milled $\left(5 \mathrm{keV}, 1 \mathrm{~min}, 3^{\circ}\right)$. The red lines are $60^{\circ}<111>$ twin boundaries. 
We also used EBSD, in conjunction with other analytical techniques, to investigate the effects of the $\mathrm{CdCl}_{2}$ treatment, performed at different temperatures and times, on the recrystallization process of physical vapor deposition (PVD) CdTe thin films. This treatment is an important step in the production of high-efficiency solar cells, and needs to be optimized for the PVD CdTe films produced at NREL. The $\mathrm{CdCl}_{2}$ treatment in $<111>$ oriented films shows ongoing recrystallization when performed at $350^{\circ} \mathrm{C}$. When performed at $400^{\circ}$ and $420^{\circ} \mathrm{C}$, the recrystallization process is complete and the microstructure reveals randomly oriented grains with a large variation in grain size-some grains reach dimensions exceeding $40 \mu \mathrm{m}$. These films are so flat that good EBSD data could be obtained without any surface preparation. The large grains have different morphologies than the small grains do, and they have $<111>$ orientation, indicating that, during the grain growth process, they enlarged at the expense of grains with less favorable orientations.

The grains sizes observed for the PVD CdTe films are the largest obtained for $\mathrm{CdTe}$ films produced at NREL and are desirable for solar cells because of the reduction in grain boundary area. Another desirable characteristic is the fact that these films are very flat, making it easier for the application of a thin, homogeneous layer of a back-contact material.

The EBSD analysis showed that both CSS and PVD CdTe films have a large density of $60^{\circ}<111>$ twin boundaries, even after recrystallization, indicating a low formation energy for these interfaces. This capability to detect the distribution of two-dimensional boundaries is a unique capability of EBSD. Before EBSD was used, the most common way to study twins in CdTe films employed TEM, which is time-consuming and cannot provide an overall picture of the twin distribution.

Investigate $\mathrm{In}_{2} \mathrm{O}_{3}$ and $\mathrm{Al}$ coverage and c-Si/a-Si interfaces in Si heterojunction cells:

The texture of Si heterojunction (SHJ) cells is an important process for light trapping, which improves the efficiency of the cells. However, the textured surface can be a potential problem for the growth of uniformly and fully covered $\ln _{2} \mathrm{O}_{3}$ and a back $\mathrm{Al}$ reflective layer. Therefore, it is critical to examine the quality of these layers for highefficiency SHJ cells. In collaboration with NREL's Si Group, the front $\ln _{2} \mathrm{O}_{3}$ coverage and back $\mathrm{Al}$ coverage of textured $\mathrm{Si}$ heterojunction cells was investigated using SEM. The c-Si/a-Si interface was also examined by high-resolution transmission electron microscopy (HRTEM). The thickness and uniformity of the a-Si layer and the quality of the a-Si/c-Si interface were examined by site-selected TEM preparation using our new focused ion beam (FIB) workstation and HRTEM. Because the cells are textured, cross-sectional TEM samples must be prepared along certain directions and at specific areas. This was achieved by using dual beam FIB milling.

Figure 5(a) is an SEM image of the front side of a $\mathrm{Si}$ heterojunction cell. Both the front and back sides are textured. On the front side, the $\ln _{2} \mathrm{O}_{3}$ layer was grown after the growth of the a-Si layer. The SEM image indicates that the Indium tin oxide (ITO) layer has very good coverage, which is necessary in order for Si heterojunction cells to achieve high performance. However, the SEM image also indicates that the texture is not very uniform.

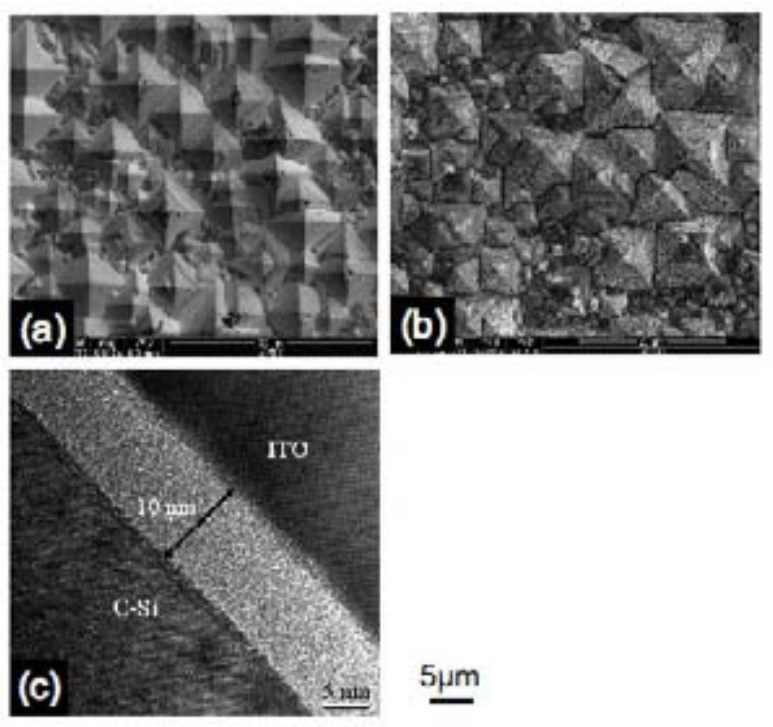

Fig. 5. (a) SEM image of front $\ln _{2} \mathrm{O}_{3}$ coverage (b) SEM image of back Al coverage of textured $\mathrm{Si}$ heterojunction cell. (c) HRTEM image of c-Si/a-Si interface.

Figure 5(b) shows an SEM image of the back side. On this side, a layer of Al was deposited on the aSi layer. The image shows that the entire backside was covered with Al. However, the Al layer is not very smooth. Small voids are seen in this layer. The mechanism of the formation of these small voids is not yet known. It is likely that these small voids in the Al contact layer will have harmful effects on transport properties. These small voids

Photovoltaic R\&D 
were not seen in the a-Si layer in a cross-sectional TEM investigation. Figure 5(c) shows an HRTEM image of the c-Si/a-Si interface in the front side. The interface in the backside showed similar structure, but with much higher thickness. The a-Si layer is about $10 \mathrm{~nm}$ thick in the front side and 43 $\mathrm{nm}$ in the back side. On both sides, flat and abrupt c-Si/a-Si interfaces were observed. Our results indicate that the $\mathrm{In}_{2} \mathrm{O}_{3}$ layer, Al-layer, and a-Si layer grown at NREL have very high quality. These critical data greatly helped the NREL Si group to achieve a record efficiency SHJ cell using a p-type Si wafer.

Investigate the electronic effects of grain boundaries in CIS:

Polycrystalline semiconductors generally exhibit poor opto-electronic properties compared with those of their single-crystal counterparts owing to the existence of grain boundaries containing dislocation cores. The latter normally create deep levels and act as effective recombination centers, as the classic grain boundary (GB) model concludes. Thus, GB passivation is extremely important for polycrystalline solar cells to suppress the harmful effects of GBs.

Surprisingly, however, without intentional GB passivation, the efficiency of polycrystalline $\mathrm{Cu}(\mathrm{In}, \mathrm{Ga}) \mathrm{Se}_{2}$ (CIGS)-based solar cells is now approaching $20 \%$, greatly surpassing that of their single-crystal counterparts ( 13\%). Therefore, understanding GB behavior in CIS chalcopyrite may lead to future designs of optoelectronic devices based on many low-cost polycrystalline materials. For a long time, GBs in polycrystalline $\mathrm{CIS}$ thin films have been explained by the classic electronic GB model. However, the classic electronic GB model cannot explain the remarkable performance of polycrystalline CISbased solar cells. Recent theoretical study has proposed that GBs in CIS could be significantly Cu-poor, act as hole-barriers, and be charge neutral.

In contrast, our first-principles density-functional theory calculations reveal that, surprisingly, GBs in CulnSe $_{2}$ do not follow the classic GB model: GBs in polycrystalline CIS do not create any deep levels because of the large expansion in the GB regions. Thus, our results show for the first time that, unlike the classic GB model, GBs in CIS are electrically benign. This explains a long-standing puzzling fact: polycrystalline CIS solar cells with remarkable efficiency can be achieved without deliberate GB passivation. This benign electrical character of GBs in CIS is confirmed by our SKPM measurements on polycrystalline $\mathrm{Cu}(\mathrm{In}, \mathrm{Ga}) \mathrm{Se}_{2}$ chalcopyrite films.

Develop luminescence spectrum imaging for characterizing industrial silicon wafers and solar cells:

NREL's spectrum imaging system is based on ultra-fast spectrum acquisition (10 ms/pixel) in synchronization with the scanning of the electron beam in the electron microscope. Spectrum imaging is used to map recombination (including extended defects such as dislocations and grain boundaries), energy levels associated with impurities and complexes, stress, composition, and other properties relevant to semiconductor technology.

We have expanded the maximum scanning range of spectrum imaging to $3 \mathrm{in} . \times 3 \mathrm{in}$. (from $100 \mu \mathrm{m} \mathrm{x}$ $100 \mu \mathrm{m})$ by adding external control to the $X-Y$ stage of the electron microscope. Both modes-X$Y$ SCAN (scanning the $X-Y$ stage to cover large areas) and E-B SCAN (scanning the electron beam for high-resolution)_-are integrated into one platform, which enables first mapping the transitions identified in the emission spectrum over the entire silicon wafer or solar cell and, subsequently, running high-resolution measurements on preselected locations (such as grain boundaries and degraded areas). This combination of X-Y SCAN and E-B SCAN in the SEM has proven very attractive in addressing uniformity concerns and providing defect mapping of mc-Si technologies for industrial partners such as Advent Solar and CaliSolar.

When running the $X-Y$ SCAN mode on silicon, researchers used the photon intensity at room temperature for lifetime mapping. At $\mathrm{LN}_{2}$ temperatures, D1-D4 and DB transitions associated with dislocations and grain boundaries are accessible. Figure 6 illustrates the combination of these modes for a 2 in. $\times 2$ in. section of an mcSi wafer.

We drive the $X-Y$ stage to generate a map of the photon intensity (which correlates with lifetime at room temperature). At the end of the X-Y SCAN [see, for example Figure 6(a)], we can select a precise location and shift to E-B SCAN to improve the resolution [see, for example, Figure 6(b) and (c)]. 


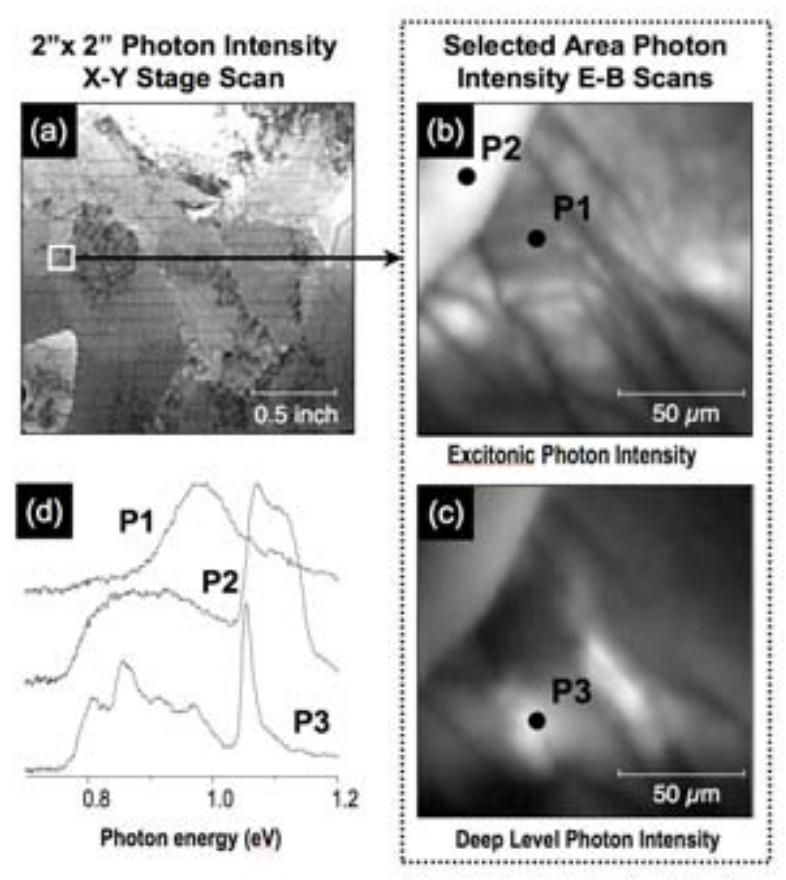

Fig. 6. (a) Photon intensity X-Y SCAN map of a 2 in. $\times 2$ in. section of an mc-Si wafer taken at $T=$ $300 \mathrm{~K}$; (b) selected area high-resolution E-B SCAN of the excitonic photon intensity (TO); (c) the luminescence associated with deep levels; (d) the emission spectrum at locations $\mathrm{P} 1, \mathrm{P} 2$, and $\mathrm{P} 3$.

A high density of dislocations is seen on the grain with reduced photon intensity (location P1 on the image); a few of the dislocations show a high density of deep levels (location P3) at $\mathrm{LN}_{2}$ temperature. Using spectrum imaging, we can extract the emission spectrum from different locations (P1, P2, and P3) and obtain information about the active electronic states responsible for the recombination.

Investigate the recombination at intragrain extended defects in polycrystalline thin-film silicon solar cells:

In polycrystalline thin-film silicon solar cells, larger grains do not always translate into higher efficiencies. This is largely the result of recombination at intragrain extended defects. Removal, or at least mitigation, of the harmful effects of such defects is therefore critical to this thin-film technology.

We investigated silicon epilayers grown by chemical vapor deposition (CVD) at high temperature $\left(1100^{\circ} \mathrm{C}\right)$ and at moderate temperatures $\left(500-600^{\circ} \mathrm{C}\right)$ that are compatible with glass. Although the temperature dramatically affects the microstructure of the epilayers, since a higher temperature gives considerably larger grains, we found that the recombination is dominated by extended defects located in grain interiors (not grain boundaries) across the entire temperature range. The infrared emission from these epilayers, where the band-to-band phononassisted transition seen in Czochralski (CZ) or float-zone (FZ) grown silicon is completely absent, can be described as band-tail recombination. The emission from the S3-type extended defects moves further into the infrared when compared with their surroundings, a signature of a higher density of deep levels contributing to the band tail. The luminescence is thermally deactivated by similar energy levels (electronic states) independently of temperature. Hydrogen treatments seem to be ineffective on the extended defects. When these findings are complemented with TEM observations, it becomes evident that the best approach to achieving better efficiencies in CVD silicon involves better control of the epilayer back interface, where these extended defects originate.

Investigate the effect of in situ stress during MOVPE growth of high-efficiency latticemismatched III-V multijunction solar cells:

NREL's high efficiency devices team recently demonstrated record-breaking efficiencies in a monolithic III-V triple-junction solar cell. This solar cell utilizes a lattice-mismatched $1.0 \mathrm{eV}$ $\ln _{0.27} \mathrm{Ga}_{0.73}$ As bottom junction and is grown in an inverted geometry with GalnP and GaAs top junctions lattice-matched to the GaAs substrate. Further improvement of cell efficiency requires a better understanding of the factors that control the threading defect density in these latticemismatched multijunction solar cells.

In collaboration with NREL's high-efficiency devices team, we have been involved in a study of the effect of in situ stress during metal organic vapor phase epitaxy (MOVPE) growth on the performance and microstructure of monolithic III-V triple-junction solar cells that were grown inverted with a metamorphic $1.0 \mathrm{eV}$ bottom $\ln _{0.27} \mathrm{Ga}_{0.73} \mathrm{As}$ junction. The in situ stress during the growth of this lattice-mismatched junction was varied by controlling the design of a step-graded $\mathrm{Ga}_{x} \mathrm{In}_{1-\mathrm{x}} \mathrm{P}$ buffer layer in which most, but not all, of the $1.9 \%$ misfit strain was relieved. Excellent performance was obtained for inverted $\operatorname{In}_{0.27} \mathrm{Ga}_{0.73}$ As solar cells grown with slight compressive or zero stress, but a degradation in performance was observed for cells grown under tensile stress. These results were 
found to correlate with the threading dislocation density in the samples, as revealed by SEM cathodoluminescence (CL) and cross-sectional TEM. For samples grown under zero or moderate compressive stress, threading dislocation densities in the low $10^{6} \mathrm{~cm}^{-2}$ were measured by $\mathrm{CL}$, and no threading dislocations were seen in cross-sectional TEM images [Figure 7(a)]. The cells had a $V_{O C}$ of $\sim 0.54 \mathrm{eV}$. For a sample grown under tensile stress $(0.17 \mathrm{GPa})$, which had a $\mathrm{V}_{\mathrm{OC}}$ of $0.32 \mathrm{eV}, \mathrm{CL}$ revealed threading dislocation densities in the high $10^{6} \mathrm{~cm}^{-2}$ range, and threading and misfit dislocations were present in crosssectional TEM images of such devices [Figure 7 (b)]. These results indicate that achieving a lower threading dislocation density is crucial in improving lattice-mismatched multijunction solar cells' performance, and that in situ tensile stress during growth should be avoided. The knowledge gained from this work should enable researchers to obtain improved, record-efficiency lattice-mismatched multi-junction solar cells in the near future.

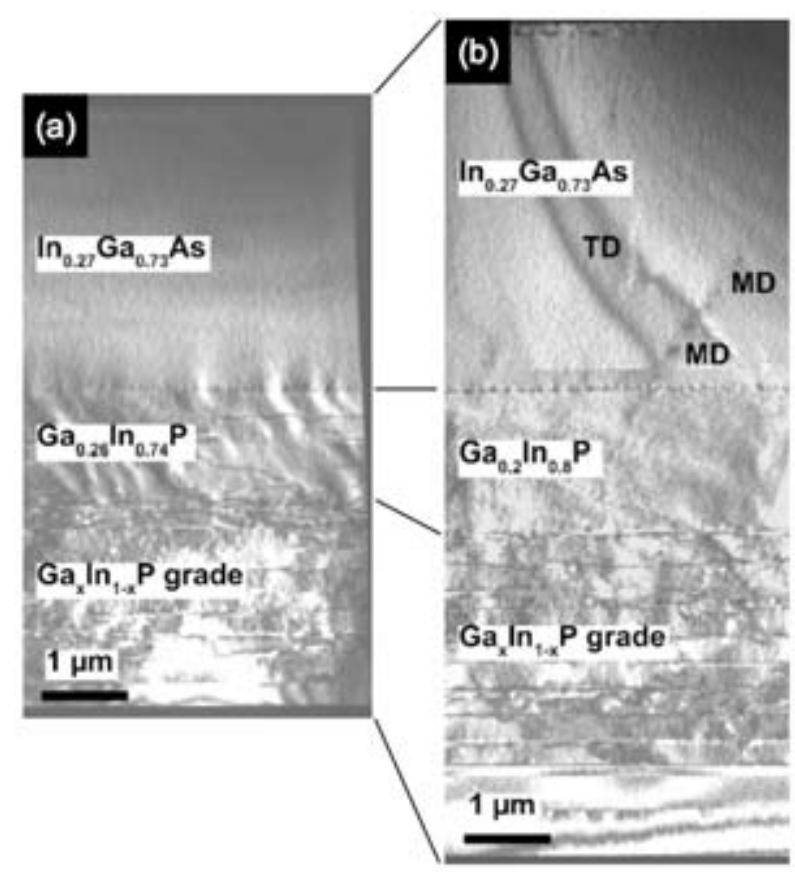

Fig. 7. TEM images (220 dark-field) of two inverted InGaAs solar cells grown with different film stress in the active layer: (a) $0.12 \mathrm{GPa}$ compressive and (b) $0.17 \mathrm{GPa}$ tensile. Threading dislocations (TD) and the ends of misfit dislocations (MD) are observed in the thick InGaAs junction layer of sample (b).

\subsection{Cell and Module Performance Task}

Provide routine and specialized measurement and characterization support for SETP PV research and industry teams:

During FY 2007, researchers made 5020 cell current-voltage (I-V), quantum efficiency (QE), and linearity measurements on 1758 samples, and 1567 I-V measurements on 408 modules. In direct support of SAI TPP and PV Incubator subcontracts, researchers made 1339 cell measurements on 414 samples and 394 module measurements on 128 samples.

\section{Reduce uncertainty in high-efficiency concentrator} measurements:

Upon release of capital equipment funds, detailed simulator specifications were submitted to procurement in order to initiate the request for proposals. The proposals have been received and reviewed by a technical team, and a statement of work has been completed with the selected vendor. We are currently awaiting an estimated delivery date. The specifications call for a spectrally adjustable simulator in at least 10 bands to accommodate all the conceivable highefficiency concentrator cell designs we might encounter over the next 10 years. The system is designed to cycle through temperatures, irradiance, and spectra to produce an energy rating for any given typical meteorological year. NREL will have complete access to the software developed for this system. This is critical for calibrations and compliance with the team's ISO quality system. Software will have to be written to take these data automatically and process the data. This tool will allow the spectral sensitivity of multijunction concentrator cells to be addressed in terms of energy production and not just their performance with respect to fixed reference conditions. The irradiance range will be approximately 1 to 2000 suns with $\pm 1 \%$ spatial nonuniformity over an area of $10 \mathrm{~cm}$ by $10 \mathrm{~cm}$.

\section{Expand capabilities to evaluate large-area} modules:

The current module solar simulator using pulsed light is limited to modules that are smaller than 61 $\mathrm{cm}$ by $122 \mathrm{~cm}$. A new pulsed class AAA Spire 4600SLP solar simulator has been ordered with an expected delivery date of August 15, 2008. The advantage of a pulsed class AAA solar simulator is that the temperature is accurately known, the spectrum is well defined throughout the life of the lamp, and the spatial nonuniformity is $\pm 2 \%$ or better. We anticipate that, once this simulator is 
brought to operational status and the software is modified to be compliant with the team's ISO quality system, the capabilities will be expanded to automatically measure I-V characteristics as a function of total irradiance and temperature. This will allow the energy to be predicted with respect to a typical meteorological year. The new simulator is capable of measuring modules as large as $137 \mathrm{~cm}$ by $200 \mathrm{~cm}$.

Reduce measurement time and uncertainty of evaluating multijunction devices at 1-sun:

Activity on this task has been delayed because of inadequate labor resources. This labor shortage has been corrected by two new hires that started in January and Feburary. Work on the task is now proceeding in parallel with training the new hires. The simulator will have features similar to those of the multisource cocntrator simulator, except that it will operate at 1-sun and with continuous light. This tool will allow the spectral sensitivity of multijunction cells to be addressed in terms of energy production as a function of spectral irradiance, total irradiance, and temperature and not just their performance with respect to fixed reference conditions.

Maintain ISO 17025 accreditation for primary and secondary cell and module calibrations; complete periodic audits, maintenance of quality systems, calibrations, software and documentation to meet A2LA requirements:

Quality calibration plays a critical role in the product-manufacturing process. ISO accreditation provides our customers with confidence that the performance reported for these products is verifiable and internationally accepted. Many of our PV industry partners currently have ISO 9001 quality programs in place. These companies rely on NREL for calibrations of the reference cells and modules they use to measure their products. Certified module-qualification facilities such as the Arizona State PV Testing Laboratory and the Florida Solar Energy Center require their reference cell calibrations to be traceable to a certified laboratory.

All PV calibrations performed by the group are traceable to primary reference cells calibrated by NREL. NREL is one of four calibration laboratories in the world certified to perform Photovoltaic Scale Primary reference cell calibrations. For this reason, it was critically important that NREL attain an ISO accreditation for the reference cells we calibrate for the PV community. The ISO 17025 accreditation provides
NREL with international credibility and recognition (Figure 8).

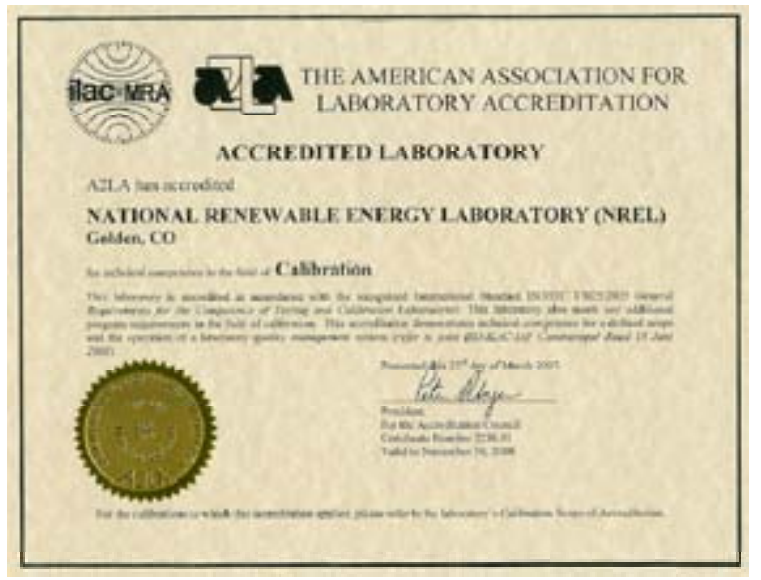

Fig. 8. NREL A2LA accreditation certificate \# 2236.01, valid to November $30^{\text {th }}, 2008$.

This process took two years to complete and involved establishing a very structured quality system, detailed work procedures, a detailed document control methodology, formalized recordkeeping process, rigorous management review process, corrective action plan process, and an instrument calibration validation process. Implementing and maintaining an ISO 17025 program is a significant and critically important task. Test beds within the PV performance team that produce numerical results for customers that are not within the scope of A2LA certificate 2236.01 are required to be in calibration as if part of the scope and the software is subjected to the ISO 17025 software review process.

\section{Concentrator module testing:}

Eleven concentrator prototype modules from six companies, including Spectrolab and Solfocus, were evaluated, generating more than $48,580 \mathrm{I}-\mathrm{V}$ curves with accompanying irradiance and other meteorological data. Direct-beam spectra also accompany the data set for 15 sunny days. Data were analyzed using multiple linear regression to project test conditions $\left(20^{\circ} \mathrm{C}\right.$ air temperature, 850 or $1000 \mathrm{~W} / \mathrm{m}^{2}$ direct irradiance, and $4 \mathrm{~m} / \mathrm{s}$ wind speed). Evaluation of the data set to develop and compare alternative rating methods, develop translation equations, and predict the energy with respect to SAI reference conditions were not performed because this enhancement in the scope of the activities, with commensurate funding, was not accepted in the FY 2007 Annual Operating Plan. 
American Society for Testing and Materials (ASTM) and International Electrotechnical Commission (IEC) standards:

We attended committee meetings and participated in standards development. We also shepherded standards for linearity determinations, rating concentrator modules and systems, and spectral responsivity measurements.

\section{Technology transfer:}

There were approximately 50 instances, lasting from 1 to 15 hours, of the transfer of I-V and QE measurement technology to SAI partners, U.S. industry, and others. Hundreds of other visits, phone conversations, and e-mail interactions relating to specific questions about I-V and QE measurement technology took less than 1 hour.

\subsection{Electro-Optical Characterization Task}

\section{Study the kinetics of Si wafer microcrack} propagation as a function of processing:

Wafer breakage is a critical issue in current lowcost solar cell production, because typically about $10 \%$ of wafers break during cell fabrication. It is now recognized that wafer breakage arises primarily because of the presence of microcracks, either on the edges or the surfaces of the wafer. In our ongoing efforts to alleviate this problem, we have performed numerical and analytical studies of the fracture properties of silicon wafers.

We developed a general fracture-mechanics model that can successfully predict the strength of cast silicon wafers used by the PV industry. The model combines Monte Carlo simulations with finite-element fracture computations. The computation procedure developed starts from virtual generation of a set of wafers $n$. Each wafer in the set contains a prescribed number of surface cracks, which are randomly distributed and oriented. Next, the maximum load for each wafer is calculated using the numerical fracturemechanics method combined with the weakestlink principle. Finally, we perform a statistical analysis of the results for all $n$ wafers to obtain the strength distribution, and we estimate the corresponding distribution parameters.

The technique is very general and allows the modeling of wafers of various sizes and shapes that are subjected to any type of loading. This understanding can now be applied to real-world crack distributions induced by different process steps and the strength of wafers relative to the various stress distributions they are subject to during solar cell processing. Ultimately, this will inform PV manufacturers about how to modify their manufacturing processes to minimize breakage.

Organize the $17^{\text {th }}$ Workshop on Crystalline Silicon Solar Cell Materials and Processes:

The 17th Workshop on Crystalline Silicon Solar Cells and Modules: Materials and Processes was held in Vail, Colorado, on August 5-8, 2007. This meeting spanned $3-1 / 2$ days and attracted a record number of attendees (179) from 16 countries, with representatives from 62 international PV and semiconductor companies and 19 universities. The greatest number of participants were from the United States (114), Germany (21), Japan (9), Canada (8), Norway (7), and Taiwan (6). The workshop's central theme, "Expanding Technology for a Future Powered by Silicon Photovoltaics," reflected the enormous growth in Si-PV and huge number of new companies. Sessions were organized around specific topics related to the theme and included several invited presentations by selected experts followed by lengthy discussions on the topic moderated by the session chair or panel leader.

This intense meeting was designed to promote extensive interactions and exchanges of ideas among participants. Evening poster sessions permitted additional research presentations and interactions. As in prior workshops, there was an informal Rump Session on Sunday evening. The theme of that session was "Achieving Low-Cost Electricity (Grid-Parity) with Si PV." Oral, poster, and discussion sessions addressed recent advances in crystal growth technologies, impurities and defects in semiconductors, feedstock issues, solar cell processing, thin-film Si and heterojunction devices, solar cell metallization, and cell and module measurement issues.

\section{Develop minority carrier lifetime measurement techniques:}

Quality control in PV manufacturing is hindered by the lack of in-line diagnostics. Because manufacturers are unable to test cells until the end of the production line, problems in the production process can go undiscovered for a day or longer. This can result in the production of large volumes of defective cells. Measurements of minority carrier lifetime (MCL) and related properties offer the promise of rapid noncontact diagnostics of materials and processes that can be deployed on the production line. Scanning or mapping

Photovoltaic R\&D

Fundamental Research 
techniques measure a sample over thousands of points, while imaging techniques measure the entire sample at once. Scanning techniques apply single-point measurement techniques that are well understood, while imaging techniques are relatively new and untested. The new imaging techniques hold great promise for in-line diagnostics because of their rapidity; however, the correlation between their images and solar cell efficiency is poorly understood.

Our group at NREL possesses a unique combination of expertise and facilities to investigate and develop advanced techniques for measuring MCL. Our goal in this project is to develop and compare the latest techniques to determine the optimum methods and conditions for on-line MCL diagnostics. In FY 2007, we made considerable progress toward developing new technique capabilities in spite of numerous delays. A commercial microwave reflection system was ordered, but we have not yet received it. In the meantime, we built a homemade version of a microwave reflection scanner that will prove useful in the design and construction of a custom system to be installed in a future PDIL vacuum system. Mapping results for a wafer intentionally contaminated with iron are shown in Figure 9.

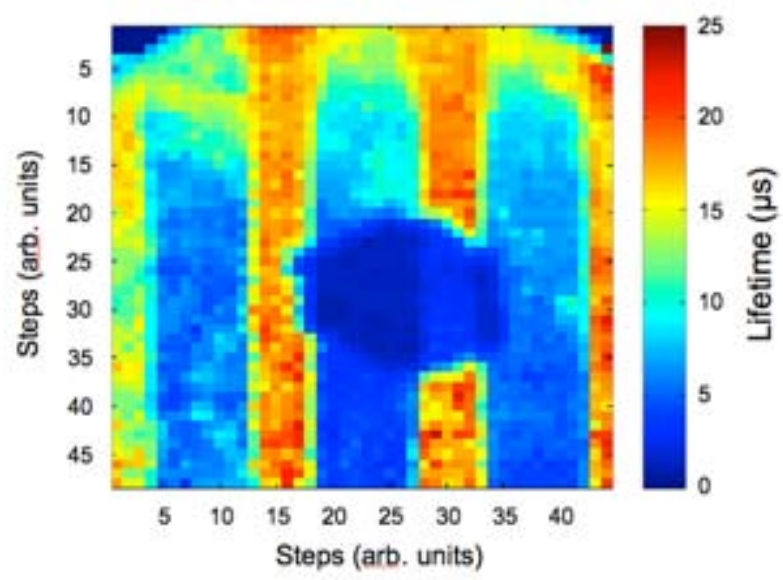

Fig. 9. Microwave reflection lifetime map of a single $100-\mathrm{mm}$ crystalline silicon wafer with features caused by iron contamination in the center and vertical lines caused by contact with grid supports during furnace annealing.
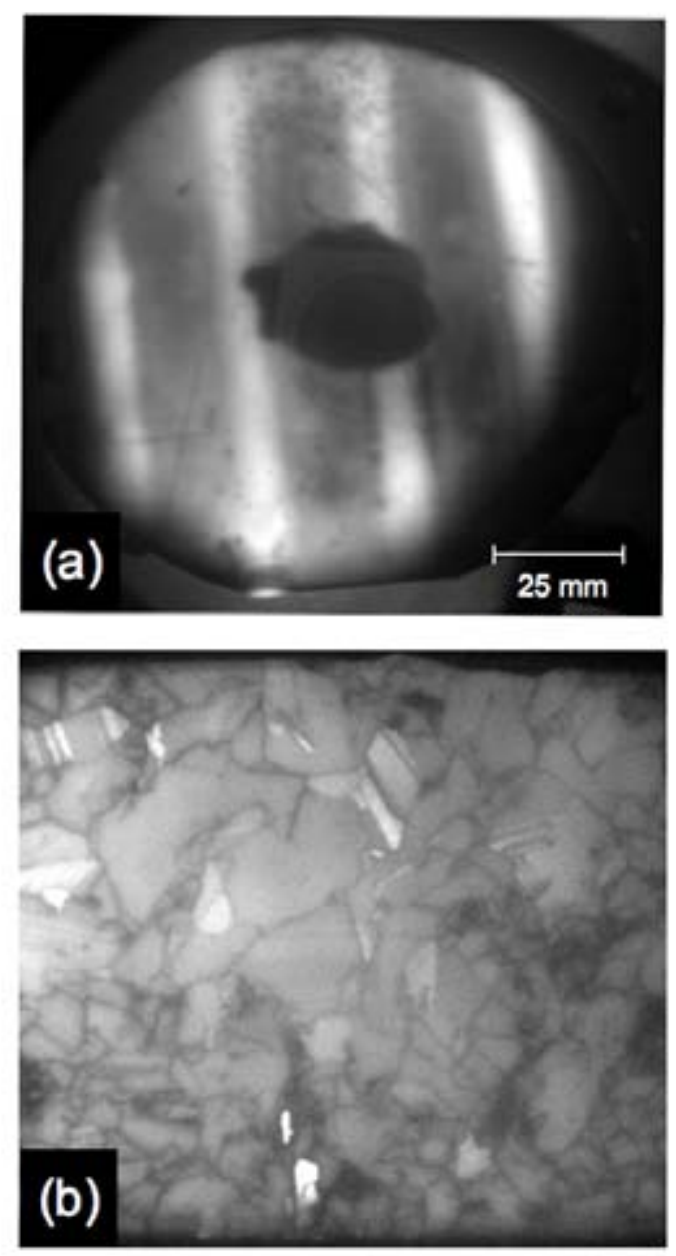

Fig. 10. (a) PL image of the c-Si wafer shown in Fig. 9; (b) PL image of multicrystalline Si wafer.

Photoluminescence imaging (PLI) is a relatively new technique in which the photoluminescence $(\mathrm{PL})$ intensity is thought to be proportional to the carrier lifetime in each area. This may provide a high-speed method for characterizing the lifetime distribution in a wafer. Figure 10(a) shows PLI data from same wafer scanned in Figure 9. Scanning takes a few seconds per point over thousands of points, so the map of Figure 9 took nearly an hour to complete. In contrast, the PL image took only a few seconds of exposure time. PLI will also be applicable to multicrystalline samples, as shown in Figure 10(b).

Carrier density imaging (CDI) is another relatively new technique under development. CDI uses an infrared camera to monitor either the absorption or emission of infrared radiation by excess carriers. CDI may have an advantage over PLI in that 
recombination of excess carriers can be any mechanism, and a strong $\mathrm{PL}$ signal is not necessary. This may make CDI more appropriate for unpassivated surfaces. CDI, however, requires extreme sensitivity, and only lock-in techniques will provide such resolution. We are currently in the early stages of developing this technique. Figure 11 shows a wafer with multiple contamination spots clearly resolved by CDI.

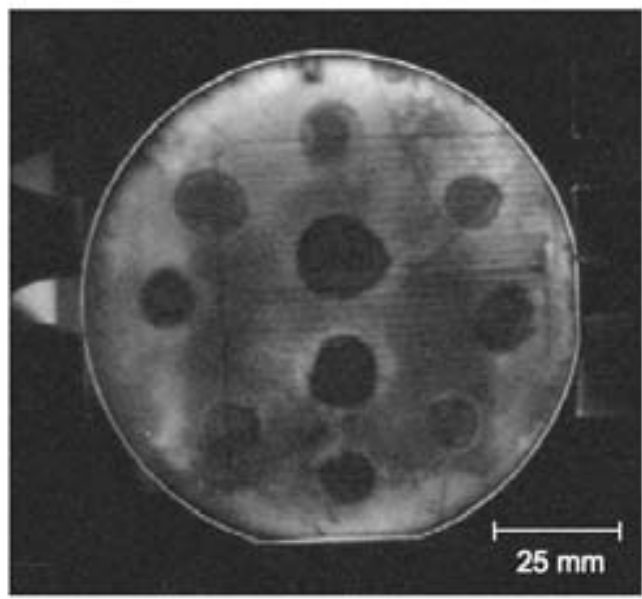

Fig. 11. Carrier density image of a c-Si wafer with multiple contamination spots as measured using an infrared camera with lock-in detection.

\section{Develop advanced multidimensional computer models for multicrystalline-Si devices:}

Multicrystalline (mc)-Si wafers made from cast ingots are significantly less expensive than singlecrystal wafers made from single-crystal boules. Unfortunately, solar cells made from mc-Si wafers are also significantly less efficient than their singlecrystal counterparts. Although there is a consensus that the lower efficiency of mc-Si solar cells is the result of the presence of grain boundaries and nonuniformities from grain to grain, there is no clear understanding of how these properties impact the function of solar cells or measurements of their properties. Numerical modeling of mc-Si wafers and solar cells provides a unique capability to do "numerical experiments" in which it is a simple matter to change the grain size, local lifetime, or recombination velocity at grain boundaries and observe the effect on cell efficiency and MCL that would be observed experimentally.

To gain a better understanding of both mc-Si solar cells and measurements of their properties, we developed advanced, two-dimensional computer models to analyze the physics introduced by GBs and nonuniformities. Figure 12 illustrates how the impact of lifetime nonuniformity depends on the grain size. In Figure 12(a), each of the grains is $3.33 \mathrm{~mm}$ wide; in Figure 12(b), each grain is 3.33 $\mu \mathrm{m}$ wide. The carrier lifetime varies from 100 to 1 to $10 \mu \mathrm{s}$ across the three grains. In the large-grain material, each grain functions as an independent diode; in the small-grain material, all three grains function with a single effective diffusion length. We find that, for grains greater than $1 \mathrm{~mm}$ across, GB recombination does not significantly affect device performance, but it can be very deleterious to smaller grain material. For macroscopic lifetime fluctuations, the regions with the shortest lifetimes generally dominate performance in a manner that can be estimated reasonably well using analytical formulas.

Models were also developed to simulate quasisteady-state photoconductivity (QSSPC), photoconductive decay (PCD), and infrared carrier density (IR-CD) lifetime mapping measurements on mc-Si solar cells with grain boundaries and lifetime fluctuations on different scales-both before and after the formation of the junction. If there is no junction, QSSPC and IR-CD measure the average lifetime for fluctuations on a scale larger than the diffusion length, whereas PCD measurements may measure the harmonic mean, the spatial average, or something else, depending on how the decay curve is analyzed.

Generally, the measured lifetime does not correspond to the aggregate lifetime, which represents device performance. So, highresolution mapping and specialized analysis are required to accurately correlate lifetime maps to device performance. Once a junction is added, charge separation significantly distorts lifetime measurements regardless of the technique used. Implementing high injection might mitigate charge separation effects, but it might also lead to undesired high-injection effects. These findings contradict the ideas of researchers who promote using QSSPC and CDI measurements in the presence of a junction to correlate lifetime maps to device performance. Much of this work has been summarized in a manuscript submitted to Solar Energy Materials and Solar Cells. 

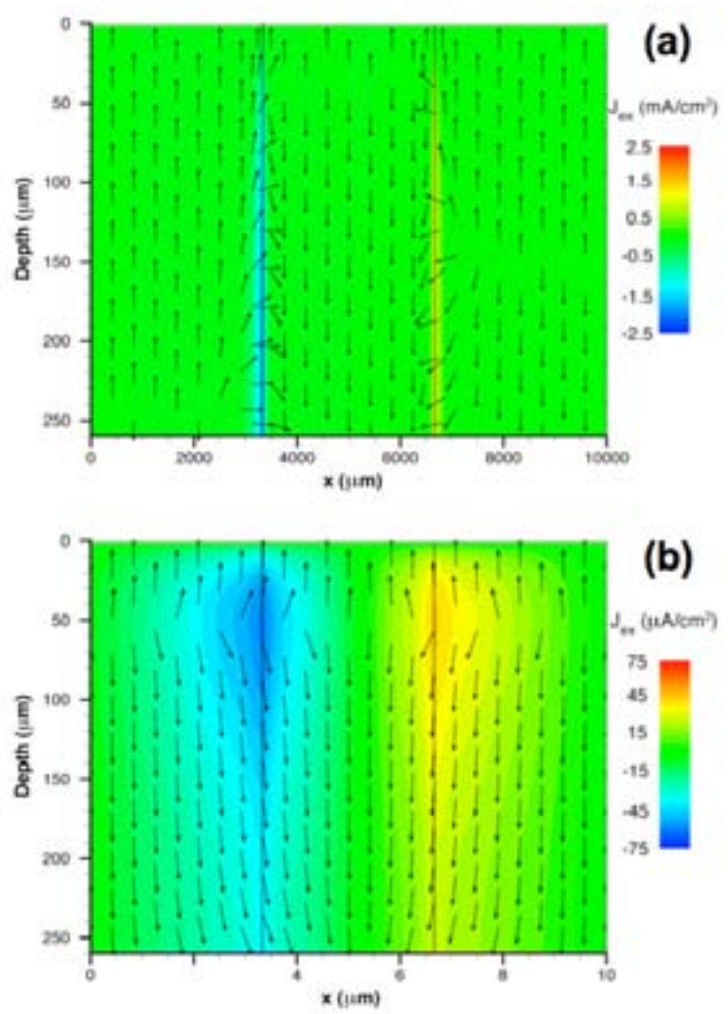

Fig. 12. The arrows indicate the direction of electron flow, and the contour colors indicate the magnitude of the electron current density in the $x$ direction $\left(\mathrm{J}_{\mathrm{ex}}\right)$ for a mc-Si solar cell under AM1.5 irradiation and no bias. For the three equally spaced regions running from left to right, $\tau$ is 100 , 1 , and $10 \mu \mathrm{s}$, respectively. In (a), each region is $3.33 \mathrm{~mm}$ across; in (b), each region is $3.33 \mu \mathrm{m}$ across and the contour color scale is different.

Develop an in situ spectroscopic ellipsometry capability for the TCO sputtering tool in the PDIL: Virtually all types of solar cell devices utilize a transparent top contact to allow light to penetrate into the cell while enabling the collection of electric current from the front surface. This requires high transparency together with high electrical conductivity, two frequently incompatible requirements.

Researchers at NREL are constantly working to develop new types of transparent conducting oxides (TCO) that can satisfy both of those requirements. Zinc oxide $(\mathrm{ZnO})$ is one the most promising of the new TCOs, and NREL researchers are actively working to advance our capabilities to simultaneously optimize both the transparency and conductivity of $\mathrm{ZnO}$. One of the most effective ways to accelerate progress in materials development is through the application of in situ diagnostic tools.

By measuring the film thickness and optical constants in real time during film deposition, in situ spectroscopic ellipsometry, also known as realtime spectroscopic ellipsometry (RTSE), provides valuable insights into the material properties and growth dynamics of the thin-film materials used in photovoltaics. Many of the deposition chambers integrated into the cluster tools being designed and installed in the PDIL will incorporate optical ports for RTSE. We hope that this capability will greatly contribute to the science and engineering of materials for PV. The TCO sputtering tool is the first of these tools to come online.

In FY 2007, we used RTSE to study the effect of substrate temperature on the growth dynamics and material properties of undoped sputterdeposited $\mathrm{ZnO}$. We found that there is a layer $40-$ $90 \mathrm{~nm}$ thick on the surface of the growing $\mathrm{ZnO}$ film that has optical properties distinct from those in the bulk of the film. Significant near-IR absorption indicates that there may be a high density of defects or free carriers in this material. During film deposition, this film stays constant in thickness while the underlying bulk $\mathrm{ZnO}$ increases in thickness, indicating a conversion of the growth zone material into bulk material at the bulk-growth zone interface. This may be an annealing effect caused by the elevated substrate temperature. We have also determined a correlation with poor conductivity in $\mathrm{ZnO}$ films less than $100 \mathrm{~nm}$ thick. Through ongoing studies we expect to gain a better understanding of the growth mechanisms of $\mathrm{ZnO}$ and obtain better control of film properties.

\subsection{Surface Analysis Task}

Provide surface analysis support:

The Surface Analysis team supported a variety of U.S. PV manufacturers during FY 2007. The most intensive efforts were with Advent Solar (XPS studies of $\mathrm{Si}_{x} \mathrm{~N}_{y}: \mathrm{H}$ passivation layers), Miasole (extensive analytical support to understand compositional and contaminant issues related to process development for CIGS), SoloPower (compositional profiling in CIGS materials), and CaliSolar (dopant profiling for silicon device structures). In FY 2007, we were able to honor all requests for analysis and support. 
Develop a new moisture barrier package and conduct barrier coated aluminum mirror screening studies:

Barrier layers for inhibiting the ingress of moisture in flexible packages must possess two properties to be effective for this application. Obviously, the barrier must inhibit the passage of water through the barrier. It is not so obvious, however, that the barrier must also adhere well to the surface it is deposited on and laminated to, in order to function properly. Previous collaborative work at NREL between the Surface Analysis team and the Reliability Packaging team has shown that PECVD-grown moisture barriers on polyethylene terephthalate (PET) can have excellent initial adhesion to PET and ethylene vinyl acetate (EVA) and exhibit moderate barrier efficacy; however, adhesion of the barrier to the PET fails after even a very brief exposure to damp heat. Weak interfacial bonds between the PECVD layer and the PET surface are suspected to contribute to the adhesion failure.

During FY 2007, we investigated a variety of new interfacial layer (IFL) coatings deposited on PET. We evaluated IFL/PET for efficacy and adhesion before and after damp heat exposure. Initial measurements showed that the barrier efficacy of IFL alone ranged from inferior to very good, when compared with PECVD barriers alone. We found that IFL-alone adhesion was similarly variable, depending on composition. It was particularly interesting that even the IFL composition displaying the highest resistance to damp heatinduced adhesion loss was still inferior in performance to a PECVD barrier alone. However, subsequent depositions of PECVD barrier overcoats on IFL-coated PET resulted in a package that exhibited some of the lowest WVTR (water vapor transmission rate) values we have seen to date, as well as $100 \%$ retention of peel strength (adhesion) even after 300+ hours of damp heat testing. Inserting the interfacial adhesion layer represents a new barrier construction that resulted in an NREL Record of Invention filed in December 2007.

Other studies performed during FY 2007 focused on determining the best composition for PECVD barrier overcoats. A variety of compositions ranging from $\mathrm{SiO}_{x} \rightarrow \mathrm{SiO}_{x} \mathrm{~N}_{y} \rightarrow \mathrm{Si}_{3} \mathrm{~N}_{4}$ were deposited on aluminum-coated glass containing scribe lines. Because thin films of aluminum on glass are very susceptible to chemical attack under damp-heat conditions and turn clear where attack has taken place, they offer a quick and effective screening method for barrier efficacy. Aluminum mirrors were deposited in 1 in. $x 1$ in. squares on glass to perform a combinatorial composition study. By using a new photocurrent measurement device to measure light transmission after varying amounts of damp-heat exposure, we found that films with high nitrogen content (such as stoichiometric $\mathrm{Si}_{3} \mathrm{~N}_{4}$ ) exhibited the highest barrier efficacy even after 2000+ hours of damp-heat exposure. In addition, the films in general are apparently highly conformal around scribe lines, as evident in no observable deterioration in the areas around the scribe lines. We intend to use a similar approach with ZNOcoated glass to evaluate barriers suitable for direct overcoats of PV absorbers.

Investigate the materials chemistry of CIGS on flexible substrates, leading to an improved understanding of long-term reliability:

This work was formulated to be a continuation of studies begun during FY 2006. In the earlier work, a sodium fluoride ( $\mathrm{NaF}$ )-induced defect was identified that appeared to show a correlation with the damp-heat-induced degradation of unencapsulated CIGS devices on flexible substrates. The intent of the current work was to study this defect with various PV manufacturers; however, we encountered difficulties because of the proprietary nature of each manufacturer's process and our inability to arrive at test structures and processing conditions that could be shared in the general literature.

The results of this work that can be shared are as follows. Sodium fluoride is often used as a source of sodium in CIGS grown on non-soda-lime-glass substrates or on diffusion-barrier coated glass. This is necessary to provide an adequate supply of sodium to produce high-efficiency CIGS films. Several previous studies reported in the literature for CIGS films grown on glass had determined that no fluorine remained in the CIGS from the $\mathrm{NaF}$ (also confirmed in previous NREL studies); however, our current study finds that, on various nonglass substrates, this result is not always the case. Certain processing conditions do not result in complete volatilization of the fluorine from the growing film, leaving high levels of this halide impurity in the film. The presence of fluorine indicates that unbound sodium may not be available to aid in CIGS film growth. Although we had limited samples to investigate these processing-related compositional differences, it appears that, to volatilize all the fluorine, it is critical that the substrate reach a high enough 
temperature. This critical temperature could be difficult to attain on a flexible substrate, where too high a temperature may also result in the diffusion of deleterious elements from the substrate or even in the melting of the substrate. Unfortunately, the details of this study cannot be disclosed because of the proprietary nature of the work done with our industry partners.

Improve the understanding of CdTe back-contact reaction kinetics:

A study describing the $\mathrm{Cu}_{x} \mathrm{Te} / \mathrm{CdTe}$ surfaceprecipitation phenomenon and the accompanying change to the CdTe surface electronic structure has been completed and published in the Journal of Applied Physics. The results were presented at the 2007 Spring Materials Research Society (MRS) Meeting in the Thin-Film Compound Semiconductor Photovoltaics Symposium. These studies shed new light on the role of $\mathrm{Cu}$ in $\mathrm{CdTe}$ PV back contacts. In particular, the segregated nanoscale $\mathrm{Cu}_{\mathrm{x}} \mathrm{Te}$ creates a metallic surface state that effectively lowers the ionization potential of the surface. Because secondary back-contact materials can readily contact the metallic $\mathrm{Cu}_{\mathrm{x}} \mathrm{Te}$ layer, this helps to explain the role of $\mathrm{Cu}$ in ohmiccontact formation in CdTe PV devices.

A second experimental paper published in Thin Solid Films describes the formation of $\mathrm{Cu}_{\mathrm{x}} \mathrm{Te}$ via the exposure of elemental $\mathrm{Cu}$ to $\mathrm{Te}$ vapor, and the decomposition kinetics via in-vacuum thermal decomposition of these films via the reaction $\mathrm{Cu}_{\mathrm{x}} \mathrm{Te}(\mathrm{s}) \rightarrow \mathrm{xCu}(\mathrm{s})+\mathrm{Te}(\mathrm{v})$. This study has relevance both to back-contact processing and long-term stability issues and was presented at the 2006 American Vacuum Society (AVS) Fall Meeting.

The lack of a suitable theory in the literature to describe the observed $\mathrm{Cu}_{\mathrm{x}} \mathrm{Te} / \mathrm{CdTe}$ surfaceprecipitation phenomenon motivated us in 2007 to develop an impurity migration model for systems with material interfaces. The model is very general and is capable of describing diffusion, segregation, and migration phenomena in a wide variety of material systems relevant to PV research. One exciting application for the model is Cu-migration in CdTe/CdS solar cells under both deviceprocessing and field-deployed conditions. Preliminary modeling of this system explains the frequently observed migration of $\mathrm{Cu}$ from the back contact and segregation in the CdS layer. Two manuscripts have been prepared that describe the development and implementation of the diffusion/segregation model. One paper addresses impurity migration phenomena in systems with material interfaces. The other paper applies the model to surface-segregation phenomena like the $\mathrm{Cu}_{\mathrm{x}} \mathrm{Te}$ surface precipitation observed on the surfaces of Cu-doped CdTe.

\section{Develop a large-platen Auger electron} spectroscopy tool:

The order for the large-platen Auger electron spectroscopy (AES) PDIL tool was placed in the final quarter of FY 2006, and the tool was to be delivered and installed in 2007. Unfortunately, the tool builder encountered several problems with various subcomponents for the Auger analysis system that repeatedly delayed the completion and testing of the tool. Initially there were difficulties with computer control of the electron spectrometer, the detectors, and the ion gun. The problems were serious enough to require modification of the Auger components and electronics at the OEM vendor. The delay in reconfiguring the Auger parts left the tool vendor unable to test the system until late in FY 2007. As testing progressed, NREL Surface Analysis staff members raised concerns about the electron spectrometer's resolution and transmission, and later about the stability of the ion gun. By February 2008, the spectrometer had exceeded NREL's performance specification for the tool. The ion gun, however, is still performing at unacceptable levels. The Surface Analysis team is working with the vendor to resolve these issues. We expect the problems to be resolved and believe the tool will be ready for acceptance testing in April 2008.

Develop the design and specification of a smallspot XPS tool:

The small-spot XPS tool based on the process integration standard for the PDIL is currently under construction, and delivery is expected to NREL during the fourth quarter of FY 2008. The tool was procured through a competitive bidding process, and four vendors responded to the request for quotations. The winning bids were from Kratos Analytical for the XPS tool and from Transfer Engineering (TE) for an integrated rotationflipping-transfer station. Both vendors provided outstanding technical excellence and value in their bids. The TE flipping station will allow the sample platen to be loaded from other tools in the facedown position, which is common in the PDIL deposition tools, and then flipped to face-up for XPS analysis. The Kratos AXIS NOVA is a highly automated, state-of-the-art imaging XPS with a capability for selected area spectroscopy with lateral resolution of $\leq 10 \mu \mathrm{m}$. The tool will be able

Photovoltaic R\&D 
to access all areas of the platen via a single $180^{\circ}$ rotation of the sample built into the flipping station. The fact that the XPS tool is based on a standard Kratos product will facilitate completion and installation. Kratos and TE have been strong partners in this endeavor.

\section{Develop a liquid-phase quartz-crystal microbalance for automated chemical-bath} deposition end-point detection:

In FY 2007, we completed the construction and testing of the liquid-phase quartz crystal microbalance (LQCM) automated chemical reaction system. This system uses inexpensive off-the-shelf components and was designed to help the Surface Analysis Team investigate processes that occur at the solid-liquid interface. A number of these processes are used in the PV industry because of their favorable combination of effectiveness and lower cost; examples include the chemical bath deposition of CdS buffer layers in $\mathrm{Cu}(\mathrm{In}, \mathrm{Ga}) \mathrm{Se}_{2}$ and $\mathrm{CulnS}_{2}$ devices, a process that is used in virtually every commercially available CIS-based module. Others are aqueous etching of silicon-based cells for AR-texturizing, cleaning, and defect removal, and solution-based methods for the growth and modification of nextgeneration quantum dot (QD)-based solar cells. The system is installed in the glove box of our cluster tool, allowing materials to be studied in liquid environments and the direct transfer of the reacted surface into the ultra-high-vacuum (UHV) environment, in order to study the surface chemistry and physics.

Initial results from the apparatus are extremely promising and will be described in detail in a presentation at the 33rd Institute of Electrical and Electronic Engineers (IEEE) PV Specialists Conference. We have demonstrated the successful operation of all hardware and software components, reagent dispensing systems, pumps, membrane contactors, a six-way valve for the sequential addition of reagents, monitoring equipment such as a $\mathrm{pH}$ meter, and the QCM itself. We have shown that the special QCM crystals, originally meant for operation in liquids only, can be heated to $>200^{\circ} \mathrm{C}$ in a sputter deposition system and coated with materials of interest, and that crystals coated with a solid material of interest still perform as expected in liquids. We have used the system to accurately measure the dissolution rate of $\mathrm{ZnO}$, an important transparent conductor, in dilute chloride solutions down to $0.008 \AA / s$. We have also shown how attaching a simple organic molecule to the oxide surface can be used to dramatically slow this corrosion. This result has obvious implications for studying the degradation of $\mathrm{PV}$ materials under various aqueous conditions, such as those that might be experienced in humid environments inside an actual module.

Multiple exciton generation collaborative $R \& D$ : Our previous efforts to integrate atmospheric pressure tools with UHV surface analysis tools generated new collaborations in FY 2007 with the Nozik group in studies of materials for multipleexciton generation in PV devices. Our teams were able to grow quantum dots with a solution-based process and study how post-growth processing enables thin films of these QDs to be transformed from electrical insulators to conducting, active elements in electronic devices. Such electronic coupling between QDs is a prerequisite for the efficient operation of a wide variety of strategies that aim to make use of the unique properties of QDs in a new generation of PV devices.

The issue here is that QDs typically are grown with long, straight-chain alkanes that have large HOMO-LUMO gaps (between the highest occupied molecular orbitals and the lowest unoccupied molecular orbitals) of $\sim 8 \mathrm{eV}$. Because each QD is encapsulated in a thick insulating shell of organic molecules, thin films of as-grown QDs are also insulators. Our plan, which was successful, was to try to exchange the long-chain organic capping groups (oleic acid) with much shorter molecules (ethanedithiol) in the hope that the exchange would be possible and that this would allow greater inter-dot electronic coupling. A key problem that was overcome with the Surface Analysis Team cluster tool stems from the fact that removing the long-chain alkane capping groups from QDs makes them extremely reactive towards one or more constituents of air. We were able to use the glove box portion of the cluster tool to perform contamination-free transfers of films between laboratories and thus do some of the very first surface analytical studies on these types of films. This work has resulted in two publications to date. A third publication is being prepared in which we elucidate the mechanisms by which QD-based devices fail upon exposure to air.

\section{Planned FY 2008 Activities}

A list of selected FY 2008 planned activities is given below. A more complete list of planned activities and milestones can be found in the Measurements and Characterization FY 2008 
Annual Operating Plan. In FY 2008, we will complete the following milestones:

- Develop an integrated plan to provide priority support to SAI TPP awardees that meets their R\&D needs within the context of available resources.

- Provide measurement support in the areas of analytical microscopy, cell and module performance, electro-optical characterization, and surface analysis to PV research partners in industry, academia, and NREL.

- Maintain ISO accreditation for primary and secondary cell and module calibrations.

- Complete the construction and fit-up of the OTF expansion project.

- Install enhanced module measurement capabilities that will improve measurement uncertainty, as necessary to support the SAI.

- Bring new solar simulators on line and make them compatible with our ISO quality systems.

- Organize the 18th Workshop on Crystalline Silicon Solar Cells \& Modules. This year's theme is "Achieving Low-Cost Electricity (GridParity) with Si PV."

- Design, procure, and install the Measurement and Characterization integrated PDIL tool set. Integrated tools include the cluster tool robot; resonantly coupled photoconductive decay lifetime tool; PL imaging tool; spectroscopic ellipsometer tool; Auger electron spectroscopy tool; sputter/plasma etch tool; and the PECVD tool.

- Design, procure, and install the Measurement and Characterization stand-alone PDIL tool set. Stand-alone tools include the $\mathrm{X}$-ray photoelectron spectroscopy tool; scanning electron microscopy tool; atomic force microscopy tool; wet chemistry workstation tool; reflectometer; optical processing furnace; and lifetime mapping tool.

\section{FY 2007 Special Recognitions, Awards, and Patents}

Awards:

- Keith Emery received the 2007 Paul Rappaport Award.

- Keith Emery was also one of the recipients of a 2007 R\&D 100 award to Spectrolab and NREL.

- Manuel Romero won an NREL outstanding performance staff award.

- Peter Sheldon was elected to the position of Director of the AVS Science and Technology Society.

Photovoltaic R\&D

Fundamental Research

Measurements and Characterization
Patents

- B. Sopori, Wafer Characteristics via Reflectometry and Wafer Processing Apparatus and Method, U.S. Patent No. 7,238,912, July 3, 2007.

- D. Levi, Optical Method for Determining the Doping Depth Profile in Silicon, U.S. Patent No. 7,179,665, Feb. 20, 2007.

- B. Sopori and P. Sheldon, Technique for Screening and Isolating, "Problem Wafers" with Fatal Cracks, Filed 2007.

- A. G. Norman and J. M. Olson, Nanostructures Produced by PhaseSeparation during Growth of (III-V)1-x(IV2)x Alloys, U.S. Patent No. 7,229,498 B2, June 12, 2007.

\section{Major FY 2007 Publications}

K. Ahn, Y. Yan, S-H. Lee, T. Deutsch, J. Turner, C.E. Tracey, C.L. Perkins, and M. Al-Jassim, "Photoelectrochemical Properties of NIncorporated ZnO Films Deposited by Reactive RF Magnetron Sputtering," J. Electrochem. Soc., 154(9), B956 (2007).

K. Ahn, T. Deutsch, Y. Yan, C-S. Jiang, C.L. Perkins, J. Turner, M. Al-Jassim, and K. Ahn et al., "Synthesis of Band-Gap-Reduced P-Type ZnO Films by Cu Incorporation," J. Appl. Phys., 102(2), 023517 (2007).

R.K. Ahrenkiel, S.W. Johnston, and P. Dippo, "Relationship of Intrinsic Luminescence to Recombination Lifetime in Single-Crystal Silicon Wafers." Sopori, B.L., ed., in 17th Workshop on Crystalline Silicon Solar Cells and Modules: Materials and Processes; Workshop Proceedings, 5-8 August 2007, Vail, Colorado, NREL Report no. BK-520-42056) (2007). Golden, CO: National Renewable Energy Laboratory (2007).

R.K. Ahrenkiel, S.W. Johnston, and W.K. Metzger, "Comparison of Techniques for Measuring Recombination Lifetime in Photovoltaic Materials: Trapping Effects," in Solar Energy Conversion, y Matt Beard, ed., Mater. Res. Soc. Symp. Proc. 974E, Warrendale, PA, 0974-CC01-01 (2007).

K. Araki, K. Emery, and M. Yamaguchi, "The First Grid-Connected Concentrator PV System in Industry Zone Using III-V Cells," Proc. Renewable Energy 2006, International Energy Society, Chiba, Japan, Oct 9-13 (2006). 
A. Barnett, D. Kirkpatrick, C. Honsberg, D. Moore, M. Wanlass, K. Emery, R. Schwartz, D. Carlson, S. Bowden, D. Aiken, A. Gray, S. Kurtz, L. Kazmerski, T. Moriarty, M. Steiner, J. Gray, T. Davenport, R. Buelow, L. Takacs, N. Shatz, J. Bortz, O. Jani, K. Goossen, F. Kiamilev, A. Doolittle, I. Ferguson, B. Unger, G. Schmidt, E. Christensen, and D. Salzman, "Milestones Toward $50 \%$ Efficient Solar Cell Modules," Proc. 22nd European Photovoltaic Solar Energy Conf., Milan, Italy, September 3 (2007).

J.R. Doyle, Y.Xu, R. Reedy, H.M. Branz, and A.H. Mahan, "Film Stoichiometry and Gas Phase Chemistry in HWCVD of a-SiGe:H," Thin Solid Films, in press.

K. Emery, "Accuracy in Solar Cell and Module Measurements and Approaches to Improve Them," Proc. 17th Workshop on Crystalline Silicon Solar Cells and Modules: Materials and Processes, Vail, CO, August 5-8 (2007).

K. Emery, "Cell and Module Performance," Proc. Solar Energies Technologies Review Meeting, April 17-19 (2007).

K. Emery, "ASTM Photovoltaic Performance Standards in Use at NREL," ASTM International Standardization News, vol. 35 (7), pp. 30-33, July (2007).

K. Emery, "Performance of Thin Film Modules," 2nd International Photovoltaic Industry Workshop on Thin Films, 11/9-10/2006, JRC/IES, Ispra, Italy (2006).

J.F. Geisz, S. Kurtz, M.W. Wanlass, J.S. Ward, A. Duda, D.J. Friedman, J.M. Olson, W.E. McMahon, T.E. Moriarty, and J.T. Kiehl, "High-Efficiency GalnP/GaAs/InGaAs Triple-Junction Solar Cells Grown Inverted with a Metamorphic Bottom Junction," Applied Physics Letters. Article No. 023502, Vol. 91(2) (2007).

T.A. Gessert, S. Asher, S. Johnston, M. Young, P. Dippo, and C. Corwine, "Analysis of CdS/CdTe Devices Incorporating a ZnTe:Cu/Ti Contact," Thin Sol. Films, 515(15), 6103 (2007).

M.A. Green, K. Emery, D.L. King, Y. Hishikawa, and W. Warta, "Solar Cell Efficiency Tables (version 29)," Progress in Photovoltaics Research and Applications, vol. 15, pp. 35-40 (2007).
M.A. Green, K. Emery, D.L. King, Y. Hishikawa, and W. Warta, "Solar Cell Efficiency Tables (version 30)," Progress in Photovoltaics Research and Applications, vol. 15, pp. 425-430 (2007).

J.B. Hurst, S.D. Lewis, M.M. Oye, A.L. Homes, Jr., A.J. Ptak, R.C. Reedy, "Unintentional Calcium Incorporation in $\mathrm{Ga}(\mathrm{Al}, \mathrm{In}, \mathrm{N}) \mathrm{As}$," J. Vac. Sci. Techn. B, 25(3), 1058 (2007).

C.-S. Jiang, B. Yan, H. R. Moutinho, M. M. AlJassim, J. Yang, and S. Guha, "Light Soaking and Thermal Annealing Effects on the Micro-Electrical Properties of Amorphous and Nanocrystalline Mixed-Phase Silicon Solar Cells," Mat. Res. Soc. Symp. Proc. Vol. 989, A02-05 (2007).

C.-S. Jiang, B. Yan, Y. Yan, C.W. Teplin, R. Reedy, H.R. Moutinho, M.M. Al-Jassim, J. Yang, and S. Guha, "Effect of $P$ Incorporation on Aggregation of Nanocrystallites in Amorphous and Nanocrystalline Mixed-Phase Silicon Thin Films," J. Non-crystalline Solids (proceedings of $22^{\text {nd }}$ ICANS), in press.

C.-S. Jiang, B. Yan, Y. Yan, C.W. Teplin, R. Reedy, H.R. Moutinho, M.M. Al-Jassim, and J. Yang, "P-Induced Dispersion of Nanocrystallite $\mathrm{Si}$ in Amorphous Matrix," J. Appl. Phys., in review.

S.W. Johnston, R.K. Ahrenkiel, P. Dippo, M. Page, and W.K. Metzger, "Comparison of Silicon Photoluminescence and Photoconductive Decay for Material Quality Characterization," Semiconductor Defect Engineering-Materials, Synthetic Structures and Devices II, S. Ashok, J. Chevallier, P. Kiesel, and T. Ogino, eds.,Mater. Res. Soc. Symp. Proc., Volume 994, Warrendale, PA (2007).

D. Levi, E. Iwanizcko, S. Johnston, Q. Wang, and H.M. Branz, "Materials Optimization for Silicon Heterojunction Solar Cells Using Spectroscopic Ellipsometry," Paper No. 0989-A24-04. Chu, V., et al., eds. Amorphous and Polycrystalline Thin-Film Silicon Science and Technology - 2007: 9-13 April 2007, San Francisco, CA. Mater. Res. Soc. Symp. Proc., Vol. 989, Warrendale, PA, pp. 569-574; NREL Report No. CP-520-41527 (2007).

F. Liu, M. J. Romero, K. M. Jones, A. G. Norman, M. M. Al-Jassim, D. Inns, and A. G. Aberle, "Intragrain Defects in Polycrystalline Silicon ThinFilm Solar Cells on Glass by Aluminum-Induced Crystallization and Subsequent Epitaxy," accepted in Thin Solid Films. 
J. M. Luther, M. Law, Q. Song, C. L. Perkins, M. C. Beard, and A. J. Nozik, "The Structural, Optical and Electrical Properties of Self-Assembled Films of $\mathrm{PbSe}$ Nanocrystals Coupled with 1,2Ethanedithiol," ACS Nano., 2(2), 271-280 (2008).

W.E. McMahon, K.E. Emery, D.J. Friedman, L. Ottoson, M.S. Young, J.S. Ward, C.M. Kramer, A. Duda, and S. Kurtz, "Daily Fill Factor Variation as a Diagnostic Probe of Multijunction Concentrator Systems During Outdoor Operation," SPIE Proceedings, vol. 6649, High and Low Concentration for Solar Electric Applications II, ISBN 9780819467973, Sept. 10 (2007).

W.K. Metzger, T.J McDonald., C.Engtrakul, J. L. Blackburn, G. D. Scholes, G. Rumbles, and M. J. Heben, "The Temperature Dependence of Excitonic Decay and Multiple States in Single-Wall Carbon Nanotubes," J. Phys. Chem. C 111(9), 3601-3606 (2007).

W.K. Metzger, "The Impact of Lifetime Fluctuations and Grain Boundary Recombination on Silicon Solar Cells and Lifetime Maps," submitted to Solar Energy Materials and Solar Cells.

H.R. Moutinho, R.G. Dhere, B. To, C.-S. Jiang, and M.M. Al-Jassim, "Electron Backscatter Diffraction of CdTe Thin Films-Effects of $\mathrm{CdCl}_{2}$ Treatment," accepted for publication in the JVST A.

H.R. Moutinho, R.G. Dhere, C.-S. Jiang, B. To, and M.M. Al-Jassim, "Electron-Backscatter Diffraction of Photovoltaic Thin Films," Materials Research Society Proceedings, in press (2007).

H.R. Moutinho, R.G. Dhere, C.-S. Jiang, T. Gessert, A. Duda, M. Young, W.K. Metzger, and M.M. Al-Jassim, "The Role of $\mathrm{Cu}$ on the Electrical Properties of CdTe/CdS Solar Cells-A CrossSectional Conductive Atomic Force Microscopy Study," J. Vac. Sci. Technol. B 25, 361 (2007).

H.R. Moutinho, R.G. Dhere, C.-S. Jiang, T. Gessert, A. Duda, M. Young, W.K. Metzger, X. Li and M.M. Al-Jassim, "Cross-Sectional Conductive Atomic Force Microscopy of CdTe/CdS Solar Cells: Effects of Etching and Back-Contact Processes," Proc. 4th World Conf. on Photovoltaic Energy Conversion, Hawaii, 404 (2006).
S. Pinegar, D. Nalley, and K. Emery, "Linearity Testing of Photovoltaic Cells," U.S. Department of Energy, Journal of Undergraduate Research, vol. 6 (2006).

M.J. Romero, J. van de Lagemaat, G. Rumbles, and M. M. Al-Jassim, "Plasmon Excitations in Scanning Tunneling Microscopy: Simultaneous Imaging of Modes with Different Localizations Coupled at the Tip," Appl. Phys. Lett. 90, 193109 (2007).

P. Rupnowski and B. Sopori, "Strength of PV Silicon Wafers-Fracture Mechanics Approach." 17th Workshop on Crystalline Silicon Solar Cells and Modules: Materials and Processes; Workshop Proceedings, Vail, Colorado, 5-8 August 2007, B.L. Sopori, ed., NREL/BK-520-42056, Golden, CO: National Renewable Energy Laboratory, 4448 (2007).

B. Sopori, V. Mehta, P. Rupnowski, J. Appel, M. Romero, H. Moutinho, D. Domine, B. To, R. Reedy, M. Al-Jassim, A. Shaikh, N. Merchant, C. Khadilkar, D. Carlson, M. Bennet, (2007). "Fundamental Mechanisms in the Fire-Through Contact Metallization of Si Solar Cells: A Review." 17th Workshop on Crystalline Silicon Solar Cells and Modules: Materials and Processes; Workshop Proceedings, Vail, Colorado 5-8 August 2007, B. L. Sopori, ed., NREL/BK-520-42056, Golden, CO: National Renewable Energy Laboratory, 93-103 (2007).

P. Stradins, D. L. Young, Y. Yan, E. Iwaniczko, Y. Xu, R. C. Reedy, H. M. Branz, and Q. Wang, "Real-Time Optical Spectroscopy Study of SolidPhase Crystallization in Hydrogenated Amorphous Silicon," Appl. Phys. Lett. 89, 121921 (2006).

P. Stradins, O. Kunz, D.L. Young, Y. Yan, Y. Xu, R. Reedy, H.M. Branz, A.G. Aberle, and Q. Wang, "Comparative Study of Solid-Phase Crystallization of Amorphous Silicon Deposited by Hot-Wire CVD, Plasma-Enhanced CVD and Electron Beam Evaporation," Proc. MRS Spring Meeting Symposium A, in press (2007).

G. Teeter, " $\mathrm{Cu}_{2} \mathrm{Te}$ Synthesis and In-Vacuum Thermal Decomposition: Chemical-Kinetics Analysis and Comparison to Equilibrium VaporPressure Measurements," Thin Sol. Films, 515, 7886-7891 (2007). 
G. Teeter, "X-Ray and Ultraviolet Photoelectron Spectroscopy Measurements of Cu-Doped CdTe(111)-B: Observation of TemperatureReversible $\mathrm{Cu}_{x} \mathrm{Te}$ Precipitation and Effect on Ionization Potential," J. Appl. Phys., 102, 0345041-7 (2007).

X. Wu, J. Zhou, A. Duda, Y. Yan, G. Teeter, S. Asher, W. K. Metzger, S. Demtsu, S. H. Wei, and R. Noufi, "Phase Control of CuxTe Film and Its Effects on CdS/CdTe Solar Cell," Thin Sol. Films 515, 5798-5803 (2007).

Y. Yan, C.-S. Jiang, R. Noufi, S.-H. Wei, H. R. Moutinho, and M. M. Al-Jassim, "Electrically Benign Behavior of Grain Boundaries in

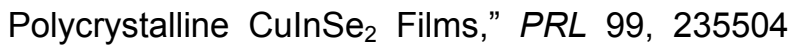
(2007).

Y. Yan, J. Li, S.-H. Wei, and M. Al-Jassim, "A Possible Approach to Overcome Doping Asymmetry in Wide Bandgap Semiconductor," Phys. Rev. Lett. 98, 135506 (2007).

Y. Yan, K.M. Jones, C.S. Jiang, X.Z. Wu, R. Noufi, and M.M. Al-Jassim, "Understanding the Defect Physics in Polycrystalline Photovoltaic Materials," Physica B, in press (2007).

J. Zhou, X. Wu, A. Duda, G. Teeter, and S. H. Demtsu, "The Formation of Different Phases of CuxTe and Their Effects on CdTe/CdS Solar Cells," Thin Solid Films, 515, 7364-7369 (2007). 


\title{
Resource and Safety Research Environmental Health and Safety
}

\author{
Performing Organization: Brookhaven National Laboratory (BNL) \\ Key Technical Contact: Vasilis Fthenakis (BNL), 631-344-2830, vmf@bnl.gov
}

DOE HQ Technology Manager: Alec Bulawka, 202-586-5633, alec.bulawka@ee.doe.gov

FY 2007 Budget: $\quad$ \$470K

\section{Objectives}

- Assist in preserving the safe and environmentally friendly nature of photovoltaics (PV) and in minimizing environmental health and safety (EH\&S) risks and associated costs, to ensure the economic viability of PV systems and public support for them.

- Identify potential EH\&S barriers for PV materials, processes, or applications and define strategies to overcome such barriers.

- Maintain the EH\&S Research Center as the world's best resource on PV EH\&S and for accurate information related to EH\&S issues and perceptions.

Accomplishments

- Conducted a life-cycle analysis of buffer options for cadmium-indium-gallium-selenium (CIGS) photovoltaics; presented the results at the $22^{\text {nd }}$ European Photovoltaic Solar Energy Conference, Milan, Italy.

- With European research collaborators, conducted a life-cycle study of greenhouse gas (GHG) use in crystalline silicon (c-Si) etching operations; the results were presented at the $22^{\text {nd }}$ European Photovoltaic Solar Energy Conference, Milan, Italy.

- Invited to and participated in the $4^{\text {th }}$ European PV Industry Forum Expert Panel on Sustainability Challenges, Milan, Italy.

- Invited to and participated in the California Energy Commission Expert Workshop on Nuclear Power in California; presented a comparison of GHG emissions in the PV and nuclear fuel cycles.

- Promoted and established international collaborative life-cycle environmental assessments (LCA) of PV energy technologies, enhancing the quality and quantity of PV environmental assessments.

- Initiated International Energy Agency Task 12; conducted the first LCA Task 12 expert meeting.

- Improved the recovery and purity of cadmium (Cd) and tellurium (Te) through recycling CdTe spent modules and manufacturing waste.

- Assisted FirstSolar, PrimeStar Solar, and the University of Toledo with site-specific EH\&S issues.

- Answered several requests for EH\&S information from industry and the public.

\section{Future Directions}

EH\&S research at Brookhaven National Laboratory (BNL) will support the objectives of the Solar America Initiative (SAI) through the following:

- $\quad$ Conduct LCA of near-commercialization technologies (e.g., III/V and c-Si PV concentrators).

- Conduct preliminary LCA of $3^{\text {rd }}$-generation PV technologies, to guide the industry toward more environmentally friendly alternatives.

- Accurately define the environmental profiles of solar technologies in comparison to those of other energy technologies.

- Define the cost of recycling spent modules and determine scenarios for cost reductions.

- Assist the industry in preventing accidents and releases of hazardous materials to the environment, and guide them toward environmentally friendly material and process options.

- Conduct LCA of integrated PV and storage systems.

- Answer inquiries from industry, the legislators, and the public about EH\&S issues in solar energy cycles. 
In addition, research at BNL will identify and characterize EH\&S hazards associated with emerging materials, including nanomaterial forms, for the U.S. Department of Energy (DOE), its contractors, and the private sector.

\section{Introduction}

The activities of the Environmental, Health and Safety (EH\&S) Research Center focus on minimizing potential EH\&S impacts associated with current and future photovoltaic (PV) energy systems and applications. This objective is accomplished by proactive research, rigorous industry outreach, and technical communications.

The overall goal is to preserve the safe and environmentally friendly nature of $\mathrm{PV}$ and minimize EH\&S risks and associated costs to ensure the economic viability of PV systems and public support for them. Minimizing EH\&S risks and costs is paramount in achieving the Solar Program's goal of $\$ 0.06 / \mathrm{kWhr}$ by 2020 , and having the support of the public is a prerequisite for viability and growth on a scale that would support that low cost.

The Center also serves as the world's best resource on PV EH\&S, providing accurate information related to EH\&S issues and perceptions. This activity supports the overall communications and outreach objectives of the Solar Program.

\section{Technical Approach}

The major areas of Brookhaven National Laboratory's (BNL's) activities are Hazard Identification and Characterization, Hazard Management, Industry Outreach, and Information Dissemination. Ongoing work is required because the PV industry is undergoing changes in types and quantities of materials as well as in manufacturing processes and scale. These activities are also needed because continuous vigilance is required for safety and loss prevention.

\section{Task 1: Identification and Characterization of} EH\&S Issues

BNL continues to monitor process, material, and application alternatives being investigated by DOE, the National Renewable Energy Laboratory (NREL), Sandia National Laboratories (SNL), and industry to determine if any potential safety, health, and environmental hazards exist and if so, to quantify those hazards. This investigation covers the entire life cycle of photovoltaics, from the production of materials used in manufacturing solar cells, modules, and systems to eventually disposing of and/or recycling them.

\section{Task 2: Hazard Management}

BNL's studies on safety, loss prevention, and environmental impact are disseminated to the industry to assist them in protecting PV facilities.

Task 3: Industry Outreach and Support to DOE and the National Center for Photovoltaics (NCPV) Industry outreach activities include frequent interactions with EH\&S personnel, site visits, guidance on EH\&S issues and concerns, and assistance with new facilities.

\section{Task 4: Information Dissemination}

Providing accurate and objective information on PV EH\&S issues is crucial for the PV industry as installations grow to levels that attract public interest and scrutiny.

\begin{tabular}{|l|c|}
\hline \multicolumn{1}{|c|}{ Task Title } & $\begin{array}{c}\text { FY 2007 } \\
\text { Budget (\$K) }\end{array}$ \\
\hline $\begin{array}{l}\text { Hazard } \\
\text { Identification/Characterization }\end{array}$ & 180 \\
\hline Hazard Management/Recycling & 90 \\
\hline $\begin{array}{l}\text { Industry Outreach/ } \\
\text { DOE/NCPV Information } \\
\text { Dissemination }\end{array}$ & 130 \\
\hline IEA Task 12 & 70 \\
\hline
\end{tabular}

\section{Results and Accomplishments}

Task 1

- Conducted and published (a) a life-cycle investigation of CdS alternatives in CIGS PV systems and (b) a life-cycle investigation of greenhouse gas emissions (GHG) in $\mathrm{c}-\mathrm{Si}$ etching operations.

- Invited to and participated in two high-impact expert panels (EPIA/sustainability and California Energy Commission/nuclear issues).

- Conceptualized, organized and currently manage Task 12 of the International Energy Agency (IEA). 
Task 2

- Advanced the recycling of CdTe PV by achieving a recovery of $99.99 \%$ pure cadmium and $99.99 \%$ pure tellurium through optimized separations.

- Accomplished the advancement just described on a laboratory scale 10 times greater than that of the previous year while incorporating a wide variety of actual manufacturing waste.

\section{Task 3}

- Provided facility-specific assistance to First Solar and PrimeStar; advised dozens of PV community members on EH\&S issues.

- Organized the first IEA PV task 12 meeting, bringing together analysts from several countries for interaction.

\section{Task 4}

- Answered several requests for EH\&S information from different agencies, business partners, citizen organizations, and the media.

- Invited to and participated in high-impact expert panel discussions.

- Published and presented extensively.

\section{Planned FY 2008 Activities}

Task 1: Hazard Identification/Characterization This task is part of BNL's proactive research to overcome EH\&S barriers to support for largescale implementation of PV. Activities planned for FY 2008 include the following:

- Conduct LCA study of III/V and C-Si PV concentrators.

- Coordinate joint research on PV LCA for c-Si and thin-film PV with European collaborators.

- Organize a Materials Research Society Symposium on LCA.

Task 2: Hazard Management/Recycling

These activities are pivotal in preserving the safe and environmentally friendly nature of the PV industry as it moves toward large-scale manufacturing. In FY 2008, research at BNL will focus on the following:

- Assist the industry in developing a recycling infrastructure and in implementing recycling options.

- Conduct a silane safety seminar with industry participation.
Task 3: Industry Outreach/Support to DOE and the NCPV

- Serve as the lead organizer and U.S. representative to IEA PV EH\&S Task 12.

- Guide the industry and R\&D laboratories on accident prevention and pollution prevention.

- Support DOE and the NCPV as needed.

\section{Task 4: Information Dissemination}

The results of BNL's research will be disseminated through new publications, e-mail, and the Web. The PV EH\&S Research Center serves as a clearinghouse for EH\&S information requested by potential customers, business partners, citizen organizations, and the media. Such inquiries have been increasing as the industry, universities, and national laboratories respond to the SAI challenge to achieve cost-effective production of solar electricity by 2020 .

\section{FY 2007 Special Recognitions}

- Invited to participate in the EPIA Expert Panel on Sustainability; the subsequent presentation was broadcast widely.

- Invited to participate in the California Energy Commission's Expert Panel on Nuclear Power in California; the subsequent testimony was used for the 2007 Integrated Energy Policy Report.

\section{Major FY 2007 Publications}

V.M. Fthenakis and H.C. Kim, "Greenhouse Gas Emissions from Solar Electric and Nuclear Power: A Life Cycle Study," Energy Policy, 35, 2549-2557 (2007).

V.M. Fthenakis, W. Wang, and H.C. Kim, "Life Cycle Inventory Analysis of the Production of Metals used in Photovoltaics," Renewable and Sustainable Energy Reviews (in press).

V.M. Fthenakis and H.C. Kim, "Photovoltaics Life Cycle Analysis," Advances of Solar Energy, invited (in press).

V.M. Fthenakis, H.C. Kim, and E. Alsema, "Emissions from Photovoltaic Life Cycles," Environmental Science and Technology (in press). 
K. Zweibel, J. Mason, and V. Fthenakis, "A Solar Grand Plan," Scientific American, 298(1), 64-73 (2008).

M. de Wild-Scholten, E. Alsema, V. Fthenakis, G. Agostinelli, H. Dekkers, K. Roth, and V. Kinzig, "Fluorinated Greenhouse Gases in Photovoltaic Module Manufacturing: Potential Emissions and Abatement Strategies," Proceedings of the $22^{\text {nd }}$ European Photovoltaic Solar Energy Conference, Milan, Italy, 3-7 September (2007).
V. Fthenakis and H.C. Kim, "Cu(InGa)Se2 ThinFilm Solar Cells: Comparative Life-Cycle Analysis of Buffer Layers," Proceedings of the $22^{\text {nd }}$ European Photovoltaic Solar Energy Conference, Milan, Italy, 3-7 September (2007).

M. Ragei, P. Frankl, E. Alsema, M. de WildScholten, V. Fthenakis, and H.C. Kim, "Life Cycle Assessment of Present and Future Photovoltaic Systems," Proceedings of the AIST Symposium Renewable Energy, Chiba, Japan, 11 October (2007). 


\title{
Resource and Safety Research Solar Resource Characterization
}

\author{
Performing Organization: $\quad$ National Renewable Energy Laboratory (NREL) \\ Key Technical Contact: Dave Renné (NREL), 303-384-7408, david_renne@nrel.gov
}

DOE HQ Technology Manager: Jeffrey Mazer, 202-586-2455, jeffrey.mazer@ee.doe.gov

FY 2007 Budget: $\quad$ \$420K

\section{Objectives}

- Complete a 15-year update (1991-2000) of the National Solar Radiation Data Base (NSRDB).

- Produce an enhanced 1998-2005 10-km gridded data solar product for the United States.

- Produce an updated Typical Meteorological Year (TMY) data set from the updated 1991-2005 NSRDB.

- Implement Task 36 "Solar Resource Knowledge Management" under the International Energy Agency Solar Heating and Cooling (IEA/SHC) Programme.

\section{Accomplishments}

- Completed the 1991-2005 NSRDB update and documentation, including the 10-km satellitederived data grid from the State University of New York (SUNY) at Albany.

- Worked with National Climatic Data Center (NCDC) and established a distribution method for the updated NSRDB and 10-km gridded data via the NCDC distribution infrastructure.

- Held NSRDB forum and rollout at the annual conference of the American Solar Energy Society (ASES).

- Technical results in several topical areas coming out of IEA Task 36, Solar Resource Knowledge Management.

\section{Future Directions}

- Produce a TMY data set based on the updated NSRDB.

- Finalize plans for producing a 10-km gridded data set for 1991-1998.

- Produce reports through the IEA Task 36 that benchmark and quantify various solar resource assessment approaches developed by different countries and international institutions, including NREL's NSRDB.

\section{Introduction}

This project addresses solar resource assessment as outlined in the U.S. Department of Energy's Solar Energy Technologies Program Multi-Year Technical Plan. The project includes access to the data and characterization of the solar resource and addresses the needs of designers, modelers, and resource assessment interests, both in the United States and internationally. This multiyear project is intended to update the 1961-1990 National Solar Radiation Data Base and derivative products such as TMY data sets as well as to implement the IEA Solar Resource Knowledge Management task (Task 36) for benchmarking international solar resource data sets. Work performed in FY 2007 included (1) the completion and release of an NSRDB update and (2) the continued implementation of several subtasks under the IEA/SHC Solar Resource Knowledge Management task.

\section{Technical Approach}

Two tasks are under way in the Solar Resource Characterization Project: (1) a domestic task focused on updating NSRDB products and (2) an international task that allows the NSRDB to be benchmarked against international solar resource assessment methods. Previous work allowed us to select a solar radiation model (METSTAT) and develop a plan for final NSRDB production. 
The IEA/SHC Solar Resource Knowledge Management task provides a collaborative mechanism to enable researchers from a number of international research institutions to compare and benchmark various approaches for assessing solar resources, allowing the new NSRDB to be benchmarked against these other methods. During this reporting period, the third and fourth task experts meetings were held (March 2007 and October 2007). In these meetings, experts from the participating countries presented research results and future plans on topics directly related to the task. In addition, a mid-term review of technical progress was presented to the IEA/SHC Executive Committee in December 2007

A breakdown of the total project funding is shown in the following table:

\begin{tabular}{|l|c|}
\hline \multicolumn{1}{|c|}{ Task Title } & $\begin{array}{c}\text { FY 2007 } \\
\text { Budget (\$K) }\end{array}$ \\
\hline $\begin{array}{l}\text { IEA Task 36 Solar Resource } \\
\text { Knowledge Management }\end{array}$ & 100 \\
\hline NSRDB Update and Release & 320 \\
\hline
\end{tabular}

\section{Results and Accomplishments}

\subsection{National Solar Radiation Data Base}

The National Weather Service's changeover to automated stations eliminated human-observed total and opaque sky cover amounts that had been used as inputs to the METSTAT model, which in turn was used for the 1961-1990 NSRDB. To adapt the model to currently available data sets, we derived equivalent sky cover inputs (total and opaque cloud cover) from a combination of Automated Surface Observing System (ASOS) and ASOS supplemental cloud measurements; the latter were derived from Geostationary Operational Environmental Satellite (GOES) satellite data. ASOS detects clouds to $12,000 \mathrm{ft}(3660 \mathrm{~m})$, whereas the ASOS supplemental cloud measurements provide sky cover estimates for heights above $12,000 \mathrm{ft}$ for a $50 \mathrm{~km} \times 50 \mathrm{~km}$ area centered on the ASOS station.

Based on foundational work in FY 2006, including coordination of a procedural review of the NSRDB update procedures by external experts, we completed the 1991-2005 NSRDB, which updated the original 1961-1990 NSRDB. This work included a 10-km gridded solar database produced in collaboration with SUNY Albany. We also worked with the NCDC in the U.S. Department of Commerce to incorporate the
NSRDB in the center's data distribution infrastructure. In July 2007, we held an NSRDB forum and product rollout at the ASES annual conference. This forum also sought input from attendees to help guide future work in solar resource assessment.

The updated NSRDB holds data for 1480 sites in the United States, about 850 of which have serially complete data for the 15-year period of record. The remaining sites were included for applications that don't require a serially complete data set but that can benefit from some characterization of the solar resource. Figure 1 is a map of the NSRDB sites overlaid with the 239 sites in the original NSRDB.

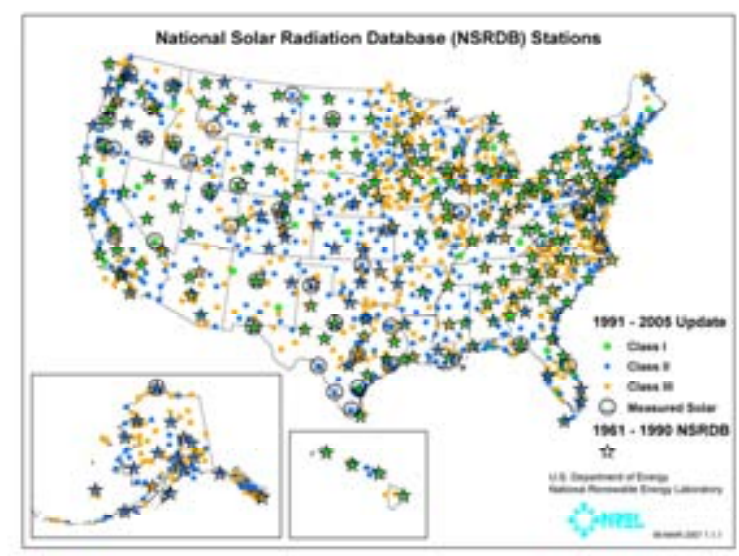

Fig. 1. Map of NSRDB sites.

Work also included the production of monthly and annual means for the $10-\mathrm{km}$ gridded data set. Figure 2 shows a map of the global horizontal latitude tilt for these summary data sets.

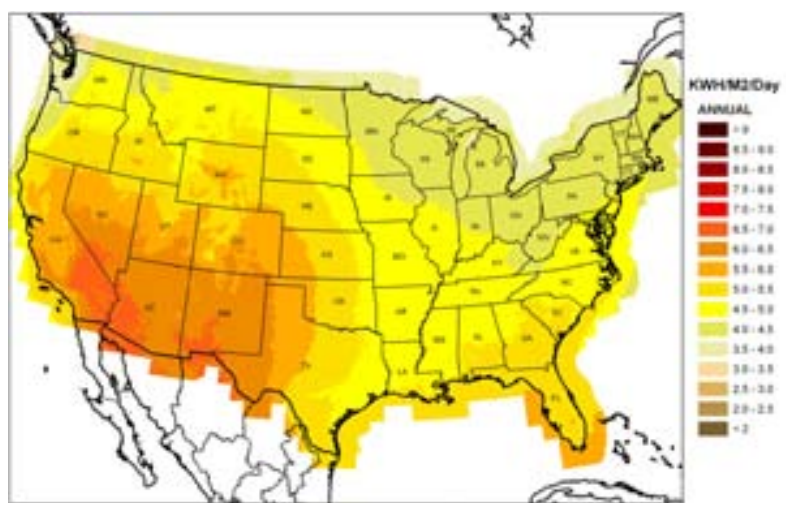

Fig. 2. Global horizontal latitude tilt derived from SUNY gridded solar data set. 


\subsection{IEA Task 36, Solar Resource Knowledge Management}

The three subtasks in Task 36 are contributing to achieving the vision of fast and easy access to relevant, qualified, and reliable solar resource information that has been benchmarked to international standards.

Subtask A: Standard qualification for solar resource products. This subtask is focusing on:

- Coherence and benchmarking of models producing surface irradiance values from satellite data; this includes SUNYA, NREL's Climatological Solar Radiation (CSR) model, and the NASA Surface Meteorology and Solar Energy (SSE) models, which are also being used for the NSRDB updates

- Ground truth validations with high-quality surface network data, such as the Baseline Surface Radiation Network (BSRN)

- Definition of validation protocols and measures of end-product confidence

- Cross-satellite platform and cross-model comparisons.

Subtask B: Common structure for archiving and accessing resource products. This subtask focuses on the following:

- Development of worldwide networking between distributed data centers, resulting in a global coverage for high-quality solar resource data

- Development of information and data exchange protocols

- Reliable and fast end-user access to specific queries

- Preparation of data documentation for specific end-user applications.

The main outcome of Subtask B will be a unique Web entry point that performs a smart network of resources and products. Specifically, Subtask B will build on existing Web services, such as the SoDa or NASA portals, to construct an advanced prototype of the distributed information system. Resources (e.g., solar resource databases) will be accessible through a Web server and data providers will be connected on a voluntary basis to this information system. Providers of such resources will be organizations such as NREL, NASA, and the German Aerospace Center (DLR). The Web service will be maintained by Task 36 partners, and, where required by the data providers, could involve possible commercial revenues.
Subtask C: Improved techniques for solar resource characterization and forecasting. This subtask covers R\&D work and focuses chiefly on:

- Improved Satellite Retrieval Methods for Solar Radiation Products: This activity focuses on key model input parameters and methodologies, such as cloud indices, radiative transfer schemes, aerosol data retrievals, and treatment of snow and other surface albedo artifacts. The activity also addresses ways of improving the spatial resolution of satellite-derived broadband solar resource products.

- Climatological Analysis of Solar Resources: To ascertain future impacts on system performance due to climate variations, this activity includes the analysis of long-term surface and satellite-derived data sets and climate models, specifically addressing natural long-term fluctuations associated within the ocean-atmosphere system, such as the Southern Oscillation/EI Nino.

- Forecasting of Solar Radiation: This activity investigates different approaches for developing solar resource forecasts based on global numerical weather predictions and extrapolation of cloud motion vectors.

Preliminary results of comparisons of long-term satellite-derived climatological solar data with high quality (BSRN) ground data are shown in Figure 3. The figure shows good agreement between the satellite-derived and ground-based data sets, with a very slight trend toward overestimates of satellite values when surface radiation values are high.

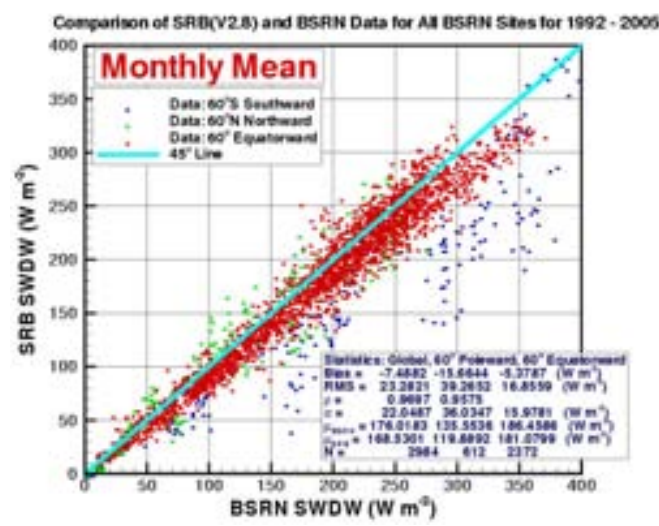

Fig. 3. Intercomparison of the NASA Surface Radiation Budget Products for total ground irradiance vs. BSRN precision measurements (from Zhang and Stackhouse, NASA; presented at the IEA/SHC Task 36 Fourth Experts Meeting). 
At the Fourth Experts Meeting, the Joint Research Center reported on the Photovoltaic Geographic Information System (PVGIS) Web site, which was developed to provide users with an easy interactive application that provides free access to solar resource data for Europe, Africa, and southwestern Asia, as well as ambient temperature data for Europe. The PVGIS site also provides assessment tools that calculate solar radiation for fixed and sun-tracking systems, calculations of energy output for grid-connected photovoltaic systems, and the performance of stand-alone PV systems (Africa only). Tools on the Web site provide the user with key overview information on investment decisions to support project developers and the manufacturing industry. The applications are based on the Google Maps interface and provide several different formats of information, including the estimated accuracy of the calculations. Web-based estimates for single sites can be accessed through the following URL: http://re.jrc.ec.europa.eu/pvgis/apps3/pvest.php. Gridded data sets at approximately $10-\mathrm{km}$ by $10-$ $\mathrm{km}$ resolution can also be accessed. An example of the PVGIS interface is shown in Figure 4.

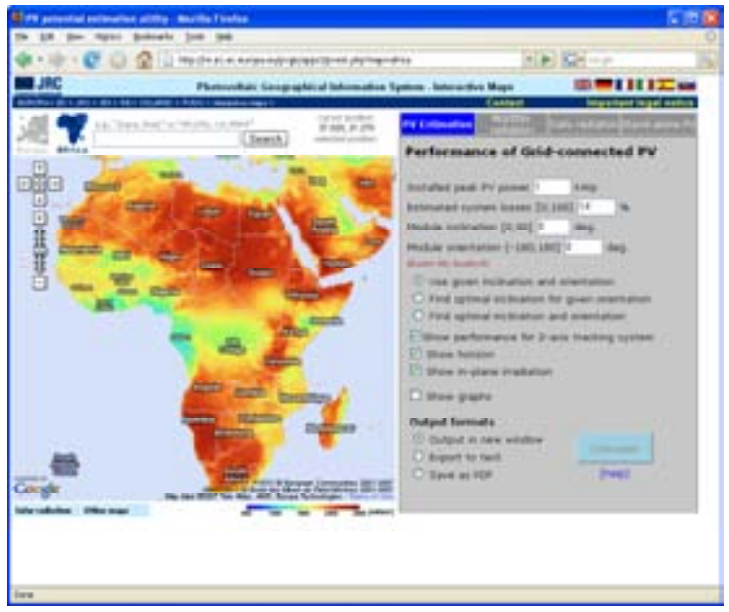

Fig. 4. Example page from the PVGIS Web site (courtesy of T. Huld, M. Šúri, and T. Cebecauer of the Joint Research Centre, Ispra, Italy).

\section{Planned FY 2008 Activities}

Activities in the Solar Resource Characterization task in 2008 will focus on releasing additional products related to the NSRDB, such as TMY data, and undertaking research in short-term solar resource forecasting to support utility operations for distributed PV generation. In addition, the participants in IEA/SHC Task 36 will focus on developing appropriate benchmarking procedures for comparing international solar data sets and on methodologies for improving satellite-derived estimates, with particular emphasis on highresolution and long-term data. Testing of various solar resource forecasting methodologies is underway in Europe, and a cooperative activity among the University of Oldenburg, NASA Langley Research Center, and SUNY/Albany is underway to test methodologies at specific locations in the United States.

\section{Major FY 2007 Publications}

S. Wilcox, M. Anderberg, W. Beckman, R. George, C. Gueymard, W. Marion, D. Myers, R. Perez, M. Plantico, D. Renne, P. Stackhouse, and F. Vignola. "Completing Production of the Updated National Solar Radiation Database for the United States," Proc. Solar 2007, American Solar Energy Society (2007).

D. Myers, "Relative Performance of Multiple Solar Radiation Resource Assessment Data Sources," Proc. Solar 2007, American Solar Energy Society (2007).

R. Perez, M. Kmiecik, S. Wilcox, and P. Stackhouse, "Enhancing the Geographical and Time Resolution of NASA SSE Time Series Using Microstructure Patterning," Proc. Solar 2007, American Solar Energy Society (2007).

R. Perez, M. Kmiecik, J. Schlemmer, L. Root, K. Moore, and P. Stackhouse, "NASA Langley Research Center: Evaluation of PV Generation Capacity Credit Forecast on Day-Ahead Utility Markets," Proc. Solar 2007, American Solar Energy Society (2007).

R. George, S. Wilcox, M. Anderberg, and R. Perez, "National Solar Radiation Database (NSRDB)-10 km Gridded Hourly Solar Database," Proc. Solar 2007, American Solar Energy Society (2007). 
Photovoltaic R\&D

Fundamental Research

Resource and Safety Research 


\section{Advanced Materials and Devices}

The Advanced Materials and Devices effort carries out research in semiconductor material properties, device mechanisms, and fabrication processes to improve the efficiency, stability, and cost of photovoltaic energy conversion. The effort focuses on thin-film materials and modules (which hold promise for major reductions in PV costs), module manufacturing methods, and module reliability.

The Thin-Film PV Partnership has formed strong research teams to focus R\&D on promising thinfilm candidates, such as amorphous silicon, cadmium telluride, copper indium diselenide, and thin silicon. These research teams comprise laboratory, industry, and university researchers who work to solve generic issues as well as industry-specific problems.

The overall objective of the PV Module Reliability Project is to work with industry to develop PV modules that have 30 -year service lifetimes. This project also provides critical performance and reliability testing and benchmarking of modules to validate the progress and accomplishments of the Solar Program's investments in PV module technology R\&D. The Inverter and BOS Development Project is directed toward improving inverters and balance of systems (BOS) through the High-Reliability Inverter Initiative.

In PV Manufacturing R\&D, strong partnerships with the U.S. PV industry have been formed with the goal of retaining and enhancing the industry's leadership in the development and manufacture of $\mathrm{PV}$ modules. Many problems in manufacturing R\&D exist whose solutions are critical to further reducing the cost of $\mathrm{PV}$.

Achievements in Advanced Materials and Devices for FY 2007 include the following:

Systems Development

- Selected 10 companies to become subcontracts, emphasizing way to overcome the barriers to manufacturing scale-up and 2010 commercialization.

- Selected 12 Technology Pathway Partnerships that foster development within the domestic PV industry. These projects will catalyze collaboration across the value chain to cut costs, optimize PV-system design, and assure superior performance and reliability.

\section{Component Development}

- Achieved a significant milestone, a higher efficiency thin-film module of $12.2 \%$.

- Evaluated U.S. industry participants to assess and determine the needs for additional manufacturing research and development.

Systems Analysis

- Completed drafts of 14 reports on "Renewable Systems Interconnection."

- Developing a model and other tools to examine the impacts of high levels of PV penetration on the U.S. electricity generation system.

- Developed a photovoltaic (PV)-system inverter model for use within the Solar Advisor Model.

Systems Testing and Evaluation

- Determined inverter performance, power quality, and utility compatibility capabilities for commercial inverters and residential PV inverters.

- Conducted performance tests to support the development of industry solar modules.

- Developed interfacial measurement technique of layer adhesion inside modules.

- Evaluated the performance of system configurations for PV manufacturing companies and characterized additional modules and arrays. 
Component Testing and Evaluation

- Performed 26 spectral and 405 solar broadband radiometer calibrations for national laboratories, industry, and academic partners.

PDIL Infrastructure, Engineering, and Integration

- Developed the design of process-integration-compatible measurement and characterization equipment developed at NREL, including resonance-coupled photoconductive decay, photoluminescence imaging, and a special spectroscopic ellipsometry chamber; integrated this equipment into a central robotic transfer chamber along with a sputtering/etching chamber and a chamber for studying plasma enhanced chemical vapor depositions. 


\title{
Systems Development Solar America Initiative Photovoltaic Incubator
}

\author{
Performing Organization: National Renewable Energy Laboratory (NREL) \\ Key Technical Contact: $\quad$ Martha Symko-Davies (NREL), 303-384-6528, \\ Martha_symko_davies@nrel.gov
}

DOE HQ Technology Manager: Marie Mapes, 202-586-3765, marie.mapes@ee.doe.gov

FY 2007 Budget: $\quad$ \$10,127K (NREL)

\section{Objectives}

- Shorten the timeline for companies to transition prototype and pre-commercial photovoltaic (PV) technologies into pilot and full-scale manufacture.

- Move companies into commercial production quickly and successfully.

- Position companies to be competitive for Technology Pathway Partnership (TPP) funding opportunities.

- Focus the efforts of subcontractors to a limited number of high-impact module technology improvement opportunities (TIOs) that lay on the critical path to scaling-up their technology to full manufacture.

\section{Accomplishments}

- Completed merit criteria and analysis to select negotiations for subcontracts.

- Selected 10 subcontracts for negotiations, including: Blue Square, Solopower, AVA, Primestar, Plextronics, Solaria, Microlink, Enfocus, Solfocus, and CaliSolar.

- Concluded fiscal year negotiations in September 2007 (FY 2007).

- Awarded the majority of subcontracts in October and November of FY 2008.

\section{Future Directions}

- Issue a second letter of interest (LOI) for the Solar America Initiative Photovoltaic (SAI PV) Incubator in FY 2008.

- Complete merit review for responses to the LOI.

- Complete stage-gate review of individual progress versus deliverables by late summer, FY 2008.

\section{Introduction}

The primary objective of the Solar America Initiative Photovoltaic (SAI PV) Technology Incubator project is to shorten the timeline for companies to transition PV technologies into pilot and full-scale manufacture. The incubator concept generally will apply to those companies that were not far enough along in technology and product development pathways to be positioned to qualify for the first of the SAl's Technology Pathway Partnership (TPP) awards. Successful participation in the SAI PV Technology Incubator project will quickly move companies into commercial production and position those companies to be competitive for the next TPP funding opportunity, which is expected to be issued in 2010 .
The SAI provides significant opportunities for collaboration and partnership among industry and university researchers to develop and improve solar-energy technologies. This SAI PV Technology Incubator project targets research and development on PV cell and module prototypes with demonstrated functionality in either large-area cell/module form or, preferably, prototypes produced in pilot-scale operations. The emphasis on proposed activities should be focused on the barriers to manufacturing scale-up and 2010 commercialization.

Advances are needed to achieve prototype modules and pilot production, which will be facilitated through projects funded under this LOI. It is expected that the subcontract duration will be 
for 18 months for each award made under this solicitation. Entrance opportunities for the Incubator project are anticipated every 9 months as funding opportunities become available. The entrance criterion is demonstrated PV cells or process lab devices or modules. A successful demonstration for the entrance criterion is a quantifiable and verifiable baseline measurement. The successful exit criterion would be for prototype modules and pilot production demonstration greater than 3 megawatts per year (MW/year). These entry and exit criteria are provided to applicants as general guidelines for maturity of technology that the DOE intends to fund through this LOI, but the guidelines are flexible-applicants may be more advanced than the stated entrance criteria at the time of application, and may plan to be more advanced than $\sim 3 \mathrm{MW} /$ year pilot production at the completion of their "incubator" project.

\section{Technical Approach}

\subsection{SAI PV Incubator Management}

The Project Management and Support subtask addresses: (1) management of the Incubator project; (2) management of subcontracts awarded; and (3) coordination of NREL in-house activities in support of the small businesses

\subsection{SAI PV Incubator Scope}

The National Renewable Energy Laboratory (NREL) solicited LOIs from individual U.S. small businesses and U.S. small-business-led teams that were working on research and development of demonstrated PV cell and module prototypes. The LOI emphasized overcoming the barriers to manufacturing scale-up and 2010 commercialization.

Topic Areas include:

- Novel wafer-based silicon modules;

- Polycrystalline thin films;

- Film silicon on a foreign substrate;

- High-efficiency cells, including multijunction, and CPV module concepts;

- Organic PV, dye-sensitized solar cells, or other polymer-based solar cells;

- Low-X concentration CPV systems with limited or 1-axis tracking module designs; and

- Low-X Si modules, 3-10X. 


\title{
Systems Development Solar America Initiative Project Monitoring
}

\author{
Performing Organizations: $\quad$ National Renewable Energy Laboratory (NREL) \\ Sandia National Laboratories (SNL) \\ DOE Golden Field Office (DOE/GO)
}

Key Technical Contacts: $\quad$ Roland Hulstrom (NREL), 303-384-6420, roland_hulstrom@nrel.gov Charles Hanley (SNL), 505-284-4435, cjhanle@sandia.gov

DOE HQ Technology Manager: Thomas Kimbis, 202-586-7055, tom.kimbis@ee.doe.gov

FY 2007 Budgets: $\quad$ \$998K (NREL), \$580K (SNL)

Objectives

- Oversee technical progress of the SAI Technology Pathway Partnerships (TPPs).

- Verify progress towards TPPs and program goals (including the use of the Solar Advisor Model tool), coordinating collaborative efforts between TPPs and the labs, coordinating T\&E activities between the labs and the TPPs, and assuring readiness on all parts for stage-gate reviews. Related metrics are those provided by TPPs in their applications, as well as the key performance parameters described in the TPP Funding Opportunity Announcement (FOA). The key protocol from this effort is an operational format for the conduct and evaluation of stage-gate reviews.

\section{Accomplishments}

- Provided the scientific/engineering foundations for the development of the plans for the Solar America Initiative (SAI) TPP FOA/Project.

- Served as technical reviewers of the industry applications, and subsequently as the technical monitors of the winning applications and projects.

\section{Future Directions}

- Continue to monitor these activities throughout the duration of SAI, slated to run until 2015. These activities will be revamped at 3-year intervals, concurrent with the issuance of new SAI solicitations.

- Monitor oversight and collaboration of stage-gate reviews and assessment of deliverable provided by TPPs to assure progress toward goals.

\section{Introduction}

NREL and SNL provide selected expertise, based on the specific nature of each of the SAI TPPs, for assisting DOE with the detailed technical assessment and monitoring of the TPPs. This expertise ranges from the applied research to the systems development area. NREL and SNL key focus of their role/responsibilities are the stagegate reviews of each of the TPPs. Along these lines, NREL and SNL anticipate that a portion of their support, specific to the TPP Technical monitoring, will include selected analyses (e.g. using the SAM model or other research and development tools), literature reviews, etc, to produce credible technical assessments of the progress, deliverables, and issues associated with the TPPs. Another aspect of the NREL/SNL roles will include attending to the integration of the technical efforts within the TPPs with the in-house R\&D at NREL and/or SNL. This is done to ensure the most effective and efficient use of the DOE investments (in the TPPs and NREL/SNL) and to help resolve any unforeseen technical and/or engineering barriers.

\section{Results and Accomplishments}

NREL and SNL scientists and engineers provided the scientific/engineering foundations for the development of the plans for the SAl's Technology Pathway Partnerships (TPPs) FOA/Project, which are subcontracted R\&D through DOE/GO. NREL/SNL experts served as technical reviewers of the industry applications and subsequently as 
the technical monitors of the winning applications and projects.

\section{Planned FY 2008 Activities}

The main areas of focus for SAI project monitoring include oversight and collaboration of stage-gate reviews and assessment of deliverable provided by TPPs to assure and verify progress toward goals. This includes utilization of the SAM tool to assess results in terms of SETP's key performance parameters. These tasks will be executed through close collaboration with other lab staff involved in test \& evaluation, systems analysis and benchmarking, and overall program management. In addition, monitors will coordinate release of public information with the communication and outreach personnel where appropriate. 


\title{
Systems Development Technology Pathway Partnership
}

\author{
Performing Organizations: Amonix \\ The Boeing Company \\ BP Solar, Inc. \\ Dow Chemical Company \\ GE Global Research \\ GreenRay, Inc. \\ Konarka Technologies, Inc. \\ Nanosolar, Inc. \\ Soliant Energy, Inc. \\ Sunpower, Inc. \\ United Solar Ovonic LLC \\ National Renewable Energy Laboratory (NREL) \\ Sandia National Laboratories (SNL) \\ Key Technical Contacts: $\quad$ Carolyn Elam, DOE Golden Field Office (DOE/GO), 303-275-4953, \\ carolyn.elam@go.doe.gov \\ Jim Payne, DOE/GO, 303-275-4756, jim.payne@go.doe.gov \\ Brad Ring, DOE/GO, 303-275-4930, bradley.ring@go.doe.gov \\ Holly Thomas, DOE/GO, 303-275-4818, holly.thomas@go.doe.gov
}

DOE HQ Technology Manager: Marie Mapes, 202-586-3765, marie.mapes@ee.doe.gov

FY 2007 Budgets: $\quad$ \$34,331,113 TPP Recipients, $\$ 898,751$ (NREL), $\$ 600,000$ (SNL)

\section{Objectives}

- Bring better products to market and enable new applications. Develop modular, turnkey PV systems that provide residential and commercial customers with a complete solution and attractive value proposition (e.g., enabling BIPV and zero-energy homes). Develop designs and supply chains for large-field PV installations to service large commercial and utility RPSgenerating requirements. Help U.S. companies to leapfrog global competition by providing the best designed, lowest-cost solar-energy solutions.

- Foster development of the domestic PV industry. Catalyze collaboration across the value chain to: (1) squeeze out costs; (2) better optimize PV-system design; and (3) assure superior performance and reliability. Demonstrate novel manufacturing processes that provide U.S. industry with a cost advantage, and that facilitate manufacturing scale-up.

- Impact the U.S. energy economy with results. Accelerate development of U.S.-produced PV systems so that PV-produced electricity reaches parity with the cost of electricity in grid-tied markets across the nation by 2015 . Enable expansion of the annual U.S. production capacity of PV systems from 240 megawatts (MW) in 2005 to as much as 2,850 MW by 2010, representing a ten-fold increase. Foster research that will lower the cost of PV-generated electricity to $\$ 0.05$ to $\$ 0.10$ per kilowatt $(\mathrm{kWh})$ by 2015 in residential, commercial, and utility markets.

\section{Accomplishments}

- Selected 12 projects, based upon merit and program review of submitted proposals.

- Defined roles and responsibilities of program management team, including technical monitors at NREL and Sandia.

- Completed 12 awards. The award recipients/subrecipients include more than 50 companies, 14 universities, 3 non-profits, and 2 national laboratories in 20 states across the United States. 


\section{Future Directions}

- Develop PV systems so that by 2015 PV-produced electricity reaches parity with the cost of electricity in select grid-tied target markets across the nation and the U.S.-installed domestic capacity of PV systems is expanded to 5 to 10 gigawatts (GW).

\section{Introduction}

In January 2006, President Bush announced the Advanced Energy Initiative. This initiative is designed to reduce the nation's dependence on foreign sources of energy by promoting broader research and development (R\&D), and to achieve substantive breakthroughs in a variety of energy resources, including solar photovoltaic systems.

An integral part of this initiative is the DOE Solar America Initiative (SAI) Technology Pathway Partnerships (TPP). Authorized under the Energy Policy Act of 2005, the SAI TPP represents a significant enhancement of DOE's business strategy of partnering with entities in the industry to accelerate commercialization of photovoltaic (PV) system R\&D to meet aggressive cost and installed-capacity goals.

The SAI TPP program will accelerate comercialization of solar photovoltaic (PV) systems by 2015. The goal is to have PV electricity generation that is competitive with conventional sources of electricity in all domestic grid-tied market sectors.

The specific goals of the 9-year TPP mission are:

- Accelerate development of U.S.-produced PV systems substantively, so that PV-produced electricity reaches parity with the cost of electricity in select grid-tied target markets across the nation (identified in Table 1, below).

- Expand the U.S.-installed domestic capacity of PV systems to 5 to 10 gigawatts (GW).

Table 1. Cost Targets for Grid-Connected PV Systems in Key Market Sectors

\begin{tabular}{|c|c|c|c|c|}
\hline \multirow{3}{*}{$\begin{array}{l}\text { Market } \\
\text { Sector }\end{array}$} & \multirow{3}{*}{$\begin{array}{l}\text { Current } \\
\text { U.S. } \\
\text { Market } \\
\text { Range } \\
\text { (c/kWh) }\end{array}$} & \multicolumn{3}{|c|}{$\begin{array}{l}\text { Solar Electricity Cost-Current } \\
\text { and Projected (c/kWh) }\end{array}$} \\
\hline & & \multirow{2}{*}{$\begin{array}{c}\text { Benchmark } \\
2005\end{array}$} & \multicolumn{2}{|c|}{ Target } \\
\hline & & & 2010 & 2015 \\
\hline Residential $^{3}$ & $5.8-16.7$ & $23-32$ & $13-18$ & $8-10$ \\
\hline Commercial $^{3}$ & $5.4-15.0$ & $16-22$ & $9-12$ & $6-8$ \\
\hline Utility $^{4}$ & $4.0-7.6$ & $13-22$ & $10-15$ & $5-7$ \\
\hline \multicolumn{5}{|c|}{$\begin{array}{l}{ }^{1} \text { Costs are based on constant } 2005 \text { dollars. } \\
{ }^{2} \text { Current costs are based on electric-generation with conven- } \\
\text { tional sources. } \\
{ }^{3} \text { Cost to customer (customer side of meter). } \\
{ }^{4} \text { Cost of generation (utility side of meter). }\end{array}$} \\
\hline
\end{tabular}

Photovoltaic R\&D

Advanced Materials and Devices

Systems Development
The cost basis of electric energy in these markets is the kilowatt hour, therefore the SAI TPP program uses targets for PV systems based on the Levelized Cost of Energy (LCOE) delivered by these systems. The LCOE is a measure of total lifetime costs of a PV system divided by expected lifetime energy output, with appropriate adjustments for such factors as time value of money. The overall cost goals for the SAI TPP projects are shown in Table 1.

The SAI Photovoltaic Systems R\&D Technology Pathway Partnerships (TPPs) program implements partnerships with U.S. industry for projects that focus on development, testing, demonstration, validation, and interconnection of new PV components, systems, and manufacturing equipment. These projects will yield new reduced-cost commercial products by the end of Phase 1 in 2010, and also are expected to initiate product and process development activities on a trajectory that will meet the SAl cost targets in 2015.

\section{Program/Technical Approach}

As noted, the TPP program is focused on developing new PV solutions for the residential, commercial, and utility market sectors of grid-tied electric power. These markets are described as follows.

- Residential rooftop market. Equipment typically is mounted on rooftops and ranges in size from less than $1 \mathrm{~kW}$ to $10 \mathrm{~kW}$, most commonly in the $3 \mathrm{~kW}$ to $4 \mathrm{~kW}$ range. These systems are connected to the grid on the retail (customer) side of the utility meter, and can be retrofitted onto existing homes or integrated into new construction through building-integrated PV (BIPV) designs.

- Commercial rooftop market. Equipment typically is mounted on the large flat roofs of commercial, institutional, and industrial buildings, and ranges in size from less than $10 \mathrm{~kW}$ to $500 \mathrm{~kW}$. Connected on the retail side of the utility meter. Retrofits and BIPV are possible applications in this market as well.

- Utility market. Large-scale (multi-megawatt) systems that displace conventional utility generated intermediate load electricity (e.g., natural gas CCT plants) on a wholesale basis. 
Utility PV systems typically are groundmounted and range in size from $1 \mathrm{MW}$ to $10 \mathrm{MW}$, although much larger systems currently are in development. Designs include both fixed and tracking configurations.

To address these market goals, the following overall approach for the SAI TPP has been implemented.

- $\quad$ SAI TPPs are industry-led. All technical details regarding approach, timelines, milestones, and system integration are formulated by applicants. The National Laboratories supports DOE in monitoring technical progress, conducting tests and evaluations, and directly supporting TPPs on specific R\&D.

- SAI TPPs are focused on near- and mid-term results. Accordingly, emphasis is on technologies with the greatest potential for cost-competitiveness in the period leading up to 2015 .

- SAI TPPs are focused on PV systems. The primary metric for SAI is LCOE, which is determined by the complete PV system rather than any component. Therefore, SAI is working towards novel integrated PV systems approaches.

- SAI TPPs are partnership-oriented. Industry participants are strongly encouraged to formulate partnerships to address the spectrum of possible technical improvements in the PVsystem value chain.

- SAI TPP is market-based. Goals are directly market-oriented in terms of cost, penetration, and job creation, and all technical objectives established through SAl directly impact these market-based goals.

Each SAI TPP project is segmented into 3 manageable 3-year phases. These phases progressively reduce the cost of commercially-available PV systems and components, and ultimately yield commercial products and producion processes that achieve the LCOE and support installed capacity targets by 2015 . The first 3-year phase is scheduled to run from calendar year (CY) 2007 through CY 2010; the second 3-year phase is expected to run from CY 2010 through CY 2013; and the third 3-year phase is expected to run from CY 2013 through 2015.

The three phases of technology development for the TPP programs are as follows:

- Phase 1. Demonstrate pilot production of lower-cost systems. R\&D Project Duration of 3 years (2007-2009) that allows companies the flexibility to align projects with their targeted business model, technical capabilities, and product/process maturity.

- Phase 2. Demonstrate replication of low-cost pilot production. Project duration of 3 years (2010-2012), with new entrants eligible.

- Phase 3. Develop supply chain and distribution infrastructure. Reduce capital expenditure intensity of manufacturing scale-up through targeted investments in such areas as equipment/feedstock suppliers and distribution channels.

The TPP partnerships are industry-led teams composed of one or more companies, universities, national laboratories, and non-governmental organizations. Team composition emphasizes a coordinated effort of diverse approaches that in combination mitigate the total project risk and maximize the potential project outcome.

DOE has made 12 awards for both systems class and subsystems class projects defined as follows:

- Systems-class projects (integrated systems) address multiple technology improvements in PV-system and PV-component design, integration, and installation.

- Subsystems-class projects (componentbased) projects focus on fewer technology developments to improve PV systems.

Both systems-class and subsystems-class projects will be required to demonstrate the benefits of a project on system-level LCOE and installed capacity.

Systems-class awards are funded up to $\$ 10$ million annually, and subsystems-class awards are funded up to $\$ 4$ million annually. Total DOE funding available for systems-class awards is limited to $\$ 20$ million through the 3-year project period. Total DOE funding available for subsystems-class awards is limited to $\$ 8$ million throughout the 3year project period. Both classes of projects require that applicants share $50 \%$ of the total project costs.

Awards have been made as cooperative agreements between the DOE and the recipient, with a maximum project period of 3 years, beginning in fiscal year (FY) 2007. The cooperative agreements are funded through (approximately) annual budget periods, each of which concludes with a Stage-Gate Review scheduled around major tech-

Photovoltaic R\&D

Advanced Materials and Devices Systems Development 
nical milestone(s) or decision point(s). At the completion of each successive Stage-Gate Review, a determination for continuation of the Phase 1 TPP project into the next budget period will be made.

\subsection{Stage-Gate Reviews}

DOE requires the use of a stage-gate management approach in Solar America Initiative (SAI) Technology Pathway Partnership (TPP) Projects, to facilitate rigorous project management and to support the DOE's continuous assessment of its investment in the partnerships. The DOE will use this process to make informed decisions regarding the strategic direction of the program in general and, more specifically, regarding the future of individual recipients. Each recipient has specified the types of data, deliverables, testing, evaluation, and reports that will be developed and be made available for stage-gate reviews. A schematic of the review process is provided in Figure 1.

At its simplest, three steps are included in the stage gate-review: Obtaining and analyzing data, performing the review, and deciding on the next steps. At each gate review, deliverables must be provided as specified in the recipient-developed project plans. These deliverables demonstrate the ability of each recipient to meet the DOE LCOE cost targets for their technology. The LCOE values are dependent on system performance and manufacturing costs, therefore these quantities are evaluated independently (performance evaluated by NREL/Sandia, and cost evaluated by an independent contractor to DOE) to assure that they are sufficient to demonstrate the stage-gate criteria have been met. Recommendations made by the reviewers are documented and provided to the DOE Solar Program management. Ultimately, the four outcomes possible from a stage-gate review (Figure 1) are: Pass (to the next stage), Recycle/Redirect (stay in the same stage but complete additional necessary work), Hold (suspend DOE support for the project until additional data supports restarting or canceling), or Stop (no further DOE support for this project). A schedule for the TPP project stage gates is shown in Figure 2 below. Blue-shaded blocks indicate times of test and evaluation activities leading to the stage-gate review.

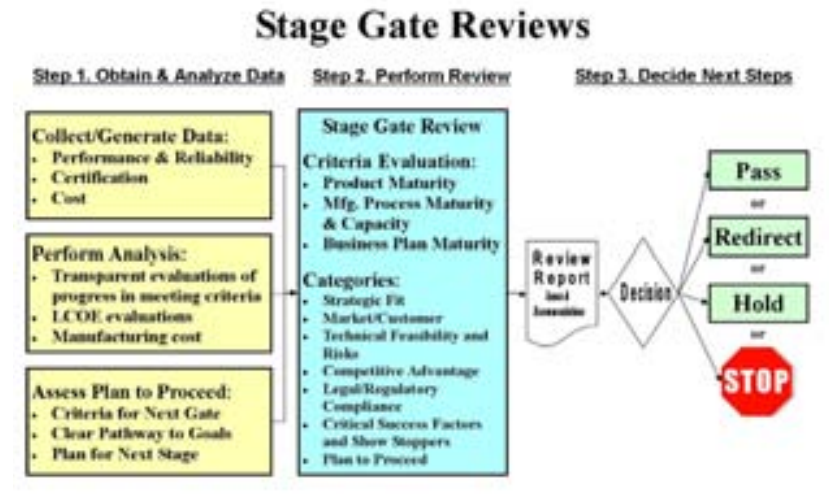

\section{Figure 1. Stage-Gate Review}

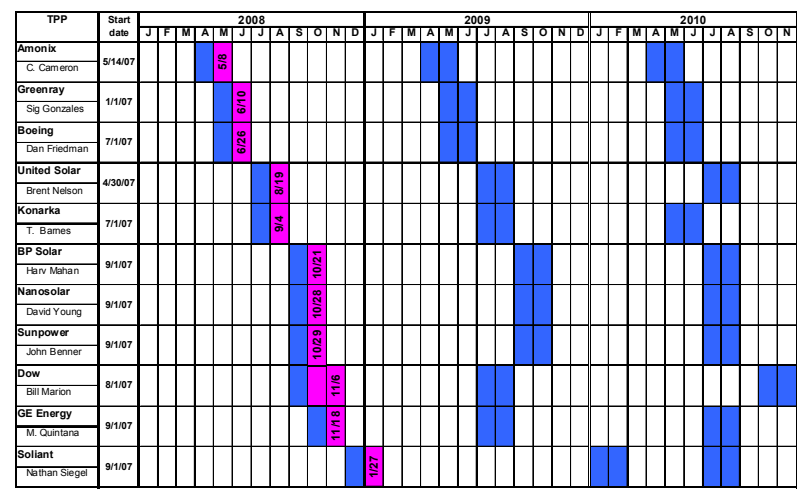

Figure 2. TPP Stage-Gate Review Schedule

\subsection{TPP Project Management Approach}

Project monitoring and technical oversight are conducted over the course of Phase 1 by a team that includes personnel from the DOE Golden Field Office, through which SAI TPP cooperative agreements will be managed and administered; DOE Headquarters; the National Renewable Energy Laboratory; and Sandia National Laboratories.

The basic management structure for TPP projects is depicted below (Figure 3). Individual responsibilities and authorities within this structure also are described below. 


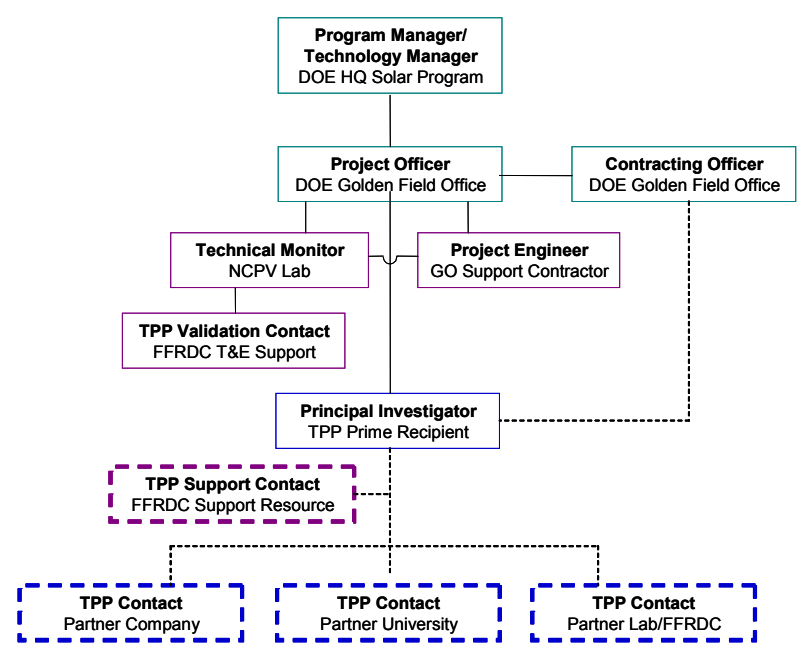

Figure 3. SAI TPP Project Management Structure

Notably, for each TPP recipient, this management approach utilizes a technical monitor that is cognizant of the technology being developed. Technical monitors have been assigned from one of the NCPV National Laboratories (NREL or Sandia). Assignments have been made based on the alignment between the skills and experiences of lab personnel and the R\&D activities of the TPP project. The technical monitor assists the project officers in overseeing and assessing the progress of TPP projects. In this capacity, they are available to provide technical assistance and guidance, facilitate interactions with experts as needed, and assure timely access to DOE-funded laboratory resources as they are required for project implementation (e.g., test facilities). The technical monitor provides the project officer with technical evaluations and reports supporting stage-gate reviews; evaluates quarterly reports on progress against milestones, go/no go decision points, and critical success factors; and makes recommendations with respect to stage-gate decisions.

\subsection{TPP Program Recipients}

A summary of the TPP program recipients is included below. A short description of the activities encompassed for each recipient is as follows.

- Amonix

Total Award Amount:

$\$ 33,635,272$

DOE Share

Recipient Cost Share

$\$ 18,029,642$

The objective of the Amonix project is to transition its concentrating photovoltaics technology to high-volume production to meet market demand and price. The main focus will be to develop the high-volume tooling, processes, robotic machines, etc. necessary to achieve high -volume production and low labor costs. Amonix's manufacturing steps, having already been well-defined by previous manufacturing experience, need to be transitioned to automation. These new processes and machines will be integrated into a pilot factory to verify their performances. The pilot factory will be used to manufacture $25-\mathrm{kW}$ and $35-\mathrm{kW}$ systems, incorporating both silicon and multijunction solar cells.

- The Boeing Company

Total Award Amount:

$\$ 45,314,582$

DOE Share

$\$ 19,980,504$

Recipient Cost Share $\$ \$ 25,334,078$

The Boeing Company program, "High Efficiency Concentrating Photovoltaic Power Systems," will draw on previously developed state-of-the-art multijunction solar cell technology used in concentrator photovoltaic systems to provide lower system costs.

- BP Solar Inc

Total Award Amount: $\quad \$ 39,693,369$

DOE Share

$\$ 19,431,635$

Recipient Cost Share $\quad \$ 20,261,734$

BP Solar's project is based on accelerated development of multicrystalline silicon technology for use in the residential and commercial markets. The program goals are to achieve grid parity and increased production volume. The BP Solar Program addresses all aspects of the PV product chain from raw materials, including silicon, through installation of the systems at the customer site. A key component of the program is the development of multi-crystalline Si with single-crystal quality, and thinner wafers for better material utilization. Lower system costs and reliability also will be developed under the program.

- Dow Chemical Company

Total Award Amount: $\quad \$ 19,648,607$

DOE Share

$\$ 9,824,303$

Recipient Cost Share $\quad \$ 9,824,304$

The Dow Chemical Company, together with residential and commercial builders, will develop building integrated photovoltaic 
roofing products specifically optimized for realworld conditions. Dow Chemical will design, engineer, and develop innovative PV-packaging solutions for building integrated applications. These will include residential shingles, slates, and tiles as well as commercial roll roofing and standing metal rib roofing. Design application packages for all of the PV technologies will enable low-cost, high-reliability installation. The PV package development will create designs that drastically simplify the installation of PV systems. This will include the PV-module installation itself, interconnect systems, and all the durability and weatherresistance issues necessary for a reliable long-life system.

- GE Global Research

Total Award Amount:

DOE Share

$\$ 46,217,121$

$\$ 19,999,991$

Recipient Cost Share

$\$ 26,217,130$

GE has assembled a team of industrial partners that will create an unbroken value chain from the raw materials to the customer's rooftop. By 2010, GE and its partners will be positioned to deliver more than $200 \mathrm{MW}$ of GE-branded products into the residential and commercial segments of the U.S. market. The team will pursue various technical pathways including a mono-crystalline silicon pathway that incorporates a high-efficiency bifacial solar cell, and a thin-film pathway that takes advantage of new GE materials technology to produce a 25 -year flexible module for building integration.

- GreenRay Inc

Total Award Amount:

DOE Share

$\$ 5,043,503$

Recipient Cost Share

$\$ 2,521,752$

GreenRay, Inc. will develop an AC-module system. The AC module will have a superior life span and will produce lower-cost energy for customers. The simplified design and installation requirements will bring photovoltaic technology to a broader class of installers. At the heart of the AC-module system is a gridtied micro-inverter with the potential to achieve a 30-year lifetime, optimally sized to operate with a high-powered, ultrahigh-efficiency photovoltaic module. The micro-inverter will have a small physical size allowing it to be factory-integrated into the frame of the

Photovoltaic R\&D

Advanced Materials and Devices

Systems Development module. Each AC-module system will have wireless communication capability enabling it to report its performance to a central display for the homeowner.

- Konarka Technologies Inc.

Total Award Amount:

$\$ 8,584,841$

DOE Share

$\$ 3,655,491$

Recipient Cost Share

$\$ 4,929,350$

The Konarka Technologies Inc. program will address technical challenges that prevent the use of organic polymer-based photovoltaic (PV) modules on rooftop applications. The first objective is to develop new barriers to prevent water and oxygen from entering a cell and impeding cell function. The second is to raise module performance to a required output level (W/m2) for commercial rooftop applications. Konarka's manufacturing process uses continuous roll-to-roll printing or coating equipment to produce lightweight, flexible modules using small quantities of inexpensive materials. This approach offers the potential for producing a low-cost $(\$ / W)$ solar material that, due to its weight and flexibility, is easier to integrate into roofing material and other products.

- Miasolé Inc.

Total Award Amount: Not awarded

DOE Share: Not awarded

Recipient Cost Share:

Miasolé will significantly reduce the cost of $\mathrm{PV}$ by bringing high-volume manufacturing technology to the production of thin-film solar cells, and introducing flexible PV modules with integrated electronics. Miasolé already has an operational 25-MW solar-cell production system and a second is near completion. These systems utilize all sputtered, roll-to roll deposition technology combined with roll-toroll lamination technology for module assembly. The resulting modules are large, lightweight, and flexible for building integrated solar-cell applications. The program includes the incorporation of AC inverters and moduleembedded semiconductor technology. 
- Nanosolar Inc.

Total Award Amount:

$\$ 42,616,356$

DOE Share

$\$ 19,991,101$

Recipient Cost Share

$\$ 22,625,255$

Nanosolar has developed a new generation of solar-cell technology-the industry's first backcontacted thin-film cell as well as the world's most-efficient cell produced with printed semiconductors. The target market for the PV system developed through this project is flatand low-sloped commercial rooftops with total installed capacity greater than $100 \mathrm{~kW}$. The program focus will be on the retrofit market with aggressive cost-reduction goals that benefit a wide range of users. The project team will bring together innovations in cell and module technology, inverter technology and systems optimization, and module-mounting technology to deliver a pilot installation with grid-parity customer economics.

- Soliant Energy Inc.

Total Award Amount:

DOE Share

Recipient Cost Share

$\$ 13,659,722$

$\$ 4,886,762$

$\$ 8,772,960$

The Soliant Energy program will develop and evaluate pilot installations of advanced concentrating solar panels for commercial rooftop applications. The 2010 direct-cost goal is $\$ 1.25 / \mathrm{W}$ with array efficiency of $28 \%$. The panels have self-powered integrated-tracking to make them drop-in alternatives for conventional modules. This breakthrough technology enables more solar power on a rooftop than any other solution without the need to modify standard installation practices. Additionally, the concentrating panel's production cost is projected to be a fraction of the cost of conventional technology.

- Sunpower Corporation

Total Award Amount:

DOE Share

Recipient Cost Share

$\$ 52,647,068$

$\$ 24,700,000$

$\$ 27,947,068$

SunPower, a manufacturer of high-efficiency silicon solar cells and modules, proposes to build an innovative network for efficient downstream distribution. The near-term focus will be achieving grid parity in the residential market, and achieving the LCOE targets in the utility market will be a longer-range objective.
PowerLight is SunPower's subsidiary and has been selected for a separate but related TPP project activity related to solar-cell development. The two selections have been integrated into a single project.

- United Solar Ovonic LLC

Total Award Amount: $\quad \$ 39,848,561$

DOE Share $\$ 19,339,034$

Recipient Cost Share $\quad \$ 20,509,527$

United Solar Ovonic is a manufacturer of thinfilm amorphous silicon alloy based photovoltaic products. The company uses a proprietary roll-to-roll manufacturing process and the product is flexible, lightweight, aesthetically pleasing, and suited for building integrated (BIPV) applications. A two-pronged approach to achieving Levelized Cost of Energy goals is proposed: (1) to improve the efficiency of the solar cell; and (2) to reduce the cost of major module components.

\section{Results and Accomplishments}

\subsection{Project Selection}

- Applications were received by the Golden Field Office in response to the SAI TPP Funding Opportunity Announcement.

- Twelve applications were chosen for negotiation, based on various program factors.

\subsection{DOE Program Review}

- A DOE program review showcasing the anticipated activities of the SAI TPP recipients was held in Denver, Colorado. (See "Major FY 2007 Publications" (below) for a presentation reference.)

\subsection{Project Kickoff Meetings}

- Following completion of the SAI TPP awards, kickoff meeting were held (see Table 2 below) at each recipients facility, to review the technology baseline and the plans for reaching the first scheduled stage gate.

\section{Planned FY 2008 Activities}

\subsection{Stage Gates}

- Stage Gates anticipated for FY 2008 are shown in Figure 2 (above). 


\subsection{Critical Milestone}

- Nanosolar Inc. critical milestone criteria is to deliver a commercial-size cell and module with solar conversion efficiency that is greater than $6 \%$ and $4.5 \%$ respectively. The milestone will be verified by NREL (3/08).

\section{Major FY 2007 Publications}

- Solar Program Peer Review Agenda Overview (April 2007).

- "Overview of Solar America Initiative Awards," Project Announcements on Technology Pathway Partnerships, 8 Mar. 2007.

Copies of the publications can be found at http:// www.energy.gov/public.

Table 2. TPP Award Recipients

\begin{tabular}{|l|c|c|c|c|}
\hline \multicolumn{1}{|c|}{ SAI TPP Recipient } & $\begin{array}{c}\text { FY 2007 } \\
\text { Obligation }\end{array}$ & Award Date & Start Date & $\begin{array}{c}\text { Project Kickoff } \\
\text { Date }\end{array}$ \\
\hline Amonix Inc. & $\$ 2,200,000$ & 30 July 2007 & 14 May 2007 & 24 Oct. 2007 \\
\hline The Boeing Co. & $\$ 3,400,000$ & 30 July 2007 & 1 July 2007 & 28 Sept. 2007 \\
\hline BP Solar Inc. & $\$ 4,000,000$ & 31 July 2007 & 1 Sept. 2007 & 18 Sept. 2007 \\
\hline Dow Chemical Co. & $\$ 1,600,000$ & 30 July 2007 & 1 Aug. 2007 & 29 Sept. 2007 \\
\hline GE Global Research .Inc. & $\$ 4,600,000$ & 30 July 2007 & 1 Sept. 2007 & 19 Sept. 2007 \\
\hline Greenray Inc. & $\$ 591,353$ & 3 July 2007 & 1 Jan. 2007 & 12 Sept. 2007 \\
\hline Konarka Technology Inc. & $\$ 868,805$ & 1 Aug. 2007 & 1 July 2007 & 11 Oct. 2007 \\
\hline Miasolé Inc. & $\$ 3,000,000$ & 30 July 2007 & 1 Sept. 2007 & - \\
\hline Nanosolar Inc. & $\$ 4,750,105$ & 23 Aug. 2007 & 1 Sept. 2007 & 25 Oct. 2007 \\
\hline Soliant Energy Inc. & $\$ 2,098,991$ & 31 July 2007 & 1 Sept. 2007 & 23 Oct. 2007 \\
\hline Sunpower Corp. & $\$ 4,400,000$ & 20 Aug. 2007 & 1 Sept. 2007 & 2 Oct. 2007 \\
\hline United Solar Ovonics LLC & $\$ 2,821,859$ & 30 July 2007 & 30 Apr. 2007 & 30 Sept. 2007 \\
\hline
\end{tabular}

\section{University and Industry Partners}

The following organizations partnered in the TPP program research activities during FY 2007.

\begin{tabular}{|c|c|c|c|c|}
\hline $\begin{array}{l}\text { Recipient and } \\
\text { Sub-Recipients }\end{array}$ & Location & $\begin{array}{c}\text { Title of Research Activity } \\
\text { and Principal } \\
\text { Investigator Information }\end{array}$ & $\begin{array}{c}\text { FY } 2007 \\
\text { (\$K) }\end{array}$ & $\begin{array}{c}\text { Cost Share } \\
\text { (\$K) }\end{array}$ \\
\hline $\begin{array}{l}\text { Amonix, Inc. } \\
\text { University of Las Vegas } \\
\text { Spectralab Inc. } \\
\text { Cryo Industries } \\
\text { Arizona State University } \\
\text { NREL } \\
\text { Xantrex Technologies Inc. } \\
\text { Imperial Irrigation District }\end{array}$ & $\begin{array}{l}\text { Torrance, CA } \\
\text { Las Vegas, NV } \\
\text { Sylmar, CA } \\
\text { Sanford, ME } \\
\text { Tempe, AZ } \\
\text { Golden, CO } \\
\text { Burnaby, BC, } \\
\text { Canada } \\
\text { Imperial, CA }\end{array}$ & $\begin{array}{l}\text { "Low Cost, High } \\
\text { Concentration Photovoltaic } \\
\text { Systems for Utility Power } \\
\text { Generation" } \\
\text { Bob McConnell } \\
\text { 310-325-8091 x18 }\end{array}$ & $3,234,471$ & $9,836,219$ \\
\hline $\begin{array}{l}\text { The Boeing Company } \\
\text { PV Powered Inc } \\
\text { Sylarus Technologies. LLC } \\
\text { Southern California Edison } \\
\text { NREL } \\
\text { Light Prescriptions } \\
\text { Innovators } \\
\text { Array Technologies } \\
\text { California Institute of } \\
\text { Technology }\end{array}$ & $\begin{array}{l}\text { Huntington Beach, CA } \\
\text { Bend, OR } \\
\text { Columbus, OH } \\
\text { Monterey Park, CA } \\
\text { Golden, CO } \\
\text { Altadena, CA } \\
\text { Albuquerque, NM } \\
\text { Pasadena, CA }\end{array}$ & $\begin{array}{l}\text { "High Efficiency Concen- } \\
\text { trating Photovoltaic } \\
\text { Power System" } \\
\\
\text { Russ Jones } \\
\text { Russ.jones@boeing.com } \\
\text { 714-206-2556 }\end{array}$ & $8,136,637$ & $11,538,846$ \\
\hline
\end{tabular}




\begin{tabular}{|c|c|c|c|c|}
\hline $\begin{array}{l}\text { Recipient and } \\
\text { Sub-Recipients }\end{array}$ & Location & $\begin{array}{c}\text { Title of Research Activity } \\
\text { and Principal } \\
\text { Investigator Information }\end{array}$ & $\begin{array}{l}\text { FY } 2007 \\
\text { (\$K) }\end{array}$ & $\begin{array}{c}\text { Cost Share } \\
(\$ K)\end{array}$ \\
\hline $\begin{array}{l}\text { BP Solar Inc. } \\
\text { Arizona State University } \\
\text { Bekaert Corp. } \\
\text { Dow Corning Corp. } \\
\text { Georgia Institute of } \\
\text { Technology } \\
\text { Ceradyne Thermo Materials } \\
\text { Palo Alto Research Center } \\
\text { ATS Ohio, Inc } \\
\text { Ferro Corp. } \\
\text { Recticle UREPP N. America } \\
\text { SMUD } \\
\text { University of Central Florida } \\
\text { Xantrex Technology Inc. } \\
\text { Fat Spaniel Technologies } \\
\text { Inc. } \\
\text { Specialized Technology } \\
\text { Resources Inc. } \\
\text { AFG Industries } \\
\text { Komax Systems, York } \\
\end{array}$ & $\begin{array}{l}\text { Frederick, MD } \\
\text { Tempe, AZ } \\
\text { Marietta, GA } \\
\text { Midland, MI } \\
\text { Atlanta, GA } \\
\\
\text { Clarkson, GA } \\
\text { Palo Alto, CA } \\
\text { Lewis Center, OH } \\
\text { Cleveland, OH } \\
\text { Clarkson, MI } \\
\text { Sacramento, CA } \\
\text { Orlando, FL } \\
\text { Burnaby, BC } \\
\text { Canada } \\
\text { San Jose, CA } \\
\text { Enfield, CT } \\
\text { Kingston, TN } \\
\text { York, PA } \\
\end{array}$ & $\begin{array}{l}\text { "Reaching Grid Parity } \\
\text { Using BP Solar Crystalline } \\
\text { Silicon Technology A } \\
\text { Systems Class Application" } \\
\text { John Wohlgemuth } \\
\text { John.wohlgemuth@bp.com } \\
\text { 301-698-4375 }\end{array}$ & $7,029,635$ & $7,099,255$ \\
\hline $\begin{array}{l}\text { Dow Chemical Company } \\
\text { Miasolé Inc. } \\
\text { Solfocus Inc. } \\
\text { University of Delaware } \\
\text { Fronius USA, LLC } \\
\text { IBIS Associates }\end{array}$ & $\begin{array}{l}\text { Midland, MI } \\
\text { Santa Clara, CA } \\
\text { Palo Alto, CA } \\
\text { Newark, DE } \\
\text { Brighton, MI } \\
\text { Waltham, MA }\end{array}$ & $\begin{array}{l}\text { "Fully Integrated Building } \\
\text { Science Solutions for Resi- } \\
\text { dential and Commercial } \\
\text { Photovoltaic Energy } \\
\text { Generation" } \\
\text { Bob Cleereman } \\
\text { RJCleereman@dow.com } \\
\text { 989-636-5425 } \\
\end{array}$ & $2,841,296$ & $2,841,296$ \\
\hline $\begin{array}{l}\text { GE Global Research LLC } \\
\text { GE Energy Inc./Energy } \\
\text { Power Generation } \\
\text { REC Silicon Inc. } \\
\text { Solaicx Inc. } \\
\text { Xantrex Technologies Inc. } \\
\text { University of Delaware } \\
\text { Georgia Tech Research } \\
\text { Institute }\end{array}$ & $\begin{array}{l}\text { Niskayuna, NY } \\
\text { Newark, DE } \\
\text { Moses Lake, WA } \\
\text { Santa Clara, CA } \\
\text { Burnaby, BC, } \\
\text { Canada } \\
\text { Newark, DE } \\
\text { Atlanta, GA }\end{array}$ & $\begin{array}{l}\text { "A Value Chain Partnership } \\
\text { to Accelerate U.S. PV } \\
\text { Industry Growth" } \\
\text { Danielle Merfeld } \\
\text { merfeldw@research.ge.co } \\
\text { m } \\
518-387-4252\end{array}$ & $9,949,710$ & $13,062,461$ \\
\hline $\begin{array}{l}\text { Greenray Inc. } \\
\text { Coal Creek Design Inc. } \\
\text { Bluepoint Associates } \\
\text { NREL } \\
\text { Sandia National Laboratory } \\
\text { Sanyo Energy USA Corp. }\end{array}$ & $\begin{array}{l}\text { Lincoln, MA } \\
\text { Lafayette, CO } \\
\text { San Luis Obispo, } \\
\text { CA } \\
\text { Golden, CO } \\
\text { Albuquerque, NM } \\
\text { Frisco, TX }\end{array}$ & $\begin{array}{l}\text { "Development of an AC } \\
\text { Module System" } \\
\text { Miles Russell } \\
\text { Miles.russell@gmail.com } \\
\text { 781-962-9878 }\end{array}$ & 591,353 & 591,353 \\
\hline $\begin{array}{l}\text { Konarka Technologies Inc. } \\
\text { University of Delaware } \\
\text { NREL }\end{array}$ & $\begin{array}{l}\text { Lowell, MA } \\
\text { Newark, DE } \\
\text { Golden, CO }\end{array}$ & $\begin{array}{l}\text { "Low Cost, Lightweight } \\
\text { Solar Modules Based on } \\
\text { Organic Photovoltaic } \\
\text { Technology" } \\
\text { Russ Gaudiana } \\
\text { rgaudiana@konarka.com } \\
\text { 978-569-1410 } \\
\end{array}$ & 868,805 & $1,847,999$ \\
\hline $\begin{array}{l}\text { Miasolé Inc. } \\
\text { University of Delaware } \\
\text { Carlisle Syntec Inc. } \\
\text { University of Colorado } \\
\text { Exeltech Inc. } \\
\text { Sandia National Laboratory } \\
\text { NREL }\end{array}$ & \begin{tabular}{|l} 
Santa Clara, CA \\
Newark, DE \\
Carlisle, PA \\
Boulder, CO \\
Ft. Worth, TX \\
Albuquerque, NM \\
Golden, CO \\
\end{tabular} & $\begin{array}{l}\text { "Flexible Integrated PV } \\
\text { System" } \\
\text { Tom Hecht } \\
\text { thecht@miasole.com } \\
\text { 408-919-5718 }\end{array}$ & $\begin{array}{l}\text { Not } \\
\text { Awarded }\end{array}$ & $\begin{array}{l}\text { Not } \\
\text { Awarded }\end{array}$ \\
\hline
\end{tabular}

Photovoltaic R\&D Advanced Materials and Devices 


\begin{tabular}{|c|c|c|c|c|}
\hline $\begin{array}{l}\text { Recipient and } \\
\text { Sub-Recipients }\end{array}$ & Location & $\begin{array}{c}\text { Title of Research Activity } \\
\text { and Principal } \\
\text { Investigator Information }\end{array}$ & $\begin{array}{c}\text { FY } 2007 \\
\text { (\$K) }\end{array}$ & $\begin{array}{c}\text { Cost Share } \\
(\$ K)\end{array}$ \\
\hline $\begin{array}{l}\text { Nanosolar Inc. } \\
\text { Suntechnics Energy } \\
\text { Systems Inc. } \\
\text { Sunlink, LLC } \\
\text { Conergy Inc. }\end{array}$ & $\begin{array}{l}\text { San Jose, CA } \\
\text { Sacramento, CA } \\
\text { Larkspur, CA } \\
\text { Santa Fe, NM }\end{array}$ & $\begin{array}{l}\text { "Delivering Grid-Parity } \\
\text { Solar Electricity on Flat } \\
\text { Commercial Rooftops" } \\
\text { Brian Sager } \\
\text { bsager@nanosolar.com } \\
408-365-5965\end{array}$ & $4,750,105$ & $5,073,118$ \\
\hline $\begin{array}{l}\text { Soliant Energy Inc. } \\
\text { Spectralab Inc. } \\
\text { MIT } \\
\text { Sandia National Laboratory }\end{array}$ & \begin{tabular}{|l} 
Pasadena, CA \\
Sylmar, CA \\
Cambridge, MA \\
Albuquerque, NM
\end{tabular} & $\begin{array}{l}\text { "Concentrating Solar } \\
\text { Panels: Bringing the } \\
\text { Highest Power and Lowest } \\
\text { Cost to the Rooftop" } \\
\text { Brad Hines } \\
\text { Brad.hines@soliant- } \\
\text { energy.com } \\
626-389-1101\end{array}$ & $2,098,991$ & $2,557,186$ \\
\hline $\begin{array}{l}\text { Sunpower Inc. } \\
\text { Dow Corning Corp. } \\
\text { Massachusetts Institute of } \\
\text { Technology } \\
\text { Xantrex Technologies Inc. } \\
\text { Solaicx Inc. } \\
\text { NREL } \\
\text { Specialized Technology } \\
\text { Resources Inc. } \\
\text { Silicon Genesis Corp. } \\
\text { New Power Technologies }\end{array}$ & \begin{tabular}{|l} 
San Jose, CA \\
Midland, MI \\
Cambridge, MA \\
Burnaby, BC, \\
Canada \\
Santa Clara, CA \\
Golden, CO \\
Enfield, CT \\
San Jose, CA
\end{tabular} & $\begin{array}{l}\text { "Grid-Competitive Residen- } \\
\text { tial and Commercial Fully } \\
\text { Automated PV Systems } \\
\text { Technology" } \\
\text { Terry Jester } \\
\text { terry.jester@ } \\
\text { sunpowercorp.com } \\
\text { 408-218-0884 }\end{array}$ & $8,469,998$ & $8,469,998$ \\
\hline $\begin{array}{l}\text { United Solar Ovonic LLC } \\
\text { Energy Conversion Devices } \\
\text { Inc. } \\
\text { Syracuse University } \\
\text { Colorado School of Mines } \\
\text { University of Oregon } \\
\text { NREL } \\
\text { PV Powered Inc. } \\
\text { Solectria Renewables LLC } \\
\text { DEERS } \\
\text { Satcon Technology Corp. } \\
\text { Sun Edison } \\
\text { SMA America Inc. }\end{array}$ & $\begin{array}{l}\text { Auburn Hills, MI } \\
\text { Richmond Hills, MI } \\
\text { Syracuse, NY } \\
\text { Golden, CO } \\
\text { Eugene, OR } \\
\text { Golden, CO } \\
\text { Bend, OR } \\
\text { Lawrence, MA } \\
\text { Ripon, CA } \\
\text { Boston, MA } \\
\text { Baltimore, MD } \\
\text { Grass Valley, CA } \\
\end{array}$ & $\begin{array}{l}\text { "Low Cost Thin-Film } \\
\text { Building-Integrated PV } \\
\text { Systems" } \\
\text { Subhendu Guha } \\
\text { sguha@uni-solar.com } \\
\text { 248-364-5707 }\end{array}$ & $4,424,948$ & $4,675,356$ \\
\hline
\end{tabular}




\title{
Component Development PV Manufacturing R\&D
}

\author{
Performing Organization: National Renewable Energy Laboratory (NREL) \\ Key Technical Contact: $\quad$ Richard Mitchell (NREL), 303-384-6479, richard_mitchell@nrel.gov
}

DOE HQ Technology Manager: Jeffrey Mazer, 202-586-2455, jeffrey.mazer@ee.doe.gov

FY 2007 Budget: $\quad$ \$8,711K (NREL)

\section{Objectives}

- Improving photovoltaic (PV) manufacturing processes and products for terrestrial applications

- Accelerating PV manufacturing cost reductions

- Increasing commercial product performance and reliability

- Laying the foundation for significantly increased production capacity

- Achieving these goals in an environmentally safe manner.

\section{Accomplishments}

- Completed reviews, required redirections, and renewals for the Large-Scale Module and Component Yield, Durability, and Reliability (YDR) project subcontracts.

- Evaluated the scope of subcontracted research under the Large-Scale Module and Component Yield, Durability, and Reliability solicitation through identifying Solar America Initiative (SAI) Technology Pathway Partnership awards and successfully transferred research efforts under the Photovoltaic Manufacturing Research and Development (PVMR\&D) project into the SAI Technology Pathway Partnership Funding Opportunity Announcement (FOA) through termination of five PVMR\&D subcontracts.

- Successfully transitioned the research of five of the PVMR\&D YDR subcontracts to support Technology Pathway Partnership research through early subcontract terminations.

- As part of the annual DOE Solar Energy Technologies Program (SETP) Review, conducted a stage-gate evaluation of U.S. industry participants in the PVMR\&D Project to assess and determine the needs for additional manufacturing R\&D and select areas for elimination or support.

- Spire - Designed an automated stringing system for back contact solar cells and transferred the long-pulse simulator technology to market.

- $\quad B P$ Solar - Demonstrated the feasibility of Mono2 technology, verified the expected efficiency gain, and reduced wafer thickness to 200 microns in production.

- Dow Corning - Designed and began development of a pilot-scale, protection-system production line, including identification, acquisition, and installation of tooling.

- Evergreen Solar - Demonstrated equipment for in situ laser cutting and wafer removal and ran five such machines continuously in a pilot line production.

- First Solar - Improved thin-film CdTe module efficiency by 1.5 efficiency points.

- GE Energy - Developed a metal wrap-through process for GE solar cell manufacturing and competed a highly accelerated lifetime testing capability for elements of roof-integrated modules.

- PowerLight - Modified manufacturing and shipping processes to accommodate design changes, streamline material flow, reduce cost, and decrease waste streams.

- Schott Solar - Demonstrated a prototype backplane interconnect process leading to prototype construct for laying back-contact cells on flexible copper patterned substrate.

- Shingleton Design - Developed a new structural design with emphasis on factory-based assembly, modular design, and rapid deployment, resulting in a first-generation platform with the potential for $5 \%-10 \%$ increased energy production at a $5 \%-6 \%$ cost reduction.

- SolarWorld - Increased the wire sawing yield to 2.78 , a $25 \%$ improvement. 
- SunPower - Improved the performance of a newly introduced magnetic-induction soldering process by reducing the heat zone while maintaining solder bond quality with a new coil design.

- Xantrex Technology - Updated product functional specification and design to insure that the 500$\mathrm{kW}$ inverter product offering remains aligned with current market requirements, and successfully tested short circuit at full rated current.

\section{Future Directions}

- Complete stage-gate review of individual progress versus milestones and required redirection for YDR subcontracts.

- Complete research subcontracts awarded under the Large-Scale Module and Component Yield, Durability, and Reliability procurement.

- Complete all remaining research under the PVMR\&D Project.

\section{Introduction}

The PV Manufacturing R\&D Project was designed to assist the U.S. photovoltaic industry through a cost-shared manufacturing R\&D partnership with the U.S. Department of Energy (DOE) and members of the U.S. PV industry. Subcontracted research has focused on the U.S. PV industry's improvement of processes and products, resulting in (1) a substantial reduction in associated manufacturing costs; (2) a technology foundation that supports significant manufacturing scale-up (500 MW total U.S. capacity); and (3) positioning the industry to meet rapidly emerging large-scale deployment opportunities. This focus has directly supported the DOE Solar Energy Technologies Program's Advanced Materials and Devices activities.

Each subcontractor has enhanced existing manufacturing technologies through cost-shared development efforts geared toward achieving the overriding PVMR\&D goals. Work areas have included (1) the improvement of module manufacturing processes to increase module reliability; (2) system and system-component packaging, system integration, manufacturing, and assembly; (3) product manufacturing flexibility; and (4) balance-of-systems (BOS) development, including storage and quality control.

\section{Technical Approach}

The PVMR\&D Project is a government/industry partnership through cost-shared, subcontracted research in PV manufacturing technologies. The approach for the FY 2007 work effort was divided into three areas: (1) Project Management and Support subtask activities; (2) research subcontracts under the FY 2001 competitive solicitation for In-Line Diagnostics and Intelligent Processing in Manufacturing Scale-Up (IDIP); and
(3) research subcontracts under the FY 2003 competitive solicitation for Large-Scale Module and Component Yield, Durability, and Reliability, or YDR.

During FY 2007, the focus of the PVMR\&D Project was redirected to support the Technology Pathway Partnership Funding Opportunity Agreement under the Solar America Initiative. As such, many of the subcontracted research activities under the YDR procurement were terminated early in order to transfer their research focus to newly awarded Technology Pathway Partnership research.

\subsection{PV Manufacturing R\&D Management}

The Project Management and Support subtask addresses (1) management of the PVMR\&D project; (2) management of subcontracts awarded under the IDIP and YDR procurements; and (3) coordination of NREL's in-house activities in support of PVMR\&D industrial partners.

\section{Table 1. PVMR\&D Project Tasks and Budget}

\begin{tabular}{|l|c|}
\hline \multicolumn{1}{|c|}{ Task Title } & $\begin{array}{c}\text { FY 2007 } \\
\text { Budget (\$K) }\end{array}$ \\
\hline $\begin{array}{l}\text { PV Manufacturing R\&D Technical } \\
\text { Coordination }\end{array}$ & 542 \\
\hline $\begin{array}{l}\text { In-Line Diagnostics and Intelligent } \\
\text { Processing }\end{array}$ & 217 \\
\hline $\begin{array}{l}\text { Module Yield, Durability, and } \\
\text { Reliability }\end{array}$ & 7,952 \\
\hline
\end{tabular}

2.2 In-Line Diagnostics and Intelligent Processing The IDIP subtask consisted of the last remaining FY 2007 cost-shared PVMR\&D subcontract with Spire Corporation, "Development of Automated Production Line Processes for Solar Brightfield Modules," which was awarded under the FY 2001 IDIP competitive solicitation. This solicitation was directed toward the improvement of module manufacturing processes; system and system 
component packaging, system integration, manufacturing, and assembly; product manufacturing flexibility; and BOS development. This subcontract emphasized new and improved in-line diagnostics and monitoring with real-time feedback for optimal process control and increased yield in the fabrication of PV modules, systems, and other system components.

\subsection{Yield, Durability, and Reliability}

The FY 2007 YDR subtask comprises the costshared PVMR\&D subcontracts in Table 2 resulting from a competitive solicitation in FY 2003. The focus is on improving module manufacturing processes to increase module reliability, system and system-component packaging, system integration, manufacturing, and assembly; product manufacturing flexibility; and BOS development, including storage and quality control. The emphasis is on enhancing the reliability of the module, system components, and the complete system. Note that many of the subcontracts under this subtask were terminated early; therefore, the funding originally under this subtask was made available for use in the SAI Technology Pathway Partnership projects.

Table 2. FY 2007 YDR Subcontractors

\begin{tabular}{|c|c|}
\hline Subcontractor & Title of Subcontract \\
\hline BP Solar & $\begin{array}{l}\text { Development of Large High-Voltage } \\
\text { PV Modules with Improved Reliability } \\
\text { and Lower Cost }\end{array}$ \\
\hline $\begin{array}{l}\text { Dow Corning } \\
\text { Corporation }\end{array}$ & $\begin{array}{l}\text { High Performance Packaging } \\
\text { Solutions for Low Cost, Reliable PV } \\
\text { Modules }\end{array}$ \\
\hline $\begin{array}{l}\text { Evergreen } \\
\text { Solar }\end{array}$ & $\begin{array}{l}\text { Low-Cost Manufacturing of High- } \\
\text { Efficiency, High-Reliability String } \\
\text { Ribbon Si PV Modules }\end{array}$ \\
\hline First Solar & $\begin{array}{l}\text { Implementation of Reliable } \\
\text { Manufacturing of Higher Efficiency } \\
\text { Module }\end{array}$ \\
\hline GE Energy & Solar Cell Design for Manufacturability \\
\hline $\begin{array}{l}\text { PowerLight } \\
\text { Corporation }\end{array}$ & $\begin{array}{l}\text { Accelerating PV Cost Effectiveness } \\
\text { Through Systems Design, } \\
\text { Engineering, and Quality Assurance }\end{array}$ \\
\hline SCHOTT Solar & $\begin{array}{l}\text { Subcontracts under PV Module And } \\
\text { Component Yield, Durability, And } \\
\text { Reliability solicitation }\end{array}$ \\
\hline Shingleton & $\begin{array}{l}\text { One-Axis Trackers - Improved } \\
\text { Reliability, Durability, Performance, } \\
\text { and Cost Reduction }\end{array}$ \\
\hline SolarWorld & $\begin{array}{l}\text { Manufacturing Improvements in CZ } \\
\text { Silicon Module Production }\end{array}$ \\
\hline SunPower & $\begin{array}{l}\text { Automated Manufacturing of High } \\
\text { Efficiency Modules }\end{array}$ \\
\hline
\end{tabular}

\begin{tabular}{|l|l|}
\hline Subcontractor & \multicolumn{1}{|c|}{ Title of Subcontract } \\
\hline Xantrex & $\begin{array}{l}\text { Advanced, High Reliability, System } \\
\text { Integrated 500-kW Photovoltaic } \\
\text { Inverter Development }\end{array}$ \\
\hline
\end{tabular}

\section{Results and Accomplishments}

\subsection{In-Line Diagnostics and Intelligent Processing} Under this subtask, the PVMR\&D project focused on completing all but one of the IDIP subcontracts to a successful conclusion during the year. The significant achievements accomplished under this subtask by the remaining IDIP subcontractor, Spire Corporation, are described below.

\section{Spire Corporation}

"Development of Automated Production Line

Processes for Solar Brightfield Modules"

- Designed an automated stringing system for back contact solar cells

- Designed and implemented a Supervisory Control and Data Acquisition (SCADA) system for photovoltaic module assembly

- Transferred the long-pulse simulator technology to market.

\subsection{Yield, Durability and Reliability}

The Large-Scale Module and Component Yield, Durability, and Reliability letter of interest issued in FY 2003 focused on addressing needs in two categories. Category A, PV System and Component Technology, largely addresses the nonmodule aspects of PV systems component manufacturing processes. Category B, PV Module Manufacturing Technology, primarily addresses aspects of module manufacturing processes. Under this subtask, the significant achievements of individual subcontractors in FY 2007 are described below.

\section{BP Solar}

"Development of Large High-Voltage PV Modules with Improved Reliability and Lower Cost"

- Demonstrated feasibility of Mono2 technology and verified the expected efficiency gain

- Qualified and implemented (in production) a U.S. supply of antireflective (AR) coated glass

- Reduced wafer thickness to 200 microns in production

- Built and populated a high-voltage test bed at the Florida Solar Energy Center

- This subcontract was terminated early as a PVMR\&D subcontract, and the work was successfully integrated into the BP Solar SAI Technology Pathway Partnership FOA.

Photovoltaic R\&D Advanced Materials and Devices 
Dow Corning Corporation

"High Performance Packaging Solutions for LowCost, Reliable PV Modules"

- Designed and began development of a pilotscale, protection-system production line, including identification, acquisition, and installation of tooling

- Applied and characterized the protection system on multicrystalline silicon ( $\mathrm{Si}$ ) cells and strings, successfully passing the industry standard humidity-freeze cycle testing of 1,000 hours, $85^{\circ} \mathrm{C}, 85 \%$ relative humidity, $200 \mathrm{TC}$, and 420 hours UV/50 TC/10

- Applied the optimized protection system to thinfilm PV devices and characterized them under humidity-freeze (HF) cycling; found that protection system effectiveness strongly depended on layer thickness; sufficiently thick layers were able to withstand HF cycling well.

\section{Evergreen Solar, Inc.}

"Low-Cost Manufacturing of High-Efficiency, HighReliability String Ribbon Si PV Modules"

- Developed concept to address the buildup of impurities in Si melt, and allow the use of impure Si by periodically removing liquid from the melt during growth

- Ran five quad machines on a continual basis in the pilot line; in some cases, a machine ran for a full 24 hours with no operator intervention at all-probably a first for silicon ribbon technology.

- Designed a machine with a chamber containing a cutting laser and associated mechanical equipment to allow in situ wafer cuts to be grasped and placed in a plastic box. Five such machines were built and placed in a pilot line to be run continuously.

\section{First Solar}

"Solar Cell Design for Manufacturability"

- Improved thin-film CdTe module efficiency by 1.5 efficiency points

- The efficiency improvement resulted from research in these module fabrication processes: $0.5 \%$ from the alternative front contact window (AFCW) substrate; $0.3 \%$ from post-deposition processing (PDP); $0.3 \%$ from initial optimization of PDP and vapor transport deposition (VTD) of AFCW and the interfacial layer; $0.2 \%$ from improvements to the wet spray process; and $0.3 \%$ from additional optimization rounds of PDP and VTD processes.
GE Energy, LLC

"Solar Cell Design for Manufacturability"

- Developed a metal wrap-through process for GE solar cell manufacturing

- Competed highly accelerated lifetime testing capability for elements of roof-integrated modules

- Developed an improved diffusion process resulting in a near-ideal blue response at moderately low emitter sheet resistance of 50 to 60 ohms per square

- This subcontract was terminated early as a PVMR\&D subcontract, and the work was successfully integrated into the GE Energy SAI Technology Pathway Partnership FOA.

\section{PowerLight Corporation}

"Accelerating PV Cost Effectiveness Through Systems Design, Engineering, and Quality Assurance"

- Implemented design improvements with the goal of reducing costs while maintaining and/or improving product quality

- Modified manufacturing and shipping processes to accommodate design changes, streamline material flow, reduce cost, and decrease waste streams.

Schott Solar, Inc.

"High Performance Multicrystalline Silicon Modules and Products"

- Demonstrated prototype backplane interconnect process; optimized materials and process, leading to prototype construct for laying backcontact cells on flexible backplane substrate containing patterned copper substrate

- Examined approaches for improving potential cell efficiency in Si wafers from edge-defined, film-fed growth process through cell design or process modifications. Identified changing the $p$ type dopant source during crystal growth from boron to gallium as especially promising, with resulting cell efficiencies as high as $16.2 \%$

- This subcontract was terminated as a PVMR\&D subcontract at the direction of DOE as part of its overall realignment of research under the SAI.

\section{Shingleton Design}

"Advanced, High Reliability, System Integrated 500-kW Photovoltaic Inverter Development"

- Completed the development of the new structural design with emphasis on factorybased assembly, modular design, and rapid deployment 
- Improved the controller and drive subassemblies for further improved tracker performance

- Completed the development of design and cost analysis tools enabling commercialization of a next-generation tracker

- Demonstrated first-generation platform potential for $5 \%-10 \%$ increased energy production at a $5 \%-6 \%$ cost reduction

- This subcontract was terminated early as a PVMR\&D subcontract, and the work was successfully integrated into the SunPower SAI Technology Pathway Partnership FOA.

\section{SolarWorld Industries America}

"Manufacturing Improvements in CZ Silicon Module Production"

- Implemented a new ethylene vinyl acetate material into production, allowing a $30 \%$ reduction in cycle time without sacrificing module reliability

- Reduced the average wafer thickness from 280 microns to 210 microns and the wire thickness from 140 microns to 120 microns

- Increased the wire sawing yield by $25 \%$.

SunPower Corporation

"Automated Manufacturing of High Efficiency Modules"

- Introduced a modified tab shape change expected to improve electrical performance at no increase in cost; tested coupons with modified tab shape and found good performance after 900 temperature cycles

- Improved the performance of a newly introduced magnetic-induction soldering process by reducing the heat zone while maintaining the solder bond quality with a new coil design; tooling automation control will benefit greatly from this change

- Identified single-layer sol-gel AR glass coating as promising for further development; found advantages in antisoiling properties as well as in the (expected) gain in energy production

- This subcontract was terminated early as a PVMR\&D subcontract, and the work was successfully integrated into the SunPower SAI Technology Pathway Partnership FOA.

\section{Xantrex Technology}

"Advanced, High Reliability, System Integrated 500-kW Photovoltaic Inverter Development"

- Updated the product functional specification and design to insure that the $500-\mathrm{kW}$ inverter product offering remains aligned with current market requirements
- Fabricated all critical subassemblies and magnetic components required to begin design verification testing

- Completed the design of the inverter packaging and enclosure

- Successfully tested the 500-kW inverter into a short circuit at full rated current.

\section{Planned FY 2008 Activities}

PVMR\&D project procurements were framed to specifically address milestones under the SETP. The focus of this project has now been directed toward supporting the Technology Pathway Partnership FOA under the Solar America Initiative. As such, many subcontracted research activities under the YDR procurement were terminated early in order to transfer the focus of industrial subcontractors to newly awarded Technology Pathway Partnership research. The remaining YDR subcontracts will continue their efforts to enhance field reliability and durability as well as manufacturing yield. The major task milestone and expected accomplishment of this project during FY 2008 will be to complete research under the Large-Scale Module and Component Yield, Durability, and Reliability procurement during this year.

The research addressed by the PVMR\&D project has been selected by participants from the U.S. $\mathrm{PV}$ industry, in the form of proposals received in response to competitive solicitations. As such, these are systems-driven issues and are those of the greatest importance to individual PV manufacturers. Actual projects have been chosen primarily by evaluators external to the government using criteria constructed to select, in a technology-neutral manner, activities that are most likely to contribute to the PVMR\&D project goals and objectives.

Subcontracts under this project continue to assist in reducing PV system costs and improving PV manufacturing processes and products. In addition, representatives of the PV industry have identified this project as one of the most, if not the most, important and successful projects in the DOE SETP to date.

\section{Major FY 2006 Publications}

J. Shingleton, "One-Axis Trackers - Improved Reliability, Durability, Performance, and Cost Reduction," Final Subcontract Technical Status 
Report, SR-520-42769, 2 May 2006-31 August (2007).

T. Ellison, "Implementation of a Comprehensive On-Line Closed-Loop Diagnostic System for Rollto-Roll Amorphous Silicon Solar Cell Production," Final Subcontract Report, SR-520-41560, 23 April 2003-30 September (2006).
T.L. Jester, "Manufacturing Improvements in Cz Silicon Module Production," Annual Subcontract Report, SR-520-42418, July 2005-October 2006 (2006).

J. Botkin, "Accelerating PV Cost Effectiveness Through Systems Design, Engineering, and Quality Assurance," Final Subcontract Report, SR520-42420, June (2007).

\section{University and Industry Partners}

The following organizations partnered in the project's research activities during FY 2007.

\begin{tabular}{|c|c|c|c|c|}
\hline $\begin{array}{c}\text { Organization/ } \\
\text { Principal Investigator }\end{array}$ & Location/e-mail & $\begin{array}{l}\text { Description/Title } \\
\text { of Research Activity }\end{array}$ & $\begin{array}{c}\text { FY } \\
2007 \\
(\$ K)\end{array}$ & $\begin{array}{l}\text { Cost } \\
\text { Share } \\
\text { (\$K) }\end{array}$ \\
\hline $\begin{array}{l}\text { Spire Corporation } \\
\text { Michael Nowlan }\end{array}$ & $\begin{array}{l}\text { Bedford, MA } \\
\text { mnowlan@spirecorp.com }\end{array}$ & $\begin{array}{l}\text { Development of Automated } \\
\text { Production Line Processes for Solar } \\
\text { Brightfield Modules }\end{array}$ & 217 & 211 \\
\hline $\begin{array}{l}\text { BP Solar International, Inc. } \\
\text { John Wohlgemuth }\end{array}$ & $\begin{array}{l}\text { Frederick, MD } \\
\text { john.wohlgemuth@bp.com }\end{array}$ & $\begin{array}{l}\text { Development of Large High-Voltage } \\
\text { PV Modules with Improved Reliability } \\
\text { and Lower Cost }\end{array}$ & 562 & 526 \\
\hline $\begin{array}{l}\text { Dow Corning Corporation } \\
\text { Barry Ketola }\end{array}$ & $\begin{array}{l}\text { Midland, MI } \\
\text { barry.ketola@dowcorning.com }\end{array}$ & $\begin{array}{l}\text { High Performance Packaging } \\
\text { Solutions for Low Cost, Reliable PV } \\
\text { Modules }\end{array}$ & 904 & 904 \\
\hline $\begin{array}{l}\text { Evergreen Solar, Inc. } \\
\text { Jack Hanoka }\end{array}$ & $\begin{array}{l}\text { Marlboro, MA } \\
\text { hanoka@evergreensolar.com }\end{array}$ & $\begin{array}{l}\text { Low-Cost Manufacturing of High- } \\
\text { Efficiency, High-Reliability String } \\
\text { Ribbon Si PV Modules }\end{array}$ & 1408 & 1935 \\
\hline $\begin{array}{l}\text { First Solar, LLC } \\
\text { Greg Helyer }\end{array}$ & $\begin{array}{l}\text { Perrysburg, OH } \\
\text { ghelyer@FIRSTSOLAR.COM }\end{array}$ & $\begin{array}{l}\text { Implementation of Reliable } \\
\text { Manufacturing of Higher Efficiency } \\
\text { Module }\end{array}$ & 1080 & 1085 \\
\hline $\begin{array}{l}\text { GE Energy, LLC } \\
\text { James Rand }\end{array}$ & $\begin{array}{l}\text { Newark, DE } \\
\text { im.rand@ps.ge.com }\end{array}$ & Solar Cell Design for Manufacturability & 554 & 579 \\
\hline $\begin{array}{l}\text { PowerLight Corporation } \\
\text { Jonothan Botkin }\end{array}$ & $\begin{array}{l}\text { Berkeley, CA } \\
\text { Jbotkin@powerlight.com }\end{array}$ & $\begin{array}{l}\text { Accelerating PV Cost Effectiveness } \\
\text { Through Systems Design, } \\
\text { Engineering, and Quality Assurance }\end{array}$ & 0 & 0 \\
\hline $\begin{array}{l}\text { SCHOTT Solar, Inc. } \\
\text { Mark Rosenblum }\end{array}$ & $\begin{array}{l}\text { Billerica, MA } \\
\text { mark.rosenblum@us.schott.com }\end{array}$ & $\begin{array}{l}\text { High Performance Multicrystalline } \\
\text { Silicon Modules and Products }\end{array}$ & 335 & 324 \\
\hline $\begin{array}{l}\text { Shingleton Design, LLC } \\
\text { Jefferson Shingleton }\end{array}$ & $\begin{array}{l}\text { Auburn, NY } \\
\text { jefferson@shingleton.com }\end{array}$ & $\begin{array}{l}\text { One-Axis Trackers - Improved } \\
\text { Reliability, Durability, Performance, } \\
\text { and Cost Reduction }\end{array}$ & 273 & 597 \\
\hline $\begin{array}{l}\text { SolarWorld Industries America } \\
\text { Theresa Jester }\end{array}$ & $\begin{array}{l}\text { Camarillo, CA } \\
\text { Theresa.jester@shellsolar.com }\end{array}$ & $\begin{array}{l}\text { Manufacturing Improvements in CZ } \\
\text { Silicon Module Production }\end{array}$ & 975 & 1164 \\
\hline $\begin{array}{l}\text { SunPower Corporation } \\
\text { Doug Rose }\end{array}$ & $\begin{array}{l}\text { Sunnyvale, CA } \\
\text { Doug.Rose@sunpowercorp.com }\end{array}$ & $\begin{array}{l}\text { Automated Manufacturing of High } \\
\text { Efficiency Modules }\end{array}$ & 535 & 558 \\
\hline $\begin{array}{l}\text { Xantrex Technology, Inc. } \\
\text { Raymond Hudson }\end{array}$ & $\begin{array}{l}\text { San Luis Obispo, CA } \\
\text { Ray.Hudson@xantrex.com }\end{array}$ & $\begin{array}{l}\text { Advanced, High Reliability, System } \\
\text { Integrated 500-kW Photovoltaic } \\
\text { Inverter Development }\end{array}$ & 451 & 451 \\
\hline
\end{tabular}




\title{
Component Development Thin Film PV Partnership Program
}

\author{
Performing Organizations: National Renewable Energy Laboratory (NREL) \\ DOE Golden Field Office (DOE/GO)
}

Key Technical Contact: Harin S. Ullal (NREL), 303-384-6486, harin_ullal@nrel.gov

DOE HQ Technology Manager: Jeffrey Mazer, 202-586-2455, jeffrey.mazer@ee.doe.gov

FY 2007 Budget: $\quad$ \$6,000K (NREL)

\section{Objectives}

- Support the Solar America Initiative Technology Partnership Pathway Funding Opportunity Announcement to achieve levelized cost of electricity by 2015.

- Support the near-term transition to first-time manufacturing and commercial introduction of reliable thin-film amorphous silicon (a-Si), copper indium diselenide (CIS), cadmium telluride (CdTe), and film silicon modules.

- Build a technology base upon which these advanced photovoltaic (PV) technologies can continue to be successful in improving manufacturing and can continue to progress in performance, reliability, and cost reductions, resulting in products that are able to compete in the PV marketplace.

- Sustain innovation to support progress toward ambitious long-term PV cost and performance goals (e.g., $15 \%$ efficient modules costing less than $\$ 50 / \mathrm{m}^{2}$ and capable of lasting 30 years), which are appropriate for cost-competitive PV-generated electricity.

\section{Accomplishments}

- Met one important OMB/DOE/EERE/SET Joule milestone.

- U.S. manufacturing facilities expanded for two technology partners: First Solar, $120 \mathrm{MWp}$, and Uni-Solar, $90 \mathrm{MWp}$.

- Production of thin films in the United States grew from about $10 \mathrm{MWp}$ in 2003 to an estimated $160 \mathrm{MWp}$ in 2007.

\section{Future Directions}

- Continue to address key issues supporting the transition to a successful first-time manufacturing operation or a major production expansion in each thin-film area.

- Significantly reduce CIS and CdTe layer thicknesses in cells and support the transfer of this advance to future manufacturing technologies.

- $\quad$ Direct thin-film CdTe solar cell research to achieve a higher open-circuit voltage.

- Investigate the use of nanocrystalline bottom cells in thin-film silicon multijunction solar cells.

\section{Introduction}

Thin-film photovoltaic (PV) technologies are considered to have good potential to meet ambitious cost and performance goals that are consistent with those of the Solar America Initiative (SAI) Technology Partnership Pathway, e.g., to achieve long-term goals for a levelized cost of electricity by the year 2015 .

The Thin Film PV Partnership Program is designed to accelerate progress toward meeting those goals. The partnership includes subcontracted research and development (R\&D) in CIS, CdTe, a-Si, and new thin films such as film silicon. The partnership members work closely with NREL's internal researchers, facilitating collaborative activities with academia and U.S. thin-film industry groups.

\section{Technical Approach}

The partnership included about 20 subcontracts during FY 2007. Subcontract funding for FY 2007

Photovoltaic R\&D Advanced Materials and Devices 
for the Industry and University Thin Film PV Partnership is shown in Table 1.

Table 1. Thin Film PV Partnership Funding

\begin{tabular}{|l|c|}
\hline \multicolumn{1}{|c|}{ Task Title } & $\begin{array}{c}\text { FY 2007 } \\
\text { Budget } \mathbf{( \$ K )}\end{array}$ \\
\hline Industry Thin Film & 2,686 \\
\hline University Thin Film & 3,382 \\
\hline
\end{tabular}

Three groups were major technology partner subcontractors: Global Solar in CIS, First Solar in $\mathrm{CdTe}$, and United Solar Ovonic (Uni-Solar) in a-Si. The rest were R\&D partners and were either small businesses making progress in establishing pilot production operations or universities supporting partnership objectives.

\section{Results and Accomplishments}

The Thin Film PV Partnership supported the transition to successful first-time manufacturing of key thin-film technologies during FY 2007. This is our most important activity in the short term, because it will help establish thin films in the marketplace, improve their chances of future growth and success, and help define the transition to the private sector of technologies that have been successfully developed through U.S. Department of Energy (DOE) funding.

This transition has been more than two decades in the making and is not yet accomplished. However, because of the substantial growth in CY 2007 to a total of more than $160 \mathrm{MW}$ of U.S. production capacity (from only $12 \mathrm{MW}$ in the United States in 2003), thin films are now making this important transition.

Surveys of the partnership's technology partners indicated that this growth might increase substantially in CY 2008, to about $260 \mathrm{MW}$ of annual U.S. production. If this happens, it will show that these key, potentially lower-cost technology options have arrived in the PV marketplace. It will also suggest the resumption of U.S. market leadership in PV, because thin films could take on a leading role in the future.

Table 2 summarizes worldwide thin-film PV production capacity achievements by 2010 . Estimated worldwide thin-film PV production capacity by that year could be approximately 4600 MW.
Table 2. Estimated Worldwide Production Capacity of Thin-Film PV Modules by 2010

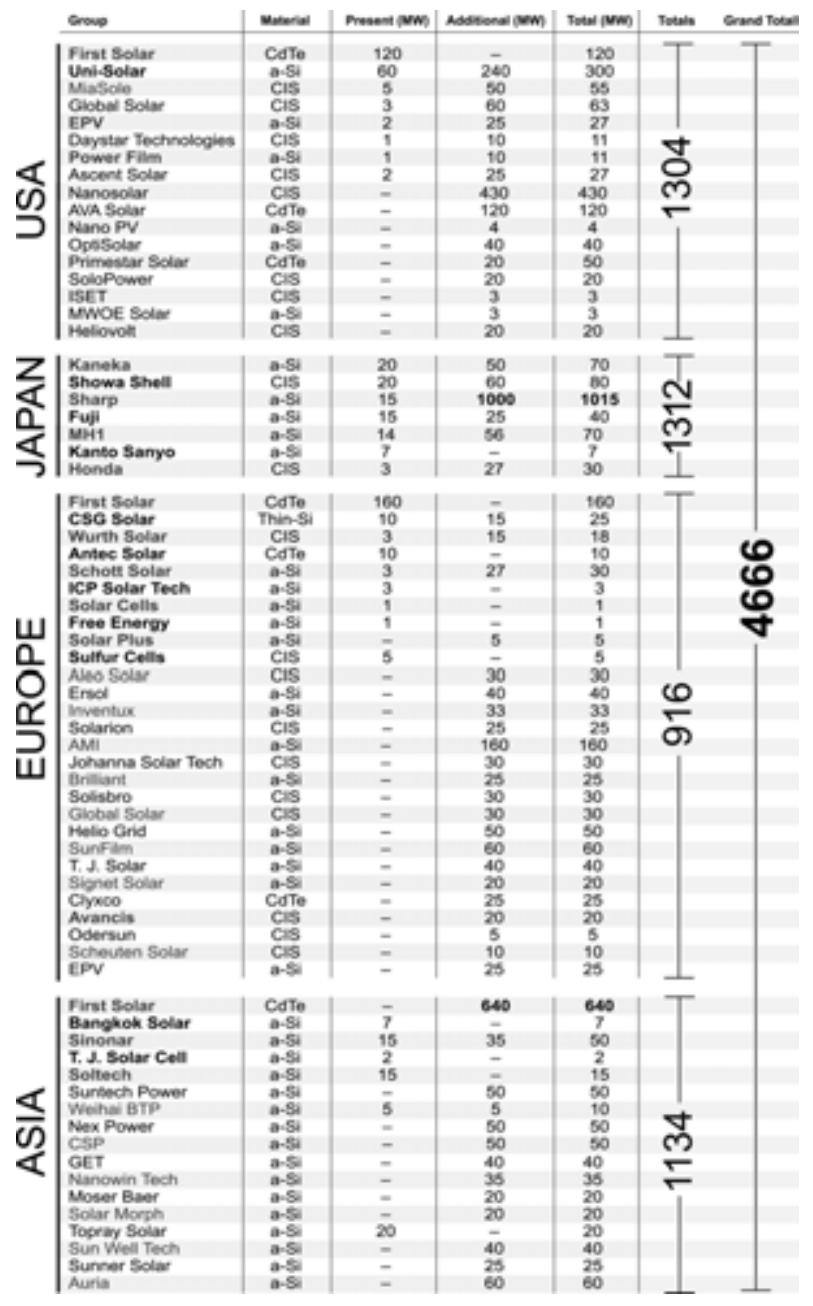

The following summaries describe some of the highlights of R\&D in FY 2007.

\subsection{First Solar Expands to 120-MWp Factory}

First Solar aggressively expanded its manufacturing in 2007 , with an installed capacity of $120 \mathrm{MW}$ and expected sales of about $100 \mathrm{MW}$ in that year. Also, First Solar's worldwide production capacity is expected to be more than 900 MW by December 2009, with projected sales of over $350 \mathrm{MW}$. This would place it among the top five PV companies in the world as well as the number one thin-film PV company. Figure 1 shows the progress that First Solar has made in module efficiency over the past several years. 


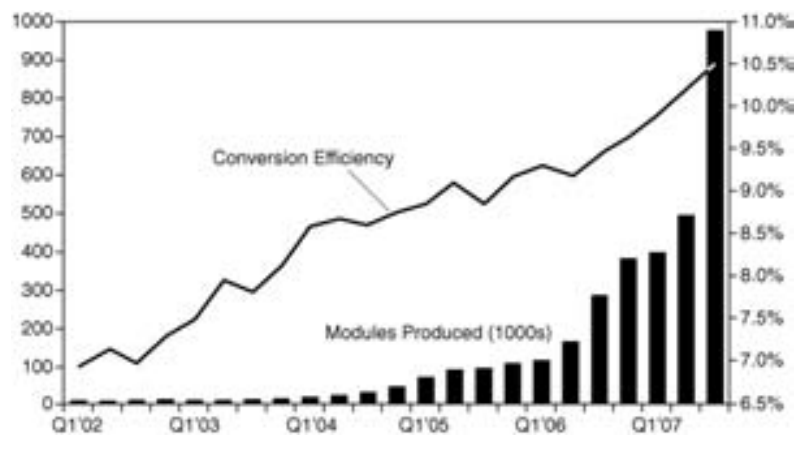

Fig. 1. First Solar's progress in module efficiency and in shipments from 2002 to 2007.

Substantial progress has been made in terms of the following:

- The new 120-MWp coater, which is now fabricating the majority of the company's products

- Reducing maintenance costs by substantially enhancing materials utilization rates

- Automating and improving most aspects of production.

First Solar planned to move to a cost structure that would allow $\$ 3 / \mathrm{Wp}$ ground-mounted PV systems to be installed in the not-too-distant future.

The DOE Solar Energy Technologies Program, NREL, the National Center for Photovoltaics (NCPV), and the Thin Film PV Partnership have supported R\&D in this very promising thin-film PV technology at First Solar for the past several years. First Solar uses a very rapid vapor transport deposition technique to deposit the semiconductor films in less than one minute, which gives it a significant advantage over its competitors. That deposition process won a prestigious R\&D 100 Award in 2003 that was shared by NREL.

"These accomplishments strengthen the position of U.S. manufacturers as leaders in the next generation of thin-film solar technologies and accelerate our nation's drive to make solar electricity competitive with conventional electricity," said DOE Under Secretary David Garman.

\subsection{Uni-Solar Attains 90-MWp Capacity}

The Uni-Solar a-Si factory is working at full capacity, about $5 \mathrm{MWp} /$ month. Because of the silicon shortage, module prices have been rising, and profitability is increasing. Recently, Uni-Solar built a third 30-MWp plant in Michigan, bringing the total manufacturing capacity to $90 \mathrm{MW}$. In describing the competitiveness of the Uni-Solar technology, company President Subhendu Guha made the case that the company's peel-and-stick roofing material is directly competitive with all other rooftop PV approaches (including those using c-Si and CdTe) because installation is easy (reducing, e.g., balance of system costs) and because of its superior aesthetics and durability (see Figure 2). He mentioned two major "wins" over such competition to large commercial rooftop projects-one for $1 \mathrm{MW}$ on a GM building and another for $750 \mathrm{~kW}$ in California.

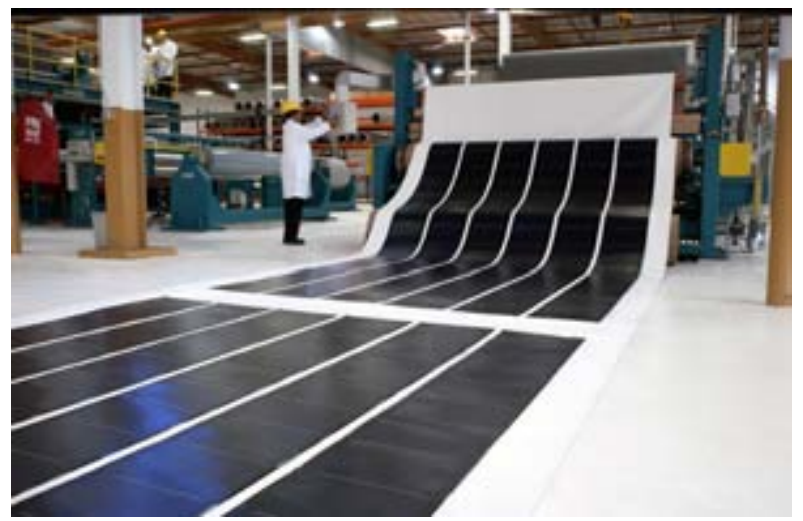

Fig. 2. The Uni-Solar a-Si factory produces peeland-stick thin-film PV roofing material, as shown in the figure.

It is interesting that First Solar and Uni-Solar have different, but complementary, focus markets: UniSolar for commercial roofs and First Solar for large, ground-mounted systems. In both markets, they are quite competitive with companies using crystalline silicon technology.

\subsection{Global Solar Expands Capacity to $40 \mathrm{MW}$}

Global Solar Energy (GSE) is expanding production capacity to $40 \mathrm{MW}$ of thin-film CIGS modules in 2008. In addition, a new 35-MW thinfilm copper indium gallium diselenide (CIGS) manufacturing plant has been set up in Germany. Thus, GSE's cumulative production capacity is at $75 \mathrm{MW}$ worldwide. Some of the new encapsulation schemes for the CIGS modules have shown exceptionally good stability, especially in dampheat tests. Tests are also being conducted at Tucson Electric Power in Springerville, Arizona.

Global Solar Energy also fabricated a 10.2\%efficient, 88.9-W thin-film CIGS power module, the highest wattage in the world for a CIGS module. 
ITN Energy Systems (ITN/ES) in Littleton, Colorado, developed an intelligent processing system to improve processing conditions and yields in cell and module fabrication that helped produce this module. The module parameters are as follows: short-circuit current $=4.07 \mathrm{~A}$, opencircuit voltage $=36 \mathrm{~V}$, fill factor $=0.606$, and area $=8709 \mathrm{~cm}^{2}$. Stainless steel webs $1000 \mathrm{ft}$ in length were used for roll-to-roll processing of the devices. The typical cell structure is ITO/CdS/CIGS/Mo/SS (i.e., indium tin oxide/cadmium sulfide/CIGS/ molybdenum/stainless steel).

The CIGS is deposited by physical vapor deposition, CdS by a modified chemical bath deposition process, and ITO and Mo by sputtering. More process optimization should improve module performance in the near future. NREL and GSE shared an R\&D 100 Award in 2004 for development of the GSE CIGS technology.

\subsection{One Critical OMB/DOE/EERE Joule Milestone Is Completed}

One OMB/DOE/EERE/SET Joule milestone was completed within the partnership. One milestone involved achieving a higher efficiency thin-film module $(12.2 \%)$ by the end of the fiscal year. The milestone was for a thin-film power module.

\subsection{University and Technical Highlights}

While technically no longer supported by the Thin Film Partnership, the University Center of Excellence (Institute of Energy Conversion (IEC), University of Delaware) continues to provide both valuable insights as well as services in the fabrication of thin-film solar cells. IEC implemented vapor transport deposition of CdTe solar cells and has fabricated and analyzed many solar cells produced using this method. A significant part of that work has been to characterize the role of impurities in the CdTe absorber and during "contacting" in cell performance. Recently, IEC began developing a CdTe cell on flexible foil.

Regarding CIGS solar cells, NREL urged IEC to put significant effort into working on the reaction kinetics of selenization and sulfurization reactions. This now includes CIS solar cells and compares their characteristics to CIGS cells with a similar band gap. Historically, IEC has developed much know-how and understanding in the field of coevaporated CIGS solar cells. However, a while ago there was not enough fundamental support for companies forming CIGS by selenization (sulfurization) of metallic precursors. One key aspect of producing CIGS by this method is shortening the selenization (sulfurization) reaction times. IEC has also implemented in-house fabrication of CIGS minimodules.

In the area of Si film solar cells, IEC recently used its deposition capabilities to produce heterojunction "HIT" solar cells. HIT cells made on textured Czochralski-grown Si wafers had reported efficiencies as high as $18.8 \%$.

IEC also continues developing a cell design with a new heterojunction wrap-through emitter. Although this work is being carried out by very talented personnel at IEC, the work (like similar work being done at other institutions outside the United States) has not yet resulted in cells with a competitive performance advantage over that of existing commercial cells produced by Sanyo.

IEC maintains a capability to produce state-of-the art or near-state-of-the-art solar cells in all thin-film PV technologies using a variety of deposition approaches. The institute continues to enable start-up companies to complete solar cells with its materials.

Solar cell fabrication continued at the University of Toledo. Amorphous silicon work (Deng and Collins) has been done as well as work on CdTe cells (Compaan, Karpov, and Collins). Work with the Florida Solar Energy Center continues on CIGS cells (Dhere], in addition to in-house efforts at NREL and at IEC. Device fabrication by university groups requires a significant long-term investment, but there are four major benefits:

1. Commercial spin-off opportunities can be created (e.g., Xunlight Corp. from the University of. Toledo, AVA Solar from Colorado State university);

2. A better understanding of solar cell physics can be obtained, because university cell makers usually reveal more detail than industrial groups do about their cell fabrication methods;

3. Specialized cells for special measurements can be fabricated that resemble regular cells; and

4. Options for changes in processing can be explored before industry has to invest in expensive modifications of pilot or production equipment.

Beyond a capability for analyzing losses in cells and modules, the University of Toledo has also 
developed mitigation schemes for reducing the losses arising from localized "weak diodes" and shunts.

The Universities of Nevada and Oregon continued work on the chemical composition and energy band gap measurements of solar cells as well as measurements using defect spectroscopes (Heske, Cohen). They moved from having specialized cell structures fabricated for the research to applying their characterization techniques to actual solar cell structures with known performance.

Research at the University of Utah (Taylor, now at Colorado School of Mines) has been providing valuable insights into light-induced degradation mechanisms (the Staebler-Wronski effect) in a$\mathrm{Si}: \mathrm{H}$ alloys and nc-Si:H. And at the University of South Florida in Tampa, researchers are investigating doping the CdTe absorber film with $P$. They are also studying the effect of a new $\mathrm{TiO}_{2}$ buffer layer and a back contact of $\mathrm{TiSe}_{2}$ produced by sputtering.

Investigations at Colorado State University (CSU) have already resulted in $12 \%$ to $13 \%$ efficient thinfilm CdTe solar cells. This work has also made valuable contributions to device stability under long-term light exposure.

The CSU group (Sites) continued to provide valuable analyses of the performance of CIGS and CdTe solar cells, identifying pathways for further enhancing cell performance. Prof. Sites' graduate students now hold many prestigious and important R\&D positions with a variety of companies and organizations. CSU's thin-film PV technology has been transferred to AVA Solar of Fort Collins, Colorado.

In addition, encapsulation research continued at Pacific Northwest National Laboratory (PNNL) (Olsen). Researchers reported encouraging progress in finding low-cost transparent encapsulation schemes for CIGS cells that show significantly reduced power losses after dampheat testing.

Other than NREL's in-house group, PNNL's is the only group dealing with cell and module packaging and encapsulation issues. This is an important area, as many current industrial start-ups prepare to produce a flexible CIGS product on a foil substrate. Currently, no low-cost, flexible transparent packaging exists for CIS products that allows a long-term (20 years or more) power warranty for flexible CIGS modules.

\subsection{Tracking Metrics}

Each year, we track cell efficiencies, best prototype module efficiencies, and commercial module efficiencies for thin-film PV (see Tables 3 and 4). Updated information is posted on our Web site and can be found via the search page.

There are currently about 40 thin-film PV companies operating in the United States. These include 15 companies focusing on a-Si/thin $\mathrm{Si}$ technologies, 10 on CdTe, and 15 on CIGS. Another 4 U.S. CIGS PV companies should be announced in 2008. Worldwide, there are about 35 PV companies producing CIGS products.

DOE Thin Film PV Partnership subcontracts and funding amounts for FY 2007 are listed in Section 7.

\section{Planned FY 2008 Activities}

In FY 2008, although most university subcontracts are being phased out, the Thin Film PV Partnership will continue to address key issues supporting successful first-time manufacturing efforts and the explosive growth in manufacturing that is occurring for each thin-film technology. These will be especially important in FY 2008, which is expected to be a key year for growth in thin-film manufacturing. U.S. production increased from about $10 \mathrm{MW}$ in CY 2003 to about $160 \mathrm{MW}$ in CY 2007. Another substantial increase could occur in CY 2008 to approximately $270 \mathrm{MW}$. 
Table 3. Best Large-Area, Thin Film Modules

(standard conditions and aperture area)

\begin{tabular}{|c|c|c|c|c|c|}
\hline Company & Device & $\begin{array}{l}\text { Size } \\
\left(\mathrm{cm}^{2}\right)\end{array}$ & Efficiency & $\begin{array}{l}\text { Power } \\
\text { (W) }\end{array}$ & Date \\
\hline $\begin{array}{l}\text { Mitsubishi } \\
\text { Heavy* }\end{array}$ & Glass/a-Si & 15625 & 6.4\% (stabilized) & 100 & $7 / 05$ \\
\hline $\begin{array}{l}\text { Global Solar } \\
\text { Energy }\end{array}$ & CdS/CIGS/SS & 8709 & $10.2 \%$ & 88.9 & $5 / 05$ \\
\hline Wurth Solar & CdS/CIGS/glass & 6500 & $13 \%$ & 84.6 & $6 / 04$ \\
\hline United Solar & a-Si/a-SiGe/a-SiGe/SS & 9276 & 7.6\% (stabilized) & 70.8 & $9 / 97$ \\
\hline First Solar & Glass/CdS/CdTe & 6624 & $12.2 \%$ & 80.2 & $12 / 07$ \\
\hline $\begin{array}{l}\text { Shell Solar } \\
\text { GMBH }\end{array}$ & CIS-alloy/CdS/glass & 4938 & $13.1 \%$ & 64.8 & $6 / 04$ \\
\hline Sharp* & Glass/a-Si/nano-Si & 4770 & $11 \%$ (stabilized) & 52.5 & $7 / 05$ \\
\hline Antec Solar* & Glass/CdS/CdTe & 6633 & $7.3 \%$ & 52.3 & $6 / 04$ \\
\hline Kaneka & Glass/a-Si & 8100 & $6.3 \%$ (stabilized) & 51 & $7 / 04$ \\
\hline $\begin{array}{l}\text { Shell Solar } \\
\text { Industries }\end{array}$ & CdS/CIS-alloy & 3644 & $12.9 \%$ & 46.8 & $5 / 05$ \\
\hline Showa Shell* & $\mathrm{Zn}(\mathrm{O}, \mathrm{S}, \mathrm{OH})_{\times} / \mathrm{CIGS} / \mathrm{Glass}$ & 3459 & $\begin{array}{l}13.4 \%\left(41-\mathrm{ft}^{2} \text { modules }\right. \\
\text { laminated together) }\end{array}$ & 46.45 & $8 / 02$ \\
\hline EPV & Glass/a-Si/a-Si & 7432 & $5.7 \%$ (stabilized) & 42.3 & $10 / 02$ \\
\hline United Solar & a-Si triple/SS & 4519 & 7.9\% (stabilized) & 35.7 & $6 / 97$ \\
\hline
\end{tabular}

*Indicates data reported by company, but not, to our knowledge, independently measured.

Table 4. Commercial Thin-Film Modules

(total-area efficiencies; data compiled from Web sites)

\begin{tabular}{|c|l|c|c|c|}
\hline $\begin{array}{c}\text { Rated Module } \\
\text { Efficiency (\%) }\end{array}$ & \multicolumn{1}{|c|}{ Description } & $\begin{array}{c}\text { Rated } \\
\text { Output } \\
(\mathbf{W p})\end{array}$ & $\begin{array}{c}\text { Estimated Price } \\
\mathbf{( \$ / W p )}\end{array}$ & $\begin{array}{c}\text { Temperature } \\
\text { Coefficient* }^{*} \\
\left(\mathbf{\%} /{ }^{\circ} \mathbf{C}\right)\end{array}$ \\
\hline 11.0 & WürthSolar WS31050/80 (CIS) & 80 & Above \$3 & -0.36 \\
\hline 9.4 & First Solar FS65 (CdTe) & 67.5 & Below \$3 & -0.25 \\
\hline 6.9 & Antec-Solar ATF50 (CdTe) & 50 & Below \$3 & -0.18 \\
\hline 6.3 & $\begin{array}{l}\text { Kaneka GEA/GSA } \\
\text { (single-junction a-Si) }\end{array}$ & 60 & Below \$3 & -0.2 \\
\hline 6.4 & $\begin{array}{l}\text { Mitsubishi Heavy MA100 (single- } \\
\text { junction a-Si, VHF deposition) }\end{array}$ & 100 & Below \$3 & -0.2 \\
\hline 6.3 & $\begin{array}{l}\text { Uni-Solar US-64 (triple-junction } \\
\text { amorphous silicon) }\end{array}$ & 64 & \$3.10-\$3.40 & -0.21 \\
\hline 5.3 & $\begin{array}{l}\text { RWE Schott ASI-F32/12 } \\
\text { (same bandgap a-Si tandem) }\end{array}$ & 32.2 & Varies & -0.2 \\
\hline
\end{tabular}

*Temperature coefficients will vary slightly, depending on the local spectral content.

Data compiled by B. von Roedern, NREL, September 2006. Note: This list could now be out of date or incomplete; some manufacturers and/or some "best" products could be missing. Prices are estimates for large quantities. 


\section{FY 2007 Awards}

Harin S. Ullal received an NREL Directors Award as NREL's designated Point of Contact for the Solar America Initiative from 2007 to 2010.

\section{Major FY 2007 Presentations and Publications}

We have published several subcontract reports and presentations and have posted them on the Thin Film PV Partnership Web site. Other important publications include the following:

Harin S. Ullal; "Thin Film Solar Photovoltaic Technologies: Progress and Outlook," Solar Power 2007, Long Beach, CA, September (2007).

Harin S. Ullal, "Thin Film Solar Electric Technologies: Challenges and Outlook," $1^{\text {st }}$ Investors PV Conference, Munich, Germany; April (2007).

Harin S. Ullal, "Thin Film Solar Electric Technologies," Solar Power 2006, San Jose, CA, October (2006).
Harin S. Ullal and Bolko von Roedern, "Thin Film CIGS and CdTe PV Technologies: Commercialization, Critical Issues and Applications," $22^{\text {nd }}$ European Photovoltaic Solar Energy Conference, Milano, Italy, September (2007).

Bolko von Roedern, "High-Efficiency Si Solar Cell Processing Requirement: Why $0.5+0.5 \neq 1$ (i.e., >3)," 17th Workshop on Crystalline Silicon Solar Cells and Modules: Materials And Processes, Vail, Colorado, August (2007).

Bolko von Roedern, "Si Thin-Film Photovoltaics Program in the U.S.," International Workshop on Thin Film Silicon Solar Cells, Nara City, Japan, February (2007).

Bolko von Roedern, "Past Progress and Future Developments in Photovoltaic Module Manufacturing," California-Germany Solar Day Workshop, San Francisco, CA, March (2007).

Bolko von Roedern, "PV Research Activities in the US," International Symposium on Silicon to Light/Light to Silicon: Materials, Characterization and Applications, Halle, Germany, July (2007).

\section{University and Industry Partners}

The following organizations partnered in the project's research activities during FY 2007.

\begin{tabular}{|l|l|l|c|c|}
\hline \multicolumn{1}{|c|}{$\begin{array}{c}\text { Organization/ } \\
\text { Principal Investigator }\end{array}$} & \multicolumn{1}{|c|}{ Location/e-mail } & \multicolumn{1}{|c|}{$\begin{array}{c}\text { Description/Title of Research } \\
\text { Activity }\end{array}$} & $\begin{array}{c}\text { FY 2007 } \\
\mathbf{( \$ K )}\end{array}$ & $\begin{array}{c}\text { Cost } \\
\text { Share } \\
\mathbf{( \$ K )}\end{array}$ \\
\hline $\begin{array}{l}\text { Colorado School of Mines; } \\
\text { Jim Sites }\end{array}$ & $\begin{array}{l}\text { Ft. Collins, CO } \\
\text { sites@lamar.colostate.edu }\end{array}$ & $\begin{array}{l}\text { Characterization and analysis of } \\
\text { CIS and CdTe devices }\end{array}$ & 195 & 0 \\
\hline $\begin{array}{l}\text { Colorado State University; } \\
\text { W.S. Sampath }\end{array}$ & $\begin{array}{l}\text { Ft. Collins, CO } \\
\text { sampath@engr.colostate.edu }\end{array}$ & $\begin{array}{l}\text { Development of a robust in-line } \\
\text { manufacturing approach for } \\
\text { CdTe, and stability assurance }\end{array}$ & 400 & 0 \\
\hline $\begin{array}{l}\text { Energy Photovoltaics; } \\
\text { Alan Delahoy }\end{array}$ & $\begin{array}{l}\text { Lawrenceville, NJ } \\
\text { a.delahoy@epv.net }\end{array}$ & $\begin{array}{l}\text { Advanced CIGS photovoltaic } \\
\text { technology }\end{array}$ & 350 & 100 \\
\hline $\begin{array}{l}\text { First Solar, LLC; } \\
\text { Peter Meyers }\end{array}$ & $\begin{array}{l}\text { Perrysburg, OH } \\
\text { pmeyers@firstsolar.com }\end{array}$ & $\begin{array}{l}\text { Expanding the limits of CdTe PV } \\
\text { Performance }\end{array}$ & 412 & 20 \\
\hline $\begin{array}{l}\text { First Solar, LLC; } \\
\text { Roger Green }\end{array}$ & $\begin{array}{l}\text { Perrysburg, OH } \\
\text { rgreen@firstsolar.com }\end{array}$ & $\begin{array}{l}\text { Research leading to high- } \\
\text { throughput processing of thin-film } \\
\text { CdTe PV technology }\end{array}$ & 1000 & 1050 \\
\hline $\begin{array}{l}\text { Florida Solar Energy } \\
\text { Center; } \\
\text { Neelkanth Dhere }\end{array}$ & $\begin{array}{l}\text { Cocoa, FL } \\
\text { dhere@fsec.ucf.edu }\end{array}$ & $\begin{array}{l}\text { CIGS solar cells by selenization } \\
\text { and sulfurization }\end{array}$ & 209 & 10 \\
\hline
\end{tabular}




\begin{tabular}{|c|c|c|c|c|}
\hline Global Solar Energy & $\begin{array}{l}\text { Tucson, AZ } \\
\text { swiedman@globalsolar.com }\end{array}$ & $\begin{array}{l}\text { Cost and reliability } \\
\text { Improvements for CIGS based } \\
\text { on flexible substrates }\end{array}$ & 690 & 732 \\
\hline $\begin{array}{l}\text { NanoSolar; } \\
\text { Chris Eberspacher }\end{array}$ & $\begin{array}{l}\text { Palo Alto, CA } \\
\text { chris@nanosolar.com }\end{array}$ & $\begin{array}{l}\text { High-productivity annealing for } \\
\text { thin film CIS PV }\end{array}$ & 200 & 10 \\
\hline $\begin{array}{l}\text { Pacific Northwest National } \\
\text { Laboratory; } \\
\text { Larry Olsen }\end{array}$ & $\begin{array}{l}\text { Richland, WA } \\
\text { Larry.Olsen@pnl.gov }\end{array}$ & $\begin{array}{l}\text { Barrier coatings for thin-film cell } \\
\text { protection }\end{array}$ & 163 & 0 \\
\hline $\begin{array}{l}\text { United Solar Ovonic; } \\
\text { Subhendu Guha }\end{array}$ & $\begin{array}{l}\text { Auburn Hills, MI } \\
\text { sguha@uni-solar.com }\end{array}$ & $\begin{array}{l}\text { High-efficiency amorphous and } \\
\text { nanocrystalline-based solar cells } \\
\text { and modules }\end{array}$ & 997 & 997 \\
\hline $\begin{array}{l}\text { University of Nevada; } \\
\text { Clemens Heske }\end{array}$ & $\begin{array}{l}\text { Las Vegas, NV } \\
\text { heske@unlv.nevada.edu }\end{array}$ & $\begin{array}{l}\text { Characterization of the electronic } \\
\text { and chemical structure at the } \\
\text { thin-film solar cell interfaces }\end{array}$ & 181 & 0 \\
\hline $\begin{array}{l}\text { University of Oregon; } \\
\text { Dave Cohen }\end{array}$ & $\begin{array}{l}\text { Eugene, OR } \\
\text { dcohen@oregon.uoregon.edu }\end{array}$ & $\begin{array}{l}\text { Innovative characterization of } \\
\text { amorphous and thin-film silicon } \\
\text { for improved module } \\
\text { performance }\end{array}$ & 200 & 0 \\
\hline $\begin{array}{l}\text { University of South } \\
\text { Florida; } \\
\text { Chris Ferekides }\end{array}$ & $\begin{array}{l}\text { Tampa, FL } \\
\text { ferekide@eng.usf.edu }\end{array}$ & $\begin{array}{l}\text { High-efficiency CdTe cells by } \\
\text { CSS }\end{array}$ & 200 & 14 \\
\hline $\begin{array}{l}\text { University of Toledo; } \\
\text { Al Compaan }\end{array}$ & $\begin{array}{l}\text { Toledo, OH } \\
\text { ADC@physics.utoledo.edu }\end{array}$ & $\begin{array}{l}\text { Fabrication and physics of CdTe } \\
\text { devices by sputtering }\end{array}$ & 328 & 100 \\
\hline $\begin{array}{l}\text { University of Toledo; } \\
\text { Xunming Deng }\end{array}$ & $\begin{array}{l}\text { Toledo, OH } \\
\text { dengx@physics.utoledo.edu }\end{array}$ & $\begin{array}{l}\text { Fabrication and characterization } \\
\text { of advanced triple-junction } \\
\text { amorphous-silicon-based solar } \\
\text { cells }\end{array}$ & 355 & 100 \\
\hline $\begin{array}{l}\text { University of Utah; } \\
\text { Craig Taylor }\end{array}$ & $\begin{array}{l}\text { Salt Lake City, UT } \\
\text { craig@physics.utah.edu }\end{array}$ & $\begin{array}{l}\text { Innovative characterization of } \\
\text { amorphous and thin-film silicon } \\
\text { for improved module } \\
\text { performance }\end{array}$ & 170 & 0 \\
\hline
\end{tabular}




\title{
Systems Analysis PV Grid Integration
}

\section{Performing Organizations: $\quad$ National Renewable Energy Laboratory (NREL)} Sandia National Laboratories (SNL)

Key Technical Contacts:

\author{
Ben Kroposki (NREL, Primary Contact), 303-384-2979, \\ benjamin_kroposki@nrel.gov \\ Robert Margolis (NREL), 202-488-2222, robert_margolis@nrel.gov \\ Juan Torres (SNL, Primary Contact), 505-844-0709, jjtorre@sandia.gov \\ Charles Hanley (SNL), 505-844-4435, cjhanle@sandia.gov
}

DOE HQ Technology Manager: Dan Ton, 202-586-4618, dan.ton@ee.doe.gov

FY 2007 Budgets: $\quad$ \$1,950K (NREL), \$700K (SNL)

\section{Objectives}

- Conduct series of 14 studies on impacts, plans, and strategies to address high penetration of photovoltaic (PV) systems on electric infrastructure.

- Complete a multi-year research plan for DOE related to Renewable Systems Interconnection (RSI) initiative.

- Develop position paper for Solar Energy Grid Integrated Systems (SEGIS) initiative as part of RSI.

- Assist in developing strategy for RSI initiative.

\section{Accomplishments}

- Completed drafts of 14 reports, including analysis and modeling. To read the executive summary, "Renewable Systems Interconnection: Executive Summary," visit www.eere.energy.gov/solar/solar_america/rsi.html.

- Presented preliminary findings to DOE.

- Completed draft RSI multi-year research plan, which is used for internal DOE communications.

- Completed SEGIS position paper as a precursor to fiscal year (FY) 2008 solicitation.

\section{Future Directions}

- Publish and release of finalized reports, including the executive summary.

- Continue to scope out a broad cross-cutting initiative within EERE, on behalf of DOE/Solar. This initiative would cover several areas effecting renewable systems interconnection including: advanced technology development, advanced distribution systems integration, system-level test and demonstrations, distributed renewable energy analysis, solar resource assessment, and codes, standards, and regulatory implementation.

- Collect field data to verify early findings and steer future technology R\&D.

- Develop field implementation sites for new concepts and hardware, including Hawaii, Mesa del Sol, Solar Technology Acceleration Center (SolarTAC), etc.

- Develop an advanced storage initiative as part of RSI.

- Initiate and complete SEGIS initiative to develop new hardware to facilitate high penetration of PV into electric grid.

- Develop lab-based test and development sites to provide leadership and early development for industry efforts.

\section{Introduction}

This effort was started late in the fiscal year, as a means of scoping out what may become a Solar
Energy Technologies Program (SETP) initiative in the near term. The objective was to develop a series of reports based on technical assessments of the impacts and needs related to high

Photovoltaic R\&D Advanced Materials and Devices Systems Analysis 
penetration of PV systems on today's electric infrastructure. These studies included analyses of utility planning tools and methods, PV system and distribution system designs, utility business models, and studies of impact and penetration. A broad team was formulated to complete this effort in a short time period, with important support coming from partners such as GE, EPRI, Navigant, and BEW (see section 6).

\section{Technical Approach}

\section{RSI Study}

The approach employed was to quickly build a team of appropriate technical experts, designate the areas of focus for the contributors, and hold regular discussions to ensure that the complete package would be well integrated with appropriate cross references. Originally, five areas were envisioned, but more needs were identified, so the effort grew to 14 reports.

\section{RSI Multi-Year Research Plan}

SNL, NREL, and DOE collaborated on utilizing the gaps that were identified in the reports to develop a 5-year plan to provide research and development (R\&D) leadership, in partnership with the U.S. industry. This plan defines near- and longer-term activities to assist in the infrastructure transition needed for minimal interruption as PV penetration continues to increase.

\section{SEGIS Position Paper}

This paper focuses specifically on the development of new inverters, controllers, and energy management systems for the solicitation that is slated to start in FY 2008. DOE worked with SNL to develop a document that establishes the objectives and scope of the solicitation.

\section{Results and Accomplishments}

By the end of FY 2007, draft reports were completed in all areas. These reports reflect the results of intensive efforts at modeling, analysis, system design studies, and research into current and future operating methodologies for utilities and other industry players. The $14 \mathrm{RSI}$ reports cover the following areas:

- Advanced Grid Planning and Operations.

- Utility Models, Analysis and Simulation Tools.

- Advanced PV System Designs and Technology Requirements.

- Development of Analysis Methodology for Evaluating the Impact of High Penetration PV
- Distribution System Performance Analysis for High Penetration PV.

- Enhanced Reliability of PV Systems with Energy Storage and Controls.

- Transmission System Performance Analysis for High Penetration PV.

- Cyber Security Analysis.

- Solar Resource Assessment: Characterization and Forecasting to Support High PV Penetration.

- Test and Demonstration Program Definition to Support High PV Penetration.

- Value Analysis.

- PV Business Models.

- Production Cost Modeling for High Levels of PV Penetration.

- PV Market Penetration Scenarios.

All of these efforts have been successful in facilitating internal DOE communications and allowing the development of well-aligned, followup activities in the context of a growing initiative. These reports have also been helpful in obtaining industry input into this process.

\section{Planned FY 2008 Activities}

Major activities are focused on completing the final versions of the RSI reports and setting up a project to gather and analyze field data to provide validation of the findings and further our understanding of the impacts of high PV penetration on the electric grid. The Hawaii Clean Energy Initiative (HCEI) will also provide a nearterm opportunity to begin addressing RSI issues in partnership with the Hawaii State Energy Office and utilities on the islands of Kauai and Lanai. Additionally, as we prepare for a larger initiative in this area, we're working to define R\&D needs with controllers, energy management systems, and integrated storage.

We've identified the following tasks:

- Collect field data at model high-penetration field sites such as communities with the Sacramento Municipal Utility District (SMUD), Nellis Air Force Base, and Xcel Energy in Alamosa, CO.

- Complete a position paper on the role of integrated storage in high penetration PV scenarios, including associated R\&D needs.

- Develop action plans and collect field data from additional partnerships such as the State of Hawaii, Mesa del Sol in Albuquerque, SolarTAC, etc. 
- Define additional laboratory development, testing, and evaluation needs to support industry and DOE-led developments.

- Initiate the SEGIS solicitation.

\section{Major FY 2007 Publications}

D. Ton, B. Kroposki, and R. Margolis, G. Kuswa, J. Torres, W. Bower, C. Hanley, J. Boyes, "DRAFT
Renewable Systems Interconnection Distributed PV Activities; Multi-Year Research Plan (MYRP) FY2008-FY2013," (2007).

D. Ton, W. Bower, C. Cameron, "DRAFT Solar Energy Grid Integration Systems (SEGIS); Concept Paper," (2007).

\section{University and Industry Partners}

The following organizations partnered in the project's research activities during FY 2007.

\begin{tabular}{|l|l|l|c|c|}
\hline $\begin{array}{c}\text { Organization/ } \\
\text { Principal Investigator }\end{array}$ & \multicolumn{1}{|c|}{ Location/e-mail } & \multicolumn{1}{|c|}{$\begin{array}{c}\text { Descrion/Title of Research } \\
\text { Activity }\end{array}$} & $\begin{array}{c}\text { FY 2007 } \\
\text { (\$K) }\end{array}$ & $\begin{array}{c}\text { Cost Share } \\
\text { (\$K) }\end{array}$ \\
\hline $\begin{array}{l}\text { Electric Power } \\
\text { Research Institute/ } \\
\text { Tom Key }\end{array}$ & Palo Alto, CA & $\begin{array}{l}\text { Renewable Systems } \\
\text { Interconnection - High Penetration } \\
\text { Distributed Photovoltaics Studies - } \\
\text { Distribution Designs and Utility } \\
\text { Models }\end{array}$ & 253 & - \\
\hline $\begin{array}{l}\text { General Electric/ } \\
\text { Jovan Bebic }\end{array}$ & Niskayuna, NY & $\begin{array}{l}\text { Renewable Systems } \\
\text { Interconnection - High Penetration } \\
\text { Distributed Photovoltaics Studies }\end{array}$ & 406 & - \\
\hline $\begin{array}{l}\text { BEW Engineering/ } \\
\text { Chuck Whitaker }\end{array}$ & San Ramon, CA & $\begin{array}{l}\text { Renewable Systems } \\
\text { Interconnection - PV Technology } \\
\text { and Field Testing }\end{array}$ & 163 & - \\
\hline $\begin{array}{l}\text { Navigant Consulting/ } \\
\text { Lisa Francis }\end{array}$ & San Francisco, CA & $\begin{array}{l}\text { Renewable Systems } \\
\text { Interconnection - High Penetration } \\
\text { Distributed Photovoltaics Studies - } \\
\text { Business Cases, Value Analysis, } \\
\text { Market Penetration }\end{array}$ & 540 & - \\
\hline $\begin{array}{l}\text { Sunpower/ } \\
\text { Gary Wayne }\end{array}$ & San Jose, CA & $\begin{array}{l}\text { Feasibility Study of PV Integrated } \\
\text { with V2G }\end{array}$ & 50 & - \\
\hline $\begin{array}{l}\text { Global Energy } \\
\text { Decisions/ }\end{array}$ & Boulder, CO & $\begin{array}{l}\text { Renewable Systems } \\
\text { Interconnection -Market } \\
\text { Penetration for PV }\end{array}$ & 50 & - \\
\hline
\end{tabular}




\title{
Systems Analysis Market, Value, and Policy Analysis
}

\author{
Performing Organizations: $\quad$ National Renewable Energy Laboratory (NREL) \\ Lawrence Berkeley National Laboratory (LBNL) \\ Key Technical Contacts: $\quad$ Robert Margolis (NREL, Primary Contact), 202-488-2222, \\ robert_margolis@nrel.gov \\ Ryan Wiser (LBNL), 510-486-5474, RHWiser@Ibl.gov
}

DOE HQ Technology Manager: Dan Ton, 202-586-4618, dan.ton@ee.doe.gov

FY 2007 Budgets: $\quad$ \$510K (NREL), \$100K (LBNL)

\section{Objectives}

- Develop long-term market penetration projections for photovoltaic (PV) technologies.

- Develop the Solar Deployment Systems (SolarDS) model-a PV market-penetration model that will serve as an alternative to the National Energy Modeling System (NEMS) and be compatible with the broader model-development effort within the Solar Energy Technologies Program.

- Evaluate policies and other factors that impact the value of solar energy technologies in a variety of markets.

\section{Accomplishments}

- Continued to develop the SolarDS model and a number of other tools, such as PVFlex, to examine the impacts of high levels of PV penetration on the U.S. electricity generation system.

- Enhanced the Web-based distributed PV cost-benefits clearinghouse.

- Carried out a wide range of policy analysis in support of the Solar Energy Technologies Program, in particular, to help provide a context for the planning and execution of research and development (R\&D) under the Solar America Initiative (SAI).

\section{Future Directions}

- Publish an annual report on solar market, cost, and performance trends.

- $\quad$ Provide analytical and technical support to the PV Industry Roadmap process.

- Continue to maintain and enhance the PV Value Clearinghouse.

- Support the annual Government Performance and Results Act (GPRA) benefits and Program Decision Support analysis efforts.

- Produce a series of topical reports that anticipate and respond to the emerging critical needs of the solar industry and the Solar Energy Technologies Program.

\section{Introduction}

The primary objective of the market, value, and policy analysis activity is to provide a broad range of analytical support to the U.S. Department of Energy's (DOE) Solar Energy Technologies Program (SETP). The types of analysis carried out under this project include the following:

Market analysis: This includes developing a PV market penetration model, the Solar Deployment Systems, or SolarDS, model. The model is being designed to gain insight into the factors influencing the market penetration of PV technology into U.S. markets.

Value/benefits analysis: This includes providing inputs to, support for, and review of the annual GPRA benefits analysis and program decision support analysis efforts. It also includes developing methods and tools for improving the quantification of the benefits and cost of solar technologies.

Policy analysis: This includes defining and carrying out analysis that meets the needs of the Solar Energy Technologies Program in a timely 
fashion, for example, related to issues such as the reliability, security, and time-of-use value of PV, as well as the potential role of solar in the energy economy in the long term.

The market, value, and policy analysis activity provides an array of support to the SETP that integrates the program's modeling and benchmarking activities into an analysis of a technology advancement's impact on market penetration. It also quantifies the potential benefits of increased solar energy use.

\section{Technical Approach}

The market, value, and policy analysis activity relies on two main technical approaches.

The first approach is to use and improve existing models and to develop new tools that can be employed to develop long-term market-penetration projections for solar technologies. This effort involves examining both the system and policy drivers of solar technologies in various markets in both the short and long term, as well as improving the analytical basis for projecting the SETP's economic and environmental benefits. Here, the emphasis has been on models and modeling, for example, using existing models-such as the Energy Information Administration's NEMS, MARKAL, and others-to carry out analyses. These analyses examine the structure of various models and provide feedback on how to improve the representation of solar technologies in existing models to modelers. They also help to develop new models, such as SolarDS and PVFlex, that will help meet the needs of the SETP and solar community more broadly.

The second approach is to employ a range of policy analysis tools and techniques to evaluate policies and other factors that impact the value of PV technologies in a variety of markets. These tools and techniques include using existing models, spreadsheets, and other tools (such as surveys and gathering and synthesizing information from a wide range of sources). Here, the emphasis is on using analytical tools to quantify how changing policies, rate structures, system designs, and other factors have or will impact the value of solar technologies to consumers, utilities, governments, and other players.

\section{Results and Accomplishments}

The market, policy, and value analysis activities resulted in a wide range of accomplishments during FY 2007. Some of the accomplishments include the following:

- Writing an internal DOE white paper and presentation material on the impact of extending the solar investment tax credit

- Writing an internal DOE white paper on the potential impact of establishing a solar manufacturing tax credit

- Providing numerous background slides and material for presentations given by the SETP Program Manager and staff on the program's activities, market trends, and future directions (such as internal DOE briefings, hill staff briefings, investor briefings, and conference presentations)

- Presenting analysis activities results at a number of major solar industry conferences and meetings (such as Solar 2007 and Solar Power 2007)

- Providing support to the California Solar Initiative's effort to design and launch its 10year, $\$ 50$ million R\&D program

- Completing a detailed analysis of the potential economic benefits of meeting the SAI targets.

Many of these activities resulted in conference papers, technical reports, or journal publications, as listed in Section 5.

\section{Planned FY 2008 Activities}

Over the next 5 years, as solar markets continue to grow at a record pace and solar technologies continue to evolve rapidly, the need for detailed, timely analysis will be critical for helping to guide policy decisions within the SETP. Thus, a number of ongoing analytical activities will be supported under this task. These ongoing activities include publishing an annual report on solar market, cost, and performance trends, working with industry to produce a semi-annual PV Industry Roadmap, maintaining and enhancing the PV Value Clearinghouse, producing and improving the annual GPRA benefits and Program Decision Support analysis, and producing a series of topical reports that anticipate and respond to the emerging critical needs of both the solar industry and the SETP. 


\section{Major FY 2007 Publications}

P. Denholm and R. M. Margolis, "Evaluating the Limits of Solar Photovoltaics (PV) in Electric Power Systems Utilizing Energy Storage and Other Enabling Technologies," Energy Policy, Vol. 35, pp. 4424-4433 (2007).

P. Denholm and R. M. Margolis, "Evaluating the Limits of Solar Photovoltaics (PV) in Traditional Electric Power Systems," Energy Policy, Vol. 35, pp. 2852-2861 (2007).

P. Denholm, R. M. Margolis, and K. Zweibel, "Tackling Climate Change in the U.S.: Potential Carbon Emissions Reductions from Solar Photovoltaics by 2030," Chapter in Tackling Climate Change in the U.S.: Potential Carbon Emissions Reductions from Energy Efficiency and Renewable Energy by 2030, Boulder, CO: American Solar Energy Society (2007).

S. Grover, Energy, Economic, and Environmental Benefits of the Solar America Initiative, Report No. NREL/SR-640-41998, Golden CO: National Renewable Energy Laboratory, August (2007).

T. E. Hoff, R. Perez, and R. M. Margolis, "Maximizing the Value of Customer-Sited PV
Systems Using Storage and Controls," Solar Energy, Vol. 81, pp. 940-945 (2007).

J. I. Levene, M. K. Mann, R. M. Margolis, and A. Milbrandt, "Analysis of Hydrogen Production from Renewable Electricity Sources," Solar Energy, Vol. 81, pp. 773-780 (2007).

R. Wiser, A. Mills, G. Barbose, and W. Golove, The Impact of Retail Rate Structures on the Economics of Commercial Photovoltaic Systems in California, Report No. LBNL-63019. Berkeley, CA: Lawrence Berkeley National Laboratory, July (2007).

R. Wiser, M. Bolinger, P. Clappers, and R. Margolis, "Analyzing Historical Cost Trends in California's Market for Customer-Sited Photovoltaics," Progress in Photovoltaics: Research and Applications, Vol. 15, pp. 69-85 (2006).

R. Wiser, M. Bolinger, P. Clappers, and R. Margolis, "PV Cost Trends: Letting the Sun Shine on Solar Costs in California," REFocus. September/October, pp. 26-31 (2006).

\section{University and Industry Partners}

The following organizations partnered in the project's research activities during FY 2007 (no cost share).

\begin{tabular}{|l|l|l|c|}
\hline \multicolumn{1}{|c|}{$\begin{array}{c}\text { Organization/ } \\
\text { Principal Investigator }\end{array}$} & \multicolumn{1}{|c|}{ Location/e-mail } & \multicolumn{1}{|c|}{$\begin{array}{c}\text { Descriotion/Title of Research } \\
\text { Activity }\end{array}$} & $\begin{array}{c}\text { FY 2007 } \\
\text { (\$K) }\end{array}$ \\
\hline $\begin{array}{l}\text { ECONorthwest } \\
\text { Steve Grover }\end{array}$ & $\begin{array}{l}\text { Portland, OR } \\
\text { grover@portland.econw.com }\end{array}$ & $\begin{array}{l}\text { Energy, Economic and } \\
\text { Environmental Benefits of the Solar } \\
\text { America Initiative }\end{array}$ & 100 \\
\hline
\end{tabular}




\title{
Systems Analysis Modeling
}

\author{
Performing Organizations: $\quad$ National Renewable Energy Laboratory (NREL) \\ Sandia National Laboratories (SNL) \\ Key Technical Contacts: $\quad$ Nate Blair (NREL, Primary Contact), 303-384-7426, nate_blair@nrel.gov \\ Mark Mehos (NREL), 303-384-7458, mark_mehos@nrel.gov \\ Chris Cameron (SNL), 505-844-8161, cpcamer@sandia.gov \\ Craig Christensen (NREL), 303-384-7510, craig_christensen@nrel.gov
}

DOE HQ Technology Manager: Dan Ton, 202-586-4618, dan.ton@ee.doe.gov

FY 2007 Budgets: $\quad$ \$550K (NREL), \$850K (SNL)

\section{Objectives}

- The system modeling efforts of this project seek to enhance the U.S. Department of Energy

(DOE) Solar Energy Technologies Program (SETP) Solar Advisor Model (SAM) to develop capabilities to calculate energy output, energy costs, and cash flows using up-to-date component and system data while enabling parametric analysis.

- These efforts will also validate SAM and, potentially, other solar models for a variety of technologies, applications, and locations.

- These tools can be used to by industry and government to guide research and development (R\&D) prioritization and to provide credible energy production and cost data using a common platform for project development, evaluation, and due diligence.

- These efforts will also provide additional tools to industry to meet their planning, R\&D, siting, and other modeling needs to help accelerate market penetration.

- These efforts will support progress evaluation at stage-gate assessments for the Solar America Initiative (SAI).

\section{Accomplishments}

- Completed an industry survey of modeling needs.

- Included concentrating solar power (CSP) parabolic trough modeling within SAM.

- Included detailed incentives within SAM for all technologies.

- Enhanced graphical outputs, parametrics, and sensitivity analysis.

- Improved speed of calculations significantly.

- Completed a dish Stirling performance model by a subcontractor.

- Developed a photovoltaic (PV)-system inverter model for use within SAM.

- Developed tools to permit validation of performance models versus and measured weather data and system output.

- Refined cost and performance estimates for PV reference systems.

- Conducted analysis in support of SAI and other program initiatives, such as the Solar Energy Grid Integration System.

\section{Future Directions}

- Develop a SAM version with:

- A major update of the user manual including documentation;

Improved PV-performance algorithms;

- Capability of using the latest California Energy Commission (CEC) and Sandia module

- and inverter databases;

- Detailed operation and maintenance (O\&M) inputs including annual cost, cost/MW, and

- cost/MWh options. 
- Release SAM version with:

- Dish Stirling CSP models incorporated;

- Enhanced graphical user interfaces (GUI) and greater graphical output capability;

- Time-of-use rates.

- Develop a 10-km-resolution combined solar radiation and meteorological data set for the PVWatts Web-based calculator.

- Complete validation of PV-performance models.

- Provide modeling support to SETP programs, including SAI stage-gate evaluations.

\section{Introduction}

The objective of this project is to provide a focal point for system-driven-approach (SDA) activities and to provide a common framework for evaluation of all solar technologies. This evaluation happens within the cost, financing, and performance modeling of PV systems, CSP, and other solar technologies.

\section{Technical Approach}

The system modeling task consists of systems performance and cost modeling and validation projects. The primary function of the Solar Advisor Model (SAM) is to allow users to investigate the impact of variations in physical and financial parameters to better understand their impact on key figures of merit for solar power systems. Figures of merit related to the cost and performance of these solar power systems include, but are not limited to, system output, peak and annual system efficiency, levelized cost of energy, and system capital and O\&M costs. SAM is intended for use by DOE, laboratory management, and research staff and is a critical element in the implementation of the systemsdriven approach to SETP program planning. The model is and will continue to be used by members of the solar industry to inform internal R\&D direction and to estimate systems cost and performance

\section{Results and Accomplishments}

For SAM, particular emphasis was placed upfront on the design of a user interface that could meet the needs of a diverse set of users. User profiles were developed to provide a general description of DOE, laboratory, and industry users and their motivation for using the modeling tool.

The working model for SAM consists of:
- A user-interface module for selecting and providing input data on the system configuration and operating environment.

- A system-performance module that simulates the hour-by-hour output of the selected system for the lifetime of a project.

- A cost-input module for providing simple or detailed cost inputs for system components.

- A financial-analysis module for calculating system economics.

The modules work in concert to generate the physical and financial figures of merit relevant to the particular user.

FY 2007 development activities for SAM primarily focused on several areas. One specific effort was to add a parabolic trough model to SAM for use by DOE solar program planners for the CSP program and by the CSP industry. The model within SAM was originally developed at NREL by Hank Price within Excel, called Excelergy. This undocumented model was not easily transferrable to industry, nor to DOE analysts. The implementation of the same algorithms within the SAM environment makes them more accessible and continuously improving documentation makes it easier to get new users up to speed.

A second area of focus was improving financial analysis methods for the residential, commercial and utility markets. Extensive efforts have been put into making the utility financing portion of the model accurate and appropriate from the perspective of the project developer. Finally, extensive efforts have been incorporated into adding the ability to factor in incentives such as infrastructure tax credits, production tax credits, and buy downs into the model for all markets. This is critically important as subsidies are so prevalent for financing solar projects.

For $\mathrm{PV}$, research efforts focused on developing the data and tools to validate the performance models. An inverter model was developed and will 
be incorporated into SAM in FY 2008. The model was also applied in support of the SETP, including the Solar America Initiative.

In carrying out these projects, we use resources at NREL and Sandia as well as the subcontracts described in Section 6.

\section{Planned FY 2008 Activities}

- Release a SAM version with additional weather-file type support.

- Incorporate a user forum and user interactivity into SAM.

- Validate SAM versus measured system data and document findings in a research paper

- Release a SAM version with:

- A major update of the user manual including documentation;

- Improved PV performance algorithms;

- capability of using latest CEC and SNL module and inverter databases;

- Detailed O\&M inputs including annual cost, cost/MW, and cost/MWh options.

- Hold a first modeling workshop concurrently with the American Solar Energy Society meeting.
- Publish a subcontractor report on financial model validation.

- Release a SAM version with:

- Dish Stirling CSP models;

- Enhanced GUI and greater graphical output capability;

- Time-of-use rates.

- Complete PV model validation.

- Provide modeling support to the SETP program.

\section{Major FY 2007 Publications}

C. Cameron and C. Cornelius, "A Systems-Driven Approach to Solar Energy R\&D," Paper presented at the IEEE International Conference on System of Systems Engineering, San Antonio, TX, April 1618, 2007, (2007).

S. Gonzalez, W. Boyson, G. Galbraith, and D. King, "Performance Model for Grid-connected Photovoltaic Inverters, Albuquerque, NM: Sandia National Laboratories, SAND2007-5036, (September 2007).

\section{University and Industry Partners}

The following organizations partnered in the project's research activities during FY 2007.

\begin{tabular}{|l|l|l|c|c|}
\hline $\begin{array}{c}\text { Organization/ } \\
\text { Principal Investigator }\end{array}$ & \multicolumn{1}{|c|}{ Location/e-mail } & \multicolumn{1}{|c|}{$\begin{array}{c}\text { Description/Title of Research } \\
\text { Activity }\end{array}$} & $\begin{array}{c}\text { FY 2007 } \\
\mathbf{( \$ K )}\end{array}$ & $\begin{array}{c}\text { Cost Share } \\
\text { (\$K) }\end{array}$ \\
\hline $\begin{array}{l}\text { Janzou Consulting } \\
\text { Steve Janzou }\end{array}$ & $\begin{array}{l}\text { Evergreen, CO } \\
\text { Steve_janzou@nrel.gov }\end{array}$ & $\begin{array}{l}\text { Program the front-end and basic } \\
\text { engine of the Solar Advisor Model }\end{array}$ & 105 & 0 \\
\hline $\begin{array}{l}\text { University of Wisconsin- } \\
\text { Madison } \\
\text { Prof. Sanford Klein }\end{array}$ & $\begin{array}{l}\text { Madison, WI } \\
\text { Klein@engr.wisc.edu }\end{array}$ & $\begin{array}{l}\text { Development of a dish-Stirling } \\
\text { model for use in SAM }\end{array}$ & 82 & 0 \\
\hline $\begin{array}{l}\text { Paul Gilman } \\
\text { Paul Gilman }\end{array}$ & $\begin{array}{l}\text { Chicago, IL } \\
\text { PaulGilman@earthlink.net }\end{array}$ & $\begin{array}{l}\text { Provides user support and } \\
\text { technical writing support }\end{array}$ & 35 & 0 \\
\hline
\end{tabular}




\title{
Systems Testing and Evaluation PV Inverter and Balance-of-System Testing
}

\author{
Performing Organizations: Sandia National Laboratories (SNL) \\ Northern Plains Power \\ Key Technical Contacts: $\quad$ Sigifredo Gonzalez (SNL, Primary Contact), 505-845-8942, \\ sgonza@sandia.gov \\ Ward Bower (SNL), 505-844-5206, wibower@sandia.gov \\ Michael Ropp (Northern Plains Power), 605-688-4664, \\ Michael.Ropp@SDSTATE.EDU
}

DOE HQ Technology Manager: Dan Ton, 202-586-4618, dan.ton@ee.doe.gov

FY 2007 Budgets: $\quad$ \$850K (SNL), \$50K (Northern Plains Power)

\section{Objectives}

- Determine effects of long-term inverter operation after 2 years of outdoor operation. Evaluating sample inverters after 2 years both provides reliability information for a small grid-connected system and provides a platform to validate system modeling activities.

- Assist in the development of new photovoltaic (PV) inverters and balance-of-system (BOS) hardware that meet today's utility interconnect standards, performance requirements, and safety requirements.

- Enable PV inverter manufacturers to meet standard and code requirements through laboratory evaluations.

- Develop a test platform and protocols to evaluate Solar America Initiative (SAI) stage-gate deliverables and Solar Energy Grid Information Systems (SEGIS) project stage-gate deliverables.

\section{Accomplishments}

- Conducted the laboratory recharacterization evaluations on the first set of inverters undergoing long-term evaluations. Inverter efficiencies are only slightly lower but the most significant finding was that the maximum continuous power rating was lower on the 4 units evaluated.

- Evaluated Xantrex's High Reliability Inverter Initiative deliverable (XW 6000). Issues that were discovered during laboratory testing led to several software revisions. The system continues to be evaluated.

- Determined inverter performance, power quality, and utility compatibility capabilities for two commercial inverters and three residential PV inverters. Feedback was provided to the respective manufacturers and most of the beta units have implemented either software or hardware modifications or rectifications.

- Implemented and conducted preliminary validation evaluations on a PV system performance model. Utilizing a complete PV system provided by USDA Rural Utilities Service (RUS) preliminary validation evaluations results were quantified.

- Conducted laboratory evaluations per American National Standards Institute's (ANSI's) ANSI C62.45 requirements on two surge-suppression circuits. Evaluated a residential inverter's integrated surge suppression circuitry for conformance to Underwriters Laboratories' (UL's) UL 1741-2005 standard and a retrofit circuit board for a three-phase commercial PV inverter.

- Sandia collaborated with Dr. Michael Ropp of South Dakota State University (SDSU) in the development of a MATLAB/Simulink model of a single-phase grid-connected photovoltaic system.

\section{Future Directions}

- Assure that DOE maintains a state-of-the-art developmental test bed for all industry, university, and laboratory developments under its new Renewable Systems Interconnection Initiative. 
- Complete the first round of the long-term inverter operation evaluations and implement any significant inverter performance issues discovered in the long-term inverter operation evaluations into the PV system performance model.

- Determine development protocols and tools needed to validate SAI stage-gate deliverables that target individual PV system components and the complete PV system. Initiate the implementation and validation of such protocols.

- Provide PV inverter manufacturers with a facility to enhance performance capabilities and communication.

- Continue to collaborate with SDSU to validate the MATLAB/Simulink inverter model and to validate high market-penetration issues that may exist between different topologies.

\section{Introduction}

A primary objective of Sandia's inverter and BOS testing and evaluation program is to provide technical support to SAl's Technology Pathway Partnership (TPP) participants and industry in developing commercial inverters/controllers that consistently meet the performance, reliability, and cost goals of the Solar America Initiative. The test protocols used will include a revised Distributed Energy Technologies Laboratory (DETL) grid-tied inverter test plan, the expanded Sandia/California Energy Commission (CEC) inverter test protocol, and a new system testing protocols developed as part of the Systems Test and Evaluation Project. A complementary objective is to assist the development and implementation of advanced concepts arising from inverter and controller and BOS research and development (R\&D) projects.

\section{Technical Approach}

\section{Inverter Performance Modeling}

A primary objective of this effort was to develop an inverter performance model applicable to all commercial inverters used in photovoltaic power systems. The model performance parameters are progressive in the sense that the accuracy of the model can be improved as more detailed test data become available. The initial inverter performance model parameters are derived from manufacturers' specifications. Utilizing field measurements during system operation provides additional parameters and accuracy. Detailed performance measurements conducted by recognized testing laboratories provide further refinement of parameters used in the model. The inverter performance model is an empirical model that simply, but accurately, replicates the power delivery characteristics of the DC-to-AC inversion process. The inverters undergoing long-term operational testing provide additional operational characteristics of the inverter and can be implemented into the inverter performance model to better represent PV systems after long term operation. Three sites have been chosen to evaluate up to four inverters at each site. These sites are the Florida Solar Energy Center (FSEC), the Southwest Technology Development Institute (SWTDI), and Sandia's DETL. Presently the longterm inverter test recharacterization evaluation has involved two inverters from the DETL. These inverters are popular residential utilityinterconnected $\mathrm{PV}$ inverters connected to enough PV to operate the inverter at rated power for a short duration each day. These inverters initially underwent a detailed laboratory characterization and after more than 2 years of outdoor operation the inverters are being brought in for a recharacterization of their performance. The information gathered from these inverters will be used to refine the inverter performance model and will be ultimately used in a system performance model.

In addition, efforts to model the interaction of today's inverter in high market-penetration situations are being simulated through the development of PV system models for use in power system simulations. Although useful in some circumstances, most simulations either resort to full switching models of the inverter, which are not suitable for high market-penetration case studies, or they do not model the maximum power point tracking (MPPT) and anti-islanding controls in sufficient detail to accurately simulate the performance and functionality of today's inverters. To address these needs, we developed a computer model of a single-phase PV inverter in the MATLAB/Simulink environment. The model was designed to accurately represent the behaviors of a PV inverter that are most relevant at the system level, especially islanding detection and MPPT. Its primary value is thus to the power system engineer, and secondarily to the power electronics designer. 
SAI/TPP and Industry Test Support

The objective of this task is to assist SAI/TPP participants and industry to develop commercial hardware that consistently demonstrates service lifetimes consistent with the SAl objectives. One aspect of this is the completion of Phase 3 of DOE's High Reliability Inverter Initiative. An additional, complementary objective is to assist in developing and evaluating advanced concepts arising from inverter R\&D projects. These concepts may include changes in materials and designs, new standardized communication protocols, internal system or hardware diagnostics, alternative anti-islanding methodologies, new wide-band high-temperature switching devices, or "smart" power distribution controllers. Providing DOE with a test facility to analyze SAI state-gate deliverables is a necessity to fulfill the objectives set forth in the initiative. Furthermore, work by DETL continues to enable existing inverter manufacturers to develop and enhance performance, reliability, and power quality capabilities. The following are examples for each of the parameters under development by the various manufacturers.

Performance enhancement examples:

- Array utilization

- Early/late and dynamic irradiance operations

- conversion efficiency

Reliability enhancements examples:

- Heat mitigation

- Component monitoring

- Surge suppression

Power quality enhancements examples:

- Improved magnetics

- Increased power factor at low power

- Reduced anti-islanding perturbation.

\section{Codes and Standards Support}

The objective of this task is to assist in the development of commercial hardware that is fully compliant with all utility-interconnection standards and applicable safety codes. As a complementary activity, Sandia actively participates in PV-related, domestic and international codes and standards committees to assure that consensus information and requirements flow between the committees and the inverter industry and through the collaboration with BEW Engineering continue the effort to harmonize the International Electrotechnical Commission and UL utility interconnection standards and test procedures.

PV Inverter and BOS Evaluation FY07 Work Plan
\begin{tabular}{|l|c|}
\hline \multicolumn{1}{|c|}{ Agreement Title } & $\begin{array}{c}\text { FY } 2007 \\
\text { Budget (\$K) }\end{array}$ \\
\hline $\begin{array}{l}\text { Inverter/BOS Performance } \\
\text { Modeling (SNL) }\end{array}$ & 140 \\
\hline $\begin{array}{l}\text { SAI/TPP and Industry Test } \\
\text { Support (SNL) }\end{array}$ & 620 \\
\hline $\begin{array}{l}\text { Codes \& Standards Support } \\
\text { (SNL) }\end{array}$ & 140 \\
\hline \multicolumn{1}{|c|}{ Total } & 900 \\
\hline
\end{tabular}

\section{Results and Accomplishments}

\section{Inverter Performance Modeling}

SNL personnel have developed an inverter performance model applicable to all commercial inverters used in photovoltaic power systems that provides a versatile numerical algorithm that accurately relates the inverter's ac-power output to the dc-power input. The model developed requires a set of measured performance parameters and the accuracy of the performance model is optimized by utilizing detailed performance measurements as conducted by recognized testing laboratories. Additionally, laboratory inverter performance data was used to assist in the implementation of the inverter performance model. With the implementation of the model into laboratory data acquisitions systems, a validation of the empirically derived inverter performance model can be validated against measured parameters. Controlled laboratory conditions assist in validating the inverter modeling tool that provides an indication of the ability for the device under test to utilize available PV and convert that available PV into usable ac power. The following are some of the significant accomplishments.

- Completed implementation of inverter model (1/07)

- Completed the implementation of 10 inverter performance parameters using CEC inverter performance protocol results (03/07)

- Initiated inverter model validation (06/07).

The inverter model developed in MATLAB/Simulink environment has been completed and initial laboratory validation of the model has commenced in single-inverter condition and in multi-inverter condition. 
- Completed the implementation of a single phase inverter model with MPPT and antiislanding functionality

- Conducted the laboratory initial model validation test.

\section{SAI/TPP and Industry Test Support}

SNL's DETL evaluations of inverters have focused on utility compatibility issues, array utilization issues, and reliability issues. A new UL 17412005 requirement is for utility interconnected inverters and 240-volt-system inverter voltage measurements between $\mathrm{L} 1-\mathrm{N}$ and $\mathrm{L} 2-\mathrm{N}$ to survive an ANSI C62.45 surge. These new requirements have been difficult for several manufacturers to achieve and laboratory evaluations have assisted the PV industry in realizing these requirements. Today's inverters do well in utilizing the PV array, but some have slight issues during low-irradiance conditions. Another issue is heat mitigation because inverters have inadequate heat sinks or because environmental element residue reduces heat sink thermal characteristics, which leads to heat buildup. The following are major results and accomplishments of the project for FY 2007.

- Completed evaluations of two commercial PV inverters (06/07)

- Completed evaluations of three residential PV inverters (09/07)

- Completed evaluations of beta surge suppression circuits for both residential and commercial PV inverters (03/07)

- Completed RUS PV system evaluations (09/07)

- Completed draft development of a PV system protocol (05/07).

\section{Codes and Standards Support}

Laboratory evaluations conducted at SNL's DETL provide a means to analyze the ability of utility interconnected PV inverters to adhere to utility interconnection requirements. Also, by participating in the National Electrical Code (NEC) review process, these evaluations help to review the implementation of required hardware. An integrated and collaborative approach is taken to address codes, standards, and related infrastructure development and issues related to solar installation. The development of codes and standards is essential for the success of SAI. The following are the major accomplishments:
- Provided feedback to industry partners when developmental product failed to meet standard requirements

- Provided input to the NEC Code Making Panel for Article 690 and 705.

\section{Planned FY 2008 Activities}

Inverter/BOS Performance Modeling and System Test Protocol Validation and Refinement

Sandia will complete the validation of Sandia's inverter and systems performance models at Sandia's PV Systems Optimization Laboratory and will assist full inclusion of these models in the Solar Advisor Model analysis tool. Work will involve the following:

- Validating the models by applying CEC inverter performance information

- Compiling a database that will incorporate test protocols for SAI stage-gate reviews

- Implementing SNL inverter performance model refinements

- Assure proper inclusion of the inverter and systems performance models in DOE's Solar Advisor Model analysis tool.

As PV inverters and their connection to the utility grid proliferate, additional questions regarding high market penetration will arise and SNL plans on continuing its multi-inverter modeling efforts.

\section{Applied SAI and R\&D Industry Support}

This task is geared toward the provision of developmental support and stage-gate evaluations of inverter and BOS improvements by TPP, participants in the SEGIS inverter initiative, and other industry development. The objectives are:

- Validation of SAI TPP's stage-gate deliverables and assistance to industry in developing commercial hardware that consistently demonstrates advanced operational functionality and performance consistent with the SAI goals

- Development of a new set of evaluation protocols to support the development of new capabilities within the inverter and energy management system

- Development of improved capabilities to collect field data on the performance of installed inverters and improvement of the linkage between field and laboratory data in reliability and system-life determinations 
Support for Development and Implementation of Codes \& Standards

The objective of this task is to assist in the development of commercial hardware that is fully compliant with all utility-interconnection standards and applicable safety codes. Efforts will involve:

- Participation in domestic and international PV-related codes and standards committees

- Sandia analysis of developmental and production hardware for compliancy with all utility-interconnection standards and applicable safety codes.

\section{Major FY 2007 Publications}

M. Ropp and S. Gonzalez, "Development of a MATLAB/Simulink model of a single-phase gridconnected photovoltaic system," Sandia National
Laboratories, Albuquerque, NM SAND2007 (2007).

J. Ginn, D. Menicucci, J. Ortiz-Moyet, Primecore, Inc., T. Byrd, S. Gonzalez, and J. Blevins, Salt

River Project, Phoenix, AZ, "Laboratory tests of IEC DER object models for grid applications", Sandia National Laboratories, Albuquerque, NM SAND2007 (2007).

D. King, S. Gonzalez, G. Galbraith, and W. Boyson, "Performance model for grid-connected photovoltaic inverters", Sandia National Laboratories, Albuquerque, NM SAND2007 (2007).

\section{University and Industry Partners}

The following organizations partnered in the project's research activities during FY 2007.

\begin{tabular}{|l|l|l|c|}
\hline $\begin{array}{c}\text { Organization/ } \\
\text { Principal Investigator }\end{array}$ & \multicolumn{1}{|c|}{ Location/e-mail } & \multicolumn{1}{|c|}{$\begin{array}{c}\text { Description/Title of Research } \\
\text { Activity }\end{array}$} & $\begin{array}{c}\text { FY 2007 } \\
\text { (\$K) }\end{array}$ \\
\hline $\begin{array}{l}\text { Northern Plains Power/ } \\
\text { Dr. Michael Ropp }\end{array}$ & $\begin{array}{l}\text { Brookings, SD } \\
\text { mropp@sdsu.edu }\end{array}$ & $\begin{array}{l}\text { Develop and report on an advanced } \\
\text { inverter integrated control modeling } \\
\text { concept... }\end{array}$ & 50 \\
\hline
\end{tabular}




\title{
Systems Testing and Evaluation PV Module and Array Testing
}

\author{
Performing Organizations: $\quad$ Sandia National Laboratories (SNL) \\ National Renewable Energy Laboratory (NREL) \\ Key Technical Contacts: $\quad$ M. A. Quintana (SNL), 505-844-0474, maquint@sandia.gov \\ C. R. Osterwald (NREL), 303-384-6764, carl_osterwald@nrel.gov
}

DOE HQ Technology Manager: Dan Ton, 202-587-4618, dan.ton@ee.doe.gov

FY 2007 Budgets: $\quad$ \$1,000K (SNL), \$1,570K (NREL)

\section{Objectives}

- Provide module and array performance evaluations for Solar America Initiative (SAI) Technology Pathway Partnership (TPP) stage-gate evaluations and in support of the photovoltaic (PV) industry's product development efforts.

- Develop test protocols and performance models that support PV investments at the U.S. Department of Energy (DOE) as well as supporting industry and TPP progress.

- Assess PV module and array reliability issues to quickly isolate, scientifically understand, and help industry mitigate module failure and/or degradation mechanisms.

- Gather and analyze outdoor, long-term exposure data for candidate module technologies.

- Develop new and improved module packaging designs that result in improved service lifetimes and reduced annual performance degradation.

- Assist industry with developing new consensus standards and codes for module performance and/or qualification testing.

- Characterize and provide models for PV module performance and reliability.

- Measure degradation rates per year of both modules and systems using real-time testing.

- Perform accelerated stress testing of modules following national and international standards for qualification and safety testing.

\section{Accomplishments}

- Tested world record performance of two production modules for SunPower having $19.8 \%$ and $20.1 \%$ efficiency.

- Provided baseline tests of Sanyo modules for GreenRay to support initial development in fulfillment of the GreenRay TPP.

- Evaluated arrays from SunPower (evaluating the performance of glass antireflective coatings) and Advent (short-term performance/degradation tests).

- Conducted performance tests to support the development of Emcore concentrating photovoltaic (CPV) modules.

- Initiated efforts to conduct a soiling test for Evergreen Solar.

\section{Future Directions}

- Increase development and stage-gate testing in support of SAI TPP progress.

- Increase module and array testing in support of reliability studies.

- Include future work that may be carried out as part of the SAI.

\section{Introduction}

One of the top research priorities identified by the PV industry year after year is module performance and reliability, as an essential ingredient for product credibility and consumer confidence. In addition, a systems-driven approach has been applied somewhat recently and used to identify technical improvement opportunities, using the Solar Advisor Model 
(SAM) for program planning. This approach has shown that a total system lifetime of 30 years and electrical output that stays within acceptable levels (e.g., no more than $0.5 \%$ to $1 \%$ annual degradation rates) are critical in order to produce the expected total kilowatt-hours of electricity over the system's 30-year lifetime to meet DOE cost goals. Photovoltaic modules are the most important system component in terms of cost, performance, and reliability. Modules make up $55 \%$ to $65 \%$ of the total PV system price and costs and directly determine the overall system conversion efficiency. Therefore, this project addresses module reliability, packaging, performance, and characterization research and development (R\&D), and is a joint effort between the National Renewable Energy Laboratory (NREL) and Sandia National Laboratories (SNL). The project continues to be an essential element of the PV R\&D work in DOE's Solar Energy Technologies Program (SETP).

During the SETP peer review in October 2005, the feedback about the relevance of the work included "critical to the achievement of DOE goals ... [and] the development of sustainable PV markets," "highly valuable to the U.S. PV industry," "relevant to the DOE objectives by providing a combination of laboratory and field testing of PV modules," and "by solving reliability problems, module life cycle costs are reduced, and thus the DOE goal of lowering system cost is supported." Also, this work is "a key element of the overall DOE program ... that complements other projects and is integral to overall program advancement [and] systems that perform to specifications over prolonged time periods show the value of PV as an energy source and lead to acceptance of the technology by utilities and other customers."

Numerical ratings given by the reviewers were the highest of all projects reviewed.

\section{Technical Approach}

The technical approach in this project consists of short-term and long-term outdoor module performance testing and characterization; selected outdoor stress testing (e.g., in highvoltage environments); accelerated indoor environmental stress testing (e.g., temperature, humidity); performance analyses, characterization, and modeling; failure and degradation analyses; and module packaging
R\&D (e.g., moisture ingress analysis and amelioration). These evaluations are performed to help mitigate failures and degradation and/or reduce module costs and improve performance.

In order to conduct these testing, analyses, and module packaging investigations, NREL and SNL develop and apply advanced measurement techniques, diagnostic methods, and instrumentation. A key aspect of the overall approach is close interactions and collaborations with PV module manufacturers. The intent is to optimize the time and funding required when advancing module technologies from the prototype to the commercial production stage, with respect to meeting acceptable performance, reliability, and cost requirements.

In FY 2007, the tasks were accomplished under four agreements, as shown in the table.

\begin{tabular}{|l|c|}
\hline \multicolumn{1}{|c|}{$\begin{array}{c}\text { Task Title } \\
\text { (Module \& Array Testing) }\end{array}$} & $\begin{array}{c}\text { FY 2007 } \\
\text { Budget } \\
\text { (In-House) } \\
\text { (\$K) }\end{array}$ \\
\hline Module \& Array Testing (NREL) & 1,940 \\
\hline $\begin{array}{l}\text { Task 1: Module Parameter } \\
\text { Database (SNL) }\end{array}$ & 140 \\
\hline $\begin{array}{l}\text { Task 2: Module/Array Degradation } \\
\text { (SNL) }\end{array}$ & 130 \\
\hline $\begin{array}{l}\text { Task 3: Testing \& Modeling } \\
\text { Protocols (SNL) }\end{array}$ & 280 \\
\hline
\end{tabular}

Accelerated stress testing is done on developmental module designs, and typically comprises tests proscribed by several International Electrotechnical Commission (IEC) standards, such as damp heat, thermal cycling, hot spot endurance, and humidity-freeze cycling. Mechanical integrity tests such as hail impact, mechanical load, robustness of terminations, and junction box securement are also available. These tests can be performed in one or more of the standard module qualification or safety testing sequences, or individualized sequences may be employed while assisting a manufacturer with product development. This collaborative testing and feedback is performed for industry contacts (e.g., SunPower, GE) and subcontractor deliverables. In addition, needs of the SAI Technology Pathway Partnerships will be assessed when the agreements are in place, 
and a plan developed for making the requisite measurements, in cooperation with SNL and the RESs.

\section{Results and Accomplishments}

\section{Task 1}

Task 1 involves coordinating and facilitating the development of databases for module and array performance parameters needed by integrators for PV system design and energy modeling. The rapid growth of the $P V$ industry has resulted in hundreds of module types and sizes (models) for inclusion in a publicly accessible database. As the industry grows, the testing and database function for commercial modules should transition to commercial testing laboratories. Likely commercial labs include Arizona State University's Photovoltaic Testing Laboratory (ASU/PTL), the Florida Solar Energy Center (FSEC), the Southwest Technology Development Institute (SWTDI), and Underwriters Laboratories (UL).

\section{Task 2}

This task involves analyzing and documenting failure mechanisms and performance degradation rates observed during long-term field exposures of modules and arrays with accelerated thermal and humidity conditions, when possible. Field exposure is a critical prerequisite and the most defensible method for demonstrating module reliability and service lifetime. This task establishes reliability baselines and opportunities for improvement through a well-controlled long-term exposure in different climates. Partners in this effort include SNL, NREL, FSEC, SWTDI, module manufacturers, and system integrators. Activities in this task will emphasize field reliability assessments for SAI TPP participants.

\section{Task 3}

Task 3 involves developing testing protocols and associated modeling algorithms needed for energy-based system design, field installation and checkout, array performance ratings, longterm performance monitoring, and diagnosis of array degradation events. The array modeling algorithms are developed in conjunction with inverter and system modeling procedures addressed in the Inverter \& BOS (Balance of System) Testing Agreement and the System Test \& Evaluation Agreement, resulting in system testing protocols.
FY 2007 Milestones

- Established a Test and Evaluation (T\&E) Working Group, coordinate lab activities, and provide T\&E support for DOE TPP participants: A Test and Evaluation document published by DOE was implemented as the basis for establishing the T\&E Working Group. Two meetings were conducted in FY 2007. The first was to establish the lab working group and the second was a seminar provided to TPP technical monitors to establish test and evaluation strategies for implementation in TPP stage-gate validations. (SNL, NREL)

- Provided outdoor module performance characterization and module database parameters for TPP participants: Progress in awarding TPP contracts minimized the amount of TPP testing that occurred during FY 2007. Baseline testing of Sanyo modules and surge tests of inverter packaging were performed for GreenRay's module scale inverter development under the TPP awarded in FY 2007.

- Initiated a new method for accelerated array field-aging for SAI TPP participants: A reliability program was formulated to address issues related to field-aging. The methodology will use information from fielded system, models, and accelerated aging efforts to model system reliability; this effort will be implemented in FY 2008. (SNL, NREL, SWTDI, FSEC)

- Developed techniques to diagnose reliability issues caused by cell/solder bond/laminate stresses resulting from the introduction of TPP-driven module technologies: Reliability needs voiced by the PV community drove the creation of a rigorous strategy to address the reliability of photovoltaics in FY 2007. Development of this strategy included research in methodologies and approaches that are being considered.

- Implemented and verified SNL's module and array testing and analysis protocols at ASU/PTL, FSEC, and SWTDI.

\section{Module \& Array Testing Task (NREL)}

This agreement provided for real-time outdoor testing on modules and small grid-tied systems, and accelerated indoor and outdoor module stress testing. These activities are performed at the NREL Outdoor Test Facility (OTF) in collaboration with PV module manufacturers (industry partners), SNL, and Underwriters' Laboratories (UL) in order to improve industry

Photovoltaic R\&D

Advanced Materials and Devices Systems Testing and Evaluation 
prototypes before large-scale commercialization, and/or to characterize real-world performance of modules representing various technologies (thinfilm, silicon, etc.).

Work on this project was adversely affected during the fourth quarter of FY 2007 by the initiation of a construction project to expand the OTF on the NREL permanent site. The laboratories used for many of these activities had to be evacuated.

\section{FY 2007 Milestones}

- Deliver system performance reports \& analyses to module manufacturers (quarterly reports transmitted to Uni-Solar, SunPower, First Solar, Schott Solar)

- Obtain UL accreditation at NREL for IEC61215 (qualification) and IEC61730 (safety) testing of modules (testing agreement with UL through a CRADA could not continue due to internal changes at UL)

- Support test and analysis for thin-film, hot \& humid module exposure contracts, and other in-house and contract research (testing performed for Advent Solar, SunPower; new Shell CIGSS system installed)

- Evaluate modules in Performance and Energy Ratings Testbed (PERT), replace with new technologies as needed; report on feasibility of using PERT data for module energy ratings to draft IEC standard (completed)

- New environmental chamber installed at OTF to replace 25-year-old unit

- Procurements for four new environmental chambers initiated using FY 2007 General Equipment funds.

\section{Planned FY 2008 Activities}

Efforts described in this activity will be folded into other projects (specifically, a Reliability project and the PV Test and Evaluation project) in FY 2008. The goal is to develop and apply methodologies to test, evaluate, and assess the reliability of components in PV systems. This information will be used to develop a reliability model. Specific objectives are as follows:

- Provide an increasing amount of effort in Test and Evaluation to support product development by SAI TPP participants.

- Perform stage-gate validations as needed to assist DOE in the administration of TPP contracts.

- Install new environmental chambers at the OTF.

\section{University and Industry Partners}

During FY 2007, university partners included New Mexico State University (SWRES) and the University of Central Florida. PowerMark Corporation and Sunset Technologies (IEC TC-82 Secretariat) subcontracts were continuations of existing subcontracts that maintain a U.S. presence in the international PV standards and product certification efforts.

\begin{tabular}{|l|l|l|c|}
\hline $\begin{array}{c}\text { Organization/ } \\
\text { Principal Investigator }\end{array}$ & \multicolumn{1}{|c|}{ Location/e-mail } & \multicolumn{1}{|c|}{ Description/Title of Research Activity } & $\begin{array}{c}\text { FY 2007 } \\
\text { (\$K) }\end{array}$ \\
\hline $\begin{array}{l}\text { Sunset Technologies, } \\
\text { H. Barikmo }\end{array}$ & $\begin{array}{l}\text { Mesa, AZ } \\
\text { HBARIKMO@aol.com }\end{array}$ & IEC TC-82 Secretariat support & 40 \\
\hline $\begin{array}{l}\text { PowerMark Corp., S. } \\
\text { Chalmers }\end{array}$ & $\begin{array}{l}\text { Mesa, AZ } \\
\text { SteveChalm@aol.com }\end{array}$ & PowerMark Corp. PV certification support & 40 \\
\hline
\end{tabular}




\title{
Systems Testing and Evaluation PV Module Failure Analysis
}

\author{
Performing Organizations: $\quad$ National Renewable Energy Laboratory (NREL) \\ DOE Golden Field Office (DOE/GO) \\ Key Technical Contacts: $\quad$ Carl Osterwald (NREL, Primary Contact), 303-384-6764, \\ carl_osterwald@nrel.gov \\ Tom McMahon (NREL), 303-384-6762, tom_mcmahon@nrel.gov
}

DOE HQ Technology Manager: Dan Ton, 202-586-4618, dan.ton@ee.doe.gov

FY 2007 Budgets: $\quad$ \$340K (NREL)

\section{Objectives}

- Investigate photovoltaic (PV) module reliability through understanding of module failure modes.

- Continue thin-film module hot-and-humid exposure testing subcontracts for one more year.

- Provide failure analysis for Solar America Initiative (SAI) Technology Pathway Partnership (TPP) participants as needed.

\section{Accomplishments}

- Developed interfacial measurement technique of layer adhesion inside modules.

- Completed thin-film hot-and-humid module exposure subcontracts.

- Continued investigating slow degradation of short-circuit current in crystalline-Si module.

\section{Future Directions}

- This activity has been reorganized into other activities for FY 2008 under the PV-Module Reliability Program.

- Perform post-exposure testing on thin-film hot-and-humid exposure modules from Florida Solar Energy Center (FSEC) and Texas A\&M University (TAMU).

\section{Introduction}

This agreement addresses module reliability, and thereby system-level performance, by elimination of failure modes that are identified from a failure investigation. If a failure mode that greatly limits module lifetime is subsequently eliminated, the levelized cost of electricity is also improved by increasing the total energy delivered. The U.S. Department of Energy Solar Energy Technologies Program (SETP) peer review in October 2005 stated that this work "...uses experimental and analytical methods to improve the reliability of PV modules. The approach includes analysis to understand failure mechanisms..." and "highlights how [t]he approach includes interaction with the academic community and PV module manufacturers." This work was given numerical ratings that were the highest of all projects reviewed.

\section{Technical Approach}

Working as closely as possible with module manufacturers, laboratory personnel attempt to identify the causes of failures observed during testing at the national laboratories or in modules deployed in the field. Analyses can also be initiated upon request of manufacturers or TPP participants. Detailed analyses of any observed failures are performed as needed, using existing resources at the national laboratories. Diagnostic tools for these analyses are available in two divisions of the National Center for Photovoltaics. They include an indoor infrared imaging camera, light and dark I-V measurements, quantum efficiency measurements, core sampling, polymer and adhesion diagnostics, surface analysis, and laser spot scanning. Findings are then documented and reported, including any recommendations for changes to module designs that might eliminate problems. A multiyear investigation into an observed slow degradation of short-circuit current in encapsulated crystalline-Si 
modules is currently underway and will be continued under this agreement. Other degradation or failure mechanisms are identified as new prototypes are submitted for evaluation or field problems arise for manufacturers, who often come to the laboratories for help. Work under this agreement also includes development of diagnostic techniques and methodologies needed to address specific failures that are identified with new modules.

Failure analysis results are communicated to the respective module manufacturers, who are then responsible for implementing any manufacturing changes to alleviate problems. For the TPPs, specific requirements may be negotiated into the cooperative agreements with the recipients.

The FSEC and TAMU hot-and-humid thin-filmmodule exposure subcontracts provide for another year of funding for this existing program, initiated as part of the former Thin-Film Partnership Program, during which time a decision will be made about continuing these projects, recompeting them, or both.

PV Module Failure Analysis FY 2007 Work Plan

\begin{tabular}{|c|c|}
\hline Agreement Title & $\begin{array}{c}\text { FY 2007 } \\
\text { Budget (\$K) }\end{array}$ \\
\hline PV Module Failure Analysis & 340 \\
\hline
\end{tabular}

\section{Results and Accomplishments}

Work on this project was adversely affected during the fourth quarter of FY 2007 by the initiation of a construction project to expand the Outdoor Test Facility (OTF) at the National Renewable Energy Laboratory (NREL). The laboratories used for many of these activities had to be evacuated.

Milestones:

- Investigation of slow short-circuit current degradation in crystalline-Si encapsulated modules was continued (09/07)

- A new measurement technique for polymer interfacial adhesion in PV modules was developed and documented (05/07)

- $\quad$ No requests for testing or failure analyses from SAI/TPP participants were received during FY 2007 (09/07).

A significant accomplishment under this project was the development of a measurement technique that allows characterization of the strength and durability of various interfaces within many types of $\mathrm{PV}$ modules. The key element is a device that measures torque as a function of twist angle on circular core samples (see Fig. 1). Analysis of modules exposed to ultraviolet (UV) radiation indicated that the interface between ethylenevinyl-acetate (EVA) encapsulation and crystallineSi top surfaces is degraded significantly, while adhesion at rear-side interfaces is not degraded. Adhesion of polymers is a key factor for protecting PV cells when packaged inside modules.

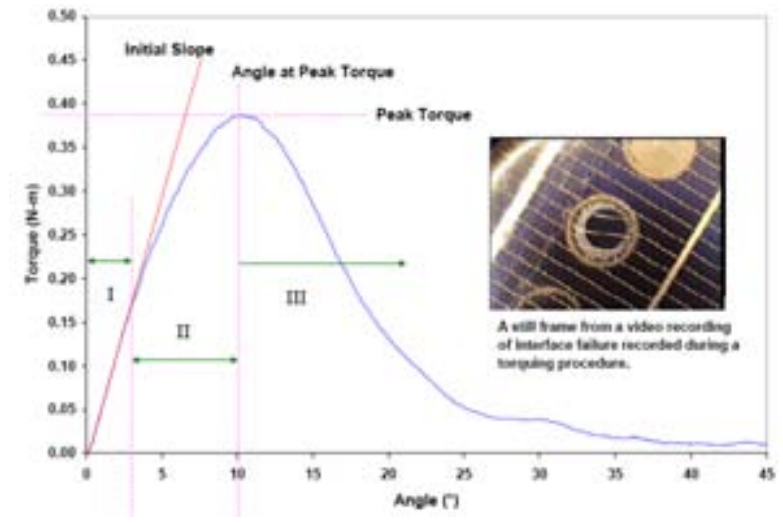

Fig. 1. Example torque measurement of interfacial adhesion of EVA polymers to crystalline-Si cells.

The long-term exposure experiment of crystallineSi cells encapsulated in module packages reached a total UV exposure dose of $4750 \mathrm{Mj} / \mathrm{m}^{2}$ of metalhalide illumination (equivalent to about 17 years of outdoor UV exposure at the NREL OTF site). Careful periodic measurements of short-circuit current have indicated that degradation vary according to manufacturer and cell technology, and a thermal degradation of $\mathrm{Si}$ cell $\mathrm{p}$-n junctions has been eliminated as a cause (see Fig. 2).

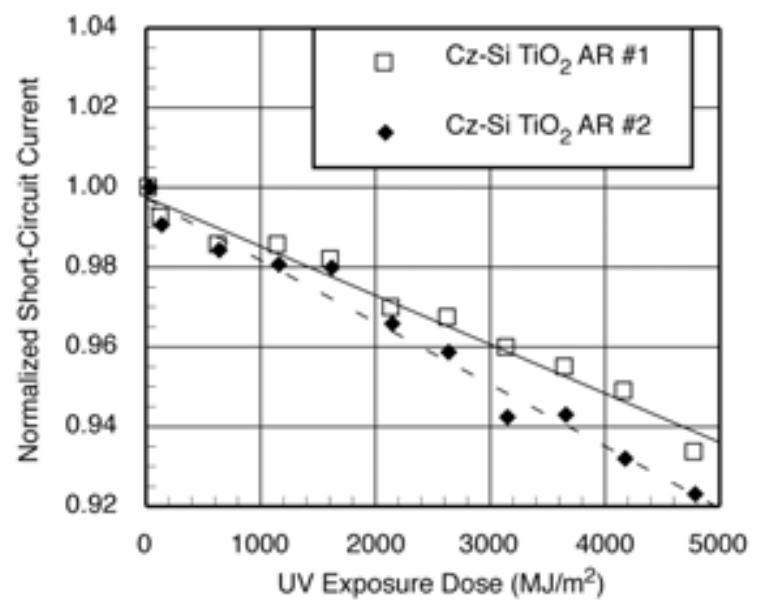


Fig. 2. Loss of short-circuit current versus UV exposure dose for a crystalline-Si cell technology with $\mathrm{TiO}_{2}$ antireflection coating.

After 1-year extensions, the thin-film module -andhumid-exposure subcontracts at both TAMU and FSEC have ended and the program was evaluated internally at NREL. Part of the evaluation included a site visit to FSEC just prior to the end of operation. The evaluation identified a number of shortcomings with both testing activities:

- Principal investigators (PI) were not familiar with PV system design practices, especially the National Electric Code

- Pls misunderstood the program intent and objectives

- Changes recommended after an earlier site visit were ignored and not implemented (FSEC)

- A principal investigator was lost at the midpoint of a subcontract (TAMU)

- There was no appreciation for the possible impact of hurricanes (NREL).

As a result of these shortcomings, the real-time data collected by both subcontractors has not been of sufficient quality to allow continuous monitoring as originally intended. The FSEC data could not be used because graduate students periodically changed corroded load resistors, which invalidated month-to-month comparisons. At TAMU, the former PI was the only person who understood the data acquisition system, which caused a number of problems when he left the university. Thus, module degradation will have to be determined when exposed modules are returned to NREL for retesting.

Module testing in diverse or harsh climates is still recognized as an important priority, and the lessons learned here need to be applied to future testing activities.

\section{Planned FY 2008 Activities}

As a result of the new structuring of the DOE PV reliability program, module failure analysis has been incorporated into a number of new program agreements. Any future equivalents of the hot \& humid exposure program have been allocated to outdoor testing activities under the Sandia PV program.

\section{Major FY 2007 Publications}

G.J. Jorgensen and T.J. McMahon, "Accelerated and outdoor aging effects on PV module interfacial toughness and shear strength". Proceedings of the 2007 DOE Solar Program Review Meeting, Denver, CO, (2007).

G.J. Jorgensen and T.J. McMahon. "Accelerated and outdoor aging effects on photovoltaic module interfacial adhesion properties." Progress in Photovoltaics: Research Applications (in press) (2008).

\section{University and Industry Partners}

The following organizations partnered in the project's research activities during FY 2007.

\begin{tabular}{|l|l|l|c|}
\hline $\begin{array}{c}\text { Organization/ } \\
\text { Principal Investigator }\end{array}$ & \multicolumn{1}{|c|}{ Location/e-mail } & \multicolumn{1}{|c|}{ Description/Title of Research Activity } & $\begin{array}{c}\text { FY } \\
\mathbf{2 0 0 7} \\
\mathbf{( \$ K )}\end{array}$ \\
\hline $\begin{array}{l}\text { Florida Solar Energy } \\
\begin{array}{l}\text { Center } \\
\text { Neekanth Dhere }\end{array}\end{array}$ & $\begin{array}{l}\text { Cocoa, FL } \\
\text { dhere@fsec.ucf.edu }\end{array}$ & $\begin{array}{l}\text { Thin-Film Hot-and-Humid Exposure: } \\
\text { continuation of research initiated under the } \\
\text { former Thin-Film Partnership Program to } \\
\text { expose thin-film PV modules in a humid climate } \\
\text { and measure and observe degradation }\end{array}$ & 145 \\
\hline $\begin{array}{l}\text { Texas A\&M University } \\
\text { Jeff Haberl }\end{array}$ & $\begin{array}{l}\text { Thin-Film Hot-and-Humid Exposure: } \\
\text { continuation of research initiated under the } \\
\text { former Thin-Film Partnership Program to } \\
\text { expose thin-film PV modules in a humid climate } \\
\text { and measure and observe degradation }\end{array}$ & 65 \\
\hline
\end{tabular}




\title{
Systems Testing and Evaluation Photovoltaic System Evaluation and Optimization
}

\author{
Performing Organization: Sandia National Laboratories (SNL) \\ Key Technical Contact: $\quad$ M.A. Quintana (SNL), 505-844-0474, maquint@sandia.gov
}

DOE HQ Technology Manager: Dan Ton, 202-587-4618, dan.ton@ee.doe.gov

FY 2007 Budgets: $\quad$ \$950K

\section{Objectives}

- Provide research and development support for DOE Solar America Initiative (SAI) participants and the photovoltaic (PV) industry to investigate advanced PV system concepts, manufacturing methods, and deployment strategies that improve performance, reliability, and cost, and to accelerate deployment.

- $\quad$ Provide SAI stage-gate validations to assist DOE administration of SAI programs.

- Operate a versatile fully instrumented PV System Optimization Laboratory (PV-SOL) for system and inverter performance and aging research.

- Develop, validate, and apply new testing and analysis procedures, based on energy production, needed to verify and optimize the performance and reliability of PV systems.

- Provide manufacturers, integrators, and software developers accurate comprehensive test data required to model and verify system, module, and inverter performance.

- Coordinate a multi-site research effort to evaluate the long-term field-aging behavior of inverters in collaboration with inverter manufacturers and the Florida Solar Energy Center (FSEC),

Southwest Technology Development Institute (SWTDI), and BEW Engineering.

- Collect and analyze system installation and operation information in collaboration with established system integrators to establish performance and cost baselines.

Accomplishments

- Completed a draft protocol on field testing for confirmation by the PV community and implementation for SAI validations.

- Evaluated the performance of system configurations for PV manufacturing companies Advent and SunPower at Sandia National Laboratories' (SNL's) Photovoltatic Systems Operations Laboratory (PV-SOL), which has the capability to perform detailed performance and long-term reliability research on 14 separate nominally 3-kW PV systems with multiple array/inverter combinations.

- Characterized additional modules and arrays; SNL's "module database," used by integrators and in commercial PV system design software, now includes more than 200 commercial modules and 12 arrays.

- Participated in a draft comparison of array-performance models to understand differences and best practices.

\section{Future Directions}

- Continue the concerted effort to enhance and document PV systems and inverter performance and reliability research through coordinated efforts in the PV-SOL with module and inverter manufacturers, integrators, FSEC, SWTDI, and BEW Engineering.

- Develop a comprehensive reliability program that captures the need of evolving business models for greater reliability of data and information.

- Develop improved field data-acquisition and analysis procedures for monitoring PV-system performance to provide more meaningful system performance indices. 


\section{Introduction}

The PV System Evaluation and Optimization activities at SNL are closely linked to the needs of manufacturers and system integrators. These activities provide laboratory and field-test information needed to establish the performance and reliability status of current PV systems and also identifies opportunities for improved system design and component integration in nextgeneration systems. These activities are key to meeting DOE Solar Energy Technologies Program multi-year program plan targets and objectives of the Solar America Initiative Program, as well as the goals of the U.S. PV industry roadmap. As such, the System Evaluation and Optimization Project is the focal point within the DOE Solar Program where the technical issues of PV component manufacturers, system integrators, and users converge.

\section{Technical Approach}

Major research activities for FY 2007 included detailed module, array, inverter, and system research aimed at understanding and improving the performance, reliability, and cost of fully integrated PV systems. This research was conducted using the capabilities and expertise associated with SNL's PV System Optimization Laboratory, PV-SOL.

The PV-SOL is equipped to accurately evaluate the energy production from 14 separate $3-\mathrm{kW}$ grid-tied systems using different combinations of the latest vintage modules and inverters. Energy flow in and out of all system components is continuously recorded, providing detailed performance characteristics, as well as longterm aging characteristics for both inverters and arrays under all weather conditions. The performance of the PV array associated with each inverter has been fully characterized and modeled, providing real-time calculation of the expected DC energy from the array for comparison with measured DC input to the inverter.

PV-SOL activities include the following:

- Validation of PV-system performance models and development of better performance indices.

- Serving as a testbed for new "system manufacturing" concepts and structural designs.
- Characterization of balance-of-system components supporting product development.

- Improvement of performance or diagnostic field tests.

- Investigation of array utilization, inverter maximum power point tracking (MPPT), and efficiency based on energy production.

- Improvement of start-up, shut-down, MPPT, and performance-monitoring algorithms for inverters.

- Thermal modeling (operating temperature) for inverters versus meteorological conditions.

- Investigation of array shading and orientation.

- Optimization of design, components, setpoints, and controls for off-grid and hybrid systems.

- Evaluation of PV-system monitoring and control hardware and software.

- Development of wireless, low-cost, accurate data acquisition hardware.

- Characterization of prototype components supporting industry product development.

\section{FY 2007 Work Plan}

\begin{tabular}{|l|c|c|}
\hline \multicolumn{1}{|c|}{ Tasks } & FTEs & $\begin{array}{c}\text { In-house } \\
\text { Funding } \\
\text { (\$K) }\end{array}$ \\
\hline System Testing Protocols & 0.5 & 140 \\
\hline SAI/Industry Test Support & 2.0 & 560 \\
\hline System Reliability \& Safety & 0.7 & 200 \\
\hline
\end{tabular}

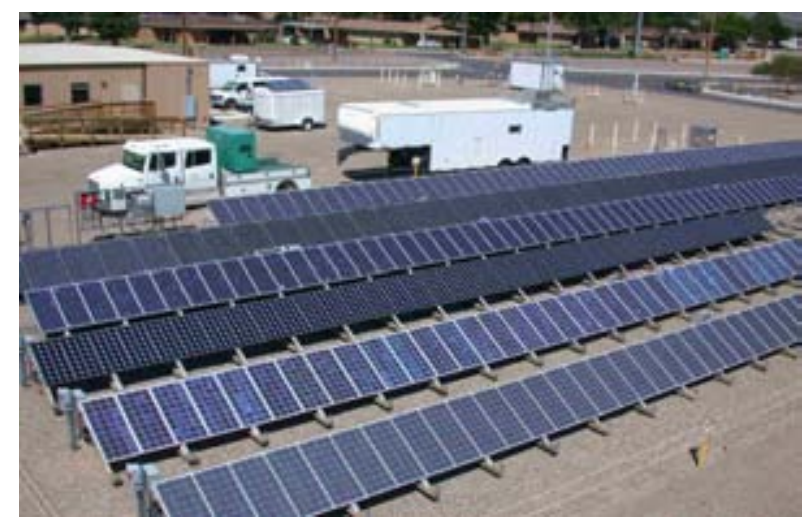

Fig. 1. PV-SOL: Six new PV array technologies 


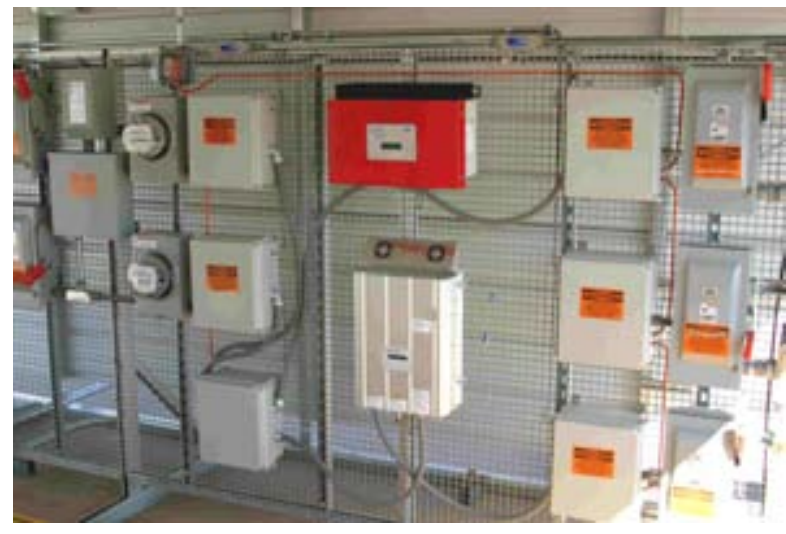

Fig. 2. PVSOL: Fully instrumented inverters in continuous system performance test

\section{Results and Accomplishments}

The FY 2007 technical milestones and related accomplishments for the System Evaluation and Optimization Project are listed below by project subtask.

- Documented field-testing protocol for array, inverter, and system performance for SAI Technology Pathway Partnership (TPP) participants-

A field test protocol was drafted in $\mathrm{FY}$ 2007. This protocol was written to provide a standardized procedure for evaluating SAl systems as a validation of stage-gates for SAI. The protocol will be further iterated and formalized in $\mathrm{FY}$ 2008.

- Conducted field survey of PV array safety status after years of operationArray safety issues have been compiled as a part of test protocol development and development of a comprehensive reliability program to be conducted in $\mathrm{FY}$ 2008.
- Calculated annual AC-energy system efficiencies for multiple sites using best-inclass technologies as SAI benchmarks-

This is an ongoing activity that has provided multiple applications for the PV Solar Advisor Model and SAI TPP planning purposes.

- Documented advanced concepts for wireless irradiance and temperature sensing and "smart" diagnostics-

This activity was investigated and terminated after industry counterparts fell short on development efforts.

\section{Planned FY 2008 Activities}

In FY 2008, the Photovoltaic System Evaluation and Optimization Project will be folded into System Modeling, PV System Reliability, and PV System Test and Evaluation projects.

The major activities for FY 2008 include:

- Initiation of a comprehensive reliability program that begins a rigorous effort to define 1) system reliability issues in the field, 2) development of system availability needs, 3) designs for system maintainability, and 4) supply chain requirements to establish and support system reliability metrics.

- Initial requests and fulfillment of SAI TPP stage-gate validations from $P V$ manufacturing companies GreenRay, Amonix, and Soliant.

- Development of additional tracker test capabilities for concentrating-PV and flatplate PV-system evaluations.

- Continue efforts to improve general performance model for inverters, including characteristics associated with DC/AC efficiency, MPPT effectiveness, start-up, shut-down, thermal foldback, and power factor.

\section{University and Industry Partners}

The Southwest Region Experiment Station of New Mexico State University and the Florida Solar Energy Center at the University of Central Florida partnered in the project's research activities during FY 2007. 


\title{
Systems Testing and Evaluation Regional Experiment Stations
}

\author{
Performing Organizations: $\quad$ Sandia National Laboratories (SNL) \\ DOE Golden Field Office (DOE/GO)
}

Key Technical Contact: $\quad$ M.A. (SNL), 505-844-0574, maquint@sandia.gov

DOE HQ Technology Manager: Dan Ton, 202-587-4618, dan.ton@ee.doe.gov

FY 2007 Budget: $\quad \$ 1,750 \mathrm{~K}(\mathrm{DOE} / \mathrm{GO})$

\section{Objectives}

- Meet Solar Program Annual Operating Plan objectives and milestones by teaming with the national laboratories.

- Assure that education, training, outreach, and technical support required to accelerate the rate of the nation's PV deployment efforts are available and effectively implemented to support growth of the PV market.

- Provide leadership and support to the industry and the national labs for: (1) systems, module, and inverter testing; (2) creating and implementing procedures, codes, and standards for quality, safe, and cost-effective installed systems; (3) hardware certification; and (4) addressing system engineering issues observed in fielded systems.

- Provide technical support to DOE, national laboratories, and industry in the execution and validation of stage gates for the Solar America Initiative (SAI) Technology Pathway Partnerships (TPP).

\section{Accomplishments}

- Completed the first-year requirement of a 3-year contract and began the second-year requirements.

- Conducted product testing, system evaluations, and research and development (R\&D) activities that related to cutting levelized cost of energy, increasing system efficiency, and cutting initial costs of PV systems; particularly as required by SAI participants.

\section{Future Directions}

- Lead technical outreach Tiger Teams to Solar America Cities and Showcases. This work, led by Southwest Regional Experiment Station (SWRES), builds on successes with Forest City Military Communities, City of Tucson, and City of Austin .

- Continue participation in the test and evaluation process of fielded systems for TPP stage-gate testing, as well as general system benchmarking of performance, cost, and reliability characterization by SWRES.

- Participate in the development and dissemination of codes and standards for solar technologies, reducing barriers and increasing responsiveness to stakeholders.

- Support codes and standards development.

- Escalate testing in support of reliability studies being initiated at the national labs.

- Increase data collection from field installations to better capture costs, system availability, and system maintainability.

\section{Introduction}

The Southeast Regional Experiment Station (SERES) and Southwest Regional Experiment Station (SWRES) are partners in the DOE Solar Energy Technologies Program. Each station has a university affiliation: University of Central Florida for SERES and New Mexico State University (NMSU) for SWRES. In addition, each station has university-level capabilities, which have been developed to provide systems and component-level research and development 
(R\&D) for DOE, the U.S. photovoltaic (PV) industry, other government agencies, and PV consumers. The work of each is aligned with activities conducted in the Technology Development and Advanced Materials and Devices portion of the DOE PV Subprogram.

Regional Experiment Station (RES) goals are to provide value-added technical support to the Solar Program that effectively and efficiently meets the R\&D needs identified by the DOE's Annual Operating Plan and the Solar America Initiative (SAI), and to pursue targets specified by the DOE Solar Program Multi-Year Program Plan.

RESs have contributed to the DOE National PV Program for 2 decades. This work is integrated into DOE's Annual PV Program plan and is highly collaborative. Throughout the years, RES support has been an integral part of program projects, such as:

- Module reliability R\&D;

- Inverter and balance-of-system development;

- PV systems engineering;

- Domestic PV applications;

- System evaluation and optimization (especially for fielded system);

- PV system analysis; and

- Education and codes and standards development.

Collaborations with SNL, National Renewable Energy Labatory (NREL), National Center for Photovoltaics (NCPV) R\&D partners, and industry counterparts are focused on reducing systems costs, improving system reliability, improving system performance, improving system safety, and removing barriers to deployment, thereby promoting market growth.

\section{Technical Approach}

Work conducted by the RESs builds on expertise with fielded systems that is unique to the DOE Solar Program. Expertise acquired as a result of extensive field investigations provides a system perspective that is the foundation for solving technical problems that are barriers to widespread deployment. A large volume of requests from the $\mathrm{PV}$ industry, as well as the alignment to an evolving U.S. PV Program, provides continuous feedback on the relevance of RES activities. The following tasks describe the technical approach to applying the RES capabilities in pursuit of DOE and industry needs.

\subsection{PV Systems Assistance Center}

The Photovoltaic Systems Assistance Center (PVSAC) is a virtual laboratory comprising engineers and staff from both SWRES and SERES. The objective of the PVSAC is to become a national one-stop resource for publicpolicy support, design reviews, specialized training and training materials, and technical field-support activities. This enables the PVSAC to be a major gateway for technical education, training, and outreach to the U.S. PV community.

The PVSAC has impaneled a board of advisors, with which it develops comprehensive strategic plans for PVSAC prioritization of activities. The board will provide annual review of progress and revise PVSAC planning to reflect changes in the needs of the U.S. PV community.

PVSAC will play an important role in the execution and validation of Technology Pathway Partnership stage gates. As an independent thirdparty evaluator, the RES will provide DOE with assistance in ensuring that stage gates are met, in order to extend cooperative agreements. Stage gates can include system performance testing, outdoor exposure tests, code compliance investigations, and hosting fielded systems. The Regional Experiment Stations will provide design and test support directly to the TPPs during product and system development activities.

\subsection{Infrastructure Development}

Infrastructure development consists of training, design review and approval, and codes and standards development activities. Training occurs through multiple venues and in several subject areas. A key issue with fielded systems is poor installation (including design practices, code compliance, and safety), which has been addressed consistently by RES staff. Activities began with providing training to interested parties and have evolved to the creation and establishment of a National Installer Certification Program, an independent activity that the Regional Experiment Stations were instrumental in creating. Similarly, training of inspectors and installers now is evolving to a system of "training 
the trainers," providing an opportunity to reach a greater audience and minimize investment.

Technical assistance to the industry and users has resulted in an evolving design review and approval standard that provides guidance for uniform designs and system documentation. This activity promotes a level of quality accepted and practiced by other industries that provide recognized products in successful markets.

Development of codes, standards, and certification addresses compliance to a set of prescribed recommendations to assure quality and safety. The proactive approach of Regional Experiment Stations provides the opportunity to guide development of codes and standards that assure performance, quality, and safety without creating a cost burden for the industry. Capabilities for test and certification of hardware are used to create and apply a uniform set of standards in a recognizable format that instills consumer confidence. Certification also is the basis for assuring optimal awards from government incentive programs.

\subsection{Long-Term Component Testing}

The Regional Experiment Stations provide unique and severe environments for stressing PV components and systems. Initially, they provided long-term exposure in hot/dry and hot/humid climates for stressing PV modules deployed in a field-like setting. More recently, a similar approach has been begun to study the long-term performance of inverters in field-like outdoor configurations. Increased reliability needs voiced by labs and industry will increase demand for this type of testing; for both commercial products and the development of prototypes/samples.

Additional activities include placing the inverters in a distributed-generation scenario to address issues associated with controls and generator interactions. Both of these activities are complementary to the Sandia National Laboratories (SNL) baseline tests, which establish initial component performance parameters while seeking to identify degradation rates for different technologies.

\section{Results and Accomplishments}

- Conducted PV Systems Assistance Center inaugural board meeting Oct. 17, 2006. The PVSAC Board meeting notes were adapted into a revised PVSAC Implementation Plan
(PVSAC-IP) during the last quarter and circulated for review. The final draft is in progress, awaiting the return of comments from some reviewers.

- The Southwest Technology Development Institute (SWTDI) and PVSAC developed the test requirements (labor, hardware, travel) for testing and evaluation (T\&E) support of the SAI TPP award winners.

- SWTDI and Florida Solar Energy Center (FSEC) staff participated in a "Tiger Team" evaluation of the National Zoo, Washington, DC, as the zoo facilities and grounds were being renovated.

- FSEC worked with BP Solar to provide an unbiased perspective in its training program. Kevin Lynn gave a presentation using materials taken from the PV Installers Class and used it to teach students about installation and the National Electric Code (NEC) as it relates to some of BP system designs.

- FSEC worked with Palm Harbor Homes to install a PV system on a manufactured home for display at the International Builders Show (Feb. 2007), at the Orange County Convention Center, Orlando, Florida.

- PVSAC participation with Sacramento Municipal Utility District (SMUD) concluded in March with the final revision and validation of the SMUD Performance Index software. Special validation was required for the oneaxis tracking algorithms used to validate performance of the utility's larger arrays.

- SWTDI staff participated in the 2007 Solar Decathlon kickoff meeting in Washington, DC. SWTDI reviewed electrical drawings and specifications submitted by all 20 participating university teams for safety, compliance with the NEC and general quality of design.

- SWTDI staff performed acceptance testing of the new 30-kW PV system at the City of Phoenix Pecos Park municipal building

- SWTDI staff tested and provided a field rating for the 1-MW PV system at the Sonoma Mountain Village, Rohnert Park, California. In addition to rating the system, SWTDI engineers used this test to develop and revise the test protocols for arrays and inverters that will be put forward for consensus adoption by the T\&E group in May.

- The FSEC conducted 80 system design reviews supporting small system manufacturing. 
- Presented PV/NEC day training for more than 1700 participants-including code officials, electricians, and inspectors-from throughout the country.

- FSEC performed a round-robin test between FSEC's Spire Sun Simulator 660, Spire's multipulse and long-pulse simulators, and indoor and outdoor module performance testing at NREL. Results were described in the report "Round Robin Testing of PV Modules 2006 Between FSEC, Spire Corp. and NREL."

- The Fronius inverter originally part of the ILTF failed in Q2 of 2007 and will be sent back to Sandia for failure analysis.

- Six ILTF monitoring systems continue operation online, collecting data and realtime displays of performance on the Web throughout FY 2007.

- Construction was completed on the 18-kW modular, prototype, PV parking structure on the NMSU campus. SWTDI staff tested and provided a complete field rating for the new 18-kW PV parking structure.

- Several one-week classes, "Installing Photovoltaic Systems," were conducted at FSEC during FY 2007, training more than 200 installers.

- SWTDI provided support for Underwriters Laboratories (UL) investigation of module grounding problems and concerns.

- SWTDI has begun working closely with a major U.S. manufacturer of nonresidential, architectural, industrial, and institutional metal buildings.

- The FSEC was the first organization to have its PV program accredited by ISP (Institute for Sustainable Power, Quality). Accreditation requires periodic review and auditing.
- The FSEC is working with several partners to investigate PV-array structural attachment and integration methods.

- Two inverters (SMA, Fronius) were removed from ILTF testing and sent to Sandia National Laboratories for the second round of full characterization.

- Kaneka of Japan has finalized plans to send modules to the FSEC for long-term performance evaluation of its thin-film modules.

- The SWTDI has developed a wireless, lowcost pyranometer for integration into the systems monitoring capabilities already available in most commercial inverters.

\section{Planned FY 2008 Activities}

- Continue to support development of Codes and Standards.

- Continue to support market transformation activities with needs that capitalize on RES strengths.

- Increase SAI TPP validation test to assist DOE administration of cooperative agreements with industry.

- Increase field-test and outdoor-validation activities in support of developing reliability enhancement methodologies with the national labs.

\section{FY 2007 Special Recognitions}

John Wiles, New Mexico State University, was elected a fellow of the American Solar Energy Society.

\section{University and Industry Partners}

The following organizations partnered in the project's research activities during FY 2007 (no cost share).

\begin{tabular}{|l|l|c|c|}
\hline \multicolumn{1}{|c|}{$\begin{array}{c}\text { Organization/ } \\
\text { Principal Investigator }\end{array}$} & \multicolumn{1}{|c|}{ Location/e-mail } & $\begin{array}{c}\text { Description/ } \\
\text { Title of Research Activity }\end{array}$ & FY 2007 (\$K) \\
\hline $\begin{array}{l}\text { Florida Solar Energy Center } \\
\text { Kevin Lynn } \\
\text { Bob Reedy }\end{array}$ & $\begin{array}{l}\text { Cocoa, FL } \\
\text { klynn@fsec.ucf.edu } \\
\text { reedy@fsec.ucf.edu }\end{array}$ & PV System Research & 875 \\
\hline $\begin{array}{l}\text { Southwest Technology } \\
\text { Development Institute } \\
\text { Andrew Rosenthal }\end{array}$ & Las Cruces, NM & PV System Research & 875 \\
\hline
\end{tabular}




\title{
Component Testing and Evaluation Solar Radiometry and Metrology
}

\author{
Performing Organizations: $\quad$ National Renewable Energy Laboratory (NREL) \\ Sandia National Laboratories (SNL) \\ DOE Golden Field Office (DOE/GO)
}

Key Technical Contact:_ Daryl R. Myers (NREL), 303-384-6768, daryl_myers@nrel.gov

DOE HQ Technology Manager: Dan Ton, 202-586-000, dan.ton@ee.doe.gov

FY 2007 Budgets: $\quad$ \$750K (NREL)

\section{Objectives}

These objectives relate to accurate measurements and models relating to the levelized cost of electricity (LCOE), efficiency, dollars per peak watt $\left(\$ / \mathrm{W}_{\mathrm{p}}\right)$, and other metrics associated with the Solar Energy Technologies Program's (SETP) goals and/or the Solar America Initiative (SAI):

- Provide accurate broadband and spectral optical radiation measurements to evaluate solar conversion device and system performance consistent with the ISO 17025 accredited scope.

- Establish and maintain optical radiation calibration references traceable to national and international standards for calibrating broadband and spectral radiometers and light sources.

- Maintain technical support to the consensus standards community (e.g., American Society for Testing and Materials, International Lighting Commission) in developing industry standards.

- Perform research and development to establish and/or reduce uncertainties in optical radiation measurements related to the solar energy conversion research and development and industry.

- Transfer technology to the solar conversion industry related to solar and optical measurements and data for the design or evaluation of solar conversion technologies.

\section{Accomplishments}

These support LCOE, efficiency, $\$ / \mathrm{W}_{\mathrm{p}}$, and other metrics associated with accurate measurements of known uncertainty and appropriate consensus standards for performance testing and reporting:

- Supported the NREL Pyrheliometer Comparison (NPC), September 24-27, 2007, verifying the stability of NREL's reference absolute cavity radiometers with respect to the World Radiometric Reference (WRR).

- Performed 26 spectral and 405 solar broadband radiometer calibrations for NREL, industry, and academic partners.

- Performed on-site spectral classification of 10 industry and two NREL flash solar simulators with respect to ASTM E-927 spectral classification standard, using NREL's unique radiometer system.

- Analyzed five sources of solar radiation resource data, reported observed differences between data sets of up to $25 \%$ in an American Solar Energy Society (ASES) conference paper.

- Jointly with a South African colleague, evaluated a passive radiometer system to separate global, direct, and diffuse solar components; reported results in a Society for Photo-Optical Instrumentation Engineers (SPIE) technical conference paper.

- Provided technical input to generate or revise/update five ASTM and CIE standards on solar reference spectra, materials degradation testing, and photovoltaic (PV) performance testing.

\section{Future Directions}

- Identify means of deriving spectral distribution information from broadband data, such as Typical Meteorological Year data, to address impacts on emerging high-efficiency PV technologies. This effort addresses needs in the SAl advanced technologies area.

- Expand the evaluation of variations among multiple solar radiation data sources used for design and performance benchmarks.

- Develop techniques to reduce uncertainties in solar and broadband measurements based on new and innovative reference sources or detailed radiometer characterization. 


\section{Introduction}

The Solar Radiometry and Metrology task provides traceable optical radiation measurements that support NREL's Photovoltaic (PV) Measurements and Characterization and Reliability tasks, the PV industry, and academic partners. The task maintains ISO 17025 accreditation levels for optical radiometry associated with the NREL accreditation scope. We maintain a traceable optical measurement chain from the World Meteorological Organization World Radiometric Reference (WMO/WRR) and the National Institute of Standards and Technology (NIST) spectral irradiance scale. NREL's optical standards calibrate broadband and spectral radiometers that measure natural and artificial source optical radiation during PV performance testing. Calibrated sensors provide accurate data for developing, testing, and validating broadband and spectral models used by the research and industry communities. We provide technical input to national and international consensus standards organizations generating standard test methods important to the solar industry. Our knowledge of solar radiation resource data, instrumentation and measurement techniques, and applications is shared or transferred to SETP program researchers, the solar industry, and academia.

\section{Technical Approach}

a. Maintain the stability of the NREL solar radiation reference (absolute cavity radiometers)

b. Execute high-quality, detailed radiometric calibrations for broadband and spectral radiometers to meet NREL research and $P V$ industry needs

c. Participate in national and international consensus standards development by contributing technical expertise, data, and analysis, where appropriate

d. Provide technical information on solar radiation resource data and applications to meet research and industry needs

e. Transfer technology in this area to other researchers and industry via publications such as conference papers and presentations.

Items $\mathrm{a}$ and $\mathrm{b}$ require regular experimental and routine operations at the NREL Solar Radiation Research Laboratory and Optical Metrology Laboratory; interactions with research, industry, subcontractor, and academic contacts to meet their needs; management of the physical reference and test instrumentation; database management of results and reports; and delivering reports of results to requestors. Items $c$ through $e$ require maintaining state-of-the-art knowledge of solar and optical radiation measurement techniques, data, applications, and technical issues. We conduct and publish research results based on available and newly developed solar radiation research in house, and in technical exchanges with contacts in this scientific field. We respond to technical requests though discussions and sharing of technical publications. The following table shows the approximate level of support for formal agreements within the FY 2007 Annual Operating Plan for this task.

\begin{tabular}{|l|c|}
\hline \multicolumn{1}{|c|}{ Agreement Title } & \multicolumn{1}{|c|}{$\begin{array}{c}\text { FY 2007 } \\
\text { Budget } \\
\text { (\$750K) }\end{array}$} \\
\hline Module and Array Testing & 200 \\
\hline Cell and Module Performance & 150 \\
\hline T\&E Technical Coordination & 100 \\
\hline System Analysis and Modeling & 50 \\
\hline $\begin{array}{l}\text { Benchmarking and Design Support } \\
\text { Database }\end{array}$ & 50 \\
\hline Market, Value, Policy Analysis & 50 \\
\hline CSP System Analysis & 75 \\
\hline Solar Resource Characterization & 50 \\
\hline $\begin{array}{l}\text { PV, thermal, concentrating, } \\
\text { daylighting, solar industry } \\
\text { technology transfer, as needed }\end{array}$ & 25 \\
(a) \\
Not an official agreement; industry technology transfer is \\
based on requests received.
\end{tabular}

In addition, Technical Partnership Agreements are used as a vehicle to address industry needs requiring relatively more resources and costsharing with requestors.

\section{Results and Accomplishments}

\subsection{NREL 2007 Pyrheliometer Comparison}

The NREL Pyrheliometer Comparison (NPC) 2007 verified the stability of NREL's reference absolute cavity radiometers with respect to WMO/WRR. For reference radiometers, NREL participated with 23 other organizations such as SNL, the European Union Joint Research Center at Ispra, the National Aeronautical and Space Administration, and the National Oceanic and Atmospheric Administration.

Reference absolute cavity radiometers were compared, establishing the stability of NREL's

Photovoltaic R\&D 
WMO/WRR factor to better than $0.1 \%$. Figure 1 shows the setup for participating cavity radiometers. Figure 2 shows that the stability of NREL's reference absolute cavity radiometer AHF 23734 with respect to WRR is known with a precision of $0.06 \%$.

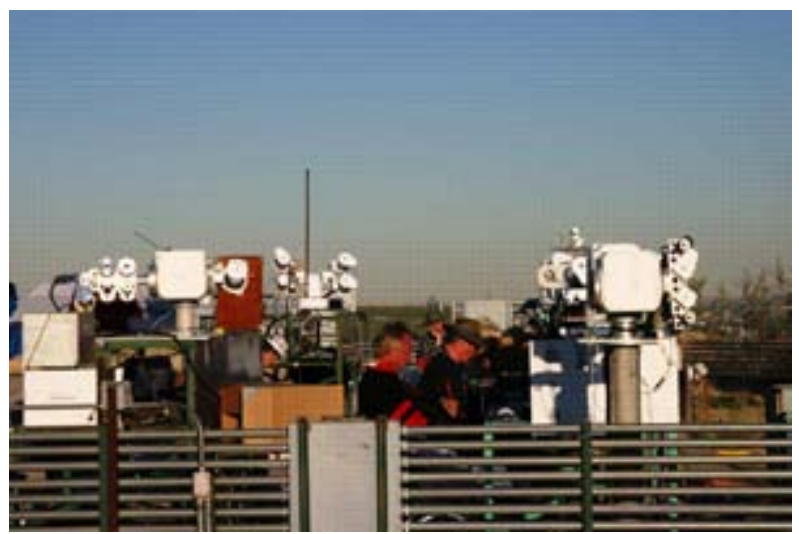

Fig.1. Sample of the absolute cavity radiometers at NPC 2007, Sept. 24-27, 2007.

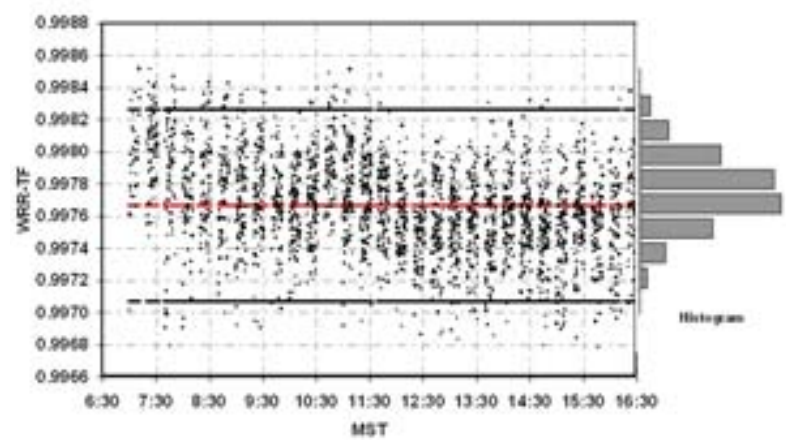

Fig. 2. NPC 2007 results for NREL's reference absolute cavity radiometer AHF 23734 showing the WRR factor to be $0.9977 \pm 0.0006$, or $\pm 0.06 \%$.

This activity is required to maintain the ISO 17025 accreditation scope for the NREL Measurement and Characterization task $\mathrm{PV}$ reference cell and $\mathrm{PV}$ reference module calibrations.

\subsection{Broadband and Spectral Radiometer Calibrations}

The task carried out three Broadband Outdoor Radiometer Calibration (BORCAL) events and the resulting calibration of 405 broadband solar radiometers traceable to WRR.

As of FY 2007, all current and historical BORCAL reports since 2001 are available on the Solar Radiation Research Laboratory (SRRL) Web site at www.nrel.gov/aim/borcal.html, as shown in Figure 3. Absolute cavity radiometer reference data for each event is also available for research purposes.

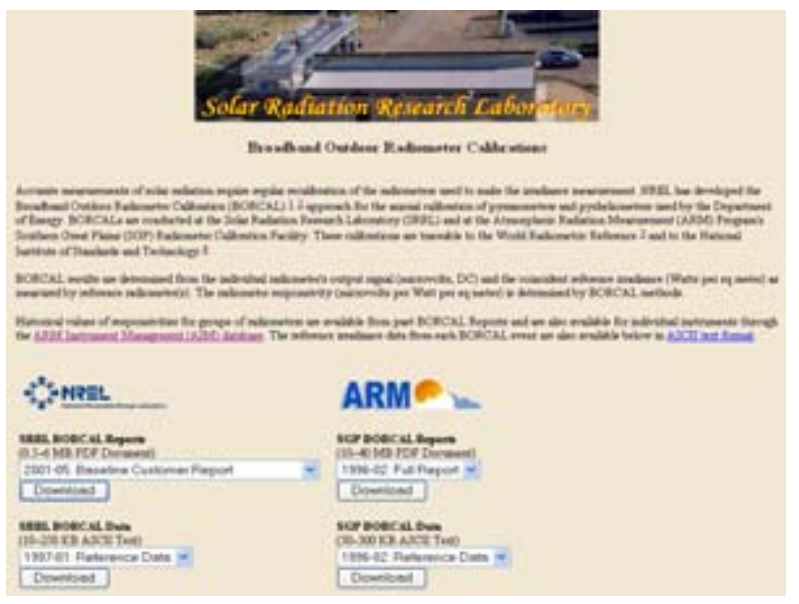

Fig. 3. Broadband radiometer calibration reports and reference data from 2001 to the present are available for download on the SRRL Web site.

We executed two biannual calibrations of 13 NREL spectroradiometers (26 calibrations in all) traceable to NIST spectral irradiance standards. The Measurements and Characterization Task reference PV cell and module calibrations uses these spectrometers under the scope of the ISO 17025 accreditation received by that task. They also aid in establishing spectral mismatch factors and characterize the natural sunlight and light sources used in PV, solar thermal, concentrating $\mathrm{PV}$, and daylighting solar technologies.

\subsection{Flash Solar Simulator Spectral Classifications}

At industry's request, NREL performed spectral classifications of 12 flash and continuous solar simulator systems. Requestors included Spire Corp., Shell Solar, Evergreen Solar, First Solar, Newport/Oriel Corp., and the Florida Solar Energy Center (FSEC). The unique Pulse Analysis Spectrometer System (PASS) developed at NREL is used to make these measurements and to regularly classify all NREL solar simulators used in the PV Measurements and Characterization Task. These data help identify and troubleshoot spectral mismatch and drift issues with industry and NREL solar simulators. Figure 4 is an example of a classification result for the FSEC Spire 660 solar simulator used to certify PV module performance for the State of Florida. 


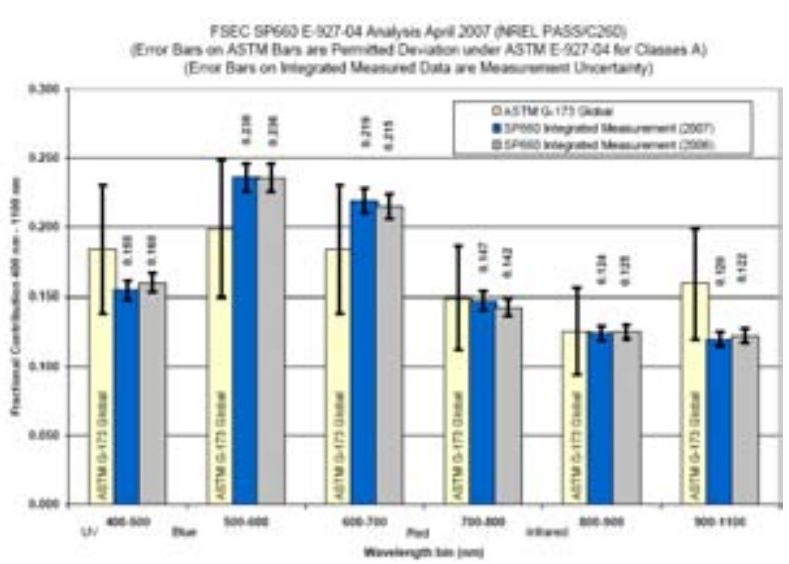

Fig. 4. April 2007 spectral classification results for the FSEC Spire 660 flash solar simulator with respect to the ASTM E-927 classification standard, using NREL's PASS spectrometer system.

\subsection{Radiometric Instrumentation Research}

With a colleague from the Kwa-Zulu Natal University in Durban, South Africa, we installed an innovative passive radiometer system for separating the global, direct, and diffuse irradiance components. The Zonal Exposure to Broadband RAdiation, or ZEBRA, shading band has regularly spaced perforations to alternately shade and expose the sensor, producing output similar to that of the rotating shadowband system, but at intervals of lower frequency and longer duration. Figure 5 shows a sketch of the system and a
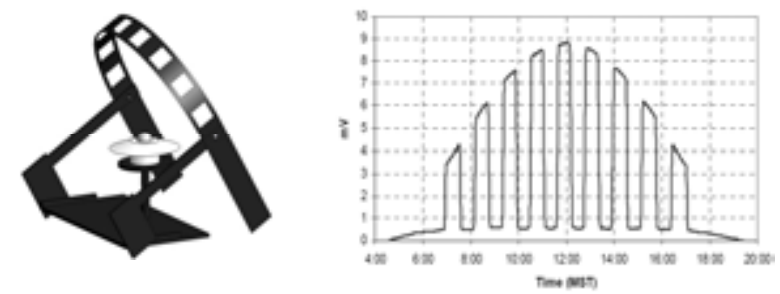

typical signal profile.

Fig. 5. Sketch of ZEBRA installation and typical clear day signal profile.

A DOE Science Undergraduate Laboratory intern from Northwestern University, Sarah Braden, developed techniques to accurately reconstruct continuous global, direct, and diffuse irradiance profiles. She applied techniques developed by Long and Ackerman [1] in identifying clear-sky profiles. She also investigated shade/unshade calibrations for pyranometers based on the system. This work resulted in a conference paper detailing promising results for the Optical Modeling and Measurements for Solar Energy Systems conference held August 24-28, 2007, in San Diego California (see the publications section).

\subsection{Solar Resource Databases and Modeling}

We undertook an investigation into the differences between five of the most popular sources for these data (NASA Surface Solar Energy [NASA SSE], European Solar Data [SoDa], Swissmeteo Meteonorm, Candian RetScreen, and the U.S. National Solar Radiation Data Base [NSRBD]). We found that, at a single site, we are able to observe differences of many tens of percent. Figure 6 compares monthly mean daily totals of solar radiation from the NASA SSE, SoDa, and Meteonorm CD-Rom. Differences of up to $25 \%$ occur between the three data sets. Many similar examples are shown in our ASES conference paper discussing the results and issues associated with the differences (see the publications section).

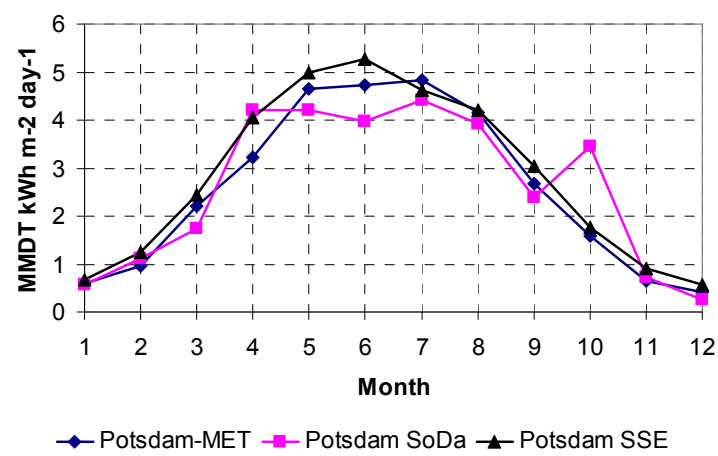

Fig. 6. Monthly mean solar irradiance data for Potsdam, Germany, from three different solar databases (NASA SSE, SoDa, Meteonorm).

We reevaluated the cloud cover modifier algorithm for the all-sky version of the Bird clear-sky model, published in 2006. We used two additional clearsky models and NSRDB cloud cover data to compare with modeled solar data. We used lqbal's Parameterization C and Gueymard's REST2 to show that a simple polynomial cloud cover modifier generates a realistic time series of hourly solar radiation data from a reasonable clear-sky model and available cloud cover data. Figure 7 compares time series of the original NSRDB data for a typical site with the Iqbal Parameterization C model cloud modified results. Similar results were obtained with the REST model. Details were published in a paper for the Optical Modeling and Measurements for Solar Energy Systems conference held August 24-28, 2007, in San Diego. 


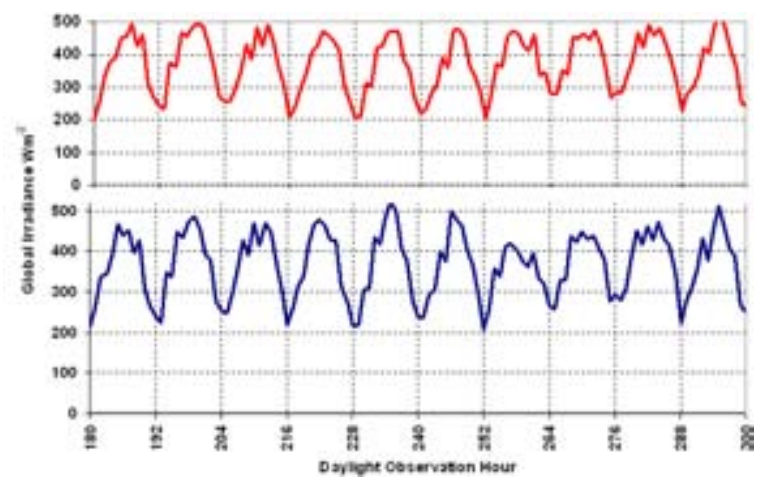

Fig. 7. Comparison of hourly time series for NSRDB data (bottom) and clear-sky model with cloud cover modifier applied for a typical NSRDB site. The model produces realistic time series data.

\subsection{Consensus Standards Activities}

We provided technical input and draft language for multiple documents at ASTM committee meetings for Committee G03 on Weathering and Durability, and for CIE technical committee TC2-17 on revising CIE-85 on Solar Spectral Irradiance. We also reviewed, commented upon, and voted on 10 new and revised ASTM Committee E-44 standards on PV performance testing.

\subsection{Technical Transfer}

We responded to more than 120 technical requests from over 100 entities on the following: solar radiation instrumentation and calibration; broadband and spectral solar models (e.g., Bird, REST2, DISC, SMARTS2, SEDES2, and SPCTRL2); data obtained using RetScreen, Meteonorm, NASA SSE, NSRDB, TMY2, WMO/WRR, SoDa, and SWERA, as well as DOE EnergyPlus weather data and SRRL baseline measurement data; and applications (e.g., PVWatts, SOLAR ADVISOR, PVFORM). We reviewed 15 journal articles at the request of editors of five different professional journals. In addition, the task leader organized and chaired two technical conferences on solar and optical radiation in FY 2007:

- Council for Optical Radiation Measurements Annual Technical Conference: Optical Radiation Standards Development for Industry, in conjunction with CIE-USA and NIST, May 8-11, 2007, Gaithersburg, Maryland.

- Optical Modeling and Measurements for Solar Energy Systems, August 24-28, 2007, in San
Diego, California, a part of the SPIE Photonics 2007 Symposium.

We also contributed three book chapters on solar radiation measurements and modeling (see the publications section). And we initiated a costshared Technical Services Agreement (TSA-07130) with SPIRE Corp. to provide the company with a PASS solar simulator classification spectrometer for internal use. The TSA is scheduled to conclude by the middle of FY 2008.

All of the technical accomplishments described above reflect the completion of the five milestones listed in the following table.

\begin{tabular}{|l|c|l|}
\hline FY 2007 Milestone & Level & Accomplished \\
\hline $\begin{array}{l}\text { Perform NPC } \\
\text { verification of } \\
\text { NREL WRR } \\
\text { traceability }\end{array}$ & 5 & Sept. 28, 2007 \\
\hline $\begin{array}{l}\text { Calibrate 13 NREL } \\
\text { spectroradiometer } \\
\text { systems }\end{array}$ & 5 & $\begin{array}{l}\text { Sept. 30, 2007 (26 } \\
\text { calibrations) }\end{array}$ \\
\hline $\begin{array}{l}\text { Calibrate broad- } \\
\text { band radiometers } \\
\text { for PV industry and } \\
\text { NREL }\end{array}$ & 5 & $\begin{array}{l}\text { Aug. 30, 2007 (405 } \\
\text { calibrations) }\end{array}$ \\
\hline $\begin{array}{l}\text { Characterize NREL } \\
\text { and industry flash } \\
\text { solar simulators }\end{array}$ & 5 & $\begin{array}{l}\text { Sept. 30, (15 total } \\
\text { characterizations) }\end{array}$ \\
\hline $\begin{array}{l}\text { Prepare technical } \\
\text { publications and } \\
\text { conduct technology } \\
\text { transfer }\end{array}$ & 4 & $\begin{array}{l}\text { Sept. 30 } \\
\text { (organized two } \\
\text { conferences, 5 } \\
\text { conf papers, 3 } \\
\text { book chapters, 2 } \\
\text { draft standards) }\end{array}$ \\
\hline
\end{tabular}

\section{Planned FY 2008 Activities}

- Conclude Spire Corp. TSA-07-130 with delivery of PASS system to Spire for internal use by March 2008

- Investigate and develop techniques for deriving solar spectral distribution data from broadband solar radiation data (such as TMY2 hourly data) to support SAl activities in emerging PV technologies

- Research the possibility for a high-accuracy detector-based spectral irradiance calibration system to reduce uncertainty in spectral calibrations

- Conduct NPC 2008 to maintain WRR traceability and ISO 17025 accreditation 
- Conduct spectral and broadband radiometer calibrations in support of SETP program needs.

\section{FY 2007 Special Recognitions}

In conjunction with Spire Corp. (TSA-07-130; innovation report No.07-43), asserted copyright on NREL PASS operational software.

\section{Major FY 2007 Publications}

D. Myers, "General Cloud Cover Modifier for Clear Sky Solar Radiation Models," Optical Modeling and Measurements for Solar Energy Systems, Conference Vol. 6652, SPIE, Bellingham, WA (2007).

D. Myers, "Relative Performance of Multiple Solar Radiation Resource Assessment Data Sources," Solar 2007, Annual Conference of the American Solar Energy Society, Cleveland OH, July 7-12, Boulder CO: American Solar Energy Society (2007).

D. Myers, Government Participation in Consensus Standards Development, OMB Circular A-119, Council for Optical Radiation Measurements Annual Technical Conference, Optical Radiation Standards Development for Industry, in conjunction with CIE-USA and NIST, May 8-11, 2007, Gaithersburg, MD.

M.J. Brooks, S. Braden, and D. Myers, "Passive Separation of Global Irradiance into Direct Normal and Diffuse Components," Optical Modeling and Measurements for Solar Energy Systems, Conference Vol. 6652, SPIE, Bellingham WA (2007).
C. Gueymard and D. Myers, "Performance Assessment of Routine Solar Radiation Measurements for Improved Solar Radiation and Radiative Modeling," Solar 2007, Annual Conference of the American Solar Energy Society, Cleveland, $\mathrm{OH}$, July 7-12, Boulder, CO: American Solar Energy Society (2007).

S. Wilcox et al., "Completing Production of the National Solar Radiation Data Base for the United States," Solar 2007, Annual Conference of the American Solar Energy Society, Cleveland, $\mathrm{OH}$, July 7-12, Boulder, CO: American Solar Energy Society (2007).

D. Myers, "The Solar Resource," Solar Hydrogen Generation, Toward a Renewable Energy Future, K. Rajeshwar, S. Licht, and R. McConnell, eds., Springer (2008).

C. Gueymard and D. Myers, Solar Radiation Measurements: Progress in Radiometry for Improved Modeling in Modeling Solar Radiation at the Earth's Surface: Recent Advances, V. Badescu, ed., Springer (2008).

C. Gueymard and D. Myers, "Validation and Ranking Methodologies for Solar Radiation Models," Modeling Solar Radiation at the Earth's Surface: Recent Advances, V. Badescu, ed., Springer (2007).

\section{References}

1. C.N. Long and T.P. Ackerman, "Identification of Clear Skies from Broadband Pyranometer Measurements and Calculation of Downwelling Shortwave Cloud Effects," Journal of Geophysical Research, vol. 105, no. D12, 15609-16626 (2000).

\section{University and Industry Partners}

The following organizations partnered in the project's research activities during FY 2007.

\begin{tabular}{|l|l|l|c|c|}
\hline $\begin{array}{c}\text { Organization/ } \\
\text { Principal } \\
\text { Investigator }\end{array}$ & \multicolumn{1}{|c|}{ Location/e-mail } & \multicolumn{1}{|c|}{$\begin{array}{c}\text { Description/Title of Research } \\
\text { Activity }\end{array}$} & $\begin{array}{c}\text { FY } \\
\mathbf{2 0 0 7} \\
\text { (a) }\end{array}$ & $\begin{array}{c}\text { Cost Share* } \\
\text { (\$K) }\end{array}$ \\
\hline $\begin{array}{l}\text { Spire Corp. } \\
\text { Harvey Serrez }\end{array}$ & $\begin{array}{l}\text { Bedford, MA } \\
\text { HSerreze@spirecorp.com }\end{array}$ & $\begin{array}{l}\text { NREL designed Pulse Analysis } \\
\text { Spectrometer System for internal } \\
\text { applications, quality control of flash } \\
\text { simulator designs, TSA-07-130 }\end{array}$ & $\begin{array}{c}20+\text { purchase } \\
\text { of equipment } \\
(30)\end{array}$ \\
\hline
\end{tabular}

${ }^{(a)}$ To be concluded in the 2nd quarter of FY 2008. 


\title{
PDIL Infrastructure, Engineering, and Integration
}

\author{
Performing Organization: \\ National Renewable Energy Laboratory (NREL) \\ Key Technical Contacts: \\ Brent Nelson (NREL, Primary Contact), 303-384-6407, \\ brent_nelson@nrel.gov \\ Steve Robbins (NREL), 303-384-6400, steven_robbins@nrel.gov \\ Robert White (NREL), 303-384-7802, robert_white@nrel.gov
}

DOE HQ Technology Manager: Marie Mapes, 202-586-3765, marie.mapes@ee.doe.gov

FY 2007 Budgets: $\quad \$ 1,750 \mathrm{~K}$

Objectives

- Develop, Improve, and implement process integration standards.

- Provide project management for securing capital equipment to go into the Process Development and Integration Laboratory (PDIL).

- Provide infrastructure development for facilities and for the installation of equipment.

- Develop an integrated software infrastructure within the PDIL that enables secure data access for National Center for Photovoltaics (NCPV) personnel and research partners.

- Work with core research teams to develop research partnerships with external collaborators, including making the PV industry aware of the PDIL in Web sites and by other means.

\section{Accomplishments}

- Provided installation support for installing the silicon cluster tool, including replacing the entire gas-handling hardware and the installation of specialty gas line infrastructure.

- Provided project management support leading to the competitive procurement of a molecular beam epitaxy (MBE)-type of deposition chamber for copper indium (gallium) diselenide (GIGS) material, a central robotic transfer chamber, and ancillary deposition chambers for metals, transparent conducting oxides (TCOs), and cadmium sulfide (CdS).

- Provided project management and engineering development for the design of an automated chemical bath deposition system for CdS growth.

- Provided project management support leading to the procurement of an atmospheric processing platform, which includes ink jet printing and spray jet deposition of metals and semiconductor materials.

- Provided project management and engineering development for the design of processintegration-compatible measurement and characterization equipment developed at NREL, including resonance-coupled photoconductive decay (RCPCD), photoluminescence (PL) imaging, and a special spectroscopic ellipsometry chamber; integrated this equipment into a central robotic transfer chamber along with a sputtering/etching chamber and a chamber for studying plasma enhanced chemical vapor depositions (PECVD).

- Provided project management support leading to the procurement of stand-alone processintegration-compatible measurement and characterization equipment, including Auger electron spectroscopy (AES), X-ray photoelectron spectroscopy (XPS), scanning electron microscopy (SEM), atomic force microscopy (AFM), a wet chemistry workstation, a reflectometer, an optical processing furnace, and a Semilab tool.

- Provided project management and engineering development in the design of a CdTe platform capable of fully processing a CdTe device.

- Provided project management and engineering development in the design of a silicon wafer replacement platform.

\section{Future Directions}

- Complete the acquisition and hardware installation of the equipment listed above. 
- Complete the development of the data infrastructure for the data feeding into, and being generated by, the equipment listed above.

- Assist the core groups in developing cooperative agreements for research to be performed with the equipment listed above or to be supplied under these agreements.

\section{Introduction}

The National Center for Photovoltaics has been working to develop a collaborative research facility where established and start-up photovoltaic (PV) companies, as well as potential university partners, can work with NREL scientists and engineers to gain the knowledge they need to further their respective PV technologies. The ultimate goal is to get the right teams of people working with the best equipment possible to try to answer the most important questions in a particular technology. Toward that end, we have built a new building and developed a set of design standards for equipment to populate the space. This equipment will be used in research that includes polycrystalline thin-films, thin silicon film, atmospheric processing of contacts and absorber materials, and a variety of characterization tools to support a spectrum of $\mathrm{PV}$ roadmap technologies.

Integration standards include the establishment of a maximum substrate size and shape, the form factor of a platen that accommodates a variety of samples, a fixed sample transfer height, a standard chamber interface that allows modular techniques to be readily reconfigured between platforms, and a mobile sample transfer pod that enables intertool transport of samples between platforms in a controlled ambient. We are also developing software and data integration schemas that allow powerful software tools to be used with full security. Finally, we have a process with which to assess proposed activities within the collaborative facility and to ensure that proper facility and equipment resources are allocated, along with bringing together the best skill sets to accomplish project goals.

The purpose of the process-integration project is to develop an infrastructure that will allow researchers to gain new knowledge that is difficult-if not impossible-to obtain with existing equipment. This difficulty is due, in part, to the state of the NCPV's existing tool set, which either lacks sufficient in situ or real-time measurement capabilities or lacks access to analytical or subsequent processing capabilities, where the sample remains in a controlled environment between measurements and/or steps. Integration of the existing tool set is virtually impossible because of the wide variety of sample sizes used and the nature of the existing equipment. Therefore, the process-integration project is involved in developing new infrastructure implementing a core set of standards that make possible an integrated collection of techniques. As NREL, industrial, and university staff collaborate to define, construct, and use specific technology platforms, this will accelerate the growth of the PV knowledge base and help to move many PV technologies forward.

\section{Technical Approach}

The first step in integrating various techniques within and between platforms is to develop standards for the common interface and transport elements. Integrating a diverse set of tools requires a "universal" maximum substrate size and shape to be held in a platen. The platen's size and shape drive the requirements for the entire design. The various core activities within the NCPV have set, by consensus, the maximum substrate size that the platen can handle to be approximately 6 in. $x 6$ in. This size supports the silicon PV industry, which has both a "6-inch square" protocol in multicrystalline $\mathrm{Si}$ and a "6-inch round" protocol in single-crystalline $\mathrm{Si}$. It also more than adequately supports the other technological areas studied by the NCPV with a commercially viable area.

Various platen designs will be needed to accommodate several different substrates, such as soda-lime glass, high-temperature glass (e.g., Corning 1737), crystalline wafers (e.g., of silicon, germanium, or gallium arsenide), and thin stainless steel, ceramic, and exotic materials. The platen is a 7 -in. $\times 7$-in. square with holes centered along each edge for alignment purposes. Individual deposition, processing, and characterization techniques will be integrated via one of several different modes. Ideally, characterization techniques will be used for realtime analysis of deposition and processing techniques. The next best solution is in situ diagnostics (in the original place, but not real-time data). 
When neither of these integration modes is possible, techniques will be integrated by transferring samples from one location to another either via intratool or intertool sample transport. Intratool transport is the movement of samples between techniques on the same platform. The actual transfer mechanism will typically be a robotic transport mechanism in a central chamber, but it could be a linear track. The intratool transfer height is the Semiconductor Equipment and Materials International (SEMI) standard of $1.1 \mathrm{~m}$ above the floor.

Intertool transport is the movement of samples between techniques when those techniques do not share a direct connection. The techniques could be in a stand-alone tool or a part of a larger platform. The sample is moved from one platform into a pod, which is sealed and disconnected from that platform before being wheeled to another platform, where the process is reversed. The transfer ambient within the pod can be either an atmosphere of ultra-high-purity inert gas or high vacuum.

This intertool transport is similar to the Standard Mechanical InterFace (SMIF) used by the integrated-circuit (IC) industry to enclose and transport wafers between 200-mm tools, or the newer Front-Opening Unified Pods (FOUPs) used on $300-\mathrm{mm}$ tools. One of the keys to the success of the IC industry was the creation of these minienvironments, in which the industry significantly reduced the contamination of wafers between processing steps. While SMIFs and FOUPs are typically operated with particulate-free, dry air, our initial pods will operate under high vacuum using a battery-powered ion pump. Thus, they will go beyond limiting particulate contamination to limiting molecular contamination (e.g., reactions of surfaces with oxygen or water vapor). Our microenvironment also allows us to integrate equipment without requiring clean-room facilities. The use of intertool transport in a high-vacuum ambient on such a large sample is a unique capability.

A final integration mode is to make some of our techniques modular so that they can be moved between platforms. All chambers connecting to platforms will use a standard 10-in. metal sealed vacuum flange (Conflat $\AA$ ), centered at $1.1 \mathrm{~m}$ above the floor; therefore, a modular deposition, processing, or characterization technique can be docked on any given platform based on project needs, strategic priorities, and available space. Not all techniques can be modular, however, because size, sensitivity, complexity, and safety issues must be taken into account.

Because very few techniques are commercially available that are integrated into a platform-and none that use our standard sample size or intertool integration scheme-participating core activities within the NCPV are defining their own platforms. They have been in consultation with their industrial and university collaborators with regard to the specific techniques built into each platform. NCPV management manages these plans within the scope of the NCPV strategic vision and available resources. The processintegration project works tactically to implement these plans according to integration standards.

\section{Results and Accomplishments}

In addition to the accomplishments listed in the summary, the following items were accomplished.

A Web site was planned and is being implemented. It includes a voice-over to a PDIL animation explaining the conceptual implementation of process integration standards. Other animations explaining PV basics and specific research within various PV technologies, and defining integration terminology, are being developed. Currently, a home page has been posted at www.nrel.gov/pv/pdil.html.

As soon as funding was allocated, the process began for hiring key PDIL staff. A senior research technician was hired who is helping with hardware installations of equipment. A controls engineer was also hired who is helping with automating hardware for sample motion, process control, and data logging. A software integrator was hired who is automating the secure databasing of diverse deposition, processing, and measurement data in collaboration with the scientific computing center, so that NCPV staff members have access to sophisticated software tools in order to analyze their data.

Project management support of equipment acquisitions by the core research teams was provided by a variety of means, depending on the need: from engineering and design, to writing statements of work, to providing assistance in negotiating the acquisition process, to helping track expenses. Project management through NREL's Earned Value Management System was also provided for the Science and Technology Facility Essential Capital Equipment. A relational 
database was developed to help meet the goal of tracking equipment to related data, such as support of the PV technology roadmaps, NCPV research plans, staffing, acquisition activity, potential industrial collaborators, and installation projects. The illustration depicts an entity relationship diagram showing how the data fit together.

\section{Planned FY 2008 Activities}

The activities planned for FY 2008 are to complete the tasks initiated in FY 2007, with added emphasis on software development and equipment installations.

\section{University and Industry Partners}

No cooperative research agreements were finalized within the PDIL during FY 2007. Because of the sensitive nature of the collaborations that the core research teams have been negating, these collaborations will be described in the annual reports for PV technologies or for measurement and characterization areas.

\section{Data Relationships in the NCPV Proposal Management Database}

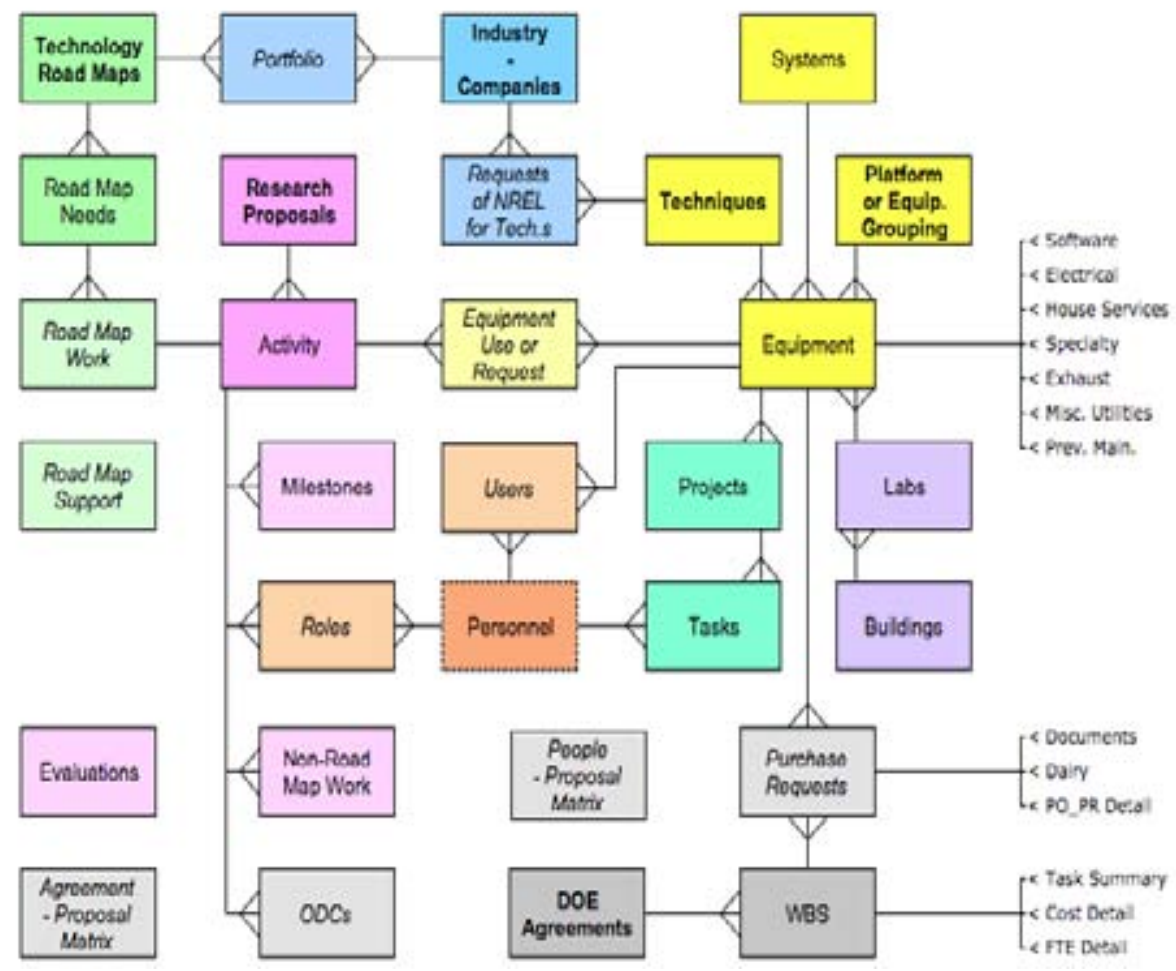

Entity relationship diagram of the NCPV proposal and equipment management database. 


\section{Market Transformation}

The Solar America Initiative (SAI) aims to make photovoltaic (PV) technologies, or solar electricity, cost-competitive with conventional forms of electricity from the utility grid by 2015 . The U.S. Department of Energy is working to accomplish this goal through work at its national laboratories and public-private partnerships with industry, universities, states, municipalities, and nongovernmental organizations. When federal solar energy research began in the 1970s, the cost of electricity from solar resources was about $\$ 2.00$ per kilowatt-hour $(\mathrm{kWh})$. Technological advances during the last two decades have reduced solar electricity costs by more than $90 \%$ to about $20 \phi$ per kWh, opening up new markets for solar energy. Due in large part to DOE-funded research, the cost of electricity from PV has dropped more than tenfold since 1976.

In addition to the research and development efforts, DOE conducts complementary activities in the area of market transformation to lower market barriers and capitalize on large-scale solar deployment opportunities. Areas of market transformation work include: solar codes \& standards, solar rating systems, education and training for installers, system financing options, and strategic stakeholder partnerships. DOE works with states, cities, non-profits, utilities, labor unions, and industry to address commercialization barriers and to educate solar stakeholders. DOE's specific market transformation activities include:

- Solar America Board of Codes \& Standards: The board works to ensure the responsiveness, effectiveness, and accessibility of PV codes and standards to U.S. stakeholders at all levels.

- Solar America Cities: Cities are both the nation's population and electricity-load centers, so this activity focuses on increasing the adoption of solar energy technologies at the local level. Partner cities engage in cost-shared activities and receive technical assistance from DOE-identified experts to help overcome barriers to increased solar installations.

- Solar America Showcases: These showcases are large, public projects that demonstrate solar energy technologies to the public. Partners receive technical assistance from DOEidentified experts to assist in the implementation of these projects.

- State Technical Outreach: DOE partners with nongovernmental organizations to build relationships with and provide necessary information to decision makers to develop energy policies and programs.

- Utility Technical Outreach: DOE partners with nongovernmental organizations to provide technical assistance and information to utilities to promote their acceptance and use of solar technologies.

Achievements in Market Transformation for FY 2007 include:

Codes and Standards

- Led an industry forum with more than 100 attendees for Article 690 of the National Electrical Code (NEC) that resulted in 46 proposals and follow-up on public comments for inclusion into the 2008 NEC.

Training and Certification

- Published 52 issues of the Interstate Renewable Energy Council/SAl e-newsletter for 1,700 subscribers 


\section{Technology Acceptance}

- Administered the photovoltaic and solar thermal exam twice, in March and September. At the end of fiscal year, 422 people were certified PV Installers and 56 Solar Thermal Certificants.

\section{Building Integration}

- Prepared for and conducted a successful 2007 Solar Decathlon university competition on the National Mall in Washington, DC., (October 2007).

- Conducted building energy monitoring and computer modeling research on past Solar Decathlon houses to improve future contests, quantify the annual performance of the houses, identify areas of technical significance, and extend the education and outreach component of the competition beyond the 10 days on the National Mall.

- Completed initial data gathering and analysis on state and local government financing of PV.

\section{Technical Partnerships}

- Prepared a report technically defining the solar energy opportunities for federally-owned Congressional office buildings in Washington, D.C.

- Established strategic partnerships with 13 cities through a competitive funding opportunity and awarded a combined $\$ 2.5$ million in financial assistance.

- Planned the installation of a 1-megawatt PV system on the roof of the Orange County Convention Center (OCCC), in partnership with the Orlando Utilities Commission (OUC).

\section{Technical Outreach}

- Created a readily accessible database of current and previous years' bills on energy, Solar State Legislation (www.ncsl.org/programs/energy/energypolicy.cfm).

- Launched a Web site (www.statesadvancingsolar.org) that serves as a resource for state policy makers and decision makers interested in developing a solar program.

- Released the "Solar Energy Technology and Policy Reference Guide."

- Released "The Peer Matching Online Tool" (www.solarelectricpower.org/peer/) to share information and best practices to help all utilities improve their solar programs. 


\title{
Codes and Standards
}

\author{
Performing Organizations: $\quad$ National Renewable Energy Laboratory (NREL) \\ Sandia National Laboratories (SNL) \\ New Mexico State University (NMSU) \\ Tucson Electric Power (TEP) \\ Research Foundation of the State University of \\ New York (SUNY-Albany) \\ Key Technical Contacts: Holly Thomas (DOE Golden Field Office, Primary Contact), \\ 303-275-4818, holly.thomas@go.doe.gov \\ Thomas Basso (NREL), 303-275-3753, thomas_basso@nrel.gov \\ Ward Bower (SNL), 505-844-5206, wibower@sandia.gov
}

DOE HQ Technology Manager: Charlie Hemmeline, 202-586-6646, charlie.hemmeline@hq.doe.gov

FY 2007 Budgets: $\quad \$ 1,998.6 \mathrm{~K}$

\section{Objectives}

- Provide consistent support for codes and standards development so that solar technology can be deployed on a large scale.

- Improve the responsiveness, effectiveness, and accessibility of codes and standards in all markets (federal, state, local, and utility).

- Address codes, standards, and related infrastructure development and issues.

- Establish utility photovoltaic (PV) capacity credits models to reduce market barriers and promote solar-energy technologies acceptance.

\section{Accomplishments}

- NREL conducted a study on external disconnect switch (EDS) for grid-connected PV systems.

- SNL led an industry forum (100+ attendees) for Article 690 of the National Electrical Code (NEC) that resulted in 46 proposals and follow-up on public comments for inclusion into the 2008 NEC. Final balloting included language from 40 of the proposals.

- SNL provided the principal member of the Code Making Panel for National Electrical Code articles 690 and 705 (Utility Interconnected Systems), to create a common code basis for interconnecting to the grid.

- SNL applied PV-related International Electrotechnical Commission (IEC) standards used in Europe and many other parts of the world.

- $\quad$ SNL continued efforts to improve the test protocol for certification of inverters for PV applications.

- NMSU established the Solar America Board for Codes and Standards (Solar ABCs) to coordinate and organize approaches to addressing market-transformation barriers.

- NMSU developed Solar ABCs Web site (www.solarabcs.org), which includes solar standards and codes documents, to be used to disseminate information on the Solar ABCs programs.

- NMSU organized PV Stakeholders Workshop at Solar Power 2007 Conference in Long Beach, California (September 2007); the workshop had approximately 250 attendees.

- TEP published a draft model for valuing the effects of short-time-frame variations on solar-electric power availability using actual data from the Springerville Generating Station Solar System to address one of the utility market barriers to implementing PV.

- SUNY-Albany prepared a catalogue of capacity credit metrics and evaluated and compared metrics with experimental case studies to assess solar capacity credit options.

- NMSU, NREL, Sandia, SUNY-Albany, and TEP presented initial results at a PV Stakeholders Workshop, leading to a preliminary consensus about the options in each of the research topics. 


\section{Future Directions}

- NREL will continue providing leadership for, participation in, and coordination with, existing and new codes and standards assisting in removing market barriers for the broad use of PV systems.

- SNL will work to improve domestic and applicable international standards primarily for interconnection and higher penetrations of PV to make way for widespread and increased deployment of PV systems in the United States.

- SNL will provide validation of proposed codes, standards, and certifications, to avoid unnecessary requirements and costs.

- Solar ABCs group will complete eight major studies on key codes and standards topics.

- Solar ABCs group will conduct a formal gap analysis and work with PV stakeholders to analyze the current state of major codes and standards for solar energy and produce a prioritized list of codes and standards most urgently needed to remove barriers and promote deployment of solar technologies.

- TEP will complete an analysis comparing traditional hourly sample analysis methods for electric load carrying capacity value with newly developed Demand Time Interval Method (DTIM) model results using actual hourly and shorter time-frame production data from two utility solar systems.

- TEP will discuss comparative results with other electric utilities and publicize results at a national meeting.

\section{Introduction}

Codes and standards are the backbone of the success of the Solar America Initiative (SAI). The goal of the Codes and Standards project is to address the critical marketplace barriers to implementing photovoltaic (PV) systems. The project focuses on codes, standards, and certifications, as well as the agreements for net metering and system interconnection that prevent or slow the acceptance of solar technologies in the mainstream marketplace.

To reduce or remove barriers to solar technology commercialization, this project also seeks consensus-based solutions to address the multiplicity of state and local jurisdictions to create more consistent standards and regulatory environment for PV. Examples of such barriers include an undue multiplicity of state and local jurisdiction requirements, which sometimes are lacking technical rationale or are based on inexperience and a misunderstanding of solar technologies. Further, historically there has been a lack of uniformity and transparency for standards requirements and best practices for PV products, systems, installation, acceptance, and interconnection with the electric utility grid.

\section{Technical Approach}

NREL and Sandia, to accomplish the goal of the project, conducted work that complemented additional work from a U.S. Department of Energy (DOE) Funding Opportunity Announcement (FOA) issued during fiscal year 2007 (FY 2007). The FOA requested assistance to provide the Solar Codes and Standards Working Group Leadership with ideas to support the development and adoption of specific capacity credit values or other utility-approved values for system benefits of PV. As a result of the FOA, three agreements were negotiated; these provide a coordinated approach for a Standards and Codes Working Group, and address standard methods to value PV. NREL and Sandia helped develop the scientific and engineering data needed to establish new and necessary codes and standards in the areas of interconnections, buildings, net metering, and $\mathrm{PV}$ ratings, by participating in the several recognized standards organizations that develop these codes to ensure that resulting regulations are compatible with PV requirements.

\begin{tabular}{|l|c|}
\hline \multicolumn{1}{|c|}{ Agreement Title } & $\begin{array}{c}\text { FY 2007 } \\
\text { Budget (\$K) }\end{array}$ \\
\hline NREL & 350 \\
\hline Sandia & 250 \\
\hline $\begin{array}{l}\text { An Integrated Partnership to Create } \\
\text { and Lead the Solar Codes and Stan- } \\
\text { dards Working Group }\end{array}$ & 1,200 \\
\hline $\begin{array}{l}\text { Utility Solar Generation Valuation } \\
\text { Methods }\end{array}$ & 100 \\
\hline $\begin{array}{l}\text { A Standard Definition of PV Capacity } \\
\text { Credit }\end{array}$ & 98.6 \\
\hline
\end{tabular}

\subsection{Technical Support-NREL}

NREL staff provides leadership for and coordination of existing and new codes, standards, and entities that have jurisdiction in these areas. An integrated and collaborative approach is used 
to address related solar codes, standards, and their adoption in conjunction with stakeholders. The NREL approach is predicated on broad consensus involving large numbers of individuals and entities.

Coordinating codes and standards development, and revision, and providing technical assistance to adopting organizations forms the cornerstone of efforts to minimize redundancy and expenses to the industry. The coordination and collaborations result in expanded and new access for PV system installations in a broad set of scenarios, with fewer and less-restrictive barriers. NREL continues to provide expert technical assistance for DOE SAI solar codes and standards approaches, activities, and performing organizations; and also interfaces with SAI Technology Pathway Partnerships grantees.

\subsection{Technical Support-Sandia}

SNL's approach focuses on reducing and eliminating barriers to the deployment of PV and other distributed systems. Sandia supports the SAI Technology Pathway Partnerships through testing and evaluation of codes, standards, and certifications-related functionality of new hardware and systems. The organization continues to use industry groups, such as the "Industry Forum," and industry requests to identify and verify issues (through testing and analysis) that must be addressed.

\subsection{Standards and Codes Working Group- NMSU}

This 5-year Solar Codes and Standards Working Group Leadership project is designed to identify current issues, establish a dialogue among key stakeholders, and catalyze appropriate activities to support the development of codes and standards that facilitate the installation of high-quality, safe photovoltaic systems.

\subsection{Utility Solar Generation Valuation Methods}

Work began on this project to develop, test, and verify a method for accurately evaluating the capacity credit of time-variant power from solar generation. Traditional methods are compared with new methods to determine approaches that appropriately and fairly evaluate the value of solar generation to electric utilities. These results will lead to verified models that accurately assess the adequate compensation that solar owners provide to utilities.

\subsection{A Standard Definition of PV Capacity Credit}

This project is designed to establish a set of consensus-driven standard methodologies to quantify PV capacity credit that are acceptable to all concerned stakeholders, ranging from utilities and grid operators to the solar industry and related advocacy groups. The project also documents and describes the methodologies as a function of the relevant parameters affecting capacity, including PV generation, load demand, and market structure.

\section{Results and Accomplishments}

\subsection{Technical Support-NREL}

NREL provided expert technical assistance in the development of SAI solar codes and standards, including:

- Recommending development of a formal charter for the Solar America Board for Codes and Standards; the recommendation was implemented in September 2007.

- Conducting a study on external disconnect switch (EDS) for grid-connected PV systems, evaluating the effects of evolving technology and standards and changing perceptions of the need for utility-accessible external disconnect switch (EDS) and related regulations (09/07). Although utility arguments for requiring utility-accessible EDSs for gridconnected PV systems might have been justifiable 5 or 10 years ago, today the EDS issue is effectively addressed by UL and IEEE standards. The utility-accessible EDS increasingly is viewed as redundant and unnecessary for residential and small-commercial PV systems with UL-listed inverters.

- NREL staff members served as: The chair of the IEEE Standards Coordinating Committee 21 (SCC 21) on Fuel Cells, Photovoltaics, Dispersed Generation and Energy Storage (http:// grouper.ieee.org/groups/scc21); officers for various individual SCC21 standards activities; and as an IEEE Standards Board Liaison to the DOE. A number of IEEE SCC21 standards were renewed or published And IEEE SCC21 continually offers to sponsor new standards for PV per stakeholder priorities (09/07).

- Participating in numerous state utility-commission workshops on interconnection and net metering (e.g., Washington, DC; Florida; lowa; Illinois; Maryland; New Mexico; South Dakota; Utah) (09/07). 


\subsection{Technical Support-SNL}

SNL staff members served as chair of the Industry Forum for Article 690 of the National Electrical Code, and as a principal member of Code Making Panel for Article 690 and Article 705. Sandia staff also served on crucial committees associated with the Underwriters Laboratories Standards for inverters and controllers for PV and other distributed-generation applications. Sandia reviewed and provided language for changes in UL1741 for inverters and controllers and worked to verify and validate testing methodologies. Sandia also provided funding to and collaborated with BEW Engineering on international standards (specifically the International Electrotechnical Commission (IEC)) as the convener of Working Group 6 (PV Inverter and BOS standards) for Technical Committee 82 (TC82). The collaborative work with BEW also extended to further work in completing an economical testing protocol for certification of inverters. Much of this work was related to eliminating barriers to integrating PV systems into the utility grid. All work was focused on collaboration with Technology Pathway Partnership recipients and Market Transformation reduction in barriers.

\subsection{An Integrated Partnership to Create and Lead the Solar Codes and Standards Working Group- NMSU \\ Work began in several areas. The Solar America Board for Codes and Standards (Solar ABCs) was organized, studies were begun, and PV stake- holder outreach was initiated. Specific accomplish- ments include:}

- Establishing Solar ABCs and adopting a charter describing its purpose.

- Initiating studies on the following topics:

- Solar system issues, including arc fault interrupter and external disconnect switch requirements and the effects of high winds;

$\circ$ Identifying causes and severity of PV module failures resulting from polymer property failure issues;

- Standardizing PV cell performance;

- Evaluating concentrating PV safety;

- Approaches to speed system permitting;

- Solar access and solar rights;

- Advanced metering infrastructure; and

- Rating and comparing the various system interconnection models.
- Developing Solar ABCs Web site (http:// www.solarabcs.org) to disseminate information on Solar ABCs programs (09/07).

- Organizing PV Stakeholders Workshop attended by approximately 250 people at Solar Power 2007 conference in Long Beach, California (09/07).

\subsection{Utility Solar Generation Valuation-Tucson} Electric Power

Electric utilities must have sufficient generating capacity available at all times to meet the load demands of customers. Many studies have evaluated the capacity credit of solar generation to utilities. Utilities, however, need tools to use highresolution (short time-scale) solar generation data to produce results accounting for regional effects on specific systems. TEP began work this year to develop a new and appropriate method for evaluating the capacity credit of solar generation. This work included:

- Identifying the need for short time interval (10 second to 5 minute) analysis of power availability because of local effects on a solar system, including cloud cover (09/07).

- Developing draft Demand Time Interval Method (DTIM), and presenting it at the Solar Power 2007 PV Stakeholder Workshop (09/07).

\subsection{A Standard Definition of PV Capacity Credit- SUNY-Albany}

As part of the SAI, SUNY began evaluating the variety of photovoltaic capacity valuation methods. It also began to bring the solar industry, electric utility, and research communities together with the goal of consensus on the most appropriate PV generation-capacity valuation methodology. Reaching consensus on methodology is an important step in removing barriers on dispersed PV generation-barriers which are the result of an incomplete and often contentious understanding of PV generation benefits. SUNY also completed and presented a draft of, "Moving Toward Consensus on a Photovoltaic Generation Capacity Valuation Methodology" for the PV Stakeholder Workshop, Solar Power 2007 Conference, Long Beach, California (09/2007).

\section{Planned FY 2008 Activities}

- NREL staff will provide leadership for and coordinate existing and new codes, standards, and entities that have jurisdiction in these 
areas and over standards and codes requirements, such as state public utility commissions.

- Sandia continues to chair the Industry Forum (now 150 members strong) and to provide leadership for Article 690 and Article 705 for the National Electrical Code (NEC). Major changes will begin to be implemented in the 2011 edition of NEC with a increased effort to include all interconnect requirements in Article 705 while maintaining the unique and PVspecific requirements in Article 690-Solar Photovoltaic Systems. Sandia staff will continue as a principal part of the codemaking-panel for PV- and distributed generation-related code requirements.

- Sandia continues to work closely with NMSU and the SAI Solar ABCs groups to provide needed verification for new requirements before they are published.

- Sandia will organize and lead the new "Inverter/controller/BOS/energy management Advisory Group" to prioritize activities for the Solar Energy Grid Integration Systems program and the Renewable System Interconnection initiative for advanced hardware for connection to the utility grid. This includes recommending updates and revisions for codes, standards, and certifications.

- Sandia is leading the U.S. DOE Solar Energy Grid Integration Systems (SEGIS) program, which focuses on developing advanced inverters, controllers, and balance of system and energy-management hardware that likely will need new codes and standards requirements.

- NMSU throughout the year will facilitate stakeholder involvement and communication on codes and standards issues, including holding stakeholder meetings and distributing electronic newsletters.

- NMSU will complete studies on standards and code topics listed in section 3 above (07/08).

- NMSU will provide recommended amendments to the National Electrical Code for solar systems (09/08).

- NMSU will conduct a formal Gap Analysis and work with PV stakeholders to analyze the current state of major codes and standards for solar, and produce a prioritized list of codes and standards most urgently needed to remove barriers and promote the deployment of solar technologies (06/08).

- TEP will discuss comparative results with several other electric utilities, and will publicize results at a national meeting (06/08).

- SUNY-Albany will recommend two to three capacity credit metric methodologies (06/08).

- SUNY-Albany will conduct "webinars" to disseminate findings and will write one to three technical articles to publicize recommended methodologies (06/08).

\section{Major FY 2007 Publications}

T. Hansen, "Utility Solar Generation Valuation Methods", Solar Power 2007, PV Capacity Value Workshop, Long Beach, California, September 2007.

J. Wiles, W. Bower, "Changes In the 2008 National Electrical Code ${ }^{\circledR}$ For PV Installations" Proceedings of the ASES Solar 2007, Cleveland, Ohio, June 2007.

\section{Partnerships}

The following organizations partnered in the project's research activities during FY 2007.

\begin{tabular}{|l|l|l|c|c|}
\hline \multicolumn{1}{|c|}{$\begin{array}{c}\text { Organization/ } \\
\text { Principal Investigator }\end{array}$} & \multicolumn{1}{|c|}{ Location/E-mail } & \multicolumn{1}{|c|}{$\begin{array}{c}\text { Description/Title of } \\
\text { Research Activity }\end{array}$} & $\begin{array}{c}\text { FY 2007 } \\
\text { (\$K) }\end{array}$ & $\begin{array}{c}\text { Cost Share } \\
\text { (\$K) }\end{array}$ \\
\hline $\begin{array}{l}\text { NREL } \\
\text { Thomas Basso }\end{array}$ & $\begin{array}{l}\text { Golden, CO } \\
\text { Thomas_basso@ } \\
\text { tion in, and coordination with } \\
\text { existing and new codes, } \\
\text { standards, and authorities } \\
\text { having jurisdiction, such as } \\
\text { utility commissions. }\end{array}$ & 350 & 0 \\
\hline
\end{tabular}




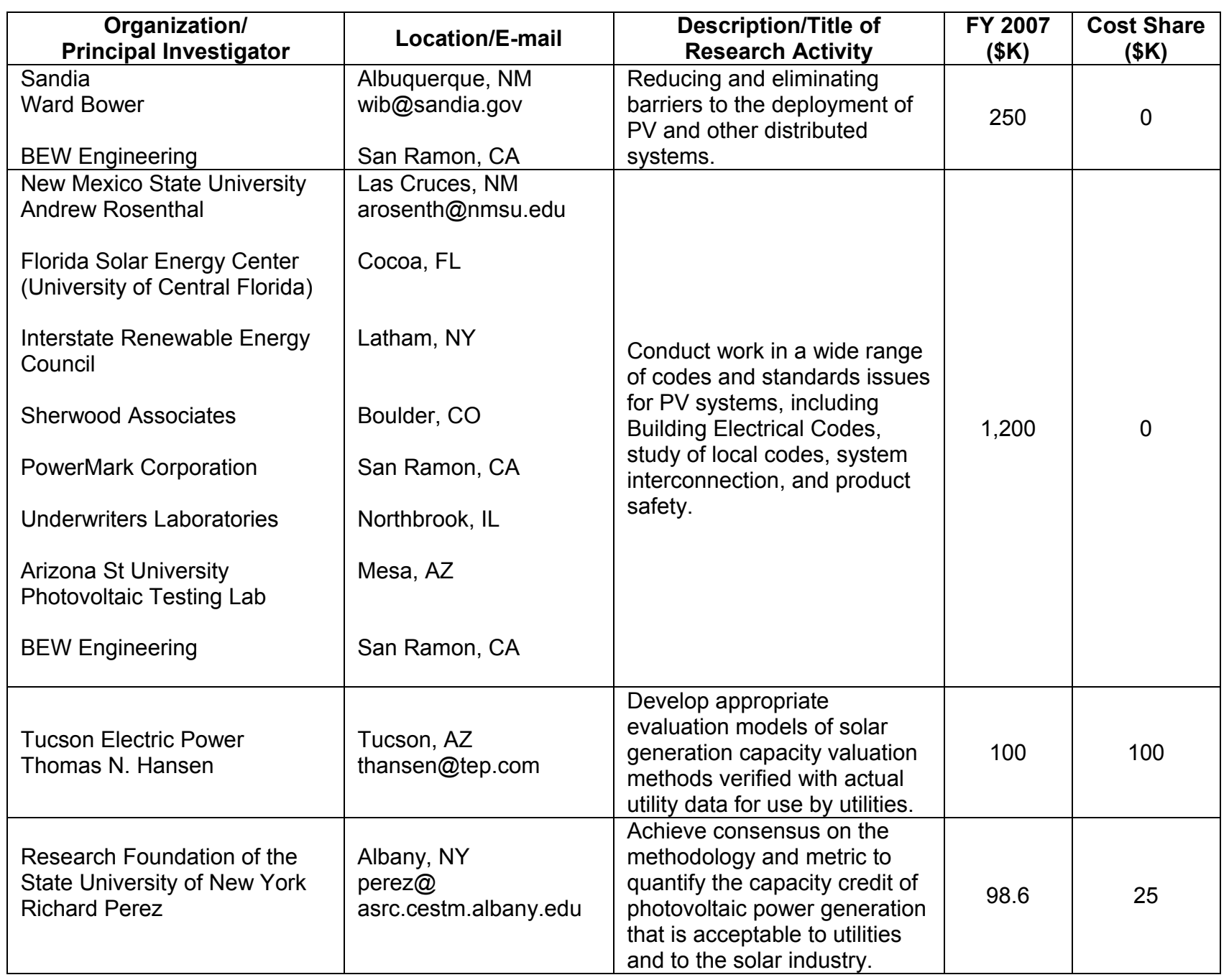




\title{
Training and Certification
}

\author{
Performing Organizations: Interstate Renewable Energy Council (IREC) \\ New Mexico State University (NMSU)
}

Key Technical Contacts: $\quad$ Margie Bates, (DOE Golden Field Office, Primary Contact), 303-275-4845, Margie.bates@go.doe.gov

Kevin Lynn (Florida Solar Energy Center), 202-586-1044, Kevin.lynn@hq.doe.gov

Ward Bower (Sandia National Laboratories), 505-844-5206, wibower@sandia.gov

John Wiles (Southwest Technology Development Institute), 505-646-6105, jwiles@nmsu.edu

DOE HQ Technology Manager: Charlie Hemmeline, 202-586-6646, charlie.hemmeline@hq.doe.gov

FY 2007 Budget: $\quad \$ 600,000$ (DOE/GO)

\section{Objectives}

Interstate Renewable Energy Council

- Promote better communications among stakeholders under the Solar America Initiative (SAI), to address infrastructure barriers to solar energy in coordination with industry, the U.S. Department of Energy (DOE), national laboratories, states, cities, and counties.

- Create a five-year plan based on getting the right information to the right people; working on and implementing sustainable solutions to institutional and market barriers to solar energy; and offering easy and accessible communication channels for sharing information. IREC's five-year plan encompasses the following:

- Web Site and Newsletter. Manage and maintain the Interstate Renewable Energy Council

Web site, which is the principal source of information for and about SAI Market

Transformation (MT) partnerships and stakeholders, offering easily accessible news, information, tools, and materials.

- Bi-weekly SAI-Market Transformation E-Newsletter. Bring up-to-date news and events to partnerships, state stakeholders, and federal agencies via e-mail.

- SAI-Market Transformation Telephone Seminars. Connect experts with SAI-MT stakeholders on key issues in a cost-effective, convenient format. Post summary and highlights of seminar on the SAI Web site.

- Connecting to the Grid Project. Provide models and assistance on net metering and interconnection to lower both barriers and cost for solar electricity installations. IREC continually updates model rules and the Connecting to the Grid guidebook, and provides technical assistance to solar stakeholders, including states, utilities, and other stakeholders.

- Workforce Training and Quality Assessment Project. Encourage quality and accessible learning opportunities, lower installation and repair costs, and enhance consumer confidence. IREC coordinates and works with the North American Board of Certified Energy Practitioners and the Institute for Sustainable Power to maintain and expand the online course catalog, provides assistance to educational providers, maintains and updates training and certification Web pages, and updates Labor Forecast and Job Trends and Occupational Profiles reports.

- Solar Codes and Standards Public Hearings. Monitor and participate, as appropriate, in public hearings and meetings and provide input using best practices that could impact solar barriers and/or commercialization (e.g., interconnection and net metering) in the wake of Energy Policy Act (EPAct) requirements for state consideration. IREC prepares and posts on the IREC Web site a report on the outcome of the public hearings.

- Annual Publication. Prepare and submit an annual report documenting trends and impacts regarding interconnection and net metering, training and certification programs, state incentives, and other relevant newsworthy issues. 
New Mexico State University

- Establish a Solar Codes and Standards Working Group (SCSWG) that is engaged in identifying current issues, establishing a dialogue among key stakeholders, and catalyzing appropriate activities to support the development of codes and standards that facilitate the installation of highquality, safe photovoltaic (PV) systems, as well as education and training in the codes and standards. This sustained effort supports the timely introduction of new technologies as they occur and the overall growth of PV deployment to new sectors of the energy market.

- Establish SCSWG activities within three major descriptive categories: study areas, coordination activities, and implementation activities. Coordination activities will be conducted by working panels designed to enable communication and planning across different codes and standardssetting processes in these five areas: building electrical codes, product safety codes, national standards, interconnection and net metering, and international standards. The working panels will provide implementation activities in support of these key stakeholder groups: code officials, state energy offices, and regulators.

- Establish an Interconnection/Net Metering Working Panel whose objectives are to focus on providing needed support to U.S. PV stakeholders in this important and often diverse context. Tasks for this working panel consist of Web-based activities, coordination activities, and training and outreach activities. The panel is coordinating with ongoing IREC activities in this area to minimize duplication of effort and maximize leveraging opportunities.

- Through the Interconnection/Net Metering Working Panel, obtain access to discussions and solutions of interconnection and net metering challenges, including facilitating communications between jurisdictions facing such challenges and those who have successfully met them. All activities and tasks are designed particularly for outreach, training, and interaction with SCSWG members and PV stakeholders, and they are critical to supporting growth in U.S. PV deployment over the next several years.

\section{Accomplishments}

Interstate Renewable Energy Council

IREC has accomplished the following to meet the objective to remove institutional and market barriers:

- Published 52 issues of the IREC/SAI e-newsletter for 1,700 subscribers and posted issues on the IREC Web site.

- Regularly updated the State-by-State Interconnection and Net Metering Tables on the Web.

- Promoted IREC's Model Rules on Interconnection and Net Metering.

- Produced Web-based, monthly updates of the EPAct tracking database of interconnection and net metering state activities.

- Published 24 issues of the Interconnection/Net Metering e-newsletter for 2,300 subscribers and posted on the IREC Web site.

- Regularly updated the State-by-State Interconnection and Net Metering Tables.

- Promoted IREC's Model Rules on Interconnection and Net Metering.

- Produced monthly updates on the EPAct tracking database of interconnection and net metering state activities.

- Published the $5^{\text {th }}$ edition of the Connecting to the Grid Guide.

- Updated Job Trends and Occupational Profile Reports.

\section{Future Directions}

\section{Interstate Renewable Energy Council}

- In the Connecting to the Grid Project, provide models and assistance on net metering and interconnection to lower both the barriers to and the cost of installations of solar electricity.

- Conduct workforce training activities to implement a sustainable solution to the market barrier of having too few trained solar professionals to meet market demand.

- Through the Workforce Training and Quality Assessment Project, provide assistance to educational providers and coordinate the project with assistance from the North American Board of Certified Energy Practitioners (NABCEP) and the Institute for Sustainable Power; coordinate training workshops with states, cities, and other SAI-MT stakeholders to facilitate training 
workshops for code officials to help them recognize codes and standards applicable to PV installations and understand important PV electrical installation issues.

- Through the Solar Codes and Standards Hearing Project, address infrastructure barriers with the states. IREC has coordinated a team of individuals (e.g., engineers, lawyers) who can provide technical information to state policymakers and other stakeholders on solar codes and standards. Additional information will be provided to policymakers and other SAI-MT stakeholders before, during, or after the hearings.

- Through the SAI-Market Transformation Recipient E-Newsletter and frequent telephone seminars, address infrastructure barriers by "getting the right information to the right people"; 26 issues of the SAI-MT E-Newsletter will be disseminated per year, and six SAI Telephone Seminars, with a final report after each one are planned.

- Continually maintain the IREC Web site, which enables focused stakeholder coordination and addresses key barriers with all stakeholders, including industry, DOE, national laboratories, and the states.

New Mexico State University

- Web-based Activities: Develop Web-based activities as an important element identified by the Interconnection/Net Metering Working Panel that will include developing and operating a listserve forum to facilitate discussions of interconnection and net metering issues identified by SCSWG members and the public.

- Coordination Activities: Through the Interconnection Standards Study Panel, perform a one-year examination of critical interconnection issues that will analyze existing utility interconnection screens (institutional forms and processes that allow approval of interconnect requests) adopted by local jurisdictions and the perceived roles of these screens in facilitating PV deployments. This panel will also determine the usefulness of the external utility disconnect switch that local jurisdictions often require but is also often described as superfluous and unneeded. The panel will prepare a final report to identify resolutions of contentious issues governing the interconnection process from both institutional and hardware perspectives.

\section{Introduction}

The Interstate Renewable Energy Council seeks to promote better communications among stakeholders under the Solar America Initiative/Market Transformation (SAI-MT) project to address infrastructure barriers to solar energy and to coordinate with industry, DOE, national laboratories, states, cities and counties. This five-year plan is based on getting the right information to the right people; working on and implementing sustainable solutions to institutional and market barriers to solar energy; and offering easy and accessible communication channels for sharing information.

\section{Technical Approach}

In 2007, IREC continued to promote better communications among stakeholders, addressed infrastructure barriers by promoting easy and fair hook-up rules to the utility grid, promoted quality training based on industry competency standards, and coordinated closely with multiple federal, state and local stakeholders.

\subsection{Net Metering and Interconnection}

The August 2005 enactment of the federal Energy Policy Act (EPAct) of 2005 and the May 2005 adoption of Federal Energy Regulatory Commission (FERC) Order 2006 have inspired several states to examine or reexamine interconnection standards and/or net-metering rules. EPAct created another reason for states to consider net metering and interconnection. Under Sections 1251 and 1254, every utility must offer interconnection-based on Institute of Electrical and Electronics Engineers (IEEE) 1547 rules_and net metering to all of their customers.

Along with this increased activity, IREC has been participating in state working groups providing legal and technical expertise. In 2007, seven states were on the priority list: Arizona, Florida, Illinois, Maryland, New Mexico, North Carolina and Texas.

IREC's approach on Interconnection Rules includes the following:

- Rules should be designed to eliminate as many barriers as possible to result in easy but safe interconnection.

Photovoltaic R\&D

Market Transformation Training and Certification 
- Rules are the collection of best practices from federal and state actions, e.g., those of FERC Order 2006, National Association of Regulatory Commissions (NARUC) New Jersey, Massachusetts, Colorado, and Texas.

- The IREC model uses as its core the recent IEEE 1547 standard and the associated Underwriters Laboratories 1741 testing standard.

- The interconnection procedures are divided into four areas to categorize interconnections from the least to the most complex:

- Level 1-10 kW and smaller for certified inverters (residential-sized systems)

- Level 2 - $2 \mathrm{MW}$ and smaller, certified (commercial net metering and other systems)

- Level 3-10 MW certified generators, nonexporting (designed for combined heat and power, or $\mathrm{CHP}$, facilities)

- Level 4 - All others up to $10 \mathrm{MW}$, including generators that attempt to meet but do not qualify for other, more expedited standards.

\subsection{New Mexico State University}

NMSU has developed an Interconnection/Net Metering Working Panel under its Solar Codes and Standards Working Group that will focus on providing necessary support to U.S. PV stakeholders in this important and often diverse context. The working panel coordinates with ongoing IREC activities in this area to minimize the duplication of effort and maximize leveraging opportunities. Examples include these:

- Web-Based Activities. NMSU Web-based activities include developing and operating a list-serve forum to facilitate discussions of interconnection and net metering issues identified by SCSWG members and the public.

- Coordination Activities. The NMSU's Interconnection/Net Metering Working Panel holds regular, open meetings for SCSWG to establish priorities and action plans for addressing the most pressing problems facing SCSWG members. Panel members participate in public forums to gain greater access to discussions and solutions of interconnection and net metering challenges, including facilitating communications between jurisdictions facing such challenges and those who have successfully met them.

\subsection{IREC's Workforce Development}

Because of the growth in the solar market over the past few years and renewed attention to solar energy solutions, workforce development and quality training have become a critical component for this sector. If the goals of the Photovoltaic Industry Road Map are met, direct employment would increase from 20,000 now to 62,000 by 2015 . DOE estimates that as many as 5,000 trained installers could be needed by 2015 to accomplish the new Solar America Initiative.

IREC continues its work with Community Colleges and with the North American Board of Certified Energy Practitioners (NABCEP). IREC focuses its work on quality training and verifies the legitimacy of the training content and trainers. In consultation with subject matter experts and educational providers, IREC's training approach is based on these recommendations:

- Design training to provide educational and skill-development experiences that lead to defined workplace knowledge, skills, and abilities.

- Address issues of safety, codes, and core competencies of an industry-approved task or job analysis.

- Conduct training in appropriate facilities with proper tools, safe practices, and in an atmosphere of administrative and managerial quality.

- Offer a formal, planned learning structure in which the learner receives feedback and the learner's progress is monitored.

- Conduct training under the administration of a legally registered entity.

- Ensure that training is offered by any accredited university, college, community college, or vocational-technical institute; or by any Joint Apprenticeship and Training Committee or U.S. Department of Laborapproved apprenticeship program; or by a training program accredited by IREC to Institute for Sustainable Power quality (ISPQ) standards or those of a similar accrediting body; or is approved by the State Contractor Licensing Boards; or is offered or taught by a certified installer with instructional experience. 


\section{Results and Accomplishments}

- Published 26 issues of the IREC/SAI enewsletter

- Published 12 issues of the Interconnection/ Net Metering e-newsletter

- Added 5,000 subscribers to the two newsletters

- Regularly updated the State-by-State Interconnection and Net Metering Tables on the Web

- Promoted IREC's Model Rules on Interconnection and Net Metering

- Produced Web-based, monthly updates of the EPAct tracking database of interconnection and net metering state activities

- Organized six phone seminars; topics included solar renewable energy credits, interconnection and net metering, feed-in tariffs, federal solar tax incentives, photovoltaic market trends, and solar access laws

- Convened six workshops for code officials

- Participated in and filed comments and reply comments at interconnection/net metering hearings and meetings in targeted states

- Updated Job Trends and Occupational Profile Reports.

\section{Planned FY 2008 Activities}

To meet the SAI objectives for Solar Outreach and Communications proposed for FY 2008, IREC will use an integrated approach that combines Web-based resources, on-site and electronic forums, print material and technical assistance by utilizing and enhancing the resources described in the following paragraphs.

The IREC Web site (www.irecusa.org) will feature news, articles, and events covering areas such as solar schools, interconnection to the grid and net metering, community and national outreach, workforce development (training and certification), and other stakeholder information.

IREC continues to coordinate and participate in stakeholder coordination activities with DOE, industry, states, and all stakeholders, and actively participates in the annual American Solar Energy Society (ASES), Solar Energy
Industries Association (SEIA), and Solar Electric Power Association (SEPA) conferences.

IREC will publish the Connecting to the Grid newsletter. Issues include state, national, international, industry news, publications and events. Three important trends have been reported: first, how the North American Electric Reliability Corporation is beginning to accommodate renewables at the grid level; second, how many utilities are planning to make significant investments in utility-scale renewables; and, third, how time-of-use pricing, as facilitated by automated metering infrastructure, has the potential to make retail rates correspond realistically to wholesale rates-a shift that changes everything.

Regarding workforce development, IREC will continue working on implementing quality assessment of training programs and instructors, a critical component. IREC is using the ISP international framework of metrics and standards to measure the quality and consistency of training programs and trainers. IREC works with educational providers such as Lane Community College, Hudson Valley Community College, Solar Energy International, the North Carolina Solar Energy Center, Florida Solar Energy Center, and other training resources. In addition, IREC will continue working closely with NABCEP and the ISP to ensure quality assessment of practitioners and training programs. IREC's proposals for two forums at the ASES 2008 May conference were accepted: one on workforce development and the other on certification.

In addition, IREC is writing an article for the Northeast Sun magazine on workforce development. And IREC is working with New York State in planning the second Workforce Education Conference, which will take place the week of March 17, 2008, at Hudson Valley Community College outside of Albany, NY. Also, during the last quarter of 2007, IREC's Annual Report on updates and trends was released. The Annual Metrics Report will be prepared in March 2008. 
At solar codes and standards public hearings, IREC and its team of experts provide legal and regulatory expertise and are currently monitoring and participating in state and public hearings that could impact interconnection standards and net metering, especially in regard to EPAct requirements. In consultation with industry and DOE, IREC has targeted seven states for interconnection and net metering rule-making activities: Arizona, Florida, Illinois, Maryland, North Carolina, New Mexico, and Texas.

The semi-monthly SAI/IREC State E-Newsletter will continue to report on DOE, state, stakeholder, and former Million Solar Roofs Initiative partner activities. More than 2,000 people receive the newsletter. Plans are underway with DOE SAI-MT staff to focus on news and interviews with Solar America cities.

IREC will also plants to continue to host SAI Telephone Seminars featuring select topics and expert speakers based on stakeholder input. The seminars, which have been widely attended, are interactive, allowing each participant to view presentations and ask questions. Seminar highlights and presentations are available on the IREC Web site.

\section{Major FY 2007 Publications}

In addition to numerous presentations at conferences and meetings, project members published the following:

Connecting to the Grid Guidebook, $5^{\text {th }}$ Edition (2007).

J. Weissman, "Workforce Education for Renewable Energy: Lessons Learned from a National Gathering of Educators," Proceedings of the ASES Annual Conference, July (2007).

L. Sherwood, "U.S. Solar Market Trends," Proceedings of the ASES Annual Conference, July (2007).

Annual Metrics Reports on Solar Installations (2007).

Annual Trends \& Update Report, September (2007).

\section{University and Industry Partners}

IREC works closely with many groups, industry, and community colleges, which include the following:

- North Carolina Solar Center at North Carolina State University

- The Southwest Technology Development Institute at New Mexico State University

- New York State Energy Research and Development Authority

- North American Board of Certified Energy Practitioners 


\title{
Technology Acceptance
}

\author{
Performing Organizations: $\quad$ DOE Golden Field Office (DOE/GO) \\ North American Board of Certified Energy Practitioners (NABCEP) \\ Key Technical Contact: $\quad$ Steve Palmeri (DOE/GO) 303-275-4832, steve.palmeri@go.doe.gov \\ DOE HQ Technology Manager: Thomas Kimbis, 202-586-7055, tom.kimbis@ee.doe.gov \\ FY 2007 Budgets: $\quad$ \$325K (DOE/GO)
}

\section{Objectives}

- Since 2003, the North American Board of Certified Energy Practitioners (NABCEP) has been awarding professional credentials to solar installers. NABCEP's provides rigorous competency standards for certification to send a clear message to consumers, financers, and public officials that the Industry stresses high quality, safe and ethical business practice, and workmanship standards.

\section{Accomplishments}

- Administered the photovoltaic (PV) exam twice, in March and September. At the end of fiscal year (FY) 2007, 422 people were certified PV Installers.

- Administered the solar thermal exam twice, in March and September. At the end of FY 2007, there were 56 Solar Thermal Certificants.

\section{Future Directions}

- $\quad$ NABCEP plans to continue offering PV and solar thermal exams, in March and September 2008.

- Due to the popularity of the PV Entry Level Certificate of Knowledge, NABCEP plans to develop a sample exam, study guide, and/or a course outline for instructors.

\section{Introduction}

Since 2003, the North American Board of Certified Energy Practitioners (NABCEP) has been awarding professional credentials to solar installers. NABCEP's rigorous competency standards for certification sends a clear message to consumers, financers, and public officials that the Industry stresses high quality, safe and ethical business practice, and workmanship standards.

NABCEP has three certification programs:

- Professional credential for Solar Electric (PV) Installers

- Professional credential for Solar Thermal Installers

- Entry level certificate of knowledge for PV

\section{Technical Approach}

NABCEP recognizes that professionals in the field of renewable energy technologies receive their training and work experiences in a variety of ways. Therefore, each requirement to qualify for the exam stipulates specific training and/or experience.

Both the PV and solar thermal credentialing programs are based on strict, psychometric principles and credentialing guidelines. The program is rigorous, requiring documentation of experience and/or training and the passing a 4hour exam.

NABCEP has developed two task analyses, one for the PV Installer and the other for the Solar Thermal Practitioners. The task analysis is a formal process for determining what people do, under what working conditions they do it, what they must know to do it, and the skills they must have to do it. A technical committee of subject matter experts develops the task analysis.

The task analysis contributes to test validity by ensuring that the critical aspects of the job become the domain of content that the test measures. 
The PV Installer Task Analysis includes 8 main tasks and 58 subtasks. The Solar Thermal Task Analysis includes 12 main tasks and 129 subtasks.

After the overall content of the test has been established through the task analysis, the next step in developing a test is to create the detailed test specifications. Test specifications include a test description component and a test blueprint component. The test description specifies aspects of the planned test such as the test purpose, the target examinee population, the overall test length, and more. The test blueprint provides a listing of the major content areas and cognitive levels intended to be included on each test form.

Once the test specifications are complete, the item writing phase of the test development project begins. A panel of subject matter experts is assembled to write a set of test items (questions). NABCEP convenes both the PV Exam Committee and the Solar Thermal Exam Committee. The Committee is assigned to write items according to the content areas and cognitive levels specified in the test blueprint. Items are written for each of the item types identified in the test specifications.

Both the PV and Solar Thermal exams are given twice a year. Each exam runs for a maximum of 4 hours and includes 60 scenario-based multiplechoice questions. The exams are administered with strict security and monitored by both a proctor and administrator.

NABCEP also offers an entry level Certificate of Knowledge aimed at students wanting to get into the solar photovoltaic field. After taking a course from an approved provider and passing a national exam, this Certificate shows that the recipient has achieved basic knowledge, comprehension and application of key terms and concepts of photovoltaic (solar electric) system operations. The Certificate by itself does not qualify an individual to install PV systems but it does prepare them for employment in the field.

As the market grows for PV, the person holding this industry-sponsored Entry Level Certificate is likely to find that their employment opportunities enhanced by starting the job with an understanding of the basic terms and operational aspects of a PV system and that their NABCEP Entry Level Certificate is noticed by potential employers.

\section{Results and Accomplishments}

Exam Administration

The PV and solar thermal exams are administered twice, in March and September.

At the end of FY 2007, 422 people were certified PV Installers. The Solar Thermal Credential was started in 2006, and at the end of FY 2007, there were 56 Solar Thermal Certificants. These certificants represent 41 states, as well as Canada, Puerto Rico, and Honduras.

By the end of the fiscal year, NABCEP had 26 institutions offering the PV Entry Level Certificate of Knowledge course and exam, a 44\% increase. These were top 10 states:

\begin{tabular}{|l||c|c|}
\hline State & $\begin{array}{c}\text { Number of PV \& } \\
\text { Solar Thermal } \\
\text { Certificants }\end{array}$ & Percent of Total \\
\hline California & 145 & $33 \%$ \\
\hline Colorado & 31 & $7 \%$ \\
\hline New York & 29 & $7 \%$ \\
\hline Wisconsin & 18 & $4 \%$ \\
\hline New Jersey & 17 & $4 \%$ \\
\hline Vermont & 17 & $4 \%$ \\
\hline New Mexico & 13 & $3 \%$ \\
\hline Texas & 13 & $3 \%$ \\
\hline Arizona & 11 & $2.5 \%$ \\
\hline Ohio & 11 & $2.5 \%$ \\
\hline
\end{tabular}

PV and Solar Thermal Exam Committee Meetings

The Solar Thermal Exam Committee met in Chicago on June 4-6, 2007, and the PV Exam Committee met in Albuquerque on June 26-28, 2007. The main purpose was to add new questions to the item bank for the upcoming exams, test assembly, pool review, and standard setting exercise.

Outreach to consumers and industry

NABCEP exhibited at:

- New York Solar Industries Exhibition in Albany, New York

- Midwest Renewable Energy Fair in Custer, Wisconsin

- ASES Solar Energy Conference in Cleveland, Ohio 
- NJATC - National Training Institute (NTI) "Train the Trainer" Conference in Knoxville, Tennessee

- Solar Power 2007 Conference in Long Beach, California

- NECA 2007 Conference in San Francisco, California

As part of our outreach strategy, a board member used SEPA's conference registration listing for the Solar Power 2007 Conference to prepare an invitation list and agenda for a state lunch and presentation at the conference.

\section{PV Entry Level Certificate of Knowledge}

At the end of FY '07, NABCEP has 26 institutions offering the Entry Level course and exam, a $44 \%$ increase. Additionally, we have noticed a marked increase in inquiries from eligible institutions. To date, 662 students have taken the exam.

\section{ANSI Accreditation}

NABCEP has been going through the application and audit process for Accreditation to the ISO Standard 17024, Bodies that Certify People. On September 10, 2007, we learned that we had earned the prestigious ANSI/ISO/IEC 17024 Accreditation. This award validates NABCEP's Solar PV Installer Certification Program by an independent, unbiased accreditation body.

ANSI/ISO/IEC 17024 specifies requirements which ensure that organizations operating certification systems for persons operate in a consistent, comparable, and reliable manner. This accreditation includes rigorous requirements for examination development and maintenance and for quality management systems. ANSI/ISO/IEC 17024 has been approved by 85 countries.

\section{Planned FY 2008 Activities}

\section{$\mathrm{PV}$ and Solar Thermal Exams}

NABCEP will be offering the PV and Solar Thermal exams for experienced installers on March 15 and September 13, 2008, at various locations across the United States.

\section{PV Entry Level Certificate of Knowledge}

This certificate has become very popular among Community Colleges and offers students a career ladder into the solar energy field. We have received numerous requests from students and instructors for a sample exam, study guide, and/or a course outline for instructors, and have plans to develop one or more of these tools in the upcoming fiscal year.

Outreach to Consumers and Industry

NABCEP plans to exhibit at the following events:

- NESEA Conference, Boston, MA (March 1113)

- Workforce Education Conference, Troy, NY (March 18-20)

- SEI/ COSEIA Conference, Fort Collins, CO (March 25-29)

- Solar NY/NYSEA Albany, NY (April 15)

- $\quad$ ASES, San Diego, CA (May 3-8)

- MREA, Custer, WI (June 20-22)

- NECA, Chicago, IL (October 4-7)

- Solar Power 2008, San Diego, CA (October 13-17)

ANSI

Quarterly meetings will be held with a subcommittee to review updates and changes to documents and procedures affected by organizational changes. We also prepare for our yearly on-site process audit.

\section{University and Industry Partners}

NABCEP works closely with representatives from the following companies and organizations:

- American Wind Energy Association

- Alternative Energy Institute

- Appalachian State University

- BP Solar

- Home Power Magazine

- IBEW

- Interstate Renewable Energy Council

- Malaspina College

- Midwest Renewable Energy Association

- National Electrical Contractors Association

- National Joint Apprenticeship \& Training Committee

- National Renewable Energy Laboratory

- North Carolina Solar Center

- NYSERDA

- Powerlight Corporation

- Sandia National Laboratories

- Sharp Solar

- Solar Energy International

- Solar Rating Certification Corporation

- Southwest Technology Development Institute

- SunEdison Corporation

- SunPower Corporation. 


\title{
Building Integration Solar Decathlon
}

\author{
Performing Organizations: National Renewable Energy Laboratory (NREL) \\ DOE Golden Field Office (DOE/GO)
}

Key Technical Contacts: $\quad$ Cécile Warner (NREL, Primary Contact), 303-384-6516, cecile_warner@nrel.gov

Glenn Doyle (DOE/GO), 303-275-4706, glenn.doyle@go.doe.gov

DOE HQ Technology Manager: Richard King, 202-586-1693, richard.king@ee.doe.gov

FY 2007 Budgets: $\quad \$ 3,700 \mathrm{~K}$ (NREL)

\section{Objectives}

- Lead and conduct the Solar Decathlon university competition of $100 \%$ solar-powered houses, which demonstrate solar technologies in marketable residential applications.

- Accelerate adoption of Building-Integrated Photovoltaics (BIPV) in new residential and commercial construction through technical outreach via the event and through successful collaborative partnerships.

\section{Accomplishments}

- Prepared for, conducted, and concluded the safe and successful implementation of the 2007 Solar Decathlon university competition on the National Mall in Washington, DC, including releasing the final regulations; solidifying sponsors; supporting teams; and scoring, monitoring, and implementing all aspects of the event (October 2007).

- Developed and released a solicitation for the 2009 Solar Decathlon event (October 2007).

\section{Future Directions}

- Conduct the 2009 Solar Decathlon in the fourth quarter, fiscal year 2009, and release a solicitation for the 2011 event.

- Monitor and guide the development of solar energy systems through the subcontracted university programs.

- Continue and expand productive interactions with the building industry.

\section{Introduction}

The Building-Integrated Photovoltaics (BIPV) Project fosters the widespread acceptance of photovoltaic-integrated buildings by overcoming technical and commercial barriers, and by facilitating the integration of photovoltaics (PV) into the built environment through technology development, applications, and key partnerships. Through this project, PV will become a routinely accepted building technology in the twenty-first century.

\section{Technical Approach}

The project's goal is to develop and facilitate widespread adoption of $\mathrm{PV}$ in the built environment, resulting in solar-powered houses and businesses that demonstrate BIPV and solar technologies in marketable applications and partnerships that build on successes. There are two interrelated activities within this overall effort, including the Solar Decathlon and research and development (R\&D) on PV in buildings.

\subsection{Conduct the 2007 Solar Decathlon}

The Solar Decathlon is an intercollegiate competition to design, build, and operate the most attractive and energy-efficient solar-powered house. Twenty teams of students from the United States, Canada, and Spain competed in the 2007 event. Teams were selected through a competitive procurement conducted in 2005 , and they worked on their projects over the intervening 2 years, under our supervision and guidance. They transported their houses to the National Mall in Washington, DC, where they built a "solar village." 
The houses were open to the public from October 12 to October 20, 2007. The teams competed against each other in ten contests that tested their abilities to produce electricity and hot water from solar panels to perform all the functions of the house-from turning on the lights to cooking, washing clothes and dishes, powering home electronics, and maintaining a comfortable temperature. These houses also were required to provide the power for an electric car. In addition to the energy-related contests, each team was judged on its house's architecture and livability. Expert homebuilders evaluated each house's "build-ability" (ease of construction and replication of design). Each team provided documentation about its house's design and communicated information about the house to the public. We hosted a Web site that informed visitors about the competition and scoring.

Production of the event, including scoring; selection of judges; review of designs; instrumentation; development of communications materials and review of exhibit designs; coordination of teams, sponsors, and volunteers; procurement of stagecraft and assembly of the village; and safe conduct of the entire event comprised the activities of this project for the NREL organizers and subcontractors. Some contests were scored by measuring performance, and others were scored by judges having expertise in appropriate fields. For more information, visit the Solar Decathlon Web site (www.solardecathlon.org). The primary sponsors of the 2007 Solar Decathlon are the U.S. Department of Energy's Office of Energy Efficiency and Renewable Energy, with its National Renewable Energy Laboratory, the American Institute of Architects, the National Association of Home Builders (NAHB), the U.S. Green Building Council (USGBC) and privatesector sponsors BP, Honeywell, and Sprint-Nextel.

\subsection{Develop and Release Solicitation for 2009} Solar Decathlon Event

While also preparing for the 2007 event, the concept for a new round of R\&D at the universities participating in the 2009 event evolved, culminating in the development of a solicitation for the 2009 event (prepared by NREL) to be announced by the Secretary of Energy in early October at the start of the 2007 event. With this solicitation, and as done in 2005 , each winning university proposal was set to receive $\$ 100 \mathrm{~K}$ in research funding (over 2 years) to support the innovative development of its entry.

\begin{tabular}{|c|c|}
\hline Task Title & $\begin{array}{c}\text { FY 2007 } \\
\text { Budget (\$K) }\end{array}$ \\
\hline Solar Decathlon (NREL) & $3,700 \mathrm{~K}$ \\
\hline
\end{tabular}

\section{Results and Accomplishments}

3.1. Major Accomplishment: Solar Decathlon 2007 During FY 2007, we successfully prepared for carrying out the 2007 Solar Decathlon, held from October 1 to October 24, 2007 on the National Mall in Washington, DC. Activities included scoring for the 10 contests; expert judging for the contest on aspects such as market appeal, architecture, engineering, Web sites, and house tours; a review of team designs for code and regulation compliance; instrumentation system development, acquisition, and shakedown, as well as installations of equipment; distribution of communications materials (brochures, media kits, official program, Web site materials, and graphics); coordination of teams; coordination of sponsors; coordination of volunteers (including a procurement for management of volunteers); procurement of stagecraft and assembly of the solar village; and execution of procedures for safely conducting the entire event. We managed crowds of more than 120,000 visitors to the Solar Decathlon and the massive media interest to view the future of solar energy and the next generation of solar practitioners and solar houses.

3.2. Major Accomplishment: Prepare for solicitation and selection of teams for the 2009 Solar Decathlon and launch the activities leading toward execution of the 2009 event. We developed a process for the selection of 20 teams (from proposal responses to a solicitation) to participate in the 2009 Solar Decathlon.

\section{Milestones Supported by DOE Funding}

\begin{tabular}{|l|c|c|}
\hline Milestone or Deliverable & Due Date & Status \\
\hline $\begin{array}{l}\text { Carry out Solar Decathlon } \\
2007 \text { event in Washington, } \\
\text { DC, on the National Mall, } \\
\text { beginning October 2007. }\end{array}$ & $11 / 01 / 07$ & Complete \\
\hline $\begin{array}{l}\text { Release solicitation for } \\
\text { university participants for } \\
\text { the 2009 event. }\end{array}$ & $10 / 12 / 07$ & Complete \\
\hline
\end{tabular}




\section{Planned FY 2008 Activities}

- Announce the 2009 Solar Decathlon Teams in the first quarter, FY 2009.

- Continue the activities leading toward execution of the 2009 Solar Decathlon event.

- Monitor and guide the development of solarenergy systems through the subcontracted university programs and through evaluation of long-term performance of selected entries.

\section{Major FY 2007 Publications}

U.S. Department of Energy, Solar Decathlon Web Site, www.solardecathlon.org.

\section{University and Industry Partners}

The following organizations partnered in the project's activities during FY 2007.

\begin{tabular}{|c|c|c|c|}
\hline $\begin{array}{c}\text { Organization/ } \\
\text { Principal Investigator }\end{array}$ & Location/E-mail & Description/Title of Research Activity & $\begin{array}{c}\text { FY } 2007 \\
\text { (\$K) }\end{array}$ \\
\hline $\begin{array}{l}\text { Colorado Code } \\
\text { Consulting, LLC } \\
\text { Thomas Meyers }\end{array}$ & $\begin{array}{l}\text { Berthoud, CO } \\
\text { codeconsultant@gmail.com }\end{array}$ & $\begin{array}{l}\text { Complete } 3 \text { plan reviews of } 20 \text { sets of } \\
\text { drawings and specifications and perform } 20 \\
\text { on-site building inspections of the competition } \\
\text { houses after installation on the National Mall in } \\
\text { fall } 2007 \text { for the Solar Decathlon competition. }\end{array}$ & 70 \\
\hline $\begin{array}{l}\text { Carnegie Mellon } \\
\text { University } \\
\text { Stephen R. Lee }\end{array}$ & $\begin{array}{l}\text { Pittsburgh, PA } 15213 \\
\text { Phone: 412-268-3528 }\end{array}$ & $\begin{array}{l}\text { Twenty teams were selected to compete in the } \\
2007 \text { Solar Decathlon. Those selected for the } \\
\text { competition were awarded } \$ 100,000 \text { over } 2 \\
\text { years, to support the Solar Decathlon's } \\
\text { research goal of reducing the cost of solar- } \\
\text { powered houses and advancing solar } \\
\text { technology. }\end{array}$ & 50 \\
\hline $\begin{array}{l}\text { Cornell University } \\
\text { Zellman Warhaft }\end{array}$ & $\begin{array}{l}\text { Ithaca, NY } 14853 \\
\text { Phone: } 607-255-3898\end{array}$ & $\begin{array}{l}\text { Twenty teams were selected to compete in the } \\
2007 \text { Solar Decathlon. The teams selected for } \\
\text { the competition were awarded } \$ 100,000 \text { over } \\
2 \text { years, to support the Solar Decathlon's } \\
\text { research goal of reducing the cost of solar- } \\
\text { powered houses and advancing solar } \\
\text { technology. }\end{array}$ & 50 \\
\hline $\begin{array}{l}\text { Georgia Institute of } \\
\text { Technology } \\
\text { Chris Jarrett }\end{array}$ & $\begin{array}{l}\text { Atlanta, GA } 30332 \\
\text { Phone: } 404-894-4885\end{array}$ & $\begin{array}{l}\text { Twenty teams were selected to compete in the } \\
2007 \text { Solar Decathlon. The teams selected for } \\
\text { the competition were awarded } \$ 100,000 \text { over } \\
2 \text { years, to support the Solar Decathlon's } \\
\text { research goal of reducing the cost of solar- } \\
\text { powered houses and advancing solar } \\
\text { technology. }\end{array}$ & 50 \\
\hline $\begin{array}{l}\text { Kansas State } \\
\text { University } \\
\text { R. Todd Gabbard }\end{array}$ & $\begin{array}{l}\text { Manhattan, KS 66506-2901 } \\
\text { Phone: 785-532-1129 }\end{array}$ & $\begin{array}{l}\text { Twenty teams were selected to compete in the } \\
2007 \text { Solar Decathlon. The teams selected for } \\
\text { the competition were awarded } \$ 100,000 \text { over } \\
2 \text { years, to support the Solar Decathlon's } \\
\text { research goal of reducing the cost of solar- } \\
\text { powered houses and advancing solar } \\
\text { technology. }\end{array}$ & 50 \\
\hline $\begin{array}{c}\text { Organization/ } \\
\text { Principal Investigator }\end{array}$ & Location/E-mail & Description/Title of Research Activity & $\begin{array}{c}\text { FY } 2007 \\
\text { (\$K) }\end{array}$ \\
\hline $\begin{array}{l}\text { Massachusetts Institute } \\
\text { of Technology } \\
\text { Kurt Keville }\end{array}$ & $\begin{array}{l}\text { Cambridge, MA } \\
\text { Phone: } 617-324-6422\end{array}$ & $\begin{array}{l}\text { Twenty teams were selected to compete in the } \\
2007 \text { Solar Decathlon. The teams selected for } \\
\text { the competition were awarded } \$ 100,000 \text { over } \\
2 \text { years, to support the Solar Decathlon's } \\
\text { research goal of reducing the cost of solar- } \\
\text { powered houses and advancing solar } \\
\text { technology. }\end{array}$ & 50 \\
\hline
\end{tabular}




\begin{tabular}{|c|c|c|c|}
\hline $\begin{array}{l}\text { New York Institute of } \\
\text { Technology } \\
\text { Thomas Rochon }\end{array}$ & $\begin{array}{l}\text { New York, NY } \\
\text { Phone: 212-261-1629 }\end{array}$ & $\begin{array}{l}\text { Twenty teams were selected to compete in the } \\
2007 \text { Solar Decathlon. The teams selected for } \\
\text { the competition were awarded } \$ 100,000 \text { over } \\
2 \text { years, to support the Solar Decathlon's } \\
\text { research goal of reducing the cost of solar- } \\
\text { powered houses and advancing solar } \\
\text { technology. }\end{array}$ & 50 \\
\hline $\begin{array}{l}\text { Pennsylvania State } \\
\text { University } \\
\text { David R. Riley }\end{array}$ & $\begin{array}{l}\text { University Park, PA } \\
\text { Phone: 814-863-2079 }\end{array}$ & $\begin{array}{l}\text { Twenty teams were selected to compete in the } \\
2007 \text { Solar Decathlon. The teams selected for } \\
\text { the competition were awarded } \$ 100,000 \text { over } \\
2 \text { years, to support the Solar Decathlon's } \\
\text { research goal of reducing the cost of solar- } \\
\text { powered houses and advancing solar } \\
\text { technology. }\end{array}$ & 50 \\
\hline $\begin{array}{l}\text { Santa Clara University } \\
\text { Jorge E. Gonzalez }\end{array}$ & $\begin{array}{l}\text { Santa Clara, CA } \\
\text { Phone: 408-554-4459 }\end{array}$ & $\begin{array}{l}\text { Twenty teams were selected to compete in the } \\
2007 \text { Solar Decathlon. The teams selected for } \\
\text { the competition were awarded } \$ 100,000 \text { over } \\
2 \text { years, to support the Solar Decathlon's } \\
\text { research goal of reducing the cost of solar- } \\
\text { powered houses and advancing solar } \\
\text { technology. }\end{array}$ & 50 \\
\hline $\begin{array}{l}\text { Team Montréal } \\
\text { (École de Technologie } \\
\text { Supérieure, Université } \\
\text { de Montréal, McGill } \\
\text { University) } \\
\text { Hughes Rivard }\end{array}$ & $\begin{array}{l}\text { Montréal, Quebec, Canada } \\
\text { Phone: 514-396-8667 }\end{array}$ & $\begin{array}{l}\text { Twenty teams were selected to compete in the } \\
2007 \text { Solar Decathlon. The teams selected for } \\
\text { the competition were awarded } \$ 100,000 \text { over } \\
2 \text { years, to support the Solar Decathlon's } \\
\text { research goal of reducing the cost of solar- } \\
\text { powered houses and advancing solar } \\
\text { technology. }\end{array}$ & 50 \\
\hline $\begin{array}{l}\text { Technische Universität } \\
\text { Darmstadt } \\
\text { Manfred Hegger }\end{array}$ & $\begin{array}{l}\text { D-64287 Darmstadt, } \\
\text { Germany } \\
\text { Phone: +49-6151-16-20-46 }\end{array}$ & $\begin{array}{l}\text { Twenty teams were selected to compete in the } \\
2007 \text { Solar Decathlon. The teams selected for } \\
\text { the competition were awarded } \$ 100,000 \text { over } \\
2 \text { years, to support the Solar Decathlon's } \\
\text { research goal of reducing the cost of solar- } \\
\text { powered houses and advancing solar } \\
\text { technology. }\end{array}$ & 50 \\
\hline $\begin{array}{l}\text { Texas A\&M University } \\
\text { Pliny Fisk }\end{array}$ & $\begin{array}{l}\text { College Station, TX } \\
\text { Phone: } 979-458-4124\end{array}$ & $\begin{array}{l}\text { Twenty teams were selected to compete in the } \\
2007 \text { Solar Decathlon. The teams selected for } \\
\text { the competition were awarded } \$ 100,000 \text { over } \\
2 \text { years, to support the Solar Decathlon's } \\
\text { research goal of reducing the cost of solar- } \\
\text { powered houses and advancing solar } \\
\text { technology. }\end{array}$ & 50 \\
\hline $\begin{array}{c}\text { Organization/ } \\
\text { Principal Investigator }\end{array}$ & Location/E-mail & Description/Title of Research Activity & $\begin{array}{c}\text { FY } 2007 \\
\text { (\$K) }\end{array}$ \\
\hline $\begin{array}{l}\text { Universidad de Puerto } \\
\text { Rico } \\
\text { Rafael A. Olivencia- } \\
\text { Martínez }\end{array}$ & $\begin{array}{l}\text { Mayagüez, Puerto Rico } \\
\text { 00681-9009 } \\
\text { Phone: } 787-832-4040 \\
\text { ext. } 5361\end{array}$ & $\begin{array}{l}\text { Twenty teams were selected to compete in the } \\
2007 \text { Solar Decathlon. The teams selected for } \\
\text { the competition were awarded } \$ 100,000 \text { over } \\
2 \text { years, to support the Solar Decathlon's } \\
\text { research goal of reducing the cost of solar- } \\
\text { powered houses and advancing solar } \\
\text { technology. }\end{array}$ & $50 \mathrm{~K}$ \\
\hline $\begin{array}{l}\text { University of Colorado } \\
\text { Michael Brandemuehl }\end{array}$ & $\begin{array}{l}\text { Boulder, CO 80309-0428 } \\
\text { Phone: } 303-492-8594\end{array}$ & $\begin{array}{l}\text { Twenty teams were selected to compete in the } \\
2007 \text { Solar Decathlon. The teams selected for } \\
\text { the competition were awarded } \$ 100,000 \text { over } \\
2 \text { years, to support the Solar Decathlon's } \\
\text { research goal of reducing the cost of solar- } \\
\text { powered houses and advancing solar } \\
\text { technology. }\end{array}$ & $50 \mathrm{~K}$ \\
\hline
\end{tabular}




\begin{tabular}{|c|c|c|c|}
\hline $\begin{array}{l}\text { University of Cincinnati } \\
\text { Dale L. Murray }\end{array}$ & $\begin{array}{l}\text { Cincinnati, OH 45221-0016 } \\
\text { Phone: 513-556-1524 }\end{array}$ & $\begin{array}{l}\text { Twenty teams were selected to compete in the } \\
2007 \text { Solar Decathlon. The teams selected for } \\
\text { the competition were awarded } \$ 100,000 \text { over } \\
2 \text { years, to support the Solar Decathlon's } \\
\text { research goal of reducing the cost of solar- } \\
\text { powered houses and advancing solar } \\
\text { technology. }\end{array}$ & $50 \mathrm{~K}$ \\
\hline $\begin{array}{l}\text { University of Illinois } \\
\text { Ty Newell }\end{array}$ & $\begin{array}{l}\text { Urbana, IL 61801 } \\
\text { Phone: 217-333-1655 }\end{array}$ & $\begin{array}{l}\text { Twenty teams were selected to compete in the } \\
2007 \text { Solar Decathlon. The teams selected for } \\
\text { the competition were awarded } \$ 100,000 \text { over } \\
2 \text { years, to support the Solar Decathlon's } \\
\text { research goal of reducing the cost of solar- } \\
\text { powered houses and advancing solar } \\
\text { technology. }\end{array}$ & $50 \mathrm{~K}$ \\
\hline $\begin{array}{l}\text { University of Maryland } \\
\text { Amy Gardner }\end{array}$ & $\begin{array}{l}\text { College Park, MD } \\
\text { 20741-1411 } \\
\text { Phone: } 301-405-6303\end{array}$ & $\begin{array}{l}\text { Twenty teams were selected to compete in the } \\
2007 \text { Solar Decathlon. The teams selected for } \\
\text { the competition were awarded } \$ 100,000 \text { over } \\
2 \text { years, to support the Solar Decathlon's } \\
\text { research goal of reducing the cost of solar- } \\
\text { powered houses and advancing solar } \\
\text { technology. }\end{array}$ & $50 \mathrm{~K}$ \\
\hline $\begin{array}{l}\text { University of Missouri- } \\
\text { Rolla } \\
\text { Stuart W. Baur }\end{array}$ & $\begin{array}{l}\text { Rolla, MO } 65409 \\
\text { Phone: 573-341-7236 }\end{array}$ & $\begin{array}{l}\text { Twenty teams were selected to compete in the } \\
2007 \text { Solar Decathlon. The teams selected for } \\
\text { the competition will be awarded } \$ 100,000 \text { over } \\
2 \text { years to support the Solar Decathlon's } \\
\text { research goal of reducing the cost of solar- } \\
\text { powered houses and advancing solar } \\
\text { technology. }\end{array}$ & $50 \mathrm{~K}$ \\
\hline $\begin{array}{l}\text { University of Texas at } \\
\text { Austin } \\
\text { Samantha Randall }\end{array}$ & $\begin{array}{l}\text { Austin, TX 78712-1160 } \\
\text { Phone: 512-466-9298 }\end{array}$ & $\begin{array}{l}\text { Twenty teams were selected to compete in the } \\
2007 \text { Solar Decathlon. The teams selected for } \\
\text { the competition were awarded } \$ 100,000 \text { over } \\
2 \text { years to support the Solar Decathlon's } \\
\text { research goal of reducing the cost of solar- } \\
\text { powered houses and advancing solar } \\
\text { technology. }\end{array}$ & $50 \mathrm{~K}$ \\
\hline
\end{tabular}




\title{
Building Integration Building-Integrated Photovoltaics (Solar Building Benchmarking)
}

\author{
Performing Organizations: $\quad$ National Renewable Energy Laboratory (NREL) \\ DOE Golden Field Office (DOE/GO) \\ Key Technical Contacts: $\quad$ Michael Wassmer (NREL, Primary Contact), 303-384-6461, \\ michael_wassmer@nrel.gov \\ Glenn Doyle (DOE/GO), 303-275-4706, glenn.doyle@go.doe.gov
}

DOE HQ Technology Manager: Richard King, 202-586-1693, richard.king@ee.doe.gov

FY 2007 Budget: $\quad$ \$250K (NREL)

\section{Objectives}

- $\quad$ Support the deployment of Building-Integrated Photovoltaics (BIPV) technologies by measuring their in situ performance in various locations throughout the country.

- Provide participating university research groups with the technical knowledge they need to conduct their own experiments on various aspects of Solar Decathlon houses.

\section{Accomplishments}

- Conducted building energy monitoring and computer modeling research on past Solar Decathlon houses to (1) improve future Solar Decathlon contests, (2) quantify the annual performance of the houses, (3) identify areas of technical significance in the houses to focus future teams' design efforts, and (4) extend the education and outreach component of the competition beyond the 10 days on the National Mall.

- Substantially completed the installation and commissioning of building energy monitoring systems in the 2005 Cornell and New York Institute of Technology (NYIT) houses (January 2007).

- Completed the design and partially completed the installation of building energy monitoring systems in the 2007 Lawrence Technological University, University of Illinois, Carnegie Mellon, Penn State, and Santa Clara University houses (September 2007).

- Completed the design of a Web-based "dashboard" display that illustrates the houses' performance in real time (September 2007).

\section{Future Directions}

- Collect data from the 2005 Cornell and NYIT houses.

- Complete the installation and commissioning of systems in five 2007 houses and begin to collect data.

- Work with the NREL Web development team to publish the real-time dashboard display on the Solar Decathlon Web site.

- Recruit participants in the project from among the 2009 Solar Decathlon teams and Solar America Cities.

\section{Introduction}

The Solar Building Benchmarking activity within the BIPV Project extends the Solar Decathlon project into a long-term research and outreach opportunity. Detailed building energy monitoring systems are installed in past Solar Decathlon houses to continue to educate the public about the houses after a particular competition has ended and to aid in the calibration of detailed computer models that will be used to improve future competitions.

This monitoring also helps to guide future Solar Decathlon teams' efforts and quantify the performance of the houses in terms of their intended occupancy patterns and the climates for which they were designed. 


\section{Technical Approach}

Many building energy research activities are conducted using computer models that are either poorly calibrated or not calibrated at all. The lack of model calibration casts doubt on the validity of the results, since certain important performance characteristics could be attributable to either the building itself or to imperfections within the model. This project seeks to substantially reduce the consequences of the latter shortcoming through detailed calibration of the computer models that are used to extrapolate the performance of the home beyond the climatic and occupancy patterns actually experienced.

The calibrated computer models will be used to project the home's performance in a range of hypothetical climates and occupancy behavior patterns. This will help both Solar Decathlon teams and organizers to identify the most and least effective system choices and design approaches in previous generations of Solar Decathlon competition houses. With this knowledge, the organizers will be able to design contests that challenge the universities to develop creative solutions in the areas of residential building design that are in the greatest need of improvement.

In the past, the incredible opportunity afforded by the Solar Decathlon for education and outreach essentially ended when the houses left the competition site. By continuously monitoring and interpreting the real-time performance of the houses on their permanent sites, and by presenting this information on the Solar Decathlon Web site, the education and outreach potential of the competition in science class curricula improves exponentially. This visibility also improves community outreach opportunities for the universities and offers home builders insight into the performance of these ultra-highefficiency houses in the real world. These insights could be some of the deciding factors in motivating builders to implement some of the design features and system choices in their designs.

\section{Results and Accomplishments}

In January 2007, we substantially completed the installation of the monitoring systems in the 2005 Cornell University and 2005 NYIT houses. These installations will be finalized and commissioned when the owners make some repairs and system adjustments that have been delayed since the houses were assembled on their final sites. Official data collection began in spring 2007, but it was suspended because some house performance problems remained as a result of incomplete repairs and adjustments.

During the spring and summer of 2007, NREL personnel worked with five 2007 Solar Decathlon teams to complete the design of monitoring systems that were assembled and partially installed in their houses during the construction stages on campus. Several of the teams used the partially installed systems to aid in house operation and outreach activities during the competition in October 2007.

The project was improved in 2007 in two significant ways designed to place more of the burden of the project on the universities so as to avoid some of the schedule and budget problems associated with the 2005 houses.

First, instead of having NREL purchase and lend the teams the sensors and data acquisition equipment (at approximately $\$ 10 \mathrm{~K}$ per house), the participating teams were required to purchase the equipment themselves. This enabled NREL to focus its efforts on system design, technical support to the students, installation assistance, and administration of the central data server. Teams had the option of letting NREL complete the entire installation without assistance from the university, or assigning one or more students to the project to help NREL complete the installation. In all cases, students from the universities were assigned to the project and made substantial contributions to the system design and installation. In two or more cases, the students involved used the systems to conduct their own research projects for class or master's thesis credit.

Second, a significant change was made to the project's structure in regard to the schedule. Based on lessons learned from experiences with the 2005 houses, NREL now requires that teams finish reassembling the houses on their permanent sites before NREL performs postcompetition reinstallation and commissioning of the monitoring systems. This change will reduce the amount of time that NREL personnel have had to spend in making multiple site visits and in troubleshooting problems that could have been 
avoided if the house had been fully assembled, finished, and occupied before the postcompetition monitoring equipment was scheduled to be installed and commissioned.

\section{Planned FY 2008 Activities}

- Continue monitoring the progress of the 2007 teams as they reassemble their houses on their permanents sites. When reassembly is complete, NREL personnel will make a site to complete the system installation and commission it so that official data collection activities can begin and then continue without interruption.

- Continue monitoring the progress of the 2005 teams as they resolve the remaining issues with their houses. When these issues are resolved, system installation and commissioning will be completed so that official data collection activities can resume.
If the remaining issues are not resolved, NREL's equipment, which was on loan to the university, will be removed from the houses and returned to NREL.

- Work with the NREL Web development team to publish real-time data displays on the Solar Decathlon Web site.

- Develop computer models that will be calibrated after several months of official data collection have taken place. Results of analyses conducted with the aid of the calibrated computer models will begin to be available in late FY 2008, assuming that the houses are reassembled some time during the spring.

- Recruit 2009 Solar Decathlon teams and Solar America Cities to participate in the project. 


\title{
Building Integration Finance and Insurance
}

\author{
Performing Organizations: $\quad$ National Renewable Energy Laboratory (NREL) \\ Lawrence Berkeley National Laboratory (LBNL) \\ Key Technical Contacts: $\quad$ Robert Margolis (NREL), 202-488-2222, robert_margolis@nrel.gov \\ Karlynn Cory (NREL), 303-384-7464, karlynn_cory@nrel.gov
}

DOE HQ Technology Manager: Charles Hemmeline, 202-586-6646, charles.hemmeline@ee.doe.gov

FY 2007 Budgets: $\quad$ \$240K (NREL)

\section{Objectives}

- Provide a series of photovoltaic (PV) application case studies illustrating how financing and insurance best practices were employed using specific examples.

\section{Accomplishments \\ - Completed initial data gathering and analysis and began drafting report on state and local government financing of PV. This project was funded during the second half of FY 2007, so most of the work and products will be completed during FY 2008.}

\section{Future Directions}

- Complete a series of papers on PV financing best practices for federal, state, and local governments as well as other sectors.

\section{Introduction}

Financing and insurance are critical components of almost all solar system purchases. Few areas can provide a more dramatic impact on the decision of a consumer, be it a utility, a commercial entity, or a homeowner, than financing mechanisms. Over the past few years, substantial innovations in the area of financing have helped facilitate PV purchases and installations. For each type of consumer, there are a wide variety of aspects to structuring financing. These include potential project revenues, such as renewable energy certificates (RECs), the availability of different financing mechanisms, federal and state incentives, and the rise of third-party financier models. The combination of these aspects results in a specific up-front expense for each consumer and ultimately substantially impacts their willingness to deploy solar PV.

The insurance industry, like the financial community, suffers from misperceptions about solar and its risks. Insurance companies often require homeowners to purchase large liability policies, in case of an accident involving the solar system. These policies can be cost prohibitive to the homeowner and wind up killing the solar purchase altogether. Often such policy requirements are backed by little or no analysis, using old data. Insurance companies need to understand the characteristics and risks associated with current solar installations so that they can formulate analysis-based and reasonable company-wide policy requirements.

\section{Technical Approach}

This project will examine the current state of private lending and insurance requirements for solar system applications across various market sectors (federal, state, and local governments, residential buildings, and commercial industries) as well as various geographic areas in the United States. A series of reports focusing on issues related to financing photovoltaics systems will be carried out. These reports will identify and explain how financial complexity and options, such as state and federal incentives and the use of REC markets, differ within each sector. They will also include specific project and financing examples from across the United States. Additionally, these reports will provide recommendations for best methods and practices for a range of solar system 
financing applications and sectors. As appropriate, the insurance requirements and barriers to implementation will also be outlined, by sector.

\section{Results and Accomplishments}

This project was funded during the second half of FY 2007, thus most of the work and products will be completed during FY 2008.

\section{Planned FY 2008 Activities}

The bulk of the work and deliverables for this project will be completed during FY 2008. In particular, the project will produce a series of solar application case studies illustrating how financing and insurance best practices were employed using specific examples. One or more of these case studies will:

- Explain the state of private lending practices and insurance requirements for PV-system applications across the federal, state, and local government and residential, commercial, and industrial sectors; specific examples of projects and financial structures will be included that cover various geographic areas in the United States.

- Identify successful novel financing mechanisms for PV-system applications and how they can be replicated, either for a niche application or when applied more broadly. Such novel approaches may include methods by which solar equipment manufacturers, utilities, and other solar technology or power providers are selling solar equipment (i.e. financing options) or power.

- Identify leading innovators with respect to financing PV systems in the United States.
- Evaluate the extent to which homeowner insurance policies cover residential PV systems in a fairly uniform or standard manner and identify any instances when excessive insurance requirements were changed to a more practical basis, with a discussion of the process used to bring about the change.

- Evaluate the residual value of PV systems if a solar system is damaged and an insurance claim is paid out.

As a set, the case studies will identify and explain the way that each of the following mechanisms is used to support solar project financing or insurance and examine their potential and impact.

- Participating parties and ownership models such as power purchase agreements.

- Compensation programs for the environmental attributes of solar power, such as renewable energy credits.

- Clean renewable energy bonds and DOE loan guarantee program authorized by the Energy Policy Act of 2005 for large-scale solar-energy projects.

- State programs such as system benefit charges that cover upfront investment incentives, production incentives, and lowinterest loans.

- Utility involvement scenarios.

- Residential green mortgage options.

- Combination of solar and energy efficiency projects in single financing packages.

- Financing systems for projects at federal, state, and other public facilities. 


\title{
Technical Partnerships Government Solar Installation Program
}

\author{
Performing Organizations: $\quad$ National Renewable Energy Laboratory (NREL) \\ Sandia National Laboratories (SNL) \\ Key Technical Contacts: $\quad$ Steven Palmeri (DOE), 303-275-4832, steve.palmeri@go.doe.gov \\ Cecile Warner (NREL), 303-384-6516, cecile_warner@nrel.gov \\ Vipin Gupta (SNL), 915-491-1158, vpgupta@sandia.gov
}

DOE HQ Technology Manager: Charles Hemmeline, 202-586-6646, charles.hemmeline@ee.doe.gov

DOE Golden Field Office, Solar Branch Chief: Carolyn Elam, 303-275-4953, carolyn.elam@go.doe.gov

FY 2007 Budgets: $\quad$ \$900K

\section{Objectives}

- $\quad$ Support federal agencies to achieve commitment to purchasing 2 gigawatts of solar power at federal facilities and 1 gigawatt at state and local facilities, with all transactions and installations to be completed by 2012 ahead of the final renewable energy purchase phase of the Energy Policy Act of 2005 (EPAct 2005).

- Lower production costs for solar components through a market-based approach of using governmental energy needs to build demand for solar products and increase production.

- Maximize installation of secure, on-site renewable energy projects at all DOE sites, optimize affordable purchases of renewable electricity by DOE facilities, or both.

\section{Accomplishments}

- Developed a model for a "Federal Photovoltaic Request for Proposals" vetted through financial and solar communities and the General Services Administration (GSA).

- Initiated development of a dynamic "Government Solar Installation Program Web-Enabled Tool."

- Prepared a report technically defining the solar energy opportunities for federally-owned Congressional office buildings in Washington, D.C.

- Prepared a report providing technical assessment of the potential for using solar energy and other key energy efficiency features as part of the Elephant House renovation in progress at the National Zoological Park in Washington, D.C.

- Planned the "Federal PV Standard Offer Contract/Power Purchase Agreement with a Standard Lease" model for release during FY 2008.

\section{Future Directions}

- Continue assessments of governmental buildings and implementation of solar rooftop installations.

- Work with the DOE Federal Energy Management Program (FEMP) to identify the best federal buildings where solar makes the most sense.

- Begin a dialog with other federal agencies to help them identify locations where solar can be installed in a cost-effective manner on their buildings.

\section{Introduction}

The Government Solar Installation Program (GSIP) is a market-based challenge to public entities-federal agencies, states, cities, counties, and other local governments-to increase their use of solar energy power. GISP is carried out in partnership with DOE's Transformational Energy Action Management (TEAM) Initiative, a department-wide effort aimed at reducing energy intensity across the nationwide DOE complex by $30 \%$. GSIP is a 
single program with a three-phased structure. In Phase One, DOE will evaluate DOE facilities for pilot sites for solar installations. In Phase Two, DOE will complete installations on the appropriate sites identified in Phase One. In Phase Three, DOE will work with other federal agencies to apply the lessons learned and assist other agencies with solar installations on their individual facilities.

The major partners in the GSIP are the DOE Solar Energy Technologies Program (SETP), DOE Federal Energy Management Program (FEMP) and General Services Administration (GSA). The organization's roles include:

\section{SETP}

- Take primary responsibility for the Phase One pilot installations.

- Participate in decision-making on solar TEAM projects in Phase Two.

- Provide technical assistance to GSA in Phase Three.

\section{FEMP}

- Provide government energy procurement assistance to SETP in Phase One.

- Take primary responsibility for Phase Two installations to complete the TEAM effort.

- Assist with Phase Three energy purchases.

GSA

- Provide procurement vehicles for Phase One power purchase agreements (PPAs).

- Develop a Web portal with strong SETP input.

- Take primary responsibility for Phase Three procurements with DOE support.

Technical assistance teams, also known as Tiger Teams, provide any needed assistance and are comprised of representatives from the national laboratories (NREL and SNL) as well as New Mexico State University and the University of Central Florida.

\begin{tabular}{|l|c|}
\hline \multicolumn{1}{|c|}{ Agreement Title } & $\begin{array}{c}\text { FY 2007 } \\
\text { Budget (\$K) }\end{array}$ \\
\hline $\begin{array}{l}\text { National Renewable Energy } \\
\text { Laboratory }\end{array}$ & 600 \\
\hline Sandia National Laboratory & 300 \\
\hline
\end{tabular}

\section{Technical Approach}

The GSIP initiative meets or exceeds energy efficiency goals mandated by EPAct 2005, as well as Executive Order 13423, directing federal agencies to:

- Reduce energy intensity and greenhouse gas emissions

- Increase energy efficiency and use of renewable energy technologies

- Adopt sustainable design practices

- Reduce petroleum use in federal fleets.

This initiative adopts a more ambitious timeline and targets changes that will have an impact on DOE's energy use as early as next year.

GSIP is a single program with a three-phased structure: Phase One includes DOE facilities and will collaborate with DOE's TEAM Initiative. The TEAM Initiative is a nationwide effort to reduce energy intensity by $30 \%$ in DOE buildings. This energy reduction will save approximately $\$ 90$ million in taxpayer dollars per year, after projects are paid for. The TEAM Initiative aims to meet or exceed the aggressive goals for increasing energy efficiency throughout the federal government as stated in the executive order.

Phase Two will focus on the most appropriate sites for solar applications identified during Phase One. The GSIP program approach is to use power purchase agreements, except where straight purchases are more cost effective. The program will initially emphasize solar installations in regions of the country with regulations or incentives in place, conducive to solar energy projects, such as in California and New Jersey. The program will then transition to other regions as the cost of PV falls and other state or local incentives for renewable energy develop.

Phase Three of the GSIP broadens the effort to include other federal agencies beyond DOE, as well as state and local governments. Lessons learned during the first two phases of the program will be useful for helping other agencies to overcome barriers to solar installations.

The strategic approach of the GSIP is to:

- Leverage federal purchase power to create significant demand pull.

- Promote U.S.-manufactured products.

- Promote an installation development model using a power purchase agreement model.

- Increase demand for installers and thereby boost U.S. jobs. 
- Facilitate achievement of EPAct and other federal goals by using a market-based approach rather than regulation.

- Use growing capital markets to finance installations.

- Support domestic power purchase agreement providers.

- Facilitate the process by minimizing government involvement.

\section{Results and Accomplishments}

GSIP was initiated during FY 2007. An initial project is to install PV panels on the Forrestal Building, the DOE's Headquarters Building in Washington, DC. Installation began late in FY 2007 and is expected to be completed in FY 2008. As part of Phase One, processes for evaluating additional projects were identified in preparation for additional installations.

A Tiger Team of solar experts from NREL, SNL, and the Florida Solar Energy Center prepared an assessment report of the U.S. Capitol Complex, detailing each building's energy consumption and potential solar PV installations. The following buildings were identified for consideration:

- Rayburn House Office Building

- Cannon House Office Building

- Ford House Office Building

- House Page Dorm

- House Parking Lot

- Longworth House Office Building

- Dirksen Senate Office Building

- Hart Senate Office Building

- Russell Senate Office Building and Senate Child Care

- Adams Building

- Madison Memorial Building.
In addition, the team assessed the potential for using solar energy and other key energy efficiency features as part of the Elephant House renovation in progress at the National Zoological Park in Washington, D.C. This assessment also analyzed the feasibility of using solar water heating in the Elephant House renovation.

\section{Planned FY 2008 Activities}

- Release of a model "Federal Photovoltaic Request for Proposals and a Federal Photovoltaic Standard Offer Contract / Power Purchase Agreement with Standard Lease" with input from the GSA and the financial and solar communities.

- Release of a dynamic "Government Solar Installation Program Web-Enabled Tool" that will allow industry to examine facility characteristics, submit inquiries, and place bids. Successful bids will be transferred automatically into "Federal PV Standard Offer Contract' format for further negotiation.

- Continue Tiger Teams efforts to implement some of the plans proposed in the reports completed in FY 2007.

\section{Major FY 2007 Publications}

- U.S. Department of Energy Solar and Renewables Tiger Team, "Energy Efficiency and Renewable Energy Recommendations: National Zoological Park, Asia Trail, Phase II, Elephant Trails." (April 13 2007).

- A. Walker, W. Cox, and S. Barkaszi, "Architect of the Capitol Solar Energy Assessment Project: Assessment of the United States Capitol Complex for Application of Solar Energy Technologies," Prepared by NREL, SNL, and FSEC, (October 1, 2007).

\section{University Partners}

The following organizations partnered in the project's research activities during FY 2007.

\begin{tabular}{|l|l|l|}
\hline \multicolumn{1}{|c|}{$\begin{array}{c}\text { Organization/ } \\
\text { Principal Investigator }\end{array}$} & \multicolumn{1}{|c|}{ Location/e-mail } & \multicolumn{1}{|c|}{ Description/Title of Research Activity } \\
\cline { 1 - 2 } $\begin{array}{l}\text { New Mexico State University } \\
\text { Andy Rosenthal }\end{array}$ & $\begin{array}{l}\text { Las Cruces, NM } \\
303-275-4864 \\
\text { arosenthal@nmsu.edu }\end{array}$ & $\begin{array}{l}\text { Technical assistance teams, also known as Tiger } \\
\text { Teams, provide any needed assistance and are } \\
\text { comprised of representatives from the national }\end{array}$ \\
\cline { 1 - 2 } $\begin{array}{l}\text { Florida Solar Energy Center } \\
\text { laboratories (NREL and SNL) as well as } \\
\text { universities. }\end{array}$ \\
\hline
\end{tabular}




\section{Technical Partnerships Solar America Cities}

Performing Organizations:

Key Technical Contacts:

DOE HQ Activity Manager:

FY 2007 Budgets:
Cities: Ann Arbor, MI; Austin, TX; Berkeley, CA; Boston, MA; Madison, WI; New Orleans, LA; New York, NY; Pittsburgh, PA; Portland, OR; Salt Lake City, UT; San Diego, CA; San Francisco, CA; and Tucson, AZ

Margie Bates, (DOE/GO), 303-275-4845, margie.bates@go.doe.gov Carla Clemons (DOE/GO), 303-275-4864, carla.clemons@go.doe.gov Steve Palmeri (DOE/GO), 303-275-4832, steve.palmeri@go.doe.gov

Thomas Kimbis, 202-586-000, tom.kimbis@ee.doe.gov

\$2.5M (DOE), \$2.5M (Technical Assistance from Labs)

\section{Objectives}

- Issue competitive funding opportunity announcement (FOA) to form strategic partnerships with U.S. cities as part of DOE's Solar America Initiative (SAI). These partnerships are intended to accelerate the adoption of solar technology at the local level by engaging city governments, key intermediaries to other end users within their jurisdiction, and regulatory entities.

- Provide financial assistance awards (cooperative agreements) of $\$ 200,000$ each to 13 cities with populations of 100,000 or more to propose activities that support the objectives of DOE and SAI market transformation activities.

- Provide up to $\$ 200,000$ in tailored technical assistance from DOE national laboratories and contractors to each of the recipient cities to accomplish the project goals.

\section{Accomplishments}

- Established strategic partnerships with 13 cities through a competitive funding opportunity.

- Awarded a combined \$2.5 million in financial assistance (cooperative agreements).

- Held kickoff meetings with each city publicizing the plans for each Solar America City.

- Developed and initiated tailored technical assistance for each of the cities from national labs (National Renewable Energy Laboratory, Sandia National Laboratories), Florida Solar Energy Center, or New Mexico State University.

\section{Future Directions}

- City of Ann Arbor will identify and reduce barriers to solar, propose commercial and residential solar installations, integrate energy efficiency and renewable energy into K-12 curriculum and develop solar installer training.

- $\quad$ City of Austin will work to reduce information barriers that prevent citizens from participating in the city's extensive renewable energy and energy conservation programs and will install highly-visible solar energy facilities at public schools.

- $\quad$ City of Berkeley will develop and implement a turn-key program to install solar photovoltaic (PV) and solar hot water and air heating (SWAH) systems in the residential and small-to-medium commercial/public sectors.

- $\quad$ City of Boston anticipates that the city-wide installation proposed for 2008-2010 to be managed by the Solar Boston Partnership's non-profit successor entity will result in the installation of 2megawatt (MW) capacity with ongoing capacity to manage at least 10 MW by 2015.

- $\quad$ City of Madison will be working towards achieving its goal of 250 kilowatts (kW) of PV and 200 solar hot water systems installed by 2010.

- $\quad$ City of New Orleans will initiate a publicity and outreach program to induce demand for solar among individuals, businesses, and institutions, analyze and recommend modifications and enhancements to the city's codes, regulations, and policies in order to foster the adoption of solar technologies.

- City of New York will use the City's resources to spur the market and create economies of scale to lower prices. 
- City of Pittsburgh will encourage adoption of solar energy by residential- and small-scale commercial users to demonstrate that the technology will lower their energy bills in the long run.

- $\quad$ City of Portland will provide high level policy support to solar market transformation and streamline city-level regulations and practices that affect solar adoption.

- $\quad$ Salt Lake City will design a comprehensive city and county-wide solar implementation plan to develop an additional 10,000 government, residential, and commercial installations by 2015.

- $\quad$ City of San Diego will update and expand GIS analysis of solar installations and potential future sites, conduct performance analysis of around $12 \mathrm{MW}$ of existing PV systems and develop case studies that explain the process used for designing, planning, installing and monitoring solar energy systems and provide energy and financial analyses.

- $\quad$ City of San Francisco will identify sites for large installations and marketing to those building owners.

- $\quad$ City of Tucson will work towards a Solar Energy Integration Plan, a Greater Tucson Solar Energy Development Plan and 2 MW to be installed by 2015.

\section{Introduction}

In January 2006, the President announced his Advanced Energy Initiative, which "provides for a 22-percent increase in funding for clean-energy technology research at the Department of Energy. An integral part of this Initiative is the U.S. Department of Energy's (DOE's) Solar America Initiative (SAI). The goal of the SAl is to reduce the cost of solar photovoltaic (PV) technologies so that they become cost-competitive by 2015 . SAI represents a significant enhancement of DOE's business strategy of partnering with key stakeholders to accelerate commercialization of PV system research and development (R\&D) to meet aggressive cost and installed capacity goals. To learn more about SAI, visit

www.eere.energy.gov/solar/solar_america/index.html

To complement the R\&D and testing/evaluation activities that are the backbone of SAI, DOE conducts Market Transformation (MT) efforts, with a mission to reduce market barriers and promote market expansion of solar energy technologies through non-R\&D activities. MT activities fall into two areas: (1) activities which provide technical, regulatory, institutional, financial and educational solutions to MT barriers; and (2) those which accelerate demand for new solar technologies primarily through provision of technical assistance.

There are several aspects to SAI MT that define it as a new approach for DOE:

- SAI MT is looking to identify and remove market barriers. Through its infrastructure development activities, DOE is seeking to identify and minimize or remove barriers to solar technology commercialization as quickly and efficiently as possible.
- $\quad$ SAI MT is looking for significant market changing activities. Given the proximity of the 2015 goal, DOE is seeking to make large and significant changes in the marketplace through its market transformation activities.

- $\quad$ SAIMT is focused on near- and mid-term results. Accordingly, emphasis will be on projects and activities with the greatest potential to assist the DOE in reaching its SAI cost-competitiveness goal by 2015 .

- $\quad$ SAIMT is looking for performers and partners who are committed to the SAI mission. In order to achieve the SAI mission of 2015, DOE is inclined to partner and work with motivated entities that will also benefit from achievement of the SAI mission.

Solar technologies addressed under this FOA included PV, concentrating solar power (CSP), and solar water/air heating technologies (SWAH).

\section{Technical Approach}

Cities play an important strategic role in SAI and present unique challenges and opportunities for solar market transformation. DOE recognizes the important role of Cities as champions of progressive energy efficiency and renewable energy efforts and wishes to support their bold and innovative approaches to accelerate solar technology adoption at the local level.

Through Solar America Cities (SAC), DOE seeks to support Cities ready to take a comprehensive, systemic, city-wide approach to solar technology that facilitates mainstream adoption and provides a model for other cities. Consistent with the mission of SAI, DOE is looking for Cities to commit to achieving a sustainable solar infrastructure, not 
simply a year or two of experimental solar projects. It was critical for each city to express a commitment to a city-wide approach to integration of solar energy into city planning and processes, as well as to large-scale implementation of solar technologies by 2015 .

Such an approach recognizes the city's role as an important end user of electricity, as a key intermediary to other end users within their jurisdiction, and as a regulatory entity. DOE expected cities to develop a fully-scoped, city-wide solar implementation plan as a deliverable under this project. Each city-wide solar plan addressed efforts to:

- Integrate solar technology into city energy planning and facilities.

- Streamline city-level regulations and practices that affect solar adoption by residents and local businesses (e.g. permitting, inspections, local codes).

- Promote solar technology among residents and local businesses (e.g., outreach, curriculum development and/or implementation, incentive programs, etc.).

Solar America Cities build on the networks and momentum of former Million Solar Roofs partnerships, and DOE encouraged their participation in this activity. To ensure maximum impact, cities were required to submit a letter of support from their mayors and local utilities.

\section{Results and Accomplishments}

The Awards

On June 21, 2007, DOE named 13 cities as inaugural Solar America Cities. In September 2007, the DOE Golden Field Office awarded a combined \$2.5 million in federal financial assistance to Solar America Cities.

Each of these cities submitted a proposal outlining its plans to build a sustainable solar infrastructure, streamline city-level regulations, and promote the adoption of mainstream solar technology among residents and businesses. Cites were selected competitively. Evaluation criteria focused on demonstrating a comprehensive city government approach to solar planning, including methods to further market expansion and to remove local market barriers. Selected cites demonstrated a high level of commitment to promote solar power throughout the city, involving local government officials, utilizes private partners.
Winning Cities for 2007

The winning cities for 2007 are the following:

\begin{tabular}{|l|c|}
\hline \multicolumn{1}{|c|}{ Solar City $\mathbf{2 0 0 7}$} & $\begin{array}{c}\text { FY 2007 Budget } \\
\text { (\$K) }\end{array}$ \\
\hline Ann Arbor, MI & $\$ 200,000$ \\
\hline Austin, TX & $\$ 186,930$ \\
\hline Berkeley, CA & $\$ 200,000$ \\
\hline Boston, MA & $\$ 150,000$ \\
\hline Madison, WI & $\$ 200,000$ \\
\hline New Orleans, LA & $\$ 200,000$ \\
\hline New York, NY & $\$ 190,140$ \\
\hline Pittsburgh, PA & $\$ 200,000$ \\
\hline Portland, OR & $\$ 200,000$ \\
\hline Salt Lake City, UT & $\$ 197,286$ \\
\hline San Diego, CA & $\$ 200,000$ \\
\hline San Francisco, CA & $\$ 200,000$ \\
\hline Tucson, AZ & $\$ 200,000$ \\
\hline
\end{tabular}

Of these 13 cities, eight are among the largest 50 cities in the United States.

\section{On-Site Technical Assistance}

In their proposals, each city identified the technical assistance their project might require in areas such as city planning, technology selection, project financing, building codes, architecture and community outreach.

Following the award, DOE appointed a technical assistance lead, called a Tiger Team leader to each city. The tiger team lead contacted the appropriate person at each city to discuss their project's technical assistance needs and then conducted a site visit to identify specific technical assistance needs, resulting in the optimal composition of the Tiger Team and in the development of a 2-year project plan.

Members of the Tiger Team were drawn from the National Renewable Energy Laboratory (NREL) in Colorado, Sandia National Laboratories (SNL) in New Mexico, and the Southwest and Southeast Regional Experiment Stations (RESs) at New Mexico State University, and the Florida Solar Energy Center.

\section{Technical Assistance MOA}

The DOE Golden Field Office developed a Technical Assistance Memorandum of Agreement (MOA) with each city that includes the 2-year technical assistance project plan, establishes the framework for cooperation, and sets the value of the technical assistance. The MOA is between the City, the Tiger Team lead organization, and DOE. The MOA is being implemented by the Golden Field Office. 


\section{$\underline{\text { SAC Goals and Project Highlights }}$}

"Ann Arbor Solar City Partnership"

Goals: Help the city reach its goal of $20 \%$ renewable energy by 2015 by utilizing a wide range of community partners and resources to remove market barriers to the adoption of solar energy. Help local solar manufactures and contractors to increase business.

Project Highlights: Develop a comprehensive solar plan. Hold solar informational workshops for consumers and installers. Implement a community-based marketing campaign. Offer city incentives and rebates for installations.

\section{"Austin Solar City Partnership"}

Goals: Educate the city's teachers and youth about the benefits of solar. Reduce barriers that prevent participation in the city's renewable energy and energy conservation programs. Increase solar installation visibility. Establish benchmarks for distributed and central solar to be integrated into Austin Energy's generation plan.

Project Highlights: Install solar energy systems in local schools and develop curricular materials to accompany these systems. Work with local nonprofits to promote and cross-market the solar, energy efficiency and green building programs of Austin Energy. Assess the rooftop area suitable for solar development. Assess the potential for hybrid solar/wind installations.

\section{"Berkeley Smart Solar Program: A Partnership to Serve the East Bay" \\ Goals: Increase the market share of solar energy technologies in the residential and small- and medium-commercial sectors in the East Bay. Build local capacity by working with local suppliers, installers, trade associations, and financiers.}

Project Highlights: Develop and implement a pilot turn-key program to install $142 \mathrm{~kW}$ of $\mathrm{PV}$ installations at 10 residential and 5 commercial sites, as well as 10 large solar hot water and air heating systems. Launch a partnership with PG\&E East Bay Energy Watch to expand depth of utility services provided. Annually install $800 \mathrm{~kW}$ of PV and 24,000 therms of thermal projects.

\section{"Solar Boston"}

Goals: Examine barriers to widespread solar deployment and develop a strategy for installing solar throughout Boston. Coordinate resources and best practices of Boston with DOE, the Commonwealth of Massachusetts, utilities, electrical workers' unions, industry and others. Create a non-profit organization to accomplish the goals of the solar partnership members.

Project Highlights: Map feasible locations for solar installations and market solar energy to prime sites. Prepare a project-labor agreement. Plan city-wide bulk purchase, financing, and installation of solar technology.

\section{"Midwest Solar City Model (MadiSUN)"}

Goals: Coordinate and galvanize substantial local and state resources to showcase how a Midwest City can dramatically increase the use of solar energy. Establish a 2-year program, MadiSUN, to provide an ongoing commitment to sustainability.

Project Highlights: Double solar energy utilization in Madison by lowering transaction costs to help building owners buy solar. Review and modify the City's procedures and policies for solar permitting and installation to be more supportive of solar systems.

\section{"New Orleans Solar Cities Initiative"}

Goals: Accelerate the adoption of solar technology by partnering with DOE. Include solar technology in the construction and renovation of new homes and businesses wherever applicable and economically feasible.

Project Highlights: Implement a publicity and outreach plan to increase demand for private solar. Evaluate and modify city regulations hindering the use of solar technologies and install solar on city government properties. Develop incentives that support solar technology in residential developments. Conduct outreach to develop a solar supply base in New Orleans.

\footnotetext{
"Solar City Strategic Partnership: NYC Solar" Goal: Achieve large-scale solar energy market growth that complements long-term sustainability planning efforts and the City's greenhouse gas reduction goals.
}

Project Highlights: Develop a long-term solar energy plan. Conduct a feasibility study of realtime pricing for $\mathrm{PV}$ net metering. Evaluate how to integrate solar into emergency planning and demand reduction programs. Create new municipal solar energy incentives. Address interconnection and code barriers through a collaborative stakeholder process. 
"The Pittsburgh Solar Initiative"

Goal: Build on Pittsburgh's reputation as a national leader in green practices by developing a distributed approach to solar adoption, as a model for other northern cities.

Project Highlights: Power traffic lights along main roads with solar power to eliminate their consumption of brown power and ensure they remain operational during a blackout. Incorporate solar on new construction in two city parks. Sponsor Carnegie Mellon's entry into the Solar Decathlon.

\section{"Portland Solar Now!"}

Goal: Build on its longstanding commitment to renewable energy by launching a robust program to facilitate the widespread adoption of solar technology and establish Portland as a leader in solar energy.

Project Highlights: Develop a marketing plan to assist property owners with the technical process of implementing solar technologies and applying financial incentives to make solar more affordable. Align City policies to promote solar technology by examining how to power municipal operations with solar, removing regulatory barriers, and adopting policies to encourage the use of solar technology.

\section{"Solar Salt Lake"}

Goal: Develop a fully-scoped city and countylevel implementation plan to facilitate an additional $10 \mathrm{MW}$ of solar PV installations by 2015 and serve as a model for other cities integrating solar into their policy, planning, and processes.

Project Highlights: Identify and reduce barriers to solar deployment in Salt Lake City and County. Implement a comprehensive plan for Salt Lake City and County that establishes a long-term commitment to solar deployment. Partner with private entities, including land developers, to advance residential solar installations in new housing developments.

\footnotetext{
"San Diego Sustainable Energy 2050 Plan" Goal: Provide a blueprint for the nation by creating an energy infrastructure that is diversified, reliable, and as self-contained as possible, as they advance the Solar America Initiative.

Project Highlights: Update GIS analysis of solar installations and potential sites. Conduct performance analysis of approximately $12 \mathrm{MW}$ of existing PV. Produce outreach materials to
}

stimulate a robust project pipeline in the city. Develop a citywide solar implementation plan. Study the impact of solar on property value/resale. Develop 3 case studies to explain solar energy systems from design to use.

\section{"Solar San Francisco"}

Goals: Realize the City's ambitious renewable energy goals established in its Electricity Resource Plan by targeting barriers facing solar technology market penetration.

Project Highlights: Develop a program to group commercial customers into one or larger, aggregated purchasing pools to be marketed to different types of perspective solar installers. Identify sites for large installations and marketing the prospects to building owners. Develop a plan to tackle problems with installing solar on multitenant buildings.

\section{"Tucson Solar Initiative"}

Goals: Expand the Tucson solar energy market through accelerated investments and establish a mechanism for sustainable solar energy integration for the next ten years. Transform knowledge and financing market barriers into opportunities for solar installations.

Project Highlights: Implement a City of Tucson Solar Energy Integration Plan and a Greater Tucson Solar Energy Development Plan. Enhance financing techniques for large-scale solar energy installations. Develop and disseminate solar best practices and other outreach.

\section{Planned FY 2008 Activities}

- Issue competitive funding opportunity announcement (FOA) and award financial assistance to approximately 12 additional U.S. Cities to form strategic partnerships.

- Begin to implement technical assistance activities to help cities achieve their goals.

- Provide for additional technical assistance resources for new cities.

- Implement planned activities by cities that include comprehensive, systemic, city-wide approaches to solar technology that facilitates mainstream adoption and provides a model for other cities.

- Hold annual meeting to bring together cities to share best practices and lessons learned. 


\section{Partners}

The following organizations partnered in the project's research activities during FY 2007.

\begin{tabular}{|c|c|c|}
\hline $\begin{array}{c}\text { Organization/ } \\
\text { Principal Investigator }\end{array}$ & Location/e-mail & $\begin{array}{c}\text { Description/Title of Research } \\
\text { Activity }\end{array}$ \\
\hline $\begin{array}{l}\text { National Renewable Energy } \\
\text { Laboratory } \\
\text { Cecile Warner }\end{array}$ & $\begin{array}{l}\text { Golden, CO 80401-3393 } \\
\text { 303-384-6516 } \\
\text { cecile_warner@nrel.gov }\end{array}$ & $\begin{array}{l}\text { Technical Assistance for Solar } \\
\text { America Cities } 2007\end{array}$ \\
\hline $\begin{array}{l}\text { Sandia National Laboratories } \\
\text { Vipin Gupta }\end{array}$ & $\begin{array}{l}\text { Albuquerque, NM } 87185 \\
\text { 915-491-1158 } \\
\text { vpgupta@sandia.g }\end{array}$ & $\begin{array}{l}\text { Technical Assistance for Solar } \\
\text { America Cities } 2007\end{array}$ \\
\hline $\begin{array}{l}\text { New Mexico State University } \\
\text { Andy Rosenthal }\end{array}$ & $\begin{array}{l}\text { Las Cruces, NM 88003-8001 } \\
\text { 303-275-4864 } \\
\text { arosenthal@nmsu.edu }\end{array}$ & $\begin{array}{l}\text { Technical Assistance for Solar } \\
\text { America Cities } 2007\end{array}$ \\
\hline $\begin{array}{l}\text { Florida Solar Energy Center } \\
\text { Robert Reedy }\end{array}$ & $\begin{array}{l}\text { Cocoa, FL 32922-5703 } \\
\text { 321-638-1000 } \\
\text { reedy@fsec.ucf.edu }\end{array}$ & $\begin{array}{l}\text { Technical Assistance for Solar } \\
\text { America Cities } 2007\end{array}$ \\
\hline
\end{tabular}




\title{
Technical Partnerships Solar America Showcases
}

\author{
Performing Organizations: $\quad$ National Renewable Energy Laboratory (NREL) \\ Sandia National Laboratories (SNL) \\ New Mexico State University (NMSU) \\ Florida Solar Energy Center (FSEC)
}

Key Technical Contacts: $\quad$ Cecile Warner (NREL), 303-384-6516, cecile_warner@nrel.gov

Vipin Gupta (SNL), 915-491-1158, vpgupta@sandia.gov

Andy Rosenthal, (NMSU), 303-275-4864, arosenthal@nmsu.edu

Robert Reedy, (FSEC), reedy@fsec.ucf.edu

DOE HQ Technology Manager: Charlie Hemmeline, 202-586-6646, charles.hemmeline@ee.doe.gov

DOE Golden Field Office, Solar Project Officer:

Steve Palmeri, 303-275-4832, steve.palmeri@go.doe.gov

FY 2007 Budgets: $\quad \$ 1,000 \mathrm{~K}$

\section{Objectives}

- Accelerate demand for solar technologies among key end-use sectors.

- Assist in creating high visibility solar projects that increase public awareness of solar power.

- Create replicable, large-scale projects that can become models for other U.S. entities.

\section{Accomplishments}

- Forest City Military Communities Project

- DOE's Technical Assistance Team supported the Forest City Military Communities to create a real estate project that will showcase the wider adoption of solar technology. This project is a public-private joint venture with the Department of Navy to build or refurbish 6,500 homes for military families on U.S. naval and marine bases in Hawaii.

- Orange County Convention Center (OCCC) Project

- DOE's Technical Assistance Team provided assistance to the OCCC, in partnership with the Orlando Utilities Commission (OUC), to plan the installation of a nominal onemegawatt (MW) photovoltaic (PV) system on the roof of and in the area surrounding its North-South Building. The system will include a large rooftop system, as well as four experimental systems showcasing new technologies at ground-level for public viewing.

- San Jose City Project:

- DOE's Technical Assistance Team provided support to the City of San Jose in identifying city-owned buildings (8) that may be suitable for solar installations. These locations are highly visible in the San Jose downtown area and have the potential for up to two MW of total solar power.

\section{Future Directions}

The Solar America Showcase Project will continue to seek solar projects to support in fiscal year (FY) 2008 that accelerate demand for solar technologies.

\section{Introduction}

The purpose of Solar America Showcases (SAS) is to accelerate demand for solar technologies among key end-use market sectors. Under this activity, DOE will provide technical assistance to large-scale, high-visibility solar installation projects that have the ability to impact the market for solar technologies through large project size, use of a novel solar technology, and/or use of a novel application for a solar technology. In addition, it is desired that the project be replicable or have 
replicable components. Although It is not expected that projects meet all of these parameters, ideally projects should reflect some or most of these qualities. Large-scale installations may include PV, concentrating solar power (CSP), and solar water heating $(\mathrm{SWH})$ applications.

DOE will not purchase hardware or provide direct funding to organizations selected for this assistance.

The types of installations DOE is looking to support are described in the following paragraphs:

Regarding the scale of the project, DOE is looking for projects with total capacity in excess of 100 kilowatt (kW). Projects may include multiple sites and do not have to be co-located. In addition to the initial installation, the $\mathrm{kW}$ total may also include planned follow-on activities (direct replication efforts). Examples include installations in residential subdivisions, shopping centers, office buildings or parks, big box retail locations, factories, and utility solar production.

Regarding the visibility of the project, DOE anticipates projects that are centrally located in towns, are sited near highly trafficked vehicle or pedestrian areas, house hundreds of residents or workers, are a part of an area frequented by tourists, are part of a popular public destination (e.g. shopping centers, courthouses, etc.), or have some other high visibility component. The project would also have an outreach component that provides information about the installation.

Regarding the novel solar technology, DOE proposes to support projects that introduce new solar technologies that hold the promise of reducing initial costs, simplifying installation, and boosting consumer confidence, but which have little testing to date that demonstrates such improvements. Examples include new cell or module technology, new materials, or innovative installation and mounting techniques. By offering technical assistance, DOE envisions helping these new solar technologies develop a performance record in the marketplace, identify technical problems early in mass product releases, and devise solutions and alternatives that move specific solar technologies to cost-competitiveness by 2015 .

Regarding the novel solar application, DOE expects to support projects that utilize solar technology in new ways. One example would be to include new methods of building integration beyond traditional roof-mounted modules. DOE also supports innovative designs and methods that open up previously untapped markets or end uses to solar technology adoption. Acceptable solar applications could also include those that are used in other geographic areas but not in the vicinity (state or region) of the proposed site.

Regarding replicability, DOE expects to support projects that can either be replicated by the entity requesting the technical assistance or by others. The entire project should be replicable, or have replicable components, unless installations are of an extremely large size that justifies DOE support without replicability. Replication of projects is a critical component to advance solar commercialization.

\section{Technical Approach}

SAS awarded technical assistance to four organizations. These organizations represented a broad spectrum of applications with cross-cutting issues that allowed the SAI to work on several barriers. These barriers included:

- Addressing financing barriers for solar applications in a municipality.

- Creating an RFP that municipalities can use for soliciting bids on solar installations.

- Developing an economically sound model for doing site surveys across a large housing complex.

- Researching inverter location and interconnection issues.

- Developing protocols for acceptance testing and commissioning processes on new solar installations.

\section{Results and Accomplishments}

For the Forest City Military Communities Project, the Technical Assistance Team accomplished the following:

- Provided technical and economic analyses as well as design recommendations for use of PV technologies on Forest City's five warehouse properties, adjacent to the airport.

- Completed technical recommendations on performance monitoring of SHW heating systems. 
- Authored a report on 'Solar Ready' specifications for residential housing.

- Provided a formal technical report on hybrid $\mathrm{PV} /$ thermal systems for cooling.

- Completed a site evaluation and solar survey on public-private venture housing areas and technical recommendations on construction of PV solar farms in open spaces, residential PV "in-fill," "PV on skids" in land bank areas, PV on community centers, PV on warehouses, PV integration on new residential rooftops/carports, rapid PV retro-fit of housing units, and adoption of solar thermal cooling systems in community centers.

For the Orange County Convention Center (OCCC) Project, the Technical Assistance Team accomplished the following:

- Assessed the feasibility of the OCCC site for the planned five PV systems.

- Developed specifications for the OCCC to use for the bid process and assisted the OCCC in determining the systems best suited for the site.

- Developed educational materials for the Climate Change Education Center, which is the core of the publicity and outreach program, designed to increase demand for solar among individuals, businesses, and institutions throughout the state.

For the City of San Jose Project, the Technical Assistance Team accomplished the following:

- Conducted site evaluations on the appropriateness for solar electric (photovoltaic or PV) and solar thermal systems at selected city sites.

- Provided project financing and procurement options evaluation and recommendation.

- Assisted with procurement language, contract negotiations, and design review on selected solar installations for the City of San Jose.

\section{Planned FY 2008 Activities}

- Issue FY 2008 competitive Notice of Technical Assistance and award Technical Assistance to up to 15 organizations.

- Complete the second phases of the Forest Cities Military Communities Project, Orange County Convention Center Project, and City of San Jose Project. 


\title{
Technical Outreach State and Utility Outreach
}

\author{
Performing Organizations: $\quad$ National Conference of State Legislatures \\ Clean Energy Group \\ National Association of Regulatory Utility Commissioners \\ Solar Electric Power Association
}

Key Technical Contact: Steve Palmeri, 303-275-4832, steve.palmeri@go.doe.gov

DOE HQ Technology Manager: Charlie Hemmeline, 202-586-6646, charlie.hemmeline@hq.doe.gov

FY 2007Federal Budgets: $\quad \$ 247,500$ National Conference of State Legislatures

$\$ 247,500$ Clean Energy Group, Inc.

$\$ 203,004$ National Association of Regulatory Utility Commissioners $\$ 614,780$ Solar Electric Power Association

\section{Objectives}

- Build relationships with State decision-makers (such as State legislatures, energy offices, public utility commissions and air quality offices) responsible for enacting policies, programs, and plans that are key drivers for solar technology market transformation.

- Provide key state actors with solar best practices and up-to-date, accurate information about solar technology characteristics.

- Enlist the assistance of a utility membership organization to deliver key technical and informational assistance to utilities to promote their acceptance and use of solar.

\section{Accomplishments}

- National Conference of State Legislatures Solar State Legislation (www.ncsl.org/programs/energy/energypolicy.cfm) was created to provide a readily accessible database of current and previous years' bills on energy issues. The database is searchable by energy topic and by state.

- $\quad$ Clean Energy Group, Inc. launched the program Web site (www.statesadvancingsolar.org) that serves as a resource for state policy makers and decision makers interested in developing a solar program.

- The National Association of Regulatory Utility Commissioners released the "Solar Energy Technology and Policy Reference Guide" (www.naruc.org/programs.cfm?c=Domestic), which includes information on Solar regulatory policies, technologies, and state and industry perspectives.

- Solar Electric Power Association released "The Peer Matching Online Tool" (www.solarelectricpower.org/peer/), a service to share information and best practices to help all utilities improve their solar programs. The database is searchable by location, utility type, experience, or by solar program type.

\section{Future Directions}

- National Conference of State Legislatures will continue working on ongoing LegisBriefs and Solar Energy Institute sessions, as well as the solar energy database for solar legislators.

- Clean Energy Group, Inc. is planning to develop a state solar program survey.

- The National Association of Regulatory Utility Commissioners plans to hold a regional dialogue for the Northeast and Mid-Atlantic to examine the regional solar initiative.

- Solar Electric Power Association is planning to develop a Solar Program Options Tool (SPOT) and an Online Resource Library. 


\section{Introduction}

In January 2006, the President announced his Advanced Energy Initiative, which "provides for a $22 \%$ increase in funding for clean-energy technology research at the U.S. Department of Energy (DOE). To change how we power our homes and offices, we will invest more in zeroemission coal-fired plants, revolutionary solar and wind technologies, and clean, safe nuclear energy." 1

An integral part of this Initiative is DOE's Solar America Initiative (SAI). The goal of SAl is to reduce the cost of solar photovoltaic (PV) technologies so that they become cost-competitive by 2015 . SAl represents a significant enhancement of DOE's business strategy of partnering with key stakeholders to accelerate commercialization of PV systems R\&D to meet aggressive cost and installed capacity goals. To learn more about SAI, visit www.eere.energy.gov/solar/solar_america/index.ht $\mathrm{ml}$.

To complement the R\&D and testing/evaluation activities that are the backbone of SAI, DOE will conduct Market Transformation ${ }^{2}$ (MT) efforts, with a mission to reduce market barriers and promote market expansion of solar energy technologies through non-R\&D activities. MT activities fall into two areas: (1) activities which provide technical, regulatory, institutional, financial, and educational solutions to market transformation barriers; and (2) those which accelerate demand for new solar technologies, primarily through technical assistance.

There are several aspects to SAI that define it as a new approach for DOE:

- SAI MT is looking to identify and remove market barriers. Through its infrastructure development activities, DOE is seeking to identify and minimize

\footnotetext{
${ }^{1}$ President George W. Bush, Advanced Energy Initiative, The White House National Economic Council, Feb. 2006.

2 "Market Transformation" was formerly referred to as "Technology Acceptance" in DOE documents and events leading up to the issuance of this Funding Opportunity Announcement. The two terms are synonymous for purposes of this FOA.
}

or remove barriers to solar technology commercialization as quickly and efficiently as possible.

- SAI MT is looking for significant market changing activities. Given the 2015 goal, DOE is seeking to make large and significant changes in the marketplace through its MT activities.

- SAI MT is focused on near- and mid-term results. Emphasis is on projects and activities with the greatest potential to assist DOE in reaching its SAI cost-competitiveness goal by 2015 .

- SAI MT is looking for performers and partners who are committed to the SAl mission. DOE is inclined to partner with motivated entities that will also benefit from achievement of the SAI mission.

\section{Technical Approach}

To reach the targeted Stakeholders in State Government and Utility Companies, SAI awarded cooperative agreements to four organizations that have expertise in working with these entities.

- The Solar Electric Power Association (SEPA) has extensive experience working with Utility Partners and was chosen to lead the outreach efforts in this area.

- The Clean Energy Group (CEG), National Association of Regulatory Utility Commissioners (NARUC), and National Council of State Legislatures (NCSL) were chosen to perform outreach to the States.

These organizations have a broad membership network that has effectively done outreach to the targeted stakeholders in the United States.

\section{Clean Energy Group, Inc. (CEG)}

Cost of Total Award (FY07-FY09): \$345,000

Using education, research and information services, CEG's project will: (1) provide information and technical assistance to state leaders and state renewable energy programs in the development of effective solar programs; (2) identify and foster solar program best practices; and (3) identify and promote strategic opportunities for states and DOE to advance solar technology deployment through partnerships, collaboration, and targeted activities.

\section{National Conference of State Legislatures (NCSL) \\ Cost of Total Award (FY07-FY09): \$263,672 \\ NCSL's Solar Energy Project will provide outreach to state policymakers on solar technology and}


policy options that can assist in integrating solar energy into the fuel mix while breaking down market barriers to the adoption of solar energy technology. The project will communicate the economic, energy security, and fuel diversity benefits of solar energy technology.

\section{National Association of Regulatory Utility Commissioners (NARUC) \\ Cost of Total Award (FY07-FY09): \$303,004}

NARUC project goals are to: (1) provide key state agencies, like Commissions and Energy Offices, with resources to help solar technologies overcome regulatory and market barriers; and (2) take advantage of emerging opportunities to encourage greater deployment and penetration of solar technologies into society. The project implementation will include outreach and education, regulatory and technical best practices, renewable portfolio standards and market structures, and other activities to encourage solar technologies.

\section{Solar Electric Power Association (SEPA)} Cost of Total Award (FY07-FY09): \$1,597,092 The overall goal of SEPA's project is to address utilities' unique roles in the increased adoption of solar electric technology, both through utilityowned systems and utility programs that facilitate customers' use and ownership. The project seeks to stimulate the increased utility adoption and integration of solar technologies, on either side of the meter, by providing a variety of support services and information to utilities throughout the United States.

\section{Results and Accomplishments}

\section{Solar State Legislation Database}

NCSL Solar State Legislation

(www.ncsl.org/programs/energy/energypolicy.cfm)

was created to provide a readily accessible

database of current and previous years' bills on energy issues. The database is searchable by energy topic and by state.

\section{Solar Energy Institute}

The Solar Energy Institute conference took place in Washington, DC, on October 18-19, 2007. Fifteen legislators and legislative staff attended the two-day conference and participated in the solar homes tour at the Solar Decathlon on the Mall. Response was overwhelmingly positive, and after attending the meeting, at least two of the attendees proceeded to introduce or consider legislation related to solar energy.
States Advancing Solar

CEG launched www.statesadvancingsolar.org to serve as a resource for state policy makers and decision makers interested in developing a solar program.

Technology and Policy Reference Guide NARUC released the "Solar Energy Technology and Policy Reference Guide" (www.naruc.org/programs.cfm?c=Domestic) which includes information on Solar regulatory policies, technologies, and state and industry perspectives.

\section{Peer Matching Online Tool}

SEPA released "The Peer Matching Online Tool" (http://www.solarelectricpower.org/peer/), a service to share information and best practices to help all utilities improve their solar programs. The database is searchable by location, utility type, experience or by solar program type.

\section{Planned FY 2008 Activities}

- Developing and disseminating a "Utility Solar Toolkit" to nearly all utilities in the US.

- Performing a State Solar PV Program Survey

- Performing state policymaker education and outreach.

- Performing solar market research and public education.

- Conducting Renewable Portfolio Standard (RPS) Implementation Collaborative.

- Hosting workshops at NARUC's 2008 Annual Convention in Anaheim and 2008 Winter Committee Meetings in Washington.

- Creating a LegisBrief, two-page summaries on important issues of the day for state legislatures, on solar technology and state policy activities.

- Conducting a seminar with area experts, targeted toward state legislators and legislative staff.

\section{Major FY 2007 Publications}

M. Taylor, "Utilities Engage Solar Electricity,"

Association of Energy Engineers, Alternative \& Renewable Energy Development Institute News, Fall 2007 Newsletter.

M. Taylor, "Utility Solar Evolution," Renewable Energy Access, Solar Power 2007, September 26, 2007. 


\section{Industry Partners}

The following organizations partnered in the project's research activities during FY 2007.

\begin{tabular}{|c|c|c|c|c|}
\hline $\begin{array}{c}\text { Organization/ } \\
\text { Principal Investigator }\end{array}$ & Location/e-mail & $\begin{array}{c}\text { Description/Title of } \\
\text { Research Activity }\end{array}$ & $\begin{array}{c}\text { FY } 2007 \\
(\$ K)\end{array}$ & $\begin{array}{c}\text { Cost Share } \\
(\$ K)\end{array}$ \\
\hline $\begin{array}{l}\text { National Conference of } \\
\text { State Legislatures } \\
\text { (NCSL) }\end{array}$ & $\begin{array}{l}7700 \text { East First Place } \\
\text { Denver, CO } \\
\text { 303-364-7700 } \\
\text { glen.andersen@ncsl.org }\end{array}$ & $\begin{array}{l}\text { State Legislative outreach on } \\
\text { Solar Technology and Policy } \\
\text { Options }\end{array}$ & 247,500 & 122,000 \\
\hline $\begin{array}{l}\text { Clean Energy Group, Inc. } \\
\text { (CEG) } \\
\text { Clean Energy States } \\
\text { Alliance, Inc. (CESA) }\end{array}$ & $\begin{array}{l}50 \text { State Street, Suite } 1 \\
\text { Montpelier, VT } \\
\text { 802-223-2554 ext. } 203 \\
\text { maria@cleanegroup.org }\end{array}$ & $\begin{array}{l}\text { Solar State Partnership } \\
\text { Project }\end{array}$ & 247,500 & 122,000 \\
\hline $\begin{array}{l}\text { National Association of } \\
\text { Regulatory Utility } \\
\text { Commissioners (NARUC) } \\
\text { NASEO }\end{array}$ & $\begin{array}{l}1101 \text { Vermont Ave., Suite } 200 \\
\text { Washington, DC } \\
\text { 202-898-2204 } \\
\text { aparraway@naruc.org }\end{array}$ & $\begin{array}{l}\text { Solar America Initiative State } \\
\text { Working Group }\end{array}$ & 203,004 & 100,00 \\
\hline $\begin{array}{l}\text { Solar Electric Power } \\
\text { Association (SEPA) } \\
\text { John Nimmons \& } \\
\text { Associates, Inc. Madison } \\
\text { Energy Consultants } \\
\text { Energy Matters } \\
\text { Sonenthal and Overall }\end{array}$ & $\begin{array}{l}1341 \text { Connecticut Ave. NW, } \\
\text { Suite } 3.2 \\
\text { Washington, DC } \\
\text { 202-857-0898 ext. } 1 \\
\text { mkimble@solarelectricpower.org }\end{array}$ & $\begin{array}{l}\text { Facilitating Utility Use and } \\
\text { Integration of Solar Electric } \\
\text { Power }\end{array}$ & 614,780 & 982,312 \\
\hline
\end{tabular}




\title{
Technical Outreach Market Transformation Support Activities
}

\author{
Performing Organizations: $\quad$ National Renewable Energy Laboratory (NREL) \\ Key Technical Contact: C Cécile Warner (NREL), 303-384-6516, cecile_warner@nrel.gov
}

DOE HQ Technology Manager: Charlie Hemmeline, 202-586-6646, charlie.hemmeline@hq.doe.gov

FY 2007 Budgets: $\quad$ \$145K (NREL), \$50K (BCS)

\section{Objectives}

- Coordinate the technical assistance support across all market transformation activities to capitalize on synergistic opportunities and efficiently apply resources and expertise across a range of projects.

- Identify and develop analytical tools and assistance products such as targeted training, which can be used by multiple tiger teams in their efforts to support Solar America Cities, Showcases, and Government Solar Installation Program (GSIP) projects.

\section{Accomplishments}

- These efforts are largely targeted for fiscal year (FY) 2008 and beyond. The work is intended to be in full swing when the memorandum-of-agreement (MOA) documents for each market transformation project have been executed, and the projects are officially launched.

- We coordinated across and among tiger teams at each of the four participating institutions that are leading the technical support to identify opportunities for capacity building among the projects' participants.

\section{Future Directions}

- Develop and convene a series of interactive seminars on financing of solar systems within municipalities, including a Clean Renewable Energy Bonds (CREB) Seminar, for Solar America City representatives.

- Coordinate technical assistance efforts among all participating institutions and identify and produce user-friendly tools and products to accelerate solar market penetration in Solar America cities, Showcases and within the GSIP federal government projects.

\section{Introduction}

Market barriers increase the price of solar systems and the time to commercialization. The Technical Partnerships and Demonstrations activity reduces barriers to the commercialization of solar energy technologies and promotes market expansion. Through this activity, we will accelerate Solar America City (SAC), Solar America Showcase, and GSIP government photovoltaic (PV) deployment by efficiently providing technical and analytical support to participating PV developers, cities, and government entities.

\section{Technical Approach}

Photovoltaic R\&D

There are three Technical Partnerships and Demonstration agreements: Solar America Showcases, Solar America Cities, and GSIP. At the direction of DOE, so-called "Tiger teams" for technical and analytical support of showcase PV installations are formed to support these requests. Tiger team personnel from several institutions, including NREL, provide projectspecific technical support that covers the gamut of large project development and installation activities, as well as coordination among diverse stakeholder groups and education and outreach activities. Specifically, the technical assistance contribution to Showcase projects, SAC partnerships, and GSIP partnerships will focus on technical aspects of project implementation. The Market Transformation support activities focus on the coordination and streamlining of 
these technical assistance efforts to identify and capitalize on synergies and to ensure efficient project implementation.

\begin{tabular}{|c|c|}
\hline Agreement Title & $\begin{array}{c}\text { FY 2007 } \\
\text { Budget (\$K) }\end{array}$ \\
\hline Market Transformation Support & $145 \mathrm{~K}$ \\
\hline & \\
\hline
\end{tabular}

\section{Results and Accomplishments}

- Because the project memorandums of agreements (MOAs) with the participating institutions (SAC, Showcases, and GSIPs), were not fully executed during fiscal year (FY) 2007, this project's accomplishments are limited.

- This work is intended to be in "full swing" when the MOA documents for each market transformation project have been executed and the projects are officially launched. Hence, this task's effort is largely targeted for FY 2008.

- We coordinated across and among tiger teams at each of the four participating institutions that are leading the technical support to identify opportunities for capacitybuilding among the projects' participants.

\section{Planned FY 2008 Activities}

- Develop performance specifications and support to solicitations related to implementation of $\mathrm{PV}$ and renewable energy projects, including review of quotes and bids, conducting acceptance tests, and ensuring appropriate user and other stakeholder training for long-term project sustainability.

- Develop and apply performance models to predict and validate performance of planned and installed systems. Produce user-friendly tools and products to accelerate solar market penetration in Solar America cities, Showcases and within the GSIP federal government projects.

- Develop success stories and best practices guides for the technical implementation of projects in all relevant market sectors, and conducting outreach activities to increase understanding of new and existing stakeholder partners.

- Coordinate across and among tiger teams at each of the four participating institutions that are leading the technical support to identify opportunities for capacity-building among each of the projects' participants and identify

- Develop and convene a series of interactive seminars on financing of solar systems within municipalities, including a CREB Seminar, for interested SAC representatives.

\section{Industry Partners}

The following organizations partnered in the project's research activities during FY 2007.

\begin{tabular}{|c|c|c|c|c|}
\hline $\begin{array}{c}\text { Organization/ } \\
\text { Principal Investigator }\end{array}$ & Location/e-mail & Description & $\begin{array}{c}\text { FY } 2007 \\
\text { (\$K) }\end{array}$ & $\begin{array}{c}\text { Cost Share } \\
(\$ K)\end{array}$ \\
\hline $\begin{array}{l}\text { BCS, Inc. } \\
\text { Suzie Lemieux }\end{array}$ & $\begin{array}{l}\text { Laurel, MD } \\
\text { slemieux@bcs-hq.com }\end{array}$ & $\begin{array}{l}\text { - } \quad \text { Coordinated logistics for FY07 } \\
\text { Annual Review. } \\
\text { Provided participants with the } \\
\text { opportunity to review and } \\
\text { comment on SETP's } \\
\text { technology roadmaps and to } \\
\text { confirm the roadmaps' utility } \\
\text { in helping formulate SETP's } \\
\text { FY08 Annual Operating Plan. }\end{array}$ & $\$ 50 \mathrm{~K}$ & \\
\hline
\end{tabular}


Photovoltaic R\&D

Market Transformation

Technical Outreach 


\title{
Solar Thermal R\&D Subprogram Overview
}

\author{
Frank (Tex) Wilkins, Team Leader, Solar Thermal R\&D
}

Fiscal year (FY) 2007 was a momentous one for the Solar Thermal Subprogram. The Office of Energy Efficiency and Renewable Energy (EERE) conducted a reorganization that had a significant impact on the Subprogram, and the Concentrating Solar Power (CSP) program saw a resurgence.

The Solar Heating and Lighting (SHL) activity was transferred from the Solar Program to EERE's Building Technologies Program, where it will become an important part of their development of zero energy buildings. Bob Hassett, who has a long history with $\mathrm{SHL}$, manages the activity in the Building Technologies Program.

In June, the sun was shining on a new CSP project when Nevada Solar One ${ }^{\mathrm{TM}}$ began operation. This 64-megawatt (MW) trough plant, located in Boulder City, Nevada, is the first commercial CSP plant built in the United States since 1991. Nevada Solar One shows the resurgence of CSP as a major option for generating carbon-free renewable energy. Another sign of CSP's resurgence during 2007 was the planning of other large CSP projects.

Recognizing the value of CSP, utilities announced planned projects that totaled more than 3,000 MW. These included dishes, troughs, and towers. However, Spain was the hotbed of CSP activity during 2007. A 10-MW tower became operational and construction begun on a 20-MW tower. At least four $50-\mathrm{MW}$ trough projects were also under construction in Spain by the end of the year.

\section{Results and Accomplishments}

The CSP budget got a boost in FY 2007 which enabled a competitive solicitation for the first time in several years. The solicitation, released through the Golden Field Office, was focused on three areas: (1) thermal storage, (2) trough component manufacturing, and (3) advanced CSP systems and components. The objective of the solicitation is to establish cooperative research and development (R\&D) contracts that will help the Solar Program achieve its CSP cost goal of 7-10 cents/kWh by 2015. A total of 12 proposals from nine companies were selected for negotiation. The selected proposals included work on troughs, dishes, and towers and will begin in FY 2008.

As the subprogram gears up, work continues at Sandia National Laboratories and National Renewable Energy Laboratory to help industry improve their technology. This is becoming more difficult because the industry is rapidly expanding, and new concepts are being touted as having the potential for low-cost power. The increased budget is enabling an increase in lab staff to handle the increased work load.

\section{New Directions}

The increased budget also provided the impetus to take a long term view of CSP R\&D. This exercise led to a scenario that would establish a new goal for CSP: providing baseload power at a competitive cost by 2020. To provide baseload power, CSP projects would require 12-17 hours of storage at low cost. As the country looks for methods of combating climate change, CSP could prove to be an attractive option to coal for providing baseload power. To reach this goal, an expanded R\&D program with a new emphasis on thermal storage would be required. Planning for an increased effort on thermal storage began with the intent of implementing it in FY 2008.

FY 2007 was a momentous year, yet FY 2008 promises to be even more exciting. 


\section{Concentrating Solar Power}

Concentrating solar power (CSP) systems use the heat generated by concentrating and absorbing the sun's energy to drive a conventional turbine or heat engine/generator and produce electric power. Three types of CSP systems-trough, dish/engine, and power tower-are all capable of producing power using the sun's energy.

Trough systems, the most commercially mature of the three systems, use linear parabolic concentrators to focus sunlight along the focal lines of the collectors. Dish/engine systems comprise a parabolic dish concentrator, thermal receiver, and heat engine/generator located at the focus of the dish to generate power. In a variation of the dish/engine system, concentrating photovoltaics (CPV), an array of high-efficiency photovoltaic cells replaces the thermal receiver and heat engine. In a power tower system, a field of two-axis tracking mirrors, called heliostats, reflects the solar energy onto a receiver that is mounted on top of a centrally located tower.

With the advent of renewables-friendly policies within the United States and abroad, there is a renewed interest in CSP technologies based on their potential for low cost and ease of largescale implementation. The Western Governors' Association (WGA) established a Solar Task Force to determine the potential of solar energy in the West and identify the incentives required to establish projects. The National Renewable Energy Laboratory (NREL) provided much of the analysis required by the WGA. In the U.S. southwestern states, CSP projects are under way in Nevada and Arizona; New Mexico and California are investigating the possibilities of developing CSP plants. R\&D priorities of the CSP Subprogram are determined, in part, by projects being developed under the state programs.

The accomplishments of the DOE Solar Program's CSP activity for FY 2007 include:

CSP Applied Research

- Performed durability testing and published results of optical materials that potentially can reduce the cost of levelized cost of energy of CSP to less than 10 cents/kWh by 2015 .

CSP Technology Acceptance

- Continued development of the Concentrating Solar Deployment System (CSDS) model.

CSP Testing and Evaluation

- Included CSP parabolic trough modeling within Solar Advisor Model.

\section{Dish Engine Development}

- Operated and improved the Stirling Energy Systems six-dish model power plant, cataloging more than 100 development areas.

- Installed Infinia 3-kilowatt system at SNL.

\section{Parabolic Trough Development}

- Developed a new selective coating to meet the long-term selective property goals for parabolic trough receivers.

- Refined its theoretical overlay photographic alignment system for evaluating the alignment of mirrors and receivers on parabolic trough collectors installed in a solar field.

- Improved the speed of infrared imaging of receivers for assessing the thermal performance of receivers in the solar field. More than 30,000 receivers were imaged at the Solar Energy Generating Systems fields to help FPL Energy categorize receiver performance in advance of a major receiver upgrade program. 


\title{
CSP Applied Research
}

\author{
Performing Organization: National Renewable Energy Laboratory (NREL) \\ Key Technical Contact: Cheryl Kennedy (NREL), 303-384-6272, cheryl_kennedy@nrel.gov
}

DOE HQ Technology Manager: Thomas Rueckert, 202-586-0942, thomas.rueckert@ee.doe.gov

FY 2007 Budgets: $\quad$ \$135K

\section{Objectives}

- Develop technology that dramatically reduces the cost of concentrating solar power (CSP) to less than 10 cents/kWh by 2015.

- For mirrors, this is accomplished through technology advances that reduce the cost of the mirrors by half by moving from heavy glass mirrors to lightweight front-surface reflectors that include surface coatings to reduce soiling.

- Develop advanced reflector materials that are low in cost (less that $\$ 1 / \mathrm{ft}^{2}$ or $\$ 10.76 / \mathrm{m}^{2}$ ) and maintain high specular reflectance (90\%-95\% into a 4-mrad cone angle) for long lifetimes (10 to 30 years) under severe outdoor environments.

- Test the durability of optical materials to determine lifetime of solar reflector materials.

\section{Accomplishments}

- Performed durability testing and published results of optical materials that potentially can reduce the cost of levelized cost of energy (LCOE) of CSP to less than 10 cents/kWh by 2015.

- Provided significant industry support to the CSP and concentrating photovoltaic (CPV) industries on solar reflectors.

\section{Future Directions}

- Continue durability testing of optical materials to determine lifetime of solar reflector materials.

- Optical characterization of advanced reflector materials, accelerated and outdoor testing of commercial, experimental, CSP FOA, CSP industry, and CRADA supplied reflector materials to determine lifetime of solar reflector materials, and support of industry/program needs.

- Analyze and publish testing results of reflector materials applied to CSP technologies.

\section{Introduction}

Commercialization of concentrating solar power (CSP) technologies requires the development of advanced reflector materials that are low in cost and maintain high specular reflectance for lifetimes of 10 to 30 years under severe outdoor environments. The DOE Solar Program Multi-Year Technical Plan targets cost reductions of up to $50 \%$ for the solar concentrator. These goals should be achieved through technology advances such as lightweight front-surface reflectors that include anti-soiling coatings. The objective of this research is to identify new, cost-effective advanced reflector materials that are durable with weathering.

\section{Technical Approach}

Candidate reflector materials were identified based on their potential for low cost and high optical performance and durability. All candidate materials were optically characterized prior to exposure testing and as a function of exposure time to assess optical durability. The hemispherical reflectance of the samples was measured from 250 to $2500 \mathrm{~nm}$ using a PerkinElmer Lambda 9 or 900 UV-VIS-NIR spectrophotometer with a $60-\mathrm{mm}$, integratingsphere attachment relative to National Institute of Science and technology (NIST) standards. The direct normal air-mass 1.5 (DIRNOR15) solarweighted hemispherical reflectance is calculated from data collected in the 250-2500-nm range. The specular reflectance is measured at 7- and 25-mrad cone angle with a Device and Services 
(D\&S) Field Portable Specular Reflectometer at $660 \mathrm{~nm}$.

The mirrors are subjected to accelerated or outdoor weathering at a variety of geographically diverse exposure sites. Outdoor exposure testing is performed in Golden, Colorado (NREL); Miami, Florida (FLA); and Phoenix, Arizona (AZ). Accelerated exposure testing can be performed at NREL in the Atlas Ci65A (Ci65) or Ci5000 (Ci5000) Weather-Ometers (WOM), and a BlueM damp heat oven (BlueM). The WOM's, and BlueM allow control of exposure temperature and ambient humidity. The WOM's use xenon-arc light source with filters designed to closely match the terrestrial air-mass 1.5 solar spectrum. The WOM's operates continuously at $60^{\circ} \mathrm{C}$ and $60 \%$ relative humidity $(\mathrm{RH})$, with light levels about equal to outdoor exposure for the $\mathrm{Ci} 65$ and twice outdoor exposure for the Ci5000. A single day of testing (24 hours) is roughly equivalent to three times the outdoor exposure for the Ci65 and six times for the $\mathrm{Ci} 5000$ in terms of light intensity. The BlueM operates continuously at $80^{\circ} \mathrm{C}$ and $80 \% \mathrm{RH}$, but the samples are not exposed to the light. The BlueM does not have the same measured acceleration factor as the WOMs, but from other experiments it is believed the acceleration factor is roughly 5 times the Ci5000.

\section{Results and Accomplishments}

- Paper on durability of thin-glass mirrors applied to CSP technologies (03/31/07)

- Paper on status of reflector materials. (07/31/07)

- Provided significant industry support about reflectors to CSP and concentrating photovoltaic (CPV) industry.

\subsection{Glass Mirrors}

Traditionally, glass mirrors have excellent durability, are readily available, have the confidence of the solar manufacturing industry, and have been commercially deployed. However, for parabolic shapes glass needs to be slumped which is expensive. Glass mirrors are heavy and require more robust support, footings and tracking hardware. If the mirrors break under wind loads, they tend to break adjacent mirrors and receivers.

Two significant changes occurred in the classical wet-chemistry process used in mirror manufacturing because of environmental concerns. The first is the use of a copper-free back layer, and the second is the use of lead-free paints. The copper-free process requires stringent cleaning and quality control, and the lead-free paints were developed for interior applications. Consequentially, the basic mirror composition of commercially available mirrors is radically different from historically durable solar mirrors, and alternatives have been limited.

Trough mirrors, used in commercial solar plants, manufactured by Flabeg have historically been very durable. They use silvered thick, slumped low-iron glass that is protected with a heavily leaded proprietary multilayer paint system designed for outdoor exposure. Flabeg converted their mirror line to 4- or 5-mm glass and a new low-lead paint system in 2003, in which the lead was reduced to the point that durability was expected to be equivalent. The base paint of the three-layer paint system now contains $2.5 \%$ lead and the intermediate paint contains $1 \%$ lead, where the lead content was reduced from $\sim 20 \%$ and $\sim 10 \%$ respectively. The white top coat with high UV stability remained the acrylic based top coat that was used in the past. Side-by-side exposure testing of the original and new construction began in 2005. The original mirrors with the high-lead paint system exhibit better optical durability than the new reduced-lead mirrors (see Fig. 1). The high-lead mirrors degraded $0.9 \%$ and the reduced-lead degraded $1.9 \%$ after 18 months of outdoor exposure in Colorado (NREL). Whereas, the high-lead mirrors degraded $2.1 \%$ and the reduced-lead degraded $3.6 \%$ after 24 months of accelerated exposure in a Ci65a Weather-Ometer (WOM).

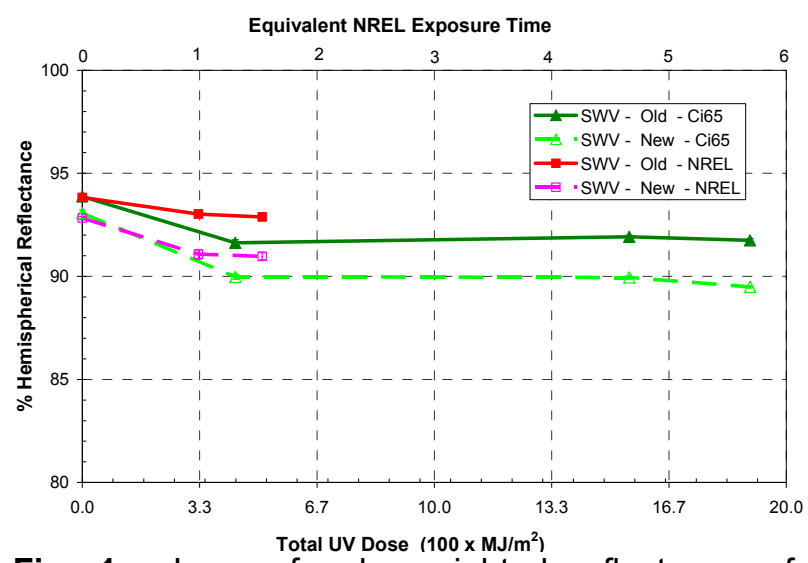

Fig. 1. Loss of solar-weighted reflectance of original high- $\mathrm{Pb}$ and new low-Pb Flabeg thickglass mirrors as function of accelerated WOM and outdoor exposure at Golden, CO (NREL), in total UV dosage.

Pilkington (4-mm copper-free) mirrors and "Spanish" (Cristaleria Espanola S.A; i.e., Saint Gobain) glass mirrors ( $3 \mathrm{~mm}$, copper-free, and 
lead-free paint), bonded to steel with four different candidate adhesives, were tested for possible use at Solar Tres. Up to this point, neither Pilkington nor Spanish mirrors exposed outdoors at NREL for 82 months show degradation; but the Pilkington mirrors exhibit better optical durability than the Spanish mirrors in accelerated WOM exposure testing (see Fig. 2). Spanish mirrors degraded $19.0 \%$, whereas Pilkington mirrors degraded $2.8 \%$ after 53 months of accelerated WOM exposure and adhesive-related degradation is more prevalent with Spanish glass mirrors. Depending on the adhesive used to bond the mirror, Spanish mirrors degraded $4.7 \%$ to $12.0 \%$, whereas Pilkington mirrors degraded $1.7 \%$ to $2.9 \%$ after 50 months of accelerated WOM exposure.

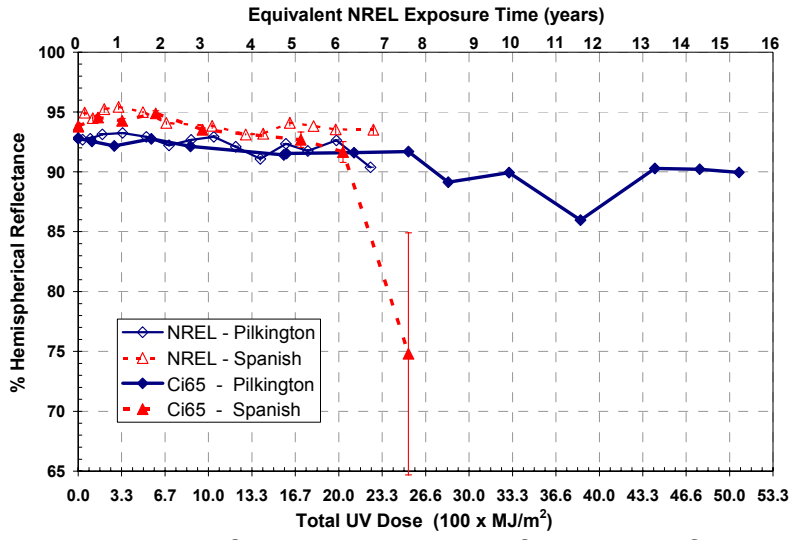

Fig. 2. Loss of solar-weighted reflectance of thick Pilkington and Spanish reflectors with copper-free back layer, $\mathrm{Pb}$-free paint, as a function of Ci65a WOM exposure and outdoor exposure at NREL.

Thin-glass mirrors also use traditional wet-silvered processes on thin $(<1 \mathrm{~mm})$, relatively lightweight glass. The choice of adhesive has been observed to affect the performance of weathered thin-glass mirrors, and corrosion has been observed in deployed mirrors, including mirrors using the new copper-free protective layer and lead-free paints. In addition, some thin-glass silvered copper-free, lead-free mirrors sold for outdoor applications have not passed the minimum ASTM standards (i.e., 120-h CASS, 480-h salt spray, and damp heat) to qualify for indoor applications.

A matrix of sample constructions prepared to identify the most promising combinations of paints and adhesives for use with solar reflectors has more than 3 years of exposure in the $\mathrm{Ci} 5000$ and in BlueM. The AGC (formerly Glaverbel Belgium) mirrors tended to outperform the Naugatuck mirrors (U.S.) in the mirror matrix experiment. However, at the time the mirrors were acquired, the Glaverbel mirrors provided were from an experienced copper-free production run that included $0.15 \% \mathrm{~Pb}$ in the two-coat paint system, and the Naugatuck mirrors were poor quality mirrors from an inexperienced pilot run that incorporated $<5 \mathrm{ppm} \mathrm{Pb}$ in a 1-coat paint system. For the copper-free constructions, adding epoxy and polyurethane back protection appears to be a poor choice because when these constructions failed, they typically failed catastrophically by silver/paint delamination. The epoxy adhesive/substrate show slight advantages over other adhesive/substrates. Edge protection and substrate and glass back-cleaning had no effect.

CPV manufacturers have expressed significant concern regarding the durability of thin-glass mirrors made with copper-free and lead-free paint systems. Naugatuck Glass responded to the mirror degradation issue and provided copper-free mirror samples for testing with a two-coat, leadfree paint system plus moisture and adhesiveresistant back protection, instead of the one-coat paint system previously used in its manufacturing line. Exposure testing results appear encouraging and testing is ongoing (see Fig. 3).

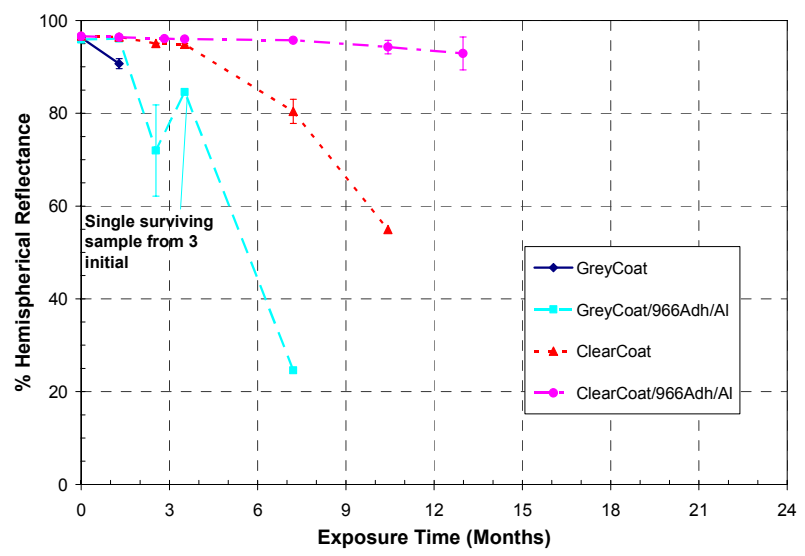

Fig. 3. Loss of solar-weighted reflectance of Naugatuck thin-glass mirrors with $\mathrm{Cu}$-free back layer and 2-layer $\mathrm{Pb}$-free paint system with and without moisture barrier clear coat and laminated substrate as a function of accelerated BlueM exposure.

Although glass mirrors with copper back layers and heavily leaded paints have been considered robust for outdoor use, the new copper-free, back layer and lead-free paint systems were designed for interior mirror applications and their outdoor durability must be determined.

\subsection{Aluminized Mirrors}

Aluminized reflectors use a polished aluminum substrate, an enhanced aluminum reflective layer, and a protective oxidized topcoat. These mirrors 
have shown poor durability in urban and industrialized (polluted) locations. The hemispherical reflectance and 25 mrad specularity had improved durability with protective polymeric overcoat incorporated onto the aluminized aluminum. However, the specularity degraded with outdoor exposure at Arizona, Florida, and Colorado (NREL) and with accelerated exposure in the Ci65a WOM. Alanod stopped selling this material in 2004 for outdoor use because of problems associated with the delamination of the overcoat. Alanod worked to improve the reflector durability and its in-house testing capability. The fluoropolymer overcoat was replaced with a nanocomposite oxide protective layer. New samples received in 2005 are undergoing testing. Preliminary exposure testing results appear encouraging and testing is ongoing (see Fig. 4). Alanod reintroduced the product for sale as MiroSun in 2006. The material is commercially available from Alanod in Germany for $\approx \$ 2.50 / \mathrm{ft}^{2}$. The initial solar-weighted hemispherical reflectance is $\approx 91.8 \%$; initial specular reflectance at 25 mrads is $\approx 83.7 \%$ and at 7 mrads is $\approx 63.9 \%$. Alanod is now working to develop a silvered solar reflector likely to be called Miro-Silver.

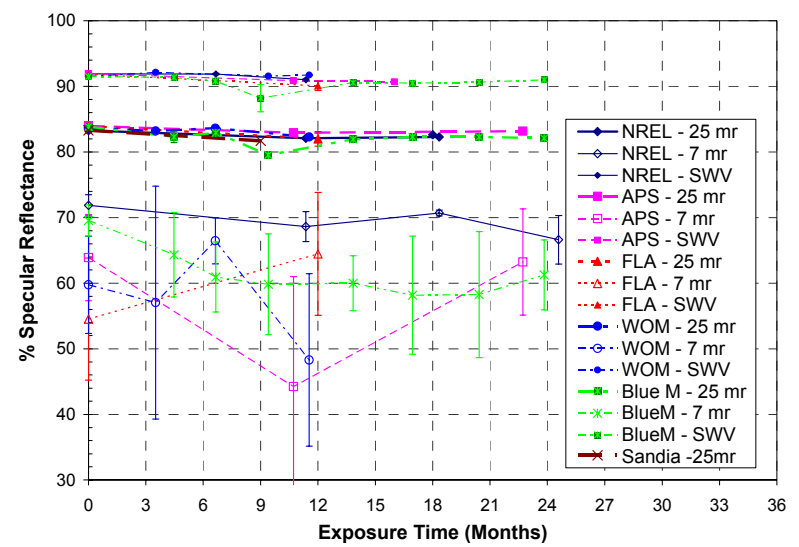

Fig. 4. Loss of solar-weighted reflectance, 25and 7-mradian specular reflectance at $660 \mathrm{~nm}$ of Alanod Miro-Sun aluminized reflectors as a function of APS, NREL, and Sandia outdoor exposure and accelerated WOM and BlueM exposure.

\subsection{Silvered Polymer Reflectors}

A polymeric solar reflector was developed through collaborative research with ReflecTech. In 2001, a small pilot run demonstrated that production could be achieved using standard commercial film converter equipment. This initial pilot-run material shows minimal loss in solar-weighted reflectance after 5 years of real-time outdoor exposure in Golden, CO. In addition, there was no significant loss in solar-weighted reflectance for samples after the equivalent of 10 years of accelerated outdoor exposure in ACUVEX (natural sunlight in Phoenix, AZ, concentrated seven to eight times with a Fresnel-reflector while samples are cooled with a fan to near-ambient conditions and sprayed with deionized water 8 minutes per natural sun hour). However, Ci65a WOM results showed significant reflectance loss earlier than anticipated from the proof-of-concept materials. Prototype materials to test modifications to the baseline construction were produced under a subcontract. These tests were successful in identifying changes to the baseline construction that dramatically improved the Ci65a WOM durability of the reflective film. Some of these improvements were then incorporated into a new pilot plant production run delivered late 2004. Initial hemispherical and specular reflectivity was low due to a vacuum problem when the silver was sputtered process. In ReflecTech's third pilot-plant run additional improvements from the subcontract were incorporated. Samples (ReflecTech [06-48, 0660]) delivered in 2006 had improved hemispherical and specular reflectivity. Both versions of the third pilot-run materials show minimal loss in solarweighted and 25-mrad and 7-mrad specular reflectance after 16 months of real-time outdoor exposure in Golden, CO. The 06-60 shows minimal loss in solar-weighted and 25-mrad and 7mrad specular reflectance, but the 06-48 shows $12-20 \%$ loss after 6 months of accelerated Ci65a WOM exposure (see Fig. 5). Durability testing is ongoing and the material is being field-tested.

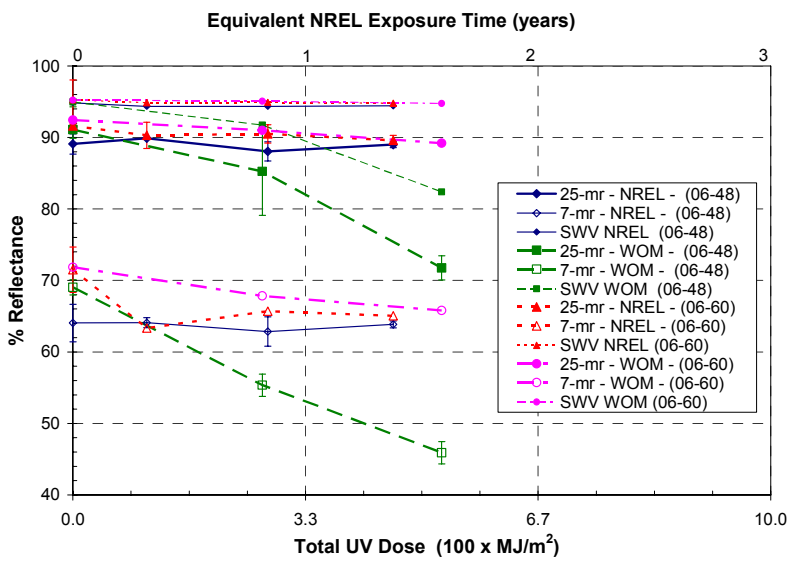

Fig. 5. Loss of solar-weighted and 25-mrad and 7-mrad specular reflectance of ReflecTech third pilot run as a function of outdoor exposure in Colorado and accelerated Ci65a WOM exposure.

Progress has been made on advanced solar reflector research and durability testing of reflectors supplied by industry is ongoing. Glass, ReflecTech, and Alanod mirrors are commercially

Solar Thermal R\&D 
available and, based on accelerated exposure testing, should meet the 10-year lifetime goals. However, predicting an outdoor lifetime based on accelerated exposure testing is risky because the accelerated failure mechanisms must exactly replicate those observed outdoors. The construction of solar reflectors has significantly changed. Because of this, all of the solar reflectors commercially available have been in outdoor realtime exposure testing for less than 3 years.

\section{Planned FY 2008 Activities}

The most significant activities planned (as part of the FY 2008 AOP) are:

- Complete installation of new accelerated exposure chambers to test durability of commercial and experimental solar mirrors. (3/08).

- Determine optical performance, lifetimes, and cost goals for advanced reflectors that are consistent with current CSP program objectives. (6/08).

- Compare the durability of silvered thin-glass copper-free and lead-free mirrors after exposure to AET ( $\mathrm{Ci} 5000$ WeatherOmeter and damp-heat at different humidity conditions) and OET (Golden, CO; Phoenix, AZ; Miami, FL; and Alice Springs, Australia) (6/08)

- Provide status of test results of candidate solar mirror samples and identify promising candidates and how advanced solar mirrors will help meet the cost goal for electricity. (09/08).

\section{Major FY 2007 Publications}

M. Kempe, G. Jorgensen, K. Terwilliger, T. McMahon, C. Kennedy, and T. Borek, "Acetic Acid Production and Glass Transition Concerns with Ethylene-Vinyl Acetate Used in Photovoltaic Devices" Sol. Energ. Mater. Sol. Cell 91, 315 (2007).

C. Kennedy, "Durability of Front Surface Solar Reflectors," 2007 TechCon Proceedings of Society of Vacuum Coaters, April 28-May 3, Louisville, KY, 2007.

C. Kennedy, K. Terwilliger, and G. Jorgensen, "Further Analysis Of Accelerated Exposure Testing Of Thin-Glass Mirror Matrix," Proceedings of Energy Sustainability 2007, June 27-30, Long Beach, CA, 2007.
C. Kennedy and K. Terwilliger, "Solar 2007: Optical Durability of Candidate Solar Reflectors for Concentrating Solar Power," Proceedings of Solar 2007, July 7-12, Cleveland, OH, 2007.

C. Kennedy, "Advances in Concentrating Solar Power Collectors: Mirrors and Solar-Selective Coatings," Proceedings of Association of Industrial Metallizers, Coaters and Laminators (AIMCAL) Fall Technical Conference 2007 and 21st International Vacuum Web Coating Conference, October 8-10, Scottsdale, AZ, 2007.

\section{University and Industry Partners}

Significant industry interaction occurred with CSP reflector manufacturers and CPV manufacturers on the durability of solar mirrors. A partial list includes: 3M, A Better Focus, Acciona, AGC (Glaverbel), Alanod, Alcoa, Applied Image, Boeing, Cool Earth, Cooper Lighting, Corning, Cosmo Films, Dow Chemical, Dow Corning, Emcore, eSolar, Flabeg, Gardner, GreenVolts, Guardian, Honeywell, Infinia, JX Crystals, Luz II, Nambia Power Tower project, Naugatuck, Nitinol, Northside, ORNL, PARC, Pilkington, PPG, Pratt \& Whitney, Praxair, RAflector, Raytheon, ReflecTech, Replex, Rio Glass, Rocky development, SAIC, Saint Gobain, Sandia, Sandvik, Schott, Solel, SolFocus, Soliant, Solucar, Solyndra, Southwall, Stirling Energy Systems, Sunray, SunTechnics, Symmorphix, United Solar, University of Baleric Islands, University of California Merced, University of Colorado, University of Hartford, University of Minnesota, Von Ardenne, West Virginia University, and Wooly Parsons.

Cooperative Research and Development Agreement's were negotiated with SolFocus and Solar Systems to determine the reliability and durability of large and small mirror dishes; front surface reflectors, adhesive and encapsulents, and III-V cells; and will help to establish the viability of producing low cost, high performance photovoltaic energy conversion modules by collector based CPV.

The following organizations partnered in the project's research activities during FY 2007. 


\begin{tabular}{|l|l|l|c|c|}
\hline \multicolumn{1}{|c|}{$\begin{array}{c}\text { Organization/ } \\
\text { Principal } \\
\text { Investigator }\end{array}$} & \multicolumn{1}{|c|}{ Location/e-mail } & $\begin{array}{l}\text { Description/Title of Research } \\
\text { Activity }\end{array}$ & $\begin{array}{c}\text { FY 2007 } \\
\mathbf{( \$ K )}\end{array}$ & $\begin{array}{c}\text { Cost Share } \\
\mathbf{( \$ K )}\end{array}$ \\
\hline $\begin{array}{l}\text { Solar Systems } \\
\text { Ken Cheah }\end{array}$ & $\begin{array}{l}\text { Melbourne, Australia } \\
\text { Kcheah@solarsystems.com.au }\end{array}$ & $\begin{array}{l}\text { Research on durability of small } \\
\text { mirror dishes and front surface } \\
\text { reflectors, and bond joints. }\end{array}$ & $8.4^{*}$ & $30.3^{* *}$ \\
\hline $\begin{array}{l}\text { SolFocus } \\
\text { Mark Spencer }\end{array}$ & $\begin{array}{l}\text { Mountain View, CA } \\
\text { mark_spencer@solfocus.com }\end{array}$ & $\begin{array}{l}\text { Research on optical durability of } \\
\text { thin-glass mirror panels. }\end{array}$ & $13.0 \dagger$ & $234.0 \ddagger$ \\
\hline
\end{tabular}

*NREL Funded Amount: \$8.4k 6/26/07 - 9/30/07

** Sponsor Contract Value \$39.3k 6/6/07 - 1/25/08

† NREL Funded Amount: \$13.0k 6/15/07 - 9/30/07

‡ Sponsor Contract Value $\$ 234.0 \mathrm{k} 6 / 15 / 07$ through 8/14/11 


\title{
CSP Laboratory Facilities
}

\author{
Performing Organizations: $\quad$ National Renewable Energy Laboratory (NREL) \\ Sandia National Laboratories (SNL) \\ Key Technical Contacts: $\quad$ Mark Mehos (NREL), 303-384-7458, mark_mehos@nrel.gov \\ Tom Mancini (SNL), 505-844-8643, trmanci@sandia.gov
}

DOE HQ Technology Manager: Thomas Rueckert, 202-586-0942, thomas.rueckert@ee.doe.gov

FY 2007 Budgets: $\quad$ \$380K (NREL), \$500K (SNL)

\begin{abstract}
Objective
- Maintain and upgrade NREL and SNL facilities to support in-house, subcontracted, and work-forothers activities.
\end{abstract}

\section{Introduction}

DOE national laboratories are government-owned, contractor-operated facilities that rely on government funding for buildings and equipment. Facilities at NREL include the High Flux Solar Furnace (HFSF), Mesa Test Area, VSHOT laboratory, advanced optical materials laboratory, advanced receiver laboratory, and other laboratory support facilities. Facilities at SNL include the National Solar Thermal Test Facility (NSTTF). Both the HFSF and NSTTF are designated by DOE as User Facilities, which means that the facilities and staff are available for use by U.S. industry, universities, other laboratories, state and local governments, and the general scientific community. Concentrating Solar Power (CSP) facilities need to be continually outfitted with the most advanced equipment to conduct full-scale, CSP research of use to near- and long-term development efforts.

\section{Technical Approach}

The technical approach to operating and maintaining the NSTTF is to support the six-dish mini power plant and to assure that all environmental safety and health (ES\&H) requirements are met at the facility, which includes a solar furnace, a 5-MWth central receiver test facility, a "mothballed" molten-salt test facility, an engine test facility, and a rotating platform for onsun, high-temperature trough testing. The facility comprises a laboratory/office/control building, a power tower building, and multiple fabrication, test, and storage buildings.
Operation and Maintenance of the NSTTF includes monthly, semi-annual, and annual inspections and ES\&H evaluations, training for all site workers, maintenance of all equipment at the site, and operation of equipment for testing and evaluation. This year we have had a significant effort in non-national research test laboratory compliance evaluation which requires that all equipment be evaluated, tested, and certified by either a nationally recognized testing laboratory or made compliant via a DOE-certified procedure.

NREL facilities funding supports facilities space located on South Table Mountain (e.g. the HFSF and the large payload 2-axis tracker), the VSHOT optical test lab, receiver test lab, optical materials laboratory, and thermal storage laboratory. Capital funds $(\$ 136 \mathrm{~K})$ were allocated for purchase and installation of a new Ci5000 Weatherometer.

\begin{tabular}{|c|c|}
\hline Task Title & $\begin{array}{c}\text { FY 2007 } \\
\text { Budget (\$K) }\end{array}$ \\
\hline 1000 MW Initiative Support - NREL & 380 \\
\hline $1000 \mathrm{MW}$ Initiative Support - SNL & 500 \\
\hline
\end{tabular}

\section{Planned FY 2008 Activities}

As a direct result of low CSP program funding over the last 7 years, there has been little maintenance done at NREL and SNL facilities. Fiscal year (FY) 2008 funding for facilities will begin to support upgrades necessary to support in-house and subcontracted (e.g. FOA) R\&D efforts as proposed in the FY 08 annual operating plan for specific project activities (dish, trough, storage, and advanced concepts). 


\title{
CSP Technology Acceptance
}

\author{
Performing Organizations: $\quad$ National Renewable Energy Laboratory (NREL) \\ Sandia National Laboratories (SNL) \\ Key Technical Contacts: $\quad$ Mark Mehos (NREL), 303-384-7458, mark_mehos@nrel.gov \\ Tom Mancini (SNL), 505-844-8643, trmanci@sandia.gov
}

DOE HQ Technology Manager: Thomas Rueckert, 202-586-0942, thomas.rueckert@ee.doe.gov

FY 2007 Budgets: $\quad$ \$580K (NREL), \$200K (SNL)

\section{Objectives}

- Provide support for Concentrating Solar Power (CSP) Subprogram analysis efforts relating to large-scale implementation of concentrating solar power in the southwestern United States.

- Support CSP-specific analysis related to implementation of the Systems-Driven Approach within the U.S. Department of Energy's (DOE) Solar Energy Technologies Program (SETP).

- Support DOE and Energy Information Administration analysis requests on an as-needed basis.

\section{Accomplishments}

- Continued development of the Concentrating Solar Deployment System (CSDS) model.

- Expanded the geographical information system (GIS)-based tool by developing a prototype dynamic mapping tool.

- Provided support to utility stakeholders, including the Southwest Joint Development Group.

\section{Future Directions}

Funding for CSP analysis and outreach has increased for fiscal year (FY) 2008 and will be funded under a new project titled "CSP Market Transformation." Specific market transformation activities will include:

- Continue CSP stakeholder outreach (e.g., staff in state energy, economic, and environment offices and utilities).

- Continue the development of tools (GIS, market analysis, economic impact analysis) for use in supporting the activities described above.

- Continue providing support of CSP model development in the Solar Advisor Model framework.

- Continue and expand work related to market penetration, with a new emphasis on grid integration and expansion studies.

- Expand the resource assessment activity to include reducing the uncertainty of satellite-derived solar resource data through improved aerosol optical depth data and ground measurements, supporting university- and industry-led resource forecasting efforts, and investigating methodologies for projecting long-term seasonal and inter-annual solar resource characteristics from short-term data.

- Initiate efforts on a Programmatic Environmental Impact Statement (PEIS) for solar energy development on southwestern lands administered by the Bureau of Land Management (BLM).

\section{Introduction}

The 1000-megawatt (MW) CSP project was initiated in FY 2002 based on a congressional request to DOE to investigate the "feasibility of $1000 \mathrm{MW}$ of concentrating solar power in the Southwest by 2006." The original charge has grown and now involves a number of activities, including outreach and support of state-level activities in the southwestern United States and analysis in support of stakeholders at the state and federal level.

The focus of the FY 2007 CSP technology acceptance activity was to accelerate the commercialization of concentrating solar powergeneration technologies. Analysis shows that cost reductions needed for the technologies to be competitive in central power-generation markets will result from a combination of advances in research 
and development, system scale-up, and learning and deployment. The technology acceptance activity primarily addresses cost reductions resulting from deployment.

This project links directly to the DOE Energy Efficiency and Renewable Energy and SETP missions to "bring clean, reliable, and affordable energy technologies to the marketplace" and to "increase the viability and deployment of renewable energy technologies." Cost reductions due to learning and deployment, the primary outcome of this project, directly support the SETP's long-term goal of achieving wholesale, central power generation from solar energy at a cost of $\$ 0.05$ $\$ 0.08 / \mathrm{kWh}$.

\section{Technical Approach}

The technology acceptance activity is conducted through the SunLab collaboration between NREL and SNL. In addition, funding is provided to outside contractors -in particular, Fred Morse and Associates-to coordinate communications and analysis with key CSP stakeholders, including the Western Governors' Association (WGA), major southwestern utilities, state energy staff, and state and local policy makers.

As described in previous annual reports, this activity originated with the development of a report on the potential of $1000 \mathrm{MW}$ of CSP power in the West, which was completed and submitted to Congress in August 2002. Following the submission of the report, a CSP "road show" was formed to provide information on the characteristics of CSP technologies, the technical potential for CSP within each of the southwestern states, and the benefits that would accrue from the implementation of CSP. In 2006, the CSP program provided substantial analytical support for the WGA's $30 \mathrm{GW}$ Clean and Diversified Energy Initiative. This and similar stakeholder outreach and analysis efforts continued into FY 2007.

Budget allocations by task are provided below.

\begin{tabular}{|c|c|}
\hline Task Title & $\begin{array}{c}\text { FY 2007 } \\
\text { Budget (\$K) }\end{array}$ \\
\hline $1000 \mathrm{MW}$ Initiative Support - NREL & 580 \\
\hline $1000 \mathrm{MW}$ Initiative Support - SNL & 200 \\
\hline
\end{tabular}

\section{Results and Accomplishments}

The technical work plan focused on the following: a. Provide analytical support for stakeholders in Southwest.

b. Develop analytical tools to support these efforts.

3.1 Analytical Support for Stakeholders in the Southwest

- Provided general analytical support to DOE and to numerous state stakeholders, as requested

- Provided specific technical support to the development of a request for proposals to industry for interest in developing a regional 250 MW Concentrating Solar Power Project.

\subsection{Analytical Tools to Support These Efforts}

- Continued the development of the CSDS Model, with emphasis on analyzing parabolic systems with thermal storage. The model was used to investigate the impact of policy scenarios on the penetration of CSP in U.S. markets.

- Initiated development of Web-based dynamic mapping tools designed to support public (state and local stakeholders) and private industry requests for siting analysis.

- Completed development of a CSP Jobs and Economic Development Impact (JEDI) Model.

\section{Planned FY 2008 Activities}

The activities of this task have increased awareness about the technologies among energy decision makers in the Southwestern United States. In FY 2008 , we will continue to provide analysis in support of stakeholders interested in deploying significant levels of CSP in the Southwest. Increased budgets in FY 2008 will support a more robust solar resource assessment, market penetration, and grid integration activity.

Specific activities identified in the FY 2008 Annual Operating Plan include the following:

- Continued CSP stakeholder outreach efforts.

- Continued development of analytical tools for use in supporting stakeholder outreach and analysis efforts. 
- Continued support of CSP model development for use in the Solar Advisor Model framework.

- Continued work related to market penetration with new emphasis on grid integration and expansion studies.

- Expanded resource assessment efforts designed to reduce the uncertainty of satellitederived solar resource data, initiate a solar resource forecasting activity, and project long- term seasonal and inter-annual solar resource characteristics from short-term data.

- Development of a PEIS for solar energy development on southwestern lands administered by the BLM.

\section{Industry Partners}

The following organizations partnered in the project's research activities during FY 2007 (no cost share).

\begin{tabular}{|l|l|l|c|}
\hline $\begin{array}{c}\text { Organization/ } \\
\text { Principal Investigator }\end{array}$ & \multicolumn{1}{|c|}{ Location/e-mail } & \multicolumn{1}{|c|}{$\begin{array}{c}\text { Description/Title of Research } \\
\text { Activity }\end{array}$} & $\begin{array}{c}\text { FY 2007 } \\
\text { (\$K) }\end{array}$ \\
\hline $\begin{array}{l}\text { Morse Associates, Inc. } \\
\text { Fred Morse }\end{array}$ & $\begin{array}{l}\text { Washington, D.C. } \\
\text { fredmorse@morseassociatesinc.com }\end{array}$ & $\begin{array}{l}\text { Consulting for government and } \\
\text { utilities on CSP applications and } \\
\text { marketing policy }\end{array}$ & 150 \\
\hline
\end{tabular}




\title{
CSP Testing and Evaluation: Systems Analysis
}

\author{
Performing Organizations: National Renewable Energy Laboratory (NREL) \\ Sandia National Laboratories (SNL) \\ Key Technical Contacts: $\quad$ Mark Mehos (NREL, Primary Contact), 303-384-7458, \\ mark_mehos@nrel.gov \\ Nate Blair (NREL), 303-384-7426, nate_blair@nrel.gov \\ Chris Cameron (SNL), 505-844-8161, cpcamer@sandia.gov \\ Craig Christensen (NREL), 303-384-7510, craig_christensen@nrel.gov
}

DOE HQ Technology Manager: Thomas Rueckert, 202-586-0942, Thomas.Rueckert@ee.doe.gov

FY 2007 Budgets: $\quad$ \$200K (NREL)

\section{Objectives}

- Develop a Solar Advisor Model (SAM) that will calculate energy output, energy costs, and cash flows using up-to-date component and system data while enabling a parametric analysis.

- Validate the Solar Advisor Model (SAM) and, potentially, other solar models for a variety of technologies, applications, and locations.

- Provide tools that can be used by industry and government to guide research and development (R\&D) priorities and to provide credible energy production and cost data using a common platform for project development, evaluation, and due diligence.

- Provide additional tools to industry to meet their planning, research and development (R\&D), siting, and other modeling needs to help accelerate market penetration.

\section{Accomplishments}

- Included concentrating solar power (CSP) parabolic trough modeling within SAM.

- Included detailed incentives within SAM for all technologies.

- Enhanced the model's graphical outputs, parametrics, and sensitivity analysis

- Significantly improved the model's calculation speed.

- Completed a dish Stirling performance model through a subcontract.

\section{Future Directions}

- Release a SAM version with the following:

- A major update of the user manual with documentation

- Improved PV performance algorithms

- The ability to use the latest California Energy Commission (CEC) and Sandia module and inverter databases

- Detailed operation and maintenance (O\&M) inputs (including annual cost, cost per megawatt, and cost per megawatt-hour options).

- Release a SAM version with the following:

- Dish Stirling CSP models present

- Enhanced graphical user interface (GUI) and greater graphical output capability.

- Time-of-use rates.

- Achieve a 10-km resolution, combined solar radiation and meteorological data set for PV Watts. 


\section{Introduction}

Note: This section replicates the section on Solar Modeling with the exception of the $\$ 200 \mathrm{~K}$ budget stated above. This budget represents the CSP contribution to the overall SAM activity.

The objective of this project is to provide a focal point for system-driven approach (SDA) activities as well as a common framework for evaluating all solar technologies. This evaluation is part of the cost, financing, and performance modeling of photovoltaic (PV) systems, concentrating solar power (CSP) systems, and other solar technologies.

\section{Technical Approach}

The Solar Advisor Model (SAM) task consists of systems performance and cost modeling and validation projects. The primary function of the model is to allow users to investigate the impact of variations in physical, cost, and financial parameters to better understand their impact on key figures of merit. Figures of merit relating to the cost and performance of these systems include, but are not limited to, system output, peak and annual system efficiency, levelized cost of energy, and system capital and operations and maintenance (O\&M) costs.

The Solar Advisor Model is intended for use by DOE and laboratory management and research staff, and it is a critical element in the implementation of SDA activities relating to Solar Energy Technologies Program (SETP) planning. The model is, and will continue to be, used by members of the solar industry to inform the internal R\&D directions and to estimate system costs and performance.

\section{Results and Accomplishments}

For the Solar Advisor Model, we placed particular emphasis up front on the design of a user interface that could meet the needs of a diverse set of users. User profiles were developed to provide a general description of
DOE, laboratory, and industry users and their motivation for using the modeling tool.

The working model consists of a user-interface module for selecting and providing input data on the system configuration and operating environment, a system-performance module that simulates the hour-by-hour output of the selected system for the lifetime of a project, a cost-input module for providing simple or detailed cost inputs for system components, and a financial-analysis module for calculating system economics. The modules work in concert to generate the physical and financial figures of merit relevant to a particular user.

The development portion of SAM focused on several areas in FY 2007. Specifically, the parabolic trough model was added to SAM for use by DOE SETP planners for the CSP program and by the CSP industry. The model within SAM was originally developed at NREL by Hank Price in Excel and called Excelergy. This undocumented model was not easily transferable to industry or to DOE analysts. Implementing the same algorithms within the SAM environment makes them more accessible, and continuously improving documentation makes it easier to help new users get up to speed.

Another area of focus was to improve financial methods for the residential, commercial, and utility markets. An extensive effort went into making the utility financing portion of the model accurate and appropriate from the perspective of the project developer. Finally, an extensive effort was made to incorporate the ability to factor in incentives (input tax credits, production tax credits, buy-downs, and so forth.) into the model for all markets. This is critically important since subsidies are so prevalent within solar financing.

In carrying out these projects, we used resources at NREL as well as subcontracts, as described in Section 5. 


\section{Planned FY 2008 Activities}

- Release a SAM version with additional weather file type support.

- Create a user forum and enhance user interactivity.

- Validate SAM in comparison to measured system data (paper).

- Release a SAM version with the following:

- A major update of the user manual with documentation.

- Improved PV performance algorithms.

- The capability of using the latest CEC and Sandia module and inverter databases.
- Detailed O\&M inputs (with annual cost, cost per megawatt, and cost per megawatt-hour options)

- Hold first modeling workshop concurrently with American Solar Energy Society meeting.

- Publish a subcontractor report on financial model validation.

- Release a SAM version with the following:

- Dish Stirling CSP models present.

- Enhanced GUI and greater graphical output capability.

- Time-of-use rates.

\section{University and Industry Partners}

The following organizations partnered in the project's research activities during FY 2007.

\begin{tabular}{|l|l|l|c|}
\hline \multicolumn{1}{|c|}{$\begin{array}{c}\text { Organization/ } \\
\text { Principal Investigator }\end{array}$} & \multicolumn{1}{|c|}{ Location/e-mail } & \multicolumn{1}{c|}{$\begin{array}{c}\text { Description/Title of Research } \\
\text { Activity }\end{array}$} & $\begin{array}{c}\text { FY 2007 } \\
\text { (\$K) }\end{array}$ \\
\hline $\begin{array}{l}\text { Janzou Consulting/ } \\
\text { Steve Janzou }\end{array}$ & $\begin{array}{l}\text { Evergreen, CO } \\
\text { Steve_janzou@nrel.gov }\end{array}$ & $\begin{array}{l}\text { This effort includes programming the } \\
\text { front-end and basic engine of the } \\
\text { Solar Advisor Model. }\end{array}$ & 105 \\
\hline $\begin{array}{l}\text { University of Wisconsin- } \\
\text { Madison/Prof. Sanford } \\
\text { Klein }\end{array}$ & $\begin{array}{l}\text { Madison, WI } \\
\text { Klein@engr.wisc.edu }\end{array}$ & $\begin{array}{l}\text { For example, development of a dish- } \\
\text { Stirling model for use in SAM. }\end{array}$ & 82 \\
\hline Paul Gilman & $\begin{array}{l}\text { Chicago, IL } \\
\text { PaulGilman@earthlink.net }\end{array}$ & $\begin{array}{l}\text { Provides user support and technical } \\
\text { writing support. }\end{array}$ & 35 \\
\hline
\end{tabular}




\title{
Dish Engine Research and Development
}

\author{
Performing Organization: Sandia National Laboratories (SNL) \\ Key Technical Contact: Charles Andraka (SNL), 505-844-8573, ceandra@sandia.gov \\ DOE HQ Technology Manager: Thomas Rueckert, 202-586-0942, thomas.rueckert@ee.doe.gov \\ FY 2007 Budget: $\quad \$ 1,000 \mathrm{~K}$
}

\section{Objectives}

- Improve the reliability and reduce the cost of dish/engine components and systems.

- Support industry in the commercialization of the technology.

- Perform research and development on dish/engine system components and systems.

- Test, evaluate, and improve the performance of dish/engine components and systems.

\section{Accomplishments}

- Continued to operate, maintain, and improve the Stirling Energy Systems (SES) six-dish model power plant, cataloging more than 100 development areas.

- Participated as a key member of the commercial product design team.

- Developed systems models for cost studies on facet designs.

- Developed components for a potential production alignment tool.

- Installed Infinia 3-kW system at SNL.

- Assisted Infinia in optical design and systems design of 3-kW system.

- Enhance CIRCE2 model to support finite element analysis-modeled deflections.

\section{Future Directions}

Primary activities in FY 2008 will support industry's efforts toward commercialization:

- Continuing to evaluate the reliability of the six-dish mini-power plant.

- Identifying and resolving operational and reliability issues.

- Testing next-generation components.

- $\quad$ Supporting SES as it begins to deploy a 1-MW power plant.

- Participating in final design processes for SES commercial systems.

- Installing two next-generation Infinia dish systems at SNL.

- Continuing to support Infinia's commercialization effort

\section{Introduction}

Staff carrying out the U.S. Department of Energy's (DOE) dish-Stirling activities in the Solar Energy Technologies Program work closely with industry to improve system performance and reliability and to support industry deployment in the near term. Both of these are explicit goals of the DOE Solar Program Multi-Year Program Plan, section 4.2.5.3. While we continued to gain operational experience with the SES 6-dish Model Power Plant (MPP) at $\mathrm{SNL}$, this year we focused on next-generation system design, with an emphasis on manufacturability. In addition to SES, we supported Infinia in its first product development and deployment effort.
The SES system is derived from the successful McDonnell Douglas Corporation (MDC) system, but it was redesigned to improve the cost. SES's objective is to put this system into production within a few years; the target market is bulk power production in the southwestern United States. Preproduction prototypes will begin deployment in the next year, based on lessons learned at SNL.

SES is pursuing the aggressive deployment of 25-kW dish-Stirling systems for bulk power generation. SES hardware is based on the triedand-true MDC design, with refinements to reduce manufacturing costs. SES is working closely with an SNL engineering team to maximize the possibility of success. 
The success of the MPP has, in part, led to SES signing agreements with Southern California Edison for up to $850 \mathrm{MW}$ of power and with San Diego Gas and Electric for up to $900 \mathrm{MW}$ of power. Operational improvements in the MPP are critical in the design process for the deployments. SES has made significant progress in developing site plans for the plants. The operational plant at SNL enabled successful partnerships to be made with the utilities and with companies developing the site plans.

This year, the emphasis regarding SES has been to convert the prototype system design deployed at MPP to a manufacturable design that facilitates the logistics of deployment and service. A team approach with suppliers was further developed, and key suppliers were involved in the design process.

Infinia, previously Stirling Technology Corporation (STC), has developed a system around a 3-kW free-piston Stirling engine. This system is hermetically sealed and requires no maintenance. Infinia plans both large and small deployments and has targeted photovoltaics as a competitor. Sandia National Laboratories was involved in the conceptual design, the detailed design, and the deployment of the first prototype systems. SNL has entered into a memorandum of understanding with Infinia to support several Infinia staff on SNL premises.

\section{Technical Approach}

SES plans to achieve cost reductions by rapidly moving to high production rates in support of bulk power production. This approach, when compared with smaller prototype installations spread out at many locations, has the advantage of lower cost through production automation early in the product design cycle and lower operations and maintenance (O\&M) cost through the consolidation of O\&M resources.

SNL has provided office, test lab, field, and infrastructure facilities to SES at the SNL National Solar Thermal Test Facility, which provides direct access to technology transfer and expertise and allows the engineers daily hands-on access to the dish systems. This is critical to accelerating the development and deployment path and to rapidly training new solar engineers. SNL has also played a consultant role in design meetings throughout the design life cycle.
The operation of the MPP at SNL has provided continued valuable information about the advantages and limitations of existing systems. Although several key reliability areas have been addressed in the field, a number of issues need to be addressed through the redesign. We have teamed with the SES design team, both at SES and at their strategic partners, to be sure reliability issues are addressed in the design-formanufacture stage. The issues identified have been systematically categorized for severity and impact to the future success of the design. Key resources have been applied to the highest priority issue areas based on this approach. The remaining issues are set aside for the redesign process. All of the dish system hardware is funded through SES investor financing, while SNL, through the DOE CSP Subprogram, provides inkind engineering support, technology transfer, training, and facilities.

Infinia is taking a similar approach. The company plans high-rate production to reduce the cost of the systems down to competitive levels. While initial markets are identified as small business and commercial installations, Infinia has proposed installations up to $300 \mathrm{MW}$ (see Solar Paces, March 2008).

Infinia has designed a system based on a 3-kW, single-cylinder, free-piston engine. Similar 1-kW engines have run very well with extended nomaintenance life. The company has designed a composite-structure dish system with glass mirrors on a composite substrate and a steel rib backing.

Two dish-related proposals in response to a DOE Funding Opportunity Announcement (FOA) were selected by the DOE Golden Field Office for negotiation. Once these negotiations are completed, we anticipate significant laboratory involvement in evaluation, testing, and design support for these systems.

\section{Results and Accomplishments}

By the end of FY 2007, the MPP dish systems had accumulated a total of 16,252 hours on sun. The performance of the system continues to exceed the performance of the MDC systems, primarily as a result of improved system optics, alignment, and cooling.

The SES and Sandia team has continued to catalog issue areas. Many of the known issues will be addressed in the design-for-manufacture stage, 
as solutions are impractical as retrofits to the existing systems. The formalized Failure Reporting, Analysis, and Corrective Action System (or FRACAS) ensures that each issue area is carried through to design and testing. These data have been made available to the entire design team for each component.

Some of the key problem areas have been addressed in the field at the MPP. These include several high-priority software issues that led to repeated nuisance faults, as well as a substantial redesign of the gas management system (GMS). The manufacturer of the gas valving has been involved in the redesign of the GMS, resulting in a substantial reduction in cost as well as a very significant reduction in fittings, tube length, and leak opportunities. The new valves have demonstrated several thousand hours of operation without faults, and a test rig at the manufacturer has demonstrated millions of valve cycles without failure.

The focus of SES this year turned from the operation of the MPP to the design of the preproduction prototypes and design for manufacture. The SES approach includes significant involvement with the entire supply chain, rather than fully in-house development. One engine unit was transferred to the proposed engine manufacturer, and the design-formanufacture process has begun, with impressive results. SES has done substantial hiring for the controls team in preparation for the development of next-generation controls for the engine and the dish.

A substantial redesign of the dish system has led to a 4000-lb weight reduction and resulted in a stiffer system. This was facilitated over the last 2 years by SNL's optical code combined with SES's structural model. SES's steel fabrication partner has designed a highly automated fabrication plant in conjunction with the redesign effort. The refinement of this design is continuing, taking into account the key environmental implications of the California sites.

SNL demonstrated components of a proposed alignment system that has the potential to allow the entire alignment process to be completed in 20-30 minutes, a key for rapid field assembly. Key areas were demonstrated and took advantage of SNL's experience with robotic vision systems.
SNL also supported Infinia in the development of its first $3-\mathrm{kW}$ prototype system. A Sandiadeveloped optical design approach provided a facet contour that deviates slightly from a true parabola but provides a flat flux profile on the receiver without compromising the aperture. This was a significant enhancement over the approach Infinia had developed, and it will improve the system performance by several points of efficiency. SNL also supported Infinia in the development of dish controls based on SNLdeveloped tracking algorithms and NRELdeveloped sun position algorithms.

In support of Infinia, SNL changed the CIRCE2 optical modeling code to support the characterization of arbitrarily deflected continuous mirror and gore-mirror structures. This change allowed the coupling of the optical model to Infinia's structural model, aiding in the optimization of the dish design.

Infinia installed its second prototype system at SNL and characterized the mirror assembly. A complete system was installed at Infinia's corporate headquarters. The installation took place less than 6 months after the conceptual design review.

\section{Planned FY 2008 Activities}

SNL and SES have successfully installed and continued operating a six-dish MPP to demonstrate the technology, develop new components and methods, and improve reliability in preparation for larger deployments. SES has developed agreements with California utilities for up to nearly $2 \mathrm{GW}$ of installed capacity. The systems have brought unprecedented publicity to both the CSP Subprogram and SES.

SNL will continue to support SES in its aggressive schedule for product improvement and deployment. The company will next install a 1-MW (40-dish) system, followed by high-rate production. The involvement of high-production suppliers and the national laboratories in the deployment of the MPP and the 1-MW plant is key to transitioning to production.

The systems are performing at expected efficiency and power production levels, which helps firm up predictions for large plant production. Initial reliability has been impacted by several known problems. SNL and SES have applied engineering resources to these problems, implemented short- 
term fixes to the MPP, and outlined development paths for the production version. During 2008, we will improve the accuracy of key performance measurements to more fully characterize system performance.

The partnership between SNL and SES is a new way of doing business that maximizes the benefit to SES while continuing to leverage the expertise developed at the national laboratories. During FY 2008, we will accomplish the following:

- Continue to operate the six-dish MPP, evaluate performance, and identify reliability issues.

- Continue to resolve known issues with field validation and design assistance feeding the design for manufacturing and assembly (DFMA) process.

- Support SES as it begins to deploy a 1-MW power plant.

- Actively participate in the DFMA of all major components.
- Develop assembly plant and field-deployable alignment tools to support rapid deployment.

- Develop rapid deployment component designs including foundation, dish structures, and son on, and test prototypes at SNL.

- Develop tools to assist in the rapid development of next-generation controls, including hardware and software simulation systems.

SNL anticipates having significant involvement with the two FOAs that are being negotiated by the DOE Golden Field Office for dish development activities-one with Infinia and one with Brayton Energy Systems. 


\title{
Parabolic Trough Research and Development
}

\author{
Performing Organizations: National Renewable Energy Laboratory (NREL) \\ Sandia National Laboratories (SNL) \\ Key Technical Contacts: $\quad$ Chuck Kutscher (NREL, Primary Contact), 303-384-7521, \\ chuck_kutscher@nrel.gov \\ Greg Kolb (SNL), 505-844-1887, gjkolb@sandia.gov
}

DOE HQ Technology Manager: Thomas Rueckert, 202-586-0942, thomas.rueckert@ee.doe.gov

FY 2007 Budgets: $\quad$ \$2,065K (NREL), \$1,080K (SNL)

\section{Objectives}

- Support the development of near-term parabolic trough technology for central-station power generation.

- Support the development of advanced technologies for next-generation parabolic trough solar fields, thermal energy storage, and power plant technologies to meet the long-term goals of the DOE Solar Program Multi-Year Technical Plan.

- Support the expansion of U.S. industry to supply parabolic trough technology.

- Support continued SunLab ${ }^{1}$ collaborations on parabolic trough technology development and testing.

\section{Accomplishments}

- During FY 2007, Acciona Solar (formerly Solargenix) completed the construction and began the operation of a 64-MW parabolic trough plant in Eldorado Valley, near Boulder City, Nevada. The plant uses a new second-generation parabolic trough collector design developed under the company's USA Trough Initiative R\&D contract during FY 2006. The new collector design provides a number of advantages over the earlier design: it's cheaper, easier to erect, and does not require any alignment of mirrors during assembly. Many of the collectors also use a new, improved receiver from Schott Glass.

- SNL refined its theoretical overlay photographic (TOP) alignment system for evaluating the alignment of mirrors and receivers on parabolic trough collectors installed in a solar field.

- NREL tested Solel UVAC-2 receiver tubes from the Solar Energy Generating Systems (SEGS) field, some of which contained hydrogen in the vacuum annulus and some which did not. This allowed us to quantify the impact of hydrogen on heat loss. We also tested the 2006 Schott PTR70 receiver model and found that its heat losses were virtually identical to those of the Solel UVAC-2, thus meeting Schott's design goal at that time. NREL published a paper on the test stand results and has since received numerous requests for testing.

- NREL continued the development of a new selective coating that appears to meet the long-term selective property goals for parabolic trough receivers. NREL modified its vacuum deposition system to allow codeposition of the materials required to make the coating. Initial samples were deposited with promising results.

- The Video Scanning Hartmann Optical Test (VSHOT) instrument was used to evaluate the accuracy of the new Solargenix SGX-1 concentrator and the improved Industrial Solar Technology (IST) PT-1 concentrator. VSHOT testing was also conducted on Luz LS-2 and LS-3 collectors to provide a baseline for comparison to the new collectors from Solargenix and IST.

- NREL has continued to improve the speed of infrared (IR) imaging of receivers for assessing the thermal performance of receivers in the solar field. NREL imaged over 30,000 receivers at SEGS III, IV, and V to help FPL Energy categorize receiver performance in advance of a major receiver upgrade program.

\footnotetext{
${ }^{1}$ SunLab is a collaboration between Sandia National Laboratory and the National Renewable Energy Laboratory in support of the U.S. Department of Energy's R\&D activities on concentrating solar power technologies.
} 
- SNL formulated molten salt mixtures of alkali metal nitrates and alkaline earth nitrates that are liquids at about $100^{\circ} \mathrm{C}$ and have useful properties as thermal energy storage fluids in parabolic trough systems, including stability in air up to $500^{\circ} \mathrm{C}$.

- Nexant completed work on several tasks to look at the optimum size of parabolic trough plants, the benefit of building plants in a power park, and the impact of dry cooling on cost and performance.

- NREL developed a new selective surface with an absorptance of 0.959 and emittance of 0.007 at $500^{\circ} \mathrm{C}$ with high thermal stability.

- NREL began work on a funds-in cooperative research and development agreement (CRADA) with Solar Systems to expand the capability of the VSHOT system for measuring reflector surface accuracy.

- NREL developed and tested a heat collection element temperature survey system with which one or two field personnel can cover $20 \mathrm{MW}$ per day.

- NREL performed a SEGS III-VII heat collection element (HCE) temperature survey for FPL Energy and then successfully transferred the HCE Temperature Survey System to FPL Energy to complete the plant surveys at Harper Lake.

- NREL completed the design of an outdoor optical efficiency test loop for parabolic trough collectors.

\section{Future Directions}

- Continue the development of advanced receiver and concentrator technologies to meet long-term DOE Solar Program Multi-Year Technical Plan goals.

- Working with the NREL Technology Transfer Office, identify interested U.S. industry partners who can commercialize the improved solar selective coating technology.

- Support the development of advanced thermal energy storage technologies.

- Support trough funding opportunity announcement (FOA) awardees in response to industry/DOE requests.

- Continue building a laboratory capability to support trough testing and analysis.

\section{Introduction}

Parabolic trough technology is being reintroduced actively into the marketplace. For example, during FY 2007, Acciona Solar (formerly Solargenix) built completed the 64-MW Nevada Solar One power plant outside Las Vegas (Figure 1).

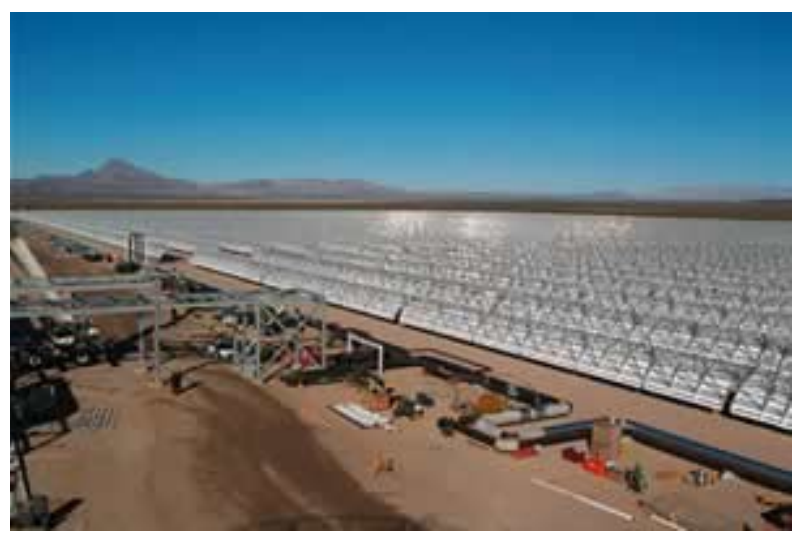

Fig. 1. New 64-MW Solar One power plant using Acciona parabolic trough concentrators and Schott receivers.
Along with this market development, the DOE parabolic trough R\&D program has focused on the following activities:

- Advance technologies that have an opportunity to be deployed in early projects.

- Encourage the development of advanced technologies that will improve the competitiveness of future parabolic trough plants.

- Encourage the expansion of U.S. industry to supply these early plants.

- Develop improved tools, testing capabilities, and the knowledge base necessary to support the needs of a growing U.S. parabolic trough industry.

\section{Technical Approach}

Parabolic trough $R \& D$ is divided into these three areas:
a. Trough solar field technology.
b. Thermal energy storage technology.
c. Trough systems integration. 


\subsection{Trough Solar Field Technology}

The solar field technology agreement focuses on SunLab's development of new parabolic trough solar technology and tools for evaluating trough technology. During FY 2007, SunLab activities focused on the following:

- Development and field testing of an IR camera system for the rapid field assessment of receiver performance.

- Development and field testing of a new field alignment system for assessing the alignment of mirrors and receivers on parabolic trough concentrators.

- Testing of advanced receiver tubes on NREL's receiver test stand.

- Continued development of advanced selective coating technologies for receivers, focusing on developing coatings that have improved thermo/optic properties and that are thermally stable in air up to $500^{\circ} \mathrm{C}$.

\subsection{Thermal Energy Storage Technology}

The cost of solar thermal energy storage is about $\$ 40-\$ 50 / \mathrm{kWh}_{\text {thermal. }}$. The objective of Thermal Energy Storage (TES) R\&D is to develop nextgeneration TES technology that will cost substantially less $\left(\$ 15-\$ 20 / \mathrm{kWh}_{\text {thermal }}\right)$. To achieve this goal, DOE's R\&D focuses on modeling advanced storage systems and improved storage and heat transfer fluids through in-house and costshared contracts with industry.

Specific FY 2007 activities included these:

- Supported the DOE Golden Field Office with the development of a Federal Opportunity Announcement (FOA) and reviews of proposals for advanced storage systems for parabolic troughs

- Began the development of molten salt heat transfer fluids with a lower freezing point (SNL)

- Measured the presence of hydrogen in field receiver tubes (NREL).

\subsection{Systems Integration}

This activity focuses on the development of systems-integration tools for evaluating trough technologies and assessing program activities. Specific FY 2007 activities included these:

- Developed a power plant and heat exchanger sizing and cost model for the Solar Advisor Model (Nexant).

- Updated the TroughNet Web site (NREL).

- Organized and held an international trough workshop (NREL).
- Generated quarterly milestone reports in support of the Concentrating Solar Power (CSP) FY 2007 Joule milestone.

Budget allocations by task are provided in the table for both NREL and SNL.

\begin{tabular}{|l|c|}
\hline \multicolumn{1}{|c|}{ Task Title } & $\begin{array}{c}\text { FY 2007 } \\
\text { Budget (\$K) }\end{array}$ \\
\hline Solar Field Technology & 1,400 \\
\hline Thermal Storage Technology & 1,400 \\
\hline Trough Systems Integration & $345 / 125^{*}$ \\
\hline
\end{tabular}

${ }^{*}$ Carry-over from FY 2006.

\section{Results and Accomplishments}

\subsection{Solar Field Technology}

In previous years, NREL developed the Video Scanning Hartmann Optical Test (VSHOT) system for measuring the optical accuracy of reflectors. In FY 2007 the instrument was used to evaluate the accuracy of the new Solargenix SGX-1 concentrator and the improved IST PT-1 concentrator. VSHOT testing was also conducted on the Luz LS-2 and LS-3 collectors to provide a baseline for comparison to the new collectors from Solargenix and IST.

In FY 2007, NREL also finalized a funds-in CRADA with Solar Systems Pty Ltd of Victoria, Australia, that will expand the capability of the VSHOT apparatus by allowing us to test larger aperture reflectors with extensions to flat mirror panels (i.e., heliostats). Planned software and hardware modifications will be applicable to both the CRADA and other program efforts.

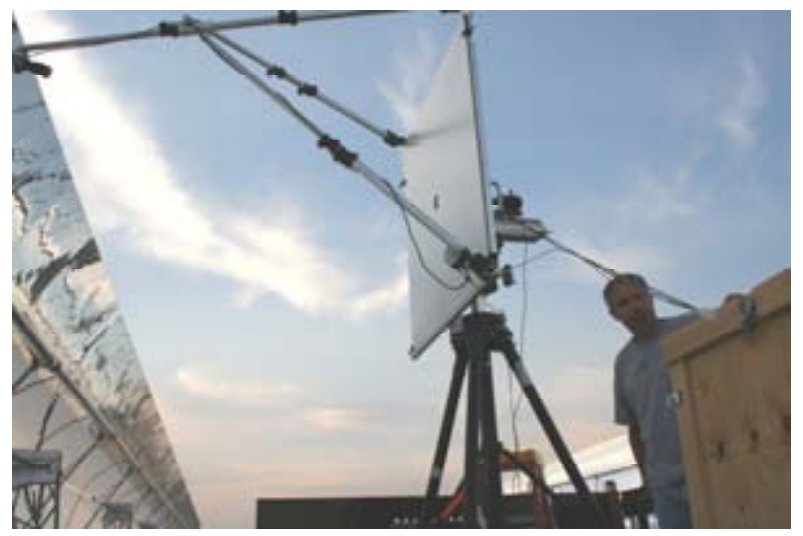

Fig. 2. Optical testing with VSHOT of LS-3 concentrator at SEGS IX. 
During FY 2007, SNL continued to field-test and improve a new prototype system for conducting field alignment checks on parabolic trough collectors. The system, called the theoretical overlay photographic, or TOP, alignment system, can be used to check for misalignment of mirrors and receivers. The system concept, shown in Figure 3, uses a modification of the distant observer approach to assess alignments. In a true distant observer approach, the collector is viewed from a long distance away and the image of the receiver completely fills the image in the mirrors.

The TOP system is a variation that observes the collector from a closer vantage point, so that the receiver fills only a portion of the image seen in the mirrors. The TOP system compares the place where the receiver image actually appears vs. where it should appear if the collector were perfectly aligned. Based on the relative position of the receiver's location in the mirror, we can determine any misalignment of mirrors or receivers. The TOP system thus allows rapid measurement and characterization of large commercial solar fields.

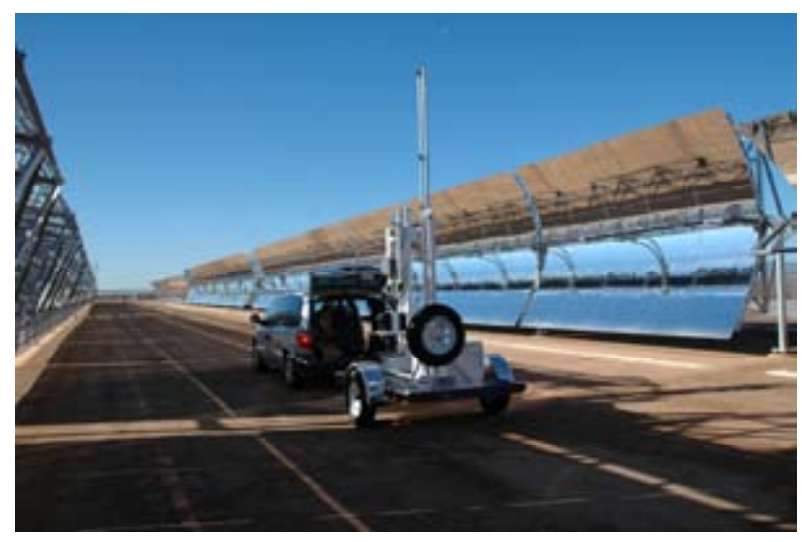

Fig. 3. Prototype TOP alignment system being tested at the APS Saguaro parabolic trough plant.

NREL used computer design software in FY 2007 to develop a model of a solar-selective coating ( $\alpha$ $=0.959$ and $\varepsilon=0.070$ at $450^{\circ} \mathrm{C}$ ) that is stable at high temperatures. Sample coatings were fabricated and characterized. The results have been encouraging, even though the measured optical performance of the deposited coatings was inferior to the modeled optical performance because of errors known to have occurred during deposition of the coating.

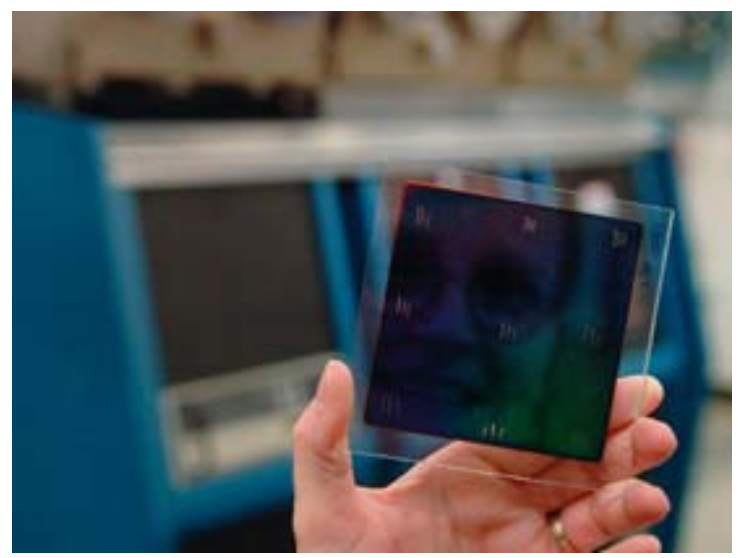

Fig. 4. A sample (foreground) of NREL \#6A solar selective coating deposited by directly and reactively evaporating the layers by elemental codeposition. The deposition system is in the background.

NREL also worked in FY 2007 to improve the speed of IR field measurements of receiver tubes and data analysis to allow a more rapid field survey of the condition of receivers. Upgrades to the IR system allowed all 9,600 receivers in the SEGS VI solar field to be imaged over a 2-day period. NREL also replaced the streaming video approach for data sampling with a global positioning system (GPS)-driven method that significantly reduced the amount of data that must be processed. This allowed us to rapidly analyze more than 30,000 receivers at SEGS III, IV, and V. This information was used to show that more than half of the receiver tubes in the field had sufficient hydrogen in the annulus to decrease trough output by as much as $20 \%$. In large part because of NREL's results, plant owner FPL decided to make a multi-million-dollar investment to replace the receiver tubes that NREL indicated were problematic.

During FY 2007, NREL tested receiver tubes from two manufacturers by using its receiver test bed (Figure 5). NREL tested Solel UVAC-2 receiver tubes from the SEGS field; some of them contained hydrogen in the vacuum annulus and some did not. This allowed us to quantify the impact of hydrogen on heat loss. We also tested the 2006 Schott PTR-70 receiver model and found that its heat losses were virtually identical to those of the Solel UVAC-2, thus meeting Schott's design goal at that time. NREL published a paper on the test stand results and has received numerous requests for testing since that time. 


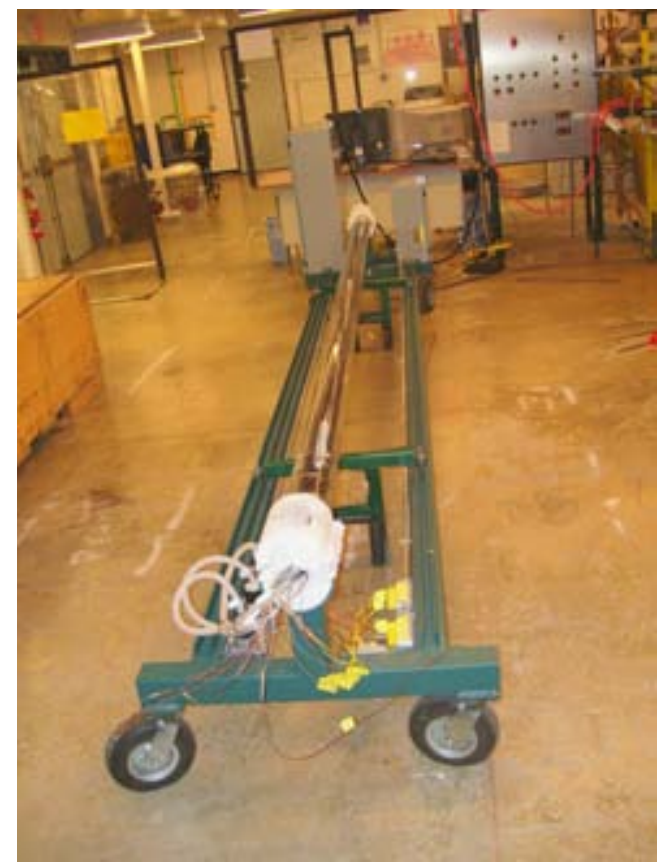

Fig. 5. Parabolic trough receiver thermal loss test bed

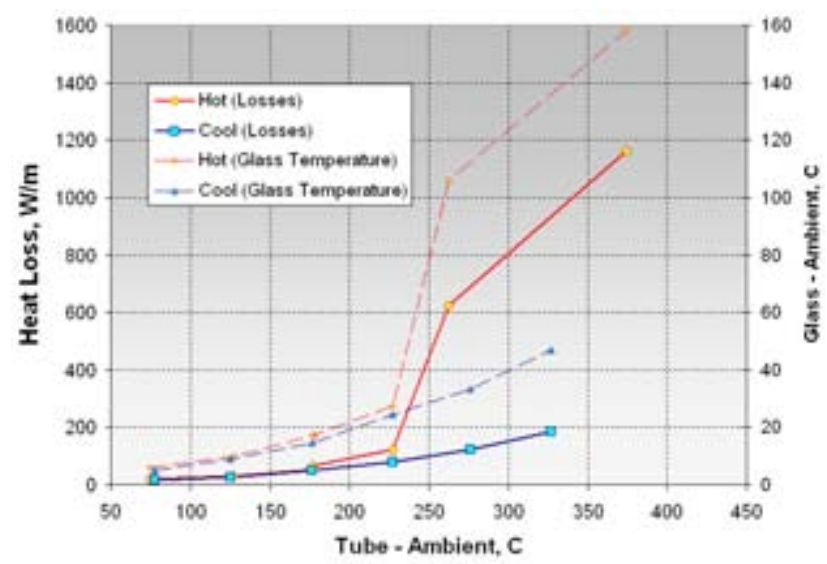

Fig. 6. Parabolic trough receiver thermal loss test bed results.

In FY 2007, the NREL outdoor optical efficiency test loop was designed using an Engineering Equation Solver, or EES, model of the system.

FY 2007 milestones achieved were as follows:

- Made laboratory receiver heat loss measurements of Schott PTR-70 and Solel UVAC2.

- Submitted detailed report describing receiver test bed.
- Conducted IR surveys of SEGS III-V receiver tubes.

- Designed the NREL outdoor optical efficiency test loop.

- Developed the HCE Temperature Survey System capable of covering 20 MW per day with one or two field personnel.

- Provided HCE Thermal Analysis support to Sunray Energy and assisted them in understanding the performance of HCEs purchased from FPL Energy and the effects of adding argon into the annulus as well as air.

- Performed a SEGS III-VII HCE temperature survey for FPL Energy and then successfully transferred the HCE Temperature Survey System to FPL Energy to complete the plant surveys at Harper Lake.

\subsection{Thermal Energy Storage Technology}

A SunLab and industry team prepared a thermal energy storage development plan for parabolic trough technology. The plan envisions a move to inorganic molten salts as the heat transfer fluid in the solar field; it appears to be the most promising opportunity for reducing costs and for improving the overall economics of parabolic trough plants in the future. In FY 2007, SunLab staff conducted a visit to the Italian National Agency for New Technologies, Energy and the Environment to see its parabolic trough molten-salt test facility. The storage team also met with staff at the German Aerospace Center to get an update on its concrete and phase-change-material thermal storage activities. The planned development of a thermocline storage system at the APS Saguaro plant was dropped because APS had to turn its attention to other projects.

During FY 2007, advanced fluid work focused on understanding the thermal decomposition mechanisms for Therminol VP-1. The decomposition of the heat transfer fluid is important not only because of the replacement cost of the fluid, but also because the decomposition of the fluid results in the presence of hydrogen in the fluid, which is an issue for maintaining the vacuum in the receiver.

NREL performed an analysis to determine the rate at which hydrogen diffuses from the working fluid into the initially evacuated annulus. NREL also performed a literature search to investigate the impact of injecting a heavier inert gas such as xenon into the vacuum space to mitigate the additional heat loss caused by the hydrogen. 


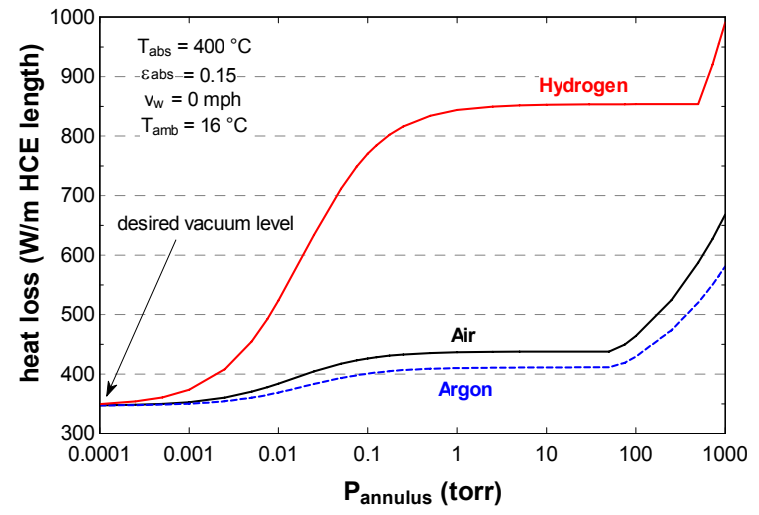

Fig. 7. Model results showing how the presence of relatively small quantities of hydrogen in the vacuum space significantly increases heat losses from a receiver.

Another option for advanced heat transfer fluids is to identify and develop alternative inorganic molten salt formulations. Current formulations, while offering many advantages over the Therminol oil used in the SEGS plants, have distinct disadvantages. Primary among these are high freezing temperatures, higher costs, and unidentified potential material interaction issues.

Recent developments of multicomponent molten salt formulations consisting of common alkali nitrate and alkaline earth nitrate salts display freeze-onset temperatures below $100^{\circ} \mathrm{C}$. In addition to phase-change behavior, several properties of these molten salts were evaluated that significantly affect their suitability as thermal energy storage fluids, including chemical stability and viscosity. These alternative molten salts have demonstrated chemical stability in the presence of air up to approximately $500^{\circ} \mathrm{C}$ in laboratory testing, and they follow chemical equilibrium relationships that have been reported for solar salt $\left(\mathrm{NaNO}_{3}\right.$ and $\mathrm{KNO}_{3}$ ), as shown in the graph of Figure 8 .

Experimental measurements of viscosity were performed from near the freeze-onset temperature to about $200^{\circ} \mathrm{C}$. Viscosities can exceed $100 \mathrm{cP}$ at the lowest temperature but are less than $10 \mathrm{cP}$ in the primary temperature range at which the mixtures would be used in a thermal energy storage system. The compatibility of container materials is not anticipated to be a problem, and experiments are in progress to confirm the corrosion behavior of a wide variety of metallic materials.

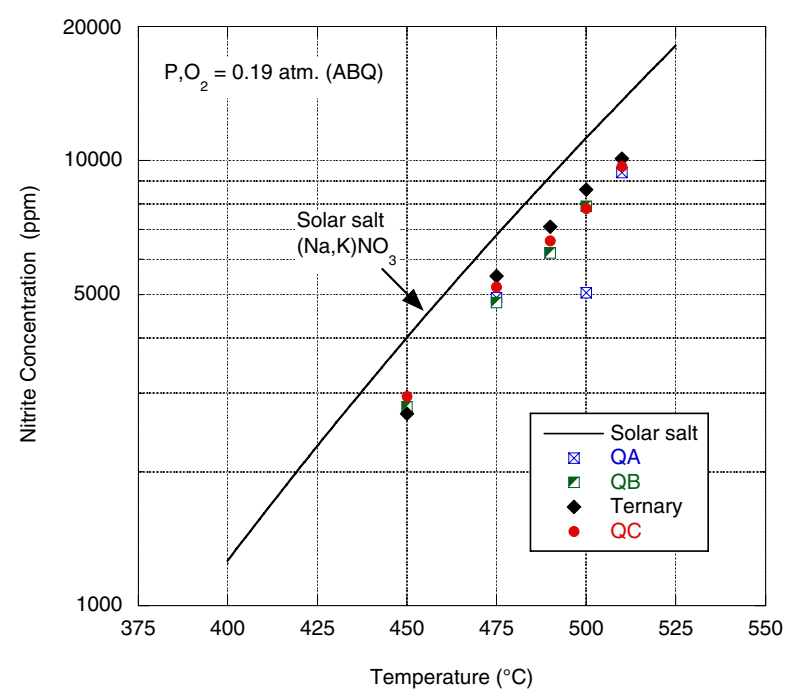

Fig. 8. The equilibrium chemistry of new molten salt mixtures (QA, QB, QC) follows the temperature dependence of binary solar salt.

Testing completed at SNL during FY 2002 through FY 2004 identified both the potential benefits associated with improved molten salt formulations and some of the key issues related to their use in parabolic trough solar fields. Planning in FY 2005 and work in FY 2006 focused on investigating a large suite of potential nitrate and nitrite salt constituents that might be combined to yield favorable heat transfer fluid properties at a reasonable cost. Detailed plans were written to continue a phased development program during FY 2007.

At the same time, freeze protection and recovery from freeze events in solar fields will remain a key issue even with improved salt formulations that exhibit lower freeze points. As such, simple modeling of likely freeze events was completed in solar fields that will contain heat collection elements with widely variable conditions and heat loss characteristics. This modeling identified the need for a comprehensive testing program involving freeze protection and recovery methods based on impedance heating designs. This testing will occur during FY 2007 and 2008.

In addition, Nexant prepared a manual on a storage model developed for the SAM model. 
FY 2007 Milestones:

- Modeled the impact of hydrogen diffusion into the vacuum space of a parabolic trough receiver.

- Formulated molten salt mixtures of alkali metal nitrates and alkaline earth nitrates that are liquids at about $100^{\circ} \mathrm{C}$ and have useful properties as thermal energy storage fluids in parabolic trough systems.

- Determined through experiments and chemical analysis that molten salt mixtures are thermally stable in air up to at least $500^{\circ} \mathrm{C}$.

- Measured the viscosity of these molten salts near the low-temperature end of the usable range.

\subsection{Systems Integration}

Using Nexant analysis and Excelergy runs, NREL authors published a paper describing the optimum size and economics of parabolic trough power plants with and without storage. The paper shows that building four 250-MW $\mathrm{MW}_{\mathrm{e}}$ plants together could reduce the cost of energy by about $10 \%$ to $12 \%$. Nexant also prepared a solar field piping model for incorporation in the SAM model.

During FY 2007, NREL updated the TroughNet Web site. A major part of that work was to have all technical reports from subcontractors updated and placed on the Web. TroughNet was moved from the EERE Web site to the NREL site (see www.nrel.gov/csp/troughnet/).

NREL conducted a trough workshop in April 2007. Approximately 140 researchers from around the world participated; presentations are online at www.nrel.gov/csp/troughnet/wkshp 2007.html.

In addition, quarterly milestone reports were generated in support of CSP.

FY 2007 Milestones:

- Held a trough workshop.

- Presented a paper on parabolic trough system sizing and economics at the American Society of Mechanical Engineers Solar Energy Division meeting.

\section{Planned FY 2008 Activities}

Key activities planned for FY 2007 include these:

- Perform modeling and testing of inert gas mixtures in receiver tubes to quantify improved heat loss characteristics of tubes containing hydrogen.

- Transfer receiver heat loss IR field measurement technology to industry.

- Provide VSHOT testing support to Abengoa Solar, testing its advanced concentrator in Seville, Spain, and its PT-2 prototype in its U.S. location.

- Provide VSHOT testing support to SkyFuel, Inc., as the company develops its trough concentrator prototype.

- Perform VSHOT characterization of new mirror technology for Guardian Glass and Naugatuck Glass.

- Develop two new VSHOT systems: one portable system for full aperture trough characterization in the field and at industry partner facilities and another for laboratory testing of flat and single axis curvature mirrors.

- Compare VSHOT results with photogrammetry results.

- Perform heat loss measurements of new Schott receiver tubes.

- Fully characterize the hydrogen generation process within the SEGS plants and develop a design that removes hydrogen from the HTF and eliminates significant migration of hydrogen into the receiver annulus.

- Perform a field demonstration of the new TOP concentrator optical alignment tool at the SEGS plants.

- Complete and release the solicitation for advanced HTF/TES and negotiate and place contracts for R\&D and demonstration work.

- Complete the construction of the NREL outdoor optical efficiency test loop.

- Perform outdoor optical tests on the Gossamer parabolic trough.

- Provide ongoing technical support for the FOA awardees, including critical review of work progress and recommendations for future technical work.

- Work with the NREL Technology Transfer Office to identify interested U.S. industry partners who could commercialize the improved solar selective coating.

- Expand the range of constituents that may further depress the initial solidification temperature of molten salt mixtures and evaluate costs.

- Evaluate the corrosion resistance of stainless steels and alloy steels in low-melting molten salt mixtures to confirm that no corrosion problems exist. 


\section{Major FY 2007 Publications}

B. Kelly, D. Brosseau, H. Price, and D. Kearney, "Adopting Nitrate/Nitrite Salt Mixtures as the Heat Transport Fluid in Parabolic Trough Power Plants," Proceedings of the 2007 Energy Sustainability (ES2007) Conference, Long Beach, CA, 27-30 June (2007).

L Moens and D. Blake, Mechanism of Hydrogen Formation in Solar Parabolic Trough Receivers, report no. NREL/TP-510-42468, Golden, CO: National Renewable Energy Laboratory, February (2008).
Nexant, Inc., Collector Field Piping Optimization Model: Inputs to User's Manual, prepared for the National Renewable Energy Laboratory under Subcontract LDC-6-66283-01, December 14 (2006).

Nexant, Inc., Thermal Energy Storage Models: Inputs to User's Manuals, prepared for the National Renewable Energy Laboratory under Subcontract LDC-6-66283-01, January 5 (2007).

H. Price, M. Mehos, C. Kutscher, and N. Blair, "Current and Future Economics of Parabolic Trough Technology," Proceedings of the 2007 Energy Sustainability (ES2007) Conference, Long Beach, CA, 27-30 June (2007).

\section{University and Industry Partners}

The following organizations received subcontract funds to support activities during FY 2007.

\begin{tabular}{|l|l|l|c|c|}
\hline $\begin{array}{c}\text { Organization/ } \\
\text { Principal Investigator }\end{array}$ & \multicolumn{1}{|c|}{ Location/e-mail } & Description/Title of Research Activity & $\begin{array}{c}\text { FY } \\
\mathbf{2 0 0 7} \\
\text { (\$K) }\end{array}$ & $\begin{array}{c}\text { Cost } \\
\text { Share }\end{array}$ \\
\hline $\begin{array}{l}\text { Nexant } \\
\text { Bruce Kelly }\end{array}$ & $\begin{array}{l}\text { San Francisco, CA } \\
\text { bdkelly@nexant.com }\end{array}$ & $\begin{array}{l}\text { Dry cooling analysis, power plant size } \\
\text { optimization study, APS thermocline } \\
\text { TES engineering design and cost }\end{array}$ & 100 \\
\hline $\begin{array}{l}\text { Kearney and } \\
\text { Associates }\end{array}$ & $\begin{array}{l}\text { Seattle, WA } \\
\text { dwk@jkearney.com }\end{array}$ & $\begin{array}{l}\text { Thermal storage and trough analysis } \\
\text { support }\end{array}$ & 25 & \\
\hline
\end{tabular}




\section{Solar Water Heating Systems Development}

The Solar Water Heating (SWH) Systems Development consists of research and technology development programs for solar water heaters and hybrid solar lighting systems. The program works with industry, the national laboratories, and others to develop and demonstrate systems and components that will improve the reliability and reduce the cost of these solar systems. The Technical Assistance Program aids builders, manufacturers, and others in designing and installing solar water heating systems. To ensure that safe and reliable systems are installed, the program supports the testing and certification activities of the Solar Rating and Certification Corporation.

Although solar water heaters have been manufactured and used for some time, there are still barriers to their widespread use, which the DOE Solar Program is working to overcome. The primary issues are the cost, reliability of systems, and the unfamiliarity of related but very necessary trades such as builders, architects, plumbers, roofers and other mechanical contractors.

SH\&L research emphasizes the development of low-cost, polymer-based solar water heaters, with the goal of reducing the levelized cost of energy for these systems by at least $50 \%$. The DOE program works with two industrial teams to develop a new generation of low-cost polymer water heaters that could reduce the cost of solar water heaters because of less expensive materials and simplified manufacturing, assembling, and installation.

Achievements in Market Transformation for FY 2007 include:

\section{Solar Thermal for Zero Energy Homes}

- Supported industry, such as teams that introduced two low-cost systems into the solar water heater market with costs reduced more than $50 \%$ in comparison to the cost of today's more conventional metal-and-glass solar water heaters.

- Established the durability of proposed polymer components, including glazings and connectors.

\section{Hybrid Solar Lighting}

- Conducted field testing at the hybrid solar lighting beta sites across the United States as part of the Sunlight Inside Initiative and then prepared a summary of the results. 


\title{
Solar Thermal for Zero-Energy Homes
}

\author{
Performing Organizations: National Renewable Energy Laboratory (NREL) \\ Sandia National Laboratories (SNL) \\ Key Technical Contacts: J Jay Burch (NREL, Primary Contact), 303-384-7508, jay_burch@nrel.gov \\ Greg Kolb (SNL), 505-844-1887, gjkolb@sandia.gov
}

DOE HQ Technology Manager: Bob Hassett, 202-586-8163, robert.hassett@hq.doe.gov

FY 2007 Budgets: $\quad$ \$2,037K (Total): \$1,407K (NREL), \$100K (SNL), \$530K (DOE Golden Field Office)

\section{Objectives}

- Identify the solar thermal systems that can significantly contribute to attaining cost-neutral zeroenergy homes.

- Support field trials and refinement of low-cost solar water heaters in mild climates that reduce the levelized cost of energy by at least $50 \%$.

- Provide technical support for the emerging U.S. solar water heater market.

\section{Accomplishments}

- Produced a strategic plan identifying how solar thermal systems can contribute to attaining costneutral zero-energy homes.

- Supported industry teams such as those that introduced two low-cost systems into the solar water heater market in FY 2007 with costs reduced more than 50\% in comparison to the cost of today's more conventional metal-and-glass solar water heaters.

- Established the durability of proposed polymer components, including glazings and connectors.

- Produced combined photovoltaic (PV)/thermal simulation models for six different configurations.

- Identified liquid desiccant-based cooling systems as preferred for solar-activated cooling, and explored synergies with strong liquid-desiccant as a latent heat storage mechanism.

\section{Future Directions}

- Begin development of exemplary low-cost solar water-heating systems for zero-energy homes in cold climates.

- Continue the development of combined PV/thermal systems for zero-energy homes that will be cost-competitive with conventional technologies and that can be used for water heating and space conditioning as well as electricity production.

- Develop tools for assessing and optimizing solar thermal systems addressing major end uses of water heating, space heating, and/or space cooling in zero-energy homes.

\section{Introduction}

Before FY 2008, the primary goal of the U.S. Department of Energy's (DOE) Solar Heating and Cooling (SHC) subprogram was the development of low-cost solar water heaters that would reduce the levelized cost of energy (LCOE) by at least $50 \%$. In FY 2008, the SHC was moved from the Solar Energy Technologies Program (SETP) to the Building Technologies Program (BTP). The primary goal of the BTP is cost-neutral zeroenergy homes in all U.S. climate zones by 2020. For residential buildings, this effort is housed in the Building America Program. Although zeroenergy homes (ZEH) are readily attainable with today's technologies, the cost is prohibitively high and not cost-neutral. Moving the SHC subprogram from the SETP to the BTP recognizes that solar thermal technology is a critical element of a costneutral ZEH. The new goal of SHC work is to develop active solar systems that cost effectively meet the thermal loads of ZEH, including water heating and space conditioning.

The development of low-cost solar water heaters (SWH) will remain part of the SHC R\&D effort, 
because the water-heating load is a relatively high percentage of the total load (especially in ZEH), and it is difficult to reduce that load by other means. Gas tankless water heaters are becoming popular, but they result in only $\sim 30 \%$ savings. Further reductions require $\mathrm{SWH}$ and are necessary to reach the $50 \%$ savings level and beyond. SHC R\&D will also continue to support the SWH industry, which is essential in providing products for ZEH.

\section{Technical Approach}

Program agreements and funding are shown in Table 1.

Table 1. Tasks in the SHC Subprogram

\begin{tabular}{|l|c|}
\hline \multicolumn{1}{|c|}{ Agreement/Task Title } & $\begin{array}{c}\text { FY 2007 } \\
\text { (\$K) }\end{array}$ \\
\hline Solar Thermal Pathways to ZEH & 607 \\
\hline Low-Cost SWH for ZEH & 575 \\
\hline Combined PV/T Systems for ZEH & 325 \\
\hline
\end{tabular}

\subsection{Solar Thermal Pathways to ZEH}

An assessment of SWH was conducted that indicated the need and potential for lowering costs through R\&D, particularly for SWH in cold climates. The United States was divided in 13 climate zones, with a representative city in each zone for solar irradiance and system performance. Aggregated quantities were population-weighted. A market analysis was then performed using empirical correlations for market ramp-up and steady-state penetration.

The ideal way to determine if solar thermal can contribute to ZEH is to model the performance and cost of all systems that could contribute cost effectively and include them in a simulation-based building optimization analysis. The BTP uses the optimization tool BEopt, which places a technology or "measure" into the design package for a building at a given savings level based on the marginal cost of energy for that measure being the lowest for all remaining options with that particular house at the current savings level. Solar water heaters were analyzed with this approach. Tools are under development for PV/thermal and space conditioning systems, and this approach cannot be used for those systems until the tools are available and integrated into BEopt.

\subsection{Low-Cost Solar Water Heaters for ZEH}

The program has supported industry teams in a stage-gate process to develop low-cost SWH for mild climates based on the use of low-cost polymer materials and manufacturing. Initially, six teams developed the low-cost concepts. After the conceptual development, two of the teams-from Davis Energy Group (DEG) and FAFCO, Inc.were selected to continue and are in the last stages of development, refining the product and developing efficient manufacturing processes. NREL and the University of Minnesota have provided technical support in modeling, performance testing, and materials durability.

To ensure that the products have an acceptable life, NREL and the University of Minnesota have conducted accelerated testing on the materials. Accelerated test methods included accelerated ultraviolet (UV) testing at 2 suns (in a temperature and humidity-controlled chamber) and at 25-50 suns (using an outdoor concentrator with cooled sample mount), as well as high-chlorine baths with high oxidation potential. Chambers for accelerated temperature aging were also used. Electron microscopy, X-ray diffraction, X-ray photoelectron spectroscopy and oxidation induction techniques were used in polymer lifetime and scaling studies.

Subcontracts were issued to two industry teams developing low-cost SWH for mild climates. Both teams have products approved by the Solar Rating and Certification Corporation (SRCC) and available to the market (albeit not yet in all intended distribution channels). The DEG subcontract supports large-scale field demonstrations in part and funds R\&D to reduce the cost of glazing and heat exchanger subassemblies. The FAFCO subcontract funds testing and field monitoring of its low-cost, unglazed drainback system.

An ongoing subcontract with the University of Minnesota funds heat exchangers work, including fundamental studies of heat exchangers and storage and in lifetimes and scaling of polymer tubing. An ongoing subcontract with Thermal Energy Systems Specialists, Inc., is helping to develop thermal modeling for the team's systems.

\subsection{Combined PV/thermal Systems for ZEH}

To analyze the potential for a PV/thermal system to contribute to $\mathrm{ZEH}$, the possible configurations are to be modeled in TRNSYS, which is compatible with BEopt. Both air and liquid systems were modeled, with variations in back-plane boundary conditions. A subcontract was issued to SunEarth, Inc., to develop the balance-of-system for its proposed combined PV/thermal system. 


\subsection{Industry Support}

Under the SETP Solar America Initiative (SAI), we maintained close connections with those leading local Solar Cities and Solar America Showcases projects, by sitting on advisory panels, participating on Tiger Teams, presenting at stakeholder meetings, and leading industry standards groups. Requests from SAI/Solar Cities have included user-friendly, Web-accessible tools for economic analyses of SWH savings and solar pool systems for municipal and school pools.

\section{Results and Accomplishments}

\subsection{Solar Thermal Pathways to ZEH}

A report issued on the technical potential for savings from SWH served as background information for a report to Congress on the potential for solar water heating. U.S. waterheating consumption is $\sim 4$ quads per year (Q/yr). A conservative approach was taken, assuming regional solar fractions averaging $\sim 1 / 2$ and available rooftops averaging $\sim 50 \%$, resulting in a potential near $1 \mathrm{Q} / \mathrm{yr}$. An economic analysis done to set SWH cost goals showed that the system cost required to attain cost-neutrality vs. electricity (a savings-to-investment ratio of 1) (see Figure 1). Even against electricity, the current installed newconstruction cost is $\$ 6000$ for a $40-\mathrm{ft}^{2}$ system $\left(\$ 150 / \mathrm{ft}^{2}\right)$, and this implies that the current technology is cost-neutral without rebates in less than $1 / 30^{\text {th }}$ of the country. This situation becomes even worse for SWH when gas is the auxiliary fuel. It is very clear that rebates and/or lower cost systems are needed to reach cost neutrality for SWH in most of the nation.

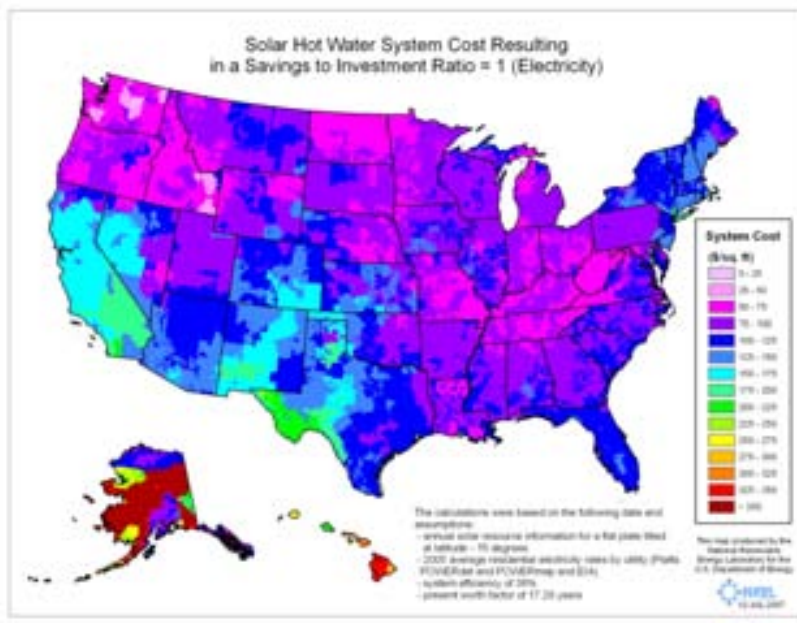

Fig. 1. System installed cost needed to produce a savings-to-investment ratio of 1 .
A report on the economics and market potential for SWH that contains those results was provided to Congress, as requested in FY 2008 congressional funding language.

A strategic plan was also developed that identified the "critical path" solar thermal technologies and systems that can contribute to achieving costneutral zero-energy homes. This is the only program FY 2008 milestone. The plan identifies three system types needed to attain cost-neutral ZEH: (1) solar water heaters are needed to achieve the $50 \%$ savings level and beyond in the near term; (2) PV/thermal systems are needed to provide water heating, some space heating, and space cooling for the $50 \%$ savings level and beyond, especially when there is limited roof space; and (3) "triple-play" systems meeting water heating, space heating, and space cooling loads are needed for ZEH to reach cost-neutrality.

Table 2. Milestones for Solar Heating and Cooling

\begin{tabular}{|c|l|c|}
\hline \multicolumn{3}{|c|}{ Milestone- Strategic Plan } \\
\hline Level & \multicolumn{1}{|c|}{ Description } & Date \\
\hline 4 & $\begin{array}{l}\text { Identify “critical path" solar thermal } \\
\text { systems to achieve cost-neutral } \\
\text { ZEH }\end{array}$ & $06 / 07$ \\
\hline
\end{tabular}

Through an analysis using BEopt, it was shown that, for houses with natural gas, SWH becomes more cost-effective than other measures at levels of savings $\geq \sim 45 \%$. At these savings levels, for example, walls have already been improved; added insulation (though inexpensive) produces very low additional savings. Installed prices assumed for SHW are shown in Table 3 and are intended to represent best attainable costs in new construction as of 2004. Today's prices are probably $\sim 25 \%-50 \%$ higher. Cost neutrality is reached at about $60 \%$, depending on climate. This is slightly after the "PV-takeoff" point (where PV is the most cost-effective remaining measure and is added until savings are $\sim 100 \%$ ). Beyond this point, cost-neutrality cannot be achieved without significant further cost reductions or rebates.

Table 3. Assumed Solar Water Heater Costs as of 2004

\begin{tabular}{|c|c|}
\hline Name/size & Installed Price \\
\hline $\mathrm{ICS} / 32 \mathrm{ft}^{2}$ & $\$ 2,654$ \\
\hline Glycol$/ 40 \mathrm{ft}^{2}$ & $\$ 4,307$ \\
\hline Glycol $/ 64 \mathrm{ft}^{2}$ & $\$ 4,768$ \\
\hline
\end{tabular}


In BEopt optimizations, the solar water heater was always paired with a gas tankless water heater (GTWH) as the optimal water heating system. However, GTWH with feedback control can cause unstable oscillations when the preheated water is too warm for the lowest available burner setting. Solar preheat voids the warranty on the majority of tankless water heaters. A paper on tankless-solar combinations was published suggesting that adding a small tank to the system can resolve the issue. Recent data shows, however, that the combination can induce other issues needing to be resolved.

NREL and SNL investigated thermally activated residential cooling technology to identify preferred system types. Absorption and desiccant technologies were candidates. A critical feature is the required temperature from the solar system. Although absorption technologies are available in large, gas-driven tonnage, they are intended for use with gas, as high temperatures (e.g., $\sim 200^{\circ} \mathrm{C}$ ) are required for double-effect chillers. This makes it challenging to use them with solar. Desiccants can be regenerated at temperatures as low as $140^{\circ} \mathrm{F}$, however. The technology is made more attractive by recent advances that include noncorrosive polymer systems, 20X reduction in flow rate through system redesign, and the elimination of demisters (zero-carryover).

Liquid desiccants have a potentially important synergy with seasonal storage for space heating. By storing both the strong desiccant regenerated with abundant summer sun and the attendant sensible heat, this technology can regenerate heat in winter when solar resources are low. This is done by the reverse of the regeneration process: water vapor produced by the low-temperature sensible storage is absorbed by the strong desiccant in a "heat generator," producing hightemperature heat. The net result is that the storage density of the desiccant tank is increased relative to that of water-based sensible storage by up to 10X, depending on the desiccant concentration lower limit where heat pumping is no longer sufficiently effective (see Figure 2).

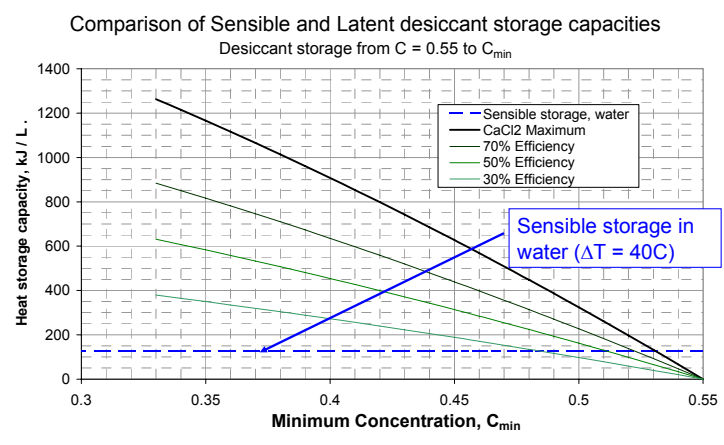

Fig. 2. Latent heat storage per unit volume of final weak desiccant, as a function of the minimum weak desiccant concentration.

\subsection{Low-Cost Solar Water Heaters for ZEH}

FAFCO introduced its unglazed drainback solar water heater to the market in February 2007 at the Homebuilder's Show in Las Vegas, Nevada (see Figure 3). More than 1000 systems have been sold to date, through FAFCO's existing distribution network. The company's development subcontract allows for the refinement of controls, and begins to resolve fundamental issues in the testing of unglazed collectors in regard to wind affects. A four-system test facility is also being constructed.

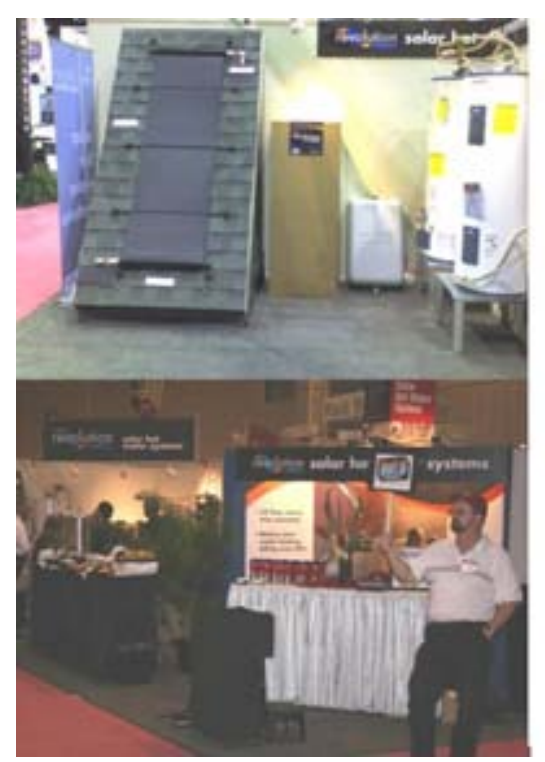

Fig. 3. The FAFCO display at the 2007 Homebuilders' Show, where the SHC-supported system was introduced to the builder market. 
Davis Energy Group was issued a subcontract funding the refinement of the glazing and heat exchanger as well as larger-scale demonstrations. The polycarbonate glazing used previously added over $\$ 200$ to the cost of the system, and the team has developed an acrylic alternative costing $~ 50 \%$ less. The previous heat exchanger design proved to be too laborious to manufacture, because of the dozens of brazed connections. The new design will use long pieces of soft copper to eliminate the majority of the brazed connections. A 40-unit demonstration project was completed at a migrant housing facility (see Figure 4). The team is also finalizing a demonstration project funded primarily through the California Air Resources Board (CARB). CARB has set aside $\$ 235 \mathrm{~K}$ for the project, which will install 80 systems in highpollution areas statewide.

During FY 2007, the Materials Durability subtask at NREL emphasized four areas of research. These included (1) continued testing of polymer sheet glazings using NREL's UV concentrator, (2) the assessment of polymer film glazing candidates, (3) accelerated testing of the mechanical properties of polymeric fittings, and (4) the development of a capability to conduct hail testing of evacuated tube collectors.

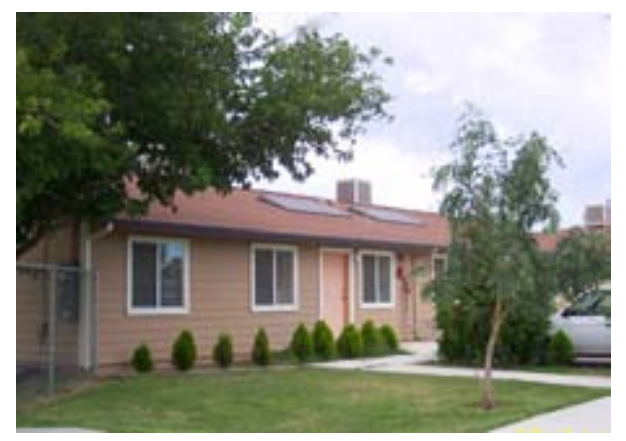

Fig. 4. SunCache glazed integrated collector storage at a migrant housing camp near Davis, California.

Solar-weighted transmittances as a function of UV dose for samples of interest to industry teams are shown in Figure 5. Optical performance stays steady after a cumulative UV dose equivalent to \% years outdoor exposure in Miami, Florida. Although acrylic films maintain optical durability, they are too brittle to withstand mechanical stress. They also sag unduly under relatively modest temperatures. Two commercial ethylene tetrafluoroethylene (ETFE) fluoropolymer films were exposed at 3 sites outdoors for 6 years and in the NREL Ci5000 weatherometer (WOM), for a UV dose equivalent to more than 39 years in Florida, without losing transmittance.

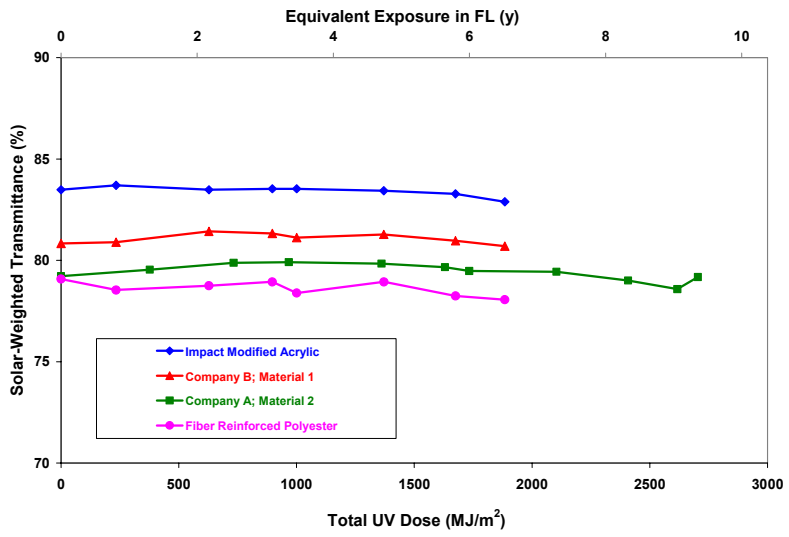

Fig. 5. Optical durability of polymer sheet glazing samples in NREL's UV concentrator.

Two candidate polymer materials used for connectors exposed outdoors (polypropylene (PP) and polysulfone (PSU)) were tested for percent elongation at break, a parameter that is indicative of ductility, a material's ability to avoid failure associated with brittle fracture. Results show that PP had superior elongation before UV exposure, and degraded less than PSU under UV. Consequently, our industrial partner chose to use PP fittings with its systems. A deluge of evacuated-tube systems has entered the U.S. market; the resistance of these tubes to hail damage is critical but unknown. In response to these needs, we have developed a facility for hail testing. Hail balls are launched by a commerciallyavailable hail gun, which is essentially a giant sling-shot. Testing will begin during FY 2008.

The University of Minnesota (UM) provides support to the industry teams and the program in the areas of storage, heat exchangers, polymer tubing durability, and scaling. Building on previous work, and at the program's request, the UM team explored ways to improve the thermal performance of storage tanks with immersed heat exchangers. The team designed a cylindrical baffle that constricts and accelerates natural convection flow around an immersed coil heat exchanger and prevents mixing of descending plumes with the hot tank water (see Figure 6a). The baffle increases the storage-side convective heat transfer coefficient to the heat exchanger by $20 \%$ (Figure $6 \mathrm{~b}$ ), with a similar increase in $\varepsilon_{\mathrm{hx}}$ if the exterior film coefficient is dominant. The UM team also evaluated the potential of metal foam 
structures to improve heat transfer to immersed heat exchangers. Experiments were conducted showing that the tested metal foam provides from $30 \%$ to $140 \%$ enhancement of heat transfer. Although commercial foams are prohibitively expensive, UM is currently building foam-like structures from low-cost screens that may also provide substantial improvements in heat transfer.

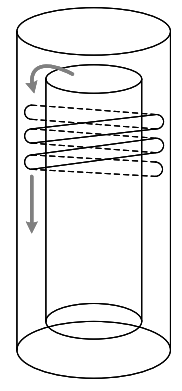

(a)

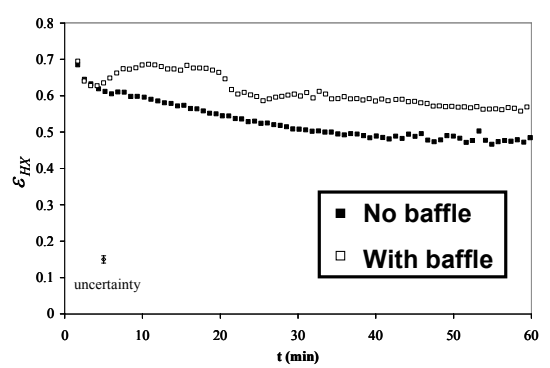

(b)
Fig. 6. Enhancement of immersed heat exchangers: (a) baffle-coil heat exchanger schematic; (b) heat exchanger effectiveness vs. time, with and without the baffle.

Low-cost polymer heat exchangers must have long life. The durability of potential polymer heat exchangers has been shown in previous work to depend mostly on the diffusion of antioxidants from the tube. Work at UM is continuing in collaboration with a well-known polymer industry partner on the experimental verification of the diffusion model, determining previously unknown diffusion coefficients. Initial data indicate significant acceleration of antioxidant loss in chlorinated water vs. deionized water, as indicated in Figure 7 (oxidation induction time is a measure of the remaining antioxidants). The oxidation induction time for unexposed resin is 95 minutes. This work is expected to lead to a relationship between the antioxidant concentration and the polymer lifetime.

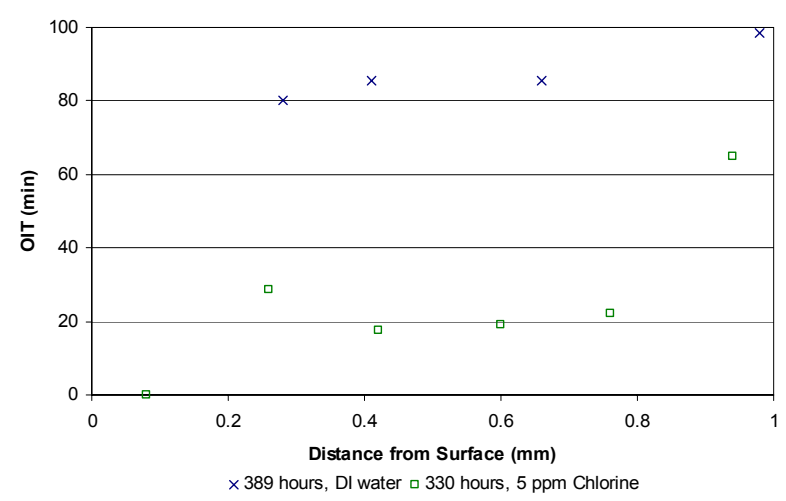

Fig. 7. Oxidation induction time data vs. depth for 2-mm-thick polyethylene samples.

Scaling, or the accumulation of mineral deposits on surfaces, is a potential problem in polymer heat exchangers operated in an open loop with hard water. Scaling was characterized in two types of flow-through systems: (1) long-term testing, with a realistic, tap water composition and temperature, and (2) short-term testing, with distilled water of high supersaturation (S). Both PP tubes and copper $(\mathrm{Cu})$ tubes were exposed to mildly supersaturated tap water at $40^{\circ} \mathrm{C}$ for times up to 8 weeks. The water composition was controlled for calcium carbonate $(S=5)$. Figure 8 a compares the accumulation of $\mathrm{CaCO}_{3}$ deposits on polypropylene and copper tubes for the tap-water case. Scale on the copper tubes was greater than that on the polypropylene.

Figure $8 \mathrm{~b}$ compares the scale accumulation in the $\mathrm{Cu}$ and PP tubes exposed to mildly supersaturated distilled water at room temperature. Under these conditions, the PP accumulates more scale than does the $\mathrm{Cu}$. Compared with the long-term study in tap water, these rates are three orders of magnitude higher. The comparison between the long-term, tap water study and the distilled water study demonstrates the importance of water chemistry in evaluating the potential for scale. Scaling in tap water, with various ionic components, is very different from scaling in distilled or deionized water with a single supersaturated component. 

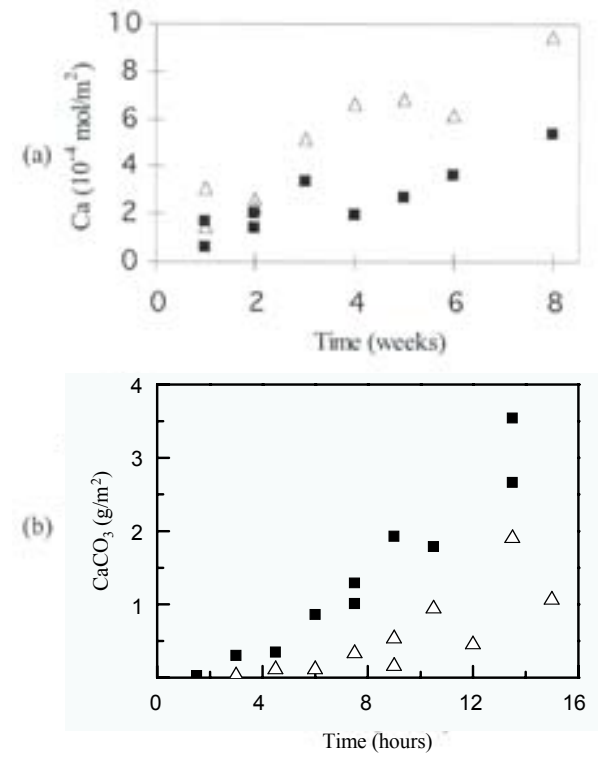

Fig. 8. Quantities of $\mathrm{CaCO}_{3}$ on polypropylene (filled squares) and copper (open triangles) as a function of exposure time, for (a) the tap water test, and (b) the distilled-water, single-species test.

\subsection{Combined PV/Thermal Systems}

$\mathrm{PV} /$ thermal $(\mathrm{PV} / \mathrm{T})$ simulation models have been developed for both liquid fin-tube and back-pass air PV/T systems. Six different models were produced, allowing variations in the back-plane boundary conditions and addition of a transparent cover that tends to thermally isolate the absorbed radiation from the ambient sink (see Figure 9 for examples). The models are being used in conjunction with building modeling to determine the extent of overlap between building loads and $P V / T$ energy delivery. Early results indicate that there is good coincidence of available thermal energy with the summer cooling load in many climates, but poor overlap with heating loads.

Under BTP funding, SunEarth previously developed and tested a prototype two-stage airbased PV/T system, as shown in Figure 10. The system draws outdoor air under the PV, picking up waste heat. The air then passes through a glazed, selective-surfaced air-heater section, increasing the outlet temperature. In this system, the hot air is then used for water heating with an air-to-liquid heat exchanger, and for space heating with direct injection into the air distribution system. Six systems have been installed in the field and are being monitored. The current system has been submitted for SRCC certification. A subcontract funded work on the development of the balance of system, including the mechanical ducting and dampers and the control system.
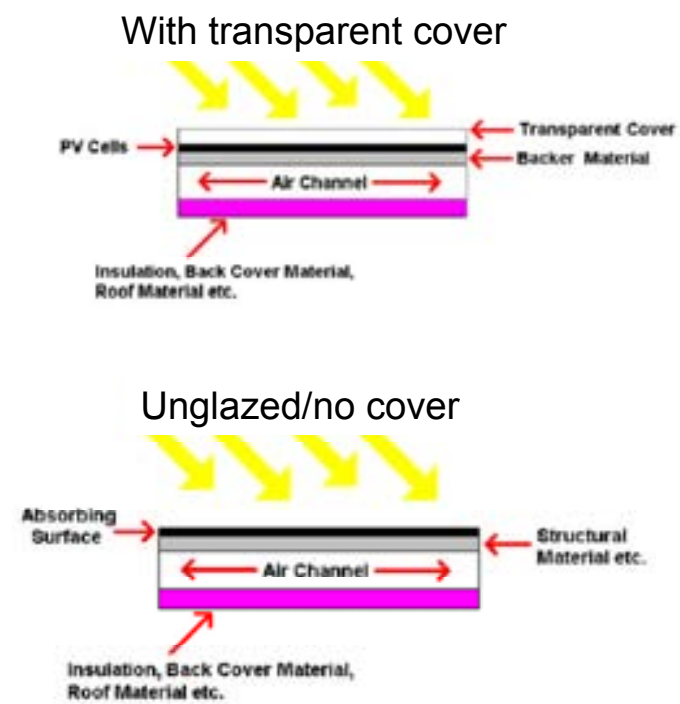

Fig. 9. Schematic air-based PV/thermal models, with and without a transparent front cover.

\subsection{Industry Support}

Under SAI, cities have expressed interest in school and municipal pool systems. Pool systems are a very cost-effective solar technology, with LCOE less than $1 \phi / \mathrm{kWh}$. Cities see this as a winwin situation but want assurance as to performance. SNL developed a Web-based calculator to estimate the energy savings for the pool system. Similarly, cities and energy-aware builders need to understand the benefits of solar water heating incentive programs. To serve this need, NREL developed a generic calculator for common SWH which is similar to PVWatts, the familiar PV calculator. The tool allows user input for system loads, location (the Typical Meteorological Year [TMY]2 site), system type, and system characteristics (e.g., area, storage volume, orientation, collector parameters). The calculator also facilitates parametrics for most user inputs.

The U.S. solar industry has encountered welding and corrosion issues that have been investigated at SNL. Solutions for these and other problems leverage the expertise available at SNL that has been developed through U.S. Department of Defense funding, which literally dwarfs any solar funding. Industry also continues to encounter rating and certification issues for solar collectors and systems. NREL led efforts to determine methods to extrapolate test data to different sizes 
of the same collector model and determine rating conditions. Ongoing efforts include fairness concerns arising from differing test standards for glazed and unglazed collectors, which suggest a bias toward unglazed systems as currently used in SRCC procedures.

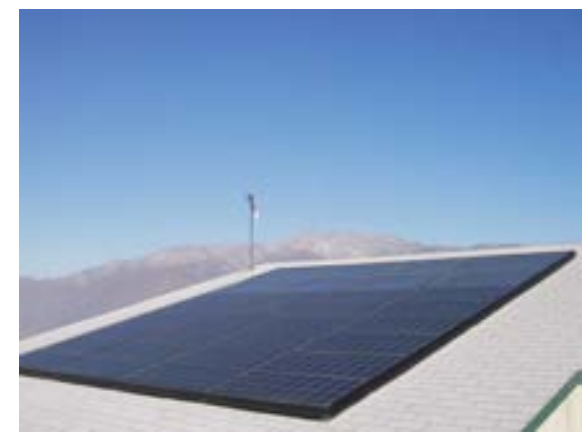

Fig. 10. A 3-kW PV system (bottom section of the system) with air heaters (top section).

\section{Planned FY 2008 Activities}

- Issue a request for proposals (RFP) for the development of cold-climate $\mathrm{SWH}$, and make at least five awards

- Identify preferred PV/T and triple-play solar thermal systems, and establish cost goals

- Begin the development of a prototype airbased PV/T system with desiccant-based space cooling

- Continue to provide industry support.

Lower cost thermal systems are essential to attain savings beyond the $50 \%$ level in Building America homes, and they are critical for attaining costeffective ZEH. If FY 2008 funding permits, an RFP will be issued for the conceptual development of low-cost cold-climate systems. At least five awards at the $\$ 100 \mathrm{~K}$ level are expected. The projects will follow a stage-gate process similar to the successful mild-climate SWH development, starting with conceptual development that results in the product's predicted LCOE and identifies significant issues. After the conceptual development ( $\sim$ year), projects will be fed into the second stage (prototype development) if they meet the requisite savings levels and don't present costly R\&D issues. The low-cost work on mildclimate systems will be phased out, with minor investment in support of ongoing field studies and manufacturing improvements.

Development of $\mathrm{PV} / \mathrm{T}$ and triple-play models for use in optimization studies will continue. Both performance and cost models are needed to compare the solar-driven systems with alternative technologies fairly. Modeling of PV/T cooling will begin in FY 2008. Savings from heat-only $P V / T$ models will be determined in conjunction with building modeling to give the timing and magnitude of the loads. Cost goals for heat-only $\mathrm{PV} / \mathrm{T}$ will be derived through this analysis.

The University of Minnesota will continue work on polymer heat exchanger lifetime and scale rates. The storage and heat exchanger task will concentrate on how to manage thermal storage with the annual-storage desiccant-based systems.

In addition, a Web-based tool for estimating SWH and combi-system performance will be developed that will allow the user to pick generic systems, generic systems with specific SRCC-listed collectors, or specific SRCC-listed SWH systems.

NREL staff leading and serving on the standards committee will continue to resolve technical issues in rating and certification that are arising in the rapidly expanding U.S. solar thermal industry

\section{FY 2007 Special Recognitions and Awards}

- University of Minnesota Professor Jane Davidson received the prestigious Charles Abbot award from the American Solar Energy Society.

- NREL's Dr. Jay Burch was elected as a fellow of the American Solar Energy Society.

\section{Major FY 2007 Publications}

J. Davidson, S. Mantell, and L. Francis, "Thermal and Material Characterization of Immersed Heat Exchangers for Solar Domestic Hot Water," Advances in Solar Energy, D.Y. Goswami, ed., American Solar Energy Society, vol. 17, 99-129 (2007).

\section{Journal Papers}

- Y. Su and J. Davidson, "Transient Natural Convection Heat Transfer Correlations for Tube Bundles Immersed in a Thermal Storage," ASME J. of Solar Energy Engineering, 129, 210-214 (2007).

- F. Kulacki, J. Davidson, and M. Hebert, "On the Effectiveness of Baffles in Indirect Solar Storage Systems," ASME J. of Solar Energy Engineering, 129, 494-498 (2007).

- Y. Su and J. Davidson, "Multi-Zone Porous Medium Model of the Thermal and Fluid Processes during Discharge of an Inclined 
Rectangular Storage Vessel via an Immersed Tube Bundle," ASME J. of Solar Energy Engineering, 129, 449-457 (2007).

\section{Conference Papers}

- J. Burch and C. Christensen, "Toward Development of an Algorithm for Mains Water Temperature," Proc. American Solar Energy Society, Cleveland, OH, June (2007).

- J. Burch, G. Shoukas, M. Brandemuhl, and M. Krarti, "Test and Rate Methods for Thermosiphon Solar Water Heaters," Proc. American Solar Energy Society, Cleveland, $\mathrm{OH}$, June (2007).

- J. Haltiwanger and J. Davidson, "Temperature and Flow in a Cylindrical Storage Tank with a Baffled Heat Exchanger: Experiments," Solar 2007, Annual Conference of the American Solar Energy Society, Cleveland (2007).

- Y. Su and J. Davidson, "Discharge of Thermal Storage Tanks via Immersed Baffled Heat Exchangers: Numerical Model of Flow and Temperature Fields," ASME Energy Sustainability, Long Beach, CA, June (2007).

- G. Jorgensen, "Durability Testing of Polymer Materials Used in Solar Thermal Systems," Society Of Plastics Engineers, Engineering Properties and Structure Division, Annual Technical Conference 2007 (SPE/ANTEC 2007), Cincinnati, OH, May 6-10, 2007.

\section{Reports and Theses}

- P. Denholm, "The Technical Potential of Solar Water Heating to Reduce Fossil Fuel Use and Greenhouse Gas Emissions in the United
States," NREL/TP 640-41157, Golden, CO: NREL, March (2007).

- J. Haltiwanger, "Analysis of a Cylindrical Baffle in Energy Discharge of a Vertical Solar Storage Tank with an Immersed Heat Exchanger," M.S. Thesis, University of Minnesota, Mechanical Engineering Department, Minneapolis, MN, October (2007).

- V. Kathare, "Natural Convection in WaterSaturated Metal Foam," M.S. Thesis, University of Minnesota, Mechanical Engineering Department, Minneapolis, MN , September (2007).

- D. Menicucci, and A. Mahoney, "Copper Corrosion and Its Relationship to Solar Collectors: A Compendium," SAND2007-4347, Albuquerque, NM: SNL, July (2007).

- T. Merrigan, Solar Heating Strategic Plan (Review Draft), Golden, CO: NREL, June 22 (2007).

- U.S. Department of Energy, Solar Water Heating: Potential Energy Savings, Market Barriers, and Strategies for Wider Deployment, Report to Congress, Washington, D.C., (2007).

- Z. Wu, "Scale Formation on Polypropylene and Copper Tubes," Ph.D. Thesis, University of Minnesota, Mechanical Engineering Department, Minneapolis, MN, November (2007).

\section{University and Industry Partners}

The following organizations partnered in the project's research activities during FY 2007.

\begin{tabular}{|c|c|c|c|c|}
\hline $\begin{array}{c}\text { Organization/ } \\
\text { Principal Investigator }\end{array}$ & Location/e-mail & $\begin{array}{l}\text { Description/Title of } \\
\text { Research Activity }\end{array}$ & $\begin{array}{l}\text { FY } \\
2007 \\
(\$ K)\end{array}$ & $\begin{array}{l}\text { Cost } \\
\text { Share } \\
(\$ K)\end{array}$ \\
\hline $\begin{array}{l}\text { Davis Energy Group } \\
\text { Eric Lee }\end{array}$ & $\begin{array}{l}\text { Davis, CA } \\
\text { elee@davisenergy.com }\end{array}$ & $\begin{array}{l}\text { Refine glazing and heat } \\
\text { exchanger, field trials }\end{array}$ & 135 & 30 \\
\hline $\begin{array}{l}\text { FAFCO, Inc } \\
\text { Mike Rubio }\end{array}$ & $\begin{array}{l}\text { Chico, CA } \\
\text { mrubio@fafco.com }\end{array}$ & $\begin{array}{l}\text { Refine new designs, test } \\
\text { prototypes, field trials }\end{array}$ & 135 & 138 \\
\hline $\begin{array}{l}\text { University of Minnesota } \\
\text { Jane Davidson }\end{array}$ & $\begin{array}{l}\text { Minneapolis, MN } \\
\text { jhd@me.umn.edu }\end{array}$ & $\begin{array}{l}\text { Stratification, pipe materials } \\
\text { testing, and scaling rates }\end{array}$ & 150 & $400^{1}$ \\
\hline $\begin{array}{l}\text { Thermal Energy System } \\
\text { Specialists, Inc. } \\
\text { Jeff Thornton }\end{array}$ & $\begin{array}{l}\text { Madison, WI } \\
\text { thornton@tess-inc.com }\end{array}$ & $\begin{array}{l}\text { Develop TRNSYS and TRNSED } \\
\text { models in support of industry } \\
\text { teams }\end{array}$ & 50 & 0 \\
\hline $\begin{array}{l}\text { SunEarth, Inc. } \\
\text { Josh Plaisted }\end{array}$ & $\begin{array}{l}\text { Fontana, CA } \\
\text { jplaisted@sunearthinc.com }\end{array}$ & $\begin{array}{l}\text { Phase 2B development of } \\
\text { PV/thermal system }\end{array}$ & $200^{2}$ & 50 \\
\hline
\end{tabular}

${ }^{1}$ High degree of co-funding through university and state grants devoted to solar thermal.

${ }^{2}$ Phase 1 and 2A funded through the DOE Building Technologies Program. 


\title{
Hybrid Solar Lighting
}

\author{
Performing Organization: Oak Ridge National Laboratory (ORNL) \\ Key Technical Contacts: Melissa Lapsa (ORNL), 865-576-8620, lapsamv@ornl.gov \\ Curt Maxey (ORNL), 865-576-7114, maxeylc@ornl.gov
}

DOE HQ Technology Manager: Robert Hassett, 202-586-8163, robert.hassett@ee.doe.gov

FY 2007 Budgets: $\quad \$ 2,000 \mathrm{~K}$

\section{Objectives}

- Evaluate the performance of the Sunlight Inside Initiative beta test sites across the United States.

- Identify technical issues and research solutions.

- Complete third-party assessment of the hybrid solar lighting (HSL) market.

\section{Accomplishments}

- Prepared a summary of the Sunlight Inside Initiative beta test site results.

- Prepared a summary of technical issues and research solutions; final report is due in fiscal year (FY) 2008.

- Completed a third-party market assessment of HSL.

\section{Future Directions}

Because of the late arrival of FY 2007 funds, FY 2008 activities will target the completion of the FY 2007 scope of work.

\section{Introduction}

In the United States, artificial lighting represents the single largest component of electricity use in commercial buildings, costing building owners nearly $\$ 17$ billion a year. Despite the high consumption of energy and the continued demand by occupants for more natural lighting, natural lighting from conventional options, such as skylights and windows, illuminates only a tiny fraction of the available commercial space. This limited use of natural lighting is a result of the architectural limitations of skylights and windows and the uncontrollable nature of sunlight itself (e.g., intensity fluctuations, glare, and unwanted heating). A significant market exists for a natural lighting product that can offer the benefits of natural light with all of the conveniences and control of an artificial lighting system.

Hybrid solar lighting (HSL) technology meets this previously unmet need and has the potential to provide a product with an economic payback of three to four years for commercial buildings in the Sunbelt regions of the world. In the U.S. Sunbelt alone, 20 billion square feet of commercial space meet the requirements for implementation of an
HSL system. Each year, this amount of applicable space grows by 600 million square feet of new construction.

The commercialization of HSL technology will focus initially on a small subset of retailers representing jewelry, furniture, and apparel markets. This niche market of early adopters is expected to increase sales volumes of HSL technology, permitting cost reductions through economies of scale. With system price reductions, we anticipate that greater penetration into this niche market and the larger commercial building market (including office buildings) will occur. Fullspectrum solar energy systems, such as HSL, provide a new and realistic opportunity for wideranging energy, environmental, and economic benefits. Their development is directly in line with the mission of the U.S. Department of Energy (DOE) Solar Energy Technologies Program to improve America's security, environmental quality, and economic prosperity through public-private partnerships that bring reliable and affordable solar energy technologies to the marketplace.

The advantages of HSL include the following: 
- Small and minimal roof penetrations, reducing the potential for leaks.

- Separation of the infrared (IR) and ultraviolet (UV) energy in sunlight from the visible light, to prevent the transmission of IR and UV light into buildings. Heating, ventilation, and airconditioning (HVAC) loads are thus reduced by $5 \%$ to $10 \%$ in comparison to those of electric lighting systems.

- Minimal use of precious plenum space-the area between the roof and the drop ceilingso there is little competition with other building services, such as HVAC ducts, sprinkler systems, and electrical conduits.

- Versatility of use for both direct ambient lighting (as in skylights) and for indirect task and accent lighting applications.

- Ease of incorporation into existing building designs (for retrofit markets). Optical fibers can also be rerouted to different locations as lighting needs change. By intentionally misaligning the solar collector from the sun, occupants can even dim or curtail distributed sunlight.

\section{Technical Approach}

FY 2007 research efforts focused on two major areas: system reliability improvement and reduction of the cost of goods sold.

\subsection{System Reliability}

Early HSL prototypes appeared to be reliable, with respect to their ability to handle the thermal load of the concentrated solar energy. However, as the manufacturing processes for the HSL primary mirrors improved, the level of concentrated energy increased and ultimately caused the reliability of the systems to become severely compromised. In FY 2006, multiple instances of damaged fiber bundles in fielded units indicated a critical need for better thermal characterization and mitigation in the HSL system design.

A series of round-robin tests was planned, and tests were conducted at four sites: Oak Ridge National Laboratory (ORNL), Utah State University, San Diego State University, and the University of Nevada at Las Vegas. Eight identical fiber optic receiver assemblies (including a receiver housing, hot mirror, mixing rod, and short fiber optic bundle) were constructed for use in the round-robin tests. Each of the bundles was to be tested for up to two weeks at each of the four locations. As a part of the preparation process for the round-robin tests, a test apparatus was developed to characterize the thermal absorption of the face of the fiber optic bundles. This enabled the bundles to be characterized before the test units were assembled.

The round-robin tests began in early July 2007 , when each of the four systems were fitted with the highest quality primary mirrors available. In the first month of testing, preliminary results began to show a damage pattern that suggested a probable cause for the system failures that were occurring in the field. Small pits in the face of the plastic mixing rod developed as a first sign of this damage. With continued exposure, the pits increased in size and number. Eventually (sometimes after several days of progressive degeneration), some of the units failed entirely. These results were essential to understanding the failure mechanism and mitigating the thermal stress.

Once the failure mechanism had been identified, the next step was to identify a safe operating condition in which the units could continue to operate. The HSL systems at the four sites were defocused to varying degrees, as the tests continued, to try to identify a safe operating level of concentration. Ultimately, the units were all operated in a defocused condition that reduced the level of concentrated light by about $30 \%$, and this appeared to be a reliable mode of operation.

At the same time, efforts began to be directed toward developing an improved hot mirror to protect the mixing rod, as well as an improved cold-mirror coating for the elliptical secondary mirror. Field tests of the two alternative designs were conducted late in CY 2007; however, the tests indicated that there had been no improvement in performance over that of the previous designs.

Since it appeared that the heating in the HSL units could not be eliminated at the source, it appeared that efforts would have to be directed toward extraction of the heat. Late in CY 2007, outside consultants were called in to assist with thermal management in the HSL receiver design. Twodimensional thermal models were constructed that corroborated many of the experimental results. These models are currently being used in the development of an alternative receiver design that will incorporate improvements in materials and airflow. The improvements are expected to 
eliminate the catastrophic failures that have been experienced in the existing receiver designs.

\subsection{Reduction of the Cost of Goods Sold}

Cost reduction has focused on two areas: manufacturing processes and system design. The development of the bundle characterization system that was used to characterize the bundles for the round-robin tests has become an important tool for quality assurance of full-system bundles. This has been valuable in the development of manufacturing processes that are resulting in bundles that are more uniform and higher in overall quality. Bundle manufacturing costs (one of the largest HSL production costs) have been reduced through processes that take less time and achieve more consistent results. Consequently, the costs associated with rework have been significantly reduced.

The overall cost of HSL systems will drop dramatically in CY 2008 as a result of the development of an improved tracker mechanism. The details of the redesign are not available for release at this time, but it will be a significantly different design that is expected to cost less, be more reliable, and greatly reduce installation costs by eliminating the need for manual calibration during setup.

\begin{tabular}{|l|c|}
\hline \multicolumn{1}{|c|}{ Agreement Title } & $\begin{array}{c}\text { FY 2007 } \\
\text { Budget (\$K) }\end{array}$ \\
\hline $\begin{array}{l}\text { Identify HSL technical issues } \\
\text { and research solutions }\end{array}$ & 1,925 \\
\hline $\begin{array}{l}\text { Conduct independent market } \\
\text { assessment }\end{array}$ & 75 \\
\hline
\end{tabular}

\section{Results and Accomplishments}

\subsection{Prepared Summary of Sunlight Inside Initiative Beta Test Site Results}

Field-testing was conducted at the HSL beta sites across the United States as part of the Sunlight Inside Initiative (see Figures 1-4). Past evaluations of the HSL fiber optic receiver showed that heating of the receiver was occurring as a result of optical absorption of the receiver's subcomponents. This heating was determined to be responsible for the failure of several test units being field-tested as part of a nationwide field trial program.

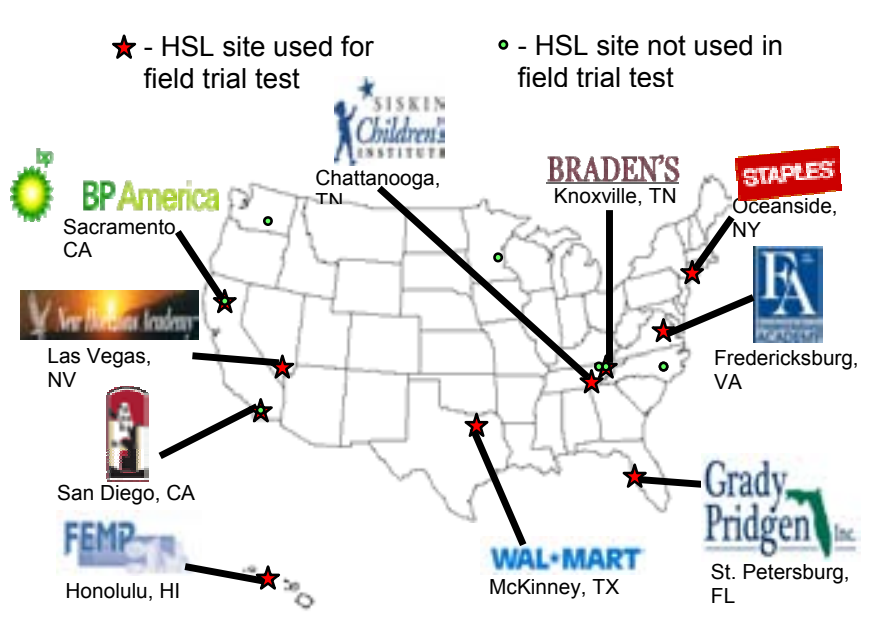

Fig. 1. U.S. locations of Sunlight Inside Initiative beta sites.
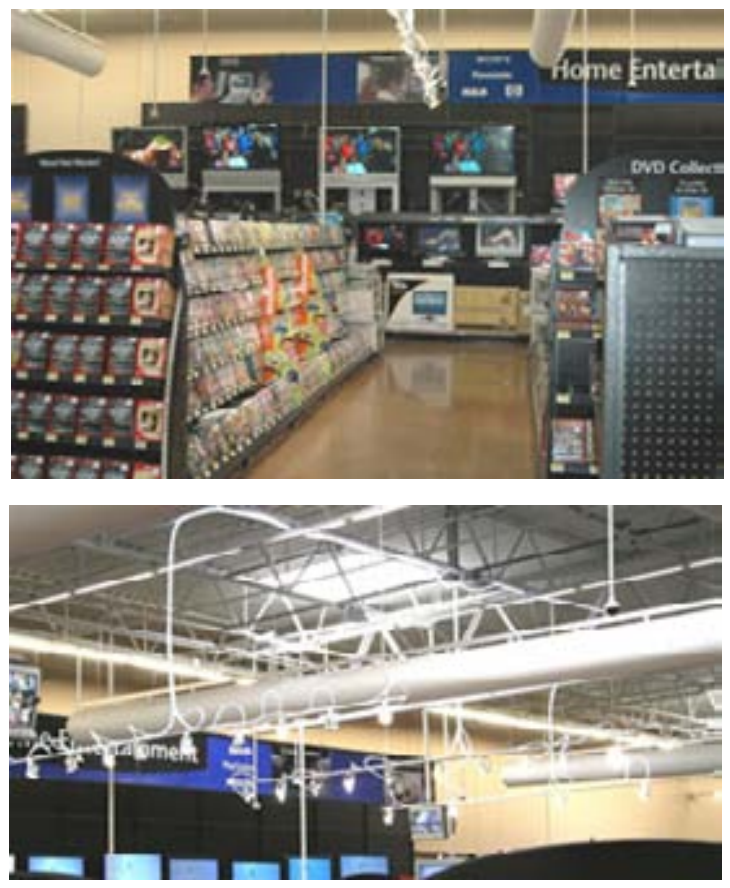

Fig. 2. An HSL system is installed in the electronics area of a Texas Wal-Mart, one of the beta sites of the Sunlight Inside Initiative. The HSL is incorporated into spot lighting to highlight various products in the home entertainment area. 


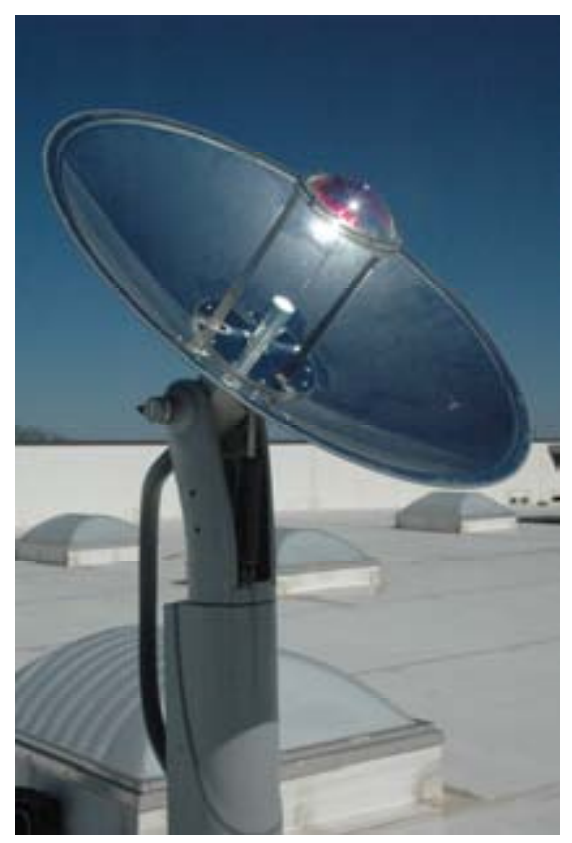

Fig. 3. Rooftop HSL system at a Texas Wal-Mart, one of the Sunlight Inside Initiative beta site locations across the United States.

\subsection{Prepared Summary of Technical Issues and Research Solutions (final report due in FY 2008)}

An experimental effort was developed in early 2007 to evaluate the heating and failure mechanisms present in the current receiver design. The intent was to ultimately mitigate the heating to a level that would support the long-term operation of the receivers at maximum input flux.

A defocused configuration of the solar collector was tested and verified. Reconfiguration of existing field-trial systems has been completed, and the field-trial fiber receivers are no longer failing. To reach maximum flux, an "optical solution" was pursued that, although it did yield some improvements, was not ultimately successful at significantly reducing the heat being produced by the receiver to levels that would ensure survivability at maximum flux. As such, it is recommended that a "thermal solution" be pursued to dissipate the heat build-up that is occurring within the receiver. FY 2008 activities are focused on redesigning the optical receiver housing, conducting field testing, and preparing the final report.

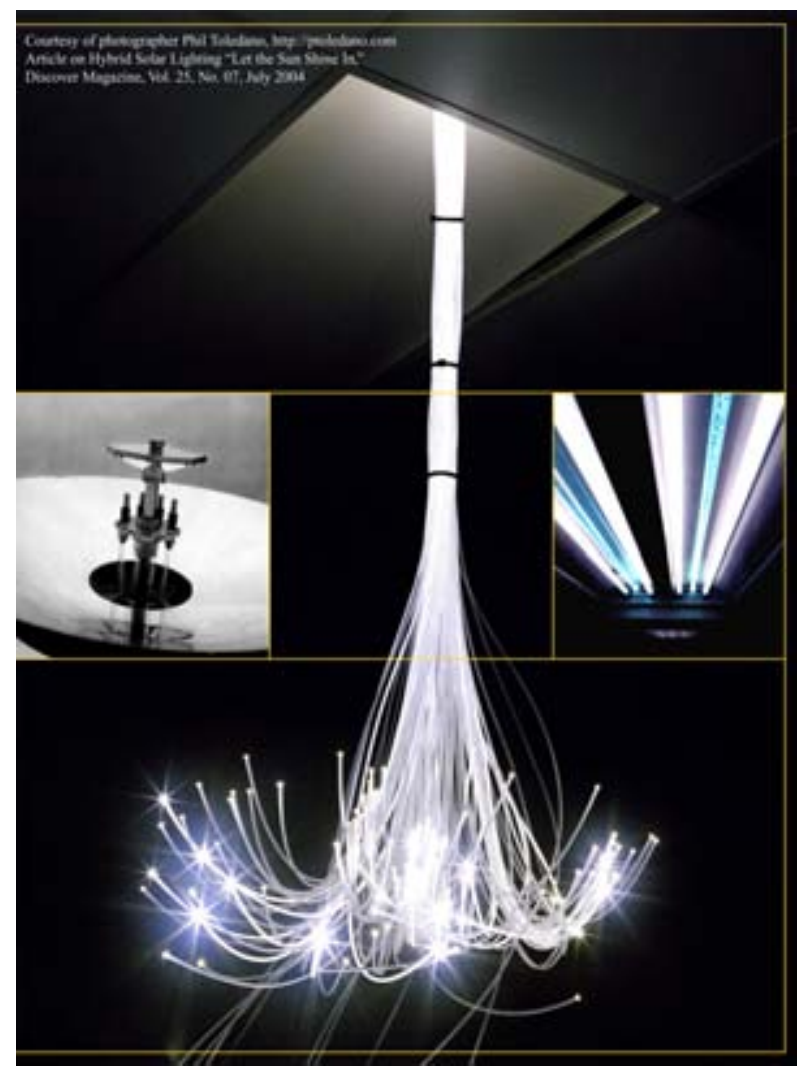

Fig. 4. Flexible 127-strand fiber optic bundle from the HSL system.

\subsection{Completed a Third-Party Market Assessment of HSL}

A third-party market potential analysis was conducted by Antares, Inc., to gauge the size and characteristics of the commercial market for the technology. The assessment identified the gross potential market for HSL as follows:

- Core building areas (enclosed areas up to within $10 \mathrm{ft}$ of the building exterior)

- Top two floors only (distribution constraints)

- Target facility primary uses: education, food sales, health care, lodging, retail, office, and public assembly

- U.S. potential market in 2008 (units installed): new construction $=356,000$ units/year; retrofit $=1.17$ million units/year.

\section{Planned FY 2008 Activities}

Because of the late arrival of FY 2007 funds, FY 2008 activities will target the completion of the FY 2007 scope of work. 


\section{FY 2007 Special Recognition, Awards, and Patents}

Awards:

On behalf of the ORNL solar team, Melissa Lapsa and David Beshears accepted the Excellence in Technology Transfer Award from the Southeastern Region of the Federal Laboratory Consortium (FLC), which was presented at the Southeast Regional Meeting, held in conjunction with the Midwest Region technology transfer conference in Nashville, Tennessee, October 25-27, 2006.

Melissa Lapsa, ORNL Solar Technologies Program Manager, received notification that "Hybrid Solar Lighting" had been selected as a national winner of the 2007 Award for Excellence in Technology Transfer by the FLC. The award recognizes laboratory employees who have accomplished outstanding work in the process of transferring a technology developed by a federal laboratory to the commercial marketplace.

\section{Patent:}

U.S. Patent No. 7,231,128 B2 for Hybrid Solar Lighting Systems and Components was issued to Jeff Muhs, Duncan Earl, Dave Beshears, Curt Maxey, John Jordan, and Randall Lind on June 12 (2007).

\section{Press Coverage:}

"Solar experts gathering at ORNL for summit," The Oak Ridger, Sept. 14 (2007). (Also appeared in the Energy Digital, All American Patriots, RxPG News, U.S. Fed News, and First Science News.)

"ORNL's Hybrid Solar Lighting Wins National Technology Transfer Award," (Azom.com, The A to $Z$ of Materials), June (2007).

"Hybrid Solar Lighting Promises 50\% Efficiency," Sara Parker, Renewable Energy World.Com, June 14, 2007.

"Experts Say Buildings Can Go Green Now," Earth and Sky podcast in the series, "A Clear Voice for Science," May 21 (2007). www.earthsky.org/clearvoices/51361/marilyn-brown-on-green-building.

"Here Comes the Sun," Sara C. Shoemaker, Business Tennessee, May (2007).

"Hybrid solar lighting earns national technology transfer award," First Science News, June (2007).
"East Tennessee cleantech companies cultivate environmentally conscious market sector," Andrew Eder, edera@knews.com, April 22 (2007).

"Sunlight Directs Hybrid Solar Lighting: Fiberoptic Brilliance," Popular Mechanics, March (2007).

"Let there be light, optical cables included," CNET Networks, Inc., March (2007).

"An Even Smarter Lighting System," Buildings, December (2006).

"DOE-Funded Research Projects Win 41 R\&D 100 Awards for 2006" U.S. Department of Energy News, Oct. 19 (2006).

"The sun in a hose," Star Tribune, MinneapolisSt. Paul, Minn., Oct. 15 (2006).

"Hybrid Solar Lighting Technology ... Soon to shine on the commercial scene!" Electrical Line Magazine, Vol. 12, No. 5, September/October (2006).

\section{Major FY 2007 Publications}

D. L. Beshears et al., "Solar Energy, Collected, Concentrated, Transported and Distributed As Light with No Energy Conversion via a Hybrid Solar Lighting System." Proceedings of Solar 2007, American Solar Energy Society, Cleveland, Ohio, July 7-12 (2007).

Federal Energy Management Program, "Hybrid Solar Lighting Illuminates Energy Savings for Government Facilities," FEMP Technology Focus, Publication Number DOE/EE-0315, April (2007). www.eere.energy.gov/femp/

M. Lapsa, D. Beshears, L. Maxey, and C. Ward, "Direct Use of Solar Energy for Lighting - Results of the Hybrid Solar Lighting Field Trial Program," Proceedings of Solar 2007, American Solar Energy Society, Cleveland, Ohio, July 7-12 (2007).

M. V. Lapsa, L. C. Maxey, D. D. Earl, D. L. Beshears, C. D. Ward, and J. E. Parks, "Hybrid Solar Lighting Provides Energy Savings and Reduces Waste Heat," Journal of Energy Engineering, Vol. 104, No. 4, 7-20 (2007).

L. C. Maxey, "Flexible Sunlight-The History and Progress of Hybrid Solar Lighting," chapter to be 
published in 2008 in Emerging Environmental Technologies, by V. Shah, submitted June (2007).

L. C. Maxey et al., "Spectral Transmission of a Solar Collector and Fiber Optic Distribution Hybrid
Lighting System," ASME Energy Sustainability 2007 Conference, Long Beach, California, June 27-30 (2007).

\section{University and Industry Partners}

The following organizations partnered in the project's research activities during FY 2007.

\begin{tabular}{|c|c|c|c|c|}
\hline $\begin{array}{l}\text { Organization/ } \\
\text { Principal } \\
\text { Investigator }\end{array}$ & Location/e-mail & $\begin{array}{l}\text { Description/Title of Research } \\
\text { Activity }\end{array}$ & $\begin{array}{l}\text { FY } 2007 \\
\quad(\$ K)\end{array}$ & $\begin{array}{c}\text { Cost } \\
\text { Share (\$K) }\end{array}$ \\
\hline $\begin{array}{l}\text { Sunlight Direct, LLC/ } \\
\text { John Morris }\end{array}$ & $\begin{array}{l}\text { Oak Ridge, TN } \\
\text { morrisjd@sunlight-direct.com }\end{array}$ & $\begin{array}{l}\text { Collaborative work on HSL for } \\
\text { fabrication of improved system } \\
\text { components }\end{array}$ & 736 & 250 \\
\hline $\begin{array}{l}\text { Antares Group, Inc./ } \\
\text { Ed Gray }\end{array}$ & $\begin{array}{l}\text { Landover, MD } \\
\text { edgray@antaresgroupinc.com }\end{array}$ & Market assessment and report & 65 & 0 \\
\hline $\begin{array}{l}\text { University of } \\
\text { Tennessee/ } \\
\text { Tony Gehl and } \\
\text { Philip Boudreaux } \\
\text { (Post-doctoral) }\end{array}$ & $\begin{array}{l}\text { Knoxville, TN } \\
\text { tonygehl@gmail.com }\end{array}$ & Research support & 58 & 0 \\
\hline
\end{tabular}




\section{Systems Integration and Coordination}

Energy efficiency and renewable energy will mean a stronger economy, a cleaner environment, and greater energy independence for the United States. Working with a wide array of state, community, industry, and university partners, the U.S. Department of Energy's Office of Energy Efficiency and Renewable Energy (EERE) invests in a diverse portfolio of energy technologies. These include solar-related research, development, and deployment projects that crosscut with, and complement, the objectives of the DOE Solar Program.

The National Center for Photovoltaics (NCPV), headquartered at the National Renewable Energy Laboratory (NREL) in Golden, Colorado, provides overall coordination of the PV Subprogram at the request of DOE. NREL and Sandia National Laboratories (SNL) in Albuquerque, New Mexico, are partners in the NCPV, and provide the management oversight for the respective projects in their laboratories, as well as management support for the NCPV. The Concentrating Solar Power (CSP) Subprogram is managed collaboratively between SNL and NREL in the virtual entity referred to as Sun Lab. NREL, SNL, and Oak Ridge National Laboratory (ORNL) in Oak Ridge, Tennessee, jointly participate in managing the Solar Heating and Lighting Subprogram.

Management activities include analysis, administration, budget control, reporting, and integration of programs, including oversight of staff, equipment, and facilities at NREL, SNL, and ORNL. The management team develops inputs for new program initiatives, conducts review meetings at the request of $\mathrm{DOE}$, and provides oversight for communications, outreach, and cross-cutting analysis activities.

Small Business Innovation Research (SBIR) is a highly competitive program that encourages small businesses to explore their technological potential and provides the incentive to profit from its commercialization. By including qualified small businesses in the nation's R\&D arena, hightech innovation is stimulated and the United States gains entrepreneurial spirit as it meets its specific research and development needs. Each year, ten federal departments and agencies (including DOE) are required by the SBIR Program to reserve a portion of their R\&D funds for award to small, U.S.-owned businesses.

Some significant accomplishments in FY 2007 are listed below.

Communications

- Maintained, expanded, and/or developed about 12 Web sites.

- Supported efforts for the publication of about 350 technical publications.

- Completed all preparations for the 2007 Solar Decathlon (the event occurred in FY08).

International Activities

- Supported participation in both International Energy Agency (IEA) Task 9, "Coordination of Renewable Energy Training and Certification Activities," and IEA Task 10, "Urban Scale PV Applications."

Small Business Innovation Research

- Adapted metallurgical techniques for purifying silicon to produce a cheaper grade of silicon for PV and developed a reusable crucible for Silicon ingot casting for PV. 


\title{
Communications and Outreach
}

\author{
Performing Organizations: National Renewable Energy Laboratory (NREL) \\ Sandia National Laboratories (SNL) \\ DOE Golden Field Office (DOE/GO)
}

Key Technical Contacts: $\quad$ Ruby Nahan (NREL), 303-384-7401, ruby_nahan@nrel.gov Don Gwinner (NREL), 303-384-6570, don_gwinner@nrel.gov Susan Moon (NREL), 303-384-6631, susan_moon@nrel.gov

DOE HQ Technology Manager: Thomas Rueckert, 202-586-0942, thomas.rueckert@ee.doe.gov

FY 2007 Budgets: $\quad$ \$545K (NREL), \$75K (SNL)

\section{Objectives}

- Find innovative ways to reach critical audiences in a timely and accurate manner to improve business performance and help the Solar Energy Technologies Program (SETP) realize its vision, mission, and goals.

- Inform and persuade audiences, move them to action, and help overcome barriers for particular technologies and applications.

- Unify the outreach efforts of the Solar Program so that communications and knowledge transfer emphasize all, rather than individual solar technologies, leading to understanding, collaboration, and partnership to advance solar energy technologies.

- Provide targeted communications support to ensure the successful launch of all activities within the Solar America Initiative (SAI) —including both R\&D and market transformation.

- Produce and maintain documents and Web sites to support the core business activities of SETP.

\section{Accomplishments}

- Completed core program and cross-cutting communications support for SETP.

- Provided critical and timely support to SETP for the SAI, including both R\&D and market transformation activities.

- Maintained, expanded, and/or developed about 12 Web sites.

- Supported efforts for the publication of about 350 technical publications.

- Employed visual display and design expertise, creating products such as 3-D animations, posters, and displays for a variety of products.

- Created and/or staffed several exhibits.

- Completed all preparations for the 2007 Solar Decathlon (the event occurred in FY08). See the Solar Decathlon report for more information.

\section{Future Directions}

- Develop a plan for communications activities, associated with all SAl market transformation activities.

- Work in conjunction with the U.S. Department of Energy's (DOE) Public Affairs office, Office of Energy Efficiency and Renewable Energy's (EERE's) Technology Advancement Office, and Golden Field Office (GO) to create branding guidelines for SAI market transformation partners.

- In addition to conducting operations and maintenance for all EERE solar Web sites:

- Create a robust concentrating solar power (CSP) Web presence

- Develop a plan for redesigning the sites to better meet the needs of critical SAI audiences.

- Conduct a needs assessment and develop an appropriate centralized information resource to answer the increased volume of inquiries about solar.

- Conduct all planning activities for the communications and outreach tasks for Solar Decathlon 2009 . 


\section{Introduction}

The Solar Communications Team supports the communications and outreach needs of many elements of the Solar Energy Technologies Program (SETP). These include the Solar America Initiative (SAI), the National Center for Photovoltaics (NCPV), and concentrating solar power (CSP) and solar heating (SH) activities at the National Renewable Energy Laboratory (NREL) and Sandia National Laboratories (SNL). If the U.S. Department of Energy's (DOE's) solar program is to be successful in its mission to accelerate market acceptance of solar technologies, it must communicate accurate and timely information to target audiences such as the solar industry, universities, nonprofit groups, public utilities, the buildings industry, consumers, and federal, state, and local governments. The Solar Communications Team is made up of several professionals from NREL and SNL. The team's accomplishments in its support of SETP's mission in 2007 include these:

- Supported SETP management by producing reports, newsletters, and strategic planning documents

- Represented the program's mission and accomplishments through Web sites, publications, and conference exhibiting

- Provided critical support to SAl through the development of print materials, redesigning the Web site, and supporting the Golden Field Office (GFO) and DOE headquarters in award selections and media events for award announcements

- Described technical accomplishments through conference papers, presentations, and posters; technical reports; journal articles; brochures; fact sheets; exhibits; displays; Web sites; CDs; and animated videos

- Managed all nonmedia communications for the 2007 Solar Decathlon.

The Solar Communications Team is a complete communications and design group with a wide variety of expertise:

- Strategic communications and outreach planning, including audience analysis, branding, program plans and assessments, marketing, and questionnaires

- Writing and editing, including technical and marketing products, speeches and presentations, journal and magazine articles, contractual reports, and Web sites

- Graphic design (print and electronic)
- Multimedia and animation development

- Web site development, including needs assessment, content development and optimization, information architecture, design, development, database applications, virtual reality, blogs, forums, RSS feeds, new media, and statistical analysis.

\begin{tabular}{|l|c|}
\hline \multicolumn{1}{|c|}{ Agreement Title } & $\begin{array}{c}\text { FY 2007 } \\
\text { Budget (\$K) }\end{array}$ \\
\hline Core Program Support & $\begin{array}{c}\text { \$150K (NREL, } \\
\text { \$50K (SNL) }\end{array}$ \\
\hline Cross-Cutting Communications & \$140K (NREL) \\
\hline Solar America Cities Partnerships & \$100K (NREL) \\
\hline State Strategic Partnerships & \$100K (NREL) \\
\hline Utility Strategic Partnerships & \$100K (NREL) \\
\hline
\end{tabular}

* Note: Communications and Outreach activities span many other SETP activities. Accomplishments discussed cover more activities than those to which these budgets were committed.

\section{Communications Approach}

The Solar Communications Team takes a comprehensive approach to its activities. We identify and respond to communications needs by:

- Identifying effective communication objectives and strategies

- Analyzing and understanding key target audiences and their perceptions of solar technologies

- Developing audience-specific messages

- Creating communications products to reinforce objectives and effectively deliver audiencespecific messages.

This process of planning and analysis, developing and producing, and effectively transferring knowledge is applied to all communications activities. The Solar Communications Team's activities fall within three primary areas:

- Core Program Support and Cross-Cutting Communications

- Solar America Initiative R\&D and market transformation activities, including State Strategic, Utility Strategic, and Solar America Cities partnerships

- Additional SETP and NCPV R\&D activities described elsewhere in this report that do not discuss communications work specifically. Note: the FY 2007 budgets for these additional activities are not reflected here. 


\section{Results and Accomplishments}

Key results and accomplishments are summarized under the three major activities listed in Section 2, Communications Approach.

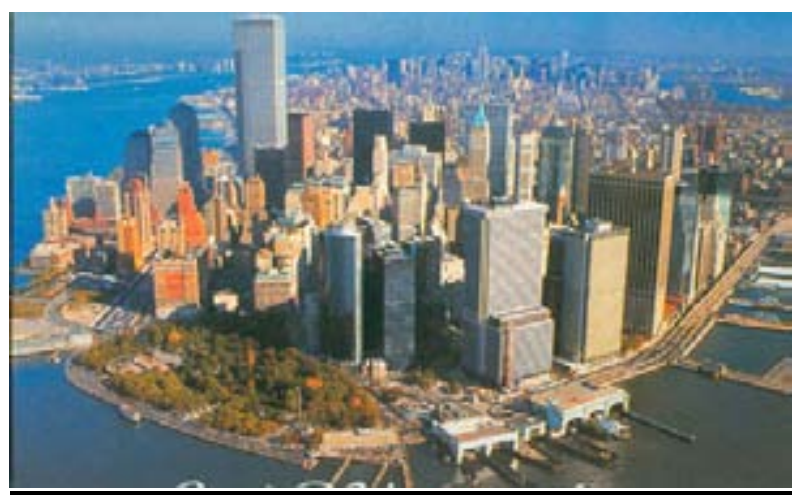

Fig. 1. The Solar Communications Team provided media kits for Energy Secretary Samuel Bodman's announcement of the Solar America Cities awards in New York.

\subsection{Core Program Support and Cross-Cutting Communications}

- Completed the DOE Solar Energy Technologies Program Annual Report 2006.

- Prepared and implemented a comprehensive Web maintenance plan for the EERE/SETP Web site, including analysis of common Webmaster inquiries to streamline the response process. We also contributed ongoing updates to the EERE News and Events databases with solar-relevant content.

- Exhibited, on behalf of the SETP, at the International Builders' Show, which had $110,000+$ visitors. The Information Resource section was also completed on the EERE/SETP Web site in time for the show, where we handed out business cards with the URL for this section.

- Attended and supported the DOE/EERE Solar Program Annual Review Meeting in Denver, Colorado. We spoke with attendees about SAI during poster sessions and produced electronic proceedings from the meeting.

- Managed weekly conference calls with SETP managers to discuss strategic communications planning to ensure that effective communications strategies are in place, to reduce duplication of effort, and to clarify the roles and responsibilities of all program participants.
- Responded to a variety of miscellaneous communication requests from DOE headquarters:

- As a benefit to DOE's sponsorship of the American Solar Energy Society (ASES) National Solar Home Tour, we designed an ad for Solar Today magazine

- At the request of DOE EERE Assistant Secretary Alexander Karsner and Tom Kimbis, we posted a DOE best practices document and coordinated with progress alert feeds.

- We provided Energy Secretary Bodman's office with talking points about International Energy Agency solar work.

- We contributed to or edited and produced three reports for Congress:
- The Effect of Polysilicon Market Conditions on the PV Market
- A CSP Energy Policy Act (EPAct) report
- A solar heating EPAct report

- We supported the development of the first SETP newsletter by providing content, editing, and posting. We continue to support subsequent issues.

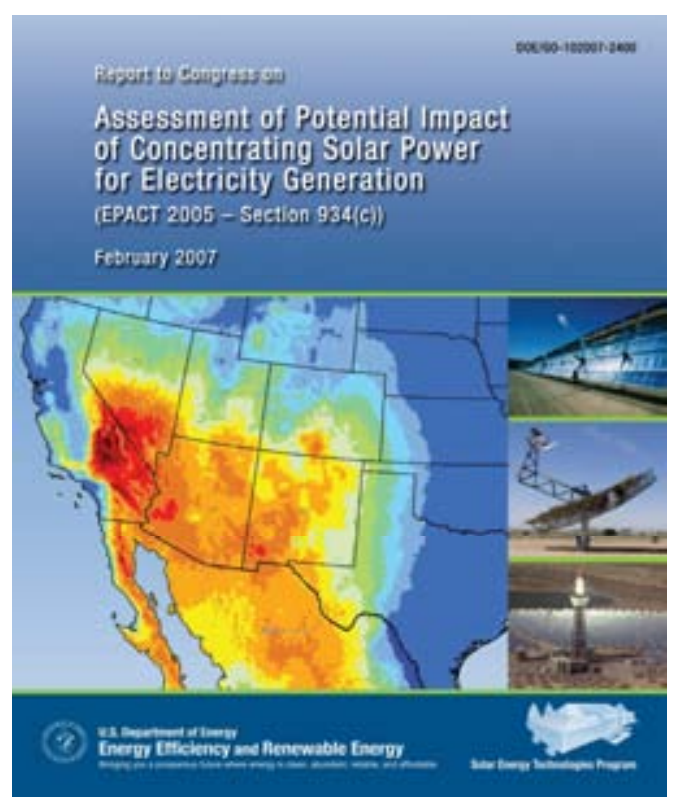

Fig. 2. The Solar Communications Team produced a variety of SETP documents in FY 2007, like the report to Congress shown above.

\subsection{SAI R\&D and Market Transformation}

- Designed a new solar program exhibit that emphasizes SAI and represented the program at two solar conferences: Solar 2007 (the annual ASES conference) and Solar Power 
2007 (the annual Solar Electric Power Association [SEPA] conference). We also developed a complementary sponsor banner and conference bag insert to promote SAI to Solar 2007 Conference attendees. At each conference, we spoke with conference attendees about SETP and SAI and directed them to the activities and resources appropriate to their interests.

- Participated in a review of proposals for the SAI State Technical Outreach, Utility Technical Outreach, and Solar America Cities partnerships and participated in two 2-day merit reviews.

- Participated in the Green Power Marketing Conference, in support of Utility Technical Outreach activities.

- Redesigned the SAI Web site, analyzing content by task and restructuring the information architecture to include project pages, so activities can be tracked and information kept current.

- Prepared and implemented a comprehensive Web site maintenance plan for the SAI site.

- Completed and published a number of print and electronic products to announce and publicize various SAl activities:

- Announced the State \& Utility Technical Outreach on the SAI Web site

- Added University and Exploratory Research Workshop content to the SAI Web site

- Developed a PV Incubator Cell \& Manufacturing Technology R\&D fact sheet and flyer

- Coordinated the Technology Pathway Partnership (TPP) award announcements for a media event and notified stakeholders through channels such as the Solar Energy Industries Association, SEPA, and the NCPV Hotline

- Prepared the February 2007 TPP Workshop Proceedings for posting on the SAI Web site

- Added For the Media and Awards sections to the SAI Web site

- Managed and developed the 2007 Solar America Cities announcement; developed a media plan for DOE and worked with GO to implement the plan (Secretary Bodman announced Solar America Cities, the PV Incubator, and highlights of TPP awards at the American Council on Renewable Energy's Wall Street Renewable Energy Finance Conference, and EERE Assistant Secretary Karsner made a second announcement at a New York solar event); developed the media kit and Web content and coordinated development of the welcome kit content for city awardees

- Assisted in completing the Solar America Showcase media kit and fact sheets for a kickoff activity.

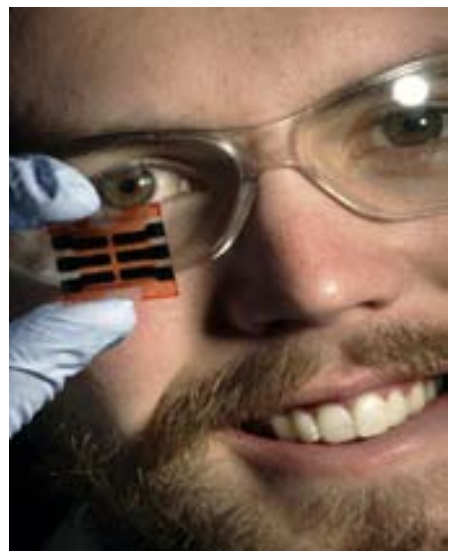

Fig. 3. The Solar Communications Team helped researchers tell the world about their new discoveries in 2007.

\subsection{Other SETP and NCPV Communications}

- Supported the NREL solar program and the NCPV by completing the FY 2007 Annual Operating Plan (AOP)

- Assisted Sarah Kurtz and Steve Eglash in strategic planning for the NCPV and prepared 10 Technology Roadmaps for use in AOP planning and other purposes. We also supported CSP strategic planning efforts by attending meetings as well as editing and preparing notes for dissemination

- Contributed to, edited, and/or produced more than 350 presentations (including numerous technical illustrations and graphics), technical reports, subcontract reports, journal articles, and conference papers and posters, including the presentations for the annual SETP Program Review and Trough Workshop.

- Completed an R\&D100 nomination package for R\&D Magazine on the High-Efficiency Metamorphic Multijunction Solar Cell developed by Spectrolab and NREL (this technology won the award); we also prepared material for the award banquet in Chicago.

- Created and updated exhibits for the new S\&T facility at NREL 
- Worked with NREL staff to develop a capital equipment plan for the Process Development Integration Laboratory.

- Supported NREL and DOE staff for various public and media events at NREL, and for visits by Congress, industry, and other dignitaries.

- Created a new Web site for the measurements and characterization work at NREL.

- We prepared and implemented a comprehensive Web site maintenance plan for the NREL PV Web site, including analysis of common Webmaster inquiries to streamline the response process. We also update the NREL News and Events databases with solarrelated content, and we continue to support posting and archiving of the NCPV Hotline.

- Because of our knowledge of solar technologies, we are asked to edit and/or write and produce various publications and projects, such as these:

- A key article on the history and development of III-V cells at NREL and their impact on industry and society for the Technology Transfer Annual Report

- A project for the NCPV on PV Conversion of Solar Energy for Terrestrial Applications

- A factsheet on Solar Energy and Air Quality for the Energy Analysis Office

- SAI poster for the Swedish Delegation and the Prime Minister's visit to NREL.

- We completed all preparations for Solar Decathlon 2007, including:

- Writing a statement of work for an event management request for proposals and participating in the selection of the contractor; also, working extensively with the contractor to prepare for the event

- Taking on sponsor relations, ensuring that their logistical needs and general participation worked smoothly

- Preparing all publications and products in anticipation of and for the event; updating and publishing the 2007 Rules and Regulations; producing and updating the pre-event brochure, posters, and various flyers; interviewing all 20 teams for the 36page competition program; preparing extensive content for signage in the village; and providing most of the content for the media kit.

- Developing a design for the Solar Decathlon home page and new subsites, such as the blog and photo database; updating all content to make it current for the event.

\section{Planned FY 2008 Activities}

- SETP Programmatic Communications-SETP management requires a variety of communications products to report its activities and results to audiences such as government, nongovernmental organizations (NGOs), the solar industry, the buildings industry, and consumers. Through management reports, Web sites, publications, and exhibiting, the Solar Communications Team will deliver messages about SETP's activities and technologies to these critical audiences. Solar Energy Technologies Programmatic Communications includes the support of SAI R\&D activities, such as Future Generation PV, PV Incubator, Technology Pathway Partnerships, and University PV Product and Process Development.

- SAl Market Transformation-SAl's market transformation activities include the Solar America Board of Codes \& Standards, Solar America Cities and Showcases, and State and Utility Technical Outreach. As these activities progress toward implementation, there is a need to ensure that the communications needs of those activities are met in an overarching way. Market transformation requires a great deal of cooperation and collaboration between a variety of participants. The interdependent nature of this work requires communications tools internal to each project, and we must also continue to develop the capacity to report the progress and successes of various projects to all relevant stakeholders.

- PV Program Management CommunicationsSolar program management at NREL and SNL requires a variety of products to report its activities to audiences such as NREL, SNL, and DOE management, government, NGOs, the solar and buildings industries, and consumers. Through management reports, Web sites, publications, and exhibiting, the Solar Communications Team delivers messages about these activities and technologies to critical audiences.

- NREL/SNL Technology- and Activity-Specific Communications-These communications activities are not represented in the technical outreach agreements in the Corporate Planning System (CPS), but it is important to acknowledge each NREL and SNL SETP activity submitted in the FY 2008 AOP and represented in CPS. Each activity explicitly or implicitly represents needs that are met by the Solar Communications Team. 


\section{FY 2007 Special Recognitions and Awards}

The Society of Technical Communicators conferred a 2007 Award of Excellence in the Online Competition for the TroughNet Parabolic Trough Solar Power Network. TroughNet is a technical resource for the evaluation of parabolic trough solar power plant technologies. The project was completed in FY 2006, but the award was given in FY 2007.

\section{Major FY 2007 Publications}

D. Gwinner et al., "DOE Solar Energy Technologies Program Newsletter," published on SETP Web site only, July-October (2007).

D. Gwinner et al., Report to Congress: Assessment of the Potential Impact of Concentrating Solar Power for Electricity Generation, DOE/GO-102007-2400, 33 pp., February (2007).

S. Moon et al., DOE Solar Energy Technologies Program: FY 2006 Annual Report, DOE/GO102007-2436, 214 pp., July (2007).

S. Moon et al., Powered by the Sun-2007 Solar Decathlon. Competition Program, DOE/GO102007-2459, 40 pp., September (2007).

S. Pedigo et al., About the Solar America Initiative, Solar America Initiative, DOE/GO-102007-2444, 2 pp., June (2007).
S. Pedigo et al., In Focus-The Buildings Industry, Solar America Initiative, DOE/GO-102007-2389, 2 pp., January (2007).

S. Pedigo et al., PV Incubator Awards, Solar America Initiative, DOE/GO-102007-2445, 2 pp., June (2007).

S. Pedigo et al., The Role of Utilities, Solar America Initiative, DOE/GO-102006-2369, 2 pp., October (2006).

S. Pedigo et al., Solar America Initiative Across America, Solar America Initiative, DOE/GO102007-2443, 2 pp., June (2007).

S. Pedigo et al., 2007 Solar America Cities Awards, Solar America Initiative, DOE/GO102007-2441, 2 pp., June (2007).

S. Pedigo et al., Solar America Initiative Web site, redesign completed in September (2007). http://www.eere.energy.gov/solar/solar america.

S. Pedigo, S. Moon, and W. Bower, "Photovoltaic Technology Status and Prospects in the United States," International Energy Agency Photovoltaic Power Systems Programme-Annual Report 2006, May (2007).

L. Poole et al., Improving Air Quality with Solar Energy, DOE Clean Energy and Air Quality Integration Initiative Fact Sheet Series, NREL/FS670-42169, September (2007). 


\title{
International Activities
}

\author{
Performing Organizations: National Renewable Energy Laboratory (NREL) \\ Sandia National Laboratories (SNL)
}

Key Technical Contacts: $\quad$ Ruby Nahan (NREL), 303-384-7401, ruby_nahan@nrel.gov Ward Bower (SNL), 505-844-5206, wibower@sandia.gov

DOE HQ Technology Manager: Tom Kimbis, 202-586-7055, tom.kimbis@ee.doe.gov

FY 2007 Budgets: $\quad$ \$150K (NREL), \$130K (SNL)

\section{Objectives}

- Understand the drivers associated with international growth in photovoltaic (PV) sales.

- Help Solar America Initiative (SAI) stakeholders with market development lessons in international growth.

- Determine the performance of PV products abroad.

- Help U.S. industry bring more affordable and reliable PV technology to the global marketplace.

- Execute DOE commitments in international agreements and activities.

\section{Accomplishments}

- Supported participation in both International Energy Agency (IEA) Task 9, "Coordination of Renewable Energy Training and Certification Activities," and IEA Task 10, "Urban Scale PV Applications."

- Drawing from insights and information gained as a result of participation in IEA tasks, developed solar technical assistance package for large-scale installations (Solar America Showcase) and city projects (City Strategic Partnerships) that use new solar technologies with the potential of achieving DOE cost goals.

- $\quad$ Presented updates on the U.S. solar industry at IEA meetings in Athens, Greece; Madrid, Spain; and Ebeltoft, Denmark.

\section{Future Directions}

- Execute SAI Market Transformation activities (e.g., technical assistance, acceptance testing, performance evaluations) to get new solar technologies developed through SAl's Technology Pathway Partnerships adopted by the U.S. and international marketplace.

- Devise specific ways to overcome newly IEA-identified barriers to international market transformation that may be associated with lack of consumer confidence, inadequate training, poor technology performance, regulatory obstacles, and high cost.

- Support participation in IEA Task 10, "Urban Scale PV Applications," for which the United States is the operating agent (NREL) and IEA Task 1, "Exchange and Dissemination of Information of Photovoltaic Power Systems" (NREL and SNL).

\section{Introduction}

The primary mission is to continually learn from the international adoption of solar technologies and improve U.S. solar technologies sold domestically and abroad. Because Germany, Japan, and Europe continue to drive the growth of the solar market, our task included: keeping current on why this is happening, understanding policy impacts, sharing this information, and determining how to improve U.S. PV product performance at a lower cost. Through our IEA involvement, as well as our strategic planning exercise, our team members also tried to provide timely data on emerging markets, nurture relationships with key manufacturers and integrators abroad, and distribute this information, where appropriate, to the U.S. solar industry. 


\section{Technical Approach}

DOE's international activities have involved NREL, SNL, and multiple university and corporate partners. This multi-institutional approach has focused on gathering useful field information in the United States and abroad on solar technology adoption (or rejection), conducting analysis on why this happened, and doing field performance assessments to determine how and why specific deployed solar systems are behaving in a particular manner. This information has then been disseminated to the DOE solar R\&D community through written reports, technical papers, posters, and briefings.

Based on our newly developed strategic plan, we enumerated four strategies to carry out this technical approach:

1. Contribute international market and system data for improved modeling and analysis.

2. Provide market information to DOE to increase the competitive edge for the U.S. solar industry.

3. Use international experience as a surrogate for U.S. market development.

4. Contribute to improved performance and reliability for U.S. solar products using international systems application samples for testing and monitoring.

\begin{tabular}{|l|c|}
\hline \multicolumn{1}{|c|}{ Task Title } & $\begin{array}{c}\text { FY 2007 } \\
\text { Budget (\$K) }\end{array}$ \\
\hline PV International (NREL) & 150 \\
\hline PV International (SNL) & 130 \\
\hline
\end{tabular}

\section{Results and Accomplishments}

Our multi-institutional team worked hand-in-hand with staff at the DOE Solar Program to define and detail the planned Solar America Initiative (SAI) Technology Acceptance activities. These activities are focused on reducing market barriers and transforming the market for wider use of solar energy technologies in the United States. This work included our team's participation in multiple Technical Exchange Meetings to solicit and garner input from U.S. industry, consumers, and state and local government officials on these new activities. All of this input-including relevant elements of the recently published international strategic plan-were then incorporated by DOE into a wider Technology Acceptance plan. This became our new guide for future activities, and the plan was used as the substantive basis for the first, second, and ongoing third round of funding opportunity announcements in Technology Acceptance.

- Presented the Task 10 status report at the IEA 29th PV Power Systems Operating Agents Meeting, hosted by the European PV Industry Association, and attended the Executive Committee Meeting, April 14-20, 2007, in Athens, Greece.

- Completed the U.S. annual contribution to the IEA Annual Report for PV Technology Status in the United States. The U.S. submission is a summary of R\&D, policy, U.S. industry, and DOE program accomplishments for 2006.

- Completed the IEA country report and presentation for the IEA ExCo Meeting in South Korea.

- Completed the U.S. country report and presentation for the IEA Executive Committee meeting held in Zaragoza, Spain.

- Reviewed and revised the final IEA National Survey Report written for IEA Task 1.

- $\quad$ Attended the annual IEA PVPS Task I meeting in Zacatecas, Mexico, and gave presentation on the state of the PV industry and policy issues for a colloquium hosted by Zacatecas State government and the United Nations.

\section{Ongoing and Planned FY 2008 Activities}

SAI represents a change from DOE's past international activities to present and future activities focused on markets and applications that can result in wider utilization of solar technologies in the United States. This transformation is well under way and consists of the following activities conducted by our team:

- Organization and formation of tiger teams for provision of technology assistance and sharing of solar knowledge gleaned from the field among the DOE solar R\&D community.

- Development of specific ways to overcome identified market barriers (e.g., lack of consumer confidence, inadequate training, poor technology performance, regulatory obstacles, and high cost).

- Continuation of support for U.S. participation in IEA Task 10, "Urban Scale PV Applications," and IEA Task 1, "Exchange and Dissemination of Information on Photovoltaic Power Systems."

- Continuation of support for SAI market transformation teams with task results through either workshops webinars or conferences. 
- Facilitation of IEA in North America/Pacific rim meetings conferences and information exchange.

\section{Major FY 2007 Publications}

C. Herig, "Bi-annual Report for FY 2007 IEA PV Power Systems Task 10: Operating Agent," AprilAugust 2007.

\section{University and Industry Partners}

The following organizations partnered in the project's research activities during FY 2007 (no cost share).

\begin{tabular}{|l|l|l|c|}
\hline \multicolumn{1}{|c|}{$\begin{array}{c}\text { Organization/ } \\
\text { Principal Investigator }\end{array}$} & \multicolumn{1}{c|}{ Location/e-mail } & \multicolumn{1}{c|}{$\begin{array}{c}\text { Description/Title of Research } \\
\text { Activity }\end{array}$} & $\begin{array}{c}\text { FY 2007 } \\
\text { (\$K) }\end{array}$ \\
\hline $\begin{array}{l}\text { Segue Energy Consulting, LLC } \\
\text { Christy Herig }\end{array}$ & $\begin{array}{l}\text { Redington Shores, FL } \\
\text { cherig@tampabay.rr.com }\end{array}$ & $\begin{array}{l}\text { IEA PV Power Systems Task 10 } \\
\text { (Urban PV) Support }\end{array}$ & 109 \\
\hline $\begin{array}{l}\text { Institute for Sustainable Power } \\
\text { Roger Taylor }\end{array}$ & $\begin{array}{l}\text { Evergreen, CO } \\
\text { roger_taylor@nrel.gov }\end{array}$ & $\begin{array}{l}\text { Coordination of Renewable } \\
\text { Activities and Support of IEA Task } \\
\text { 9 Activities }\end{array}$ & 38.8 \\
\hline
\end{tabular}




\title{
Small Business Innovation Research
}

\author{
Performing Organization: $\quad$ DOE HQ Solar Energy Technologies Program
}

DOE HQ Technology Manager: Alec Bulawka, 202-586-5633, alec.bulawka@ee.doe.gov

FY 2007 Budget: $\quad$ \$2,093K

\section{Objectives}

- Support small business energy R\&D.

- Implement Executive Order 13329, which involves assisting the private sector in manufacturing innovation.

- Continue to pursue wise cost/benefit investments.

- Augment the core research of the DOE Solar Program.

- Support effectively the Solar America Initiative.

\section{Accomplishments}

- Developed a PV system designed for $\mathrm{H} 2$ production by electrolysis with the goal of reducing the cost of large-scale PV-generated H2 production. (project began in 2005 and finished in 2007)

- Adapted metallurgical techniques for purifying silicon much more cheaply than the standard process, to produce a cheaper grade of silicon for photovoltaics (PV), and developed a reusable crucible for Silicon ingot casting for PV. (project began in 2004 and finished in 2007)

\section{Future Directions}

- Focus on material and process cost-saving techniques, as well as associated manufacturing diagnostics for manufacturing solar/PV (silicon and other thin films, as well as organics).

- Seek new solar concentrator structural (non-cell) designs for ease of manufacturing and cost reduction.

- Incorporate emerging innovative ways to use waste thermal energy in PV concentrators' electric output.

- Continue aggressive pursuit of organic PV solar cells incorporating nanotechnology.

- Achieve significant cost reduction in manufacture of crystalline silicon PV products.

- Seek effectiveness in PV-powered, renewable, hydrogen production as storage for PV energy.

- Focus on cost reduction via improvement of non-cell mechanical ancillary hardware.

\section{Introduction}

Each year, ten federal departments and agencies (including DOE) are required by the Small Business Innovation Research (SBIR) Program to reserve a portion of their R\&D funds for award to small, U.S.owned businesses. Over the life of the SBIR Program, the Solar Program has contributed \$16 million and received $\$ 34$ million in research funding.

The Solar Program has also benefited to a large extent from the Office of Basic Energy Sciences contribution in nanotechnology topics for PV in 2006. The 2007 Solar Program is nested mainly in the Renewable Energy Sources SBIR category (Topic 2). SBIR activities fit very nicely into the DOE Solar Program Multi-Year Technical Plan, because they continue to augment and support the core program, in all aspects, with integrated solutions from the vast U.S. small business community. Also, this year, the community has the opportunity to partake actively in the Solar America Initiative (SAI) through carefully selected and tailored supportive solicitations.

\section{Technical Approach}

Renewable energy technologies have achieved significant advances in recent years, but further improvements are needed if they are to reach their full potential. The solar technologies included in the scope of this SBIR work address both solar electric (photovoltaic or PV) and concentrating solar power (CPS) systems. Grant applications for FY 2007 were required to clearly demonstrate the applicants' 
ability to proceed to hardware development, fabrication, testing and manufacture of technologies.

\section{Results and Accomplishments}

Several SBIR awards advanced their goals and produced very encouraging results of their R\&D to date. (See table below.)

\section{Planned FY 2008 Activities}

Further development of PV and CSP systems will be addressed through creative and innovative approaches in engineering and design, and new materials and processes. A concerted effort has been made to have the SBIR activity dovetail in support of the SAI.

\subsection{Monitoring and Self-Diagnosing PV Systems,} Components, and Modules

Reliability is particularly important for new module and inverter technologies. Innovative methods will be sought to monitor PV system and component performance and to relate performance to actual weather, so as to ascertain failure and loss mechanisms as quickly as possible. Such monitoring and diagnostics can be embedded in system components resulting in, for example, state-of-health system sensors, smart metering, load-management controllers, and smart inverters.

\subsection{PV (Crystalline Silicon and Thin Film)} Manufacturing Diagnostics

Diagnostic technologies will be sought to improve yield and reduce cost of crystalline silicon PV manufacturing of cells and modules. Focus will be on identification and resolution of wafer stress and wafer cracks, wafer-handling technologies in production, improved interconnect technologies for wafer assembly, stress management, and improved manufacturing data tracking. Also, diagnostic and control technologies to improve yield, increase materials utilization, and reduce the cost of thin-film PV module manufacturing will be pursued.

4.3 Non-Inverter Balance-of-System (BOS) Components and Net-Metering Technologies

This effort involves improving non-inverter BOS components for PV applications for grid-interactive systems. Customized circuit breakers, simplified or standardized wiring methodologies for buildingintegrated PV applications, junction boxes and innovative inter-array wiring, as well as mounting methodologies and installation concepts, will be pursued. State-of-system health monitoring capabilities, system-predictive monitoring, and safety and logic controls for complete system code and standards compliance will also be solicited. These are only some examples of a vast complement of ancillary needs.

\subsection{Non-Cell Concentrator Photovoltaic System Components}

With the development of the high-efficiency (40\%) multijunction solar cell, concentrating PV (CPV) systems will become much more cost effective. The SBIR focus will shift to innovation in optical concentration designs (refractive, reflective, and holographic concepts). Tracking structures, control logic, torque leveraging, gears, hydraulics, and wind-loading protection schemes will now be addressed. Reduction of costly steel content (yet maintaining structural integrity), avoidance of mechanical resonances under wind loading, and innovative ideas in cell cooling will also get attention. Integrated CPV concepts, building CPV, and luminescent concentration are also on the agenda.

\section{Major FY 2007 Publications}

The SBIR Program holds the awardee responsible for a final report at the end of both Phase 1 and Phase 2. The SBIR Office in Germantown, MD, has on file the final reports of all the projects awarded in the past.

\section{University and Industry Partners}

The following organizations partnered in the project's research activities during FY 2007.

\begin{tabular}{|l|l|l|}
\hline $\begin{array}{c}\text { Organization/ } \\
\text { Principal } \\
\text { Investigator }\end{array}$ & \multicolumn{1}{|c|}{ Location/e-mail } & Description/Title of Research Activity \\
\hline $\begin{array}{l}\text { Luna Innovations, } \\
\text { Inc. }\end{array}$ & $\begin{array}{l}\text { Roanoke, VA } \\
\text { kocherginv@lunainnovations.com }\end{array}$ & $\begin{array}{l}\text { Develop an in-line high-throughput PV } \\
\text { manufacturing diagnostic system capable of }\end{array}$ \\
\hline
\end{tabular}




\begin{tabular}{|c|c|c|}
\hline $\begin{array}{l}\text { Dr. Vladimir } \\
\text { Kochergin }\end{array}$ & & $\begin{array}{l}\text { fast and accurate identification of the } \\
\text { distribution of stress and coating uniformity, } \\
\text { allowing improved process control, } \\
\text { increased yield and reduced cost. }\end{array}$ \\
\hline $\begin{array}{l}\text { Ultrasonic } \\
\text { Technologies, Inc. } \\
\text { Sergei Ostapenko }\end{array}$ & $\begin{array}{l}\text { Wesley Chapel, Florida } \\
\text { sergei.ostapenko@ultrasonictech.com }\end{array}$ & $\begin{array}{l}\text { Justify a commercial prototype of the } \\
\text { proprietary Resonance Ultrasonic Vibrations } \\
\text { (RUV) system for use as a real-time in-line } \\
\text { automatic process control tool for } \\
\text { identification and rejection from a solar cell } \\
\text { production line }\end{array}$ \\
\hline $\begin{array}{l}\text { Advanced Cooling } \\
\text { Technologies, Inc. }\end{array}$ & $\begin{array}{l}\text { Lancaster, PA } \\
\text { info@1-ACT.com }\end{array}$ & $\begin{array}{l}\text { Use heat pipe technology to efficiently } \\
\text { remove the heat from the device } \\
\text { overcoming a key hurdle to improving the } \\
\text { overall system level efficiency. }\end{array}$ \\
\hline Luminit, LLC & $\begin{array}{l}\text { Torrance, CA } \\
\text { kyu@luminitco.com }\end{array}$ & $\begin{array}{l}\text { Develop a new thin, chromatic dispersion } \\
\text { corrected, high efficiency, rugged, and low- } \\
\text { cost flexible spectrum splitting holographic } \\
\text { concentrator (SSHOC). }\end{array}$ \\
\hline $\begin{array}{l}\text { SVV Technology } \\
\text { Innovations Inc. } \\
\text { Dr. Sergey Vasylyev }\end{array}$ & $\begin{array}{l}\text { McClellan, CA } \\
\text { vasilyev@svvti.com }\end{array}$ & $\begin{array}{l}\text { Improve the sunlight concentration and } \\
\text { optical efficiency in photovoltaic modules } \\
\text { through the use of a novel reflective lens } \\
\text { concept. }\end{array}$ \\
\hline Nanosolar, Inc. & $\begin{array}{l}\text { Palo Alto, CA } \\
\text { bsager@nanosolar.com }\end{array}$ & $\begin{array}{l}\text { Construct foil-based solar cells with a } \\
\text { relative } 25 \% \text { increased active-area power } \\
\text { conversion efficiency. }\end{array}$ \\
\hline $\begin{array}{l}\text { TDA Research, Inc. } \\
\text { Michael D. Diener }\end{array}$ & $\begin{array}{l}\text { Wheat Ridge, CO } \\
\text { mikee@tda.com }\end{array}$ & $\begin{array}{l}\text { Develop new fullerene-based n-type } \\
\text { materials for solvent- processable low-cost } \\
\text { organic photovoltaics (OPV). }\end{array}$ \\
\hline MWOE Solar, Inc. & Toledo, $\mathrm{OH}$ & $\begin{array}{l}\text { Develop process that will interconnect the } \\
\text { cells after all thin-film deposition steps are } \\
\text { complete, by utilizing a sequence of ink-jet } \\
\text { printing and scribing steps. }\end{array}$ \\
\hline NanoSonic, Inc. & $\begin{array}{l}\text { Blacksburg, VA } \\
540-953-1785 \text { (phone) }\end{array}$ & $\begin{array}{l}\text { Develop flexible mirror technology } \\
\text { And environmental coating materials for the } \\
\text { mirror surfaces. }\end{array}$ \\
\hline $\begin{array}{l}\text { GT Solar, Inc. } \\
\text { Dr. P. Santhana } \\
\text { Raghavan }\end{array}$ & $\begin{array}{l}\text { Merrimack, } \mathrm{NH} \\
\text { raghavan@gtsolar.com }\end{array}$ & $\begin{array}{l}\text { Develop low cost processes for producing } \\
\text { crystalline (multicrystalline and single } \\
\text { crystal) silicon ingots and use of reusable } \\
\text { crucibles. }\end{array}$ \\
\hline $\begin{array}{l}\text { MetroLaser, Inc. } \\
\text { Bauke Heeg }\end{array}$ & $\begin{array}{l}\text { Irvine, CA } \\
\text { bheeg@metrolaserinc.com }\end{array}$ & $\begin{array}{l}\text { Develop process to provide a direct means } \\
\text { to extract energy from waste heat as well as } \\
\text { from solar radiation. }\end{array}$ \\
\hline $\begin{array}{l}\text { GT Solar, Inc. } \\
\text { Dr. P. Santhana } \\
\text { Raghavan }\end{array}$ & $\begin{array}{l}\text { Merrimack, } \mathrm{NH} \\
\text { raghavan@gtsolar.com }\end{array}$ & $\begin{array}{l}\text { Produce solar grade polysilicon directly } \\
\text { from metallurgical grade silicon (MGSi). }\end{array}$ \\
\hline $\begin{array}{l}\text { Crystal Systems, } \\
\text { Inc. } \\
\text { Dr. David B. Joyce }\end{array}$ & $\begin{array}{l}\text { Salem MA } \\
\text { djoyce@crystalsystems.com }\end{array}$ & $\begin{array}{l}\text { Adapted metallurgical techniques for } \\
\text { purifying silicon much more cheaply than } \\
\text { the standard process, to produce a cheaper } \\
\text { grade of silicon for photovoltaics (PV). }\end{array}$ \\
\hline $\begin{array}{l}\text { UQM Technologies, } \\
\text { Inc. }\end{array}$ & $\begin{array}{l}\text { Frederick, CO } \\
303-278-2002\end{array}$ & $\begin{array}{l}\text { Improve power density and reliability for } \\
\text { next-generation, grid-capable inverter } \\
\text { technology. }\end{array}$ \\
\hline Amonix & $\begin{array}{l}\text { Torrance, CA } \\
\text { info@amonix.com }\end{array}$ & $\begin{array}{l}\text { Develop a PV system designed for } \mathrm{H} 2 \\
\text { production by electrolysis. The project's } \\
\text { aim was to reduce the cost of large-scale } \\
\text { PV-generated } \mathrm{H} 2 \text { production. }\end{array}$ \\
\hline
\end{tabular}




\section{Funding Table}

Below are the complete budgets for specific NREL PV conversion technologies, referenced in the Fundamental Research section of the FY 2008 Annual Report.

\begin{tabular}{|c|c|c|}
\hline Conversion Technologies & Research Areas & FY07 Budget (\$K) Estimates \\
\hline \multirow[t]{7}{*}{ Wafer Silicon } & Silicon Materials \& Devices & 1,272 \\
\hline & Processes \& Advanced Concepts & 764 \\
\hline & Concentrator Crystalline Cells & 20 \\
\hline & Analytical Microscopy & 140 \\
\hline & Electro-Optical Characterization & 190 \\
\hline & Surface Analysis & 33 \\
\hline & TOTAL & 2,419 \\
\hline \multirow[t]{8}{*}{ Film Silicon } & Film Silicon & 1,272 \\
\hline & Thin-Film Polycrystalline Compounds & 137 \\
\hline & Processes \& Advanced Concepts & 509 \\
\hline & Concentrator Crystalline Cells & 20 \\
\hline & Analytical Microscopy & 80 \\
\hline & Electro-Optical Characterization & 40 \\
\hline & Surface Analysis & 33 \\
\hline & TOTAL & 2,091 \\
\hline \multirow[t]{5}{*}{ OPV } & Processes \& Advanced Concepts & 509 \\
\hline & Exploratory Research - OPV & 205 \\
\hline & Electro-Optical Characterization & 44 \\
\hline & Surface Analysis & 6 \\
\hline & TOTAL & 764 \\
\hline \multirow[t]{7}{*}{ CdTe } & Thin-Film Polycrystalline Compounds & 1,302 \\
\hline & Fundamental R\&D & 535 \\
\hline & Processes \& Advanced Concepts & 255 \\
\hline & Concentrator Crystalline Cells & 40 \\
\hline & Analytical Microscopy & 70 \\
\hline & Electro-Optical Characterization & 60 \\
\hline & $\overline{T \text { TOTAL }}$ & 2,262 \\
\hline
\end{tabular}




\begin{tabular}{|c|c|c|}
\hline Conversion Technologies & Research Areas & FY07 Budget (\$K) Estimates \\
\hline \multirow[t]{9}{*}{ CIGS } & Thin-Film Polycrystalline Compounds & 1,097 \\
\hline & Fundamental R\&D & 180 \\
\hline & Silicon Materials \& Devices & 30 \\
\hline & Processes \& Advanced Concepts & 509 \\
\hline & Concentrator Cyrstalline Cells & 60 \\
\hline & Analytical Microscopy & 70 \\
\hline & Electro-Optical Characterization & 44 \\
\hline & Surface Analysis & 120 \\
\hline & TOTAL & 2,110 \\
\hline \multirow[t]{7}{*}{$C P V$} & Concentrator Cyrstalline Cells & 2,229 \\
\hline & Fundamental R\&D & 405 \\
\hline & Analytical Microscopy & 40 \\
\hline & Electro-Optical Characterization & 36 \\
\hline & Surface Analysis & 27 \\
\hline & Cell and Module Performance & 62 \\
\hline & TOTAL & 2,799 \\
\hline
\end{tabular}




\section{Performing Organizations By Name}

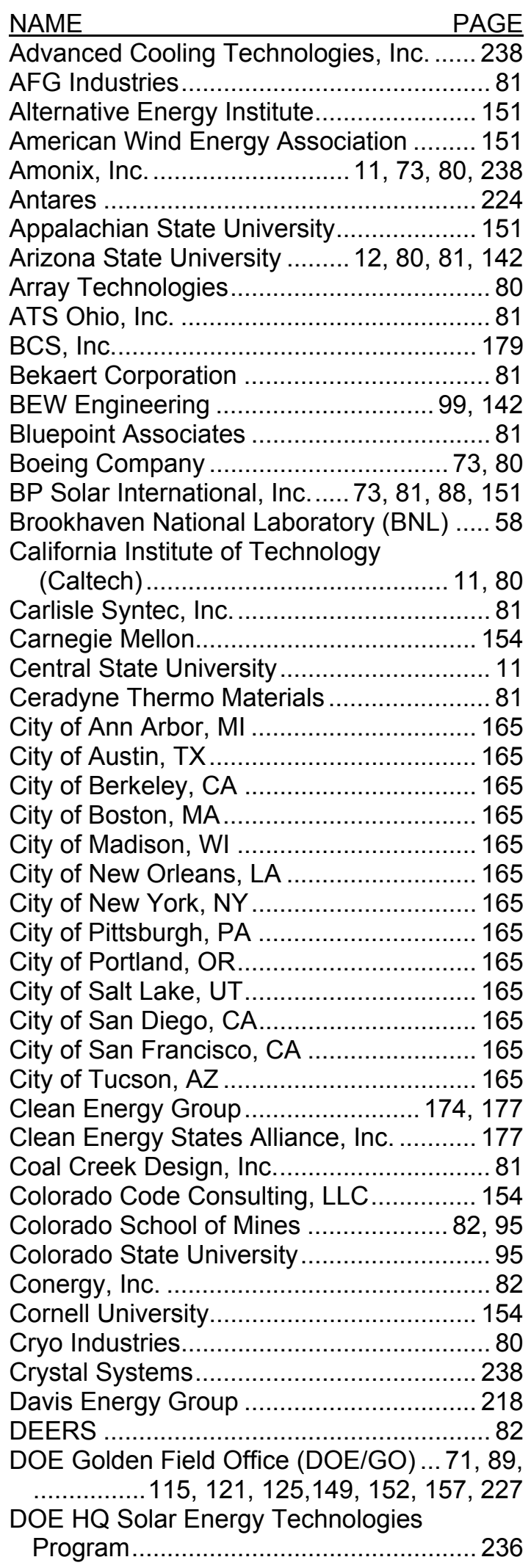

NAME

PAGE

Dow Chemical Company..................73, 81, 88

Dow Corning Corporation.................81, 82, 88

Duke University .......................................11

ECO Northwest .......................................102

Energy Conversion Devices, Inc.................82

Electric Power Research Institute ...............99

Energy Matters .........................................177

Energy Photovoltaics ................................95

Evergreen Solar, Inc. ................................. 88

Exeltech, Inc............................................... 81

FAFCO, Inc. .......................................218

Fat Spaniel Technologies, Inc....................81

Ferro Corporation ....................................... 81

First Solar, LLC ...................................88, 95

Fisk University .........................................82

Florida Solar Energy Center (FSEC) ...... 95, 117, 120, 124, 142, 164, 170, 171

Fronius USA, LLC ..................................81

General Electric (GE)

Company $73,81,88,99$

Georgia Institute of Technology

(Georgia Tech) ........................11, 81, 154

Georgia Tech Research Institute ...............81

Gilman, Paul..................................105, 196

Global Energy Decisions............................99

Global Solar Energy ..................................96

GreenRay, Inc....................................73, 81

GT Solar, Inc.........................................238

Home Power Magazine .............................151

Howard University ....................................11

International Brotherhood of Electrical

Workers (IBEW) ..................................151

IBIS Associates .......................................... 81

Imperial Irrigation District ............................80

Innovators................................................... 80

Institute for Sustainable Power .................235

Interstate Renewable Energy Council

(IREC) ............................... 142, 143, 151

Janzou Consulting...........................105, 196

Kansas State University ...........................154

Kearney and Associates ..........................208

Komax Systems, York ................................81

Konarka Technologies, Inc...................73, 81

Lawrence Berkeley National

Laboratory (LBNL) …...................100, 160

Light Prescriptions.......................................80

Luminit, LLC ..........................................238

Luna Innovations ......................................237

Madison Energy Consultants ....................177

Malaspina College....................................151

Massachusetts Institute of

Technology (MIT) ...........................82, 154 
NAME

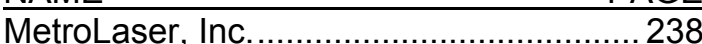

Miasolé, Inc............................................ 81

Midwest Renewable Energy Association . 151

Morse Associates, Inc ........................... 193

MWOE Solar, Inc................................. 238

Nanosolar

$73,82,96,238$

NanoSonic, Inc. ....................... 73, 96, 238

NASEO ............................................ 177

National Association of Regulatory

Utility Commissioners (NARUC).... 174, 177

National Conference of State

Legislatures (NCSL).

174,177

National Electrical Contractors

Association

National Joint Apprenticeship and

Training Committee 151

National Renewable Energy Laboratory

(NREL)......................... 4, 13, 20, 25, 30

$34,37,62,69,71,73,80,81,82,83,89$,

$97,100,103,111,115,125,131,137,141$, $151,152,157,160,162,170,171,178$,

184, 190, 191, 194, 201, 210, 227, 233

Navigant Consulting 99

New Mexico State University (NMSU)

.....120, 137, 142, 143, 148, 164, 170, 171

New York Institute of Technology 155

New York State Energy Research and

Development Authority (NYSERDA)148, 151

Nexant 208

Nimmons, John \& Associates, Inc. 177

North American Board of Certified

Energy Practitioners (NABCEP)... 148, 149

North Carolina A\&T State University .......... 11

North Carolina Central University .............. 11

North Carolina State University (NCSU)/

North Carolina Solar Center.... 11, 148, 151

Northern Plains Power.

106,110

Northwestern University

11

Oak Ridge National Laboratory (ORNL)... 219

Oregon State University 11

Pacific Northwest National Laboratory (PNNL). 96

Palo Alto Research Center... 81

Pennsylvania State University 11,155

PowerLight Corporation 88,151

PowerMark Corporation 114,142

Primestar Solar 24

PV Powered, Inc. 80,82

REC Silicon, Inc 81

Recticle UREPP N. America. 81

Sandia National Laboratories ....... 71, 73, 81, $81,82,97,103,106,111,118,121,125$, $137,142,151,162,170,171,190,191$, 194, 197, 201, 210, 227, 233

Santa Clara University. 155
NAME

PAGE

Sanyo Energy USA Corporation ................81

Satcon Technology Corporation .................82

SCHOTT Solar, Inc. .................................88

Segue Energy Consulting, LLC................235

Sharp Solar ..........................................151

Sherwood Associates..............................142

Shingleton Design LLC ............................8

Silicon Genesis Corporation.......................82

SMA America, Inc. ............................... 82

SMUD .................................................. 81

Solaicx, Inc...................................81, 82

Solar Electric Power Association

(SEPA)

174,177

Solar Energy International......................151

Solar Rating Certification Corporation ......151

Solar Systems .....................................189

SolarWorld Industries America .................88

SolFocus ......................................81, 189

Solectric Renewables LLC .......................82

Soliant Energy, Inc.............................73, 82

Sonenthal and Overall............................177

Southern California Edison ........................80

Southern University and A\&M College........11

Southwest Technology Development Institute (SWTDI) ............... 124, 148, 151

Specialized Technology

Resources, Inc

$78,81,82$

Spectrolab, Inc. $12,80,82$

Spire Corporation 88,130

State University of New York (SUNY),

Albany - Research Foundation .....137, 142

SunEarth 218

SunEdison 82,151

Sunlight Direct, LLC .............................224

Sunlink, LLC .......................................82

SunPower Corporation..... 73, 82, 88, 99, 151

Sunset Technologies............................114

Suntechnics Energy System, Inc. ...............82

SVV Technology Innovations, Inc. ............238

Syracuse University .................................8 82

Sylarus Technologies, LLC ....................80

TDA Research....................................238

Team Montreal ...................................155

Technische Universität Darmstadt ...........155

Texas A\&M University....................117, 155

Texas Tech ............................................. 12

Thermal Energy System Specialists, Inc. .218

Tucson Electric Power ....................137, 142

Underwriters Laboratories.................12, 142

Ultrasonic Technologies, Inc.................238

UQM Technologies, Inc.........................238

United Solar Ovonic .......................73, 82, 96

Universidad de Puerto Rico .....................155

University of Central Florida .......................81

University of Cincinnati.........................156 
University of Colorado at Boulder. 12, 81, 155

University of Delaware........................ 12, 81

University of Illinois ................................... 156

University of Maryland .............................. 156

University of Minnesota ........................... 218

University of Missouri - Rolla ................... 156

University of Nevada, Las Vegas

(UNLV).

80,96

University of Oregon ......................12, 82, 96

University of South Florida .........................96

University of Tennessee ............................ 224

University of Texas at Austin .................... 156

University of Texas at Brownsville.............. 12

University of Texas at El Paso..................... 12

University of Toledo..............................12, 96

University of Utah ................................... 96

University of Wisconsin, Madison..... 105, 196

Xantrex Technologies, Inc........ 80, 81, 82, 88 


\section{Performing Organizations By State/Country}

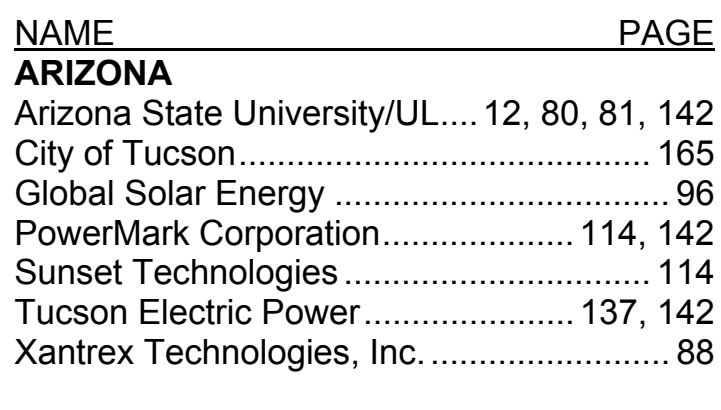

AUSTRALIA

Solar Systems 189

\section{CALIFORNIA}

Amonix, Inc. $11,73,80,238$

Array Technologies 80

Bekaert Corporation

BEW Engineering ....

Bluepoint Associates

Boeing Company

California Institute of Technology

(Caltech)....

City of Berkeley, CA ....

City of San Diego, CA.....

City of San Francisco, CA

Davis Energy Group

DEERS

Electric Power Research Institute $\quad 99$

FAFCO, Inc......................................... 218

Fat Spaniel Technologies, Inc. ................... 81

Imperial Irrigation District...

Lawrence Berkeley National

Laboratory (LBNL)

Light Prescriptions

100,160

Luminit, LLC.

238

MetroLaser, Inc.

238

Miasolé, Inc

81

Nanosolar

$73,82,96,238$

Navigant Consulting

99

Nexant

208

Palo Alto Research Center

.81

PowerLight Corporation. 88

Primestar Solar 24

Santa Clara University..... 155

Silicon Genesis Corporation.....

82

SMA America, Inc.

82

SMUD 81

Solaicx, Inc. 81,82

SolarWorld Industries America

SolFocus .88

Soliant Energy, Inc. 81,189

Southern California Edison....
NAME

PAGE

Spectrolab, Inc............................12, 80, 82

SunEarth ...............................................218

Sunlink, LLC ........................................... 82

SunPower Corporation..... 73, 82, 88, 99, 151

Suntechnics Energy System, Inc. ...............82

SVV Technology Innovations, Inc. ............238

Xantrex Technologies, Inc........ 80, 81, 82, 88

\section{CANADA}

Malaspina College. 151

Team Montreal ..... 155

Xantrex Technologies, Inc $80,81,82$

\section{COLORADO}

Coal Creek Design .81

Colorado Code Consulting, LLC ...............154

Colorado School of Mines .....................82, 95

Colorado State University ..........................95

DOE Golden Field Office (DOE/GO).....71, 89 $115,121,125,149,152,157,227$

Global Energy Decisions.... . .99 Institute for Sustainable Power .................235 Janzou Consulting............................105, 196

National Conference of State

Legislatures (NCSL)... 174,177

National Renewable Energy Laboratory

(NREL) ....................... 4, 13, 20, 25, 30 $34,37,62,69,71,73,80,81,82,83,89$, $97,100,103,111,115,125,131,137,141$, $151,152,157,160,162,170,171,178$, 184, 190, 191, 194, 201, 210, 227, 233

Sherwood Associates..............................142

Solar Energy International........................151

TDA Research.........................................238 University of Colorado at Boulder .12, 81, 155 UQM Technologies 238

\section{CONNECTICUT}

Specialized Technology

Resources, Inc. $78,81,82$

\section{DELAWARE}

General Electric (GE)

Company..... $73,81,88,99$

University of Delaware 12,81

\section{DISTRICT OF COLUMBIA}

American Wind Energy Association 151

DOE HQ Solar Energy Technologies

Program 236 
NAME

PAGE

Energy Matters .................................... 177

Howard University.................................... 11

International Brotherhood of Electrical

Workers (IBEW) 151

Madison Energy Consultants................... 177

Morse Associates, Inc ............................ 193

NASEO ................................................. 177

National Association of Regulatory

Utility Commissioners (NARUC).... 174, 177

National Joint Apprenticeship and

Training Committee 151

Nimmons, John \& Associates, Inc.

Solar Electric Power Association (SEPA)

174,177

Sonenthal and Overall 177

\section{FLORIDA}

Florida Solar Energy Center (FSEC) $95,117,120,124,142,164,170,171$

Segue Energy Consulting, LLC ................ 235

Solar Rating Certification Corporation (SRCC) 151

Ultrasonic Technologies, Inc. 238

University of Central Florida 81

University of South Florida 96

\section{GEORGIA}

Ceradyne Thermo Materials 81

Georgia Institute of Technology

(Georgia Tech) .......................11, 81, 154

Georgia Tech Research Institute.... 81

\section{GERMANY}

Technische Universität Darmstadt. 155

ILLINOIS

Gilman, Paul 105, 196

Northwestern University 11

Underwriters Laboratories 12,142

University of Illinois 156

\section{KANSAS}

Kansas State University 154

LOUISIANA

City of New Orleans, LA 165

Southern University and A\&M College

MAINE

Cryo Industries 80

\section{MARYLAND}

Antares 224

BCS, Inc 179

BP Solar International, Inc. $73,81,88$
NAME PAGE

National Electrical Contractors

Association. 151

SunEdison

82,151

University of Maryland 156

MASSACHUSETTS

City of Boston, MA 165

Crystal Systems 238

Evergreen Solar, Inc. .88

GreenRay, Inc. 73,81

IBIS Associates ....81

Konarka Technologies, Inc...................73, 81

Massachusetts Institute of Technology

(MIT) 82,154

Satcon Technology Corporation ..................82

SCHOTT Solar, Inc. 88

Solectric Renewables LLC .........................82

Spire Corporation 88,130

\section{MICHIGAN}

City of Ann Arbor, MI 165

Dow Chemical Company $73,81,88$

Dow Corning Corporation. $81,82,88$

Energy Conversion Devices, Inc. .82

Fronius USA, LLC .... 81

Recticle UREPP N. America

United Solar Ovonic $.73,82,96$

\section{MINNESOTA}

University of Minnesota 218

\section{MISSOURI}

University of Missouri - Rolla. 156

\section{NEVADA}

University of Nevada, Las Vegas

(UNLV) $.80,96$

\section{NEW HAMPSHIRE}

GT Solar, Inc. 238

\section{NEW JERSEY}

Energy Photovoltaics 95

Sharp Solar 151

\section{NEW MEXICO}

Conergy, Inc. 82

Innovators 80

New Mexico State University (NMSU) .. 120, 137, 142, 143, 148, 164, 170, 171 Sandia National Laboratories.........71, 73, 81, $81,82,97,103,106,111,118,121,125$, $137,142,151,162,170,171,190,191$, $194,197,201,210,227,233$ 
NAME

Southwest Technology Development

Institute (SWTDI)... $124,148,151$

\section{NEW YORK}

Brookhaven National Laboratory (BNL) .....58

City of New York, NY 165

Cornell University 154

General Electric (GE)

Company

$73,81,88,99$

Interstate Renewable Energy Council

(IREC) $142,143,151$

New York Institute of Technology....

New York State Energy Research and

Development Authority (NYSERDA)148, 151

North American Board of Certified

Energy Practitioners (NABCEP)... 148, 149

Shingleton Design LLC. .88

State University of New York (SUNY),

Albany - Research Foundation..... 137, 142

Syracuse University....

\section{NORTH CAROLINA}

Appalachian State University 151

Duke University 11

North Carolina A\&T State University 11

North Carolina Central University 11

North Carolina State University (NCSU)/

North Carolina Solar Center.... 11, 148, 151

OHIO

ATS Ohio, Inc 81

Central State University. 11

Ferro Corporation 81

First Solar, LLC. 8,95

MWOE Solar, Inc. 238

Sylarus Technologies, LLC. 80

University of Cincinnati 156

University of Toledo 12,96

\section{OREGON}

City of Portland, OR 165

ECO Northwest. 102

Home Power Magazine 151

PV Powered, Inc. 80,82

Oregon State University

University of Oregon $12,82,96$

\section{PENNSYLVANIA}

Advanced Cooling Technologies, Inc. ...... 238

Carlisle Syntec, Inc.................................. 81

Carnegie Mellon University........................ 154

City of Pittsburgh, PA .............................. 165

Komax Systems, York ............................... 81

Pennsylvania State University ............11, 155
NAME

PUERTO RICO

Universidad de Puerto Rico

PAGE 155

\section{SOUTH DAKOTA}

Northern Plains Power 106,110

\section{TENNESSEE}

AFG Industries

Fisk University 11,82

Oak Ridge National Laboratory (ORNL) ...219

Sunlight Direct, LLC .................................224

University of Tennessee............................224

\section{TEXAS}

Alternative Energy Institute 151

City of Austin, TX 165

Concurrent Designs 144

Exeltech, Inc. .81

Sanyo Energy USA Corporation .81

Texas A\&M University 115,155

Texas Tech .12

University of Texas at Austin.....................156

University of Texas at Brownsville ..............12

University of Texas at El Paso

.12

\section{UTAH}

City of Salt Lake, UT 165

University of Utah

\section{VERMONT}

Clean Energy Group 174,177

Clean Energy States Alliance, Inc 177

\section{VIRGINIA}

Luna Innovations. 237

NanoSonic, Inc.... $73,96,238$

\section{WASHINGTON}

Kearney and Associates 208

Pacific Northwest National Laboratory

(PNNL) .96

REC Silicon, Inc. 81

\section{WISCONSIN}

City of Madison, WI 165

Midwest Renewable Energy Association ..151 Thermal Energy System Specialists, Inc. 218 University of Wisconsin, Madison .....105, 196 


\section{Acronyms and Abbreviations}

\begin{tabular}{|c|c|}
\hline $\begin{array}{l}\text { A2LA } \\
A C\end{array}$ & $\begin{array}{l}\text { American Association for Laboratory Accreditation } \\
\text { alternating current }\end{array}$ \\
\hline AES & Auger electron spectroscopy \\
\hline AFM & atomic force microscopy \\
\hline $\mathrm{AIC}$ & aluminum-induced crystallization \\
\hline AOP & Annual Operating Plan \\
\hline APD & antiphase domain \\
\hline APS & Arizona Public Service \\
\hline AR & antireflection \\
\hline ASES & American Solar Energy Society \\
\hline $\begin{array}{l}\text { ASHRAE } \\
\text { a-Si }\end{array}$ & $\begin{array}{l}\text { American Society of Heating, Refrigeration, and Air-conditioning Engineers } \\
\text { amorphous silicon }\end{array}$ \\
\hline ASOS & Automated Surface Observing System \\
\hline ASRC & Atmospheric Sciences Research Center (at State University of New York) \\
\hline ASRM & advanced solar reflective mirror \\
\hline ASSET & Analysis of State Energy Tradeoffs Databank \\
\hline ASTM & American Society for Testing and Materials \\
\hline ASU & Arizona State University \\
\hline BES & Basic Energy Sciences (within U.S. DOE Office of Science) \\
\hline BEW & Behnke, Erdman \& Whitaker Engineering \\
\hline BIPV & building-integrated photovoltaics \\
\hline BLM & Bureau of Land Management \\
\hline BNL & Brookhaven National Laboratory \\
\hline BOS & balance of systems \\
\hline BSC & Basic Sciences Center (within the National Renewable Energy Laboratory) \\
\hline BSF & back-surface field \\
\hline Btu & British thermal unit \\
\hline BU & Boston University \\
\hline CAD & computer-assisted design \\
\hline C-AFM & conductive atomic force microscopy \\
\hline Caltech & California Institute of Technology \\
\hline CBD & chemical bath deposition \\
\hline CdTe & cadmium telluride \\
\hline CEC & California Energy Commission \\
\hline CEG & Clean Energy Group, Inc. \\
\hline CET & Center for Ecological Technology \\
\hline CIGS & copper indium gallium diselenide \\
\hline CIGSS & copper indium gallium sulfur selenide \\
\hline CIS & copper indium diselenide \\
\hline $\mathrm{CL}$ & cathodoluminescence \\
\hline CNT & carbon nanotube \\
\hline COP & coefficient of performance \\
\hline COSE & cost of saved energy \\
\hline COTS & commercial off the shelf \\
\hline CPS & Corporate Planning System \\
\hline CPUC & California Public Utilities Commission \\
\hline CPV & concentrating photovoltaics \\
\hline CRADA & Cooperative Research and Development Agreement \\
\hline$C_{\text {save }}$ & cost of saved energy \\
\hline CSDS & Concentrating Solar Deployment System \\
\hline$c-S i$ & crystalline silicon \\
\hline CSR & Climatological Solar Radiation \\
\hline
\end{tabular}




\begin{tabular}{|c|c|}
\hline CSS & close-spaced sublimation \\
\hline CSP & concentrating solar power \\
\hline $\mathrm{CU}$ & University of Colorado \\
\hline CVD & chemical vapor deposition \\
\hline CY & calendar year \\
\hline $\mathrm{CZ}$ & Czochralski \\
\hline $\mathrm{DC}$ & direct current \\
\hline DEG/SE & Davis Energy Group/SunEarth \\
\hline DETL & Distributed Energy Technologies Laboratory (at Sandia National Laboratories) \\
\hline DFMA & design for manufacturing and assembly \\
\hline DFMECA & design failure mode effects and criticality analysis \\
\hline DFR & design for reliability \\
\hline DJ & dual junction \\
\hline DLR & German Aerospace Center \\
\hline DLTS & deep-level transient spectroscopy \\
\hline DMA & dynamic mechanical analysis \\
\hline DNI & direct normal incident \\
\hline DoD & Department of Defense \\
\hline DOE & Department of Energy \\
\hline DSC & differential scanning calorimetry \\
\hline DSP & digital signal processing \\
\hline EAO & Energy Analysis Office \\
\hline EBSD & electron backscatter diffraction \\
\hline EERE & Energy Efficiency and Renewable Energy (U.S. Department of Energy office) \\
\hline EFG & Edge-defined, Film-fed Growth \\
\hline $\mathrm{Eg}$ & bandgap energy \\
\hline $\mathrm{EH} \& \mathrm{~S}$ & environmental health and safety \\
\hline EIA & Energy Information Administration \\
\hline EM\&D & Electronic Materials and Devices \\
\hline ENEA & Italian National Agency for New Technologies, Energy and the Environment \\
\hline EPA & Environmental Protection Agency \\
\hline EPAct & Energy Policy Act \\
\hline EPC & Engineer, Procure, Construct \\
\hline EPS & environmental portfolio standard \\
\hline EPV & Energy Photovoltaics \\
\hline EUL & enhanced use leasing \\
\hline EVA & ethylene vinyl acetate \\
\hline EVMS & Earned Value Management System \\
\hline FAQ & frequently asked questions \\
\hline FF & fill factor \\
\hline FFPT & fixed focal point trough \\
\hline FIB & focused ion beam \\
\hline FOA & Funding Opportunity Announcement \\
\hline FOUP & Front-Opening Unified Pod \\
\hline FR & flame retardant \\
\hline FSEC & Florida Solar Energy Center (at University of Central Florida) \\
\hline FTIR & Fourier transform infrared \\
\hline FY & fiscal year \\
\hline $\mathrm{FZ}$ & float zone \\
\hline $\mathrm{GB}$ & grain boundary \\
\hline GE & General Electric \\
\hline GIS & geographical information system \\
\hline GMS & gas management system \\
\hline GO & Golden Field Office (U.S. Department of Energy) \\
\hline GOES & Geostationary Operational Environmental Satellite \\
\hline GPRA & Government Performance and Results Act \\
\hline
\end{tabular}




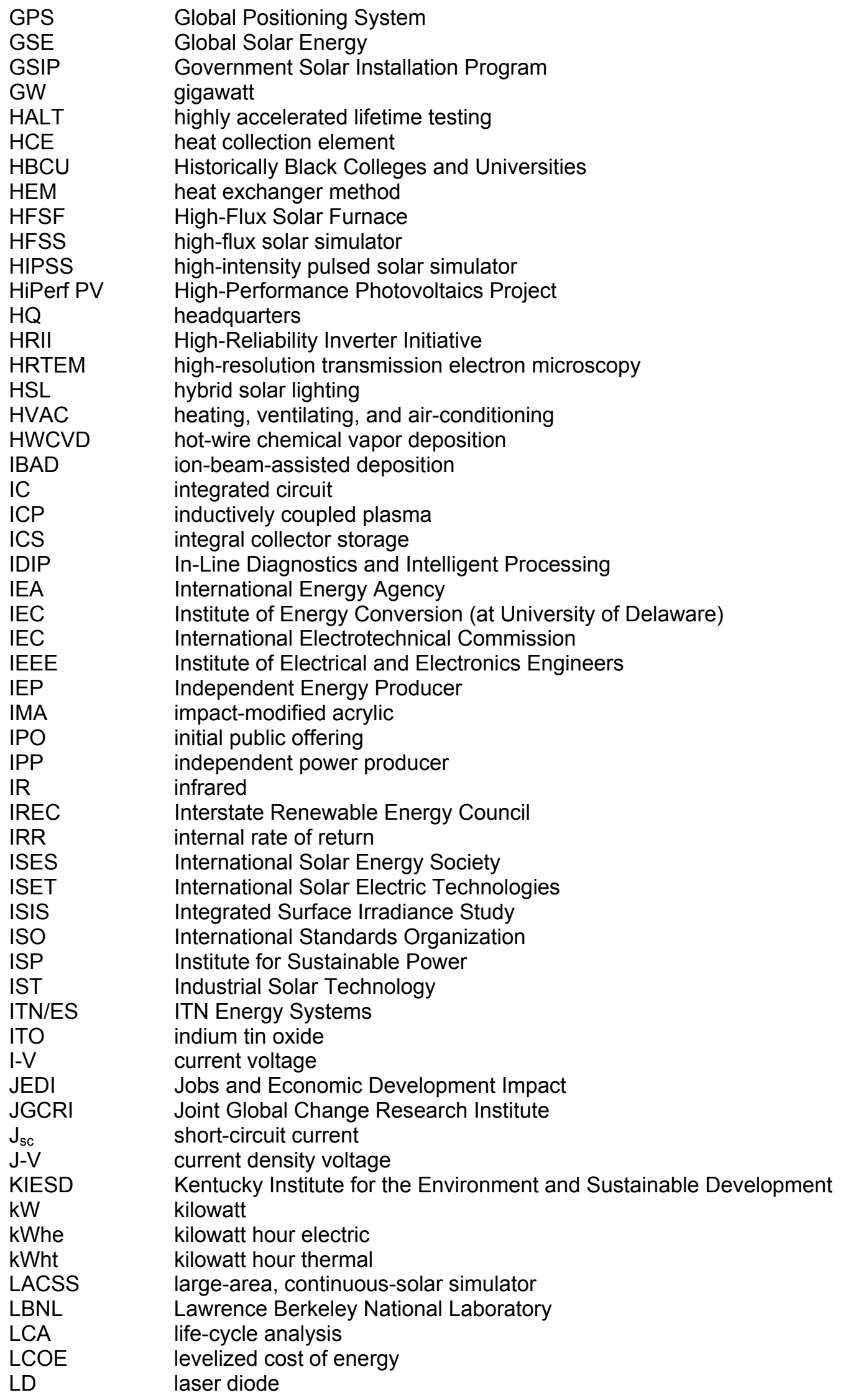




\begin{tabular}{|c|c|}
\hline LED & light-emitting diode \\
\hline LEED & Leadership in Energy and Environmental Design \\
\hline LIPA & Long Island Power Authority \\
\hline LOI & letter of interest \\
\hline LP QCM & liquid-phase quartz crystal microbalance \\
\hline MBE & molecular beam epitaxy or mean bias error \\
\hline MBMDPE & metallocene-based multi-density polyethylene \\
\hline $\mathrm{mc}$ & multicrystalline \\
\hline MDC & McDonnell Douglas Corporation \\
\hline MEG & Multiple-exciton generation \\
\hline MLTE & module long-term exposure \\
\hline MOCVD & metal organic chemical vapor deposition \\
\hline MPP & model power plant \\
\hline MPPT & maximum power point tracking \\
\hline MSR & Million Solar Roofs \\
\hline MT & market transformation \\
\hline MTBF & mean time between failure \\
\hline MURA & Minority University Research Associates \\
\hline MW & megawatt \\
\hline MYPP & Multi-Year Program Plan \\
\hline MYTP & Multi-Year Technical Plan \\
\hline NABCEP & North American Board of Certified Energy Practitioners \\
\hline NAHB & National Association of Home Builders \\
\hline NARUC & National Association of Regulatory Utility Commissioners \\
\hline NASA & National Aeronautics and Space Administration \\
\hline NCPV & National Center for Photovoltaics \\
\hline nc-Si & nanocrystalline silicon \\
\hline NEC & National Electrical Code \\
\hline NEMS & National Energy Modeling System (of the International Energy Agency) \\
\hline NEPA & National Environmental Policy Act \\
\hline NETL & National Energy Technology Laboratory \\
\hline NGO & non-governmental organization \\
\hline NIR & near infrared \\
\hline NIST & National Institute of Standards and Technology \\
\hline NMSU & New Mexico State University \\
\hline NOCT & normal operating cell temperature \\
\hline NRCC & Northeast Regional Climate Center \\
\hline NREL & National Renewable Energy Laboratory \\
\hline NSRDB & National Solar Radiation Data Base \\
\hline NSTTF & National Solar Thermal Test Facility (at Sandia National Laboratories) \\
\hline NTUA & Navajo Tribal Utility Authority \\
\hline NWS & National Weather Service \\
\hline NYSERDA & New York State Energy Research and Development Authority \\
\hline OATS & Outdoor Accelerated-weathering Testing System \\
\hline O\&M & operations and maintenance \\
\hline OMB & Office of Management and Budget \\
\hline OMCVD & organometalic chemical vapor deposition \\
\hline OPV & organic photovoltaics \\
\hline ORC & Organic Rankine Cycle \\
\hline ORNL & Oak Ridge National Laboratory \\
\hline OTF & Outdoor Test Facility (at National Renewable Energy Laboratory) \\
\hline OWIP & Office of Weatherization and Intergovernmental Programs \\
\hline PAE & planning, analysis, and evaluation \\
\hline PBA & Office of Planning, Budget, and Analysis \\
\hline PC & polycarbonate \\
\hline PCD & photoconductive de \\
\hline
\end{tabular}




\begin{tabular}{|c|c|}
\hline PCU & power conversion unit \\
\hline $\begin{array}{l}\text { PDIL } \\
\text { PEC }\end{array}$ & $\begin{array}{l}\text { Process Development and Integration Laboratory } \\
\text { photoelectrochemical }\end{array}$ \\
\hline PECVD & plasma-enhanced chemical vapor deposition \\
\hline PED & pulsed electron-beam deposition \\
\hline PERT & Performance and Energy Ratings Testbed \\
\hline PET & polyethylene terephthalate \\
\hline PI & principal investigator \\
\hline PIER & Public Interest Energy Research (program of the California Energy Commission) \\
\hline PLD & pulsed laser deposition \\
\hline PMMA & polymethyl methacrylate \\
\hline PNNL & Pacific Northwest National Laboratory \\
\hline PPR & $\begin{array}{l}\text { polypropylene } \\
\text { polypropylene random copolymer }\end{array}$ \\
\hline PTL & Photovoltaic Testing Lab (at Arizona State University) \\
\hline PV & photovoltaics \\
\hline PVD & physical vapor deposition \\
\hline PVME & polyvinylmethylether \\
\hline PVMR\&D & PV Manufacturing R\&D \\
\hline PVPS & Photovoltaic Power Systems Programme (of the International Energy Agency) \\
\hline PVSAC & Photovoltaic Systems Assistance Center \\
\hline PVSAM & PV Systems Analysis Model \\
\hline PVSC & Photovoltaic Specialists Conference \\
\hline PVSOL & PV System Optimization Laboratory (at Sandia National Laboratories) \\
\hline QCM & quartz crystal microbalance \\
\hline QD & quantum dot \\
\hline QDLED & quantum dot light-emitting diode \\
\hline QE & quantum efficiency \\
\hline QSSPC & quasi-steady-state photoconductance \\
\hline RCPCD & resonant-coupled, photoconductive decay \\
\hline R\&D & research and development \\
\hline REAP & Renewable Energy Academic Partnership \\
\hline REC & renewable energy certificate \\
\hline RES & Regional Experiment Station \\
\hline RFP & request for proposal \\
\hline RFQ & request for qualifications \\
\hline RITH & roof-integrated thermosiphon \\
\hline RMOTC & Rocky Mountain Oilfields Testing Center \\
\hline RMSE & root mean square error \\
\hline RO & reverse osmosis \\
\hline ROI & return on investment \\
\hline ROWPU & reverse osmosis water purification unit \\
\hline RPS & renewable portfolio standard \\
\hline RSI & renewable systems integration \\
\hline RSM & reciprocal space map \\
\hline RT & room temperature \\
\hline RTA & rapid thermal annealing \\
\hline RTSE & real-time spectroscopic ellipsometry \\
\hline RUS & Rural Utilities Service (of the U.S. Department of Agriculture) \\
\hline SAC & Solar America Cities \\
\hline SAl & Solar America Initiative \\
\hline SAIC & Science Applications International Corporation \\
\hline SAM & Solar Advisor Model \\
\hline SAS & Solar America Showcases \\
\hline SBC & systems benefit charge \\
\hline SBIR & Small Business Innovation Research \\
\hline
\end{tabular}




\begin{tabular}{|c|c|}
\hline SDA & Systems-Driven Approach \\
\hline SDHW & solar domestic hot water \\
\hline SDSU & South Dakota State University \\
\hline SEGIS & Solar Energy Grid Integration Systems \\
\hline SEIA & Solar Energy Industries Association \\
\hline SEM & scanning electron microscope \\
\hline SEPA & Solar Electric Power Association \\
\hline SERES & Southeast Regional Experiment Station (at University of Central Florida) \\
\hline SERF & Solar Energy Research Facility (at National Renewable Energy Laboratory) \\
\hline SETP & Solar Energy Technologies Program \\
\hline SES & Stirling Energy Systems \\
\hline $\mathrm{SHC}$ & solar heating and cooling \\
\hline SHGR & Solar Hydrogen Generation Research \\
\hline $\mathrm{SHJ}$ & silicon heterojunction \\
\hline SHW & solar hot water \\
\hline SIF & stress intensity factor \\
\hline SIMS & secondary ion mass spectrometry \\
\hline SKPM & scanning Kelvin probe microscopy \\
\hline SMIF & Standard Mechanical InterFace \\
\hline SMUD & Sacramento Utility District \\
\hline SNL & Sandia National Laboratories \\
\hline Solar PACES & Solar Power and Chemical Energy Systems \\
\hline SolarDS & Solar Deployment Systems (model) \\
\hline SOW & statement of work \\
\hline SPC & solid-phase crystallized \\
\hline SPIE & International Society for Optical Engineering \\
\hline SRCC & Solar Rating and Certification Corporation \\
\hline SRP & Salt River Project \\
\hline SSE & Surface Meteorology and Solar Energy (a NASA project) \\
\hline SSI & Shell Solar Industries \\
\hline STC & Standard Test Conditions \\
\hline STCH & solar thermochemical hydrogen \\
\hline S\&TF & Science \& Technology Facility (at National Renewable Energy Laboratory) \\
\hline SUNY & State University of New York \\
\hline SURFRAD & Surface Radiation Budget Network \\
\hline SWH & solar water heating \\
\hline SWRES & Southwest Regional Experiment Station (at New Mexico State University) \\
\hline SWTDI & Southwest Technology Development Institute (at New Mexico State University) \\
\hline TA & technical assistance \\
\hline TBD & to be determined \\
\hline TCA & thermal cycle annealing \\
\hline TCC & transparent conductive coating \\
\hline TCO & transparent conducting oxide \\
\hline TDMS & thermal-desorption mass spectrometry \\
\hline TEM & transmission electron microscopy; also technical exchange meeting \\
\hline TEP & Tucson Electric Power \\
\hline TES & thermal energy storage \\
\hline TIO & Technology Improvement Opportunity \\
\hline TMY & typical meteorological year \\
\hline TOP & theoretical overlay photographic \\
\hline TOU & time of use \\
\hline TPD & temperature-programmed desorption \\
\hline TPP & Technology Pathway Partnership \\
\hline TRNSYS & TRaNsient SYstem Simulation Program \\
\hline TRPL & time-resolved photoluminescence \\
\hline TVA & Tennessee Valley Authority \\
\hline
\end{tabular}




$\begin{array}{ll}\text { TW } & \text { terrawatt } \\ \text { UHV } & \text { ultrahigh vacuum } \\ \text { UL } & \text { Underwriters Laboratories } \\ \text { ULRF } & \text { University of Louisville Research Foundation } \\ \text { UN } & \text { United Nations } \\ \text { UNLV } & \text { University of Nevada Las Vegas } \\ \text { UNM/ME } & \text { University of New Mexico Mechanical Engineering Department } \\ \text { U of L } & \text { University of Louisville } \\ \text { UPS } & \text { ultraviolet photoelectron spectroscopy } \\ \text { USAID } & \text { U.S. Agency for International Development } \\ \text { USDA } & \text { U.S. Department of Agriculture } \\ \text { USGBC } & \text { U.S. Green Building Council } \\ \text { UV } & \text { ultraviolet } \\ \text { VASE } & \text { variable-angle spectroscopic ellipsometry } \\ \text { VB } & \text { valence band } \\ \text { VBM } & \text { valence band maximum } \\ \text { Voc } & \text { open-circuit voltage } \\ \text { VSHOT } & \text { Video Scanning Hartmann Optical Test } \\ \text { VTD } & \text { vapor transport deposition } \\ \text { WCPEC } & \text { World Conference on Photovoltaic Energy Conversion } \\ \text { WGA } & \text { Western Governors' Association } \\ \text { WIP-I } & \text { Weatherization and Intergovernmental Program-International } \\ \text { WMO } & \text { World Meteorological Organization } \\ \text { WOM } & \text { weatherometer } \\ \text { WREC } & \text { World Renewable Energy Congress } \\ \text { WRR } & \text { World Radiometric Reference } \\ \text { WVTR } & \text { water vapor transport rate } \\ \text { XPS } & \text { X-ray photoelectron spectroscopy } \\ \text { XRD } & \text { X-ray diffraction } \\ \text { YDR } & \text { yield, durability, and reliability } \\ \text { ZEH } & \text { zero energy homes } \\ & \end{array}$




\section{NOTICE}

This report was prepared as an account of work sponsored by an agency of the United States government. Neither the United States government nor any agency thereof, nor any of their employees, makes any warranty, express or implied, or assumes any legal liability or responsibility for the accuracy, completeness, or usefulness of any information, apparatus, product, or process disclosed, or represents that its use would not infringe privately owned rights. Reference herein to any specific commercial product, process, or service by trade name, trademark, manufacturer, or otherwise does not necessarily constitute or imply its endorsement, recommendation, or favoring by the United States government or any agency thereof. The views and opinions of authors expressed herein do not necessarily state or reflect those of the United States government or any agency thereof.

\section{Available electronically at http://www.osti.gov/bridge}

Available for a processing fee to U.S. Department of Energy

and its contractors, in paper, from:

U.S. Department of Energy Office of Scientific and Technical Information P.O. Box 62

Oak Ridge, TN 37831-0062

phone: 865.576.8401

fax: 865.576 .5728

email: mailto:reports@adonis.osti.gov
Available for sale to the public, in paper, from:

U.S. Department of Commerce

National Technical Information Service

5285 Port Royal Road

Springfield, VA 22161

phone: 800.553.6847

fax: 703.605.6900

email: orders@ntis.fedworld.gov

online ordering: http://www.ntis.gov/ordering.htm 
